\title{
Cochrane
}

Library

Cochrane Database of Systematic Reviews

\section{Parenteral opioids for maternal pain management in labour} (Review)

Smith LA, Burns E, Cuthbert A

Smith LA, Burns E, Cuthbert A.

Parenteral opioids for maternal pain management in labour.

Cochrane Database of Systematic Reviews 2018, Issue 6. Art. No.: CD007396.

DOI: 10.1002/14651858.CD007396.pub3.

www.cochranelibrary.com 
TABLE OF CONTENTS

ABSTRACT

PLAIN LANGUAGE SUMMARY

SUMMARY OF FINDINGS

BACKGROUND

OBJECTIVES

METHODS

RESULTS

Figure 1.

Figure 2.

Figure 3.

DISCUSSION

AUTHORS' CONCLUSIONS

ACKNOWLEDGEMENTS

REFERENCES

CHARACTERISTICS OF STUDIES

DATA AND ANALYSES

Analysis 1.1. Comparison $1 \mathrm{IM}$ pethidine $50 \mathrm{mg} / 100 \mathrm{mg}$ versus placebo, Outcome 1 Maternal satisfaction with analgesia measured during labour (number of women satisfied or very satisfied after 30 minutes).

Analysis 1.2. Comparison $1 \mathrm{IM}$ pethidine $50 \mathrm{mg} / 100 \mathrm{mg}$ versus placebo, Outcome 2 Maternal pain score or pain measured in labour (described as good or fair after 1 hour).

Analysis 1.3. Comparison $1 \mathrm{IM}$ pethidine $50 \mathrm{mg} / 100 \mathrm{mg}$ versus placebo, Outcome 3 Maternal pain score or pain measured in labour (reduction in VAS of at least $40 \mathrm{~mm}$ after 30 minutes).

Analysis 1.4. Comparison $1 \mathrm{IM}$ pethidine $50 \mathrm{mg} / 100 \mathrm{mg}$ versus placebo, Outcome 4 Additional analgesia required. .................

Analysis 1.5. Comparison $1 \mathrm{IM}$ pethidine $50 \mathrm{mg} / 100 \mathrm{mg}$ versus placebo, Outcome 5 Epidural.

Analysis 1.6. Comparison $1 \mathrm{IM}$ pethidine $50 \mathrm{mg} / 100 \mathrm{mg}$ versus placebo, Outcome 6 Nausea and vomiting.

Analysis 1.7. Comparison $1 \mathrm{IM}$ pethidine $50 \mathrm{mg} / 100 \mathrm{mg}$ versus placebo, Outcome 7 Maternal sleepiness.

Analysis 1.8. Comparison $1 \mathrm{IM}$ pethidine $50 \mathrm{mg} / 100 \mathrm{mg}$ versus placebo, Outcome 8 Assisted vaginal delivery.

Analysis 1.9. Comparison $1 \mathrm{IM}$ pethidine $50 \mathrm{mg} / 100 \mathrm{mg}$ versus placebo, Outcome 9 Caesarean section.

Analysis 1.10. Comparison $1 \mathrm{IM}$ pethidine $50 \mathrm{mg} / 100 \mathrm{mg}$ versus placebo, Outcome 10 Neonatal resuscitation.

Analysis 1.11. Comparison $1 \mathrm{IM}$ pethidine $50 \mathrm{mg} / 100 \mathrm{mg}$ versus placebo, Outcome 11 Low Apgar score $(\leq 7)$ at 1 and $5 \mathrm{minutes}$.

Analysis 1.12. Comparison $1 \mathrm{IM}$ pethidine $50 \mathrm{mg} / 100 \mathrm{mg}$ versus placebo, Outcome 12 Admission to NICU.

Analysis 2.1. Comparison $2 \mathrm{IM}$ pentazocine versus placebo, Outcome 1 Maternal pain score measured during labour.

Analysis 2.2. Comparison 2 IM pentazocine versus placebo, Outcome 2 Nausea and vomiting.

Analysis 2.3. Comparison 2 IM pentazocine versus placebo, Outcome 3 Caesarean section.

Analysis 2.4. Comparison 2 IM pentazocine versus placebo, Outcome 4 Assisted vaginal birth.

Analysis 3.1. Comparison $3 \mathrm{IM}$ tramadol versus no treatment, Outcome 1 Maternal satisfaction with analgesia (Analgesic effect described as satisfactory (not clear when measured)).

Analysis 4.1. Comparison 4 IM meptazinol versus pethidine, Outcome 1 Maternal pain score or pain measured in labour (Maternal pain relief poor or none (3-5 PN)).

Analysis 4.2. Comparison $4 \mathrm{IM}$ meptazinol versus pethidine, Outcome 2 Maternal pain score or pain measured in labour (Pain intensity 4 or 5 on 5-point scale (1 hour)).

Analysis 4.3. Comparison 4 IM meptazinol versus pethidine, Outcome 3 Additional analgesia required.

Analysis 4.4. Comparison 4 IM meptazinol versus pethidine, Outcome 4 Epidural.

Analysis 4.5. Comparison 4 IM meptazinol versus pethidine, Outcome 5 Maternal sleepiness.

Analysis 4.6. Comparison 4 IM meptazinol versus pethidine, Outcome 6 Nausea and vomiting.

Analysis 4.7. Comparison $4 \mathrm{IM}$ meptazinol versus pethidine, Outcome 7 Caesarean section.

Analysis 4.8. Comparison $4 \mathrm{IM}$ meptazinol versus pethidine, Outcome 8 Assisted vaginal birth.

Analysis 4.9. Comparison $4 \mathrm{IM}$ meptazinol versus pethidine, Outcome 9 Breastfeeding at discharge (problems).

Analysis 4.10. Comparison $4 \mathrm{IM}$ meptazinol versus pethidine, Outcome 10 Fetal heart rate changes (decelerations).

Analysis 4.11. Comparison 4 IM meptazinol versus pethidine, Outcome 11 Naloxone administration.

Analysis 4.12. Comparison 4 IM meptazinol versus pethidine, Outcome 12 Neonatal resuscitation (by gestation). 
Analysis 4.14. Comparison 4 IM meptazinol versus pethidine, Outcome 14 Apgar score $\leq 7$ at 1 minute.

Analysis 4.15. Comparison 4 IM meptazinol versus pethidine, Outcome 15 Apgar score $\leq 7$ at 5 minutes.

Analysis 4.16. Comparison 4 IM meptazinol versus pethidine, Outcome 16 Admission to NICU.

Analysis 5.1. Comparison $5 \mathrm{IM}$ diamorphine + prochlorperazine versus pethidine + prochlorperazine, Outcome $1 \mathrm{Maternal}$ satisfaction with analgesia in labour measured during the postnatal period (Global assessment of pain relief at 24 hours). ....

Analysis 5.2. Comparison $5 \mathrm{IM}$ diamorphine + prochlorperazine versus pethidine + prochlorperazine, Outcome 2 Maternal pain score or pain measured in labour (Pain intensity at 1 hour (moderate or severe)).

Analysis 5.3. Comparison 5 IM diamorphine + prochlorperazine versus pethidine + prochlorperazine, Outcome 3 Additonal analgesia required.

Analysis 5.4. Comparison 5 IM diamorphine + prochlorperazine versus pethidine + prochlorperazine, Outcome 4 Epidural. .... Analysis 5.5. Comparison $5 \mathrm{IM}$ diamorphine + prochlorperazine versus pethidine + prochlorperazine, Outcome $5 \mathrm{Maternal}$ sleepiness during labour.

Analysis 5.6. Comparison $5 \mathrm{IM}$ diamorphine + prochlorperazine versus pethidine + prochlorperazine, Outcome 6 Vomiting in labour.

Analysis 5.7. Comparison $5 \mathrm{IM}$ diamorphine + prochlorperazine versus pethidine + prochlorperazine, Outcome 7 Caesarean section.

Analysis 5.8. Comparison 5 IM diamorphine + prochlorperazine versus pethidine + prochlorperazine, Outcome 8 Assisted vaginal birth.

Analysis 5.9. Comparison 5 IM diamorphine + prochlorperazine versus pethidine + prochlorperazine, Outcome 9 Neonatal resuscitation.

Analysis 5.10. Comparison $5 \mathrm{IM}$ diamorphine + prochlorperazine versus pethidine + prochlorperazine, Outcome 10 Apgar $<7$ at 1 minute.

Analysis 5.11. Comparison $5 \mathrm{IM}$ diamorphine + prochlorperazine versus pethidine + prochlorperazine, Outcome 11 Apgar $<7$ at 5 minutes.

Analysis 5.12. Comparison $5 \mathrm{IM}$ diamorphine + prochlorperazine versus pethidine + prochlorperazine, Outcome $12 \mathrm{Admission}$ to NICU.

Analysis 6.1. Comparison $6 \mathrm{IM}$ tramadol versus pethidine, Outcome 1 Maternal pain score or pain measured in labour (Pain intensity: women with poor pain relief).

Analysis 6.2. Comparison $6 \mathrm{IM}$ tramadol versus pethidine, Outcome 2 Additional analgesia required.

Analysis 6.3. Comparison $6 \mathrm{IM}$ tramadol versus pethidine, Outcome 3 Maternal sleepiness in labour.

Analysis 6.4. Comparison $6 \mathrm{IM}$ tramadol versus pethidine, Outcome 4 Nausea and vomiting in labour.

Analysis 6.5. Comparison 6 IM tramadol versus pethidine, Outcome 5 Caesarean section.

Analysis 6.6. Comparison $6 \mathrm{IM}$ tramadol versus pethidine, Outcome 6 Assisted vaginal birth.

Analysis 6.7. Comparison $6 \mathrm{IM}$ tramadol versus pethidine, Outcome 7 Neonatal resuscitation.

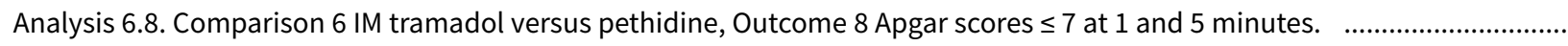

Analysis 6.9. Comparison $6 \mathrm{IM}$ tramadol versus pethidine, Outcome 9 Neonatal respiratory distress.

Analysis 6.10. Comparison $6 \mathrm{IM}$ tramadol versus pethidine, Outcome 10 Admission to NICU.

Analysis 7.1. Comparison $7 \mathrm{IM}$ tramadol + triflupromazine versus pethidine + triflupromazine, Outcome 1 Maternal sleepiness in labour.

Analysis 7.2. Comparison $7 \mathrm{IM}$ tramadol + triflupromazine versus pethidine + triflupromazine, Outcome 2 Nausea and vomiting in labour.

Analysis 8.1. Comparison $8 \mathrm{IM}$ dihydrocodeine $50 \mathrm{mg}$ versus pethidine $100 \mathrm{mg}$, Outcome 1 Maternal pain score or pain measured in labour (Maternal pain relief poor at 1 hour).

Analysis 8.2. Comparison $8 \mathrm{IM}$ dihydrocodeine $50 \mathrm{mg}$ versus pethidine $100 \mathrm{mg}$, Outcome 2 Maternal sleepiness in labour. ...... Analysis 8.3. Comparison $8 \mathrm{IM}$ dihydrocodeine $50 \mathrm{mg}$ versus pethidine $100 \mathrm{mg}$, Outcome 3 Nausea and vomiting in labour. .... Analysis 8.4. Comparison $8 \mathrm{IM}$ dihydrocodeine $50 \mathrm{mg}$ versus pethidine $100 \mathrm{mg}$, Outcome 4 Apgar $\leq 7$ at 1 minute. .................. Analysis 9.1. Comparison $9 \mathrm{IM}$ pentazocine versus pethidine, Outcome 1 Maternal satisfaction with analgesia measured during labour (Pain relief (good or very good) at delivery).

Analysis 9.2. Comparison 9 IM pentazocine versus pethidine, Outcome 2 Maternal pain score or pain measured in labour (Pain relief poor (partial, none or worse)).

Analysis 9.3. Comparison 9 IM pentazocine versus pethidine, Outcome 3 Additional analgesia required.

Analysis 9.4. Comparison 9 IM pentazocine versus pethidine, Outcome 4 Maternal sleepiness in labour.

Analysis 9.5. Comparison $9 \mathrm{IM}$ pentazocine versus pethidine, Outcome 5 Nausea and vomiting in labour.

Analysis 9.7. Comparison $9 \mathrm{IM}$ pentazocine versus pethidine, Outcome 7 Naloxone administration. 
Analysis 9.8. Comparison 9 IM pentazocine versus pethidine, Outcome 8 Apgar score $\leq 7$ at 1 minute.

Analysis 9.9. Comparison $9 \mathrm{IM}$ pentazocine versus pethidine, Outcome 9 Apgar score $\leq 7$ at 5 minutes.

Analysis 10.1. Comparison $10 \mathrm{IM}$ nalbuphine versus pethidine, Outcome 1 Maternal satisfaction with analgesia measured during the postnatal period (numbers dissatisfied).

Analysis 10.2. Comparison $10 \mathrm{IM}$ nalbuphine versus pethidine, Outcome 2 Maternal satisfaction with analgesia measured during labour (Pain free).

Analysis 10.3. Comparison $10 \mathrm{IM}$ nalbuphine versus pethidine, Outcome 3 Maternal pain score or pain measured in labour (Pain intensity at 30 minutes: women with severe pain).

Analysis 10.4. Comparison $10 \mathrm{IM}$ nalbuphine versus pethidine, Outcome 4 Maternal pain score or pain measured in labour (VAS at 60 minutes (at peak of contraction)).

Analysis 10.5. Comparison $10 \mathrm{IM}$ nalbuphine versus pethidine, Outcome 5 Additional analgesia required.

Analysis 10.6. Comparison $10 \mathrm{IM}$ nalbuphine versus pethidine, Outcome 6 Epidural.

Analysis 10.7. Comparison $10 \mathrm{IM}$ nalbuphine versus pethidine, Outcome 7 Maternal sleepiness in labour.

Analysis 10.8. Comparison $10 \mathrm{IM}$ nalbuphine versus pethidine, Outcome 8 Nausea and vomiting in labour.

Analysis 10.9. Comparison $10 \mathrm{IM}$ nalbuphine versus pethidine, Outcome 9 Caesarean section.

Analysis 10.10. Comparison $10 \mathrm{IM}$ nalbuphine versus pethidine, Outcome 10 Assisted vaginal birth.

Analysis 10.11. Comparison $10 \mathrm{IM}$ nalbuphine versus pethidine, Outcome 11 Naloxone administration.

Analysis 10.12. Comparison $10 \mathrm{IM}$ nalbuphine versus pethidine, Outcome 12 Apgar score $\leq 7$ at 1 and 5 minutes. ....................

Analysis 10.13. Comparison $10 \mathrm{IM}$ nalbuphine versus pethidine, Outcome $13 \mathrm{Admission}$ to NICU.

Analysis 10.14. Comparison 10 IM nalbuphine versus pethidine, Outcome 14 Neonatal neurobehavioural (Scanlon) 2-4 hours PN.

Analysis 11.1. Comparison $11 \mathrm{IM}$ phenazocine versus pethidine, Outcome 1 Epidural.

Analysis 11.2. Comparison $11 \mathrm{IM}$ phenazocine versus pethidine, Outcome 2 Vomiting.

Analysis 12.1. Comparison $12 \mathrm{IM}$ diamorphine/morphine versus pethidine, Outcome 1 Maternal satisfaction with analgesia (number of women satisfied or very satisfied).

Analysis 12.2. Comparison $12 \mathrm{IM}$ diamorphine/morphine versus pethidine, Outcome 2 Maternal satisfaction with analgesia measured during labour or during the postnatal period (Pain relief described as poor).

Analysis 12.3. Comparison $12 \mathrm{IM}$ diamorphine/morphine versus pethidine, Outcome 3 Maternal pain score or pain measured in labour (pain relief at 30 mins).

Analysis 12.4. Comparison $12 \mathrm{IM}$ diamorphine/morphine versus pethidine, Outcome 4 Maternal pain score or pain measured in labour (pain relief at 60 mins).

Analysis 12.5. Comparison 12 IM diamorphine/morphine versus pethidine, Outcome 5 Additional analgesia required. ...........

Analysis 12.6. Comparison $12 \mathrm{IM}$ diamorphine/morphine versus pethidine, Outcome 6 Maternal sleepiness. ..........................

Analysis 12.7. Comparison $12 \mathrm{IM}$ diamorphine/morphine versus pethidine, Outcome 7 Nausea and vomiting. .........................

Analysis 12.8. Comparison $12 \mathrm{IM}$ diamorphine/morphine versus pethidine, Outcome 8 Caesarean section.

Analysis 12.9. Comparison $12 \mathrm{IM}$ diamorphine/morphine versus pethidine, Outcome 9 Assisted vaginal birth.

Analysis 12.10. Comparison $12 \mathrm{IM}$ diamorphine/morphine versus pethidine, Outcome 10 Naloxone administration.

Analysis 12.11. Comparison $12 \mathrm{IM}$ diamorphine/morphine versus pethidine, Outcome 11 Neonatal resuscitation.

Analysis 12.12. Comparison $12 \mathrm{IM}$ diamorphine/morphine versus pethidine, Outcome $12 \mathrm{Apgar}<7$ at 1 minute.

Analysis 12.13. Comparison $12 \mathrm{IM}$ diamorphine/morphine versus pethidine, Outcome 13 Admission to NICU.

Analysis 13.1. Comparison $13 \mathrm{IM}$ butorphanol versus pethidine, Outcome 1 Additional analgesia required.

Analysis 13.2. Comparison $13 \mathrm{IM}$ butorphanol versus pethidine, Outcome 2 Nausea.

Analysis 13.3. Comparison $13 \mathrm{IM}$ butorphanol versus pethidine, Outcome 3 Vomiting.

Analysis 13.4. Comparison $13 \mathrm{IM}$ butorphanol versus pethidine, Outcome 4 Neonatal resuscitation.

Analysis 13.5. Comparison $13 \mathrm{IM}$ butorphanol versus pethidine, Outcome 5 Naloxone administration (neonatal). ...................

Analysis 14.1. Comparison 14 IM Avacan ${ }^{\circledR}$ versus IM pentazocine, Outcome 1 Additional analgesia required - Entonox. ............

Analysis 14.2. Comparison 14 IM Avacan ${ }^{\circledast}$ versus IM pentazocine, Outcome 2 Additional analgesia required - pudendalparacervical block.

Analysis 14.3. Comparison 14 IM Avacan ${ }^{\circledR}$ versus IM pentazocine, Outcome 3 Caesarean section.

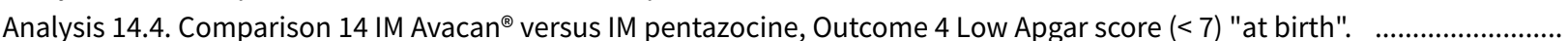

Analysis 15.1. Comparison 15 IM pentazocine versus IM Pethilorfan ${ }^{\circledR}$, Outcome 1 Maternal pain score measured during labour (Pain relief (women NOT obtaining pain relief) at 1 hour).

Analysis 15.2. Comparison 15 IM pentazocine versus IM Pethilorfan ${ }^{\circledR}$, Outcome 2 Additional analgesia required. ......................

Analysis 15.3. Comparison 15 IM pentazocine versus IM Pethilorfan ${ }^{\circledR}$, Outcome 3 Assisted vaginal birth. 
Analysis 15.4. Comparison 15 IM pentazocine versus IM Pethilorfan ${ }^{\circledR}$, Outcome 4 Apgar $<8$ at 1 minute (non pre-specified). .... Analysis 15.5. Comparison $15 \mathrm{IM}$ pentazocine versus IM Pethilorfan ${ }^{\circledast}$, Outcome 5 Apgar $<8$ at 5 minutes (non pre-specified). ... Analysis 16.1. Comparison $16 \mathrm{IM}$ pentazocine versus complementary and alternate medicine (CAM), Outcome 1 Maternal pain score measured during labour.

Analysis 16.2. Comparison $16 \mathrm{IM}$ pentazocine versus complementary and alternate medicine (CAM), Outcome 2 Nausea and vomiting.

Analysis 16.3. Comparison 16 IM pentazocine versus complementary and alternate medicine (CAM), Outcome 3 Caesarean section.

Analysis 16.4. Comparison $16 \mathrm{IM}$ pentazocine versus complementary and alternate medicine (CAM), Outcome 4 Assisted vaginal delivery.

Analysis 17.1. Comparison 17 IM pentazocine versus IM tramadol, Outcome 1 Maternal satisfaction with analgesia measured during labour (pain relief after 30 mins).

Analysis 17.2. Comparison 17 IM pentazocine versus IM tramadol, Outcome 2 Maternal satisfaction with analgesia measured during labour (pain after 60 mins).

Analysis 17.3. Comparison 17 IM pentazocine versus IM tramadol, Outcome 3 Maternal pain score or pain measured in labour (moderate or severe at 30 mins).

Analysis 17.4. Comparison 17 IM pentazocine versus IM tramadol, Outcome 4 Maternal pain score or pain measured in labour (moderate or severe at 60 mins).

Analysis 17.5. Comparison $17 \mathrm{IM}$ pentazocine versus IM tramadol, Outcome 5 Maternal sleepiness during labour. ...................

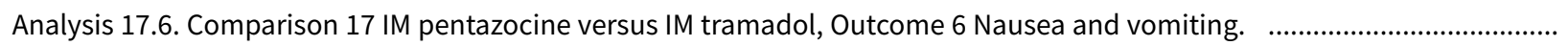

Analysis 17.7. Comparison 17 IM pentazocine versus IM tramadol, Outcome 7 Caesarean section.

Analysis 17.8. Comparison 17 IM pentazocine versus IM tramadol, Outcome 8 Assisted vaginal delivery.

Analysis 17.9. Comparison 17 IM pentazocine versus IM tramadol, Outcome 9 Apgar score $<7$ at 1 minute.

Analysis 17.10. Comparison 17 IM pentazocine versus IM tramadol, Outcome 10 Apgar score $<7$ at 5 minutes.

Analysis 17.11. Comparison 17 IM pentazocine versus IM tramadol, Outcome 11 Admission to NICU.

Analysis 18.1. Comparison $18 \mathrm{IM}$ pethidine versus Entonox, Outcome 1 Maternal pain score or pain measured in labour (after 30 mins).

Analysis 18.2. Comparison $18 \mathrm{IM}$ pethidine versus Entonox, Outcome 2 Maternal pain score or pain measured in labour (after 60 mins).

Analysis 19.1. Comparison 19 IV pethidine versus placebo, Outcome 1 Maternal pain score or pain measured in labour (Pain score 30 mins post analgesia).

Analysis 19.2. Comparison 19 IV pethidine versus placebo, Outcome 2 Nausea and vomiting.

Analysis 19.3. Comparison 19 IV pethidine versus placebo, Outcome 3 Caesarean section.

Analysis 19.4. Comparison 19 IV pethidine versus placebo, Outcome 4 Assisted vaginal birth.

Analysis 19.5. Comparison 19 IV pethidine versus placebo, Outcome 5 Admission to NICU.

Analysis 20.1. Comparison 20 IV fentanyl versus no treatment, Outcome 1 Maternal pain score or pain measured in labour (Pain score 1 hour post-analgesia).

Analysis 20.2. Comparison 20 IV fentanyl versus no treatment, Outcome 2 Maternal pain score or pain measured in labour (Pain intensity (Severe) after 1 hour).

Analysis 20.3. Comparison 20 IV fentanyl versus no treatment, Outcome 3 Caesarean section.

Analysis 21.1. Comparison 21 IV fentanyl versus IV pethidine, Outcome 1 Maternal pain score or pain measured in labour (Pain score 1 hour after drug administration).

Analysis 21.2. Comparison 21 IV fentanyl versus IV pethidine, Outcome 2 Mean doses of analgesia (non pre-specified). .......... Analysis 21.3. Comparison 21 IV fentanyl versus IV pethidine, Outcome 3 Maternal sleepiness in labour (sedation). ................ Analysis 21.4. Comparison 21 IV fentanyl versus IV pethidine, Outcome 4 Nausea and/or vomiting.

Analysis 21.5. Comparison 21 IV fentanyl versus IV pethidine, Outcome 5 Anti-emetic required (non pre-specified).

Analysis 21.6. Comparison 21 IV fentanyl versus IV pethidine, Outcome 6 Caesarean section.

Analysis 21.7. Comparison 21 IV fentanyl versus IV pethidine, Outcome 7 Naloxone administered.

Analysis 21.8. Comparison 21 IV fentanyl versus IV pethidine, Outcome 8 Babies requiring resuscitation/ventilatory support. ..

Analysis 21.9. Comparison $21 \mathrm{IV}$ fentanyl versus IV pethidine, Outcome 9 Apgar score $<7$ at 1 minute. 
Analysis 22.2. Comparison 22 IV nalbuphine versus IV pethidine, Outcome 2 Apgar score $<7$ at 1 minute.

Analysis 22.3. Comparison 22 IV nalbuphine versus IV pethidine, Outcome 3 Apgar score $<7$ at 5 minutes.

Analysis 23.1. Comparison 23 IV phenazocine versus IV pethidine, Outcome 1 Maternal satisfaction with analgesia measured during labour (women with fair or poor relief).

Analysis 23.2. Comparison 23 IV phenazocine versus IV pethidine, Outcome 2 Nausea with vomiting.

Analysis 23.3. Comparison 23 IV phenazocine versus IV pethidine, Outcome 3 Perinatal death.

Analysis 23.4. Comparison 23 IV phenazocine versus IV pethidine, Outcome 4 Apgar score $<7$ at 1 minute. ............................

Analysis 24.1. Comparison 24 IV butorphanol versus IV pethidine, Outcome 1 Maternal pain score or pain measured in labour (Pain relief score).

Analysis 24.2. Comparison 24 IV butorphanol versus IV pethidine, Outcome 2 Maternal pain score or pain measured in labour (Pain score (1 hour after drug administration)).

Analysis 24.3. Comparison 24 IV butorphanol versus IV pethidine, Outcome 3 Additional analgesia required.

Analysis 24.4. Comparison 24 IV butorphanol versus IV pethidine, Outcome 4 Epidural.

Analysis 24.5. Comparison 24 IV butorphanol versus IV pethidine, Outcome $5 \mathrm{Nausea}$ and/or vomiting.

Analysis 24.6. Comparison 24 IV butorphanol versus IV pethidine, Outcome 6 Caesarean section.

Analysis 24.7. Comparison 24 IV butorphanol versus IV pethidine, Outcome 7 Assisted vaginal birth.

Analysis 24.8. Comparison 24 IV butorphanol versus IV pethidine, Outcome 8 Apgar score $<7$ at 1 minute.

Analysis 24.9. Comparison 24 IV butorphanol versus IV pethidine, Outcome 9 Apgar score $<7$ at 5 minutes.

Analysis 25.1. Comparison 25 IV morphine versus IV pethidine, Outcome 1 Maternal satisfaction with analgesia (assessed 3 days postpartum).

Analysis 25.2. Comparison 25 IV morphine versus IV pethidine, Outcome 2 Additional analgesia required.

Analysis 25.3. Comparison 25 IV morphine versus IV pethidine, Outcome 3 Nausea and vomiting.

Analysis 25.4. Comparison 25 IV morphine versus IV pethidine, Outcome 4 Caesarean section.

Analysis 26.1. Comparison 26 IV Nisentil versus IV pethidine, Outcome 1 Nausea and vomiting.

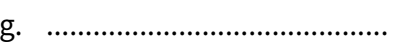

Analysis 26.2. Comparison 26 IV Nisentil versus IV pethidine, Outcome 2 Neonatal resuscitation/ventilatory support. .............

Analysis 27.1. Comparison 27 IV fentanyl versus IV butorphanol, Outcome 1 Additional analgesia required. .............................

Analysis 27.2. Comparison 27 IV fentanyl versus IV butorphanol, Outcome 2 Epidural.

Analysis 27.3. Comparison 27 IV fentanyl versus IV butorphanol, Outcome 3 Matenal sleepiness (required tactile rousing). .....

Analysis 27.4. Comparison 27 IV fentanyl versus IV butorphanol, Outcome 4 Caesarean section.

Analysis 27.5. Comparison 27 IV fentanyl versus IV butorphanol, Outcome 5 Naloxone required.

Analysis 27.6. Comparison 27 IV fentanyl versus IV butorphanol, Outcome 6 Neonatal resuscitation (Babies requiring ventilatory support).

Analysis 27.7. Comparison 27 IV fentanyl versus IV butorphanol, Outcome 7 Apgar score $<7$ at 5 minutes. ............................. Analysis 27.8. Comparison 27 IV fentanyl versus IV butorphanol, Outcome 8 Newborn neurobehavioural score at 2-4 hours. ... Analysis 27.9. Comparison 27 IV fentanyl versus IV butorphanol, Outcome 9 Newborn neurobehavioural score at 24-36 hours. . Analysis 28.1. Comparison 28 PCA pentazocine versus PCA pethidine, Outcome 1 Maternal pan score or pain measured in labour.

Analysis 28.2. Comparison 28 PCA pentazocine versus PCA pethidine, Outcome 2 Maternal pan score or pain measured in labour (rated as good one day after birth).

Analysis 28.3. Comparison 28 PCA pentazocine versus PCA pethidine, Outcome 3 Epidural.

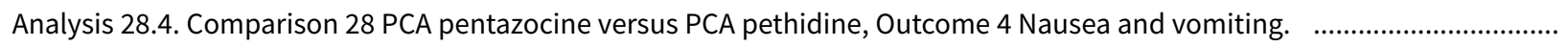
Analysis 28.5. Comparison 28 PCA pentazocine versus PCA pethidine, Outcome 5 Maternal sleepiness during labour (Sedation).

Analysis 28.6. Comparison 28 PCA pentazocine versus PCA pethidine, Outcome 6 Caesarean section.

Analysis 28.7. Comparison 28 PCA pentazocine versus PCA pethidine, Outcome 7 Breastfeeding at discharge.

Analysis 28.8. Comparison 28 PCA pentazocine versus PCA pethidine, Outcome 8 Apgar score $<7$ at 5 minutes.

Analysis 29.1. Comparison 29 PCA remifentanil versus PCA pethidine, Outcome 1 Maternal pain score in labour.

Analysis 29.2. Comparison 29 PCA remifentanil versus PCA pethidine, Outcome 2 Additional analgesia required. 
Analysis 29.8. Comparison 29 PCA remifentanil versus PCA pethidine, Outcome 8 Satisfaction with childbirth experience. ..... Analysis 29.9. Comparison 29 PCA remifentanil versus PCA pethidine, Outcome 9 Naloxone administered. ............................ Analysis 29.10. Comparison 29 PCA remifentanil versus PCA pethidine, Outcome 10 Apgar score $<7$ at 5 minutes. .................. Analysis 29.11. Comparison 29 PCA remifentanil versus PCA pethidine, Outcome 11 Admission to NICU. ................................ Analysis 29.12. Comparison 29 PCA remifentanil versus PCA pethidine, Outcome 12 Newborn neurobehavioural score (15 minutes post delivery).

Analysis 29.13. Comparison 29 PCA remifentanil versus PCA pethidine, Outcome 13 Newborn neurobehavioural score ( 2 hours post delivery).

Analysis 30.1. Comparison 30 PCA nalbuphine versus PCA pethidine, Outcome 1 Maternal satisfaction with analgesia in labour measured during the postnatal period (rated good or excellent).

Analysis 30.2. Comparison 30 PCA nalbuphine versus PCA pethidine, Outcome 2 Maternal satisfaction with analgesia in labour measured during the postnatal period (Would use the same pain relief again).

Analysis 30.3. Comparison 30 PCA nalbuphine versus PCA pethidine, Outcome 3 Maternal pain score or pain measured in labour.

Analysis 30.4. Comparison 30 PCA nalbuphine versus PCA pethidine, Outcome 4 Additional analgesia required.

Analysis 30.5. Comparison 30 PCA nalbuphine versus PCA pethidine, Outcome 5 Nausea and vomiting.

Analysis 30.6. Comparison 30 PCA nalbuphine versus PCA pethidine, Outcome 6 Apgar score $<7$ at 5 minutes.

Analysis 31.1. Comparison 31 PCA fentanyl versus PCA alfentanil, Outcome 1 Maternal satisfaction with analgesia in labour measured during the postnatal period (described as adequate).

Analysis 31.2. Comparison 31 PCA fentanyl versus PCA alfentanil, Outcome 2 Maternal pain score or pain measured in labour (Pain score at 4-6 cm cervical dilatation).

Analysis 31.3. Comparison 31 PCA fentanyl versus PCA alfentanil, Outcome 3 Nausea.

Analysis 31.4. Comparison 31 PCA fentanyl versus PCA alfentanil, Outcome 4 Caesarean section.

Analysis 31.5. Comparison 31 PCA fentanyl versus PCA alfentanil, Outcome 5 Naloxone required.

Analysis 32.1. Comparison 32 PCA fentanyl versus PCA pethidine, Outcome 1 Maternla pain score measured in labour. .......... Analysis 32.2. Comparison 32 PCA fentanyl versus PCA pethidine, Outcome 2 Epidural.

Analysis 32.3. Comparison 32 PCA fentanyl versus PCA pethidine, Outcome 3 Maternal sleepiness during labour. .................. Analysis 32.4. Comparison 32 PCA fentanyl versus PCA pethidine, Outcome 4 Nausea and vomiting.

Analysis 32.5. Comparison 32 PCA fentanyl versus PCA pethidine, Outcome 5 Caesarean section.

Analysis 32.6. Comparison 32 PCA fentanyl versus PCA pethidine, Outcome 6 Assisted vaginal birth.

Analysis 32.7. Comparison 32 PCA fentanyl versus PCA pethidine, Outcome 7 Newborn neurobehavioural score (15 minutes post delivery).

Analysis 32.8. Comparison 32 PCA fentanyl versus PCA pethidine, Outcome 8 Newborn neurobehavioural score (2 hours post delivery).

Analysis 33.1. Comparison 33 PCA (IM) meptazinol versus PCA (IM) pethidine, Outcome 1 Maternal pain score or pain measured in labour (measured 1 day after delivery).

Analysis 33.2. Comparison 33 PCA (IM) meptazinol versus PCA (IM) pethidine, Outcome 2 Satisfied with mode of administration (PCA IM) (non pre-specified).

Analysis 33.3. Comparison 33 PCA (IM) meptazinol versus PCA (IM) pethidine, Outcome 3 Epidural.

Analysis 33.4. Comparison 33 PCA (IM) meptazinol versus PCA (IM) pethidine, Outcome 4 Maternal sleepiness in labour (Drowsiness score in labour rated 1 day after delivery).

Analysis 33.5. Comparison 33 PCA (IM) meptazinol versus PCA (IM) pethidine, Outcome 5 Nausea (score in labour rated 1 day after delivery).

Analysis 33.6. Comparison 33 PCA (IM) meptazinol versus PCA (IM) pethidine, Outcome 6 Naloxone administered. ..................

Analysis 34.1. Comparison 34 Opioids versus TENS, Outcome 1 Maternal satisfaction with analgesia measured post delivery (rated as good).

Analysis 34.2. Comparison 34 Opioids versus TENS, Outcome 2 Maternal pain score measured during labour.

Analysis 34.3. Comparison 34 Opioids versus TENS, Outcome 3 Maternal pain score in labour.

Analysis 34.4. Comparison 34 Opioids versus TENS, Outcome 4 Maternal sleepiness during labour (Drowsiness).

Analysis 34.5. Comparison 34 Opioids versus TENS, Outcome 5 Nausea and vomiting.

Analysis 34.6. Comparison 34 Opioids versus TENS, Outcome 6 Caesarean section. 
[Intervention Review]

\section{Parenteral opioids for maternal pain management in labour}

Lesley A Smith ${ }^{1}$, Ethel Burns², Anna Cuthbert ${ }^{3}$

1Department of Psychology, Social Work and Public Health, Oxford Brookes University, Oxford, UK. 2Department of Psychology, Social Work and Public Health, Faculty of Health and Life Sciences, Oxford Brookes University, Oxford, UK. ${ }^{3}$ Cochrane Pregnancy and Childbirth Group, Department of Women's and Children's Health, The University of Liverpool, Liverpool, UK

Contact: Lesley A Smith, Department of Psychology, Social Work and Public Health, Oxford Brookes University, Jack Straws Lane, Marston, Oxford, OX3 0FL, UK. Lesley.Smith@hull.ac.uk.

Editorial group: Cochrane Pregnancy and Childbirth Group.

Publication status and date: New search for studies and content updated (no change to conclusions), published in Issue 6, 2018.

Citation: Smith LA, Burns E, Cuthbert A. Parenteral opioids for maternal pain management in labour. Cochrane Database of Systematic Reviews 2018, Issue 6. Art. No.: CD007396. DOI: 10.1002/14651858.CD007396.pub3.

Copyright @ 2018 The Cochrane Collaboration. Published by John Wiley \& Sons, Ltd.

\section{A B S T R A C T}

\section{Background}

Parenteral opioids (intramuscular and intravenous drugs including patient-controlled analgesia) are used for pain relief in labour in many countries throughout the world. This review is an update of a review first published in 2010.

\section{Objectives}

To assess the effectiveness, safety and acceptability to women of different types, doses and modes of administration of parenteral opioid analgesia in labour. A second objective is to assess the effects of opioids in labour on the baby in terms of safety, condition at birth and early feeding.

\section{Search methods}

We searched Cochrane Pregnancy and Childbirth's Trials Register, ClinicalTrials.gov, the WHO International Clinical Trials Registry Platform (ICTRP) (11 May 2017) and reference lists of retrieved studies.

\section{Selection criteria}

We included randomised controlled trials examining the use of intramuscular or intravenous opioids (including patient-controlled analgesia) for women in labour. Cluster-randomised trials were also eligible for inclusion, although none were identified. We did not include quasi-randomised trials. We looked at studies comparing an opioid with another opioid, placebo, no treatment, other nonpharmacological interventions (transcutaneous electrical nerve stimulation (TENS)) or inhaled analgesia.

\section{Data collection and analysis}

Two review authors independently assessed trials for inclusion and risk of bias, extracted data and checked them for accuracy. We assessed the quality of each evidence synthesis using the GRADE approach.

\section{Main results}

We included 70 studies that compared an opioid with placebo or no treatment, another opioid administered intramuscularly or intravenously or compared with TENS applied to the back. Sixty-one studies involving more than 8000 women contributed data to the review and these studies reported on 34 different comparisons; for many comparisons and outcomes only one study contributed data. All of the studies were conducted in hospital settings, on healthy women with uncomplicated pregnancies at 37 to 42 weeks' gestation. We excluded studies focusing on women with pre-eclampsia or pre-existing conditions or with a compromised fetus. Overall, the evidence was graded as low- or very low-quality regarding the analgesic effect of opioids and satisfaction with analgesia; evidence was downgraded because of study design limitations, and many of the studies were underpowered to detect differences between groups and so effect 
estimates were imprecise. Due to the large number of different comparisons, it was not possible to present GRADE findings for every comparison.

For the comparison of intramuscular pethidine $(50 \mathrm{mg} / 100 \mathrm{mg})$ versus placebo, no clear differences were found in maternal satisfaction with analgesia measured during labour (number of women satisfied or very satisfied after 30 minutes: 50 women; 1 trial; risk ratio (RR) $7.00,95 \%$ confidence interval $(\mathrm{Cl}) 0.38$ to 128.87 , very low-quality evidence), or number of women requesting an epidural (50 women; 1 trial; RR $0.50,95 \% \mathrm{Cl} 0.14$ to 1.78 ; very low-quality evidence). Pain scores (reduction in visual analogue scale (VAS) score of at least $40 \mathrm{~mm}$ : 50 women; 1 trial; RR 25, 95\% Cl 1.56 to 400, low-quality evidence) and pain measured in labour (women reporting pain relief to be "good" or "fair" within one hour of administration: 116 women; 1 trial; RR $1.75,95 \% \mathrm{Cl} 1.24$ to 2.47 , low-quality evidence) were both reduced in the pethidine group, and fewer women requested any additional analgesia (50 women; 1 trial; RR $0.71,95 \% \mathrm{Cl} 0.54$ to 0.94 , low-quality evidence).

There was limited information on adverse effects and harm to women and babies. There were few results that clearly showed that one opioid was more effective than another. Overall, findings indicated that parenteral opioids provided some pain relief and moderate satisfaction with analgesia in labour. Opioid drugs were associated with maternal nausea, vomiting and drowsiness, although different opioid drugs were associated with different adverse effects. There was no clear evidence of adverse effects of opioids on the newborn. We did not have sufficient evidence to assess which opioid drug provided the best pain relief with the least adverse effects.

\section{Authors' conclusions}

Though most evidence is of low- or very-low quality, for healthy women with an uncomplicated pregnancy who are giving birth at 37 to 42 weeks, parenteral opioids appear to provide some relief from pain in labour but are associated with drowsiness, nausea, and vomiting in the woman. Effects on the newborn are unclear. Maternal satisfaction with opioid analgesia was largely unreported. The review needs to be examined alongside related Cochrane reviews. More research is needed to determine which analgesic intervention is most effective, and provides greatest satisfaction to women with acceptable adverse effects for mothers and their newborn.

\section{PLAIN LANGUAGE SUMMARY}

\section{Intramuscular and intravenous opioid pain relieving drugs in labour}

\section{What is the issue?}

We set out to determine the effectiveness, side effects and acceptability to women of different opioids (pain killers), the doses used and how they are given during labour. We were also concerned about the effects of the opioids on the baby in terms of its safety, alertness at birth and early feeding.

Uterine contractions cause pain during labour, particularly as they reach their peak. The pain lessens as the contraction goes and the uterus relaxes. As labour progresses the uterine contractions become stronger, more frequent and longer lasting; at the same time they become more painful. The strongest, most frequent, and most intense uterine contractions generally occur at the end of the first stage of labour as the cervix reaches full dilatation. The mother then has the urge to push or bear down, which assists the birth of the baby. The severity of the pain varies considerably from woman to woman, and is influenced by mental and emotional factors. For example, continuous support during labour can help women to cope with the pain and help with their overall satisfaction with the childbirth experience.

\section{Why is this important?}

In many maternity units, intramuscular injections of opioid drugs are widely used for pain relief in labour. Options for intravenous administrations, often controlled by the woman, may also be available. Injected opioids can make women drowsy and interfere with their ability to engage in decision making about their care. They may also experience nausea and vomiting. Opioids can increase variations in fetal heart rate during labour and depress breathing. A number of different opioid drugs are available. The increasing use of epidural analgesia in resource-rich countries means that opioids are now less likely to be the drugs of choice in these settings. Yet in many parts of the world and in midwifery-led settings epidural analgesia is not available, and injected opioids are still widely used. They are relatively inexpensive. It is not clear how effective these drugs are, which opioid is best, and how adverse effects (such as vomiting or sleepiness) or harm to women or their babies can be avoided. This review is an update of a review first published in 2010.

\section{What evidence did we find?}

We searched for trials on 11 May 2017. We included 70 studies though only 61 studies involving more than 8000 women contributed data to the review. All of the trials were conducted in hospital settings, on healthy women with uncomplicated pregnancies at 37 to 42 weeks' gestation. The trials compared an opioid (intramuscular or intravenous) with placebo (dummy treatment), no treatment, another opioid (or in three trials another medication or inhaled nitrous oxide) or transcutaneous electrical nerve stimulation (TENS) in 34 different comparisons. There were few opportunities to pool the findings, and for many outcomes only one trial contributed findings. The quality of the evidence was mainly assessed as low or very low for the outcomes of pain in labour and satisfaction with analgesia. Many of the studies included insufficient numbers of women to detect differences between groups.

\section{What does this mean?}

Parenteral opioids for maternal pain management in labour (Review) 
Overall, our findings indicate that opioids provided some pain relief during labour, although substantial proportions of women still reported moderate or severe pain. Opioid drugs were associated with nausea, vomiting and drowsiness, with different types of opioids causing different side effects. We did not have sufficient evidence to assess which opioid drug provided the best pain relief with the least adverse effects. Nor did we find clear evidence of adverse effects of opioids on the newborn. Maternal satisfaction with opioid analgesia appeared moderate although it was often unreported or reported in different ways. We did not have sufficient evidence to assess which opioid drugs women were most satisfied with.

In this review we did not examine the effectiveness and safety of intramuscular or intravenous opioids compared with other methods of pain relief in labour such as epidural analgesia. The review needs to be examined alongside related Cochrane reviews. As injected opioid drugs are so widely used it is important that more research is carried out so that women can make informed choices about pain relief. 


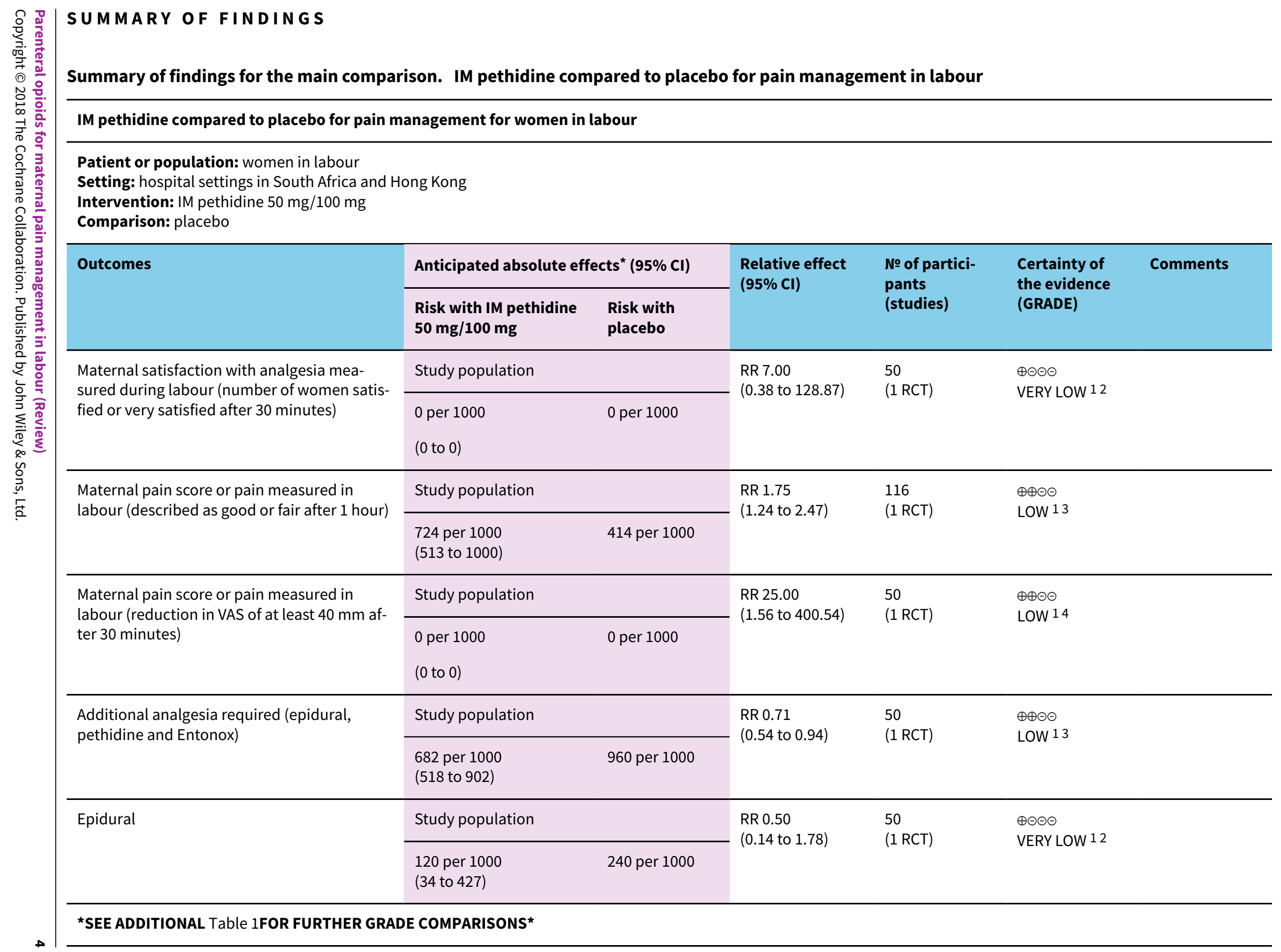




\begin{tabular}{|c|c|c|c|c|}
\hline \multicolumn{5}{|l|}{$\begin{array}{l}{ }^{*} \text { The risk in the intervention group (and its } 95 \% \\
\text { its } 95 \% \mathrm{Cl} \text { ). } \\
\text { Cl: confidence interval; RR: risk ratio }\end{array}$} \\
\hline \multicolumn{5}{|c|}{$\begin{array}{l}\text { GRADE Working Group grades of evidence } \\
\text { High certainty: we are very confident that the true effect lies close to that of the estimate of the effect } \\
\text { Moderate certainty: we are moderately confident in the effect estimate: The true effect is likely to be close to the estimate of the effect, but there is a possibility that it is } \\
\text { substantially different } \\
\text { Low certainty: our confidence in the effect estimate is limited: The true effect may be substantially different from the estimate of the effect } \\
\text { Very low certainty: we have very little confidence in the effect estimate: The true effect is likely to be substantially different from the estimate of effect }\end{array}$} \\
\hline \multicolumn{5}{|c|}{$\begin{array}{l}1 \text { Risk of bias: serious (effect estimate from single study with design limitations) } \\
2 \text { Imprecision: very serious (wide confidence interval crossing the line of no effect, few events, and small sample size) } \\
3 \text { Imprecision: serious (small sample size) } \\
4 \text { Imprecision: serious (small sample size and few events) }\end{array}$} \\
\hline \multirow[t]{2}{*}{ OUTCOME } & \multirow[t]{2}{*}{ N STUDIES (n women) } & \multicolumn{2}{|l|}{ EFFECT } & \multirow{2}{*}{$\begin{array}{l}\text { CERTAINTY OF EVI- } \\
\text { DENCE }\end{array}$} \\
\hline & & $\begin{array}{l}\text { Relative } \\
(95 \% \mathrm{CI})\end{array}$ & $\begin{array}{l}\text { Absolute } \\
(95 \% \mathrm{Cl})\end{array}$ & \\
\hline \multicolumn{5}{|l|}{ IM pethidine $50 \mathrm{mg} / 100 \mathrm{mg}$ versus placebo } \\
\hline $\begin{array}{l}\text { Maternal satisfaction with analgesia measured dur- } \\
\text { ing labour (number of women satisfied or very satis- } \\
\text { fied after } 30 \text { minutes) }\end{array}$ & $1(50)$ & $\begin{array}{l}\text { RR } 7.00 \\
\text { (0.38 to } 128.87 \text { ) }\end{array}$ & $\begin{array}{l}\text { O fewer per } 1000 \\
\text { (from } 0 \text { fewer to } 0 \text { fewer) }\end{array}$ & $\begin{array}{l}\oplus \odot \odot \odot \\
\text { VERY LOW a,b }\end{array}$ \\
\hline $\begin{array}{l}\text { Maternal pain score or pain measured in labour (de- } \\
\text { scribed as good or fair after } 1 \text { hour) }\end{array}$ & $1(118)$ & $\begin{array}{l}\text { RR } 1.75 \\
\text { (1.24 to } 2.47)\end{array}$ & $\begin{array}{l}\mathbf{3 1 0} \text { more per } 1000 \\
\text { (from } 99 \text { more to } 608 \text { more) }\end{array}$ & $\begin{array}{l}\oplus \oplus \ominus \ominus \\
\text { LOW a,c }\end{array}$ \\
\hline $\begin{array}{l}\text { Maternal pain score or pain measured in labour (re- } \\
\text { duction in VAS of at least } 40 \mathrm{~mm} \text { after } 30 \text { minutes) }\end{array}$ & $1(50)$ & $\begin{array}{l}\text { RR } 25.00 \\
\text { (1.56 to } 400.54)\end{array}$ & $\begin{array}{l}0 \text { fewer per } 1000 \\
\text { (from } 0 \text { fewer to } 0 \text { fewer) }\end{array}$ & $\begin{array}{l}\oplus \oplus \ominus \ominus \\
\text { LOW a,d }\end{array}$ \\
\hline Additional analgesia required & $1(50)$ & $\begin{array}{l}\text { RR } 0.71 \\
(0.54 \text { to } 0.94)\end{array}$ & $\begin{array}{l}\mathbf{2 7 8} \text { fewer per } 1000 \\
\text { (from } 58 \text { fewer to } 442 \text { fewer) }\end{array}$ & $\begin{array}{l}\oplus \oplus \ominus \ominus \\
\text { LOW a,c }\end{array}$ \\
\hline Epidural & $1(50)$ & $\begin{array}{l}\text { RR } 0.50 \\
(0.14 \text { to } 1.78)\end{array}$ & $\begin{array}{l}\mathbf{1 2 0} \text { fewer per } 1000 \\
\text { (from } 187 \text { more to } 206 \text { fewer) }\end{array}$ & $\begin{array}{l}\oplus \odot \odot \odot \\
\text { VERY LOW a,b }\end{array}$ \\
\hline
\end{tabular}




\begin{tabular}{|c|c|c|c|c|}
\hline Maternal pain score measured during labour & $1(89)$ & - & $\begin{array}{l}\text { MD 3.60 lower } \\
\text { (9.91 lower to } 2.71 \text { higher) }\end{array}$ & $\begin{array}{l}\oplus \oplus \ominus \ominus \\
\text { LOWe }\end{array}$ \\
\hline \multicolumn{5}{|l|}{ IM tramadol versus no treatment } \\
\hline $\begin{array}{l}\text { Maternal satisfaction with analgesia (Analgesic ef- } \\
\text { fect described as satisfactory (not clear when mea- } \\
\text { sured)) }\end{array}$ & $1(60)$ & $\begin{array}{l}\text { RR } 11.00 \\
(0.64 \text { to } 190.53)\end{array}$ & $\begin{array}{l}0 \text { fewer per } 1000 \\
\text { (from } 0 \text { fewer to } 0 \text { fewer) }\end{array}$ & $\begin{array}{l}\oplus \ominus \Theta \odot \\
\text { VERY LOW b,f }\end{array}$ \\
\hline $\begin{array}{l}\text { Maternal pain score or pain measured in labour (Ma- } \\
\text { ternal pain relief poor or none (3-5 PN)) }\end{array}$ & $1(801)$ & $\begin{array}{l}\text { RR } 1.01 \\
(0.91 \text { to } 1.12)\end{array}$ & $\begin{array}{l}6 \text { more per } 1000 \\
\text { (from } 57 \text { fewer to } 77 \text { more) }\end{array}$ & $\begin{array}{l}\oplus \oplus \ominus \odot \\
\text { LOW a,g }\end{array}$ \\
\hline $\begin{array}{l}\text { Maternal pain score or pain measured in labour (Pain } \\
\text { intensity } 4 \text { or } 5 \text { on } 5 \text {-point scale ( } 1 \text { hour)) }\end{array}$ & $2(239)$ & $\begin{array}{l}\text { RR } 1.11 \\
(0.69 \text { to } 1.80)\end{array}$ & $\begin{array}{l}79 \text { more per } 1000 \\
\text { (from } 223 \text { fewer to } 576 \text { more) }\end{array}$ & $\begin{array}{l}\oplus \ominus \ominus \ominus \\
\text { VERY LOW e,h }\end{array}$ \\
\hline Additional analgesia required & $2(233)$ & $\begin{array}{l}\text { RR } 1.03 \\
(0.88 \text { to } 1.20)\end{array}$ & $\begin{array}{l}20 \text { more per } 1000 \\
\text { (from } 81 \text { fewer to } 134 \text { more) }\end{array}$ & $\begin{array}{l}\oplus \ominus \ominus \ominus \\
\text { VERY LOW e,h }\end{array}$ \\
\hline Epidural & $4(788)$ & $\begin{array}{l}\mathbf{R R} 0.96 \\
(0.71 \text { to } 1.29)\end{array}$ & $\begin{array}{l}7 \text { fewer per } 1000 \\
\text { (from } 52 \text { fewer to } 52 \text { more) }\end{array}$ & $\begin{array}{l}\oplus \ominus \ominus \ominus \\
\text { VERY LOW g,i }\end{array}$ \\
\hline \multicolumn{5}{|c|}{ IM diamorphine + prochlorperazine versus pethidine + prochlorperazine } \\
\hline $\begin{array}{l}\text { Maternal satisfaction with analgesia in labour mea- } \\
\text { sured during the postnatal period (Global assess- } \\
\text { ment of pain relief at } 24 \text { hours) }\end{array}$ & $1(133)$ & $\begin{array}{l}\mathbf{R R} \mathbf{0 . 8 8} \\
(0.67 \text { to } 1.16)\end{array}$ & $\begin{array}{l}78 \text { fewer per } 1000 \\
\text { (from } 104 \text { more to } 214 \text { fewer) }\end{array}$ & $\begin{array}{l}\oplus \ominus \ominus \ominus \\
\text { VERY LOW a,e }\end{array}$ \\
\hline $\begin{array}{l}\text { Maternal pain score or pain measured in labour (Pain } \\
\text { intensity at } 1 \text { hour (moderate or severe)) }\end{array}$ & $1(133)$ & $\begin{array}{l}\mathbf{R R} 0.85 \\
(0.72 \text { to } 1.01)\end{array}$ & $\begin{array}{l}130 \text { fewer per } 1000 \\
\text { (from } 9 \text { more to } 243 \text { fewer) }\end{array}$ & $\begin{array}{l}\oplus \Theta \Theta \odot \\
\text { VERY LOW a,e }\end{array}$ \\
\hline Additional analgesia required & $1(133)$ & $\begin{array}{l}\text { RR } 1.35 \\
(0.53 \text { to } 3.40)\end{array}$ & $\begin{array}{l}36 \text { more per } 1000 \\
\text { (from } 48 \text { fewer to } 247 \text { more) }\end{array}$ & $\begin{array}{l}\oplus \ominus \ominus \ominus \\
\text { VERY LOW a,b }\end{array}$ \\
\hline Epidural & $1(133)$ & $\begin{array}{l}\text { RR } 1.22 \\
(0.72 \text { to } 2.07)\end{array}$ & $\begin{array}{l}\mathbf{5 8} \text { more per } 1000 \\
\text { (from } 74 \text { fewer to } 283 \text { more) }\end{array}$ & $\begin{array}{l}\oplus \ominus \ominus \ominus \\
\text { VERY LOW a,b }\end{array}$ \\
\hline $\begin{array}{l}\text { Maternal pain score or pain measured in labour (Pain } \\
\text { intensity: women with poor pain relief) }\end{array}$ & $4(243)$ & $\begin{array}{l}\text { RR } 1.56 \\
\text { (1.10 to } 2.21)\end{array}$ & $\begin{array}{l}142 \text { more per } 1000 \\
\text { (from } 25 \text { more to } 307 \text { more) }\end{array}$ & $\oplus \oplus \ominus \ominus$ \\
\hline
\end{tabular}




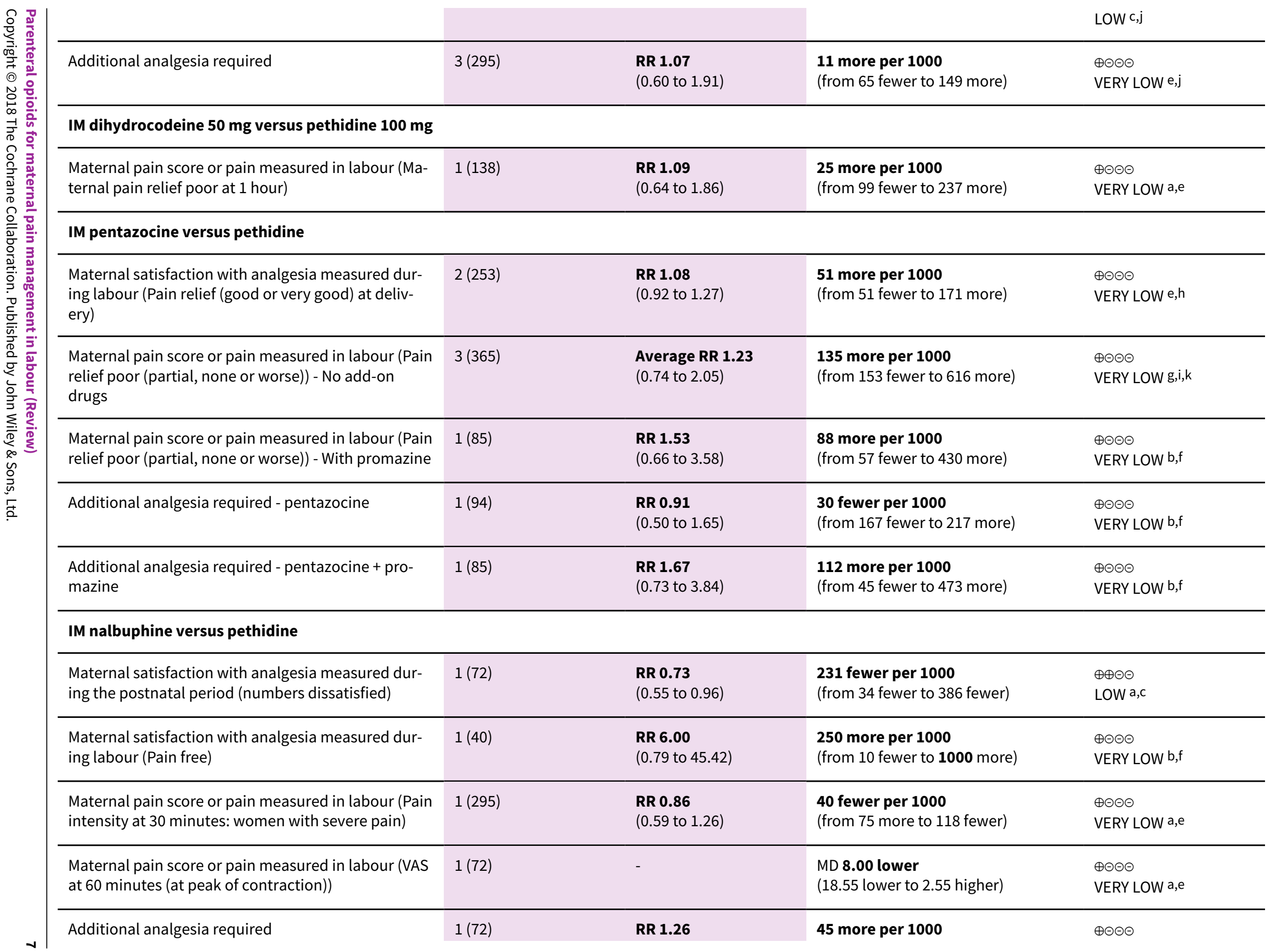




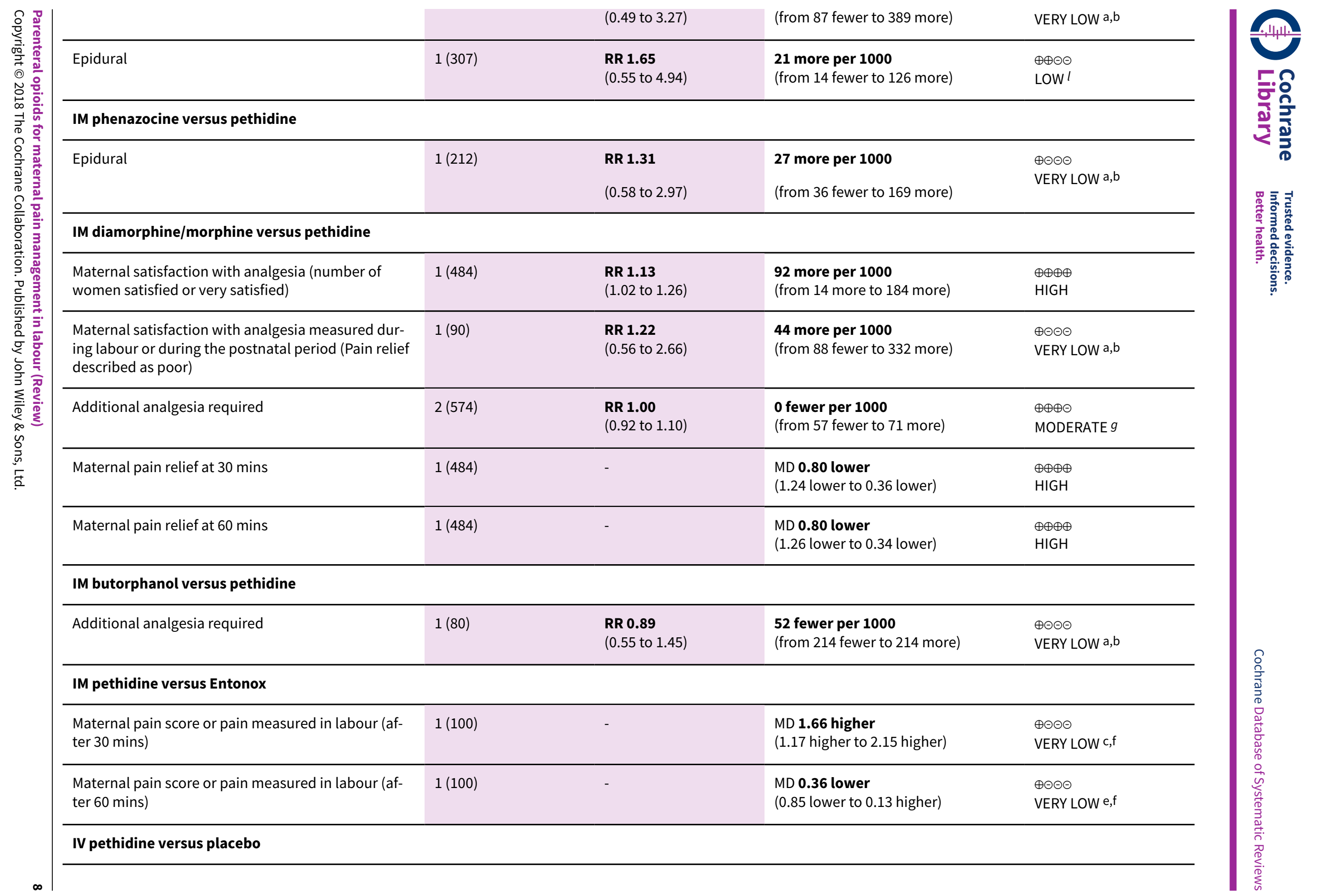




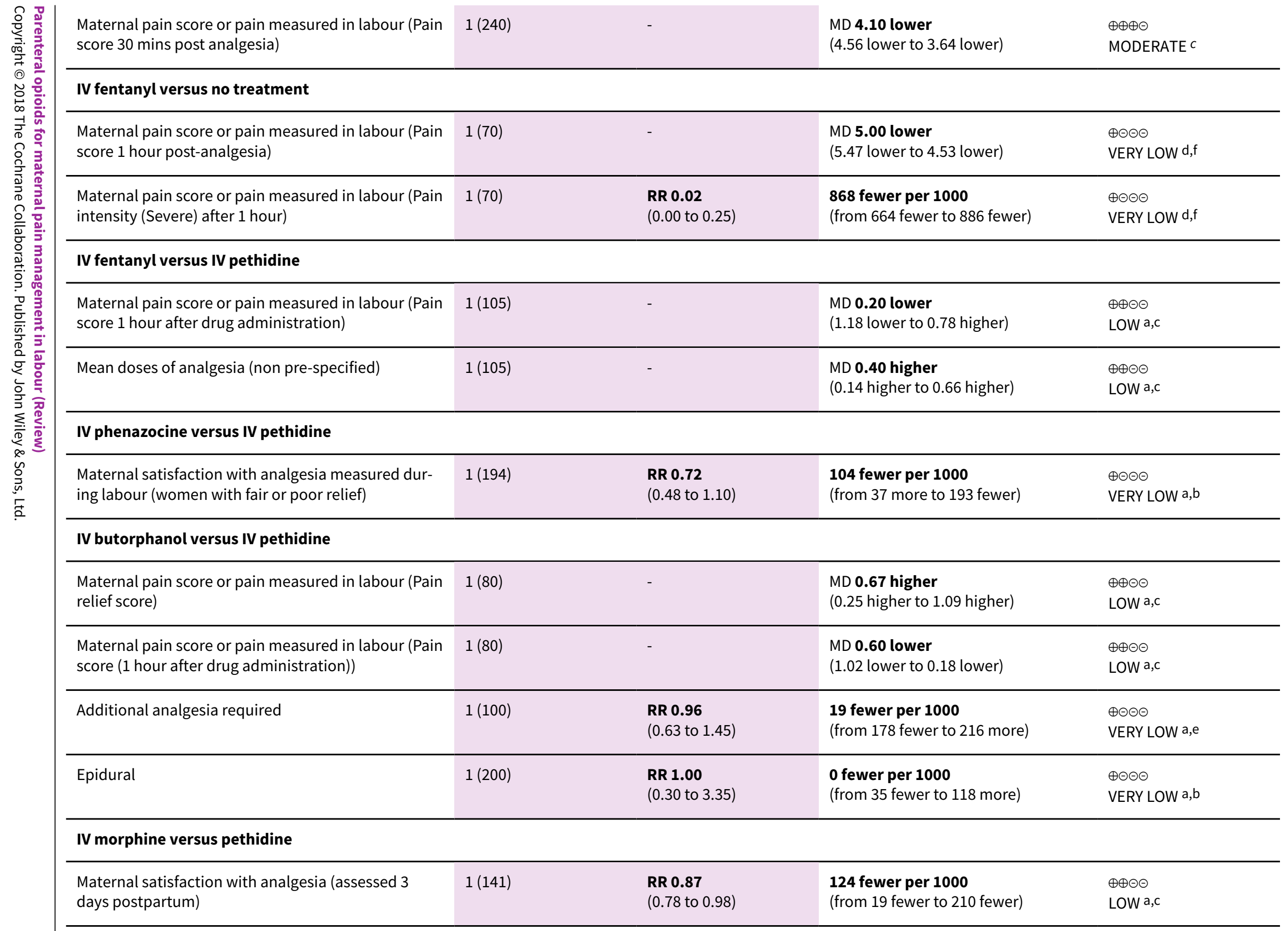




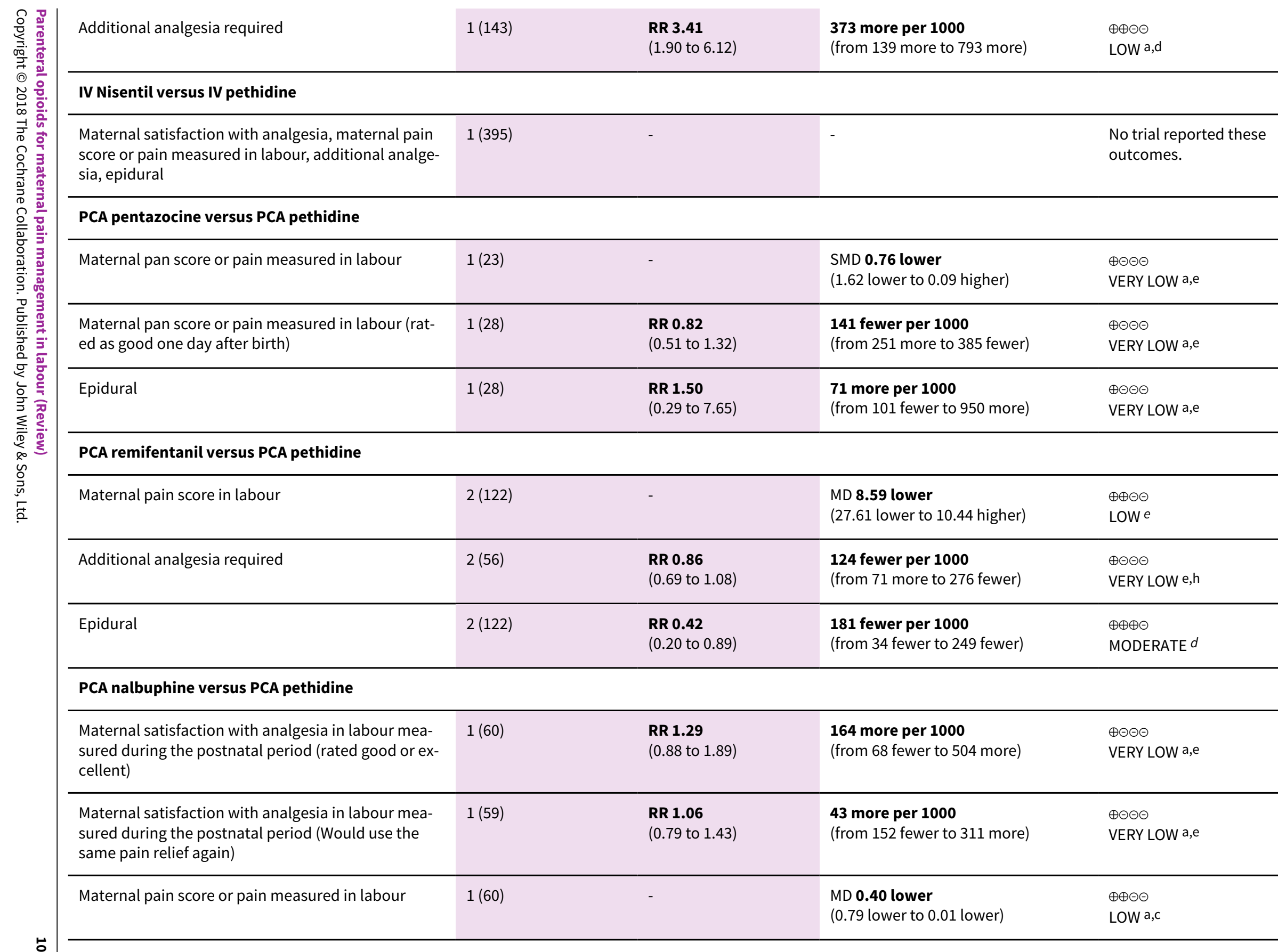




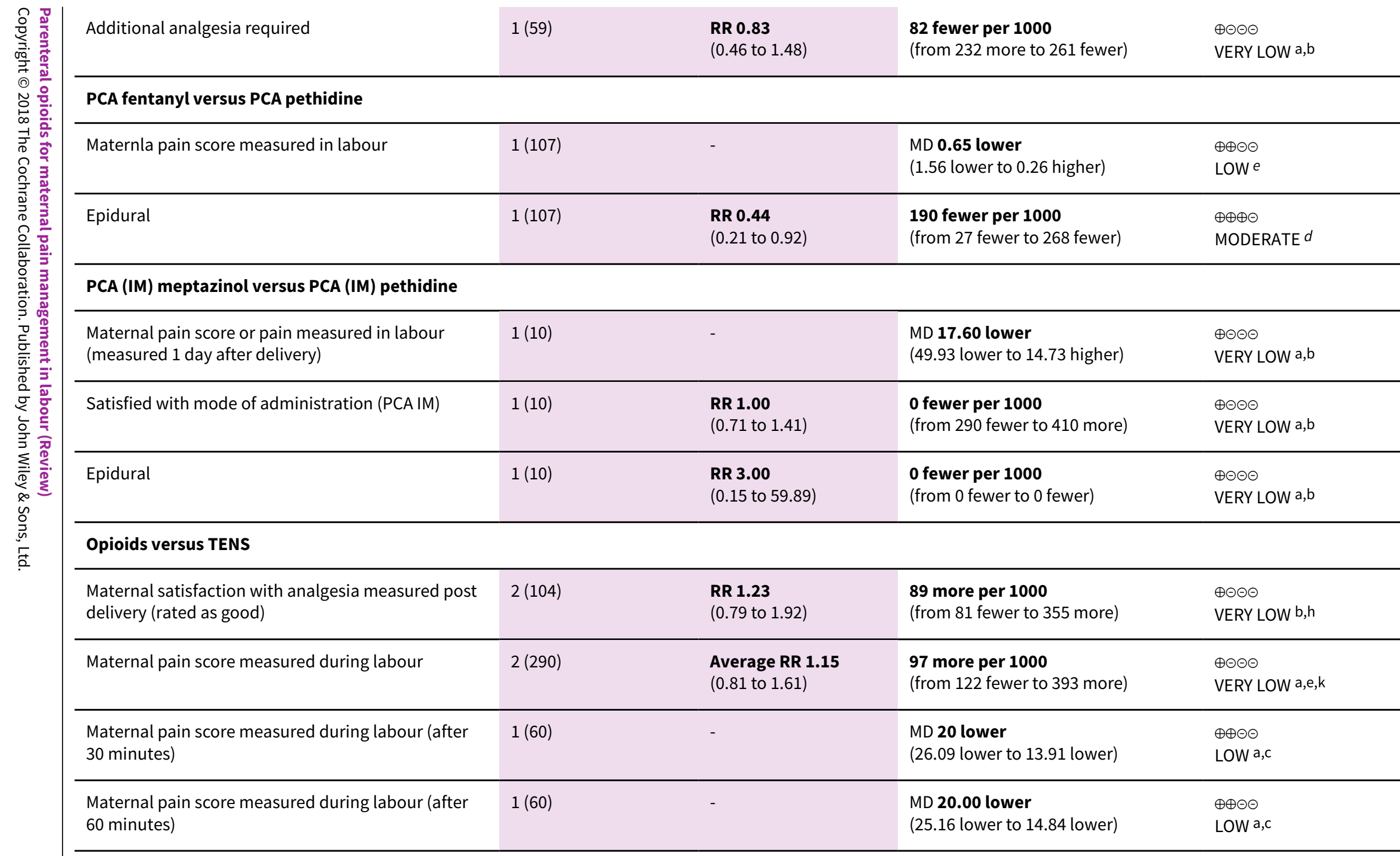

Cl: confidence interval; RR: risk ratio; MD: mean difference

$a^{a}$ Risk of bias: serious (Effect estimate from single study with design limitations)

$b$ Imprecision: very serious (Wide confidence interval crossing the line of no effect, few events, and small sample size)

c Imprecision: serious (Small sample size)

$d$ Imprecision: serious (Small sample size and few events)

e Imprecision: very serious (Wide confidence interval crossing the line of no effect, and small sample size) 
Risk of bias: very serious (Effect estimate from single study with serious design limitations)

$g$ Imprecision: serious (Wide confidence interval crossing the line of no effect)

$h$ Risk of bias: serious (Pooled effect provided by studies with design limitations)

i Risk of bias: very serious (Pooled effect provided by studies with serious design limitations)

jRisk of bias: serious (Pooled effect estimate mainly from studies with design limitations)

$k$ Inconsistency: serious (unexplained substantial heterogeneity)

I Imprecision: very serious (Wide confidence interval crossing the line of no effect, and few events) 


\section{B A C K G R O U N D}

This review was last published in 2010 (Ullman 2010) as one of a series of Cochrane reviews examining pain management in labour. These reviews contributed to an overview of systematic reviews of pain management for women in labour (Jones 2012), and shared a generic protocol (Jones 2011). This current review is an update from the previous version (Ullman 2010).

\section{Description of the condition}

Pain during labour is a physiological phenomenon, being one of the few examples of pain which does not signal pathology or harm. This does not make the experience of pain any less, but it may alter the way pain is perceived, both by the labouring woman and those providing her care.

Pain during labour is intermittent; it accompanies uterine contractions, particularly as they reach their peak with the activation of oxytocin receptors around the cervix, and then diminishes as the contraction goes and the uterus relaxes (Eisenach 2010). Between contractions the uterus is at rest and there is usually no associated pain. As labour progresses the uterine contractions grow stronger, more frequent and longer lasting; at the same time they become more painful. Typically, the strongest, most frequent, and most intense uterine contractions occur at the end of the first stage of labour as the cervix reaches full dilatation. While the vast majority of women will describe at least some stages of labour as painful, the severity of reported pain varies considerably (Jones 2011a).

\section{Pain relief in labour - physiology and pain perceptions}

Labour pain as perceived by women is a unique, subjective and complex neuro-hormonal phenomenon, which involves the interaction of physiological and psychological factors (Genesi 1998a; Genesi 1998b; Trout 2004). Several factors have been shown to reduce pain experienced by women in labour. These include continuous support of a caregiver, attendance of a birth companion and a relaxed birth environment (Bohren 2017; Hodnett 2012; Sandall 2016). Additional key determinants that may influence the pain that a woman experiences are feeling in control, level of anxiety, her rapport with her caregivers and her birth companions, and the care setting where she gives birth (Anim-Somuah 2018; Klomp 2014; Lang 2006). Having more control fosters a woman's sense of self-belief and confidence in her capacity to labour and give birth, which also affects her pain perception (Cook 2012; Lowe 2002). The extent to which a woman can actively participate in negotiating the care she receives has also been linked to overall maternal satisfaction with the childbirth experience (Green 2003; Hodnett 2002). The degree to which a woman is satisfied with the birth experience is not, therefore, solely associated with the pain felt. From the clinical point of view, the management of pain during labour involves much more than simply the provision of a pharmacological intervention. It is important that decisions for coping with the pain of labour are based on informed choice (Green 2003; Hawkins 2003).

Practitioners' attitudes to maternal pain vary (Leap 2004). Characteristics such as philosophical perspective, length of time in practice, knowledge and experience, care setting, cultural differences, and beliefs may all influence the approach midwives will adopt when caring for women during labour; some adopt a rescue position to relieve the pain and recommend the use of analgesia, whilst others facilitate the woman to optimise coping mechanisms, using strategies involving breathing and/or relaxation techniques and positions that offer her more comfort (Aziato 2016; Lally 2014; Lamm 2007; Leap 2004; Williams 2013).

Women's attitudes towards, and preferences for, intrapartum pain relief vary widely. Whilst some women prefer to labour without the use of pharmacological analgesia, others opt, for example, to use epidural analgesia throughout labour. Good communication and sensitive support from caregivers improves a woman's experience of labour, and her overall satisfaction with care, regardless of her choice of pain relief or levels of reported pain (Hodnett 2002). It is important that decisions for coping with the pain of labour are based on informed choice (Green 2003; Hawkins 2003).

\section{Description of the intervention}

\section{Pain relief in labour - the use of opioids}

The use of pain-relieving drugs during labour is now standard care in many countries throughout the world (Bricker 2002; Tveit 2009; Wong 2009). The extent of usage of parenteral (intramuscular and intravenous drugs including patient-controlled analgesia) opioids during labour is unclear; however, most obstetric units in middleand high-income countries offer intramuscular opioids, along with facilities for epidural analgesia. Opioids are relatively inexpensive, and use of the opioid drugs pethidine, meptazinol or diamorphine during labour is common midwifery and obstetric practice in some countries. In other parts of the world, parenteral opioids commonly used in labour include morphine, nalbuphine, fentanyl and remifentanil (Evron 2007). Worldwide, pethidine is the most commonly used opioid (Bricker 2002; Wong 2009). Other opioids include: meperidine, butorphanol, buprenorphine, pentazocine, tramadol, alfentanil and sufentanil. In the UK, a midwife can take responsibility for giving a woman an intramuscular injection of either pethidine or diamorphine, without a prescription from a medical practitioner, whether she is working in the hospital or community care setting (MHRA 2007).

In the UK, data from a random sample of 4571 women who gave birth over a two-week period during 2014 showed that 25\% used pethidine or a similar opioid during labour (Redshaw 2015). This reflects a decreasing trend in parenteral opioid use from $33 \%$ of women in a similar survey in 2006 (Redshaw 2007). In contrast, reported epidural/regional analgesia use has remained constant; $28 \%$ in 2006 (Redshaw 2007), and 29\% in 2014 (Redshaw 2015). This latest survey indicates a higher proportion of nulliparous women using an opioid (with or without an epidural) compared with multiparous women (Redshaw 2015). Studies in New Zealand and the UK have revealed that more than $95 \%$ of hospitals surveyed routinely offered intramuscular pethidine (Lee 2004; Saravanakumar 2007). In the UK study, approximately half (49\%) of the units surveyed offered patient-controlled intravenous opioid analgesia for use in labour (Saravanakumar 2007).

Some maternity practitioners have voiced concerns about the use of parenteral opioid analgesia during labour. These centre on doubt about analgesic effectiveness, and anxiety about the sedative effects on women and babies. Concerns relating to maternal outcomes include an impaired capacity to engage in decision making about care, nausea and/or vomiting, and the slowing down of gastric emptying, which increases the risk of 
inhalation of gastric contents should a general anaesthetic be required in an emergency situation. If a woman feels drowsy or sedated, she is less likely to mobilise and adopt an upright position, and as a result this may lengthen her labour, and make it more painful (Lawrence 2013). These concerns are particularly relevant to midwives who are caring for women in midwiferyled community settings where strategies such as mobilisation and water immersion are implemented to optimise labour progress.

\section{Effects on the baby}

Opioids readily cross the placenta by passive diffusion, and have been shown to compromise fetal well-being during labour (Reynolds 2002; Sosa 2006). Pethidine has been shown to significantly affect fetal heart rate variability, accelerations and decelerations during labour (Solt 2002). Changes in normal fetal heart indices have consequences for the woman. She will be required to have electronic fetal heart rate monitoring (EFM) if she is in hospital, and transfer to hospital if she is in a community setting. Results from observational studies have reported effects of opioids on the newborn that include inhibited sucking at the breast and decreased alertness, resulting in delayed effective breastfeeding (Brimdyr 2015; Fleet 2017; Jordan 2005; Lind 2014; Nissen 1995; Ransjo-Arvidson 2001; Righard 1990). There is clear evidence showing that early skin-to-skin contact and the successful onset of early breastfeeding have major benefits for mothers and their babies with far-reaching benefits into adulthood (Aghdas 2014; Carberry 2013; Moore 2016; Victora 2016; Widstrom 2011). It has been suggested that interventions which compromise this contact and early suckling can impact on neonatal mortality (Edmond 2006). It is estimated that it can take a newborn three to six days to eliminate pethidine, and its metabolite, norpethidine, from its system (Hogg 1977).

\section{How the intervention might work}

Opioid drugs are narcotic drugs that work by binding to opioid receptors in the brain and spinal cord, thereby inhibiting the transmission of pain signals. A range of opioids have been used to treat both acute and chronic pain, and they are often used to control cancer pain. Opioids have mainly been used to treat moderate and severe pain. Although opioids have been used to treat pain in labour for many years, there have been concerns about their use relating to their sedative effects, and questions have been raised about their effectiveness in labour and about their safety for women and babies (Lawrence 2013).

\section{Why it is important to do this review}

This review evaluates the effectiveness and safety of parenteral opioids for analgesia in labour. The use of intramuscular injections of opioid analgesia in labour became a traditional part of midwifery practice without evidence from randomised controlled trials demonstrating analgesic effectiveness, impact on labour outcomes or acceptability to women. It is thought that the perceived analgesic efficacy of parenteral opioids may be due, at least in part, to their sedative effects rather than a true reduction in maternal pain perception (NICE 2014; Wong 2009). There remains uncertainty amongst practitioners as to which opioid provides the most effective pain relief, and whether opioids used during labour are acceptable to women. The most effective and acceptable mode of administration also remains unknown. In addition, there are concerns about the potential adverse effects associated with the use of opioids in labour, particularly the effects on the newborn in relation to infant feeding.

At present, the choice of opioid for analgesia in labour depends on what is available in different hospitals. However, no matter what facilities and drugs are available, women often have no choice as to which drug is used, and healthcare professionals have little information to guide decision-making. Whilst there have been previous reviews on this topic (Bricker 2002; Elbourne 2006), this review provides an up-to-date summary of existing knowledge. We aim to provide best evidence to facilitate discussions between maternity practitioners and women to enable them to make informed decisions about their choice of analgesia during labour. This review is an update of a review first published in 2010 (Ullman 2010).

\section{O B JECT IVES}

To assess the effectiveness, safety and acceptability to women of different types, doses and modes of administration of parenteral opioid analgesia in labour. A second objective is to assess the effects of opioids in labour on the baby in terms of safety, condition at birth and early feeding.

\section{METHODS}

\section{Criteria for considering studies for this review}

\section{Types of studies}

Randomised controlled trials. Cluster-randomised trials were also eligible for inclusion, although none were identified. We did not include quasi-randomised or cross-over trials. Trials using a crossover design are not suitable for interventions in labour. We included studies presented only in abstracts provided that there was enough information to allow us to assess eligibility and risk of bias; if there was insufficient information we attempted to contact study authors.

\section{Types of participants}

Women in labour. We excluded studies focusing specifically and exclusively on women in high-risk groups, or women in premature labour (before 37 weeks' gestation), but have included studies which include such women as part of a broader sample.

\section{Types of interventions}

Parenteral opioids (intramuscular and intravenous drugs, including patient-controlled analgesia).

Drugs for comparison include pethidine or meperidine, morphine, nalbuphine, butorphanol, diamorphine, buprenorphine, meptazinol, pentazocine, tramadol, alfentanil, sufentanil, remifentanil and fentanyl.

The following comparisons were eligible for the review.

1. An opioid versus placebo using the same route of administration.

2. An opioid versus another opioid using the same route of administration.

3. An opioid plus an add-on drug versus another opioid plus the same add-on drug using the same route of administration.

4. One opioid versus the same opioid but a different dose. 
We planned to use trialists' definitions of higher and lower doses of the same drugs, as high and low doses are different for different opioids.

Where different doses of the same drug were compared with the same comparator (e.g. $40 \mathrm{mg}$ pethidine versus placebo, and $80 \mathrm{mg}$ pethidine versus placebo), we planned to use subgroup analyses to examine findings.

This previous version of this review was one in a series of Cochrane reviews examining pain management in labour. These reviews contributed to an overview of systematic reviews of interventions for pain management in labour (Jones 2012), and shared a generic protocol (Jones 2011). To avoid duplication, the different methods of pain management were listed in a specific order, from one to 15. Individual reviews focusing on particular interventions included comparisons with only the interventions above it on the list. The current list is as follows.

1. Placebo

2. No treatment

3. Hypnosis (Madden 2016)

4. Biofeedback (Barragán 2011)

5. Intracutaneous or subcutaneous sterile water injection (Derry 2012)

6. Immersion in water (Cluett 2009)

7. Aromatherapy (Smith 2011a)

8. Relaxation techniques (yoga, music, audio) (Smith 2018a)

9. Acupuncture or acupressure (Smith 2011b)

10.Massage, reflexology and other manual methods (Smith 2018b)

11.Transcutaneous electrical nerve stimulation (TENS) (Dowswell 2009)

12.Inhaled analgesia (Klomp 2012)

13.Opioids (this review)

14.Non-opioid drugs (Othman 2012)

15.Local anaesthetic nerve blocks (Novikova 2011)

16. Epidural (including combined spinal epidural) (Anim-Somuah 2018; Simmons 2012)

Accordingly, this review includes comparisons of an opioid with: 1. placebo/no treatment; 2. hypnosis; 3. biofeedback; 4. intracutaneous or subcutaneous sterile water injection; 5. immersion in water; 6 . aromatherapy; 7 . relaxation techniques (yoga, music, audio); 8. acupuncture or acupressure; 9. manual methods (massage, reflexology); 10. TENS; 11. inhaled analgesia; or 12. another opioid (as specified above).

\section{Types of outcome measures}

\section{Primary outcomes}

1. Maternal satisfaction with analgesia measured during labour

2. Maternal satisfaction with analgesia in labour measured during the postnatal period

\section{Secondary outcomes}

\section{For women}

1. Maternal pain score or pain measured in labour

2. Additional analgesia required

3. Epidural
4. Maternal sleepiness during labour

5. Nausea and vomiting in labour

6. Caesarean section

7. Assisted vaginal birth

8. Postpartum haemorrhage (as defined by the trial authors)

9. Breastfeeding at discharge

10. Breastfeeding in the postnatal period (four to six weeks)

11.Sense of control in labour (as defined by trialists)

12.Satisfaction with childbirth experience (as defined by trialists)

13.Effect (negative) on mother/baby interaction

\section{For babies}

1. Fetal heart rate changes in labour (persistent decelerations or tachycardia)

2. Naloxone administration

3. Neonatal resuscitation

4. Apgar score less than seven at one minute

5. Apgar score less than seven at five minutes

6. Apgar score less than seven at ten minutes

7. Admission to special care baby unit/neonatal intensive care unit (as defined by trialists)

8. Newborn neuro-behavioural scores

9. Neurodevelopment outcomes during infancy

\section{Other}

1. Cost (as defined by trialists)

\section{Search methods for identification of studies}

The following search methods section of this review is based on a standard template used by Cochrane Pregnancy and Childbirth.

\section{Electronic searches}

We searched Cochrane Pregnancy and Childbirth's Trials Register by contacting their Information Specialist (11 May 2017).

The Register is a database containing over 24,000 reports of controlled trials in the field of pregnancy and childbirth. For full search methods used to populate Pregnancy and Childbirth's Trials Register including the detailed search strategies for CENTRAL, MEDLINE, Embase and CINAHL; the list of handsearched journals and conference proceedings, and the list of journals reviewed via the current awareness service, please follow this link to the editorial information about the Cochrane Pregnancy and Childbirth in the Cochrane Library and select the 'Specialized Register' section from the options on the left side of the screen.

Briefly, Cochrane Pregnancy and Childbirth's Trials Register is maintained by their Information Specialist and contains trials identified from:

1. monthly searches of the Cochrane Central Register of Controlled Trials (CENTRAL);

2. weekly searches of MEDLINE (Ovid);

3. weekly searches of Embase (Ovid);

4. monthly searches of CINAHL (EBSCO);

5. handsearches of 30 journals and the proceedings of major conferences; 
6. weekly current awareness alerts for a further 44 journals plus monthly BioMed Central email alerts.

Search results are screened by two people and the full text of all relevant trial reports identified through the searching activities described above is reviewed. Based on the intervention described, each trial report is assigned a number that corresponds to a specific Pregnancy and Childbirth review topic (or topics), and is then added to the Register. The Information Specialist searches the Register for each review using this topic number rather than keywords. This results in a more specific search set that has been fully accounted for in the relevant review sections (Included studies; Excluded studies; Studies awaiting classification; Ongoing studies).

In addition, we searched ClinicalTrials.gov and the WHO International Clinical Trials Registry Platform (ICTRP) for unpublished, planned and ongoing trial reports using the methods detailed in Appendix 1 (searched 11 May 2017).

\section{Searching other resources}

We searched the reference lists of background review articles and the reference lists of papers retrieved by the search.

We did not apply any language or date restrictions.

\section{Data collection and analysis}

For methods used in the previous version of this review, see Ullman 2010.

For this update, the following methods were used for assessing the 70 reports that were identified as a result of the updated search.

The following methods section of this review is based on a standard template used by Cochrane Pregnancy and Childbirth.

\section{Selection of studies}

In this update two review authors (A Cuthbert (AC), Lesley Smith (LS) independently assessed for inclusion all the new reports identified as a result of the search strategy. We resolved any disagreement through discussion or, if required, we consulted a third author (E Burns).

\section{Data extraction and management}

For eligible studies, two same two review authors extracted the data using an agreed form. We resolved discrepancies through discussion or, if required, we consulted the third review author. Data were entered into Review Manager software (RevMan 2014) and checked for accuracy.

When information regarding any of the above was unclear, we contacted authors of the original reports to provide further details.

\section{Assessment of risk of bias in included studies}

Two review authors independently assessed risk of bias for each study using the criteria outlined in the Cochrane Handbook for Systematic Reviews of Interventions (Higgins 2011a). Any disagreement was resolved by discussion or by involving the third assessor.

\section{(1) Random sequence generation (checking for possible} selection bias)

We described the method used to generate the allocation sequence in sufficient detail to allow an assessment of whether it should produce comparable groups.

For each included study we assessed the method as being at:

- low risk of bias (any truly random process, e.g. random number table; computer random number generator);

- high risk of bias (any non-random process, e.g. odd or even date of birth; hospital or clinic record number);

- unclear risk of bias.

\section{(2) Allocation concealment (checking for possible selection bias)}

For each included study we described the method used to conceal allocation to interventions prior to assignment and assessed whether intervention allocation could have been foreseen in advance of, or during recruitment, or changed after assignment.

We assessed the methods as being at:

- low risk of bias (e.g. telephone or central randomisation; consecutively numbered sealed opaque envelopes);

- high risk of bias (open random allocation; unsealed or nonopaque envelopes, alternation; date of birth);

- unclear risk of bias.

\section{(3.1) Blinding of participants and personnel (checking for possible performance bias)}

For each included study we described the methods used, if any, to blind study participants and personnel from knowledge of which intervention a participant received. We considered that studies were at low risk of bias if they were blinded, or if we judged that the lack of blinding was unlikely to affect results. We assessed blinding separately for different outcomes or classes of outcomes.

We assessed the methods as being at:

- low, high or unclear risk of bias for participants;

- low, high or unclear risk of bias for personnel.

\section{(3.2) Blinding of outcome assessment (checking for possible detection bias)}

For each included study we described the methods used, if any, to blind outcome assessors from knowledge of which intervention a participant received. We assessed blinding separately for different outcomes or classes of outcomes.

We assessed methods used to blind outcome assessment as being at:

- low, high or unclear risk of bias.

\section{(4) Incomplete outcome data (checking for possible attrition bias due to the amount, nature and handling of incomplete outcome data)}

For each included study, and for each outcome or class of outcomes, we described the completeness of data including attrition and exclusions from the analysis. We stated whether attrition and exclusions were reported and the numbers included 
in the analysis at each stage (compared with the total randomised participants), reasons for attrition or exclusion where reported, and whether missing data were balanced across groups or were related to outcomes. Where sufficient information was reported, or could be supplied by the trial authors, we planned to re-include missing data in the analyses that we undertook.

We assessed methods as being at:

- low risk of bias (e.g. no missing outcome data; missing outcome data balanced across groups);

- high risk of bias (e.g. numbers or reasons for missing data imbalanced across groups; 'as treated' analysis done with substantial departure of intervention received from that assigned at randomisation);

- unclear risk of bias.

\section{(5) Selective reporting (checking for reporting bias)}

For each included study we described how we investigated the possibility of selective outcome reporting bias and what we found.

We assessed the methods as being at:

- low risk of bias (where it was clear that all of the study's prespecified outcomes and all expected outcomes of interest to the review have been reported);

- high risk of bias (where not all the study's prespecified outcomes were reported; one or more reported primary outcomes were not prespecified; outcomes of interest were reported incompletely and so could not be used; study failed to include results of a key outcome that would have been expected to have been reported);

- unclear risk of bias.

(6) Other bias (checking for bias due to problems not covered by (1) to (5) above)

For each included study we described any important concerns we had about other possible sources of bias.

\section{(7) Overall risk of bias}

We made explicit judgements about whether studies were at high risk of bias, according to the criteria given in the Cochrane Handbook for Systematic Reviews of Interventions (Higgins 2011a). With reference to (1) to (6) above, we planned to assess the likely magnitude and direction of the bias and whether we considered it was likely to have an impact on the findings. In future updates, we will explore the impact of the level of bias through undertaking sensitivity analyses (Sensitivity analysis).

\section{Measures of treatment effect}

\section{Dichotomous data}

For dichotomous data, we presented results as summary risk ratio with $95 \%$ confidence intervals.

\section{Continuous data}

We used the mean difference if outcomes were measured in the same way between trials. In future updates as appropriate, we will use the standardised mean difference to combine trials that measure the same outcome, but use different methods.

\section{Unit of analysis issues}

\section{Cluster-randomised trials}

We intended to include cluster-randomised trials in the analyses along with individually-randomised trials, no cluster-randomised trials were identified for inclusion in this version of the review. If such trials are identified in future updates, we will adjust their sample sizes using the methods described in the Handbook using an estimate of the intracluster correlation co-efficient (ICC) derived from the trial (if possible), from a similar trial or from a study of a similar population. If we use ICCS from other sources, we will report this and conduct sensitivity analyses to investigate the effect of variation in the ICC. If we identify both cluster-randomised trials and individually-randomised trials, we plan to synthesise the relevant information. We will consider it reasonable to combine the results from both if there is little heterogeneity between the study designs and the interaction between the effect of intervention and the choice of randomisation unit is considered to be unlikely.

We will also acknowledge heterogeneity in the randomisation unit and perform a sensitivity analysis to investigate the effects of the randomisation unit.

\section{Cross-over trials}

Trials using a cross-over design are not suitable for interventions in labour and were not included.

\section{Other unit of analysis issues}

In this update, trials with more than two treatment groups only contributed data into different comparisons and so unit of analysis error was not an issue. In future updates, where necessary, we will follow the methods as described in the Cochrane Handbook for Systematic Reviews of Interventions (Higgins 2011b, Section 16.5.4) in order to avoid unit of analysis errors (combine groups to create a single pair-wise comparison, divide the control group between intervention arms to avoid double-counting or select one pair of interventions and exclude others).

\section{Dealing with missing data}

For included studies, we noted levels of attrition. In future updates, if more eligible studies are included in any of the comparisons, we will explore the impact of including studies with high levels of missing data in the overall assessment of treatment effect by using sensitivity analysis.

For all outcomes, we carried out analyses, as far as possible, on an intention-to-treat basis, i.e. we attempted to include all participants randomised to each group in the analyses. The denominator for each outcome in each trial was the number randomised minus any participants whose outcomes were known to be missing.

\section{Assessment of heterogeneity}

We assessed statistical heterogeneity in each meta-analysis using the $\mathrm{Tau}^{2}, \mathrm{I}^{2}$ and $\mathrm{Chi}^{2}$ statistics. We regarded heterogeneity as substantial if an $\mathrm{I}^{2}$ was greater than $30 \%$ and either a $\mathrm{Tau}^{2}$ was greater than zero, or there was a low $P$ value (less than 0.10 ) in the $\mathrm{Chi}^{2}$ test for heterogeneity. Had we identified substantial heterogeneity (above 30\%), we planned to explore it by prespecified subgroup analysis. 


\section{Assessment of reporting biases}

In future updates, if there are 10 or more studies in the metaanalysis we will investigate reporting biases (such as publication bias) using funnel plots. We will assess funnel plot asymmetry visually. If asymmetry is suggested by a visual assessment, we will perform exploratory analyses to investigate it.

\section{Data synthesis}

We carried out statistical analysis using the Review Manager software (RevMan 2014). We used fixed-effect meta-analysis for combining data where it was reasonable to assume that studies were estimating the same underlying treatment effect: i.e. where trials were examining the same intervention, and the trials' populations and methods were judged sufficiently similar.

If there was clinical heterogeneity sufficient to expect that the underlying treatment effects differed between trials, or if substantial statistical heterogeneity was detected, we used random-effects meta-analysis to produce an overall summary if an average treatment effect across trials was considered clinically meaningful. The random-effects summary was treated as the average range of possible treatment effects and we discussed the clinical implications of treatment effects differing between trials. If the average treatment effect was not clinically meaningful, we did not combine trials. Where we used random-effects analyses, we presented the results as the average treatment effect with $95 \%$ confidence intervals, and the estimates of $\mathrm{Tau}^{2}$ and $\mathrm{I}^{2}$.

\section{Subgroup analysis and investigation of heterogeneity}

We intended to conduct planned subgroup analysis using the methods described by Deeks 2001 and set out in the Cochrane Handbook for Systematic Reviews (Higgins 2011a).

We had planned to carry out the following subgroup analyses.

1. By parity (nulliparous versus multiparous women).

2. By spontaneous versus induced or augmented labour.

3. Term versus preterm birth.

4. Continuous support in labour versus no continuous support.

Where different doses of the same drug were examined (e.g. pethidine $40 \mathrm{mg}$ or pethidine $80 \mathrm{mg}$ versus a placebo), we separated analyses into subgroups to examine the impact of different doses.

We planned to assess subgroup differences by interaction tests available within RevMan (RevMan 2014) reporting the results of subgroup analyses quoting the $\mathrm{Chi}^{2}$ statistic and $\mathrm{P}$ value, and the interaction test $\mathrm{I}^{2}$ value. In this version of the review there were too few studies contributing data to any particular comparison to make such additional analyses worthwhile. If more data become available in the future we will carry out planned subgroup analysis.

\section{Sensitivity analysis}

We planned to carry out sensitivity analyses to explore the effect of risk of bias for important outcomes in the review. Where there was risk of bias associated with a particular risk of bias domain (e.g. inadequate allocation concealment), we planned to explore this by temporarily excluding studies at high risk of bias to see if this had any impact on the results. In this version of the review we did not carry out this planned analysis due to too few studies contributing data.

\section{Summary of findings tables}

For this update we assessed the quality of the evidence using the GRADE approach as outlined in the GRADE handbook; we assessed the quality of the body of evidence relating to the following outcomes.

1. Maternal satisfaction with analgesia measured during labour

2. Maternal satisfaction with analgesia in labour measured during the postnatal period

3. Maternal pain score or pain measured in labour

4. Additional analgesia required

Selecting the most important comparisons for GRADE and the 'Summary of findings' tables was not simple, as different types and routes of opioid drugs are used in different parts of the world and in different settings. We therefore created a single table summarising findings for pain outcomes for all comparisons which involved an opioid versus placebo/no treatment, or where comparisons included pethidine as a control group. Whilst there are several other comparisons between different opioids in the review, most were reported in single studies which were of low quality.

We used the GRADEpro Guideline Development Tool to import data from Review Manager 5.3 (RevMan 2014) in order to create the 'Summary of findings' tables. We produced a summary of the intervention effect and a measure of quality for each of the above outcomes using the GRADE approach. The GRADE approach uses five considerations (study limitations, consistency of effect, imprecision, indirectness and publication bias) to assess the quality of the body of evidence for each outcome. The evidence can be downgraded from 'high quality' by one level for serious (or by two levels for very serious) limitations, depending on assessments for risk of bias, indirectness of evidence, serious inconsistency, imprecision of effect estimates or potential publication bias.

\section{RES U LTS}

\section{Description of studies}

Results of the search

See: Figure 1. 
Figure 1. Study flow diagram.

\begin{abstract}
57 studies included in the previous version of the review (Ullman 2010).
\end{abstract}

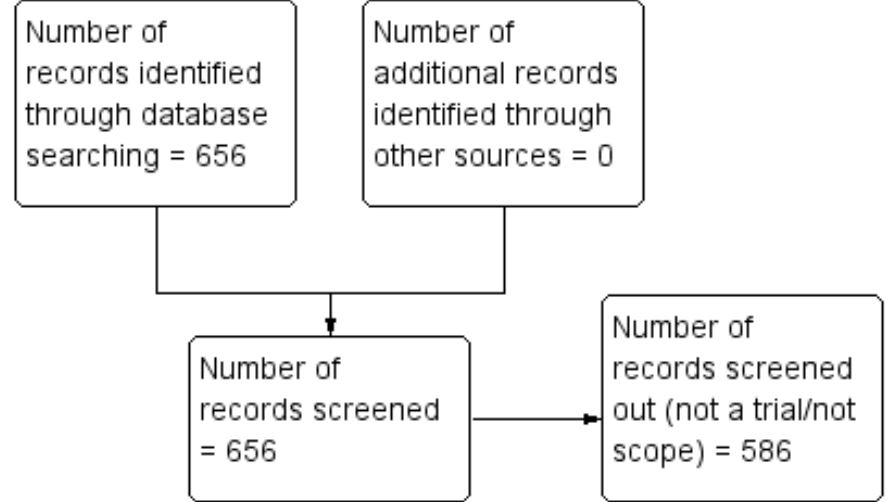

Number of new studies excluded, with reasons $=34$ (48 reports)

(see:

Characteristics of excluded studies)

Number of studies ongoing $=5$

(see:

Characteristics of ongoing studies)

Number of studies awaiting further classification $=2$ (see:

Characteristics of studies awaiting classification). 
Figure 1. (Continued)

$$
\begin{aligned}
& \text { Number of studies } \\
& \text { included in } \\
& \text { quantitative } \\
& \text { synthesis } \\
& \text { (meta-analysis) = } \\
& 61
\end{aligned}
$$

We retrieved 656 citations from the updated search in May 2017. We screened out 586 (not scope or not a trial), and assessed 70 trial reports which related to 54 new trials. We included 13 new trials and excluded 34 trials. Two trials are awaiting classification (Mohan 2015; Sereshti 2013), and five are ongoing (Kokki 2015; Raheja 2016; Reyes 2013; Sahin 2012; Shen 2008).

\section{Included studies}

Altogther in this update we have included 70 studies, 61 of which contributed data. The studies that contributed data involved more than 8000 women (see Characteristics of included studies).

Trials with more than two arms may be included in more than one comparison. Nine studies did not contribute any data to this review: Fieni 2000; Kamyabi 2003; Kermani 2015; Lalooha 2017; Lisboa 1997; Tharamas 1999; Wahab 1988; Wali 2012; Zhu 2013.

\section{Design}

All included studies were randomised controlled trials although the randomisation method was not always well described. All studies involved two trial arms except for Douma 2010, Kainz 1992, and Nelson 2005, which had three trial arms, and Liu 2015, which had four although only three were relevant to this review.

All women were randomised in labour. Though most studies do not report specifically when randomisation took place, 26 studies reported that women were randomised when they requested pain relief (Atkinson 1994; Campbell 1961; Frank 1987; Kainz 1992; Khooshideh 2009; Lardizabal 1999; Li 1988; Mitterschiffthaler 1991; Morley-Forster 2000; Morrison 1987; Mowat 1970; Nel 1981; Nelson 2005; Nicholas 1982; O'Dwyer 1971; Osler 1987; Prasertsawat 1986; Rayburn 1989a; Refstad 1980; Sekhavat 2009; Sheikh 1986; Sliom 1970; Tsui 2004; Viegas 1993; Volikas 2001; Wilson 1986).

\section{Participants}

All studies included healthy pregnant women in either induced or spontaneous early labour. All women were classed as having a 'low-risk' pregnancy. Most studies included both nulliparous and multiparous women, or did not specify parity. Thirteen studies included nulliparous women only (Direkvand-Moghadam 2014; ElRefaie 2012; Hamann 1972; Kamyabi 2003; Keskin 2003; Lalooha 2017; Levy 1971; Li 1988; Olofsson 1996; Tawfik 1982; Tharamas 1999; Viegas 1993; Zhu 2013), and two included multiparous women only (Jahani 2013; Wahab 1988).

\section{Interventions and comparisons}

Most of the studies included in the review examined an opioid drug administered intramuscularly (IM) and compared with either a placebo, no treatment, or with another opioid. A smaller number of studies examined opioid drugs administered intravenously (IV), sometimes with a degree of patient control over the amount of drug infused (patient-controlled anaesthesia; PCA). None of the included studies examined subcutaneous administration of opioids. Some of the studies compared opioids with other non-pharmacological interventions such as transcutaneous electrical nerve stimulation (TENS) (four studies).

\section{IM comparisons}

1. IM pethidine versus IM placebo (all studies used saline as placebo) (four studies) (Direkvand-Moghadam 2014; Sekhavat 2009; Sliom 1970; Tsui 2004).

2. IM pentazocine versus placebo (saline placebo) (one study) (Zafar 2016).

3. IM tramadol versus no treatment (one study) (Li 1994).

4. IM meptazinol versus IM pethidine (eight studies) (De Boer 1987; Jackson 1983; Morrison 1987; Nel 1981; Nicholas 1982; Osler 1987; Sheikh 1986; Wheble 1988) (in the studies by De Boer 1987 and Jackson 1983, women in both study groups also received add-on drugs)

5. IM diamorphine + prochlorperazine versus IM pethidine + prochlorperazine (one study) (Fairlie 1999).

6. IM tramadol versus IM pethidine (six studies) (Bitsch 1980; Husslein 1987; Keskin 2003; Khooshideh 2009; Prasertsawat 1986; Viegas 1993). Fieni 2000 did not contribute any data.

7. IM tramadol + triflupromazine versus pethidine + triflupromazine (one study) (Kainz 1992).

8. IM dihydrocodeine versus IM pethidine (one study) (Sliom 1970).

9. IM pentazocine versus IM pethidine (six studies) (Borglin 1971; Duncan 1969; Levy 1971; Moore 1970; Mowat 1970; Refstad 1980). Refstad 1980 gave both group promazine - subtotals only reported.

10.IM nalbuphine versus IM pethidine (three studies) (Lardizabal 1999; Mitterschiffthaler 1991; Wilson 1986).

11.IM phenazocine versus IM pethidine (one study) (Grant 1970).

12.IM morphine or diamorphine versus pethidine (two studies) (Prasertsawat 1986; Wee 2014).

13.IM butorphanol versus IM pethidine (one study) (Maduska 1978).

14.IM pentazocine versus a spasmolytic drug (Avacan ${ }^{\circledR}$ ) (one study) (Hamann 1972).

15.IM pentazocine versus IM Pethilorphan ${ }^{\circledR}$ (one study) (O'Dwyer 1971).

16.IM pentazocine versus complementary and alternative medicine (one study) (Zafar 2016).

17.IM pentazocine versus IM tramadol (one study) (Kuti 2008).

18.IM pethidine versus inhaled nitrous oxide (one study) (Mobaraki 2016). 


\section{IV comparisons}

1. IV pethidine versus placebo (one study) (El-Refaie 2012).

2. IV fentanyl versus no treatment (one study) (Jahani 2013).

3. IV fentanyl versus IV pethidine (one study) (Rayburn 1989).

4. IV nalbuphine versus IV pethidine (one study) (Giannina 1995).

5. IV phenazocine versus IV pethidine (one study) (Olson 1964).

6. IV butorphanol versus IV pethidine (three studies) (Hodgkinson 1979; Nelson 2005; Quilligan 1980).

7. IV morphine versus IV pethidine (two studies) (Campbell 1961; Olofsson 1996).

8. IV alphaprodine (Nisentil) versus IV pethidine (one study) (Gillam 1958).

9. IV fentanyl versus butorphanol (one study) (Atkinson 1994).

\section{IV/PCA comparisons}

1. PCA pentazocine versus PCA pethidine (one study) (Erskine 1985).

2. PCA remifentanil versus PCA pethidine (three studies) (Blair 2005; Douma 2010; Volikas 2001).

3. PCA nalbuphine versus PCA pethidine (one study) (Frank 1987).

4. PCA fentanyl versus PCA alfentanil (one study) (Morley-Forster 2000).

5. PCA fentanyl versus PCA pethidine (one study) (Douma 2010).

\section{IM/PCA comparisons}

1. IM meptazinol PCA versus IM pethidine PCA administration (one study) (Li 1988).

\section{Opioids versus TENs}

1. IV pethidine $(50 \mathrm{mg}$ ) versus TENS to lower back (Neumark 1978), IM pethidine (50 mg) versus TENS to back (Tawfik 1982), IM tramadol (100 mg) versus TENS to back (Thakur 2004), PCA ondansetron and tramadol versus Han's acupoint nerve stimulator (Liu 2015).

\section{Outcomes}

There are pain outcomes reported under most comparisons including maternal satisfaction with analgesia, pain severity, or additional analgesia required. The way that pain outcomes were reported in studies were not consistent. Adverse effects, neonatal outcomes, and costs were not reported in all the studies.

\section{Setting}

All studies took place in hospital settings. Most studies were conducted in the USA (Atkinson 1994; Campbell 1961; Giannina 1995; Gillam 1958; Hodgkinson 1979; Levy 1971; Maduska 1978; Nelson 2005; Olson 1964; Quilligan 1980; Rayburn 1989a), or the UK (Blair 2005; De Boer 1987; Duncan 1969; Fairlie 1999; Frank 1987; Grant 1970; Jackson 1983; Moore 1970; Morrison 1987; Mowat 1970; Nicholas 1982; O'Dwyer 1971; Sheikh 1986; Volikas 2001; Wee 2014; Wheble 1988; Wilson 1986). Eight were conducted in Iran (Direkvand-Moghadam 2014; Jahani 2013; Kamyabi 2003; Kermani 2015; Khooshideh 2009; Lalooha 2017; Mobaraki 2016; Sekhavat 2009), three each in Germany (Bitsch 1980; Kainz 1992; Mitterschiffthaler 1991), Egypt (El-Refaie 2012; Tawfik 1982; Wahab 1988), South Africa (Erskine 1985; Nel 1981; Sliom 1970), and China (Li 1988; Li 1994; Liu 2015), and one in each of the Netherlands (Douma 2010), Italy (Fieni 2000), Austria
(Husslein 1987), Turkey (Keskin 2003), Nigeria (Kuti 2008), Argentina (Lardizabal 1999), Brazil (Lisboa 1997), Canada (Morley-Forster 2000), Sweden (Olofsson 1996), Denmark (Osler 1987), Thailand (Prasertsawat 1986), Norway (Refstad 1980), India (Thakur 2004), Hong Kong (Tsui 2004), Singapore (Viegas 1993), and Pakistan (Zafar 2016).

Six studies did not explicitly state where they were conducted (Borglin 1971; Hamann 1972; Neumark 1978; Tharamas 1999; Wali 2012; Zhu 2013).

\section{Dates of study}

Hamann 1972 took place between 1969 and 1971; Bitsch 1980 in the 1970s; Prasertsawat 1986, Rayburn 1989a, and Wahab 1988 in the 1980s; Atkinson 1994, Fairlie 1999, Giannina 1995, Lardizabal 1999, Li 1994, and Tharamas 1999 in the 1990s; El-Refaie 2012, Khooshideh 2009, Kuti 2008, Sekhavat 2009, Tsui 2004, and Zafar 2016 in the 2000s; and Direkvand-Moghadam 2014, Liu 2015, and Mobaraki 2016 in the 2010s.

All other studies did not report study dates.

\section{Funding}

Smith and Nephew (Pharmaceutics) Ltd provided the marked drug ampoules in Grant 1970; Bronovo Research Fund funded Douma 2010; pentazocine was supplied by Bayer products in Duncan 1969; Dupont (UK) Ltd funded Frank 1987; The Scientific Achievement and Appropriate Technology Extension Project of Beijing Municipal Commission of Health and Family Planning (TG-2014-12) funded Liu 2015; Bristol laboratories, Syracuse, New York funded Maduska 1978; Ardabil Medical Sciences University funded Mobaraki 2016; Sterling Winthrop Research Division supplied the drugs in Mowat 1970; National Institutes of Health, Bethesda, Maryland (grant No. NS41386) funded Nelson 2005; Karolinska Institute foundations and the Swedish Medical Research Council funded Olofsson 1996; Sterling-Winthrop company supplied trial drugs in Refstad 1980; Sekhavat 2009 reported to not be funded be any pharmaceutical company; Wyeth laboratories supplied the coded ampoules of the trial drugs in Sheikh 1986; BDH (South Africa) Pty Ltd supplied dihydrocodeine bitartrate in Sliom 1970; Wee 2014 was independent research funded by the National Institute for Health Research (NIHR) under its Research for Patient Benefit (RfPB) Programme (Grant Reference Number PB-PG-0407-13170) with additional support costs funded by the Western Comprehensive Local Research Network; Medical Research Council and Wyeth Research (UK) funded Wheble 1988; and the Higher Education Commission (Pakistan) funded Zafar 2016.

All other studies did not report funding sources.

\section{Conflicts of interest}

Two studies declared to have no conflicts of interest (DirekvandMoghadam 2014; Wee 2014).

All other studies did not report whether or not there were conflicts of interest.

\section{Excluded studies}

We have excluded 121 studies (see Characteristics of excluded studies). 
Reasons for exclusions (some of the studies were excluded for more than one reason).

1. In 26 studies, the focus was on epidural analgesia (Camann 1992; El-Kerdawy 2010; Evron 2007; Evron 2008; Freeman 2012; Gambling 1998; Ginosar 2003; Grandjean 1979; John 2013; Karadjova 2016; Logtenberg 2017; Marshalov 2012; McGrath 1992; Morris 1994; Nafisi 2006; Polley 2000; Rabie 2006; Sabry 2011; Samanta 2013; Solek-Pastuszka 2009; Stocki 2014; Stourac 2014; Volmanen 2008; Weissman 2006; Wiener 1979; Wong 2005). The use of epidural analgesia for pain management in labour is covered in related Cochrane reviews (Anim-Somuah 2018; Simmons 2012).

2. In 13 studies, women in both groups received the same opioid and the focus of studies was on add-on drugs; so, for example, both groups received pethidine with one group, in addition, receiving a sedative. The focus of these trials was on the effects of the add-on drug (Aiken 1971; Ballas 1976; De Lamerens 1964; Hodgkinson 1978; Malkasian 1967; McQuitty 1967; Posner 1960; Powe 1962; Ron 1984; Roberts 1960; Spellacy 1966; Wan 1965; Williams 1962).

3. Nineteen studies were not randomised trials, or it was not clear that there was any random allocation to groups (Balcioglu 2007; Bredow 1992; Brelje 1966; Callaghan 1966; Chandnani 2013; Cincadze 1978; Cullhed 1961; Eliot 1975; MacVicar 1960; Moore 1974; Pandole 2003; Rowley 1963; Savage 1955; Singh 2001; Soontrapa 2002; Suvonnakote 1986; Tripti 2006; Vavrinkova 2005; Volmanen 2005).

4. In three studies, it was not clear that participants were in labour (Chang 1976; Krins 1969; Tomlin 1965).

5. In three studies, the intervention was not an opioid (Abd-ElMaeboud 2014; Bare 1962; Elhalwagy 2017).

6. In the study by Kaltreider 1967, the focus was on a highrisk group (women in preterm labour) and post-randomisation exclusions meant that results were difficult to interpret.

7. We excluded two studies as levels of attrition meant that results were at high risk of bias. There were serious methodological problems in the study by Robinson 1980 and complete data were available for only approximately one-third of those randomised. In the study by De Kornfeld 1964, data on pain outcomes were available for less than half the sample at one hour; results from this study were therefore very difficult to interpret.

8. Five trials were reported in trial registers or in brief abstracts and we were unable to assess risk of bias or extract results. We attempted to contact authors for more information without success (Goodlin 1988; Kalaskar 2007; Morgan 2004; Overton 1992; Taskin 1993).
9. The focus of four studies was not on pain relief, so women may have received an opioid with the purpose of promoting progress in labour (Sosa 2004; Tournaire 1980; Treisser 1981; Von Vorherr 1963). In one of these studies, women were specifically excluded if they complained of pain (Sosa 2004), and in another, women in the two groups also received oxytocin with each study group receiving a different dose (Von Vorherr 1963). A further two studies did not focus on pain relief but rather on newborn serum bilirubin (McDonald 1964) or platelet function (Greer 1988).

10.Seven studies focused on drugs no longer in use, or drugs not used nowadays for obstetric analgesia (Cahal 1960; Cavanagh 1966; Eames 1964; Ransom 1966; Roberts 1957; Sentnor 1966; Walker 1992).

11.In eight studies, the same opioid was given to women in both arms of trials and the difference between groups was mode of administration; (different modes of administration of parenteral opioids will be considered in a separate Cochrane review) (Balki 2007; Balki 2012; Isenor 1993; Khooshideh 2015; McInnes 2004; Rayburn 1989; Rayburn 1991; Volmanen 2009).

12.In four studies, women in one arm of the trial, as well as receiving an opioid, were also given another add-on drug that the comparison group did not receive. In these studies results are difficult to interpret, as any differences between groups may be due to the add-on drug rather than the opioid (Busacca 1982; Calderon 2006; Dan 1991; Fernandez 2015).

13.In the studies by Brookes 2013, Calderon 2006, Evron 2005, Fleet 2015, Li 1995, Ng 2011, Nikkola 2000; Shahriari 2007, Thurlow 2002, and Wilson 2016, different drugs were administered using different methods, and so it is difficult to interpret results as any differences between groups may be due to drug, method or both together.

14.In one study, the effect of the opioid analgesia was not assessed during childbirth, but for second trimester labour following termination of pregnancy (Castro 2004).

15.Opioid was compared with a non-opioid drug: IV paracetamol (Abdollahi 2014; Alhashemi 2011; Ankumah 2016; Bhatia 2013; Dahiya 2015; Elbohoty 2012; Gupta 2016; Hashemiyan 2014; Kaur 2015; Lallar 2015), NSAIDs (El Kinawy 2015b).

16.Four trials were cross-over trials (Easton 2016; Jost 2015; Rahimi 2012; Volmanen 2005).

\section{Risk of bias in included studies}

See Figure 2; Figure 3. We have only described the 61 studies below that contributed data to the review; Fieni 2000; Kamyabi 2003; Kermani 2015; Lalooha 2017; Lisboa 1997; Tharamas 1999; Wahab 1988; Wali 2012; Zhu 2013 are therefore not included in the descriptions below. 
Figure 2. 'Risk of bias' graph: review authors' judgements about each risk of bias item presented as percentages across all included studies.

Random sequence generation (selection bias)

Allocation concealment (selection bias)

Blinding of participants and personnel (performance bias)

Blinding of outcome assessment (detection bias)

Incomplete outcome data (attrition bias)

Selective reporting (reporting bias)

Other bias

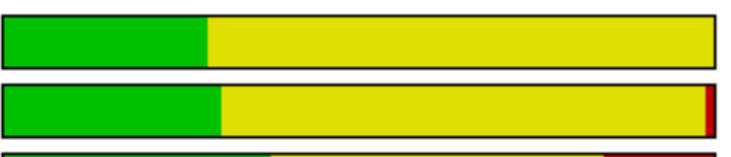

L
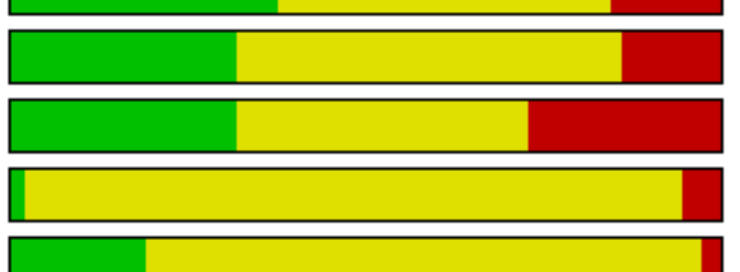

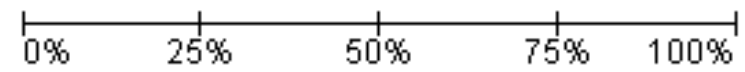


Figure 3. 'Risk of bias' summary: review authors' judgements about each risk of bias item for each included study.

\begin{tabular}{|c|c|c|c|c|c|c|c|}
\hline & 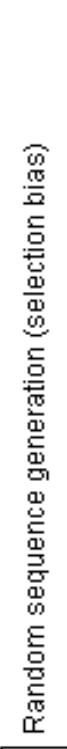 & 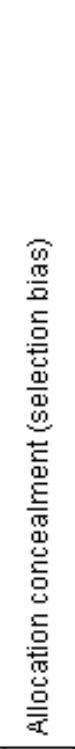 & 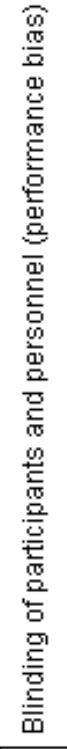 & 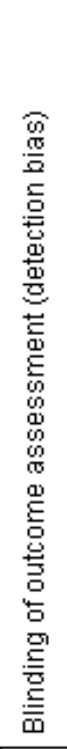 & 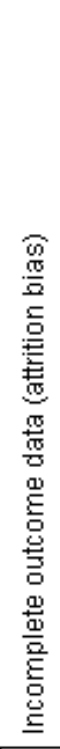 & 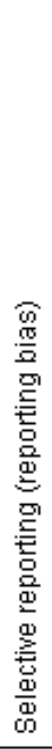 & 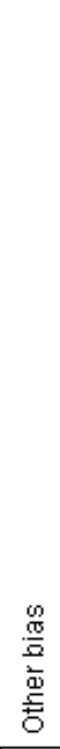 \\
\hline Atkinson 1994 & + & + & + & + & $?$ & $?$ & + \\
\hline Bitsch 1980 & $?$ & $?$ & $?$ & + & $\odot$ & $?$ & $?$ \\
\hline Blair 2005 & $?$ & $?$ & $?$ & $?$ & + & $?$ & + \\
\hline Borglin 1971 & $?$ & $?$ & $?$ & $?$ & + & $?$ & + \\
\hline Campbell 1961 & $?$ & + & + & + & $?$ & $\odot$ & $?$ \\
\hline De Boer 1987 & $?$ & $?$ & $?$ & $?$ & $\odot$ & $\odot$ & + \\
\hline Direkwand-Moghadam 2014 & + & $?$ & $\Theta$ & 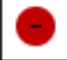 & $?$ & $?$ & $?$ \\
\hline Douma 2010 & + & + & + & + & + & $?$ & + \\
\hline Duncan 1969 & $?$ & $?$ & $?$ & $?$ & - & $?$ & $?$ \\
\hline El-Refaie 2012 & + & + & + & $?$ & + & $?$ & $?$ \\
\hline Erskine 1985 & + & $?$ & $?$ & $?$ & $?$ & $?$ & $?$ \\
\hline Fairlie 1999 & $?$ & + & + & + & 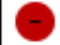 & ? & + \\
\hline Fieni 2000 & + & $?$ & $?$ & $?$ & $?$ & $?$ & $\theta$ \\
\hline Frank 1987 & $?$ & $?$ & $?$ & $?$ & $?$ & $?$ & $?$ \\
\hline Giannina 1995 & + & + & $?$ & $?$ & $?$ & ? & + \\
\hline Gillam 1958 & $?$ & + & + & + & $\theta$ & $?$ & $?$ \\
\hline Grant 1970 & $?$ & + & + & + & $?$ & $?$ & $?$ \\
\hline Hamann 1972 & + & $?$ & $?$ & $?$ & O & $?$ & $?$ \\
\hline Hodgkinson 1979 & $?$ & $?$ & $?$ & $?$ & + & $?$ & $?$ \\
\hline Husslein 1987 & $?$ & $?$ & $?$ & $?$ & + & $?$ & $?$ \\
\hline
\end{tabular}


Figure 3. (Continued)

\begin{tabular}{|c|c|c|c|c|c|c|c|}
\hline Husslein 1987 & $?$ & $?$ & $?$ & $?$ & $\oplus$ & $?$ & $?$ \\
\hline Jackson 1983 & $?$ & $?$ & $?$ & $?$ & $\odot$ & $?$ & $?$ \\
\hline Jahani 2013 & $?$ & $\odot$ & $\odot$ & $\odot$ & $?$ & $\odot$ & + \\
\hline Kainz 1992 & + & $?$ & $?$ & $?$ & $?$ & $?$ & $?$ \\
\hline Kamyabi 2003 & $?$ & $?$ & $\odot$ & $\odot$ & $?$ & $?$ & $?$ \\
\hline Kermani 2015 & ? & $?$ & - & $?$ & $?$ & ? & ? \\
\hline Keskin 2003 & ? & $?$ & ? & $\odot$ & $\Theta$ & ? & $?$ \\
\hline Khooshideh 2009 & $\odot$ & $\odot$ & ? & $\odot$ & + & ? & $?$ \\
\hline Kuti 2008 & $\odot$ & $\odot$ & $\odot$ & $\odot$ & $?$ & $?$ & $?$ \\
\hline Lalooha 2017 & $?$ & ? & + & $?$ & $?$ & ? & $?$ \\
\hline Lardizabal 1999 & $\odot$ & $\odot$ & + & $?$ & + & ? & $?$ \\
\hline Lew 1971 & $?$ & $?$ & + & + & - & ? & ? \\
\hline Li 1988 & $?$ & $?$ & ? & $?$ & + & ? & $?$ \\
\hline Li 1994 & $?$ & $?$ & - & - & $?$ & ? & ? \\
\hline Lisboa 1997 & $?$ & $?$ & ? & $?$ & $?$ & ? & ? \\
\hline Liu 2015 & + & $?$ & 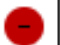 & - & $?$ & $?$ & $?$ \\
\hline Maduska 1978 & $?$ & + & + & $?$ & + & ? & $?$ \\
\hline Mitterschiffthaler 1991 & $?$ & $?$ & ? & $?$ & $\Theta$ & ? & $?$ \\
\hline Mobaraki 2016 & $?$ & $?$ & 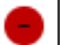 & $\odot$ & $?$ & ? & $?$ \\
\hline Moore 1970 & $?$ & $?$ & ? & $?$ & - & $?$ & $?$ \\
\hline Morley-Forster 2000 & + & $\odot$ & + & + & ? & ? & $?$ \\
\hline Morrison 1987 & $?$ & $\odot$ & + & + & $\Theta$ & ? & ? \\
\hline Mowat 1970 & $?$ & $?$ & ? & $?$ & $\Theta$ & ? & + \\
\hline Nel 1981 & ? & $?$ & ? & $?$ & - & $?$ & ? \\
\hline Nelson 2005 & + & $?$ & + & $?$ & $\Theta$ & ? & $?$ \\
\hline Neumark 1978 & ? & $?$ & ? & $?$ & $?$ & $?$ & $?$ \\
\hline Nicholas 1982 & ? & $?$ & ? & $?$ & $\Theta$ & ? & $?$ \\
\hline O'Dwyer 1971 & ? & $?$ & ? & $?$ & - & $?$ & $?$ \\
\hline Olofsson 1996 & $?$ & $\odot$ & + & $?$ & + & $?$ & $?$ \\
\hline Olson 1964 & $?$ & $\odot$ & $?$ & $?$ & + & $?$ & $\odot$ \\
\hline Osler 1 & $?$ & $?$ & $?$ & $?$ & $\odot$ & $?$ & $?$ \\
\hline
\end{tabular}


Figure 3. (Continued)

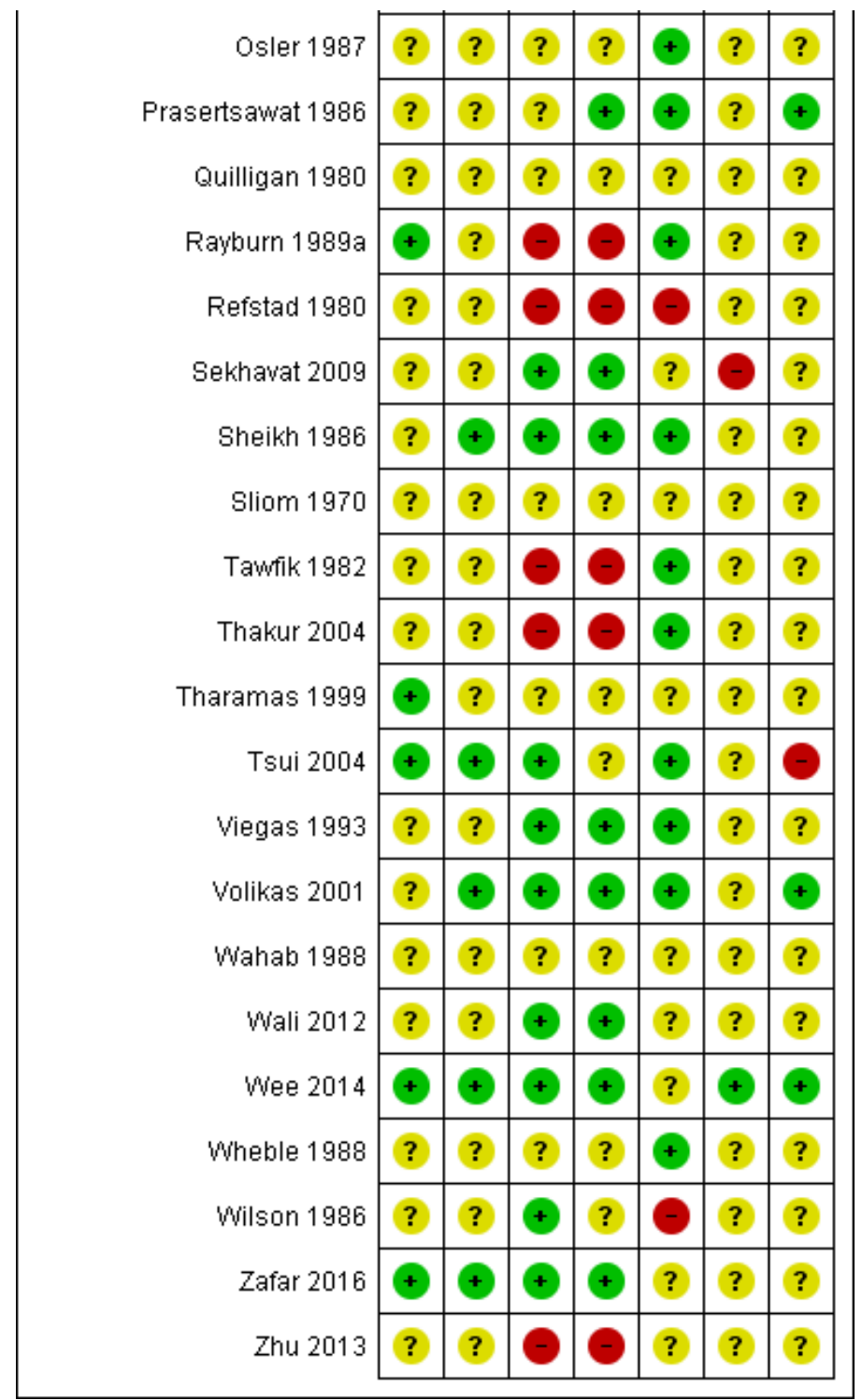

\section{Allocation}

\section{Sequence generation}

Eighteen studies were assessed as having adequate random sequence generation: in 11 studies a computer-generated random sequence was used (Atkinson 1994; Douma 2010; El-Refaie 2012; Giannina 1995; Khooshideh 2009; Kuti 2008; Lardizabal 1999; Nelson 2005; Tsui 2004; Wee 2014; Zafar 2016); two used an external randomisation service (Morley-Forster 2000; Rayburn 1989a); and five studies used random number tables (Direkvand-Moghadam 2014; Erskine 1985; Hamann 1972; Kainz 1992; Liu 2015). The remaining 43 included studies were unclear about how the randomisation sequence was generated.

\section{Allocation concealment}

Allocation concealment was not generally described in sufficient detail to allow assessment of risk of bias; it was not always clear at what stage randomisation took place, and whether or not the person carrying out randomisation was aware of group allocation.
Seven studies described using numbered opaque sealed envelopes to conceal allocation (El-Refaie 2012; Giannina 1995; Khooshideh 2009; Kuti 2008; Tsui 2004; Volikas 2001; Zafar 2016). Thirteen studies described using identical coded drug boxes (although it may not have been clear who had access to the code or when the code was broken) (Atkinson 1994; Campbell 1961; Douma 2010; Fairlie 1999; Gillam 1958; Grant 1970; Lardizabal 1999; Maduska 1978; Morley-Forster 2000; Morrison 1987; Olofsson 1996; Olson 1964; Sheikh 1986). One trial used two identical syringes labelled only with the trial number to conceal group allocation and to ensure that if two doses were given, the same opioid was given both times, which were prepared by trial centre pharmacies (Wee 2014). One study appeared to randomise at the time of a coin toss and did not attempt allocation concealment (Jahani 2013), so was assessed to be at high risk of selection bias. In the remaining studies it was not clear what steps were taken to conceal allocation at the point of randomisation. 


\section{Blinding}

Many of the studies were described as double-blind; in the majority of these trials women in the control arms were given preparations of similar appearance to those given to women in the experimental arms (either a placebo or an indistinguishable comparison drug). It was not always clear that blinding was effective; for example, some IM drugs may appear similar, but different consistencies may be apparent to experienced staff. It was also not generally clear at what point blinding ended, and whether outcome assessors were blind to group allocation.

\section{Performance bias (participants and personnel)}

In 25 studies it appears that adequate blinding of women and caregivers was achieved with identical administration of placebo or comparison drugs. Nine studies were at high risk of performance bias: four administered study drugs of interventions via different routes (Direkvand-Moghadam 2014; Mobaraki 2016; Tawfik 1982; Thakur 2004); three compared the study drug with no analgesia (Jahani 2013; Li 1994; Liu 2015); two did not blind staff to the intervention (Rayburn 1989a; Refstad 1980). Blinding of women and caregivers was unclear in 28 studies (Bitsch 1980; Blair 2005; Borglin 1971; De Boer 1987; Duncan 1969; Erskine 1985; Frank 1987; Giannina 1995; Hamann 1972; Hodgkinson 1979; Husslein 1987; Jackson 1983; Kainz 1992; Keskin 2003; Khooshideh 2009; Li 1988; Moore 1970; Mowat 1970; Nel 1981; Neumark 1978; Nicholas 1982; O'Dwyer 1971; Olson 1964; Osler 1987; Prasertsawat 1986; Quilligan 1980; Sliom 1970; Wheble 1988). Some studies reported to be double-blind but did not give details of blinding. The remaining studies blinded the women and caregivers by using identical volumes and syringes.

\section{Detection bias (outcome assessor)}

Twenty studies reported blinding of outcome assessor (Atkinson 1994; Bitsch 1980; Campbell 1961; Douma 2010; Fairlie 1999; Gillam 1958; Grant 1970; Keskin 2003; Khooshideh 2009; Kuti 2008; Levy 1971; Morley-Forster 2000; Morrison 1987; Prasertsawat 1986; Sekhavat 2009; Sheikh 1986; Viegas 1993; Volikas 2001; Wee 2014; Zafar 2016). Nine studies did not blind outcome assessors or likely used caregivers to record labour outcomes (Direkvand-Moghadam 2014; Jahani 2013; Li 1994; Liu 2015; Mobaraki 2016; Rayburn 1989a; Refstad 1980; Tawfik 1982; Thakur 2004). In the remaining studies, it was unclear if outcome assessors were blinded or not.

\section{Incomplete outcome data}

Assessing levels of attrition was very difficult in these studies, as denominators were frequently absent from results tables. In addition, even where all women appeared to be accounted for at follow-up, there were frequently missing data for specific outcomes.

Nineteen studies were assessed to be at high risk of bias. In 14 studies loss to follow-up or missing data were greater than $10 \%$ (Bitsch 1980; Fairlie 1999; Hamann 1972; Levy 1971; Moore 1970; Mowat 1970; Wilson 1986), or greater than 20\% (De Boer 1987; Frank 1987; Giannina 1995; Gillam 1958; Nicholas 1982; O'Dwyer 1971; Refstad 1980). Jackson 1983 excluded on the grounds of fetal distress and heart defects post randomisation. Four studies (Duncan 1969; Keskin 2003; Mowat 1970; Nel 1981) reported unexplained loss to follow-up. Sixty-five women were excluded due to clerical errors or administration of wrong drug in Morrison 1987.

Parenteral opioids for maternal pain management in labour (Review)

Copyright $\odot 2018$ The Cochrane Collaboration. Published by John Wiley \& Sons, Ltd.
In several studies there were missing data on pain outcomes. This may have occurred because drugs were given at a late stage in labour, so that women had already given birth before the first scheduled pain assessment. For example, in Fairlie 1999 17\%, and in O'Dwyer 1971 and Refstad 1980 more than one-third of women had given birth within an hour of drug administration. These three studies were rated as high risk of bias.

In some studies women were explicitly excluded from the analysis because of factors that may have related to study medication; in Hamann 1972, 13\% of women were excluded after randomisation because they had a long labour or a caesarean section, and in Moore 1970, women were excluded because they received additional pain relief. Wilson 1986 excluded $10 \%$ of the sample because women reported that they received inadequate pain relief. Mitterschiffthaler 1991 excluded women who reported insufficient pain relief. In the study by Nelson 2005, any woman undergoing artificial rupture of membranes, commencing oxytocin or requesting epidural was excluded after randomisation and were replaced. Further, any women who reached $10 \mathrm{~cm}$ cervical dilation within one hour of drug administration were also excluded from the analysis; it was not clear how many women were lost and replaced for these reasons.

Twenty-two studies reported little explained, or no loss to followup. The remaining studies were assessed to be at unclear risk of attrition bias (Atkinson 1994; Campbell 1961; DirekvandMoghadam 2014; Erskine 1985; Frank 1987; Giannina 1995; Grant 1970; Jahani 2013; Kainz 1992; Kuti 2008; Li 1994; Liu 2015; Mobaraki 2016; Morley-Forster 2000; Neumark 1978; Quilligan 1980; Sekhavat 2009; Sliom 1970; Wee 2014; Zafar 2016).

\section{Selective reporting}

Most of the studies were assessed to have unclear risk of reporting bias as we had access only to study reports and without study protocols for most studies, it is difficult to assess whether all outcomes have been accounted for. One study reported all outcomes pre-specified in their protocol (Wee 2014). Four studies (Campbell 1961; De Boer 1987; Jahani 2013; Sekhavat 2009) did report all the outcomes pre-specified in their methods and were at high risk of reporting bias (see Characteristics of included studies).

We were not able to explore possible publication bias by using funnel plots as too few studies were included in different comparisons.

\section{Other potential sources of bias}

Most of the studies reported that there was no apparent baseline imbalance between groups although this was not always explicit, and where tables describing characteristics of the two groups were provided, they frequently included only a small number of obstetric or demographic variables. In the study by Tsui 2004, there was imbalance between groups in terms of the numbers of women undergoing induction of labour in the two groups (20/25 in the pethidine group and $12 / 25$ in the placebo group), and this may have had an impact on outcomes so this study was assessed to be at high risk of other bias. In the study by Rayburn 1989a, women were only recruited to the study at very limited times (weekdays 8am to 3pm), and while this may not put findings at high risk of bias, it may mean that those recruited were not representative of the population served by the study hospital. Most studies were assessed to be at unclear risk of other bias due to lack of information to adequately 
assess, or poor reporting. Thirteen studies had no other apparent risk of bias and were assessed to be at low risk (Atkinson 1994; Blair 2005; Borglin 1971; De Boer 1987; Douma 2010; Fairlie 1999; Giannina 1995; Jahani 2013; Mowat 1970; Olson 1964; Prasertsawat 1986; Volikas 2001; Wee 2014).

In the Characteristics of included studies and 'Risk of bias' tables, we have set out more information which will assist in the interpretation of results.

\section{Effects of interventions}

See: Summary of findings for the main comparison IM pethidine compared to placebo for pain management in labour; Summary of findings 2 Placebo and pethidine comparisons for pain management in labour

In this section where several studies have contributed data to a comparison, we have reported primary and secondary outcomes separately. For some comparisons single studies provided data on a very limited number of outcomes; for these comparisons we have reported outcomes under one heading. We had planned subgroup analysis by parity, by whether or not the labour was induced or augmented, by gestational age (preterm versus term birth), and by whether or not women had continuous support during labour. In this version of the review we were unable to carry out this analysis, as data were not provided by subgroups. In addition, we did not carry out planned sensitivity analysis by risk of bias domains because for most outcomes only one or two studies contributed data.

\section{Intramuscular opioids for pain relief in labour}

\section{IM pethidine $50 \mathrm{mg} / 100 \mathrm{mg}$ versus placebo}

Four studies with 486 women contributed data to this comparison (Direkvand-Moghadam 2014; Sekhavat 2009; Sliom 1970; Tsui 2004), although for most outcomes only a single study contributed data. Kamyabi 2003 did not contribute any data.

\section{Primary outcomes}

\section{Maternal satisfaction with analgesia measured during labour}

One study involving 50 women (Tsui 2004) showed no clear difference in maternal satisfaction 30 minutes after administration of study drug (risk ratio (RR) 7.00, 95\% confidence interval (Cl) 0.38 to 128.87 , very low-quality evidence); only three of 25 women receiving pethidine and none of the women receiving placebo reported to be 'satisfied' or 'very satisfied' with analgesia (Analysis 1.1).

\section{Maternal satisfaction with analgesia in labour measured during the postnatal period}

No study reported this outcome.

\section{Secondary outcomes}

\section{Maternal}

\section{Maternal pain score or pain measured in labour}

One study involving 116 women (Sliom 1970), reported more women in the pethidine group with "fair" or "good" pain relief within an hour of receiving the drug (RR $1.75,95 \% \mathrm{Cl} 1.24$ to 2.47 , low-quality evidence; Analysis 1.2).
Maternal pain relief 30 minutes after study drug administration, defined as a reduction in visual analogue scale (VAS) score of at least $40 \mathrm{~mm}$, was measured in one study with 50 women (Tsui 2004), and was greater for pethidine $100 \mathrm{mg}$ compared with placebo (RR $25.00,95 \% \mathrm{Cl} 1.56$ to 400.54 , low-quality evidence) though the $\mathrm{Cl}$ for this estimate is very wide (Analysis 1.3).

\section{Additional analgesia required}

In one study (Tsui 2004), the majority of women in both groups required additional analgesia (epidural, pethidine, and Entonox); this applied to fewer women with pethidine $100 \mathrm{mg}$ compared with placebo (RR $0.71,95 \% \mathrm{Cl} 0.54$ to 0.94 , low-quality evidence; Analysis 1.4). However, $12 / 25$ women in the placebo group had pethidine at 30 minutes as rescue analgesia confounding interpretation of reported outcomes after 30 minutes.

\section{Epidural}

There was no evidence of clear differences between groups the number of women requiring an epidural ( $R R 0.50,95 \% \mathrm{Cl} 0.14$ to 1.78; 1 study, 50 women; very low-quality evidence; Analysis 1.5).

\section{Maternal sleepiness during labour}

More women reported sleepiness with pethidine $100 \mathrm{mg}$, with half of those receiving pethidine feeling sedated compared with $11 \%$ of controls (RR 4.67, 95\% Cl 2.43 to 8.95; 2 studies, 166 women; Analysis 1.7).

There was no evidence of clear differences between groups in:

1. nausea and vomiting (RR $1.47,95 \% \mathrm{Cl} 0.65$ to $3.31 ; 2$ studies, 166 women; Analysis 1.6);

2. caesarean sections (RR $0.71,95 \% \mathrm{Cl} 0.36$ to $1.37 ; 2$ studies, 140 women; Analysis 1.9);

3. assisted vaginal births (RR $0.86,95 \% \mathrm{Cl} 0.34$ to $2.19 ; 1$ study, 50 women; Analysis 1.8).

Postpartum haemorrhage (as defined by the trial authors), breastfeeding at discharge, breastfeeding in the postnatal period (four to six weeks), sense of control in labour (as defined by trialists), satisfaction with childbirth experience (as defined by trialists), effect (negative) on mother/baby interaction, and cost (as defined by trialists) were not reported for this comparison.

\section{Neonatal}

\section{Neonatal resuscitation}

The incidence of newborn resuscitation was low; no clear differences between groups was detected (RR 1.67, 95\% Cl 0.45 to 6.24 ; 1 study; 50 infants; Analysis 1.10).

\section{Apgar score less than seven at one minute and Apgar score less than} seven at five minutes

The number of babies with Apgar scores of seven or less at one minute did not differ between the placebo and pethidine groups; for this outcome we used a random-effects model because of high heterogeneity (average RR $1.64,95 \% \mathrm{Cl} 0.52$ to 5.18); 2 studies, 166 infants; (heterogeneity: $\mathrm{I}^{2}=61 \%$, $\mathrm{Tau}^{2}=0.46, \mathrm{Chi}^{2}$ test for heterogeneity $\mathrm{P}=0.11$ ) (Analysis 1.11 ). No babies had Apgar scores less than or equal to seven at five minutes in two studies that reported this outcome (200 infants; Analysis 1.11). 
Admission to special care baby unit/neonatal intensive care unit (as defined by trialists)

Admission to neonatal intensive care unit (NICU) was low; no clear differences between groups was detected (RR 1.00, 95\% Cl 0.07 to 15.12; 1 study; 50 infants; Analysis 1.12).

One study reported the incidence of fetal respiratory depression, but the study drugs were given late in labour to assess maximum fetal effect. Participants were not included in the analysis if birth was less than 30 minutes or more than four hours after administration of study drugs (Sliom 1970).

We were unable to include any results from one study that met the inclusion criteria, as it was unclear when outcomes were measured how they were defined and how many participants were included in the analysis (Kamyabi 2003). In this study, mean Apgar scores at one minute were reported to be higher $(P=0.008)$ in the pethidine $75 \mathrm{mg}$ group compared with placebo group (data not shown).

No other neonatal outcomes were reported.

\section{IM pentazocine versus placebo}

IM pentazocine versus placebo was reported by one three-armed study involving 150 women (Zafar 2016). One hundred women contributed to the data for this comparison.

\section{Primary outcomes}

No outcomes regarding maternal satisfaction were reported.

\section{Secondary outcomes}

\section{Maternal}

This small study reported no clear differences between groups for:

1. maternal pain scores measured during labour (measured on a VAS) (mean difference (MD) $-3.60,95 \% \mathrm{Cl}-9.91$ to $2.71 ; 1$ study, 89 women; low-quality evidence;Analysis 2.1)

2. nausea and vomiting (no events reported in either group; 1 study, 89 women; Analysis 2.2);

3. caesarean section (RR $0.89,95 \% \mathrm{Cl} 0.24$ to $3.35 ; 1$ study, 89 women; Analysis 2.3);

4. assisted vaginal births (RR $0.60,95 \% \mathrm{Cl} 0.10$ to $3.39 ; 1$ study, 89 women; Analysis 2.4).

No other maternal or neonatal outcomes were reported.

\section{IM tramadol versus no treatment}

IM tramadol versus no treatment was reported by one small study involving 60 women (Li 1994). This study reported one outcome relevant to this review. Maternal satisfaction with analgesia was reported as "analgesic effect" and was described as "satisfactory" by 5/30 women in the tramadol group, and 0/30 in the no treatment group (RR $11.00,95 \% \mathrm{Cl} 0.64$ to 190.53 ; very low-quality evidence; Analysis 3.1). It is not clear from the trial report when this outcome was measured.

\section{IM meptazinol versus IM pethidine}

IM meptazinol versus IM pethidine was evaluated in six studies with 1898 women (Morrison 1987; Nel 1981; Nicholas 1982; Osler 1987; Sheikh 1986; Wheble 1988), and in two additional studies where women in both study groups also received add-on drugs (De Boer
1987; Jackson 1983). These two studies are reported at the end of this comparison.

\section{Primary outcomes}

Maternal satisfaction with analgesia measured during labour and Maternal satisfaction with analgesia in labour measured during the postnatal period

One study (Morrison 1987), involving 801 women showed no evidence of a difference between meptazinol $100 \mathrm{mg}$ to $150 \mathrm{mg}$ compared with pethidine $100 \mathrm{mg}$ to $150 \mathrm{mg}$ for assessment of analgesic effect measured at three to five days postpartum (RR $1.01,95 \% \mathrm{Cl} 0.91$ to 1.12 ; low-quality evidence; Analysis 4.1 ). In this study, more than half of the women receiving either of these opioids reported that they received no or poor relief despite the fact that women in both groups could also receive an additional dose of study drug, epidural or nitrous oxide as required.

\section{Secondary outcomes}

\section{Maternal}

\section{Maternal pain score or pain measured in labour}

In two studies (Nel 1981; Sheikh 1986), involving 239 women, there was no evidence of a difference between groups in pain intensity one hour after administration of meptazinol $100 \mathrm{mg}$ or pethidine $100 \mathrm{mg}$; more than two-thirds of women in both groups were rating their pain as severe (four or five on a five-point scale) at one hour (average RR $1.11,95 \% \mathrm{Cl} 0.69$ to 1.80 (random-effects; heterogeneity: $\mathrm{I}^{2}=43 \%, \mathrm{Tau}^{2}=0.08, \mathrm{Chi}^{2}$ test for heterogeneity $\mathrm{P}=$ 0.18 , very low-quality evidence; Analysis 4.2)).

\section{Additional analgesia required}

Two studies (Osler 1987; Wheble 1988), involving 233 women found no evidence of a difference in requirement for additional analgesia between those who received meptazinol compared with pethidine (RR $1.03,95 \% \mathrm{Cl} 0.88$ to 1.20 , very low-quality evidence; Analysis 4.3). This outcome is difficult to interpret as women in the study by Osler 1987 were allowed up to three doses of study drug (meptazinol $100 \mathrm{mg}$ or pethidine $75 \mathrm{mg}$ ). Overall, 56 women required a second dose and 15 a third dose, but the number per group was not reported. Whereas in the study by Wheble 1988, women were allowed a second dose of study drug (meptazinol 100 $\mathrm{mg}$ or $150 \mathrm{mg}$ or pethidine $100 \mathrm{mg}$ or $150 \mathrm{mg}$ ) or epidural or nitrous oxide at the discretion of the caregiver. Additional analgesia relates to a pudendal block in the one study (Osler 1987), and a second dose of study drug in the other (Wheble 1988).

\section{Epidural}

The use of epidural analgesia was similar between meptazinol and pethidine ( $\mathrm{RR} 0.96,95 \% \mathrm{Cl} 0.71$ to 1.29 , very low-quality evidence) in four studies (Nicholas 1982; Osler 1987; Sheikh 1986; Wheble 1988) involving 788 women (Analysis 4.4).

\section{Maternal sleepiness during labour}

Fewer women in the meptazinol group reported sleepiness (average RR $0.55,95 \% \mathrm{Cl} 0.28$ to $1.07 ; 3$ studies, 1590 women), although there was moderate heterogeneity for this outcome (heterogeneity: $\mathrm{I}^{2}=44 \%, \mathrm{Tau}^{2}=0.18, \mathrm{Chi}^{2}$ test for heterogeneity $\mathrm{P}=$ 0.17) and the Cls crossed the line of no effect (Analysis 4.5). 


\section{Nausea and vomiting in labour}

Three studies each reported nausea and vomiting (Morrison 1987; Nicholas 1982; Sheikh 1986). There was no evidence for a difference in nausea (RR $1.11,95 \% \mathrm{Cl} 0.95$ to 1.28 ; 3 studies, 1590 women; Analysis 4.6); however, more women reported vomiting (RR 1.25, $95 \% \mathrm{Cl} 1.06$ to 1.47 ; 3 studies, 1589 women; Analysis 4.6) with meptazinol compared with pethidine.

\section{Caesarean section}

There was no evidence of a difference in rates of caesarean section between meptazinol and placebo. However, substantial heterogeneity was detected; therefore, we used a random-effects model (average RR 0.56, 95\% Cl 0.16 to 2.00) (heterogeneity: $1^{2}=$ $75 \%, \mathrm{Tau}^{2}=0.84, \mathrm{Chi}^{2}$ test for heterogeneity $\mathrm{P}=0.02$; Analysis 4.7).

\section{Assisted vaginal birth}

Instrumental birth was reported in three studies (Morrison 1987; Osler 1987; Wheble 1988) involving 1266 women, and rates were similar between groups (RR 1.00, 95\% Cl 0.81 to 1.22; Analysis 4.8).

No other maternal outcomes were reported.

\section{Neonatal}

\section{Fetal heart rate changes in labour (persistent decelerations or} tachycardia)

One study (34 women) (De Boer 1987) reported decelerations during labour but found no clear difference between the meptazinol or pethidine groups (RR $1.23,95 \% \mathrm{Cl} 0.92$ to 1.64 Analysis 4.10). One study compared IM meptazinol $1.8 \mathrm{mg} / \mathrm{kg}$ with IM pethidine $1.8 \mathrm{mg} / \mathrm{kg}$; all women also received promazine 25 mg IM (Jackson 1983). A second study compared IM meptazinol $1.5 \mathrm{mg} / \mathrm{kg}$ with IM pethidine $1.5 \mathrm{mg} / \mathrm{kg}$; all women also received metoclopramide $10 \mathrm{mg}$ IM (De Boer 1987). Women could receive a second dose of study drug after three hours in both studies. Both studies were conducted to assess effects of the study drugs on the newborn only. There was no evidence of difference in the number of babies with fetal heart rate changes (decelerations).

\section{Naloxone administration}

We found no evidence of a difference between meptazinol compared with pethidine for naloxone administration (RR 0.89, $95 \% \mathrm{Cl} 0.77$ to $1.02 ; 1$ study, 998 infants; Analysis 4.11 ). In one study (Morrison 1987), $40 \%$ of the babies were given naloxone, reflecting local practice at the time rather than low Apgar scores; with $41 \%$ of the babies having Apgar scores greater than or equal to eight at the time of administration.

\section{Neonatal resuscitation}

We found no evidence of a difference between meptazinol compared with pethidine for newborn resuscitation before and after 36 weeks' gestation (RR 1.00, 95\% Cl 0.95 to 1.05; 2 studies, 1356 infants; Analysis 4.12). In one study (Jackson 1983), three babies in the meptazinol group and two in the pethidine group required resuscitation ( $\mathrm{RR} 1.50,95 \% \mathrm{Cl} 0.26$ to $8.60 ; 100$ infants; Analysis 4.13).

\section{Apgar score less than seven at one minute and Apgar score less than} seven at five minutes and Apgar score less than seven at $\mathbf{1 0}$ minutes

Six studies involving 791 women reported number of babies with Apgar scores less than or equal to seven at one minute (De Boer
1987; Jackson 1983; Nel 1981; Nicholas 1982; Osler 1987; Wheble 1988), and three studies reported this outcome at five minutes (Nel 1981; Nicholas 1982; Osler 1987). There was no evidence of a difference between groups at one minute (RR $0.79,95 \% \mathrm{Cl} 0.56$ to 1.11; 6 studies; 791 infants; Analysis 4.14) or five minutes (RR 0.49, $95 \% \mathrm{Cl} 0.05$ to 5.37; 3 studies, 616 infants; Analysis 4.15) with three babies with low scores at five minutes reported in one study (Osler 1987), and none in the other two (Nel 1981; Nicholas 1982).

In the study by De Boer 1987, Apgar at five and 10 minutes were reported as 'similar' in both groups. No babies in either group had Apgar scores less than or equal to seven at 10 minutes.

\section{IM diamorphine + prochlorperazine versus IM pethidine + prochlorperazine}

One study involving 133 women compared IM diamorphine $5 \mathrm{mg}$ with $7.5 \mathrm{mg}$ versus IM pethidine $100 \mathrm{mg}$ to $150 \mathrm{mg}$. All women also received IM prochlorperazine $12.5 \mathrm{mg}$ at the same time as the study drug (Fairlie 1999).

\section{Primary outcomes}

Maternal satisfaction with analgesia in labour measured during the postnatal period

Global assessment of pain relief was evaluated at 24 hours; there was no evidence of a difference between groups in the number of women reporting 'fair' or 'poor' as opposed to 'good' pain relief, with more than half of the women in both groups having inadequate relief (RR $0.88,95 \% \mathrm{Cl} 0.67$ to 1.16 ; very low-quality evidence; Analysis 5.1). Maternal satisfaction was not measured in labour.

\section{Secondary outcomes}

\section{Maternal}

\section{Maternal pain score or pain measured in labour}

More women reported pain intensity as moderate or severe one hour post administration of study drug with pethidine compared with diamorphine, though there was no evidence of a clear difference between groups, with the majority of women in both groups reporting moderate or severe pain (RR $0.85,95 \% \mathrm{Cl} 0.72$ to 1.01; very low-quality evidence; Analysis 5.2).

\section{Additional analgesia required}

There was no evidence for a difference between groups in the number of women requiring additional analgesia (second dose of study drug) (RR 1.35, 95\% Cl 0.53 to 3.40; very low-quality evidence; Analysis 5.3).

\section{Epidural}

There was no evidence for a difference between groups in the number of women requiring an epidural (RR $1.22,95 \% \mathrm{Cl} 0.72$ to 2.07; very low-quality evidence; Analysis 5.4).

\section{Maternal sleepiness during labour}

The number of women moderately drowsy or asleep one hour after study drug administration was similar between groups (RR 0.93, $95 \% \mathrm{Cl} 0.52$ to 1.66 ; Analysis 5.5). The attending midwife measured sedation on a four-point scale where: 0 = alert; 1 = mildly drowsy; 2 = moderately drowsy; 3 = asleep. 


\section{Nausea and vomiting in labour}

The number of women vomiting was lower with diamorphine compared with pethidine (RR 0.39, $95 \% \mathrm{Cl} 0.17$ to 0.86 ; Analysis 5.6).

\section{Caesarean section}

There was no evidence for a difference between groups in the number of women who had a caesarean section (RR $0.52,95 \% \mathrm{Cl}$ 0.10 to 2.76; Analysis 5.7).

\section{Assisted vaginal birth}

There was no evidence for a difference between groups in the number of women who had an assisted vaginal birth (RR 0.96, 95\% $\mathrm{Cl} 0.46$ to 2.02; Analysis 5.8).

No other maternal outcomes were reported.

\section{Neonatal}

\section{Neonatal resuscitation}

There were no clear differences between groups for the number of babies needing resuscitation (RR $1.21,95 \% \mathrm{Cl} 0.73$ to 2.02; 133 infants; Analysis 5.9).

\section{Apgar score less than seven at one minute and Apgar score less than seven at five minutes}

Fewer babies had Apgar scores less than seven at one minute with diamorphine compared with pethidine ( $\mathrm{RR} 0.41,95 \% \mathrm{Cl} 0.18$ to 0.91 ; 133 infants; Analysis 5.10). However, there was no evidence of a clear difference between groups at five minutes, with few babies with an Apgar score less than seven in either group (RR 0.35, 95\% Cl 0.04 to 3.27 ; 133 infants; Analysis 5.11).

\section{Admission to special care baby unit/neonatal intensive care unit (as defined by trialists)}

There were no clear differences between groups for the number of babies needing admission to NICU (RR $0.58,95 \% \mathrm{Cl} 0.21$ to $1.64 ; 133$ infants; Analysis 5.12).

No other neonatal outcomes were reported.

\section{IM tramadol versus IM pethidine}

Seven studies involving 569 women compared IM tramadol versus IM pethidine (Bitsch 1980; Fieni 2000; Husslein 1987; Keskin 2003; Khooshideh 2009; Prasertsawat 1986; Viegas 1993). Tramadol and pethidine doses varied between studies and were $50 \mathrm{mg}, 75 \mathrm{mg}$ or $100 \mathrm{mg}$.

\section{Primary and secondary outcomes}

\section{Maternal}

Women's satisfaction with analgesia was not measured in any of the studies.

\section{Maternal pain score or pain measured in labour}

Pain intensity was defined in disparate ways in the studies; however, more women had poor pain relief with tramadol compared with pethidine (RR $1.56,95 \% \mathrm{Cl} 1.10$ to 2.21 ; 4 studies, 243 women; low-quality evidence; Analysis 6.1).

\section{Additional analgesia required}

In three studies which reported requirement for additional analgesia, no evidence of a difference was detected (average RR $1.07,95 \% \mathrm{Cl} 0.60$ to $1.91 ; 3$ studies, 295 women; very low-quality evidence; Analysis 6.2). Bitsch 1980 administered second and third doses of the study drug, Khooshideh 2009 offered a second dose, and Prasertsawat 1986 gave a second dose but half the amount.

\section{Maternal sleepiness during labour}

More women in the pethidine group reported sleepiness although heterogeneity was high and we used a random-effects model (average RR $0.57,95 \% \mathrm{Cl} 0.33$ to $0.97 ; 5$ studies, 409 women) (heterogeneity $\mathrm{I}^{2}=72 \%, \mathrm{Tau}^{2}=0.24, \mathrm{Chi}^{2}$ test for heterogeneity $\mathrm{P}=$ 0.007 ; Analysis 6.3).

\section{Nausea and vomiting in labour}

There was no evidence for a clear difference in incidence of nausea and/or vomiting with tramadol compared with placebo (average RR $0.97,95 \% \mathrm{Cl} 0.34$ to $2.76 ; 6$ studies, 454 women; Analysis 6.4). There was a substantial level of heterogeneity detected for this outcome $\left(\mathrm{I}^{2}=72 \%, \mathrm{Tau}^{2}=1.09, \mathrm{Chi}^{2}\right.$ test for heterogeneity $\left.\mathrm{P}=0.003\right)$ therefore we used a random-effects model for the analysis.

\section{Caesarean section and assisted vaginal birth}

There was no clear difference between the tramadol and pethidine groups for incidence of caesarean section (RR $0.71,95 \% \mathrm{Cl} 0.23$ to 2.18; 3 studies, 260 women; Analysis 6.5) or assisted vaginal birth (RR $0.56,95 \% \mathrm{Cl} 0.12$ to $2.56 ; 3$ studies, 260 women; Analysis 6.6).

\section{Neonatal}

Only two studies reported Apgar scores (Khooshideh 2009; Prasertsawat 1986), and reported no babies in either group with Apgar scores less than or equal to seven at one or five minutes, and no babies requiring resuscitation (Analysis 6.8; Analysis 6.7).

One study (Keskin 2003), reported the incidence of respiratory distress and admission to NICU which occurred more frequently with tramadol $100 \mathrm{mg}$ compared with pethidine $100 \mathrm{mg}$, though Cls crossed the line of no effect for both outcomes (RR 2.26, 95\% Cl 0.64 to 7.89 ; 1 study; 59 infants; Analysis 6.9 and RR 2.26, $95 \% \mathrm{Cl} 0.64$ to 7.89; 1 study; 59 infants; Analysis 6.10).

No other maternal or neonatal outcomes were reported.

\section{IM tramadol + triflupromazine versus IM pethidine + triflupromazine}

One study involving 66 women compared tramadol $500 \mathrm{mg}$ with pethidine $50 \mathrm{mg}$, and both groups also received triflupromazine 10 mg (Kainz 1992). A third study arm received tramadol $100 \mathrm{mg}$.

\section{Primary and secondary outcomes}

Maternal satisfaction with analgesia measured during labour or maternal satisfaction with analgesia in labour measured during the postnatal period was not reported.

Data for effects on pain were not reported (P values for the change within groups were reported; not the between group differences; data not shown). 
Sleepiness was more frequently reported by women who received tramadol, though Cls crossed the line of no effect (RR 2.86, 95\% $\mathrm{Cl} 0.68$ to $12.12 ; 1$ study, 40 women; Analysis 7.1 ). The incidence of nausea or vomiting was reported and was infrequent, with no evidence of differences between groups (RR $0.82,95 \% \mathrm{Cl} 0.13$ to 5.25 and RR $0.40,95 \% \mathrm{Cl} 0.02$ to 9.35 , respectively; 1 study, 40 women; Analysis 7.2).

The authors report that there were no negative effects on the newborn; though no data were presented.

\section{IM dihydrocodeine versus IM pethidine}

One study involving 196 women compared a single dose of IM dihydrocodeine $50 \mathrm{mg}$ with IM pethidine $100 \mathrm{mg}$ (Sliom 1970). An additional study arm received placebo.

\section{Primary and secondary outcomes}

\section{Maternal pain score or pain measured in labour}

There was no evidence of a clear difference in pain relief between groups with a substantial proportion of women in each group reporting poor pain relief one hour after administration of study drug (RR $1.09,95 \% \mathrm{Cl} 0.64$ to $1.86 ; 1$ study, 138 women; very lowquality evidence; Analysis 8.1).

\section{Maternal sleepiness and nausea and vomiting in labour}

There was no evidence of a difference between dihydrocodeine and pethidine for nausea and vomiting (RR $0.87,95 \% \mathrm{Cl} 0.40$ to 1.88 ; 1 study, 138 women; Analysis 8.3), or sleepiness (RR $0.67,95 \% \mathrm{Cl} 0.43$ to 1.04 ; 1 study, 138 women; Analysis 8.2).

\section{Apgar score less than seven at one minute}

Fewer babies had Apgar scores less than or equal to seven at one minute with dihydrocodeine compared with pethidine (RR $0.57,95 \% \mathrm{Cl} 0.39$ to $0.84 ; 138$ infants; Analysis 8.4 ). Apgar score at five minutes was reported as mean scores rather than number of babies in each group: there was no clear difference between groups reported (data not shown).

\section{IM pentazocine versus pethidine}

Five studies with 792 women compared IM pentazocine versus pethidine (Borglin 1971; Duncan 1969; Levy 1971; Moore 1970; Mowat 1970). One study with 85 women also compared IM pentazocine versus pethidine but all women received promazine 25 mg IM before first injection (Refstad 1980).

\section{Primary outcomes}

\section{Maternal satisfaction with analgesia measured during labour}

Two studies reported on the numbers of women rating pain relief as good or very good at birth (Borglin 1971; Mowat 1970), and there was no clear difference between IM pentazocine or IM pethidine without add-on drugs in either study, or when results were pooled (RR 1.08, 95\% Cl 0.92 to 1.27 ; 253 women; very low-quality evidence; Analysis 9.1).

\section{Secondary outcomes}

Maternal

\section{Maternal pain score or pain measured in labour}

Four studies reported poor pain relief (Duncan 1969; Levy 1971; Moore 1970; Refstad 1980). More than half of the women in both groups had only partial or poor relief and there was no clear difference between groups for women who received promazine (RR $1.53,95 \% \mathrm{Cl} 0.66$ to 3.58 ; 1 study, 85 women, very low-quality evidence) or those who did not (average RR $1.23,95 \% \mathrm{Cl} 0.74$ to 2.05; 3 studies, 365 women; very low-quality evidence; Analysis 9.2). There was a substantial level of heterogeneity detected for this outcome $\left(\mathrm{I}^{2}=83 \%, \mathrm{Tau}^{2}=0.16, \mathrm{Chi}^{2}\right.$ test for heterogeneity $\left.\mathrm{P}=0.003\right)$, therefore we used a random-effects model for the analysis.

\section{Additional analgesia required}

The use of additional analgesic drugs (second dose of study drug) was reported by two studies (Mowat 1970; Refstad 1980). There was no clear difference between groups in either study (Analysis 9.3): pentazocine and pethidine alone (RR $0.91,95 \% \mathrm{Cl} 0.50$ to $1.65 ; 94$ women, very low-quality evidence); and with promazine (RR 1.67, $95 \% \mathrm{Cl} 0.73$ to $3.84 ; 85$ women, very low-quality evidence).

There was no clear evidence of a difference between groups for:

1. maternal sleepiness in labour (Analysis 9.4)

a. pentazocine versus pethidine alone (RR $1.00,95 \% \mathrm{Cl} 0.89$ to 1.12; 3 studies, 391 women);

2. nausea in labour (Analysis 9.5)

a. pentazocine versus pethidine alone ( $\mathrm{RR} 0.46,95 \% \mathrm{Cl} 0.24$ to 0.90; 3 studies, 391 women);

3. vomiting in labour (Analysis 9.5)

a. pentazocine versus pethidine alone ( $R R=.92,95 \% \mathrm{Cl} 0.27$ to 3.14; 1 study, 73 women);

4. assisted vaginal birth (Analysis 9.6)

a. pentazocine versus pethidine alone (RR $5.22,95 \% \mathrm{Cl} 0.63$ to 42.97; 1 study, 94 women);

b. pentazocine versus pethidine with promazine (RR $0.78,95 \%$ $\mathrm{Cl} 0.23$ to 2.71 ; 1 study, 85 women).

No other maternal outcomes were reported.

\section{Neonatal}

There was no clear evidence of a difference between groups for:

1. naloxone administration (Analysis 9.7)

a. pentazocine versus pethidine with promazine (RR 0.49 , 95\% $\mathrm{Cl} 0.09$ to 2.53 ; 1 study, 85 infants);

2. low Apgar score (less than seven) at one minute (Analysis 9.8)

a. pentazocine versus pethidine alone (average RR $1.39,95 \% \mathrm{Cl}$ 0.06 to $32.97 ; 2$ studies, 242 infants, $\mathrm{I}^{2}=67 \%$, $\mathrm{Tau}^{2}=3.56 ; \mathrm{Chi}^{2}$ test for heterogeneity $\mathrm{P}=0.08$ );

b. pentazocine versus pethidine with promazine (RR 1.13, 95\% Cl 0.07 to 17.30 ; 1 study, 66 infants);

3. low Apgar score (less than seven) at five minutes (Analysis 9.9)

a. pentazocine versus pethidine alone ( $\mathrm{RR} 0.23,95 \% \mathrm{Cl} 0.01$ to 4.54; 1 study, 62 infants);

b. pentazocine versus pethidine with promazine (RR $0.38,95 \%$ $\mathrm{Cl} 0.02$ to $8.88 ; 1$ study, 66 infants).

No other neonatal outcomes were reported. 


\section{IM nalbuphine versus pethidine}

Four studies with 486 women are included in this comparison (Lardizabal 1999; Lisboa 1997; Mitterschiffthaler 1991; Wilson 1986).

\section{Primary outcomes}

\section{Maternal satisfaction with analgesia measured during labour and during the postnatal period}

One study reported maternal satisfaction with analgesia at 24 hours (Wilson 1986). The majority of women receiving both nalbuphine and pethidine thought that analgesia had been "minimally effective" ( $63 \%$ and $85 \%$ respectively), although fewer women who received nalbuphine reported to be dissatisfied with their analgesia (RR $0.73,95 \% \mathrm{Cl} 0.55$ to $0.96 ; 72$ women, 1 study; low-quality evidence; Analysis 10.1). One study reported the number of women that were free of pain (Mitterschiffthaler 1991); there was no clear difference between groups, with few women in either group having no pain (RR $6.00,95 \% \mathrm{Cl} 0.79$ to 45.42 ; 1 study, 40 women; very lowquality evidence; Analysis 10.2).

\section{Secondary outcomes}

\section{Maternal}

\section{Maternal pain score or pain measured in labour}

Two studies reported pain intensity: one reported severe pain at 30 minutes (Lardizabal 1999), and the other VAS at 60 minutes (Wilson 1986). There were no clear differences between groups in either analysis (RR $0.86,95 \% \mathrm{Cl} 0.59$ to 1.26 ; 1 study, 295 women; very lowquality evidence; Analysis 10.3 ; and (MD $-8.00,95 \% \mathrm{Cl}-18.55$ to 2.55 ; 1 study, 72 women; very low-quality evidence; Analysis 10.4).

\section{Additional analgesia required}

One study reported the use of additional analgesia (second dose of study drug) but found no difference between the groups (RR 1.26, $95 \% \mathrm{Cl} 0.49$ to 3.27 ; 1 study, 72 women; very low-quality evidence; Analysis 10.5).

\section{Epidural}

One study reported the use of epidural (Lardizabal 1999); there was no clear difference between groups (RR $1.65,95 \% \mathrm{Cl} 0.55$ to 4.94; 307 women; low-quality evidence; Analysis 10.6).

\section{Nausea and vomiting in labour}

One study reported nausea and vomiting as separate outcomes (Lardizabal 1999), and another reported nausea and vomiting as a single outcome (Wilson 1986). Fewer women who received nalbuphine reported nausea alone (RR $0.62,95 \% \mathrm{Cl} 0.42$ to 0.91 , 301 women), or vomiting (RR $0.41,95 \% \mathrm{Cl} 0.22$ to $0.76 ; 301$ women) compared with women who received pethidine. Likewise, fewer women who received nalbuphine reported nausea and vomiting combined (RR $0.41,95 \% \mathrm{Cl} 0.18$ to $0.94 ; 72$ women; Analysis 10.8 ).

There was no evidence of clear differences between groups for:

1. maternal sleepiness (RR $3.78,95 \% \mathrm{Cl} 0.86$ to $16.60 ; 1$ study, 72 women; Analysis 10.7);

2. caesarean section (RR $0.45,95 \% \mathrm{Cl} 0.12$ to $1.69 ; 1$ study, 310 women; Analysis 10.9);

3. assisted vaginal births (average RR $0.98,95 \% \mathrm{Cl} 0.25$ to 3.85 ; 2 studies, 382 women; $I^{2}=41 \% ; \mathrm{Tau}^{2}=0.50 ; \mathrm{Chi}^{2}$ test for heterogeneity $\mathrm{P}=0.19$; Analysis 10.10 ).
No other maternal outcomes were reported.

\section{Neonatal}

Two studies reported neonatal outcomes (Lardizabal 1999; Wilson 1986).

There was no clear difference between groups for:

1. naloxone administration (RR $6.63,95 \% \mathrm{Cl} 0.35$ to $123.93 ; 1$ study, 72 infants; Analysis 10.11);

2. Apgar score less than seven at one (average RR $1.18,95 \% \mathrm{Cl} 0.72$ to $1.95 ; 2$ studies, 382 infants; $\mathrm{I}^{2}=44 \%$; $\mathrm{Tau}^{2}=0.07 ; \mathrm{Chi}^{2}$ test for heterogeneity $\mathrm{P}=0.18$ ), and Apgar score less than seven at five minutes (RR $0.47,95 \% \mathrm{Cl} 0.04$ to $4.99 ; 1$ study, 72 infants; Analysis 10.12);

3. admission to NICU (RR 1.07, 95\% CI 0.61 to $1.89 ; 1$ study, 299 infants; Analysis 10.13).

\section{Newborn neuro-behavioural scores}

One study reported a neonatal neuro-behavioural score two to four hours following birth (Wilson 1986); babies of women who received nalbuphine had lower scores than babies born to women in the control group (MD $-3.70,95 \% \mathrm{Cl}-6.14$ to -1.26 ; 72 infants; Analysis 10.14).

No other neonatal outcomes were reported.

\section{IM phenazocine versus pethidine}

One study with 212 women (Grant 1970) compared IM phenazocine versus IM pethidine.

\section{Primary and secondary outcomes}

This study reported only two outcomes: epidural and nausea and vomiting in labour. There was no clear difference between groups for epidural (RR 1.31, 95\% $\mathrm{Cl} 0.58$ to 2.97; very lowquality evidence; Analysis 11.1), but fewer women who received phenazocine reported nausea and vomiting in labour (RR 0.39, 95\% $\mathrm{Cl} 0.20$ to 0.78 ; Analysis 11.2) compared with those who received pethidine.

\section{IM diamorphine/morphine versus pethidine}

We included two studies with 619 women in this comparison (Prasertsawat 1986; Wee 2014).

\section{Primary outcomes}

Maternal satisfaction with analgesia measured during labour or during the postnatal period

One study (Wee 2014), found that more women in the diamorphine group reported to be 'satisfied' or 'very satisfied' with the analgesia compared with the pethidine group (RR $1.13,95 \% \mathrm{Cl} 1.02$ to 1.26; 484 women; high-quality evidence Analysis 12.1). However, the smaller study reported no clear difference between groups in the number of women describing their pain relief as poor (RR 1.22, $95 \% \mathrm{Cl} 0.56$ to 2.66 ; 1 study, 90 women; very low-quality evidence; Analysis 12.2).

\section{Secondary outcomes}

Maternal 


\section{Maternal pain score or pain measured in labour}

Women in the diamorphine group reported less pain than the pethidine group at 30 minutes (MD $-0.80,95 \% \mathrm{Cl}-1.24$ to $-0.36 ; 1$ study, 484 women; high-quality evidence; Analysis 12.3), and at 60 minutes (MD $-0.80,95 \% \mathrm{Cl}-1.26$ to -0.34 ; 1 study, 484 women; highquality evidence; Analysis 12.4) after receiving analgesia.

There was no clear difference between groups for:

1. additional analgesia required (RR $1.00,95 \% \mathrm{Cl} 0.92$ to $1.10 ; 2$ studies, 574 women; moderate-quality evidence; Analysis 12.5);

2. maternal sleepiness during labour (RR $0.60,95 \% \mathrm{Cl} 0.29$ to 1.23 ; 1 study, 90 women; Analysis 12.6);

3. nausea and vomiting in labour (RR $1.00,95 \% \mathrm{Cl} 0.21$ to $4.69 ; 1$ study, 90 women; Analysis 12.7);

4. caesarean section (RR $0.94,95 \% \mathrm{Cl} 0.66$ to $1.35 ; 1$ study, 484 women; Analysis 12.8);

5. assisted vaginal birth ( $\mathrm{RR} 1.28,95 \% \mathrm{Cl} 0.91$ to $1.80 ; 1$ study, 484 women; Analysis 12.9).

\section{Neonatal}

There was no clear difference between morphine and pethidine for:

- naloxone administration (RR 0.98, 95\% Cl 0.20 to 4.83; 1 study, 484 infants; Analysis 12.10);

- neonatal resuscitation (RR $0.96,95 \% \mathrm{Cl} 0.66$ to $1.41 ; 2$ studies, 574 infants; Analysis 12.11). No babies received resuscitation in Prasertsawat 1986;

- Apgar score less than seven at one minute (RR 1.15, 95\% Cl 0.76 to 1.73; 2 studies, 574 infants; Analysis 12.12);

- admission to special care baby unit/neonatal intensive care unit (RR 0.87, 95\% Cl 0.34 to 2.23; 1 study, 484 infants; Analysis 12.13).

No other neonatal outcomes were reported.

\section{IM butorphanol versus pethidine}

One study with 80 women compared IM butorphanol with IM pethidine (Maduska 1978).

\section{Primary and secondary outcomes}

This study did not report on the review's primary outcomes. There was no evidence of clear differences between groups for additional analgesia required (second dose of study drug) (RR 0.89, 95\% Cl 0.55 to 1.45 ; very low-quality evidence; Analysis 13.1), nausea (RR $0.20,95 \% \mathrm{Cl} 0.01$ to 4.04; Analysis 13.2), or vomiting (RR $0.50,95 \% \mathrm{Cl}$ 0.05 to 5.30; Analysis 13.3). Likewise, there was no clear difference between groups for neonatal resuscitation (RR $0.33,95 \% \mathrm{Cl} 0.01$ to 7.95; Analysis 13.4) or naloxone administration ( $R R 0.33,95 \% \mathrm{Cl} 0.01$ to 7.95 ; Analysis 13.5).

\section{IM Avacan ${ }^{\circledR}$ versus IM pentazocine}

We included one study with 185 women in this comparison (Hamann 1972).

\section{Primary and secondary outcomes}

This study did not report on either of our primary outcomes.

There were no clear differences between groups for additional analgesia required (Entonox) (RR $0.92,95 \% \mathrm{Cl} 0.53$ to $1.63 ; 1$ study, 160 women; Analysis 14.1). More women in the Avacan ${ }^{\circledR}$ group received a pudendal-paracervical block (RR 2.02, 95\% Cl 1.16 to $3.53 ; 160$ women; Analysis 14.2). There was no evidence of a clear difference between groups for the number of women having a caesarean section (RR $0.62,95 \% \mathrm{Cl} 0.21$ to $1.84 ; 184$ women; Analysis 14.3), or babies born with an Apgar score less than or equal to seven at birth ((RR $0.59,95 \% \mathrm{Cl} 0.27$ to $1.26 ; 160$ women; Analysis 14.4). This study did not report on any other maternal or neonatal outcomes.

\section{IM pentazocine versus IM Pethilorfan ${ }^{\circledR}$}

One trial involving 98 women compared pentazocine with Pethilorfan $^{\circledast}$ (O'Dwyer 1971).

\section{Primary and secondary outcomes}

This trial reported maternal satisfaction with analgesia in labour in the form of the number of women saying that they did not obtain any relief from medication at one hour. There were no clear differences between groups for this outcome (RR 1.22, 95\% Cl 0.77 to 1.95 ; 69 women; Analysis 15.1).

No clear differences were reported for any of the secondary outcomes recorded: additional analgesia required (second dose of study drug) (RR 0.52, 95\% Cl 0.10 to 2.71; 98 women; Analysis 15.2), assisted vaginal birth (RR 1.04, 95\% Cl 0.07 to 16.19; 98 women; Analysis 15.3). Apgars scores less than seven were not reported, however, Apgar scores less than eight were reported at one minute (RR 5.71, 95\% Cl 0.72 to 45.39; 82 infants; Analysis 15.4), and at five minutes (no events in either group, 82 infants; Analysis 15.5) finding no clear differences across groups.

\section{IM pentazocine versus complementary and alternative medicine (CAM)}

One study (Zafar 2016) involving 150 women contributed to this outcome, one control arm of 50 women were not included in this comparison. The homeopathy group received $1 \mathrm{~mL}$ of saline injection and oral homeopathic medicine prescribed by a qualified homeopath.

\section{Primary and secondary outcomes}

No primary outcomes were reported.

There were no clear differences between the groups for: maternal pain score during labour (MD $-0.40,95 \% \mathrm{Cl}-7.61$ to $6.81 ; 89$ women; Analysis 16.1), nausea and vomiting (RR $0.30,95 \% \mathrm{Cl} 0.01$ to $7.14 ; 89$ women; Analysis 16.2), caesarean section (RR $0.89,95 \% \mathrm{Cl} 0.24$ to 3.35; 89 women; Analysis 16.3), and assisted vaginal birth (RR 0.89, $95 \% \mathrm{Cl} 0.13$ to $6.07 ; 89$ women; Analysis 16.4 ).

\section{IM pentazocine versus IM tramadol}

One study (Kuti 2008) involving 100 women reported this comparison.

\section{Primary outcomes}

Maternal satisfaction with analgesia measured during labour or during the postnatal period

More women in the pentazocine group than the tramadol group reported to be satisfied with their analgesia 30 minutes after receiving the injection (RR $2.40,95 \% \mathrm{Cl} 1.28$ to $4.48 ; 100$ women; Analysis 17.1), however this difference was no longer clear after 
60 minutes had passed (RR 1.62, 95\% Cl 0.91 to 2.86; 100 women; Analysis 17.2).

\section{Secondary outcomes}

\section{Maternal}

\section{Maternal pain score or pain measured in labour}

It appears that fewer women in the pentazocine group reported moderate or severe pain 30 minutes following administration of the drug however $\mathrm{Cls}$ cross the line of no effect so this result is not certain (RR 0.75, 95\% Cl 0.55 to 1.02; 100 women; Analysis 17.3). At 60 minutes following administration there is not a clear difference between the groups (RR $0.81,95 \% \mathrm{Cl} 0.60$ to $1.08 ; 100$ women; Analysis 17.4) though results still appear to favour pentazocine.

There were no clear differences between the groups for:

1. maternal sleepiness during labour ( $\mathrm{RR} 1.67,95 \% \mathrm{Cl} 0.66$ to 4.24; Analysis 17.5);

2. nausea and vomiting during labour (RR $1.00,95 \% \mathrm{Cl} 0.06$ to 15.55; Analysis 17.6);

3. caesarean section ( $\mathrm{RR} 1.50,95 \% \mathrm{Cl} 0.45$ to 4.99; Analysis 17.7);

4. assisted vaginal birth (RR $2.00,95 \% \mathrm{Cl} 0.19$ to 21.36 ; Analysis 17.8).

No other maternal outcomes were reported.

\section{Neonatal}

There were no clear differences between the groups for:

1. Apgar score less than seven at one minute (RR 1.67, 95\% Cl 0.42 to $6.60 ; 100$ infants; Analysis 17.9);

2. Apgar score less than seven at five minutes (RR 3.00,95\% $\mathrm{Cl} 0.13$ to $71.92 ; 100$ infants; Analysis 17.10);

3. admission to neonatal intensive care unit (RR $2.87,95 \% \mathrm{Cl} 0.12$ to 68.47 ; 86 infants; Analysis 17.11).

No other neonatal outcomes were reported in this study.

\section{IM pethidine versus inhaled nitrous oxide (Entonox)}

One study (Mobaraki 2016) with 100 women reported this comparison.

\section{Primary and secondary outcomes}

\section{Maternal pain score or pain measured during labour}

This study only reported pain relief following analgesia using a pain score; at 30 minutes women who received pethidine reported better pain relief than those with inhaled nitrous oxide (MD 1.66, $95 \% \mathrm{Cl} 1.17$ to 2.15; very low-quality evidence; Analysis 18.1). After 60 minutes, there was not a clear difference in pain relief reported by the groups (MD $-0.36,95 \% \mathrm{Cl}-0.85$ to 0.13 ; very lowquality evidence; Analysis 18.2), although interestingly, pain relief reported in the pethidine group had dropped compared to 30 minute readings, whilst the pain relief in the nitrous oxide group had risen.

\section{Intravenous opioids for pain relief in labour}

\section{IV pethidine versus placebo}

One study (El-Refaie 2012) with 240 women contributed data to this comparison.

Primary and secondary outcomes

Maternal

This study did not report the primary outcomes.

\section{Maternal pain score or pain measured in labour}

Women who received IV pethidine reported lower pain scores than those who received a placebo (MD $-4.10,95 \% \mathrm{Cl}-4.56$ to -3.64 ; moderate-quality evidence; Analysis 19.1).

\section{Nausea and vomiting}

Fewer women in the placebo group experienced nausea and vomiting in labour (RR 2.43, $95 \% \mathrm{Cl} 1.05$ to 5.64; Analysis 19.2).

\section{Caesarean section; assisted vaginal birth}

There was no clear difference between the groups in number of women who had a caesarean section (RR $0.88,95 \% \mathrm{Cl} 0.46$ to 1.68 ; Analysis 19.3) or assisted vaginal birth (RR $0.75,95 \% \mathrm{Cl} 0.33$ to 1.71 ; Analysis 19.4).

No other maternal outcomes reported.

\section{Neonatal}

There was no clear difference between the groups in number of babies admitted to neonatal intensive care (RR $0.67,95 \% \mathrm{Cl} 0.11$ to 3.92; 240 infants; Analysis 19.5).

No other neonatal outcomes were reported.

\section{IV fentanyl versus no treatment}

One study (Jahani 2013) involving 70 women reported this comparison. It was not made clear in this study whether or not the women in the control group were able to request pain relief. The pain scores were noticeably worse in the control group with $31 / 35$ women reporting severe pain, and $0 / 35$ reporting this in the fentanyl group.

\section{Primary and secondary outcomes}

This study did not report the primary outcomes, many maternal, or any neonatal outcomes.

\section{Maternal pain score or pain measured in labour}

IV fentanyl resulted in lower pain scores (MD -5.00, 95\% Cl -5.47 to -4.53; very low-quality evidence; Analysis 20.1), and no women reporting "severe pain" after 60 minutes (RR $0.02,95 \% \mathrm{Cl} 0.00$ to 0.25 ; very low-quality evidence; Analysis 20.2 ). There was no clear difference between groups for the number of women who had caesarean sections (RR 1.50, 95\% Cl 0.27 to 8.43; Analysis 20.3).

\section{IV fentanyl versus IV pethidine}

We included one study with 105 women in this comparison (Rayburn 1989a). The study recruited women only during a limited time period Monday to Friday and allocation was not blinded due to the different half-lives of the treatment options. 


\section{Primary and secondary outcomes}

The primary outcomes were not reported in this study.

\section{Maternal}

\section{Maternal pain score or pain measured in labour}

The mean maternal pain scores for women allocated to the IV fentanyl compared with those in the IV pethidine group were similar; women in both groups reported mean pain scores of approximately six on a $10 \mathrm{~mm}$ scale (MD $-0.20,95 \% \mathrm{Cl}-1.18$ to 0.78 ; low-quality evidence; Analysis 21.1). It is not clear from the trial report whether 0 or 10 equalled less pain. It is reported that both treatments "took the edge off" the contraction pain (Rayburn 1989a).

\section{Additional analgesia required}

Women in the pethidine group required fewer doses than those in the fentanyl group (MD $0.40,95 \% \mathrm{Cl} 0.14$ to 0.66 ; low-quality evidence; Analysis 21.2).

\section{Maternal sleepiness in labour}

Maternal sedation was lower in women allocated to the IV fentanyl group compared with those in the IV pethidine group (RR 0.05, 95\% $\mathrm{Cl} 0.00$ to 0.82 ; Analysis 21.3 ).

There were no clear differences for all other reported outcomes including nausea and vomiting ( $\mathrm{RR} 0.51,95 \% \mathrm{Cl} 0.17$ to 1.55 ; Analysis 21.4), anti-emetic required (RR $0.09,95 \% \mathrm{Cl} 0.01$ to 1.52 ; Analysis 21.5), and caesarean section (RR $1.14,95 \% \mathrm{Cl} 0.24$ to 5.40 ; Analysis 21.6).

No further maternal outcomes were reported.

\section{Neonatal}

There were no clear differences for all neonatal outcomes reported:

1. naloxone required ( $\mathrm{RR} 0.16,95 \% \mathrm{Cl} 0.02$ to 1.28 ; Analysis 21.7 );

2. neonatal resuscitation/ventilatory support (RR $1.03,95 \% \mathrm{Cl} 0.46$ to 2.32; Analysis 21.8);

3. Apgar score less than seven at one minute (RR $0.63,95 \% \mathrm{Cl} 0.23$ to 1.77 ; Analysis 21.9);

4. Apgar score less than seven at five minutes (RR $0.38,95 \% \mathrm{Cl} 0.02$ to 9.12; Analysis 21.10);

5. newborn neuro-behavioural score (one to two hours after delivery) (MD 1.30, 95\% Cl 0.15 to 2.45; Analysis 21.11);

6. newborn neuro-behavioural score (two hours to 24 hours) (MD $0.90,95 \% \mathrm{Cl}-0.42$ to 2.22 ; Analysis 21.12 ).

No other neonatal outcomes were reported.

\section{IV nalbuphine versus IV pethidine}

We included one study involving 28 women compared IV nalbuphine with IV pethidine (Giannina 1995).

\section{Primary and secondary outcomes}

No outcomes relating to maternal pain during labour were reported.

This study reported estimable data for only two relevant secondary outcomes (caesarean section and Apgar score less than seven at one and five minutes), neither of which showed any clear difference between the two groups: caesarean section (RR 5.00, 95\% Cl 0.26 to 95.61; Analysis 22.1), Apgar scores less than seven at one minute (RR 3.00, 95\% Cl 0.13 to 67.91; Analysis 22.2; no babies had Apgar less than seven at five minutes; Analysis 22.3).

\section{IV phenazocine versus IV pethidine}

We included one study including 194 women compared IV phenazocine with IV pethidine (Olson 1964).

\section{Primary and secondary outcomes}

\section{Maternal}

There was no clear difference between groups for maternal satisfaction with analgesia measured during labour (comparing the number of women with "fair" or "poor" pain relief one hour after administration) (RR $0.72,95 \% \mathrm{Cl} 0.48$ to 1.10 ; very lowquality evidence; Analysis 23.1). No other primary outcomes were reported.

Only one identified secondary outcome reported estimable data: nausea with vomiting. There was no clear difference between the two groups for this outcome (RR $0.40,95 \% \mathrm{Cl} 0.08$ to 2.01; Analysis 23.2).

\section{Neonatal}

There were no babies that had an Apgar score less than seven at one minute (Analysis 23.3; Analysis 23.4).

\section{IV butorphanol versus IV pethidine}

Three studies involving a total of 330 women compared IV butorphanol with IV pethidine (Hodgkinson 1979; Nelson 2005; Quilligan 1980), though most outcomes only include data from single studies.

\section{Primary outcomes}

No outcomes relating to maternal satisfaction with analgesia were reported.

\section{Secondary outcomes}

\section{Maternal}

\section{Maternal pain score or pain measured in labour}

One study (Quilligan 1980), involving 100 women (findings for these primary outcomes reported for 80 women) included two measures of women's pain during labour; women's reported pain relief and pain score. Women's mean pain relief score was higher for those in the group receiving butorphanol (MD 0.67, 95\% Cl 0.25 to 1.09 ; lowquality evidence; Analysis 24.1). This finding was supported by data regarding reported pain scores one hour after drug administration, which were lower for women in the butorphanol group (MD -0.60, $95 \% \mathrm{Cl}-1.02$ to -0.18 ; low-quality evidence; Analysis 24.2). The clinical significance of a difference of this magnitude (i.e. 0.6 on a 10-point scale) is more difficult to determine.

\section{Additional analgesia required}

There was no clear difference between the groups for numbers of women requesting second doses of analgesia (RR 0.96, 95\% Cl 0.63 to 1.45; very low-quality evidence; Analysis 24.3). The other two 
studies comparing IV butorphanol with IV pethidine did not report any outcomes relating to women's pain during labour.

\section{Epidural}

Other secondary outcomes were reported by Hodgkinson 1979: no clear differences between groups were shown (RR 1.00, 95\% Cl 0.30 to 3.35 ; 200 women; very low-quality evidence; Analysis 24.4),

\section{Nausea and vomiting}

One study (Hodgkinson 1979) involving 200 women reported a lower incidence of nausea and vomiting associated with butorphanol compared with pethidine $(0 / 100$ in the butorphanol group versus $12 / 100$ in the pethidine group; RR $0.04,95 \% \mathrm{Cl} 0.00$ to 0.67; Analysis 24.5).

Other secondary outcomes were reported by Hodgkinson 1979: no clear differences between groups were shown for caesarean section (RR $0.80,95 \% \mathrm{Cl} 0.22$ to 2.89; 200 women; Analysis 24.6), and assisted vaginal birth (RR 1.30, 95\% Cl 0.60 to 2.83; 200 women; Analysis 24.7).

No other maternal outcomes were reported.

\section{Neonatal}

There was no clear difference between groups for the only neonatal outcome reported: Apgar score less than seven at one (RR 0.50, 95\% $\mathrm{Cl} 0.15$ to $1.61 ; 2$ studies, 230 infants; Analysis 24.8) and five minutes (RR $1.00,95 \% \mathrm{Cl} 0.06$ to $15.77 ; 2$ studies, 230 infants; Analysis 24.9).

\section{IV morphine versus IV pethidine}

Two trials involving a total of 163 women compared IV morphine with IV pethidine (Campbell 1961; Olofsson 1996).

\section{Primary and secondary outcomes}

One study involving 143 women reported maternal satisfaction with pain relief assessed three days postpartum (Campbell 1961). Fewer women allocated to receive IV morphine during labour were satisfied with pain relief than those allocated to receive pethidine (RR $0.87,95 \% \mathrm{Cl} 0.78$ to 0.98 ; low-quality evidence; 141 women; Analysis 25.1), although the proportion of women who reported that they were satisfied was high in both groups (60/72 and 66/69).

Campbell 1961 also reported that women allocated to receive IV morphine were more likely to request additional analgesia compared with women allocated to receive IV pethidine (RR 3.41, $95 \% \mathrm{Cl} 1.90$ to 6.12 ; 143 women; low-quality evidence; Analysis 25.2). This difference may simply reflect a lack of equivalence in the study doses of analgesia given (pethidine initial dose $=100 \mathrm{mg}$; morphine initial dose $=8 \mathrm{mg}$ ) rather than true differences between analgesic effects.

A second study which investigated this comparison (Olofsson 1996) included only 10 women in each trial arm. No clear differences were found for each of the three secondary outcomes reported: nausea (RR 0.17, 95\% Cl 0.02 to 1.14), vomiting (RR 0.25 , 95\% $\mathrm{Cl} 0.03$ to 1.86 ; Analysis 25.3), and caesarean section (no events in either group; Analysis 25.4), although the incidence of nausea was lower in the morphine group (6/10 pethidine versus $1 / 10$ morphine).

\section{IV Nisentil versus IV pethidine}

One study including 395 women compared IV Nisentil with IV pethidine (Gillam 1958).

\section{Primary and secondary outcomes}

The study did not report any outcomes relating to women's pain relief.

Women allocated to the Nisentil group were less likely to suffer vomiting than those receiving pethidine (RR $0.38,95 \% \mathrm{Cl} 0.22$ to 0.66). There was also less risk of nausea in the Nisentil group, although this difference was not clear (RR $0.71,95 \% \mathrm{Cl} 0.33$ to 1.52; Analysis 26.1).

The incidence of babies requiring resuscitation and/or ventilatory support was higher in babies born to women in the Nisentil group (14/185) compared to those in the pethidine group (8/210) (RR $1.99,95 \% \mathrm{Cl} 0.85$ to 4.63 ; Analysis 26.2). Although this difference is not clear due to wide Cls crossing the line of no effect, and this finding may have occurred by chance, if this is a true reflection of differences between groups then this degree of harmful effect on newborn babies is not clinically acceptable.

\section{IV fentanyl versus IV butorphanol}

One trial involving 100 women compared IV fentanyl with IV butorphanol (Atkinson 1994).

\section{Primary and secondary outcomes}

The study did not report any outcomes relating to maternal satisfaction with analgesia measured during labour or maternal satisfaction with analgesia in labour measured during the postnatal period.

\section{Additional analgesia required}

Women allocated to receive IV fentanyl were more likely to request additional doses (two or more) of the study analgesia compared with women allocated to receive IV butorphanol (RR 1.39, 95\% Cl 1.05 to 1.85; Analysis 27.1). The study author claims the study doses of drug were equivalent (IV fentanyl $50 \mu \mathrm{g}$ to $100 \mu \mathrm{g}$ every one to two hours; IV butorphanol $1 \mathrm{mg}$ to $2 \mathrm{mg}$ every one to two hours).

\section{Epidural}

Additionally, women in the fentanyl group were twice as likely as those in the butorphanol group to go on to request an epidural (RR $2.00,95 \% \mathrm{Cl} 1.00$ to 4.02 ; Analysis 27.2).

Other maternal outcomes reported (maternal sleepiness during labour and caesarean section) showed no clear difference between study groups (RR $3.00,95 \% \mathrm{Cl} 0.64$ to 14.16 ; Analysis 27.3, and RR $0.80,95 \% \mathrm{Cl} 0.23$ to 2.81 ; Analysis 27.4 , respectively).

There were no clear differences observed between groups for any of the neonatal outcomes reported:

1. naloxone administration ( $\mathrm{RR} 1.75,95 \% \mathrm{Cl} 0.81$ to 3.80 ; Analysis 27.5);

2. neonatal resuscitation ( $\mathrm{RR} 11.00,95 \% \mathrm{Cl} 0.62$ to 193.80 ; Analysis 27.6);

3. Apgar score less than seven at five minutes (RR $1.20,95 \% \mathrm{Cl} 0.39$ to 3.68; Analysis 27.7); 
4. newborn neuro-behavioural score at two to four hours (MD 0.00, $95 \% \mathrm{Cl}-1.61$ to 1.61 ; Analysis 27.8 );

5. newborn neuro-behavioural score at 24 to 36 hours (MD -0.50, $95 \% \mathrm{Cl}-1.62$ to 0.62 ; Analysis 27.9 ).

No other outcomes were reported.

\section{Intravenous patient-controlled opioids for pain relief in labour}

\section{PCA pentazocine versus PCA pethidine}

One trial involving 29 women compared PCA pentazocine with PCA pethidine (Erskine 1985).

\section{Primary and secondary outcomes}

\section{Maternal pan score or pain measured in labour}

Women's self-reported pain score during labour was found to be lower for those allocated to the pentazocine group compared with women in the pethidine group, although this difference was not clear between the groups (SMD $-0.76,95 \% \mathrm{Cl}-1.62$ to $0.09 ; 23$ women; very low-quality evidence; Analysis 28.1), a difference of 1.6 $\mathrm{cm}$ on a $10 \mathrm{~cm}$ pain scale might be considered clinically important. Similar numbers of women in the two treatment groups rated their pain relief as good one day after the birth (RR $0.82,95 \% \mathrm{Cl} 0.51$ to 1.32; 28 women; very low-quality evidence; Analysis 28.2).

None of the maternal and neonatal secondary outcomes studied showed a clear difference between the two study groups with low numbers of events recorded for a number of these outcomes:

1. epidural ( $\mathrm{RR} 1.50,95 \% \mathrm{Cl} 0.29$ to $7.65 ; 28$ women; very lowquality evidence; Analysis 28.3);

2. maternal sleepiness during labour (not clear how this was measured) (RR $0.21,95 \% \mathrm{Cl} 0.01$ to 4.09; 29 women; Analysis 28.5);

3. nausea and vomiting in labour ( $\mathrm{RR} 0.10,95 \% \mathrm{Cl} 0.01$ to $1.61 ; 29$ women; Analysis 28.4);

4. caesarean section ( $\mathrm{RR} 0.36,95 \% \mathrm{Cl} 0.02$ to $8.07 ; 29$ women; Analysis 28.6);

5. breastfeeding at discharge (RR $1.00,95 \% \mathrm{Cl} 0.85$ to $1.17 ; 23$ women; Analysis 28.7);

6. Apgar score less than seven at five minutes (no events in either group; Analysis 28.8).

\section{PCA remifentanil versus $P C A$ pethidine}

Three trials involving a total of 161 women compared PCA remifentanil with PCA pethidine (Blair 2005; Douma 2010; Volikas 2001).

\section{Primary}

No primary outcomes were reported upon in these studies.

\section{Secondary outcomes}

\section{Maternal}

\section{Maternal pain score or pain measured in labour}

Two studies (Volikas 2001; Douma 2010), involving 122 women reported women's pain score during labour. In both studies pain was assessed using a VAS ranging from 0 ("no pain") to $10 \mathrm{~cm}$ ("worst imaginable pain"). In both studies women were asked to mark the level of pain experienced every hour, starting before analgesia was administered. Results for the Volikas 2001 study were recorded in a graph and so values have been estimated from the graph. There was no evidence of a clear difference in mean pain scores at one hour between the remifentanil and pethidine groups (average MD $-8.59,95 \% \mathrm{Cl}-27.61$ to $10.44 ; 122$ women; low-quality evidence; Analysis 29.1). There was substantial heterogeneity for this outcome and so a random-effects model has been used (heterogeneity $\mathrm{I}^{2}=62 \%, \mathrm{Tau}^{2}=136.73, \mathrm{Chi}^{2}$ test for heterogeneity $\mathrm{P}=0.10)$.

\section{Additional analgesia required}

Two included studies (Blair 2005; Volikas 2001) reported number of women requiring additional analgesia $\left(\right.$ Entonox $\left.^{\circledR}\right)$ as an outcome, with most women in both study groups requiring additional analgesia (22/29 versus $24 / 27$; RR $0.86,95 \%$ Cl 0.69 to 1.08 ; 56 women; very low-quality evidence; Analysis 29.2).

\section{Epidural}

Two studies reported number of women crossing over to epidural as an outcome (Douma 2010; Volikas 2001), with fewer women in the remifentanil group requiring an epidural ( $R R 0.42,95 \% \mathrm{Cl} 0.20$ to $0.89 ; 122$ women; moderate-quality evidence; Analysis 29.3).

\section{Maternal sleepiness during labour}

Maternal sleepiness was reported in one study (Douma 2010). This outcome was assessed using an observer sedation score recorded hourly (1, awake; 2 , sleepy; 3 eyes closed, but rousable by vocal stimuli; 4 , eyes closed, but rousable by physical stimulus; and 5 , unrousable). Mean hourly scores at inclusion and then at one, two and three hours after analgesia were reported. There was no evidence of a clear difference in mean sedation scores at one hour between the remifentanil and pethidine groups (MD 0.40, 95\% $\mathrm{Cl} 0.14$ to 0.66 ; 105 women; Analysis 29.4).

There was no clear difference found between groups for any of the other secondary outcomes reported:

1. nausea and vomiting (RR $0.95,95 \% \mathrm{Cl} 0.61$ to $1.49 ; 2$ studies, 119 women; Analysis 29.5);

2. caesarean section (RR $1.81,95 \% \mathrm{Cl} 0.60$ to $5.46 ; 2$ studies, 97 participants; Analysis 29.6);

3. assisted vaginal birth (RR $0.96,95 \% \mathrm{Cl} 0.46$ to $2.00 ; 2$ studies, 97 participants; Analysis 29.7).

\section{Satisfaction with childbirth experience}

Satisfaction with childbirth experience was reported in one study (Douma 2010). Two hours after delivery women were asked to score their overall satisfaction on a 10-point scale (tool not specified). Women in the remifentanil groups had slightly higher mean satisfaction scores (MD 1.10, 95\% $\mathrm{Cl} 0.46$ to 1.74 ; 68 women; Analysis 29.8).

\section{Neonatal}

There was no clear difference found between groups for any of the neonatal outcomes reported:

1. naloxone administration ( $\mathrm{RR} 0.30,95 \% \mathrm{Cl} 0.01$ to $6.47 ; 2$ studies, 56 infants; Analysis 29.9);

2. Apgar score less than seven at five minutes (RR $0.13,95 \% \mathrm{Cl} 0.01$ to 2.16; 1 study, 17 infants; Analysis 29.10); Douma 2010 provided 
mean and standard deviation (SD) values for Apgar scores at five minutes and so these data could not be included in an analysis;

3. admission to NICU (RR $0.30,95 \% \mathrm{Cl} 0.01$ to $6.47 ; 1$ study, 17 infants; Analysis 29.11);

4. newborn neuro-behavioural scores - The Neurologic and Adaptive Capacity Score (NACS) was recorded at 15 minutes and two hours after delivery (MD $0.20,95 \% \mathrm{Cl}-0.93$ to $1.33 ; 1$ study, 56 infants; Analysis 29.12; and MD $0.60,95 \% \mathrm{Cl}-0.66$ to $1.86 ; 1$ study, 56 infants; Analysis 29.13; respectively). A maximum score of 40 indicates the neonate scored "normal" scores in all neurobehavioural areas.

No other neonatal outcomes were reported under this comparison.

\section{PCA nalbuphine versus PCA pethidine}

One trial involving 60 women compared PCA nalbuphine with PCA pethidine (Frank 1987).

\section{Primary outcomes}

Maternal satisfaction with analgesia measured during labour

The included study did not report this outcome.

\section{Maternal satisfaction with analgesia in labour measured during the postnatal period}

There was no clear difference between the groups for this outcome (RR $1.29,95 \% \mathrm{Cl} 0.88$ to 1.89 ; very low-quality evidence; Analysis 30.1). Similarly, there was no clear difference between the groups in the frequency of women who reported that they would use the same pain relief in future (RR $1.06,95 \% \mathrm{Cl} 0.79$ to 1.43 ; 59 women; very low-quality evidence; Analysis 30.2).

\section{Secondary outcomes}

\section{Maternal}

\section{Maternal pain score or pain measured in labour}

Women who received PCA nalbuphine reported lower pain scores, measured on a five-point scale, than those who received PCA pethidine (MD $-0.40,95 \% \mathrm{Cl}-0.79$ to $-0.01 ; 60$ women; low-quality evidence; Analysis 30.3).

\section{Additional analgesia required}

There was no clear difference between the groups for women required Entonox ( $\mathrm{RR} 0.83,95 \% \mathrm{Cl} 0.46,1.48 ; 59$ women; very lowquality evidence; Analysis 30.4).

\section{Nausea and vomiting in labour}

There was no clear difference between the groups for this outcome (RR 0.68, 95\% Cl 0.30 to 1.54; 59 women; Analysis 30.5).

The included study did not report any other maternal outcomes.

\section{Neonatal}

\section{Apgar score less than seven at five minutes}

There was no clear difference between the groups for this outcome (RR 0.42, 95\% Cl 0.02 to 9.76; 41 infants; Analysis 30.6).

The included study did not report any other neonatal outcomes.

\section{PCA fentanyl versus PCA alfentanil}

One study involving 23 women compared PCA fentanyl with PCA alfentanil (Morley-Forster 2000).

\section{Primary outcomes}

\section{Maternal satisfaction with analgesia measured during labour}

This outcome was not reported in the included study.

\section{Maternal satisfaction with analgesia in labour measured during the postnatal period}

There was no clear difference between the groups for this outcome, although women allocated to receive fentanyl were slightly less likely to describe their satisfaction with their pain relief as "adequate" or "good" within six hours of giving birth compared with women allocated to receive alfentanil ( $10 / 11$ versus $7 / 12$; RR $1.56,95 \% \mathrm{Cl} 0.93$ to 2.60; Analysis 31.1).

\section{Secondary outcomes}

\section{Maternal}

\section{Maternal pain score or pain measured in labour}

There was no clear difference between the groups in pain score measured in labour (MD $-12.80,95 \% \mathrm{Cl}-32.12$ to $6.52 ; 21$ women; Analysis 31.2).

No clear differences were found for any of the other secondary outcomes reported: nausea (RR 2.73, 95\% Cl 0.66 to 11.30; 23 women; Analysis 31.3), caesarean section (RR $1.64,95 \% \mathrm{Cl} 0.33$ to 8.03; 23 women; Analysis 31.4), naloxone administration (RR 2.36, $95 \% \mathrm{Cl} 0.53$ to $10.55 ; 24$ women; Analysis 31.5$)$.

The included study did not report any other maternal outcome.

\section{Neonatal}

The included study did not report any of the neonatal outcome.

\section{PCA fentanyl versus PCA pethidine}

One trial involving 107 women compared PCA fentanyl with PCA pethidine (Douma 2010).

\section{Primary outcomes}

No primary outcomes were reported in this study (Douma 2010).

\section{Secondary outcomes}

\section{Maternal}

\section{Maternal pain score or pain measured in labour}

Pain scores were assessed using a VAS ranging from 0 ("no pain") to $10 \mathrm{~cm}$ ("worst imaginable pain"). Mean pain scores were presented at baseline and at one, two and three hours after analgesia. There was no clear difference in mean pain scores at one hour between the fentanyl and pethidine groups (MD $-0.65,95 \% \mathrm{Cl}-1.56$ to 0.26 ; 107 women; low-quality evidence; Analysis 32.1).

\section{Epidural}

There was moderate-quality evidence to suggest that fewer women in the fentanyl group required epidural compared to pethidine group (RR 0.44, 95\% Cl 0.21 to 0.92; Analysis 32.2). 
There was no clear difference found between groups for any of the other secondary outcomes reported:

1. maternal sleepiness during labour (MD $-0.06,95 \% \mathrm{Cl}-0.25$ to 0.13; 107 women; Analysis 32.3); this outcome was assessed using an observer sedation score ( $1=$ awake to $5=$ un-rousable) recorded hourly;

2. nausea and vomiting (RR $0.87,95 \% \mathrm{Cl} 0.55$ to 1.37 ; 102 women; Analysis 32.4);

3. caesarean section ( $\mathrm{RR} 0.25,95 \% \mathrm{Cl} 0.03$ to $2.34 ; 81$ women; Analysis 32.5);

4. assisted vaginal birth (RR $0.57,95 \% \mathrm{Cl} 0.22$ to $1.49 ; 81$ women; Analysis 32.6).

\section{Neonatal}

Douma 2010 only provided mean and SD values for Apgar scores at five minutes and so these data could not be included in an analysis.

There was no clear difference found between groups for any of the other neonatal outcomes reported:

1. neurobehavioural score (NACS 15 minutes post delivery) (MD $-0.90,95 \% \mathrm{Cl}-2.31$ to $0.51 ; 63$ infants; Analysis 32.7 );

2. neurobehavioural score (NACS two hours post delivery) (MD $-0.50,95 \% \mathrm{Cl}-1.95$ to $0.95 ; 64$ infants; Analysis 32.8$)$.

\section{PCA (IM) meptazinol versus PCA (IM) pethidine}

One study involving 10 women examined the feasibility of IM meptazinol versus IM pethidine with PCA administration (Li 1988).

\section{Primary outcomes}

The included study did not report any of the primary outcomes.

\section{Secondary outcomes}

\section{Maternal}

\section{Maternal pain score or pain measured in labour}

Pain scores measured one day postpartum were lower with meptazinol compared with pethidine; however, there was no evidence of a clear difference (MD $-17.60,95 \% \mathrm{Cl}-49.93$ to 14.73 ; 10 women; very low-quality evidence; Analysis 33.1). All women in both groups were satisfied with the mode of administration (very low-quality evidence; Analysis 33.2).

There were no clear differences found between groups for any of the other secondary outcomes reported: additional analgesia required: epidural (RR 3.00, 95\% Cl 0.15 to 59.89; very low-quality evidence; Analysis 33.3), maternal sleepiness during labour as measured by drowsiness scores one day postpartum (MD 5.60, $95 \% \mathrm{Cl}-28.19$ to 39.39; Analysis 33.4), nausea measured one day postpartum (MD $-8.00,95 \% \mathrm{Cl}-48.70$ to 32.70 ; Analysis 33.5 ).

\section{Neonatal}

There was no clear difference between groups for naloxone administration (RR $1.00,95 \% \mathrm{Cl} 0.08$ to $11.93 ; 10$ infants; Analysis 33.6).

\section{Opioids versus TENS for pain relief in labour}

\section{Opioids versus TENS}

Four trials involving 365 women are included in this comparison. One trial compared IV pethidine (50 $\mathrm{mg}$ ) versus TENS to the lower back (Neumark 1978), another IM pethidine (50 mg) versus TENS to the back (Tawfik 1982), another IM tramadol (100 mg) versus TENS to the back (Thakur 2004), and the fourth compared PCA IV ondansetron and tramadol versus HANS (Han's acupoint nerve stimulator) (Liu 2015).

\section{Primary outcomes}

Maternal satisfaction with analgesia measured during labour or during the postnatal period

Two studies (Neumark 1978; Tawfik 1982) involving 105 women reported on maternal satisfaction with analgesia measured post delivery. In the study by Neumark 1978 women were asked to rate their satisfaction with analgesia the day after the birth as having "good", "inadequate" or "no" analgesic effect. In the study by Tawfik 1982 women were asked about the degree of relief they had obtained during the whole period of delivery. This was scored as being "excellent", "good" or "satisfactory". We found no evidence of a clear difference in maternal satisfaction with analgesia rated as "good/excellent" between the TENS and opioid groups (RR $1.23,95 \% \mathrm{Cl} 0.79$ to 1.92 , 2 studies; 104 women; very low-quality evidence; Analysis 34.1).

\section{Secondary outcomes}

\section{Maternal}

\section{Maternal pain score measured in labour}

Four studies (Liu 2015, Neumark 1978; Tawfik 1982; Thakur 2004) reported on maternal pain measured in labour. In the study by Neumark 1978, pain was assessed on a six-point pain scale for a 70-minute period (from 1, "no pain" through 6 , "unbearable pain"). However, data were reported in graphical form which we were not able to include in the analysis. Tawfik 1982 assessed pain relief 30 minutes after analgesia as being complete, excellent or good versus slight relief, while Thakur 2004, assessed pain on a verbal response scale during labour as complete or moderate relief; versus mild or no relief (the time of measurement was not stated). There was no evidence of a clear difference in maternal pain scores between the opioid and TENS groups (average RR $1.15,95 \% \mathrm{Cl} 0.81$ to 1.61 , 2 studies; 290 women; very low-quality evidence; Analysis 34.2). There was substantial heterogeneity for this outcome and so a random-effects model has been used (heterogeneity $\mathrm{I}^{2}=64 \%$, $\mathrm{Tau}^{2}$ $=0.04, \mathrm{Chi}^{2}$ test for heterogeneity $\left.\mathrm{P}=0.10\right)$.

Liu 2015 reported pain scores 30, and 60 minutes following analgesia. Pain scores were lower in the opioids group compared with the TENS group at 30 minutes (MD $-20.00,95 \% \mathrm{Cl}-26.09$ to $-13.91 ; 60$ women), and 60 minutes (MD $-20.00,95 \% \mathrm{Cl}-25.16$ to $-14.84 ; 60$ women, low-quality evidence; Analysis 34.3 ).

\section{Maternal sleepiness during labour}

Two studies (Tawfik 1982; Thakur 2004), reported drowsiness in labour. Women in the opioid group were more likely to report drowsiness (RR 8.96, 95\% Cl 1.13 to $71.07 ; 290$ women; Analysis 34.4) compared with those in the TENS group, although the $95 \% \mathrm{Cls}$ were very wide for this outcome. 


\section{Nausea and vomiting}

Three studies (Liu 2015; Tawfik 1982; Thakur 2004) reported nausea and vomiting in labour. Women in the opioid group were more likely to report nausea and vomiting compared to the TENS group (RR $13.73,95 \% \mathrm{Cl} 2.72$ to 69.24 ; 350 women; Analysis 34.5 ).

\section{Caesarean section; assisted vaginal birth}

Two studies reported on caesarean section and assisted vaginal birth rates (Liu 2015; Thakur 2004). There were no caesarean sections reported in either the opioid or TENS groups in Thakur 2004. There was no evidence of a clear difference in the number of caesarean sections (RR 2.00, $95 \% \mathrm{Cl} 0.19$ to 20.90; 260 women; Analysis 34.6), or assisted vaginal births between groups (RR 1.80, $95 \% \mathrm{Cl} 0.40$ to 8.18 ; 260 women; Analysis 34.7 ).

No other maternal outcomes were reported.

\section{Neonatal}

Fetal heart rate changes in labour (persistent decelerations or tachycardia)

One study reported on "fetal distress" (Thakur 2004) and found no evidence of a clear difference between groups (RR 5.00, 95\% Cl 0.24 to 102.85 ; 200 women; Analysis 34.8).

Two studies reported on Apgar scores (Tawfik 1982; Thakur 2004). However, both studies reported mean scores and these data are very difficult to interpret. None of the studies reported information on the number of babies with Apgar scores less than seven at five minutes (prespecified outcome).

No other neonatal outcomes were reported.

\section{Subgroup analysis}

We did not carry out planned subgroup analysis because most meta-analyses included data from only one or two studies and separate breakdown on subgroup categories were rarely provided. We therefore did not think that examining outcomes for subgroups would affect the conclusions of the review or offer any other helpful insights.

\section{DISCUSSION}

\section{Summary of main results}

We set out to answer the question of the effectiveness of parenteral opioids and their adverse effects for women and babies. We included a total of 70 studies, with 61 studies involving more than 8000 women contributing data. This updated review includes 34 different comparisons, where an opioid was compared with placebo, no treatment, with another opioid, or with transcutaneous electrical nerve stimulation (TENS). For many comparisons there was a lack of consistency in what outcomes were measured, how they were measured, and when they were recorded. For most comparisons, and many outcomes, only one or two studies contributed data, and there were few opportunities to pool data in meta-analysis. For many comparisons, data were not reported for many of our prespecified outcomes. The quality of the evidence was mainly assessed as low or very low for pain outcomes. Evidence was downgraded for study design limitations (most of the studies were not blinded), many of the studies had relatively small sample sizes and were underpowered to detect differences between groups and so results were downgraded for imprecision of effect estimates.

All of the studies were conducted in hospital settings, on healthy women with uncomplicated pregnancies at 37 to 42 weeks' gestation. We excluded studies focusing on women with preeclampsia or pre-existing conditions or with a compromised fetus.

\section{Summary of results}

1. Parenteral opioids provided some pain relief during labour as indicated in eight out of the 24 comparisons that reported maternal pain scores or pain measured in labour. The remainder did not report clear differences between the groups.

2. Satisfaction with analgesia was not reported under most comparisons, and was variable where reported.

3. Opioid drugs were associated with nausea, vomiting and drowsiness, although different types of opioids were associated with different adverse effects.

4. For most outcomes there was no good quality evidence of differences between treatment groups.

5. There was insufficient evidence to assess the safety of opioids in labour.

6. The quality of the evidence for pain and pain relief outcomes was predominantly poor or very poor.

\section{Intramuscular (IM) administration}

1. For pethidine versus placebo, there was better pain relief with pethidine measured by women describing pain relief as good or fair after one hour, or a reduction in visual analogue scale (VAS) of at least $40 \mathrm{~mm}$ after 30 minutes, with maternal sleepiness in labour as the main adverse effect. There was no evidence of clear differences in other adverse effects on the woman or on the neonate.

2. For pentazocine versus placebo, there was no clear evidence of differences between groups for any of the outcomes reported.

3. For tramadol versus no treatment, there was no clear difference in maternal satisfaction with analgesia. No other outcomes were reported.

4. For meptazinol versus pethidine, there was no clear evidence of a difference in maternal satisfaction with analgesia or pain measured in labour whether assessed either early or late during labour, although more women had vomiting with meptazinol. There was no clear evidence of a difference in outcomes for the neonate.

5. For diamorphine versus pethidine, when an antiemetic was given as co-therapy to both groups, there was no clear evidence of difference in maternal satisfaction, pain scores in labour, or maternal sleepiness in labour. Vomiting occurred more frequently in women given pethidine. Whilst more babies had an Apgar score less than seven at one minute with pethidine, by five minutes there was no difference between groups, and no clear evidence of differences in other neonatal outcomes.

6. For diamorphine versus pethidine, without an antiemetic, more women in the diamorphine group reported to be satisfied or very satisfied with their analgesia compared with the pethidine group. There was no clear difference between groups for number of women requesting additional analgesia, but women reported less pain at 30 and 60 minutes following administration of diamorphine compared with pethidine. This was high-quality 
evidence. No clear differences were seen between groups for adverse effects or neonatal outcomes.

7. For tramadol versus pethidine, maternal pain scores in labour were better with pethidine than tramadol, and there was no evidence of a difference in adverse effects on mother or baby.

8. For dihydrocodeine versus pethidine, only one study contributed data and there was no evidence of a clear difference in maternal pain scores in labour or adverse effects. More babies had Apgar scores less than seven at one minute with pethidine compared with dihydrocodeine, but the difference was not apparent by five minutes, and there was no evidence of other differences in neonatal adverse effects.

9. Other IM comparisons, most of which were tested in only one study, provided few clear differences in their findings. For pentazocine versus pethidine (six studies, one with antiemetic addition to opioid), phenazocine versus pethidine, morphine versus pethidine, butorphanol versus pethidine, and tramadol versus no treatment, there was no evidence of a clear difference in maternal or neonatal outcomes between groups.

10.For nalbuphine versus pentazocine, one study found a clear difference in maternal satisfaction with analgesia, in favour of nalbuphine. Fewer women who received nalbuphine experienced nausea or vomiting.

\section{Intravenous (IV) administration including patient-controlled anaesthesia (PCA)}

1. For most comparisons very few studies contributed data, and for most outcomes there was no clear evidence of differences between groups. Several IV opioids (including fentanyl, butorphanol and morphine) appeared to perform better than pethidine in terms of analgesic effect (either satisfaction with analgesia or pain scores). Pethidine was associated with worse side effects. Compared with pethidine, maternal sleepiness in labour was lower with fentanyl (one study), and nausea was less with butorphanol and morphine (one study for each comparison). When fentanyl and butorphanol were compared, butorphanol was associated with fewer requests for additional analgesia, a reduced need for neonatal resuscitation, and fewer babies required naloxone (one study).

\section{Opioids versus transcutaneous electrical nerve stimulation (TENS)}

1. For most outcomes there was no evidence of clear differences between groups (maternal satisfaction with analgesia; maternal pain scores; caesarean section; assisted vaginal birth; fetal distress). The only clear finding was that women in the opioid group were more likely to experience drowsiness and nausea and vomiting than women in the TENS group.

\section{Overall completeness and applicability of evidence}

This review is one of a series of Cochrane reviews examining pain management in labour; other reviews have examined pharmacological and non-pharmacological methods of pain management in labour including biofeedback (Barragán 2011), aromatherapy (Smith 2011a), relaxation techniques (Smith 2018a), acupuncture (Smith 2011b), manual methods (Smith 2018b), TENS (Dowswell 2009), epidural analgesia (Anim-Somuah 2018), and a range of other methods of pain management. Smith $2011 \mathrm{~b}$ is currently being updated. No studies were identified that compared an opioid with hypnosis, biofeedback, intracutaneous or subcutaneous sterile water injection, immersion in water, aromatherapy, relaxation techniques (yoga, music, audio), acupuncture or acupressure, or manual methods (massage, reflexology).

Studies included in the review were carried out over a long time period (1958 to 2017), during which time there have been major changes in women's and clinicians' expectations and views of childbirth and analgesia during labour. Some drugs commonly used in the 1950s and 1960s may no longer be available in some countries. The increasing use of epidural analgesia in resource-rich countries means that opioids are now less likely to be the drugs of choice in these settings. However, in many parts of the world epidural analgesia is not available to all women, and parenteral opioids are still widely used. It is important for all women to make an informed choice about pain relief options available to them; however, providing clear information on the effectiveness and safety of parenteral opioids is a challenge in the light of the findings from this review.

With so many different comparisons and outcomes, we are not able to provide clear information on the acceptability, effectiveness and adverse outcomes associated with different opioids. In this review, we have not compared the effectiveness of parenteral opioids as a co-therapy although in many of the studies we looked at, women were in fact able to have other analgesia, and this may or may not have been reported. The use of other analgesia and co-interventions may have differed by randomisation group, and may have had an independent or synergistic effect on outcomes for women and babies which we were not able to detect. For example, women's use of nitrous oxide was not consistently reported; the fact that it was not mentioned in a study does not necessarily mean that it was not used by the women involved. It was also difficult to determine equivalence in terms of dosages of different trial drugs used, their duration of effect and speed of metabolism. Studies also varied in terms of number of doses available to women, and the stage of labour at which further doses were not allowed in order to avoid detrimental effects on the baby.

There was considerable heterogeneity between studies in the outcomes measured and how they were reported. In some of the older studies (pre-1970), maternal sedation may have been regarded as a desired effect of opioid drugs, and pain relief was sometimes reported by carers rather than by women themselves. There were varied definitions of similar outcomes such as nausea, vomiting (or both), sleepiness, drowsiness, etc. and even greater variation in the way pain and pain relief were measured, and the time points at which measurements were made.

Despite including 70 studies and including data from 61, there were relatively few clear results. Many of the studies had small samples and most did not have the statistical power (singly or pooled) to detect differences between groups for intended or unintended effects that occur infrequently or rarely. In view of the large number of comparisons and outcomes, it is likely that some of the findings where we have reported a difference between groups this may have occurred by chance. On the other hand, for some less frequent outcomes (e.g. low Apgar scores or the need for neonatal resuscitation), some findings suggested that there may have been a difference between groups but the studies often had small sample sizes, and differences between groups were not clear. In addition, we are aware that statistical and clinical significance may not be the same thing. For example, it is difficult to know what a $0.6 \mathrm{~cm}$ 
difference in scores on a $10 \mathrm{~cm}$ VAS means in relation to a difference in actual pain.

We were surprised by the number of studies where women's views of pain relief, or their assessments of pain in labour, were not measured at all. We were also surprised at the paucity of data on breastfeeding outcomes. Even more recent studies did not generally collect data on this important outcome, even though observational studies have suggested that opioids are associated with sedation in babies and suppression of sucking in the minutes and hours after birth. We had also hoped to collect information on the costs associated with using opioid drugs; none of the included studies provided data on the costs incurred by health service providers.

It is known that opioids cross the placental barrier, and short-term effects such as the impact of opioids on fetal heart rate patterns and very early neurological scores have been well documented in observational and randomised studies. It is not clear that these effects have any clinical significance or lasting impact on infant well-being. It has also been suggested that exposure to opioids during labour may predispose children to serious long-term effects; however, much more research is needed to confirm or refute these findings from observational studies (Jacobson 1990; Nyberg 2000). None of the studies included in the review followed up women and babies for more than a few hours or days so we are not able to contribute to these debates.

All of the included studies examined IV or IM administration; two excluded studies examined the subcutaneous administration of opioids (Cahal 1960; De Kornfeld 1964); three studies compared opioids with TENS (Neumark 1978; Tawfik 1982; Thakur 2004). Two trials compared an opioid with no treatment (Jahani 2013; Li 1988). The lack of placebo in these two trials confound the comparison as the placebo effect from the IM/IV administration cannot be separated out from the effect of the investigated opioid. Further updates of this review will exclude such trials.

\section{Quality of the evidence}

Overall we found the evidence to be of low quality regarding the analgesic effect of opioids and satisfaction with analgesia, and poorly reported regarding adverse effects to women and babies. Risk of bias was variable in all the studies. Most studies reported post-randomisation exclusions for varying reasons such as women having an instrumental or caesarean birth, protocol violations, and birth happening within a certain time of the study drug being administered. Most studies did not give reasons for withdrawals or exclusions. Generally, study reporting was poor and assessing risk or bias was challenging.

The quality of the evidence assessed using GRADE ranged from very low to high (Summary of findings for the main comparison; Summary of findings 2), but the majority of evidence was downgraded and generally the evidence was assessed as low- or very low-quality. The reasons for downgrading included study design limitations and some heterogeneity, and for most comparisons few studies contributed data and results were frequently imprecise. Due to the large number of comparisons and small amounts of data for each, we produced one Summary of Findings table (Summary of findings for the main comparison) and one additional table (Summary of findings 2) displaying all the outcomes relating to pain for each comparison. These outcomes included maternal satisfaction with analgesia measured during labour, maternal satisfaction with analgesia in labour measured during the postnatal period, maternal pain score or pain measured in labour, additional analgesia required, and epidural.

In some studies women were not included in the analysis if they received the study drug within 30 to 60 minutes of giving birth or more than four hours before giving birth. Such exclusions are likely to introduce serious bias; we do not know whether these women had different outcomes from the rest of the sample, and it is possible that outcomes may have differed by randomisation group.

The review's primary outcomes, maternal satisfaction with analgesia reported during labour and postnatally, were reported in different ways (for example, reports of satisfaction, global assessment of pain relief) and were often poorly reported. It was not always clearly stated to whom women reported their pain levels; indeed in some cases clinicians may have made assessments. These methodological problems may mean there was serious response bias in some studies.

\section{Potential biases in the review process}

We are aware that the possibility of introducing bias was present at every stage of the reviewing process. We attempted to minimise bias in a number of ways; two review authors carried out data extraction and assessed risk of bias. Each worked independently. Nevertheless, the process of assessing risk of bias, for example, is not an exact science and includes many personal judgements.

We are also aware that publication bias is a possibility, as the review includes several small studies which reported a number of large results. Although we did attempt to assess reporting bias, lack of trial protocols meant that this assessment relied on information available in the published trial report so reporting bias was not usually apparent.

In previous updates, we may have introduced some bias by converting three-, four- and five-point categorical scales for the measurement of pain or pain relief into binary outcomes. We attempted to be consistent across studies, but this was not always possible as the wording of categories varied in different studies. We have tried to indicate in the results section, and in forest plots, what event rates in treatment groups signify.

\section{Agreements and disagreements with other studies or reviews}

The findings and recommendations of this review are similar to other reviews on this topic (Bricker 2002; NICE 2014) and to an earlier Cochrane review looking at IM opioids (Elbourne 2006). Clinical practice guidelines in the UK recommend that women should be informed of the risks of IV and IM opioids and of their limitations; NICE 2014 guidelines suggest that IM and IV opioids should be available for women to choose, women should be informed of the alternatives, and should be made aware that parenteral opioids may have side effects (such as nausea and drowsiness) and may interfere with breastfeeding. 


\section{AUTHORS' CONCLUSIONS}

\section{Implications for practice}

Though most evidence is of low or very-low quality, for healthy women with an uncomplicated pregnancy who are giving birth at 37 to 42 weeks, parenteral opioids appear to provide some relief from pain in labour but are associated with drowsiness, nausea, and vomiting in the woman. Effects on the newborn are unclear. Maternal satisfaction with opioid analgesia was largely unreported. The review needs to be examined alongside related Cochrane reviews. More research is needed to determine which analgesic intervention is most effective, and provides greatest satisfaction to women with acceptable adverse effects for mothers and their newborn.

\section{Implications for research}

The question many women would like answered is how opioids compare with other forms of pain relief available for use during labour, in terms of analgesic effectiveness and the risk of adverse effects for both women and babies. Given the paucity of useful information from the current review, it is likely that the evidence underlying this further question is also limited. It is important that this evidence is reviewed, however, so that women can be provided with information that is as complete and accurate as possible, and so that remaining gaps in knowledge can be identified and addressed through further research.

A large pragmatic randomised controlled trial (RCT) could be undertaken to compare pain relief that includes an opioid with a pain relief regimen not including an opioid, that collects data prospectively on all important prognostic factors such as cointerventions. These factors include additional analgesia and antiemetics, labour augmentation by means of artificial rupture of membranes or intravenous (IV) infusion of oxytocin, and use of electronic fetal monitoring. Outcomes for women and their babies in the short and longer term are also required. Future studies could also be in the form of multi-armed/and/or adaptive designs to try and focus in on the most effective interventions more quickly.

Maternal outcomes that would be important to guide practice are actual pain relief and maternal satisfaction with analgesia, and important unintended effects such as nausea, vomiting and sedation. For the neonate, Apgar scores at five and 10 minutes, resuscitation including use of naloxone, neonatal intensive care unit admission, initial effective suckling and establishment of breastfeeding, sedation and irritability. Future updates of this review should include all of these maternal and neonatal outcomes.

With respect to measuring the effectiveness of an opioid for labour pain, there are a number of issues. Assessment of pain should be measured in the pause between contractions. In order to minimise response bias, it is important that maternal pain assessment be recorded by the woman herself and not by the woman's caregiver. Lastly, it is important to assess maternal satisfaction to encompass more than just the effects on pain but include other central nervous system (CNS) effects. It would be important to measure satisfaction in the short term (within 24 hours of delivery) and again several days postpartum. In addition, it is known that maintaining control in labour is important to women and this relates to pain and pain control; formal assessment of sense of control in labour would therefore be useful such as the use of the Labour Agentry Scale (Hodnett 1987).

Stratification at baseline of two important predictors of outcome should include maternal parity and spontaneous or induced labour onset.

All studies were conducted on women labouring in hospital settings exclusively. Many women labour and give birth in community settings, the proportion of which is likely to increase due to the international initiative to normalise birth, and reduce interventions associated with complications. Therefore, more research in midwifery-led units and at home would inform practitioners using opioids in these settings.

If recruitment of women to RCTs is hampered due to strong maternal preferences for pain relief, then a prospective observational study, across different care settings, which collects data on important predictors and outcomes as described for the RCT would also be informative.

\section{ACKNOWLEDGEMENTS}

We would like to thank GJ Hofmeyr and referees for their helpful feedback on early drafts of the protocol. We also thank the translators of papers assessed for inclusion in the review: Angela Cooke, Graham Dane, Sarah Dodd, John Finch, Catherine Fowler, Youngmee Hahn, Kate Kaminski, Andreas Schwab, Caroline Summers, Bunpode Suwannachat, Andrea Svobodova, Elizabeth Whiteley and Darren J Wright.

A previous version of this review forms part of a series of reviews focusing on pain management in labour that were included in a Cochrane overview of reviews (Jones 2012); contributing reviews shared a generic protocol (Jones 2011). We would like to thank Leanne Jones for her valuable help in updating this review so as to improve consistency between this and other pain management reviews.

This project was supported by the National Institute for Health Research, via Cochrane Infrastructure funding to Cochrane Pregnancy and Childbirth. The views and opinions expressed therein are those of the authors and do not necessarily reflect those of the Systematic Reviews Programme, NIHR, NHS or the Department of Health.

As part of the pre-publication editorial process, this review has been commented on by three peers (an editor and two referees who are external to the editorial team), a member of Cochrane Pregnancy and Childbirth's international panel of consumers and the Group's Statistical Adviser.

We would like to thank Roz Ullman and Rintaro Mori who both contributed as authors on previous versions of this review. We would also like to thank Therese Dowswell, Research Associate, Cochrane Pregnancy and Childbirth, who contributed to study assessment and data extraction for this current update (2018). 


\section{R E F E R E N C E S}

\section{References to studies included in this review}

Atkinson 1994 \{published data only\}

Atkinson BD, Truitt LJ, Rayburn WF, Turnbull GL, Christensen HD, Wlodaver A. Double-blind comparison of intravenous butorphanol (Stadol) and fentanyl (Sublimaze) for analgesia during labor. American Journal of Obstetrics and Gynecology 1994;171(4):993-8.

Bitsch 1980 \{published data only\}

Bitsch M, Emmrich J, Hary J, Lippach G, Rindt W. Obstetrical analgesia with tramadol [Geburtshilfliche Analgesie mit Tramadol]. Fortschritte der Medizin 1980;98(16):632-4.

\section{Blair 2005 \{published data only\}}

Blair JM, Dobson GT, Hill DA, Fee JPH. Patient-controlled analgesia for labor: a comparison of remifentanil and pethidine [abstract]. Anesthesiology 2001;95:Abstract no: A1063.

* Blair JM, Dobson GT, Hill DA, McCracken GR, Fee JPH. Patient controlled analgesia for labour: a comparison of remifentanil with pethidine. Anaesthesia 2005;60(1):22-7.

\section{Borglin 1971 \{published data only\}}

Borglin NE, Klottrup P. Pethidine and pentazocine. A double blind investigation in obstetric material. Lakartidningen 1971;68 Suppl 3:41-4.

\section{Campbell 1961 \{published data only\}}

Campbell C, Phillips OC, Frazier TM. Analgesia during labor: a comparison of pentobarbital, meperidine and morphine. Obstetrics \& Gynecology 1961; Vol. 17:714-8.

\section{De Boer 1987 \{published data only\}}

De Boer F, Shortland D, Simpson RL, Clifford WA, Catley DM. A comparison of the effects of maternally administered meptazinol and pethidine on neonatal acid-base status. British Journal of Obstetrics and Gynaecology 1987;94(3):256-61.

\section{Direkvand-Moghadam 2014 \{published data only\}}

Direkvand-Moghadam A, Delpisheh A, Direkvand-Moghadam A Fathollahi $E$. The effects of pethidine on the duration of active labor in nulliparous women. Journal of Basic Research in Medical Sciences 2014;1(3):60-4.

\section{Douma 2010 \{published data only\}}

* Douma MR, Verwey RA, Kam-Endtz CE, Van der Linden PD, Stienstra R. Obstetric analgesia: a comparison of patientcontrolled meperidine, remifentanil, and fentanyl in labour. British Journal of Anaesthesia 2010;104(2):209-15.

ISRCTN12122492. Obstetric analgesia: a comparison of patient controlled pethidine, remifentanil and fentanyl in labour. isrctn.com/ISRCTN12122492 (first received 14 February 2006).

Duncan 1969 \{published data only\}

Duncan SL, Ginsburg J, Morris NF. Comparison of pentazocine and pethidine in normal labor. American Journal of Obstetrics and Gynecology 1969;105(2):197-202.
El-Refaie 2012 \{published data only\}

El-Refaie TA, El-Said MM, Shoukry AA, Khafagy SM, El-Din AS, Badawy MM. Meperidine for uterine dystocia and its effect on duration of labor and neonatal acid-base status: a randomized clinical trial. Journal of Obstetrics and Gynaecology Research 2012;38(2):383-9.

Erskine 1985 \{published data only\}

Erskine WA, Dick A, Morrell DF, Vital M, van den Heever J. Self-administered intravenous analgesia during labour. A comparison between pentazocine and pethidine. South African Medical Journal 1985;67(19):764-7.

\section{Fairlie 1999 \{published data only\}}

Fairlie FM, Marshall L, Walker JJ. Pethidine compared with diamorphine for pain relief in labour. American Journal of Obstetrics and Gynecology 1992;166:394.

* Fairlie FM, Marshall L, Walker JJ, Elbourne D. Intramuscular opioids for maternal pain relief in labour: a randomised controlled trial comparing pethidine with diamorphine. British Journal of Obstetrics and Gynaecology 1999;106(11):1181-7.

Fieni 2000 \{published data only\}

Fieni S, Angeri F, Kaihura CT, Ricci L, Bedocchi L, Galanti B, et al. Evaluation of the peripartum effects of 2 analgesics: meperidine and tramadol, used in labor. Acta Bio-Medica de 1 Ateneo Parmense 2000;71 Suppl 1:397-400.

Frank 1987 \{published data only\}

Frank M, McAteer EJ, Cattermole R, Loughnan B, Stafford LB, Hitchcock AM. Nalbuphine for obstetric analgesia: a comparison of nalbuphine with pethidine for pain relief in labour when administered by patient-controlled analgesia (PCA). Anaesthesia 1987;42(7):697-703.

\section{Giannina 1995 \{published data only\}}

Giannina G, Guzman ER, Lai YL, Lake MF, Cernadas M, Vintzileos AM. Comparison of the effects of meperidine and nalbuphine on intrapartum fetal heart rate tracings. Obstetrics \& Gynecology 1995;86(3):441-5.

Gillam 1958 \{published data only\}

Gillam JS, Hunter GW, Darner CB, Thompson GR. Meperidine hydrochloride and alphaprodine hydrochloride as obstetric analgesic agents. A double blind study. American Journal of Obstetrics and Gynecology 1958;75(5):1105-10.

Grant 1970 \{published data only\}

Grant A, Holt EM, Noble AD. A comparison between pethidine and phenazocine (Narphen) for relief of pain in labour. Journal of Obstetrics and Gynaecology of the British Commonwealth 1970;77(9):824-9.

Hamann 1972 \{published data only\}

Hamann GO. Avacan vs fortral. A controlled double blind investigation on parturient patients. Ugeskrift for Laeger 1972;134:2261-5. 
Hodgkinson 1979 \{published data only\}

Hodgkinson R, Huff RW, Hayashi RH, Husain FJ. Doubleblind comparison of maternal analgesia and neonatal neurobehaviour following intravenous butorphanol and meperidine. Journal of International Medical Research 1979;7(3):224-30.

\section{Husslein 1987 \{published data only\}}

Husslein P, Kubista E, Egarter C. Obstetrical analgesia with tramadol - results of a prospective randomized comparison with pethidine. Zeitschrift fur Geburtshilfe und Perinatologie 1987;191:234-7.

\section{Jackson 1983 \{published data only\}}

Jackson MB, Robson PJ. Preliminary clinical and pharmacokinetic experiences in the newborn when meptazinol is compared with pethidine as an obstetric analgesic. Postgraduate Medical Journal 1983;59(Suppl 1):47-51.

\section{Jahani 2013 \{published data only\}}

Jahani N, Ebrahimzadeh S, Mirzakhani K, Mazlom SR. The effect of intravenous fentanyl on pain and duration of the active phase of first stage labor. Oman Medical Journal 2013;28(5):306-10.

\section{Kainz 1992 \{published data only\}}

Kainz C, Joura E, Obwegeser R, Plockinger B, Gruber W. Efficacy and tolerance of tramadol with or without antiemetic compared to pethidine in obstetric analgesia. Zeitschrift fur Geburtshilfe und Perinatologie 1992;196:78-82.

\section{Kamyabi 2003 \{published data only\}}

* Kamyabi Z, Naderi T, Ramazani A. A randomized, placebocontrolled trial of the effects of pethidine on labor pain, uterine contractions and infant Apgar score. Annals of Saudi Medicine 2003;23(5):318-20.

Kamyabi Z, Zamiri Z, Ramazani A. A randomized double-blind survey of the effects of pethidine on the relief of labour pains, length of labour, uterine contractions and infant's Apgar score. Journal of Obstetrics and Gynaecology Research 2002;28(1):47.

\section{Kermani 2015 \{published data only\}}

Kermani S, Derogar M, Moghadam MB, Bahri N, Mahmoudian AS, Mojtabavi SJ. Comparison of the effects of SP6 acupressure and use of pethidine on the intensity of labor pain in nulliparous women. Avicenna Journal of Phytomedicine 2015;5(Suppl 1):23.

\section{Keskin 2003 \{published data only\}}

Keskin HL, Aktepe Keskin E, Avsar AF, Tabuk M, Caglar GS. Pethidine versus tramadol for pain relief during labor. International Journal of Gynecology \& Obstetrics 2003;82(1):11-6.

\section{Khooshideh 2009 \{published data only\}}

Khooshideh M, Shahriari A. A comparison of tramadol and pethidine analgesia on the duration of labour: a randomised clinical trial. Australian and New Zealand Journal of Obstetrics and Gynaecology 2009;49(1):59-63.
Kuti 2008 \{published data only\}

Kuti O, Faponle AF, Adeyemi AB, Owolabi AT. Pain relief in labour: A randomized controlled trial comparing pentazocine with tramadol. Nepal Journal of Obstetrics and Gynaecology 2008;3(1):14-8.

\section{Lalooha 2017 \{published data only\}}

Lalooha F, Barikani A, Hashemian N-B, Esmailzadehha N. Effect of pethidine (meperidine) on decreasing the duration of first and second stages of labor. Iranian Journal of Obstetrics, Gynecology and Infertility 2017;19(39):1-7.

\section{Lardizabal 1999 \{published data only\}}

Lardizabal JL, Belizan JM, Carroli G, Gonzalez L, Campodonico L, Aguillaume $\mathrm{CJ}$. A randomized trial of nalbuphine versus meperidine for analgesia during labor. References en Gynecologie Obstetrique 1999;6(3):245-8.

\section{Levy 1971 \{published data only\}}

Levy DL. Obstetric analgesia. Pentazocine and meperidine in normal primiparous labor. Obstetrics \& Gynecology 1971;38(6):907-11.

\section{Li 1988 \{published data only\}}

Li DF, Rees GA, Rosen M. Feasibility of self-administration analgesia by the intramuscular route in labour. European Journal of Obstetrics \& Gynecology and Reproductive Biology 1988;27(2):99-104.

\section{Li 1994 \{published data only\}}

Li YF, Li E, Tie LP, Weng LJ. Tramadol in labor analgesia. Beijing Medical Journal 1994;16:265-8.

\section{Lisboa 1997 \{published data only\}}

Lisboa AP, Cunha RD, Silva JC, Mamede JAV, Ennes DK. Random clinical study, comparing nalbufine (IM) and meperidine (IM) during labour - 1996. [abstract]. Acta Obstetricia et Gynecologica Scandinavica 1997;76(167):1.

\section{Liu 2015 \{published data only\}}

Liu Y, Xu M, Che X, He J, Guo D, Zhao G, et al. Effect of direct current pulse stimulating acupoints of Jia Ji (T10-13) and Ciliao (BL 32) with Han's Acupoint Nerve Stimulator on labour pain in women: a randomized controlled clinical study. Journal of Traditional Chinese Medicine 2015;35(6):620-5.

\section{Maduska 1978 \{published data only\}}

Maduska AL, Hajghassemali M. A double-blind comparison of butorphanol and meperidine in labour: maternal pain relief and effect on the newborn. Canadian Anaesthetists Society Journal 1978;25(5):398-404.

\section{Mitterschiffthaler 1991 \{published data only\}}

Mitterschiffthaler G, Huter O. Pethidin or nalbuphin for analgesia in labour?. Geburtshilfe und Frauenheilkunde 1991;51:362-5.

Mobaraki 2016 \{published data only\}

Mobaraki N, Yousefian M, Seifi S, Sakaki M. A randomized controlled trial comparing use of enthonox with pethidine for 
pain relief in primigravid women during the active phase of labor. Anesthesiology and Pain Medicine 2016;6(4):e37420.

\section{Moore 1970 \{published data only\}}

Moore J, Carson RM, Hunter RJ. A comparison of the effects of pentazocine and pethidine administered during labour. Journal of Obstetrics and Gynaecology of the British Commonwealth 1970;77(9):830-6.

\section{Morley-Forster 2000 \{published data only\}}

Morley-Forster PK, Reid DW, Vandeberghe H. A comparison of patient-controlled analgesia fentanyl and alfentanil for labour analgesia. Canadian Journal of Anaesthesia 2000;47(2):113-9.

Morrison 1987 \{published data only\}

Morrison CE, Dutton D, Howie H, Gilmour H. Pethidine compared with meptazinol during labour. Anaesthesia 1987;42(1):7-14.

\section{Mowat 1970 \{published data only\}}

Mowat J, Garrey MM. Comparison of pentazocine and pethidine in labour. BMJ 1970;2(5712):757-9.

\section{Nel 1981 \{published data only\}}

Nel CP, Bloch B, Rush JM. A comparison of meptazinol and pethidine for pain relief during the first stage of labour. South African Medical Journal 1981;59(25):908-10.

\section{Nelson 2005 \{published data only\}}

Nelson KE, Eisenach JC. A comparison of butorphanol and meperidine for labor analgesia [abstract]. Anesthesiology 2004;101 Suppl:Abstract no: A1221.

* Nelson KE, Eisenach JC. Intravenous butorphanol, meperidine, and their combination relieve pain and distress in women in labour. Anesthesiology 2005;102(5):1008-13.

\section{Neumark 1978 \{published data only\}}

Neumark J, Pauser G, Scherzer W. Pain relief in childbirth; an analysis of the analgesic effects of transcutaneous nerve stimulation (TNS), pethidine and placebos. Praktische Anaesthesie, Wiederbelebung und Intensivtherapie 1978;13:13-20.

\section{Nicholas 1982 \{published data only\}}

Nicholas ADG, Robson PJ. Double-blind comparison of meptazinol and pethidine in labour. British Journal of Obstetrics and Gynaecology 1982;89(4):318-22.

\section{O'Dwyer 1971 \{published data only\}}

O'Dwyer E. A comparison of the analgesics pentazocine and pethilorfan in the relief of pain during labour. Journal of the Irish Medical Association 1971;64(408):173-6.

\section{Olofsson 1996 \{published data only\}}

Olofsson Ch, Ekblom A, Ekman-Ordeberg G, Hjelm A, Irestedt L. Lack of analgesic effect of systemically administered morphine or pethidine on labour pain. British Journal of Obstetrics and Gynaecology 1996;103(10):968-72.
Olson 1964 \{published data only\}

Olson RO, Riva HL. Evaluation of phenazocine with meperidine as an analgesic agent during labor, by the double blind method. American Journal of Obstetrics and Gynecology 1964;88:601-11.

Osler 1987 \{published data only\}

Osler M. A double-blind study comparing meptazinol and pethidine for pain relief in labour. European Journal of Obstetrics \& Gynecology and Reproductive Biology 1987;26(1):15-8.

Prasertsawat 1986 \{published data only\}

Prasertsawat OP, Herabutya Y, Chaturachinda K. Obstetric analgesia: comparison between tramadol, morphine, and pethidine. Current Therapeutic Research, Clinical and Experimental 1986;40(6):1022-8.

Quilligan 1980 \{published data only\}

Quilligan EJ, Keegan KA, Donahue MJ. Double-blind comparison of intravenously injected butorphanol and meperidine in parturients. International Journal of Gynecology \& Obstetrics 1980;18(5):363-7.

Rayburn 1989a \{published data only\}

Rayburn WF, Smith CV, Parriott JE, Woods RE. Randomized comparison of meperidine and fentanyl during labor. Obstetrics \& Gynecology 1989; Vol. 74, issue 4:604-6.

Refstad 1980 \{published data only\}

Refstad SO, Lindbaek E. Ventilatory depression of the newborn of women receiving pethidine or pentazocine. A double-blind comparative trial. British Journal of Anaesthesia 1980;52(3):265-71.

Sekhavat 2009 \{published data only\} Sekhavat L, Behdad S. The effects of meperidine analgesia during labor on fetal heart rate. International Journal of Biomedical Science 2009;5(1):59-62.

Sheikh 1986 \{published data only\}

Sheikh A, Tunstall ME. Comparative study of meptazinol and pethidine for the relief of pain in labour. British Journal of Obstetrics and Gynaecology 1986;93(3):264-9.

Sliom 1970 \{published data only\}

Sliom CM. Analgesia during labour: a comparison between dihydrocodeine and pethidine. South African Medical Journal 1970;44(11):317-9.

Tawfik 1982 \{published data only\}

Tawfik O, Badraoui MHH, El-Ridi FS. The value of transcutaneous nerve stimulation (TNS) during labour in Egyptian mothers. Schmerz 1982;2:98-105.

Thakur 2004 \{published data only\}

Thakur R, Rekha P. Comparative study of transcutaneous electrical nerve stimulation (TENS) and tramadol hydrochloride for pain relief in labor. Journal of Obstetrics and Gynecology of India 2004;54(4):346-50. 
Tharamas 1999 \{published data only\}

Tharamas W. Buprenorphine versus meperidine for analgesia in labor in nullipara at Chon Buri Hospital. Chon Buri Hospital Journal 1999;24(2):25-34.

\section{Tsui 2004 \{published data only\}}

Tsui MHY, Warwick D, Kee N, Ng FF, Lau TK. A double blinded placebo-controlled study of intramuscular pethidine for pain relief in the first stage of labour. British Journal of Obstetrics and Gynaecology 2004;111(7):648-55.

\section{Viegas 1993 \{published data only\}}

Viegas OA, Khaw B, Ratnam SS. Tramadol in labour pain in primiparous patients: a prospective comparative clinical trial. European Journal of Obstetrics \& Gynecology and Reproductive Biology 1993;49(3):131-5.

\section{Volikas 2001 \{published data only\}}

Volikas I, Male D. A comparison of pethidine and remifentanil patient-controlled analgesia in labour. International Journal of Obstetric Anesthesia 2001;10(2):86-90.

\section{Wahab 1988 \{published data only\}}

Wahab SA, Askalani AH, Amar RA, Ramadan ME, Neweigy SB, Saleh AA. Effect of some recent analgesics on labor pain and maternal and fetal blood gases and $\mathrm{pH}$. International Journal of Gynecology \& Obstetrics 1988;26(1):75-80.

\section{Wali 2012 \{published data only\}}

Wali AS, Ajaz S, Azam SI, Ariff S. Labor analgesia: Tramadol vs. Pentazocine. Anaesthesia, Pain and Intensive Care 2012;16(1):98

\section{Wee 2014 \{published data only\}}

Wee MY, Tuckey JP, Thomas P, Burnard S. The IDvIP trial: a twocentre randomised double-blind controlled trial comparing intramuscular diamorphine and intramuscular pethidine for labour analgesia. BMC Pregnancy and Childbirth 2011;11:51.

Wee MY, Tuckey JP, Thomas P, Burnard S, Jackson D. The IDvIP Trial: A two-centre double-blind randomised controlled trial comparing i.m. diamorphine and i.m. pethidine for labour analgesia. International Journal of Obstetric Anesthesia 2012;21:S15.

* Wee MY, Tuckey JP, Thomas PW, Burnard S. A comparison of intramuscular diamorphine and intramuscular pethidine for labour analgesia: a tow-centre randomised blinded controlled trial. BJOG: an international journal of obstetrics and gynaecology 2014;121(4):447-56.

Wheble 1988 \{published data only\}

Wheble AM, Dawes GS, Gillmer MD, Sykes GS. A double blind quantitative study of the effects of meptazinol and pethidine on the fetal heart rate in labour. Journal of Obstetrics and Gynaecology 1988;8(3):248-52.

\section{Wilson 1986 \{published data only\}}

* Wilson CM, McClean E, Moore J, Dundee JW. A double-blind comparison of intramuscular pethidine and nalbuphine in labour. Anaesthesia 1986;41(12):1207-13.
Wilson CM, Moore J, McClean E, Dundee JW. Maternal analgesia and neonatal neuro-behaviour following nalbuphine and pethidine (abstract). British Journal of Clinical Pharmacology 1986;21:613P.

\section{Zafar 2016 \{published data only\}}

Zafar S, Najam Y, Arif Z, Hafeez A. A randomized controlled trial comparing Pentazocine and Chamomilla recutita for labor pain relief. Homeopathy 2016;105(1):66-70.

Zhu 2013 \{published data only\}

Zhu HX, Yao Y, Wu YS, Liu Y, Yan LR, Su XJ. Influence of acupoint injection with small dose of fentanyl-droperidol mixed liquor on labor analgesia and level of stress hormone in parturient. Chinese acupuncture \& moxibustion 2013;33(4):342-6.

\section{References to studies excluded from this review}

\section{Abd-El-Maeboud 2014 \{published data only\}}

Abd-El-Maeboud KH, Elbohoty AE, Mohammed WE, Elgamel HM, Ali WA. Intravenous infusion of paracetamol for intrapartum analgesia. Journal of Obstetrics and Gynaecology Research 2014;40(11):2152-7.

\section{Abdollahi 2014 \{published data only\}}

* Abdollahi MH, Mojibian M, Pishgahi A, Mallah F, Dareshiri S, Mohammadi S, et al. Intravenous paracetamol versus intramuscular pethidine in relief of labour pain in primigravid women. Nigerian Medical Journal : Journal of the Nigeria Medical Association 2014;55(1):54-7.

IRCT201207215506N5. Intravenous paracetamol versus intramuscular pethidine in relief of labor pain in primigravid women. en.search.irct.ir/view/10319 (first received 2 February 2012).

\section{Aiken 1971 \{published data only\}}

Aiken RA, Cope E. The value of promazine and diazepam as adjuncts to pethidine in labour. Proceedings of $3 \mathrm{rd}$ International Congress on Psychosomatic Medicine in Obstetrics and Gynaecology; 1971; London, UK. 1971:241-3.

\section{Alhashemi 2011 \{published data only\}}

Alhashemi JA, NCT01394731. Analgesic effects of intravenous acetaminophen on labor pain. clinicaltrials.gov/ct2/show/ NCT01394731 (first received 12 July 2011).

* Alhashemi JA, Tawfeeq NA, Sadat M, Mujallid RH. Intravenous acetaminophen vs. intramuscular meperidine for labor analgesia. http://www.asaabstracts.com/strands/asaabstracts/ abstractList.htm;jsessionid=0507CB47FEB444D841EEF290BF35A8BF? year=2011\&index=13 (accessed 1 February 2012). 2011.

\section{Ankumah 2016 \{published data only\}}

Ankumah NA, Tsao M, Hutchinson M, Pedroza C, Mehta J, Blackwell S, et al. The comparative effectiveness of intravenous acetaminophen versus intravenous morphine for pain relief in early labor: a randomized controlled trial. American Journal of Obstetrics and Gynecology 2016;214(1 Suppl):S62, Abstract no: 89. 
Balcioglu 2007 \{published data only\}

Balcioglu O, Akin S, Demir S, Aribogan A. Patient-controlled intravenous analgesia with remifentanil in nulliparous subjects in labor. Expert Opinion on Pharmacotherapy 2007;8(18):3089-96.

\section{Balki 2007 \{published data only\}}

Balki M, Kasodekar S, Dhumne S, Bernstein P, Carvalho J. Patient-controlled analgesia with background remifentanil infusion for labor pain [abstract]. Anesthesiology 2006;104(Suppl 1):13.

* Balki M, Kasodekar S, Dhumne S, Bernstein P, Carvalho JC. Remifentanil patient-controlled analgesia for labour: optimizing drug delivery regimens. Canadian Journal of Anaesthesia 2007;54(8):626-33.

\section{Balki 2012 \{published data only\}}

NCT01563939. Patient-controlled intravenous analgesia with remifentanil infusion for labour: is demand bolus required for optimal analgesia. clinicaltrials.gov/ct2/show/NCT01563939 (first received 23 March 2102).

\section{Ballas 1976 \{published data only\}}

Ballas S, Toaff ME, Toaff R. Effects of intravenous meperidine and meperidine with promethazine on uterine activity and fetal heart rate during labor. Israel Journal of Medical Sciences 1976;12(10):1141-7.

\section{Bare 1962 \{published data only\}}

Bare WW. Double-blind evaluation of hydroxyzine hydrochloride for labour and delivery. American Journal of Obstetrics and Gynecology 1962;83(1):18-21.

\section{Bhatia 2013 \{published data only\}}

Bhatia N, Makkar JK, Jain K, Jain V. Comparison of analgesic efficacy of paracetamol and tramadol for pain relief in early labour: A randomized double blind study. Journal of Obstetric Anaesthesia and Critical Care 2013;3(2):118.

\section{Bredow 1992 \{published data only\}}

Bredow V. Use of tramadol versus pethidine versus denaverine suppositories in labor--a contribution to noninvasive therapy of labor pain [Die Anwendung von Tramadol- versus Pethidinversus Denaverin-suppositorien unter der Geburt--ein Beitrag zur nichtinvasiven Geburtsschmerztherapie]. Zentralblatt fur Gynakologie 1992;114(11):551-4.

\section{Brelje 1966 \{published data only\}}

Brelje MC, Garcia-Bunuel R. Meperidine-hydroxyzine in obstetric analgesia. Obstetrics \& Gynecology 1966;27(3):350-4.

\section{Brookes 2013 \{published data only\}}

EUCTR2012-005257-22-GB. Remifentanil intravenous patient controlled analgesia (PCA) versus intramuscular pethidine for pain relief in labour: a randomised controlled trial - RESPITE. clinicaltrialsregister.eu/ctr-search/search?query=eudract_ number:2012-005257-22 (first received 21 June 2013).

\section{Busacca 1982 \{published data only\}}

Busacca M, Gementi P, Gambini E, Lenti C, Meschi F, Vignali M. Neonatal effects of the administration of meperidine and promethazine to the mother in labor. Double blind study. Journal of Perinatal Medicine 1982;10(1):48-53.

Cahal 1960 \{published data only\}

Cahal DA, Dare JG, Keith D. A sequential trial of analgesics in labour. Journal of Obstetrics and Gynaecology of the British Commonwealth 1961;63:88-93.

\section{Calderon 2006 \{published data only\}}

Calderon E, Martinez E, Roman MD, Pernia A, GarciaHernandez R, Torres LM. Intravenous remifentanil delivered through an elastomeric device versus intramuscular meperidine comparative study for obstetric analgesia [Remifentalino intravenoso mediante infusor elastomerico frente a meperidina intramuscular. Estudio comparativo en analgesia obstetrica]. Revista de la Sociedad Espanola del Dolor 2006;13(7):462-7.

Callaghan 1966 \{published data only\} Callaghan PE, Zelenik JS. Methotrimeprazine for obstetric analgesia. American Journal of Obstetrics and Gynecology 1966;95(5):636-9.

\section{Camann 1992 \{published data only\}}

Camann WR, Denney RA, Holby ED, Datta S. A comparison of intrathecal, epidural and intravenous sufentanil for labor analgesia. Anesthesiology 1992; Vol. 77, issue 5:884-7.

\section{Castro 2004 \{published data only\}}

Castro C, Tharmaratnam U, Brockhurst N, Tureanu L, Tam K, Windrim R. Patient-controlled analgesia with fentanyl provides effective analgesia for second trimester labour: a randomized controlled study. Canadian Journal of Anaesthesia 2004;50(10):1039-46.

\section{Cavanagh 1966 \{published data only\}}

Cavanagh D, Le Cart C, Cassady JC, Kiem IM. A comparison of anileridine and meperidine as obstetric analgesia. A doubleblind study of 471 patients. American Journal of Obstetrics and Gynecology 1966;96(2):213-20.

\section{Chandnani 2013 \{published data only\}}

Chandnani K, Sainee HB. Pain relief in labour: tramadol versus pentazocine. International Journal of Reproduction, Contraception, Obstetrics and Gynecology 2013;2(2):186-9.

\section{Chang 1976 \{published data only\}}

Chang A, Wood C, Humphrey M, Gilbert M, Wagstaff C. The effects of narcotics on fetal acid base status. British Journal of Obstetrics and Gynaecology 1976;83(1):56-61.

\section{Cincadze 1978 \{published data only\}}

Cincadze II, Bagdany S, Kintraia PJ, Mamtavrisvili II. Intensive fetal monitoring within obstetrical analgesia. Proceedings of 6th European Congress of Perinatal Medicine; 1978 Aug 29-Sept 1; Vienna, Austria. 1978:Abstract no: 52. 
Cullhed 1961 \{published data only\}

Cullhed S, Lofstrom B. Obstetric analgesia with pethidine and scopolamine. Lancet 1961;1(7168):75-7.

\section{Dahiya 2015 \{published data only\}}

Dahiya K, Malik R. Intravenous infusion of paracetamol versus intravenous tramadol as an intrapartum analgesic in active labor. International Journal of Gynecology and Obstetrics 2015;131(Suppl 5):E215.

\section{Dan 1991 \{published data only\}}

Dan U, Barkai G, Rabinovici J, Echin A, Modan M, Mashiah S. A prospective double blind comparison between intravenous nalbuphine and pethidine administered during labor. Proceedings of 11th European Congress of Perinatal Medicine; 1988 April 10-13; Rome, Italy. 1988.

* Dan U, Rabinovici Y, Barkai G, Modan M, Etchin A, Mashiach S. Intravenous pethidine and nalbuphine during labor: a prospective double-blind comparative study. Gynecologic and Obstetric Investigation 1991;32(1):39-43.

\section{De Kornfeld 1964 \{published data only\}}

De Kornfeld TJ, Pearson JW, Lasagna L. Methotrimeprazine in the treatment of labor pain. New England Journal of Medicine 1964;270:391-4.

\section{De Lamerens 1964 \{published data only\}}

De Lamerens S, Tuttle AH, Aballi AJ. Neonatal bilirubin levels after use of phenothiazine derivatives for obstetrical analgesia. Journal of Pediatrics 1964;65:925-8.

Eames 1964 \{published data only\}

Eames GM, Pool KRS. Clinical trial of oxymorphone in labour. BMJ 1964;2:353-5.

\section{Easton 2016 \{published data only\}}

NCT02783508. Pethidine versus nitrous oxide for pain relief during labor among multiparous. a randomized controlled trial. clinicaltrials.gov/ct2/show/NCT02783508 (first received:18 May 2016).

\section{Elbohoty 2012 \{published data only\}}

Elbohoty AE, Abd-Elrazek H, Abd-El-Gawad M, Salama F, ElShorbagy M, Abd-El-Maeboud KH. Intravenous infusion of paracetamol versus intravenous pethidine as an intrapartum analgesic in the first stage of labor. International Journal of Gynecology and Obstetrics 2012;118(1):7-10.

\section{Elhalwagy 2017 \{published data only\}}

JPRN-UMIN000026415. Intranasal Ketamine versus intramuscular Pethidine in labor pain analgesia. upload.umin.ac.jp/cgi-open-bin/ctr_e/ctr_view.cgi? recptno=R000030347 (first received 7 March 2017).

\section{Eliot 1975 \{published data only\}}

Eliot BW, Hill JG, Cole AP, Hailey DM. Continuous pethidine/ diazepam infusion during labour and its effects on the newborn. British Journal of Obstetrics and Gynaecology 1975;82(2):126-31.

\section{El-Kerdawy 2010 \{published data only\}}

El-Kerdawy H, Farouk A. Labor analgesia in preeclampsia: remifentanil patient controlled intravenous analgesia versus epidural analgesia. Middle East Journal of Anesthesiology 2010;20(4):539-45.

\section{El Kinawy 2015b \{published data only\}}

El Kinawy H, NCT02549118. Efficacy of intravenous tenoxicam as an analgesic during the first stage of labor: a randomized controlled trial. clinicaltrials.gov/ct2/show/record/ NCT02549118 (first received 10 September 2015).

El Kinawy H, NCT02557087. Efficacy of intravenous hyoscine butylbromide as an analgesic during the first stage of labor: a randomized controlled trial. clinicaltrials.gov/ct2/show/record/ NCT02557087. NCT02557087 (first received 21 September 2015).

El Kinawy H, NCT02578251. Efficacy of intravenous paracetamol as an analgesic during the first stage of labor: a randomized controlled trial. clinicaltrials.gov/ct2/show/record/ NCT02578251. NCT02578251 (first received 15 October 2015).

\section{Evron 2005 \{published data only\}}

Evron S, Glezerman M, Sadan O, Boaz M. Remifentanil patient controlled analgesia for labor pain. Anesthesiology 2002;96 Suppl:Abstract no: A1032.

* Evron S, Glezerman M, Sadan O, Boaz M, Ezri T. Remifentanil: a novel systematic analgesic for labor pain. Anesthesia \& Analgesia 2005;100:233-8.

Evron S, Sadan O, Ezri T, Boaz M, Glezerman M. Remifentanil: a new systemic analgesic for labor pain and an alternative to dolestine [abstract]. American Journal of Obstetrics and Gynecology 2001;185(6 Suppl):S210.

\section{Evron 2007 \{published data only\}}

Evron S, Parameswaran R, Zipori D, Ezri T, Sadan O, Koren R. Activin beta $A$ in term placenta and its correlation with placental inflammation in parturients having epidural or systemic meperidine analgesia: a randomized study. Journal of Clinical Anesthesia 2007;19(3):168-74.

\section{Evron 2008 \{published data only\}}

Evron S, Ezri T, Protianov M, Muzikant G, Sadan O, Herman A, et al. The effects of remifentanil or acetaminophen with epidural ropivacaine on body temperature during labor. Journal of Anesthesia 2008;22(2):105-11.

\section{Fernandez 2015 \{published data only\}}

Fernandez J, NCT02493192. Birth ball versus meperidine and haloperidol injection for pain relief during first stage of labour. clinicaltrials.gov/ct2/show/record/NCT02493192 (first received 23 June 2015).

\section{Fleet 2015 \{published data only\}}

ACTRN12609001027202. Obstetric analgesia: a comparison of intranasal or subcutaneously administered fentanyl with intramuscular administered pethidine in labour and its effects on mother and baby. anzctr.org.au/Trial/Registration/ TrialReview.aspx?ACTRN=12609001027202 (first received 27 November 2009). 
Fleet J, Belan I, Jones M. Women's experience of intranasal fentanyl, subcutaneous fentanyl or intramuscular pethidine for labour analgesia. Women and Birth 2015;28 Suppl:S14.

* Fleet J, Belan I, Jones MJ, Ullah S, Cyna AM. A comparison of fentanyl with pethidine for pain relief during childbirth: A randomised controlled trial. BJOG: an international journal of obstetrics and gynaecology 2015;122(7):983-92.

Fleet J, Cyna A, Belan I, Jones M, Ullah S. Fentanyl versus pethidine for pain relief during labour and childbirth: $A$ randomised controlled trial. Australian and New Zealand College of Anaesthetists Annual Meeting; 2013 May 4-8; Melbourne, Australia. 2013

Fleet J, Jones M, Belan I. A comparison of intranasal or subcutaneous administered fentanyl with intramuscular pethidine during childbirth: a randomised controlled trial. International Confederation of Midwives 30th Triennial Congress. Midwives: Improving Women's Health; 2014 June 1-4; Prague, Czech Republic. 2014:P105.

\section{Freeman 2012 \{published data only\}}

Freeman LM, Bloemenkamp KW, Franssen MTM, Papatsonis DNM, Hajenius PJ, van ME, et al. Remifentanil patient controlled analgesia versus epidural analgesia in labour. a multicentre randomized controlled trial. BMC Pregnancy and Childbirth 2012;12:63.

\section{Gambling 1998 \{published data only\}}

Gambling DR, Sharma SK, Ramin SM, Lucas MJ, Leveno KJ, Wiley J, et al. A randomized study of combined spinal-epidural analgesia versus intravenous meperidine during labor: impact on cesarean delivery rate. Anesthesiology 1998;89(6):1336-44.

\section{Ginosar 2003 \{published data only\}}

Ginosar Y, Columb MO, Cohen SE, Mirikatani E, Tingle MS, Ratner EF, et al. The site of action of epidural fentanyl infusions in the presence of local anesthetics: a minimum local analgesic concentration infusion study in nulliparous labor. Anesthesia \& Analgesia 2003;97(5):1439-45.

\section{Goodlin 1988 \{published data only\}}

Goodlin RC. Prevention of in utero meconium aspiration by narcotic administration. Personal communication 1988.

\section{Grandjean 1979 \{published data only\}}

Grandjean H, De Mouzon J, Cabot JA, Desprats R, Pontonnier G. Peridural analgesia and by phenoperidine in normal labor. Therapeutic trial with a control series. Archives Francaises de Pediatrie 1979;36(9 Suppl):LXXV-LXXXI.

\section{Greer 1988 \{published data only\}}

Greer IA, Johnston J, Tulloch I, Walker JJ. Effect of maternal ketorolac administration on platelet function in the newborn. European Journal of Obstetrics \& Gynecology and Reproductive Biology 1988;29(4):257-60.

\section{Gupta 2016 \{published data only\}}

CTRI/2013/09/003968. Intravenous paracetamol as an adjunct to patient-controlled epidural analgesia with levobupivacaine and fentanyl in labour: a randomised controlled trial. ctri.nic.in/Clinicaltrials/pdf_generate.php? trialid=6573\&EncHid=\&modid $=\&$ compid $=\% 27, \% 276573$ det $\% 27$ (first received 11 September 2013).

* Gupta K, Mitra S, Kazal S, Saroa R, Ahuja V, Goel P. I.V. paracetamol as an adjunct to patient-controlled epidural analgesia with levobupivacaine and fentanyl in labour: a randomized controlled study. British Journal of Anaesthesia 2016;117(5):617-22.

Mitra S, Gupta K, Kazal S, Saroa R, Ahuja V, Goel P. Intravenous acetaminophen as an adjunct to patient-controlled epidural analgesia with levobupivacaine and fentanyl in labor: a randomized controlled study. Society for Obstetric Anesthesia and Perinatology (SOAP) 48th Annual Meeting; 2016 May 18-22; Boston USA. 2016:T-27.

\section{Hashemiyan 2014 \{published data only\}}

IRCT2014012016283N1. The effect of pethidine in shortening of first and second stage of labor. en.search.irct.ir/view/16722 (first received 14 April 2014).

\section{Hodgkinson 1978 \{published data only\}}

Hodgkinson R, Bhatt M, Grewal G, Marx GF. Neonatal neurobehavior in the first 48 hours of life: effect of the administration of meperidine with and without naloxone in the mother. Pediatrics 1978; Vol. 62, issue 3:294-8.

\section{Isenor 1993 \{published data only\}}

Isenor L, Penny-MacGillivray T. Intravenous meperidine infusion for obstetric analgesia. Journal of Obstetric, Gynecologic and Neonatal Nursing 1993;22(4):349-56.

\section{John 2013 \{published data only\}}

John C, Fyneface-Ogan S, Enyindah C. A comparison of the effect of spinal analgesia and sedo-analgesia on maternal cortisol levels during labour. 1st FIGO African Regional Conference of Gynecology and Obstetrics; 2013 Oct 2-5; Addis Ababa, Ethiopia. 2013.

\section{Jost 2015 \{published data only\}}

Jost A, Ban B, Kamenik M. Modified patient-controlled remifentanil bolus delivery regimen for labour pain. Anaesthesia 2013;68(3):245-52.

* Jost A, Blagus R, Ban B, Kamenik M. Effect-site concentration of remifentanil during patient-controlled analgesia in labour. International Journal of Obstetric Anesthesia 2015;24(3):230-6.

Kalaskar 2007 \{published data only\}

Kalaskar A, Nayak AH. Comparative evaluation of analgesic efficacy and safety of intramuscular tramadol with pentazocine for labour analgesia: a prospective study. 31st British International Congress of Obstetrics and Gynaecology; 2007 July 4-6; London, UK. 2007:112

Kaltreider 1967 \{published data only\}

Kaltreider DF. Premature labor and meperidine analgesia. American Journal of Obstetrics and Gynecology 1967;99(7):989-93. 


\section{Karadjova 2016 \{published data only\}}

Karadjova D, Shosholceva M, Spasovski S, Ivanov E, Sivevski A, Zlatkova M, et al. Intravenous patient controlled analgesia with remifentanil versus continuous epidural for labor analgesia. Anesthesia \& Analgesia 2016;123(3 Suppl):PR199.

Kaur 2015 \{published data only\}

Kaur Makkar J, Jain K, Bhatia N, Jain V, Mal Mithrawal S. Comparison of analgesic efficacy of paracetamol and tramadol for pain relief in active labor. Journal of Clinical Anesthesia 2015;27(2):159-63.

\section{Khooshideh 2015 \{published data only\}}

Khooshideh M, Shahriari A, Sheikh M. Comparison of the effect of incremental bolus and incremental infusion regimens of remifentanil on labour pain. Shiraz E Medical Journal 2015;16(5):e25626.

\section{Krins 1969 \{published data only\}}

Krins AJ, Mitchell WR, Wood C. Effect of morphine upon maternal capillary blood oxygen and carbon dioxide tension. Journal of Obstetrics and Gynaecology of the British Commonwealth 1969;76(4):359-61.

\section{Lallar 2015 \{published data only\}}

Lallar M, Anam H, Nandal R, Singh Sunder P, Katyal S. Intravenous paracetamol infusion versus intramuscular tramadol as an intrapartum labor analgesic. Journal of Obstetrics and Gynecology of India 2015;65(1):17-22.

\section{Li 1995 \{published data only\}}

Li E, Weng L. Influence of dihydroetorphine hydrochloride and tramadol on labor pain and umbilical blood gas. ChungHua Fu Chan Ko Tsa Chih [Chinese Journal of Obstetrics and Gynaecology] 1995;30(6):345-8.

\section{Logtenberg 2017 \{published data only\}}

Logtenberg SLM, Oude Rengerink K, van der Post JA, Verhoeven CJ, Freeman LM, Middeldorp JM, et al. Labour pain with remifentanil patient-controlled analgesia versus epidural analgesia: a randomised equivalence trial. BJOG: an International Journal of Obstetrics and Gynaecology 2017;124(4):652-60.

\section{MacVicar 1960 \{published data only\}}

MacVicar J, Murray MH. Clinical evaluation of promazine as an adjunct to predelivery sedation. British Medical Journal 1960;1(5173):595-8.

\section{Malkasian 1967 \{published data only\}}

Malkasian GD, Smith RA, Decker DG. Comparison of hydroxyzine-meperidine and promethazine-meperidine for analgesia during labor. Obstetrics \& Gynecology 1967;30(4):568-75

\section{Marshalov 2012 \{published data only\}}

Marshalov D, Salov I, Shifman E, Petrenko A. Influence of epidural analgesia on abdominal wall pain tension and level of abdominal pressure in labor. Regional Anesthesia and Pain Medicine 2012;37(7 Suppl):E278.
McDonald 1964 \{published data only\}

McDonald R, Shaw M, Craig C. Effect of phenothiazines and analgesics given during labour on neonatal serum bilirubin. British Medical Journal 1964;1(5384):677.

\section{McGrath 1992 \{published data only\}}

McGrath J, Chestnut D, Debruyn C. The effect of epidural bupivacaine vs intravenous nalbuphine on fetal heart rate during labor. Anesthesiology 1992;77:A983.

McInnes 2004 \{published data only\}

Hillan E. Diamorphine for pain relief in labour: a randomised controlled trial comparing intramuscular injection and patient controlled analgesia. http://controlled-trials.com (accessed 12 June 2002) 2002.

Hillan EM. Diamorphine for pain relief in labour: a randomized controlled trial comparing intramuscular injection and patientcontrolled analgesia. 16th International Nursing Research Congress; 2005 14-16 July; Hawaii. 2005.

* McInnes RJ, Hillan E, Clark D, Gilmour H. Diamorphine for pain relief in labour: a randomised controlled trial comparing intramuscular injection and patient-controlled analgesia. BJOG: an International Journal of Obstetrics \& Gynaecology 2004;111(10):1081-9.

\section{McQuitty 1967 \{published data only\}}

McQuitty FM. Relief of pain in labour A controlled doubleblind trial comparing pethidine and various phenothiazine derivatives. Journal of Obstetrics and Gynaecology of the British Commonwealth 1967;74(6):925-8.

\section{Moore 1974 \{published data only\}}

Moore J, Ball HG. A sequential study of intravenous analgesic treatment during labour. British Journal of Anaesthesia 1974;46(5):365-72.

\section{Morgan 2004 \{published data only\}}

Morgan PJ, Palmer SK, Kung R, Halpern SH, Yee JA. Effect of intramuscular opioids on subsequent epidural analgesia [abstract]. Canadian Journal of Anesthesia 2004;51(Suppl 1):A58

\section{Morris 1994 \{published data only\}}

Morris GF, Gore-Hickman W, Lang SA, Yip RW. Can parturients distinguish between intravenous and epidural fentanyl?. Canadian Journal of Anaesthesia 1994;41(8):667-72.

Nafisi 2006 \{published data only\}

Nafisi S. Effects of epidural lidocaine analgesia on labor and delivery: a randomized, prospective, controlled trial. $B M C$ Anesthesiology 2006;6:15.

\section{Ng 2011 \{published data only\}}

Ng TK, Cheng BC, Chan WS, Lam KK, Chan MT. A double-blind randomised comparison of intravenous patient-controlled remifentanil with intramuscular pethidine for labour analgesia. Anaesthesia 2011;66(9):796-801. 
Nikkola 2000 \{published data only\}

Nikkola EM, Jahnukainen TJ, Eklad UU, Kero PO, Salonen MA. Neonatal monitoring after maternal fentanyl analgesia in labor. Journal of Clinical Monitoring \& Computing 2000;16(8):597-608.

\section{Overton 1992 \{published data only\}}

Overton C, Haddad N, Williams J. Trial to study the effectiveness and suitability of sublingual diamorphine hydrochloride as an alternative in labour and to compare it with the presently available methods. Proceedings of 26th British Congress of Obstetrics and Gynaecology; 1992 July 7-10; Manchester, UK. 1992:431.

\section{Pandole 2003 \{published data only\}}

Pandole A, Akolekar R, Sardeshpande N, Kore S, Ambiye VR. A comparative study between tramadol and pethidine as a form of labour analgesia. Bombay Hospital Journal 2003;45:4.

\section{Polley 2000 \{published data only\}}

Polley LS, Columb MO, Naughton NN, Wagner DS, Dorantes DM, van de Ven JM. Effect of intravenous versus epidural fentanyl on the minimum local analgesic concentration of epidural bupivacaine in labor. Anesthesiology 2000;93(1):122-8.

\section{Posner 1960 \{published data only\}}

Posner AC. Combined pethidine and antagonists in obstetrics. British Medical Journal 1960;1:124-5.

\section{Powe 1962 \{published data only\}}

Powe CE, Kiem IM, Fromhagen C, Cavanagh D. Propiomazine hydrochloride in obstetrical analgesia. JAMA 1962;181:290-4.

Rabie 2006 \{published data only\}

Rabie ME, Negmi HH, Moustafa AM, Al Oufi H. Remifentanil by patient controlled analgesia compared with epidural analgesia for pain relief in labour [abstract]. Regional Anesthesia and Pain Management 2006;31(5 Suppl 1):52.

Rahimi 2012 \{published data only\}

IRCT201104026115N1. The effect of adding Remifentanil to Entonox in reducing labour pain in first stage of active phase of labour in parturients. en.search.irct.ir/view/5636 (first received 14 August 2012).

\section{Ransom 1966 \{published data only\}}

Ransom S. Oxymorphone as an obstetric analgesic - a clinical trial. Anaesthesia 1966;21(4):464-71.

\section{Rayburn 1989 \{published data only\}}

Rayburn W, Leuschen MP, Earl R, Woods M, Lorkovic M, Gaston-Johansson F. Intravenous meperidine during labor: a randomized comparison between nursing- and patientcontrolled administration. Obstetrics \& Gynecology 1989; Vol. 74 , issue 5:702-6.

\section{Rayburn 1991 \{published data only\}}

Rayburn WF, Smith CV, Leuschen MP, Hoffman KA. Patientcontrolled analgesia using fentanyl during labor. Proceedings of 10th Annual Meeting of Society of Perinatal Obstetricians; 1990 Jan 23-27; Houston, Texas, USA. 1990:51.
* Rayburn WF, Smith CV, Leuschen MP, Hoffman KA, Flores CS. Comparison of patient-controlled and nurseadministered analgesia using intravenous fentanyl during labor. Anesthesiology Review 1991;18(1):31-6.

\section{Roberts 1957 \{published data only\}}

Roberts H, Kane KM, Percival N, Snow P, Please NW. Effects of some analgesic drugs used in childbirth with special reference to variation in respiratory minute volume of the newborn. Lancet 1957; Vol. 1, issue 6960:128-32.

\section{Roberts 1960 \{published data only\}}

Roberts H, Kuck MAC. Use of alphaprodine and levallorphan during labour. Canadian Medical Association Journal 1960;83:1088-93.

\section{Robinson 1980 \{published data only\}}

Evans JM, David H, Rosen M, Revill SI, Robinson J, McCarthy J, et al. Patient activated intravenous narcotic. Obstetric Anaesthetists Assn Report. Anaesthesia 1976; Vol. 31:847.

* Robinson JO, Rosen M, Evans JM, Revill SI, David H, Rees GAD. Self-administered intravenous and intramuscular pethidine - a controlled trial in labour. Anaesthesia 1980; Vol. 35, issue 8:763-70.

\section{Ron 1984 \{published data only\}}

Ron M, Menashe M, Hochner-Celnikier D, Palti Z. Maternal blood pressure response to the intravenous administration of pethidine-promethazine during labor. European Journal of Obstetrics \& Gynecology and Reproductive Biology 1984;18(1):25-8.

\section{Rowley 1963 \{published data only\}}

Rowley WF, Tannrikulu O, Grossman A, Hsia DY. A controlled study on effect of promethazine hydrochloride and meperidine hydrochloride upon serum bilirubin levels in the newborn infant. Journal of Pediatrics 1963;62:934-5.

\section{Sabry 2011 \{published data only\}}

NCT01290289. Analgesia in labor, a prospective parallel single blind study to compare regional analgesia (combined spinal epidural analgesia (cse), epidural analgesia (e)) and intravenous (iv) pethidine analgesia. clinicaltrials.gov/show/NCT01290289 (first received 4 February 2011).

Samanta 2013 \{published data only\}

Samanta S, Jain K, Bhardwaj N, Jain V, Singla V. Doppler velocimetric changes following labour epidural analgesia in growth restricted fetuses with impaired umbilical blood flow: A randomised controlled trial. Journal of Obstetric Anaesthesia and Critical care 2013;31(1):57.

\section{Savage 1955 \{published data only\}}

Savage D. Chlorpromazine (Largactil) as an analgesic in labour. British Journal of Anaesthesia 1955;27(7):346-53.

Sentnor 1966 \{published data only\}

* Sentnor MH, Posner NA, Kohl SG, Pomerance W.

Oxymorphone re-evaluated. The addition of a respiratory 
antagonist. American Journal of Obstetrics and Gynecology 1966;96(3):430-6.

Sentnor MH, Solomons E, Kohl SG. An evaluation of oxymorphone in labor. American Journal of Obstetrics and Gynecology 1962;84:956-61.

\section{Shahriari 2007 \{published data only\}}

Shahriari A, Khooshideh M. A randomized controlled trial of intravenous remifentanil compared with intramuscular meperidine for pain relief in labor. Journal of Medical Sciences 2007;7(4):635-9.

\section{Singh 2001 \{published data only\}}

Singh S, Mathur V, Srivastava U, Pandey DN, Gupta N. Comparative evaluation of efficacy of tramadol with pentazocine for labour analgesia and their effects on foetal outcome. Journal of Obstetrics and Gynecology of India 2001;51(2):55-7.

\section{Solek-Pastuszka 2009 \{published data only\}}

Solek-Pastuszka J, Kepinski S, Makowski A, Celewicz Z, Zukowski M, Safranow K, et al. Patient-controlled continuous epidural analgesia vs intravenous remifentanil infusion for labour anaesthesia [Porownanie jakosci znieczulenia u rodzacych otrzymujacych remifentanil metoda analgezji dozylnej sterowanej przez pacjenta lub ciaglego znieczulenia zewnatrzoponowego]. Anestezjologia Intensywna Terapia 2009;41(2):84-8.

\section{Soontrapa 2002 \{published data only\}}

Sookpanya S, Suntrapa S, Komwilaisak R. Effectiveness of intravenous pethidine for pain relief in the first stage of labour. Thai Journal of Obstetrics and Gynaecology 1999;11(4):272.

* Soontrapa S, Somboonporn W, Komwilaisak R, Sookpanya S, Soontrapa Sukree, Somboonporn Woraluk, et al. Effectiveness of intravenous meperidine for pain relief in the first stage of labour. Journal of the Medical Association of Thailand 2002;85(11):1169-75.

\section{Sosa 2004 \{published data only\}}

* Sosa CG, Balaguer E, Alonso JG, Panizza R, Laborde A, Berrondo C. Meperidine for dystocia during the first stage of labor: a randomized controlled trial. American Journal of Obstetrics and Gynecology 2004;191(4):1212-8.

Sosa CG, Buekens P, Hughes JM, Balaguer E, Sotero G, Panizza $R$, et al. Effect of pethidine administered during the first stage of labor on the acid-base status at birth. European Journal of Obstetrics \& Gynecology and Reproductive Biology 2006;129(2):135-9.

\section{Spellacy 1966 \{published data only\}}

Spellacy WN, Shattuck CA, Loffer FD. A double-blind study of the comparative effects of meperidine with secobarbital, hydroxyzine, or a placebo on labor and delivery. Obstetrics \& Gynecology 1966;27(2):290-3.

\section{Stocki 2014 \{published data only\}}

Stocki D, Matot I, Einav S, Eventov-Friedman S, Ginosar Y, Weiniger CF. A randomized controlled trial of the efficacy and respiratory effects of patient-controlled intravenous remifentanil analgesia and patient-controlled epidural analgesia in laboring women. Anesthesia \& Analgesia 2014;118(3):589-97.

\section{Stourac 2014 \{published data only\}}

Stourac P, Suchomelova H, Stodulkova M, Huser M, Krikava I, Janku $P$, et al. Comparison of parturient-controlled remifentanil with epidural bupivacain and sufentanil for labour analgesia: randomised controlled trial. Biomedical Papers: Journal of the Palacky University 2014;158(2):227-32.

\section{Suvonnakote 1986 \{published data only\}}

Suvonnakote T, Thitadilok W, Atisook R. Pain relief during labour. Journal of the Medical Association of Thailand 1986;69(11):575-9.

\section{Taskin 1993 \{published data only\}}

Taskin O, Saade G, Belfort M, Moise K. The effect of narcotics and spasmolytics on cervical dilatation in labor: a randomized placebo-controlled study. American Journal of Obstetrics and Gynecology 1993;168:362.

\section{Thurlow 2002 \{published data only\}}

Thurlow JA, Laxton CH, Dick A, Waterhouse P. A comparison of patient controlled analgesia (PCA) using remifentanil with intramuscular pethidine for pain relief in labour [abstract]. International Journal of Obstetric Anesthesia 2000;9:200.

* Thurlow JA, Laxton CH, Dick A, Waterhouse P, Sherman L, Goodman NW. Remifentanil by patient-controlled analgesia compared with intramuscular meperidine for pain relief in labour. British Journal of Anaesthesia 2002;88(3):374-8.

Tomlin 1965 \{published data only\}

Tomlin PJ. Pethidine compared with pethidine plus levallorphan and with a placebo. British Journal of Anaesthesia 1965;37:23-8.

\section{Tournaire 1980 \{published data only\}}

Tournaire M, Catinat-Ozil D, Breart G, Scherrer P, Baron JM, Leroy $B$. The influence of pethidine on uterine activity and dilatation of the cervix in spontaneous labour. Journal de Gynecologie, Obstetrique et Biologie de la Reproduction 1980;9(2):261-6.

\section{Treisser 1981 \{published data only\}}

Treisser A, Breart G, Blum F, Jouhet P, Pigne A, Barrat J. Dystocia at the onset of labour. An evaluation of the different treatments available. Journal de Gynecologie, Obstetrique et Biologie de la Reproduction 1981;10(1):91-8.

\section{Tripti 2006 \{published data only\}}

Tripti N, Jyotsna A. Pain relief in labor tramadol versus pentazocine. Journal of Obstetrics and Gynecology of India 2006;56(5):406-9.

\section{Vavrinkova 2005 \{published data only\}}

Vavrinkova B, Oborna L, Binder T, Horak J. Nalbuphine in obstetrical analgesia [Nalbuphine v porodnicke analgezii]. Ceska Gynekologie 2005;70(3):180-3. 
Volmanen 2005 \{published data only\}

* Volmanen P, Akural E, Raudakoski T, Ohtonen P, Alahuhta S. Comparison of remifentanil and nitrous oxide in labour analgesia. Acta Anaesthesiologica Scandinavica 2005;49:453-8.

Volmanen P, Akural E, Raudaskoski, Alahuhta S. Comparison of maternal haemodynamic effects and respiratory indices during remifentanil and nitrous oxide labour analgesia. International Journal of Obstetric Anesthesia 2004;13(3):S19.

Volmanen 2008 \{published data only\}

Volmanen P, Sarvela J, Akural El, Raudaskoski T, Korttila K, Alahuhta S. Intravenous remifentanil vs. epidural levobupivacaine with fentanyl for pain relief in early labour: a randomised, controlled, double-blinded study. Acta Anaesthesiologica Scandinavica 2008;52(2):249-55.

\section{Volmanen 2009 \{published data only\}}

Volmanen P, Akural E, Alahuhta S. In early labour, IVPCA remifentanil bolus during the contraction pause does not improve the analgesic effect but reduces sedation compared with bolus given during the uterine contraction. European Journal of Anaesthesiology 2009;26(Suppl 45):148, Abstract no: 11AP1-4.

* Volmanen PV, Akural El, Raudaskoski T, Ranta P, Tekay A, Ohtonen P, et al. Timing of intravenous patient-controlled remifentanil bolus during early labour. Acta Anaesthesiologica Scandinavica 2011; Vol. 55, issue 4:486-94.

\section{Von Vorherr 1963 \{published data only\}}

Von Vorherr $\mathrm{H}$. Is there a pharmacological acceleration of childbirth? [Gibt es eine medikamentose

Geburtsbeschleunigung?]. Deutsche Medizinische Wochenschrift 1963;88:1426-30.

\section{Walker 1992 \{published data only\}}

Walker JJ, Johnston J. A randomised study of non-steroidal anti-inflammatory drug ketolorac against pethidine in labour. Proceedings of 11th European Congress of Perinatal Medicine; 1988 April 10-13; Rome, Italy. 1988:163.

* Walker JJ, Johnston J, Fairlie FM, Lloyd J, Bullingham R. A comparative study of intramuscular ketorolac and pethidine in labour pain. European Journal of Obstetrics \& Gynecology and Reproductive Biology 1992;46(2):87-94.

Walker JJ, Johnstone J, Lloyd J, Rocha CL. The transfer of ketorolac tromethamine from maternal to foetal blood. European Journal of Clinical Pharmacology 1988;34(5):509-11.

Wan 1965 \{published data only\}

Wan LS, Emich JP. Use of propiomazine hydrochloride during labor - a double-blind study on 236 patients. Obstetrics \& Gynecology 1965;25:68-71.

\section{Weissman 2006 \{published data only\}}

NCT00296751. Epidural analgesia versus iv meperidine for labor pain control. objective evaluation of the pain intensity influence on the autonomic nervous system. clinicaltrials.gov/ct2/show/ record/NCT00296751 (first received 24 February 2006).

\section{Wiener 1979 \{published data only\}}

Wiener PC, Hogg MI, Rosen M. Neonatal respiration, feeding and neurobehavioural state: effects of intrapartum bupivacaine, pethidine and pethidine reversed by naloxone. Anaesthesia 1979; Vol. 34, issue 10:996-1004.

\section{Williams 1962 \{published data only\}}

Williams G, Cope I. An evaluation of a combination of pethidine and levallorphan ("pethilorfan'" in labour. Medical Journal of Australia 1962;49(2):499-503.

\section{Wilson 2016 \{published data only\}}

NCT02179294. A randomised controlled trial of remifentanil intravenous patient controlled analgesia ( $\mathrm{pca}$ ) versus intramuscular pethidine for pain relief in labour. clinicaltrials.gov/ct2/show/record/NCT02179294 (first received 11 June 2014).

* Wilson M, MacArthur C, Gao Smith F, Homer L, Handley K, Daniels J. The respite trial: remifentanil intravenously administered patient-controlled analgesia (pca) versus pethidine intramuscular injection for pain relief in labour: study protocol for a randomised controlled trial. Trials 2016;17(1):591.

\section{Wong 2005 \{published data only\}}

Scavone BM, Sullivan JT, Peaceman AM, Strauss-Hoder TP, Wong CA. Fetal heart rate and uterine contraction pattern abnormalities after combined spinal/epidural vs systemic labor analgesia [abstract]. Anesthesiology 2002;96 Suppl:Abstract no: A1049.

Sullivan JT, Scavone BM, McCarthy RJ, Wong CA. Does type of labor analgesia alter the pattern of oxytocin use? [abstract]. Anesthesiology 2002;96(Suppl 1):Abstract no: P48.

Sullivan JT, Scavone BM, McCarthy RJ, Wong CA. Neuraxial labor analgesia is associated with an altered pattern of oxytocin use [abstract]. Anesthesiology 2002;96 Suppl:Abstract no: A1039.

Wong CA, McCarthy RJ, Sullivan JT, Scavone BM, Gerber SE, Yaghmour EA. Early compared with late neuraxial analgesia in nulliparous labor induction: a randomized controlled trial. Obstetrics \& Gynecology 2009;113(5):1066-74.

* Wong CA, Scavone BM, Peaceman AM, McCarthy RJ, Sullivan JT, Diaz NT, et al. The risk of cesarean delivery with neuraxial analgesia given early versus late in labor. [See comment]. New England Journal of Medicine 2005;352(7):655-65.

Wong CA, Scavone BM, Sullivan JT, Ebarvia MJ, McCarthy RJ. The risk of cesarean delivery with early neuraxial analgesia in nulliparous induction of labor. Anesthesiology 2007;107:Abstract no: A1204.

Wong CA, Scavone BM, Sullivan JT, Strauss-Hoder TP, McCarthy RJ. Randomized trial of neuraxial vs systemic analgesia for latent phase labor: effect on incidence of cesarean delivery [abstract]. Anesthesiology 2002;96 Suppl:Abstract no: A1047.

Wong CA, Sullivan JT, McCarthy RJ, Scavone BM, Patel R, Ebarvia MJ. Randomized trial of neuraxial vs. systemic analgesia 
for labor induction: effect on incidence of cesarean delivery [abstract]. Anesthesiology 2007;106(Suppl 1):21.

\section{References to studies awaiting assessment}

Mohan 2015 \{published data only\}

Mohan H, Ramappa R, Sandesh M, Akash BK. Intravenous paracetamol infusion versus intramuscular tramadol as an intrapartum labor analgesic. International Journal of Reproduction, Contraception, Obstetrics and Gynecology 2015;4(6):1726-9.

\section{Sereshti 2013 \{published data only\}}

Sereshti M, Asefi F, Shabanian M, Banaeian S. Comparing the effects of massage and intra intramuscular pethidine on pain relief in the stages of labor and the length of labor. Iranian Journal of Obstetrics, Gynecology and Infertility 2013;16(80):6-16.

\section{References to ongoing studies}

Kokki 2015 \{published data only\}

EUCTR2015-000185-59-FI. The effect of oxycodone to placental and fetal circulation during the phase I of labor and the efficacy, safety and neonatal effects of oxycodone. clinicaltrialsregister.eu/ctr-search/search?query=eudract_ number:2015-000185-59 (first received 27 January 2015).

\section{Raheja 2016 \{published data only\}}

NCT02999594. Tramadol for labor analgesia in low risk women: a placebo controlled randomized trial. clinicaltrials.gov/show/ NCT02999594 (first received 2 December 2016).

\section{Reyes 2013 \{published data only\}}

NCT01889979. Tramadol for labour analgesia in low risk primiparous women. double blind, randomized, controlled trial. clinicaltrials.gov/ct2/show/NCT01889979 (first received 26 June 2013).

\section{Sahin 2012 \{published data only\}}

NCT01555671. Is there any effect of meperidine on the length of duration of labor? a prospective randomized controlled trial. clinicaltrials.gov/ct2/show/NCT01555671 (first received 14 March 2012).

\section{Shen 2008 \{published data only\}}

NCT00710086. Remifentanil intravenous patient-controlled labor analgesia for nulliparous women. clinicaltrials.gov/ct2/ show/NCT00710086 (first received 2 July 2008).

\section{Additional references}

\section{Aghdas 2014}

Aghdas K, Talat K, Sepideh B. Effect of immediate and continuous mother-infant skin-to-skin contact on breastfeeding self-efficacy of primiparous women: a randomised control trial. Women \& Birth: Journal of the Australian College of Midwives 2014;27(1):37-40.

\section{Anim-Somuah 2018}

Anim-Somuah M, Smyth RMD, Cyna AM, Cuthbert A. Epidural versus non-epidural or no analgesia for pain management in labour. Cochrane Database of Systematic Reviews 2018, Issue 5. [DOI: 10.1002/14651858.CD000331.pub4]

\section{Aziato 2016}

Aziato L, Ohemeng HA, Omenyo CN. Experiences and perceptions of Ghanaian midwives on labour pain and religious beliefs and practices influencing their care of women in labour. Reproductive Health 2016;13(1):136.

\section{Barragán 2011}

Barragán Loayza IM, Solà I, Juandó Prats C. Biofeedback for pain management during labour. Cochrane Database of Systematic Reviews 2011, Issue 6. [DOI: 10.1002/14651858.CD006168.pub2]

\section{Bohren 2017}

Bohren MA, Hofmeyr GJ, Sakala C, Fukuzawa RK, Cuthbert A. Continuous support for women during childbirth. Cochrane Database of Systematic Reviews 2017, Issue 7. [DOI: 10.1002/14651858.CD003766]

\section{Bricker 2002}

Bricker L, Lavender T. Parenteral opioids for labor pain relief: a systematic review. American Journal of Obstetrics and Gynecology 2002;186(5 Suppl):S94-S109.

\section{Brimdyr 2015}

Brimdyr K, Cadwell K, Widstroem AM, Svensson K, Neumann M, Hart EA, et al. The association between common labor drugs and suckling when skin-to-skin during the first hour after birth. Birth 2015;42(4):319-28.

\section{Carberry 2013}

Carberry AE, Raynes-Greenow CH, Turner RM, Jeffery HE. Breastfeeding within the first hour compared to more than one hour reduces risk of early-onset feeding problems in term neonates: a cross-sectional study. Breastfeeding Medicine 2013;8(6):513-4.

\section{Cluett 2009}

Cluett ER, Burns E. Immersion in water in labour and birth. Cochrane Database of Systematic Reviews 2009, Issue 2. [DOI: 10.1002/14651858.CD000111.pub3]

\section{Cook 2012}

Cook K, Loomis C. The impact of choice and control on women's childbirth experiences. Journal of Perinatal Education 2012;21(3):158-68.

\section{Deeks 2001}

Deeks JJ, Altman DG, Bradburn MJ. Statistical methods for examining heterogeneity and combining results from several studies in meta-analysis. In: Egger M, Davey Smith G, Altman DG editor(s). Systematic reviews in health care: meta-analysis in context. London: BMJ Books, 2001.

\section{Derry 2012}

Derry S, Straube S, Moore RA, Hancock H, Collins SL. Intracutaneous or subcutaneous sterile water injection 
compared with blinded controls for pain management in labour. Cochrane Database of Systematic Reviews 2012, Issue 1. [DOI: 10.1002/14651858.CD009107.pub2]

\section{Dowswell 2009}

Dowswell T, Bedwell C, Lavender T, Neilson JP. Transcutaneous electrical nerve stimulation (TENS) for pain relief in labour. Cochrane Database of Systematic Reviews 2009, Issue 2. [DOI: 10.1002/14651858.CD007214.pub2]

\section{Edmond 2006}

Edmond KM, Zandoh C, Quigley MA, Amenga-Etego S, Owusu-Agyei S, Kirkwood BR. Delayed breastfeeding initiation increases risk of neonatal mortality. Pediatrics 2006;117(3):e380-6.

\section{Eisenach 2010}

Eisenach J. Neurophysiology of labour pain. European Society of Anaesthesiology lecture 2010.

\section{Elbourne 2006}

Elbourne D, Wiseman RA. Types of intra-muscular opioids for maternal pain relief in labour. Cochrane Database of Systematic Reviews 2006, Issue 3. [DOI: 10.1002/14651858.CD001237.pub2]

\section{Fleet 2017}

Fleet JA, Jones M, Belan I. The influence of intrapartum opioid use on breastfeeding experience at 6 weeks post partum: A secondary analysis. Midwifery 2017;50:106-9.

\section{Genesi 1998a}

Genesi L, Niescierowicz R. Neuroendocrinology and birth 1: stress. British Journal of Midwifery 1998;6(10):659-64.

\section{Genesi 1998b}

Genesi L, Niescierowicz R. Neuroendocrinology and birth 2: the role of oxytocin. British Journal of Midwifery 1998;6(12):791-6.

\section{Green 2003}

Green JM, Baston HA. Feeling in control during labour: concepts, correlates, and consequences. Birth 2003;30(4):235-47.

\section{Hawkins 2003}

Hawkins J. Obstetric analgesia and anaesthesia. In: Scott JR, Gibbs RS, Karlan BY, Haney AF editor(s). Darnforth's Obstetrics and Gynaecology. 9th Edition. London: Lippincott, Williams and Wilkins, 2003.

\section{Higgins 2011a}

Higgins JPT, Green S, editors. Cochrane Handbook for Systematic Reviews of Interventions Version 5.1.0 [updated March 2011]. The Cochrane Collaboration, 2011. Available from www.cochrane-handbook.org.

\section{Higgins 2011b}

Higgins JPT, Deeks JJ, Altman DG (editors). Chapter 16: Special topics in statistics. In: Higgins JPT, Green S (editors), Cochrane Handbook for Systematic Reviews of Interventions Version 5.1.0 (updated March 2011). The Cochrane Collaboration, 2011. Available from www.cochrane-handbook.org.

\section{Hodnett 1987}

Hodnett ED, Simmons-Tropea DA. The labour agentry scale: Psychometric properties of an instrument measuring control during childbirth. Research in Nursing and Health 1987;10(5):301-10.

\section{Hodnett 2002}

Hodnett ED. Pain and women's satisfaction with the experience of childbirth: a systematic review. American Journal of Obstetrics and Gynecology 2002;186(5 Suppl Nature):S160-S172.

\section{Hodnett 2012}

Hodnett ED, Downe S, Walsh D. Alternative versus conventional institutional settings for birth. Cochrane Database of Systematic Reviews 2012, Issue 8. [DOI: 10.1002/14651858.CD000012.pub4]

\section{Hogg 1977}

Hogg MI, Wiener PC, Rosen M, Mapleson WW. Urinary excretion and metabolism of pethidine and norpethidine in the newborn. British Journal of Anaesthesia 1977;49(9):891-9.

\section{Jacobson 1990}

Jacobson B, Nyberg K, Grönbladh L, Eklund G, Bygdeman M, Ryberg $U$. Opiate addiction in adult offspring through possible imprinting after obstetric treatment. BMJ 1990;301(6760):1067-70.

\section{Jones 2011}

Jones L, Dou L, Dowswell T, Alfirevic Z, Neilson JP. Pain management for women in labour: generic protocol. Cochrane Database of Systematic Reviews 2011, Issue 6. [DOI: 10.1002/14651858.CD009167]

\section{Jones 2012}

Jones L, Othman M, Dowswell T, Alfirevic Z, Gates S, Newburn $M$, et al. Pain management for women in labour: an overview of systematic reviews. Cochrane Database of Systematic Reviews 2012, Issue 3. [DOI: 10.1002/14651858.CD009234.pub2]

\section{Jordan 2005}

Jordan S, Emery S, Bradshaw C, Watkins A, Friswell W. The impact of intrapartum analgesia on infant feeding. BJOG: an international journal of obstetrics and gynaecology 2005;112(7):927-34

\section{Klomp 2012}

Klomp T, van Poppel M, Jones L, Lazet J, Di Nisio M, LagroJanssen ALM. Inhaled analgesia for pain management in labour. Cochrane Database of Systematic Reviews 2012, Issue 9. [DOI: 10.1002/14651858.CD009351.pub2]

\section{Klomp 2014}

Klomp T, Mannien J, de Jonge A, Hutton EK, Lagro-Janssen ALM What do midwives need to know about approaches of women towards labour pain management? A qualitative interview study into expectations of management of labour pain for pregnant women receiving midwife-led care in the Netherlands. Midwifery 2014;30(4):432-8 


\section{Lally 2014}

Lally JE, Thomson RG, MacPhail S, Exley C. Pain relief in labour: a qualitative study to determine how to support women to make decisions about pain relief in labour. BMC Pregnancy \& Childbirth 2014;14:6.

\section{Lamm 2007}

Lamm C, Batson CD, Decety J. The neural substrate of human empathy: effects of perspective-taking and cognitive appraisal. Journal of Cognitive Neuroscience 2007;19(1):42-58.

\section{Lang 2006}

Lang AJ, Sorrell JT, Rodgers CS, Lebeck MM. Anxiety sensitivity as a predictor of labor pain. European Journal of Pain 2006;10(3):263-70.

\section{Lawrence 2013}

Lawrence A, Lewis L, Hofmeyr GJ, Styles C. Maternal positions and mobility during first stage labour. Cochrane Database of Systematic Reviews 2013, Issue 10. [DOI: 10.1002/14651858.CD003934.pub4]

\section{Leap 2004}

Leap N, Anderson T. The role of pain in normal birth and the empowerment of women. Chapter 2. In: Downe, S editor(s). Normal Childbirth: Evidence and Debate. Churchill Livingstone, 2004.

\section{Lee 2004}

Lee K, Ho KM. Obstetric regional analgesia services in New Zealand: a national survey. New Zealand Medical Journal 2004;117(1206):U1177.

\section{Lind 2014}

Lind JN, Perrine CG, Li R. Relationship between use of labor pain medications and delayed onset of lactation. Journal of Human Lactation 2014;30(2):167-73.

\section{Lowe 2002}

Lowe NK. The nature of labor pain. American Journal of Obstetrics and Gynecology 2002;186(5 Suppl Nature):S16-S24.

\section{Madden 2016}

Madden K, Middleton P, Cyna AM, Matthewson M, Jones L. Hypnosis for pain management during labour and childbirth. Cochrane Database of Systematic Reviews 2016, Issue 5. [DOI: 10.1002/14651858.CD009356.pub3]

\section{MHRA 2007}

The Medicines and Healthcare products Regulatory Agency (MHRA). Midwives: Prescribing. http:// www.mhra.gov.uk/Howweregulate/Medicines/ Availabilityprescribingsellingandsupplyingofmedicines/ ExemptionsfromMedicinesActrestrictions/Midwives/index.htm (accessed 5 May 2010) 2007.

\section{Moore 2016}

Moore ER, Bergman N, Anderson GC, Medley N. Early skin-toskin contact for mothers and their healthy newborn infants. Cochrane Database of Systematic Reviews 2016, Issue 11. [DOI: 10.1002/14651858.CD003519.pub4]

\section{NICE 2014}

National Institute for Health and Care Excellence (NICE). NICE Clinical Guideline CG190. Intrapartum Care for Healthy Women and Babies. London: NICE, 2014.

\section{Nissen 1995}

Nissen E, Lilja G, Matthiesen AS, Ransjo-Arvidsson AB, UvnasMoberg K, Widstrom AM. Effects of maternal pethidine on infants' developing breast feeding behaviour. Acta Paediatrica 1995;84(2):140-5.

\section{Novikova 2011}

Novikova N, Cluver C. Local anaesthetic nerve block for pain management in labour. Cochrane Database of Systematic Reviews 2011, Issue 7. [DOI: 10.1002/14651858.CD009200]

\section{Nyberg 2000}

Nyberg K, Buka SL, Lipsitt LP. Perinatal medication as a potential risk factor for adult drug abuse in a North American cohort. Epidemiology 2000;11(6):715-6.

\section{Othman 2012}

Othman M, Jones L, Neilson JP. Non-opioid drugs for pain management in labour. Cochrane Database of Systematic Reviews 2012, Issue 7. [DOI: 10.1002/14651858.CD009223.pub2]

\section{Ransjo-Arvidson 2001}

Ransjo-Arvidson AB, Matthiesen AS, Lilja G, Nissen E, Widstrom AM, Uvnas-Moberg K. Maternal analgesia during labor disturbs newborn behavior: effects on breastfeeding, temperature, and crying. Birth 2001;28(1):5-12.

\section{Redshaw 2007}

Redshaw M, Rowe R, Hockley C, Brocklehurst P. Recorded Delivery: a National Survey of Women's Experience of Maternity Care 2006. Oxford: National Perintal Epidemiology Unit, University of Oxford, 2007.

\section{Redshaw 2015}

Redshaw M, Henderson J. Safely Delivered: a National Survey of Women's Experience of Maternity Care 2014. Oxford: The National Perinatal Epidemiology Unit, University of Oxford, 2015.

\section{RevMan 2014 [Computer program]}

The Nordic Cochrane Centre, The Cochrane Collaboration. Review Manager (RevMan). Version 5.3. Copenhagen: The Nordic Cochrane Centre, The Cochrane Collaboration, 2014.

\section{Reynolds 2002}

Reynolds F, Sharma SK, Seed PT. Analgesia in labour and fetal acid-base balance: a meta-analysis comparing epidural with systemic opioid analgesia. BJOG: an international journal of obstetrics and gynaecology 2002;109(12):1344-53.

\section{Righard 1990}

Righard L, Alade MO. Effect of delivery room routines on success of first breast-feed. Lancet 1990;336(8723):1105-7. 


\section{Sandall 2016}

Sandall J, Soltani H, Gates S, Shennan A, Devane D. Midwife-led continuity models versus other models of care for childbearing women. Cochrane Database of Systematic Reviews 2016, Issue 4. [DOI: 10.1002/14651858.CD004667.pub5]

\section{Saravanakumar 2007}

Saravanakumar K, Garstang JS, Hasan K. Intravenous patientcontrolled analgesia for labour: a survey of UK practice. International Journal of Obstetric Anesthesia 2007;16(3):221-5.

\section{Simmons 2012}

Simmons SW, Taghizadeh N, Dennis AT, Hughes D, Cyna AM. Combined spinal-epidural versus epidural analgesia in labour. Cochrane Database of Systematic Reviews 2012, Issue 10. [DOI: 10.1002/14651858.CD003401.pub3]

\section{Smith 2011a}

Smith CA, Collins CT, Crowther CA. Aromatherapy for pain management in labour. Cochrane Database of Systematic Reviews 2011, Issue 7. [DOI: 10.1002/14651858.CD009215]

\section{Smith 2011b}

Smith CA, Collins CT, Crowther CA, Levett KM. Acupuncture or acupressure for pain management in labour. Cochrane Database of Systematic Reviews 2011, Issue 7. [DOI: 10.1002/14651858.CD009232]

\section{Smith 2018a}

Smith CA, Levett KM, Collins CT, Armour M, Dahlen HG, Suganuma M. Relaxation techniques for pain management in labour. Cochrane Database of Systematic Reviews 2018, Issue 3. [DOI: 10.1002/14651858.CD009514.pub2]

\section{Smith 2018b}

Smith CA, Levett KM, Collins CT, Dahlen HG, Ee CC, Suganuma M. Massage, reflexology and other manual methods for pain management in labour. Cochrane Database of Systematic Reviews 2018, Issue 3. [DOI: 10.1002/14651858.CD009290.pub3]

\section{Solt 2002}

Solt I, Ganadry S, Weiner Z. The effect of meperidine and promethazine on fetal heart rate indices during the active phase of labor. Israel Medical Association Journal 2002;4(3):178-80.

\section{Sosa 2006}

Sosa CG, Balaguer E, Alonso JG, Panizza R, et al. Effect of pethidine administered during the first stage of labor on the

\section{CHARACTERISTICS OF STUDIES}

Characteristics of included studies [ordered by study ID] acid-base status at birth. European Journal of Obstetrics \& Gynecology and Reproductive Biology 2006;129(2):135-9.

\section{Trout 2004}

Trout KK. The neuromatrix theory of pain: implications for selected nonpharmacologic methods of pain relief for labor. Journal of Midwifery and Womens Health 2004;49(6):482-8.

\section{Tveit 2009}

Tveit T O, Halvorsen A, Rosland J H. Analgesia for labour: a survey of Norwegian practice - with a focus on parenteral opioids. Acta Anaesthesiologica Scandinavica 2009;53(6):794-9.

\section{Victora 2016}

Victora CG, Bahl R, Barros JD, França GV, Horton S Krasevec $\mathrm{J}$, et al. Breastfeeding in the 21st century:epidemiology, mechanisms, and lifelong effect. Lancet 2016;387(6736):475-90.

\section{Widstrom 2011}

Widstrom AM, Lilja G, Aaltomaa-Michalias P, Dahllof A, Lintula M, Nissen E. Newborn behaviour to locate the breast when skin-toskin: a possible method for enabling early self-regulation. Acta Paediatrica 2011;100(1):79-85.

\section{Williams 2013}

Williams AC, Morris J, Stevens K, Gessler S, Cella M, Baxter J. What influences midwives in estimating labour pain?. European Journal of Pain 2013;17(1):86-93.

\section{Wong 2009}

Wong C. Advances in labor analgesia. International Journal of Women's Health 2009;1:139-54.

\section{References to other published versions of this review \\ Ullman 2008}

Ullman R, Dowswell T, Mori R. Parenteral opioids for maternal pain relief in labour. Cochrane Database of Systematic Reviews 2008, Issue 4. [DOI: 10.1002/14651858.CD007396]

\section{Ullman 2010}

Ullman R, Smith LA, Burns E, Mori R, Dowswell T. Parenteral opioids for maternal pain management in labour. Cochrane Database of Systematic Reviews 2010, Issue 9. [DOI: 10.1002/14651858.CD007396.pub2]

* Indicates the major publication for the study

Atkinson 1994

\begin{tabular}{ll} 
Methods & RCT 2-arm parallel-group design \\
\hline Participants & Setting: (not clear) hospital in Oklahoma, USA
\end{tabular}


Atkinson 1994 (Continued)

100 women in early active labour (with regular contractions and cervical dilatation $3 \mathrm{~cm}$ to $4 \mathrm{~cm}$ ); at term (at or > 37 weeks' gestation); no medical or obstetric complications or evidence of fetal distress; requesting a "pain shot" rather than an epidural (all women were offered epidural).

Interventions

Both groups had continuous electronic fetal monitoring and intrauterine pressure catheters.

Experimental: IV fentanyl $50 \mu \mathrm{g}$ to $100 \mu \mathrm{g}$ every 1 to $2 \mathrm{hrs}$ to a max of 5 doses

Control: IV butorphanol $1 \mathrm{mg}$ to $2 \mathrm{mg}$ every 1 to 2 hrs to a max 5 doses

(Doses of drugs were approximately equivalent in both arms of the trial.)

\begin{tabular}{ll}
\hline Outcomes & $\begin{array}{l}\text { Maternal uterine activity; adverse effects and sid } \\
\text { scored using 10-point VAS ( } 0=\text { no pain, } 10=\text { excr } \\
\text { scores at } 1 \text { and } 5 \text { mins; infant neurological exam }\end{array}$ \\
\hline Notes & Start and end date: December 1992 - June 1993 \\
& Power calculation: unclear \\
& Baseline imbalances between groups: unclear \\
Funding source: not specified & Conflicts of interest: not specified
\end{tabular}

\section{Risk of bias}

\begin{tabular}{lll}
\hline Bias & Authors' judgement & Support for judgement \\
\hline $\begin{array}{l}\text { Random sequence genera- } \\
\text { tion (selection bias) }\end{array}$ & Low risk & Computer-generated randomisation schedule \\
\hline $\begin{array}{l}\text { Allocation concealment } \\
\text { (selection bias) }\end{array}$ & Low risk & Pharmacy prepared identical unlabelled, coded syringes \\
\hline $\begin{array}{l}\text { Blinding of participants } \\
\text { and personnel (perfor- } \\
\text { mance bias) } \\
\text { All outcomes }\end{array}$ & Low risk & Identical syringes. Described as double-blind. \\
\hline
\end{tabular}

\begin{tabular}{lll}
$\begin{array}{l}\text { Blinding of outcome as- } \\
\text { sessment (detection bias) } \\
\text { All outcomes }\end{array}$ & Low risk & Outcome assessors reported as blinded \\
\hline $\begin{array}{l}\text { Incomplete outcome data } \\
\text { (attrition bias) }\end{array}$ & Unclear risk & $\begin{array}{l}\text { It was not clear at what point women were randomised.155 women enrolled; } \\
\text { All outcomes }\end{array}$ \\
& $\begin{array}{l}\text { not this was after randomisation); } 19 \text { women delivered within } 1 \text { hr of first dose } \\
\text { and } 12 \text { did not request analgesia and were not included in the analysis. Data } \\
\text { available for } 100 \text { women; if loss occurred after randomisation this represents a } \\
\text { very high level of attrition. }\end{array}$
\end{tabular}

\begin{tabular}{lll}
\hline $\begin{array}{l}\text { Selective reporting (re- } \\
\text { porting bias) }\end{array}$ & Unclear risk & Unclear \\
\hline Other bias & Low risk & None apparent \\
\hline
\end{tabular}


Bitsch 1980

\begin{tabular}{|c|c|}
\hline Methods & RCT, 2-arm parallel groups \\
\hline \multirow[t]{2}{*}{ Participants } & Setting: hospital, Germany \\
\hline & 45 women, in labour, cephalic presentation \\
\hline \multirow[t]{2}{*}{ Interventions } & Experimental: IM tramadol $50 \mathrm{mg}(\mathrm{N}=23)$ \\
\hline & Control: IM pethidine $50 \mathrm{mg}(\mathrm{N}=22)$ \\
\hline \multirow[t]{2}{*}{ Outcomes } & $\begin{array}{l}\text { Primary outcome: maternal analgesia. Pain assessed as good, not good relief } 5 \text { to } 10 \text { mins after injec- } \\
\text { tion. }\end{array}$ \\
\hline & Secondary outcomes: maternal side effects and fetal heart changes \\
\hline \multirow[t]{9}{*}{ Notes } & German language paper, translation obtained. Tramadol 100 mg plus antiemetic arm not extracted. \\
\hline & If additional analgesia required, repeat doses could be administered within $<1 \mathrm{hr}$. \\
\hline & Tramadol: could have up to 3 repeat doses, $50 \mathrm{mg}$ \\
\hline & Pethidine: could have up to 3 repeat doses, $25 \mathrm{mg}$ \\
\hline & Start and end date: August 1978 - December 1978 \\
\hline & Power calculation: unclear \\
\hline & Baseline imbalances between groups: unclear \\
\hline & Funding source: unclear \\
\hline & Conflicts of interest: unclear \\
\hline
\end{tabular}

\section{Risk of bias}

\begin{tabular}{|c|c|c|}
\hline Bias & Authors' judgement & Support for judgement \\
\hline $\begin{array}{l}\text { Random sequence genera- } \\
\text { tion (selection bias) }\end{array}$ & Unclear risk & Not reported \\
\hline $\begin{array}{l}\text { Allocation concealment } \\
\text { (selection bias) }\end{array}$ & Unclear risk & Not reported \\
\hline $\begin{array}{l}\text { Blinding of participants } \\
\text { and personnel (perfor- } \\
\text { mance bias) } \\
\text { All outcomes }\end{array}$ & Unclear risk & Not reported \\
\hline $\begin{array}{l}\text { Blinding of outcome as- } \\
\text { sessment (detection bias) } \\
\text { All outcomes }\end{array}$ & Low risk & Assessor was described as unaware of treatment assignment. \\
\hline $\begin{array}{l}\text { Incomplete outcome data } \\
\text { (attrition bias) } \\
\text { All outcomes }\end{array}$ & High risk & $\begin{array}{l}\text { Women not having a normal birth were excluded from analyses. No informa- } \\
\text { tion on pain relief was available for } 7 / 45 \text { women. }\end{array}$ \\
\hline $\begin{array}{l}\text { Selective reporting (re- } \\
\text { porting bias) }\end{array}$ & Unclear risk & Unclear \\
\hline Other bias & Unclear risk & Unclear \\
\hline
\end{tabular}


Blair 2005

\begin{tabular}{|c|c|}
\hline Methods & RCT, 2-arm parallel groups \\
\hline \multirow[t]{3}{*}{ Participants } & Setting: Belfast hospital, UK \\
\hline & 40 women (healthy and well) in labour, ASA I or II \\
\hline & $\begin{array}{l}\text { Exclusion criteria: women planning to have epidural analgesia, with pre-eclampsia, multiple pregnan- } \\
\text { cy, premature labour, allergy to study medications }\end{array}$ \\
\hline \multirow[t]{3}{*}{ Interventions } & Experimental: PCA remifentanil $40 \mu \mathrm{g}$ with lock-out of 2 mins \\
\hline & Control: PCA pethidine $15 \mathrm{mg}$ with lock-out of $10 \mathrm{mins}$ \\
\hline & Nitrous oxide was available to all women and women were free to choose an epidural at any stage. \\
\hline Outcomes & $\begin{array}{l}\text { Maternal sedation score ( } 1 \text { to } 5 \text { fully awake to unrousable); VAS } 0 \text { to } 10 \text { for pain and satisfaction with } \\
\text { pain relief; nausea; anxiety; Apgar scores at } 1 \text { min and } 5 \text { mins; infant neurological adaptive capacity } \\
\text { score ( } 2 \text { hrs and } 24 \text { hrs after birth). }\end{array}$ \\
\hline \multirow[t]{6}{*}{ Notes } & $\begin{array}{l}\text { VAS scores were reported as median with inter-quartile range. We were not able to enter data into } \\
\text { RevMan tables but have described findings briefly in the text. }\end{array}$ \\
\hline & Start and end date: not reported. \\
\hline & $\begin{array}{l}\text { Power calculation: "prospective power calculation showed that a sample size of } 20 \text { would give } 85 \% \\
\text { power for detecting a difference of } 20 \mathrm{~mm} \text { on the VAS for overall pain, with SD } 21.2 \text { from previous } \\
\text { work". }\end{array}$ \\
\hline & $\begin{array}{l}\text { Baseline imbalances between groups: "The two groups were similar as to characteristics and duration, } \\
\text { stage of labour and use of PCA". }\end{array}$ \\
\hline & Funding source: not specified \\
\hline & Conflicts of interest: not declared \\
\hline
\end{tabular}

\section{Risk of bias}

\begin{tabular}{|c|c|c|}
\hline Bias & Authors' judgement & Support for judgement \\
\hline $\begin{array}{l}\text { Random sequence genera- } \\
\text { tion (selection bias) }\end{array}$ & Unclear risk & Quote: "women were randomly allocated." \\
\hline $\begin{array}{l}\text { Allocation concealment } \\
\text { (selection bias) }\end{array}$ & Unclear risk & Not clear when randomisation occurred or how it was carried out \\
\hline $\begin{array}{l}\text { Blinding of participants } \\
\text { and personnel (perfor- } \\
\text { mance bias) } \\
\text { All outcomes }\end{array}$ & Unclear risk & Described as double-blind study \\
\hline $\begin{array}{l}\text { Blinding of outcome as- } \\
\text { sessment (detection bias) } \\
\text { All outcomes }\end{array}$ & Unclear risk & It was reported that for some outcomes assessment was blinded \\
\hline $\begin{array}{l}\text { Incomplete outcome data } \\
\text { (attrition bias) } \\
\text { All outcomes }\end{array}$ & Low risk & $\begin{array}{l}40 \text { women were randomised, } 1 \text { women was not included in the analysis be- } \\
\text { cause of a "protocol violation". } 1 \text { woman that withdrew from the study was in- } \\
\text { cluded in the analysis. }\end{array}$ \\
\hline
\end{tabular}


Blair 2005 (Continued)

Selective reporting (re- Unclear risk Unclear
porting bias)

Other bias Low risk No baseline imbalance apparent

\section{Borglin 1971}

\begin{tabular}{|c|c|}
\hline Methods & RCT, 2-arm parallel groups \\
\hline \multirow[t]{3}{*}{ Participants } & Hospital setting \\
\hline & 199 women: in labour, at term gestation, following normal pregnancy \\
\hline & No inclusion or exclusion criteria reported \\
\hline \multirow[t]{2}{*}{ Interventions } & Experimental: IM pentazocine $20 \mathrm{mg}$ to $40 \mathrm{mg}(\mathrm{N}=91)$ \\
\hline & Control: IM pethidine $50 \mathrm{mg}$ to $100 \mathrm{mg}(\mathrm{N}=89)$ \\
\hline \multirow[t]{2}{*}{ Outcomes } & $\begin{array}{l}\text { Primary: analgesic and sedative effects. Pain assessed at time of birth or when second injection admin- } \\
\text { istered, as very good, good, moderate or none. }\end{array}$ \\
\hline & Secondary: maternal and neonatal side effects \\
\hline \multirow[t]{6}{*}{ Notes } & $\begin{array}{l}\text { If additional analgesia required opioid repeated once after } 3 \text { or }>\text { hrs of first injection. Actual dose re- } \\
\text { ceived by women not reported. }\end{array}$ \\
\hline & Start and end date: unclear \\
\hline & Power calculation: unclear \\
\hline & Baseline imbalances between groups: unclear \\
\hline & Funding source: not specified \\
\hline & Conflicts of interest: not specified \\
\hline
\end{tabular}

\section{Risk of bias}

\begin{tabular}{lll}
\hline Bias & Authors' judgement & Support for judgement \\
\hline $\begin{array}{l}\text { Random sequence genera- } \\
\text { tion (selection bias) }\end{array}$ & Unclear risk & Not reported \\
\hline $\begin{array}{l}\text { Allocation concealment } \\
\text { (selection bias) }\end{array}$ & Unclear risk & Ampoules numbered and in random order \\
\hline $\begin{array}{l}\text { Blinding of participants } \\
\text { and personnel (perfor- } \\
\text { mance bias) }\end{array}$ & Unclear risk & $\begin{array}{l}\text { Reported as double-blind, but no description of how achieved. Identical vol- } \\
\text { All outcomes }\end{array}$ \\
\hline $\begin{array}{l}\text { Blinding of outcome as- } \\
\text { sessment (detection bias) } \\
\text { All outcomes }\end{array}$ & Unclear risk & Not reported \\
\hline $\begin{array}{l}\text { Incomplete outcome data } \\
\text { (attrition bias) }\end{array}$ & Low risk & \\
\hline
\end{tabular}


Borglin 1971 (Continued)

All outcomes

Selective reporting (re- Unclear risk Unclear
porting bias)

Other bias Low risk Balanced at baseline for age, parity, blood pressure, pulse, frequency contractions, FHR, augmented labour, intensity of labour, membranes intact or ruptured.

\section{Campbell 1961}

\begin{tabular}{ll}
\hline Methods & RCT, 3-arm parallel-group design \\
\hline Participants & Setting: hospital in Baltimore, USA \\
& 212 women randomised (141 included in the analyses in this review). \\
& Inclusion criteria: women admitted to hospital for planned vaginal birth, at term, requesting analgesia \\
& (birth under regional anaesthesia) \\
& Exclusions: imminent birth, allergy to any study medication or requiring birth under general anaesthe- \\
& sia
\end{tabular}

Interventions Interventions at $3 \mathrm{~cm}$ to $4 \mathrm{~cm}$ dilatation for primiparous, and $4 \mathrm{~cm}$ to $5 \mathrm{~cm}$ for multiparous women.

Group 1: pentobarbital IV (initial dose $200 \mathrm{mg}$ ) dosage varied

Group 2: pethidine IV (initial dose $100 \mathrm{mg}$ ), (69 women)

Group 3: morphine IV (initial dose $8 \mathrm{mg})$, (72 women)

All 3 groups also received $0.4 \mathrm{mg}$ of scopolamine. If further analgesia was required, women were given a half of the initial dose and $0.2 \mathrm{mg}$ of scopolamine. If more than 2 additional doses were required analgesia was at the discretion of the attending doctor.

In this review we have included groups 2 and 3 only in the analyses; pentobarbital (a barbiturate) is no longer used for pain relief in labour.

Outcomes Length of labour, amount of analgesia required, obstetric complications and neonatal condition (Apgar score at $1 \mathrm{~min}$ ). Maternal perceptions were recorded 3 days after birth (satisfaction and amnesia). A focus of this paper was the perception of staff on whether women were "manageable". Unmanageable women were those who were "possibly dangerous to others or themselves, perhaps by leaving her bed". Staff had the option of removing unmanageable women from the study and prescribing whatever medication was deemed suitable.

Notes $\quad$ All women included delivered under regional anaesthesia.

Start and end date: not reported

Power calculation: not specified

Baseline imbalances between groups: unclear

Funding source: not specified

Conflicts of interest: not specified

\section{Risk of bias}


Campbell 1961 (Continued)

\begin{tabular}{|c|c|c|}
\hline Bias & Authors' judgement & Support for judgement \\
\hline $\begin{array}{l}\text { Random sequence genera- } \\
\text { tion (selection bias) }\end{array}$ & Unclear risk & Quote: "in a random manner." \\
\hline $\begin{array}{l}\text { Allocation concealment } \\
\text { (selection bias) }\end{array}$ & Low risk & Coded vials containing study drugs were provided by pharmacy. \\
\hline $\begin{array}{l}\text { Blinding of participants } \\
\text { and personnel (perfor- } \\
\text { mance bias) } \\
\text { All outcomes }\end{array}$ & Low risk & $\begin{array}{l}\text { Quote: "None of the personnel concerned with the administration of the drugs } \\
\text { or the evaluation of the patients' reaction had access to the master list at any } \\
\text { time." }\end{array}$ \\
\hline $\begin{array}{l}\text { Blinding of outcome as- } \\
\text { sessment (detection bias) } \\
\text { All outcomes }\end{array}$ & Low risk & $\begin{array}{l}\text { Quote: "None of the personnel concerned with the administration of the drugs } \\
\text { or the evaluation of the patients' reaction had access to the master list at any } \\
\text { time." }\end{array}$ \\
\hline $\begin{array}{l}\text { Incomplete outcome data } \\
\text { (attrition bias) } \\
\text { All outcomes }\end{array}$ & Unclear risk & $\begin{array}{l}\text { All women appear to be accounted for in the analysis and there were few miss- } \\
\text { ing data. The data regarding babies were less clear, denominators were not } \\
\text { provided. }\end{array}$ \\
\hline $\begin{array}{l}\text { Selective reporting (re- } \\
\text { porting bias) }\end{array}$ & High risk & $\begin{array}{l}\text { Results were not provided for babies. There was a statement in the text "there } \\
\text { were few infant complications in the neonatal period; none of these appeared } \\
\text { related to the drugs". }\end{array}$ \\
\hline Other bias & Unclear risk & Baseline characteristics described as similar. \\
\hline
\end{tabular}

\section{De Boer 1987}

\begin{tabular}{|c|c|}
\hline Methods & $\mathrm{RCT}$, 2-arm parallel groups \\
\hline \multirow[t]{3}{*}{ Participants } & Setting: hospital, UK \\
\hline & $\begin{array}{l}46 \text { women ( } 20 \text { primiparous and } 14 \text { multiparous women included in the analyses). Uncomplicated preg- } \\
\text { nancy. }\end{array}$ \\
\hline & $\begin{array}{l}\text { Exclusions: first stage of labour }>12 \mathrm{hr} \text {, second stage }>1 \mathrm{hr} \text {, body weight }<45 \mathrm{~kg} \text {, multiple pregnancy, } \\
\text { non-vertex presentation, preterm or postmature labour, previous caesarean section, birthweight out- } \\
\text { side the } 5 \text { th and 95th centiles for gestational age, congenital fetal abnormality. }\end{array}$ \\
\hline \multirow[t]{2}{*}{ Interventions } & $\begin{array}{l}\text { Experimental: IM meptazinol } 1.5 \mathrm{mg} / \mathrm{kg} \text { body weight plus } 10 \mathrm{mg} \text { metoclopramide hydrochloride }(\mathrm{N}= \\
\text { 17) }\end{array}$ \\
\hline & Control: IM pethidine $1.5 \mathrm{mg} / \mathrm{kg}$ body weight plus $10 \mathrm{mg}$ metoclopramide hydrochloride $(\mathrm{N}=17)$ \\
\hline Outcomes & $\begin{array}{l}\text { Neonatal acid-base balance. Maternal pH pre injection, repeated at head crowning, neonatal } \mathrm{pH} \text { at } 10 \\
\text { and } 60 \text { mins PN. }\end{array}$ \\
\hline \multirow[t]{5}{*}{ Notes } & $\begin{array}{l}\text { If additional analgesia required opioid repeated }>3 \text {-hourly. Actual dose received by women not report- } \\
\text { ed. }\end{array}$ \\
\hline & Start and end date: not reported \\
\hline & Power calculation: not specified \\
\hline & Baseline imbalances between groups: unclear \\
\hline & Funding source: not specified \\
\hline
\end{tabular}


De Boer 1987 (Continued)

Conflicts of interest: not specified

\section{Risk of bias}

\begin{tabular}{|c|c|c|}
\hline Bias & Authors' judgement & Support for judgement \\
\hline $\begin{array}{l}\text { Random sequence genera- } \\
\text { tion (selection bias) }\end{array}$ & Unclear risk & Not reported \\
\hline $\begin{array}{l}\text { Allocation concealment } \\
\text { (selection bias) }\end{array}$ & Unclear risk & Not reported \\
\hline $\begin{array}{l}\text { Blinding of participants } \\
\text { and personnel (perfor- } \\
\text { mance bias) } \\
\text { All outcomes }\end{array}$ & Unclear risk & States double-blind but not described. \\
\hline $\begin{array}{l}\text { Blinding of outcome as- } \\
\text { sessment (detection bias) } \\
\text { All outcomes }\end{array}$ & Unclear risk & States double-blind but not described. \\
\hline $\begin{array}{l}\text { Incomplete outcome data } \\
\text { (attrition bias) } \\
\text { All outcomes }\end{array}$ & High risk & 12 women excluded from analysis, reasons for all exclusions not explained. \\
\hline $\begin{array}{l}\text { Selective reporting (re- } \\
\text { porting bias) }\end{array}$ & High risk & $\begin{array}{l}\text { Reasons why some participant data excluded not explained. } 3 / 12 \text { excluded be- } \\
\text { cause problem with } \mathrm{pH} \text { analyser (meptazinol group). }\end{array}$ \\
\hline Other bias & Low risk & No baseline imbalances \\
\hline
\end{tabular}

Direkvand-Moghadam 2014

\begin{tabular}{ll}
\hline Methods & Randomised clinical trial using individual randomisation. \\
\hline Participants & Setting: hospital in Iran \\
90 women randomised: nulli-parous, aged between 18 and 35 years, singleton pregnancy, spontaneous \\
active labour, cervical dilation between $4 \mathrm{~cm}$ and $5 \mathrm{~cm}$, gestational age between 38 and 40 weeks, nor- \\
mal FHR tracings, intact membranes, and vertex presentation. \\
Exclusion criteria: elective labour induction, emergency caesarean delivery, known cephalopelvic dis- \\
proportion, diagnosed pre eclampsia, chorioamnionitis, pyelonephritis, maternal cardiac, renal dis- \\
ease, intrauterine growth restriction and cervical dilation greater than $5 \mathrm{~cm}$.
\end{tabular}

Interventions

Experimental group: pethidine $50 \mathrm{mg} I \mathrm{M}$ - no further detail given. Not clear if it was given as requested or to all women or whether women could request a subsequent dose. $(N=45)$.

Control group: normal saline IV same volume as pethidine. $(\mathrm{N}=45)$.

Amniotomy was performed by a trained midwife when cervical dilation reached $5 \mathrm{~cm}$ if the membranes had not ruptured spontaneously.

$\begin{array}{ll}\text { Outcomes } & \text { Mode of birth } \\ & \text { Duration of active phase }\end{array}$

Notes

Start and end date: December 2012 to March 2014 
Direkvand-Moghadam 2014 (Continued)

Funding: not stated

Col: reported no conflicts of interest

\section{Risk of bias}

\begin{tabular}{lll}
\hline Bias & Authors' judgement & Support for judgement \\
\hline $\begin{array}{l}\text { Random sequence genera- } \\
\text { tion (selection bias) }\end{array}$ & Low risk & $\begin{array}{l}\text { Randomisation was carried out in the obstetric triage unit using a ran- } \\
\text { dom-number chart. }\end{array}$ \\
\hline $\begin{array}{l}\text { Allocation concealment } \\
\text { (selection bias) }\end{array}$ & Unclear risk & Method of concealment not described. \\
\hline $\begin{array}{l}\text { Blinding of participants } \\
\begin{array}{l}\text { and personnel (perfor- } \\
\text { mance bias) } \\
\text { All outcomes }\end{array}\end{array}$ & High risk & $\begin{array}{l}\text { Equal volumes of normal saline and pethidine given but by different routes. } \\
\text { Likely that caregiver would realise allocation. Participants likely to be aware of } \\
\text { treatment. }\end{array}$ \\
\hline
\end{tabular}

Blinding of outcome as- High risk sessment (detection bias)

All outcomes
Labour outcomes were collected by caregiver.

\begin{tabular}{|c|c|c|}
\hline $\begin{array}{l}\text { Incomplete outcome data } \\
\text { (attrition bias) } \\
\text { All outcomes }\end{array}$ & Unclear risk & $\begin{array}{l}\text { Reported that none of the } 90 \text { enrolled women withdrew for any reason. Data } \\
\text { reported for all women. However not all data are reported in absolute num- } \\
\text { bers and denominators and results are not clear for Apgar scores or neonatal } \\
\text { admission to intensive care. }\end{array}$ \\
\hline
\end{tabular}

\begin{tabular}{|c|c|c|}
\hline $\begin{array}{l}\text { Selective reporting (re- } \\
\text { porting bias) }\end{array}$ & Unclear risk & $\begin{array}{l}\text { Protocol not available. Outcomes are not clearly pre-specified. It was not clear } \\
\text { which outcomes the power calculation related to. Important outcomes were } \\
\text { not reported. }\end{array}$ \\
\hline
\end{tabular}

Other bias Unclear risk Similar baseline characteristics. Generally poorly reported.

\section{Douma 2010}

\begin{tabular}{|c|c|}
\hline Methods & RCT, 3-arm parallel groups \\
\hline \multirow[t]{4}{*}{ Participants } & Setting: the Netherlands, Department of Obstetrics and Gynaecology \\
\hline & 180 enrolled, 159 completed the study. \\
\hline & $\begin{array}{l}\text { Inclusion criteria: healthy ASA physical status I or II term parturients in an active stage of labour, with } \\
\text { singleton cephalic presentation, without prior administration of opioid analgesics. }\end{array}$ \\
\hline & $\begin{array}{l}\text { Exclusion criteria: obesity (BMI } \geq 40 \mathrm{~kg} \mathrm{~m}^{-2} \text { ), opioid allergy, substance abuse history, and high-risk pa- } \\
\text { tients (pre-eclampsia, severe asthma, insulin-dependent diabetes mellitus, hepatic insufficiency, or re- } \\
\text { nal failure). }\end{array}$ \\
\hline \multirow[t]{3}{*}{ Interventions } & $\begin{array}{l}\text { 1. Remifentanil, patient controlled IV, } 40 \mu \mathrm{g} \text { loading dose, remifentanil } 40 \mu \mathrm{g} \text { per bolus with a lockout of } \\
2 \text { mins and max dose limit of } 1200 \mu \mathrm{g} \mathrm{h}-1\end{array}$ \\
\hline & $\begin{array}{l}\text { 2. Meperidine, patient controlled IV, } 49.5 \mathrm{mg} \text { loading dose and } 5 \mathrm{mg} \text { bolus with lockout of } 10 \mathrm{mins} \text { and } \\
\text { max dose limit of } 200 \mathrm{mg}\end{array}$ \\
\hline & $\begin{array}{l}\text { 3. Fentanyl, patient controlled IV, } 50 \mu \mathrm{g} \text { loading dose and } 20 \mu \mathrm{g} \text { bolus with lockout of } 5 \text { mins and a max } \\
\text { dose limit of } 240 \mu \mathrm{g} \mathrm{h}-1\end{array}$ \\
\hline
\end{tabular}


Douma 2010 (Continued)

Outcomes
Outcomes: pain scores (VAS) every hr; sedation score ( 1 awake, 2 sleepy, 3 eyes closed, 4 eyes closed but rousable, 5 unrousable; overall satisfaction on 10-point scale $2 \mathrm{hrs}$ after delivery; side effects - nausea,vomiting, itching; Apgar scores at 1 min, 5 mins; cord blood gas analysis; NACS scores at 15 mins and $2 \mathrm{hrs}$ after delivery; oxytocin use; instrumental delivery; CS; spontaneous delivery.

Notes
Quote: "All women received similar instructions on how to use the PCA device: all parturients were instructed to press the bolus button whenever they needed pain relief."

Start and end date: not reported

Power calculation: 'For sample size calculation, we hypothesized that average pain scores in the remifentanil or fentanyl group would differ at least $10 \%$ from the meperidine group. Assuming an SD of $15 \mathrm{~mm}$ based on the previous studies, we calculated a sample size of 60 parturients per group for a power of 0.95 and a two-sided a level of 0.05 to detect this difference'.

Baseline imbalances between groups: 'The characteristics of the parturients did not differ statistically.'

Funding source: Bronovo Research Fund

Conflicts of interest: not specified

\section{Risk of bias}

\begin{tabular}{lll}
\hline Bias & Authors' judgement & Support for judgement \\
\hline $\begin{array}{l}\text { Random sequence genera- } \\
\text { tion (selection bias) }\end{array}$ & Low risk & $\begin{array}{l}\text { Quote: "Established using a computer generated random sequence in num- } \\
\text { bered envelopes." }\end{array}$ \\
\hline $\begin{array}{l}\text { Allocation concealment } \\
\text { (selection bias) }\end{array}$ & Low risk & Quote: "Study medication was prepared and blinded by hospital pharmacy." \\
\hline $\begin{array}{l}\text { Blinding of participants } \\
\text { and personnel (perfor- } \\
\text { mance bias) } \\
\text { All outcomes }\end{array}$ & Low risk & $\begin{array}{l}\text { Quote: "Observants and medical personnel attending to the parturient were } \\
\text { unaware of the drug assignment." }\end{array}$ \\
\hline
\end{tabular}

\begin{tabular}{|c|c|c|}
\hline $\begin{array}{l}\text { Blinding of outcome as- } \\
\text { sessment (detection bias) } \\
\text { All outcomes }\end{array}$ & Low risk & $\begin{array}{l}\text { Quote: "with exception of baseline data, all observations and measurements } \\
\text { were made by blinded observers." }\end{array}$ \\
\hline
\end{tabular}

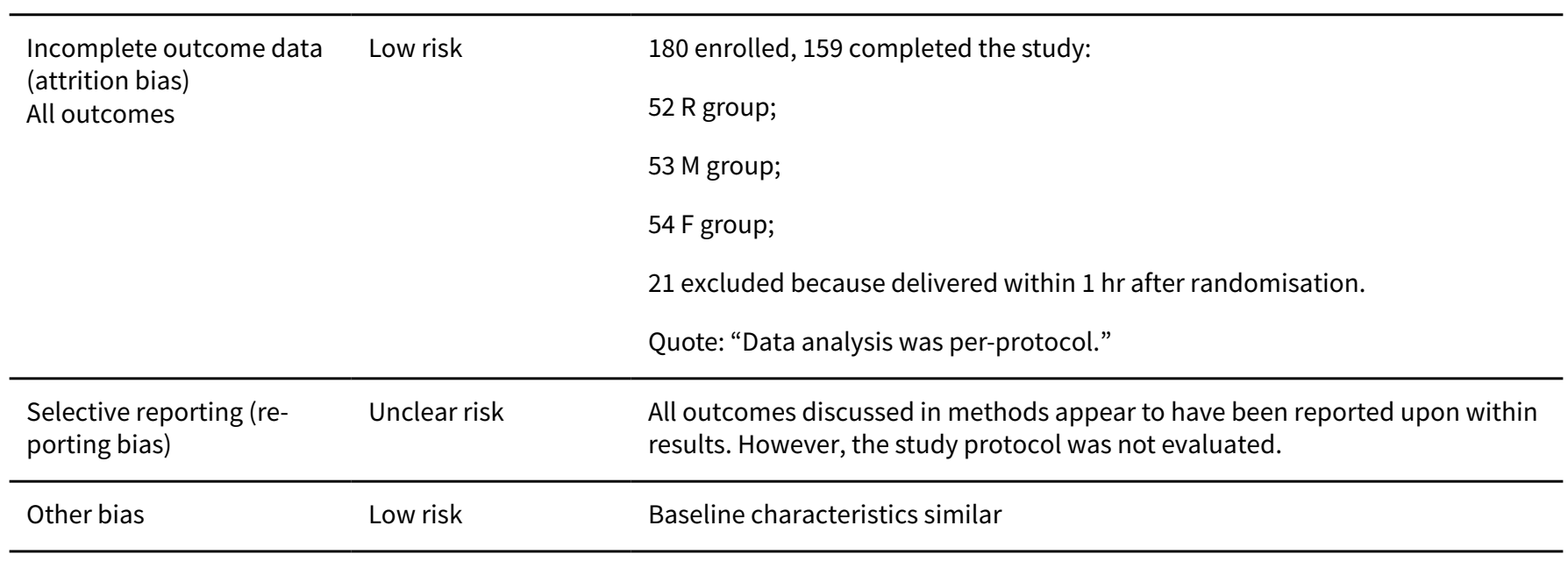


Duncan 1969

\begin{tabular}{|c|c|}
\hline Methods & RCT, 2-arm parallel groups \\
\hline Participants & $\begin{array}{l}\text { Setting: hospital, UK } \\
200 \text { women. } 66 \% \text { primips, 34\% multips, > } 35 \text { weeks' gestation. Singleton, uncomplicated pregnancy. } \\
\text { Exclusions: toxaemia, chronic medical disease, isoimmunisation, obstetric complication }\end{array}$ \\
\hline Interventions & $\begin{array}{l}\text { Experimental: IM pentazocine } 48 \mathrm{mg}(\mathrm{N}=100) \\
\text { Control: IM pethidine } 120 \mathrm{mg}(\mathrm{N}=100) \\
\text { Nalorphine hydrobromide + methylphenidate given if opioid administered within } 2 / 24 \text { of second stage } \\
\text { diagnosis and, or fetal distress. }\end{array}$ \\
\hline Outcomes & $\begin{array}{l}\text { Primary outcome: analgesic effects: pain assessed at time of injection and every } 30 \text { mins for } 4 \text { hrs. Se- } \\
\text { vere or moderate pain. Pain relief complete, partial or none. } \\
\text { Secondary outcomes: maternal: vomiting, blood pressure and pulse. Neonatal: Apgar at } 1 \text { min in babies } \\
\text { born within } 4 \text { hrs of opioid. }\end{array}$ \\
\hline Notes & $\begin{array}{l}\text { If additional analgesia required opioid repeated after } 4 \text { hrs. As inclusion criteria > } 35 \text { weeks' gestation, } \\
\text { may include preterm infants. } \\
\text { Start and end date: not reported } \\
\text { Power calculation: not specified } \\
\text { Baseline imbalances between groups: the } 100 \text { women given each drug was comparable in respect of } \\
\text { age, parity, height, last antenatal weight and blood pressure, attendance at preparation classes, and } \\
\text { infant weight. } \\
\text { Funding source: drug - Pentazocine was supplied by Bayer products } \\
\text { Conflicts of interest: not specified }\end{array}$ \\
\hline
\end{tabular}

\section{Risk of bias}

\begin{tabular}{|c|c|c|}
\hline Bias & Authors' judgement & Support for judgement \\
\hline $\begin{array}{l}\text { Random sequence genera- } \\
\text { tion (selection bias) }\end{array}$ & Unclear risk & Not reported \\
\hline $\begin{array}{l}\text { Allocation concealment } \\
\text { (selection bias) }\end{array}$ & Unclear risk & Not reported \\
\hline $\begin{array}{l}\text { Blinding of participants } \\
\text { and personnel (perfor- } \\
\text { mance bias) } \\
\text { All outcomes }\end{array}$ & Unclear risk & States "double blind" but does not report how achieved. \\
\hline $\begin{array}{l}\text { Blinding of outcome as- } \\
\text { sessment (detection bias) } \\
\text { All outcomes }\end{array}$ & Unclear risk & States "double blind" but does not report how achieved. \\
\hline $\begin{array}{l}\text { Incomplete outcome data } \\
\text { (attrition bias) } \\
\text { All outcomes }\end{array}$ & High risk & $\begin{array}{l}200 \text { women randomised. Exclusion of women from analyses if inadequacy of } \\
\text { records, reached second stage before analgesic assessment, operative birth } \\
\text { or another intervention. Exclusion of babies from Apgar analysis if additional } \\
\text { analgesia given, GA, antidote given to mother pre-birth or clinical explanation } \\
\text { for depressed baby. Denominators for outcomes not clear. }\end{array}$ \\
\hline
\end{tabular}


Duncan 1969 (Continued)

Selective reporting (re- Unclear risk Unclear
porting bias)

Other bias

Unclear risk

Balanced at baseline for age, parity, height, weight, blood pressure, attendance at antenatal classes and infant weight.

El-Refaie 2012

\begin{tabular}{ll}
\hline Methods & RCT, 2-arm parallel groups \\
\hline Participants & Setting: Ain Shams University Maternity Hospital, Egypt \\
& 240 women randomised \\
& Inclusion criteria: healthy, nulliparous, women aged between 18 and 30 years, at term ( $37-42$ weeks of \\
& gestation) with a single fetus in vertex presentation, and diagnosed with prolonged labour due to uter- \\
ine dystocia during the first stage of labour with a cervical dilatation of $4 \mathrm{~cm}$ to $6 \mathrm{~cm}$. (Uterine dysto- \\
cia was defined as crossing of the alert line on the partogram without abnormal fetal presentation or \\
cephalopelvic disproportion.) \\
Exclusion criteria: meperidine allergy, any contraindication for vaginal delivery, labour induction, use \\
of oxytocin or any type of analgesia prior to randomisation, maternal request of pain relief, fetal death, \\
or evidence of fetal distress.
\end{tabular}

Interventions

Experimental: Meperidine - single dose of $50 \mathrm{mg}$ meperidine in $10 \mathrm{~mL}$ of isotonic saline by slow intravenous administration over 2 mins (50 mg pethidine, 2-mL solution; Misr Pharmaceutics, Cairo, Egypt) $(\mathrm{N}=120)$.

Control: placebo - $10 \mathrm{~mL}$ of isotonic saline supplied in identical vials. $(\mathrm{N}=120)$.

Outcomes

Primary outcomes: (i) duration of labour (from the time of the beginning of the intervention to the time of expulsion of the fetal head) and (ii) neonatal acid-base balance in arterial and venous.

umbilical cord blood samples at birth.

Secondary outcomes: severity of labour pain, as assessed by the $10-\mathrm{cm}$ visual analogue scale (VAS) score ( 0 defined as no pain) before the intervention and 15, 30, and 60 mins after drug or placebo administration, and during the second stage of labour; maternal adverse effects; requirement for oxytocin augmentation after intervention; mode of delivery; and Apgar score at 1 and 5 mins.

Notes

When labour crossed the alert line on partograph, women were randomised and oxytocin commenced.

Start and end date: July 2007 and October 2009

Power calculation: 'The sample size was calculated using a power of $80 \%$, an alpha of 0.05 , expected 60-min reduction in the length of labour, and assumed standard deviation of 158 mins based on a previous report of the length of labor in a population of women similar to our population. A sample size of 220 women was calculated to be necessary on the basis of these assumptions.'

Baseline imbalances between groups: 'There were no significant differences between the two groups with regard to maternal age, body mass index, gestational age at delivery, cervical dilatation and length before intervention, and VAS score before drug or placebo administration'.

Funding source: not reported

Conflicts of interest: not reported

\section{Risk of bias}


El-Refaie 2012 (Continued)

\begin{tabular}{lll} 
Bias & Authors' judgement & Support for judgement \\
\hline $\begin{array}{l}\text { Random sequence genera- } \\
\text { tion (selection bias) }\end{array}$ & Low risk & Computer-generated sequence \\
\hline $\begin{array}{l}\text { Allocation concealment } \\
\text { (selection bias) }\end{array}$ & Low risk & $\begin{array}{l}\text { Randomisation codes were placed in sequentially-numbered, opaque, sealed } \\
\text { envelopes to be opened at time of enrolment by a nurse who prepared the } \\
\text { study drug and had no further involvement with the care of the participants. }\end{array}$
\end{tabular}

\begin{tabular}{ll}
\hline $\begin{array}{l}\text { Blinding of participants } \\
\begin{array}{l}\text { and personnel (perfor- } \\
\text { mance bias) }\end{array}\end{array}$ & $\begin{array}{l}\text { The study is described as double-blind, placebo trial. If the neonatologists } \\
\text { needed to know the administered intervention to manage a neonatal side ef- } \\
\text { All outcomes }\end{array}$ \\
\end{tabular}

\begin{tabular}{lll}
\hline $\begin{array}{l}\text { Blinding of outcome as- } \\
\text { sessment (detection bias) } \\
\text { All outcomes }\end{array}$ & Unclear risk & Not reported \\
\hline $\begin{array}{l}\text { Incomplete outcome data } \\
\text { (attrition bias) } \\
\text { All outcomes }\end{array}$ & Low risk & $\begin{array}{l}\text { There was no loss to follow-up and all women reportedly received their allo- } \\
\text { cated intervention. }\end{array}$ \\
\hline $\begin{array}{l}\text { Selective reporting (re- } \\
\text { porting bias) }\end{array}$ & Unclear risk & All outcomes described in methods appear to be reported. \\
\hline Other bias & Unclear risk & $\begin{array}{l}\text { Similar baseline characteristics. Some lack of clarity in results, e.g. unclear if } \\
\text { labour durations include women who had a caesarean. }\end{array}$ \\
\hline
\end{tabular}

Erskine 1985

\begin{tabular}{ll}
\hline Methods & RCT 2-arm parallel-group design \\
\hline Participants & Setting: Cape Town, South Africa \\
& $\begin{array}{l}29 \text { women in established labour, not clear how many primips, mean age 24 years, women were expect- } \\
\text { ed to have a vaginal birth and have no antenatal medical or obstetric problems. }\end{array}$
\end{tabular}

\begin{tabular}{ll}
\hline Interventions & Experimental: pethidine, IV PCA 10-min lock out, $0.3 \mathrm{mg}$ per kg. \\
& Control: pentazocine, IV PCA 10-min lock out, $0.15 \mathrm{mg}$ per kg. \\
\hline
\end{tabular}

Outcomes Pain relief in labour (assessed by midwife); pain relief (measured immediately after labour (10 cm VAS) and 24 hrs postpartum from mother); satisfaction with pain relief; maternal and neonatal serum samples; Apgar score at $1 \mathrm{~min}$ and 5 mins; infant weight; neuro-behavioural examination on 1st and 5th day.

\section{Notes} The study also included a non-randomised control group; we have not included this group in the analysis.

Start and end date: not reported

Power calculation: not specified

Baseline imbalances between groups: unclear

Funding source: not specified 
Erskine 1985 (Continued)

Conflicts of interest: not specified

\section{Risk of bias}

\begin{tabular}{|c|c|c|}
\hline Bias & Authors' judgement & Support for judgement \\
\hline $\begin{array}{l}\text { Random sequence genera- } \\
\text { tion (selection bias) }\end{array}$ & Low risk & Random number table \\
\hline $\begin{array}{l}\text { Allocation concealment } \\
\text { (selection bias) }\end{array}$ & Unclear risk & Not described \\
\hline $\begin{array}{l}\text { Blinding of participants } \\
\text { and personnel (perfor- } \\
\text { mance bias) } \\
\text { All outcomes }\end{array}$ & Unclear risk & $\begin{array}{l}\text { It was reported that women were attended by the same midwife throughout } \\
\text { labour who was not informed what medication women received. It is not clear } \\
\text { whether this blinding was achieved for all staff. }\end{array}$ \\
\hline $\begin{array}{l}\text { Blinding of outcome as- } \\
\text { sessment (detection bias) } \\
\text { All outcomes }\end{array}$ & Unclear risk & $\begin{array}{l}\text { Outcome assessors of neonatal outcomes were reported to be blind to group } \\
\text { allocation. }\end{array}$ \\
\hline $\begin{array}{l}\text { Incomplete outcome data } \\
\text { (attrition bias) } \\
\text { All outcomes }\end{array}$ & Unclear risk & $\begin{array}{l}\text { Overall attrition not clear, there were some missing data for some outcomes. } \\
\text { Denominators were not provided in all of the results tables. }\end{array}$ \\
\hline $\begin{array}{l}\text { Selective reporting (re- } \\
\text { porting bias) }\end{array}$ & Unclear risk & Unclear \\
\hline Other bias & Unclear risk & No baseline imbalance apparent \\
\hline
\end{tabular}

Fairlie 1999

\begin{tabular}{ll}
\hline Methods & RCT 2-arm parallel-group design \\
\hline Participants & Setting: hospital, UK \\
& $\begin{array}{l}161 \text { women randomised, data available for } 133 \text { women. } 52 \% \text { primips, } 48 \% \text { multips, cx at least } 3 \mathrm{~cm} \text { di- } \\
\text { lated, } 37 \text { or }>\text { weeks' gestation in spontaneous or induced labour (induction by amniotomy and IV infu- } \\
\text { sion oxytocin). }\end{array}$
\end{tabular}

Interventions

Experimental: IM diamorphine $7.5 \mathrm{mg}$ (primips), $5 \mathrm{mg}$ (multips) plus $12.5 \mathrm{mg}$ prochlorperazine $(\mathrm{N}=65)$

Control: IM pethidine $150 \mathrm{mg}$ (primips), $100 \mathrm{mg}$ (multips) plus $12.5 \mathrm{mg}$ prochlorperazine $(\mathrm{N}=68)$

\section{Outcomes}

Primary outcome: maternal pain at $1 \mathrm{hr}$ VAS $(0-100)$, pain intensity $(0=$ no pain, $1=$ mild pain, $2=$ moderate pain, $3=$ severe pain), pain relief $(0=$ none, $1=$ slight, $2=$ moderate, $3=$ good, $4=$ complete $)$.

Secondary outcomes: maternal: vomiting, sedation, global analgesia assessment at $24 \mathrm{hr}$ (good or poor). Neonatal: Apgar at $1 \mathrm{~min}$ and 5 mins, resuscitation, naloxone administration, SCBU admission, significant morbidity (seizures, respiratory distress, intraventricular haemorrhage, necrotising enterocolitis).

\section{Notes}

Second dose at maternal request: her choice of drug or epidural. Stratified by maternal parity. Trial stopped early after recruitment of 150 women. Planned sample size was 200 women.

Start and end date: May 1990 - February 1992

Power calculation: not specified 
Fairlie 1999 (Continued)

Baseline imbalances between groups: unclear

Funding source: not specified

Conflicts of interest: not specified

\section{Risk of bias}

\begin{tabular}{|c|c|c|}
\hline Bias & Authors' judgement & Support for judgement \\
\hline $\begin{array}{l}\text { Random sequence genera- } \\
\text { tion (selection bias) }\end{array}$ & Unclear risk & Block sizes of 6 \\
\hline $\begin{array}{l}\text { Allocation concealment } \\
\text { (selection bias) }\end{array}$ & Low risk & Coded drug containers, randomisation code not broken until analysis. \\
\hline $\begin{array}{l}\text { Blinding of participants } \\
\text { and personnel (perfor- } \\
\text { mance bias) } \\
\text { All outcomes }\end{array}$ & Low risk & States double-blind, drug containers identical in appearance. \\
\hline $\begin{array}{l}\text { Blinding of outcome as- } \\
\text { sessment (detection bias) } \\
\text { All outcomes }\end{array}$ & Low risk & $\begin{array}{l}\text { It was stated that the randomisation code was not broken until the analysis } \\
\text { stage. }\end{array}$ \\
\hline $\begin{array}{l}\text { Incomplete outcome data } \\
\text { (attrition bias) } \\
\text { All outcomes }\end{array}$ & High risk & $28(17 \%)$ excluded as delivered within $1 \mathrm{hr}$ of administration of study drug. \\
\hline $\begin{array}{l}\text { Selective reporting (re- } \\
\text { porting bias) }\end{array}$ & Unclear risk & Unclear \\
\hline Other bias & Low risk & Balanced at baseline \\
\hline
\end{tabular}

Fieni 2000

\begin{tabular}{ll}
\hline Methods & RCT 2-arm parallel-group design \\
\hline Participants & Italy: hospital care setting \\
& 40 women. Full-term pregnancy, $c x \geq 4 \mathrm{~cm}$, in spontaneous active labour and requiring analgesia.
\end{tabular}

Interventions

Experimental: IM tramadol $100 \mathrm{mg}(\mathrm{N}=20)$

Control: IM pethidine $75 \mathrm{mg}(\mathrm{N}=20)$

Outcomes

Primary outcome: maternal pain relief and acceptability. Pain assessed hourly up to 5 hrs, VAS 1-3.

Secondary outcomes: maternal: observations (pulse, BP, respiratory rate, arterial oxygen saturation). Neonatal: Apgar at $1 \mathrm{~min}$ and 5 mins. Umbilcal cord $\mathrm{pH}$.

Notes

Second dose of study drug allowed after 2 hrs as required. Italian language, translation obtained. Data were presented in a way in which we were not able to incorporate them into data tables in RevMan.

Start and end date: unclear

Power calculation: unclear 
Fieni 2000 (Continued)

Baseline imbalances between groups: unclear

Funding source: unclear

Conflicts of interest: unclear

\section{Risk of bias}

\begin{tabular}{lll}
\hline Bias & Authors' judgement & Support for judgement \\
\hline $\begin{array}{l}\text { Random sequence genera- } \\
\text { tion (selection bias) }\end{array}$ & Low risk & Computer generated \\
\hline $\begin{array}{l}\text { Allocation concealment } \\
\text { (selection bias) }\end{array}$ & Unclear risk & Not reported \\
\hline
\end{tabular}

Blinding of participants $\quad$ Unclear risk $\quad$ Not reported
and personnel (perfor-
mance bias)

\begin{tabular}{lll}
\hline $\begin{array}{l}\text { Blinding of outcome as- } \\
\text { sessment (detection bias) } \\
\text { All outcomes }\end{array}$ & Unclear risk & Not reported \\
\hline $\begin{array}{l}\text { Incomplete outcome data } \\
\text { (attrition bias) } \\
\text { All outcomes }\end{array}$ & Unclear risk & Unclear how many women analysed as only percentages reported. \\
\hline $\begin{array}{l}\text { Selective reporting (re- } \\
\text { porting bias) }\end{array}$ & Unclear risk & Unclear \\
\hline $\begin{array}{l}\text { Other bias } \\
\text { High risk }\end{array}$ & No baseline characteristics table - unclear re maternal parity. \\
& & $\begin{array}{l}\text { Likely response bias as no information on whom women reported to about } \\
\text { their pain post injection. }\end{array}$
\end{tabular}

Frank 1987

\begin{tabular}{ll}
\hline Methods & RCT 2-arm parallel-group design \\
\hline Participants & Setting: London hospital, UK \\
& 60 healthy women at term (38-42 weeks) requiring pain relief in labour. \\
& $\begin{array}{l}\text { Women requesting epidural, that had already received opioid analgesia, were receiving treatment for } \\
\text { depression or where the fetus was at risk were excluded }\end{array}$
\end{tabular}

Interventions $\quad$ Experimental: (30 women) nalbuphine, $3 \mathrm{mg}$ with $3 \mathrm{mg}$ increments to a max of $18 \mathrm{mg}$ per hr; lockout time 10 mins (total max dose $=42 \mathrm{mg}$ ).

Control: (30 women) pethidine, $15 \mathrm{mg}, 15 \mathrm{mg}$ increments to a max of $90 \mathrm{mg}$ per hr; lockout time 10 mins (total max dose $=210 \mathrm{mg}$ ).

Entonox ${ }^{\circledR}$ was available to women in both groups but was withheld for 30 mins for analgesia assessment. Analgesia was stopped in the 2 nd stage if there were side effects or if the woman requested an alternative method. 
Frank 1987 (Continued)

Outcomes

Pain (measured on 5-point scale from 1- no pain to 5 - very severe); pain relief (assessed 1 day after birth; pain relief rated as good or excellent and women saying they would use the same method again); sedation (1 awake, 3 asleep); neuro-behavioural assessment 6 to 10 hrs after birth; FHR.
Start and end date: not reported

Power calculation: not specified

Baseline imbalances between groups: unclear

Funding source: Dupont (UK) Ltd

Conflicts of interest: not specified

\section{Risk of bias}

\begin{tabular}{|c|c|c|}
\hline Bias & Authors' judgement & Support for judgement \\
\hline $\begin{array}{l}\text { Random sequence genera- } \\
\text { tion (selection bias) }\end{array}$ & Unclear risk & Quote: "randomly allocated." \\
\hline $\begin{array}{l}\text { Allocation concealment } \\
\text { (selection bias) }\end{array}$ & Unclear risk & Described as double-blind but allocation concealment was not described. \\
\hline $\begin{array}{l}\text { Blinding of participants } \\
\text { and personnel (perfor- } \\
\text { mance bias) } \\
\text { All outcomes }\end{array}$ & Unclear risk & Very little information. Described as double-blind. \\
\hline $\begin{array}{l}\text { Blinding of outcome as- } \\
\text { sessment (detection bias) } \\
\text { All outcomes }\end{array}$ & Unclear risk & Unclear \\
\hline $\begin{array}{l}\text { Incomplete outcome data } \\
\text { (attrition bias) } \\
\text { All outcomes }\end{array}$ & Unclear risk & $\begin{array}{l}\text { There were some outcome data for all but one of the women randomised, but } \\
\text { there were high levels of missing data for some neonatal outcomes (e.g. neu- } \\
\text { rological infant assessments } 40 / 60 \text { babies available for analysis). }\end{array}$ \\
\hline $\begin{array}{l}\text { Selective reporting (re- } \\
\text { porting bias) }\end{array}$ & Unclear risk & Unclear \\
\hline Other bias & Unclear risk & $\begin{array}{l}\text { There was some baseline imbalance; } 6 / 30 \text { in the nalbuphine group were mul- } \\
\text { tiparous compared with } 12 / 30 \text { in the pethidine group. The authors report that } \\
\text { they took this into account in the analysis. In this review data have not been } \\
\text { adjusted for baseline imbalance. }\end{array}$ \\
\hline
\end{tabular}

\section{Giannina 1995}

\begin{tabular}{ll}
\hline Methods & RCT, 2-arm parallel groups \\
\hline Participants & New Jersey USA, hospital setting, 1994 \\
& 28 women in labour ( 36 randomised) with uncomplicated pregnancies, singleton, vertex presentation, \\
at term ( 37 to 41 weeks), 4 cm or less cervical dilatation, at least 3 contractions in 10 mins, no known \\
maternal or fetal conditions that would affect FHR tracings, fetal reactive, no medications that would \\
affect FHR in the previous 2 weeks.
\end{tabular}


Giannina 1995 (Continued)

Exclusions criteria: meconium staining, pregnancy-induced hypertension, fetal tachy- or brady-cardia, arrhythmias or decelerations, chorioamnionitis, FGR, abnormal placenta, maternal fever, fetal chromosomal disorder of structural abnormality.

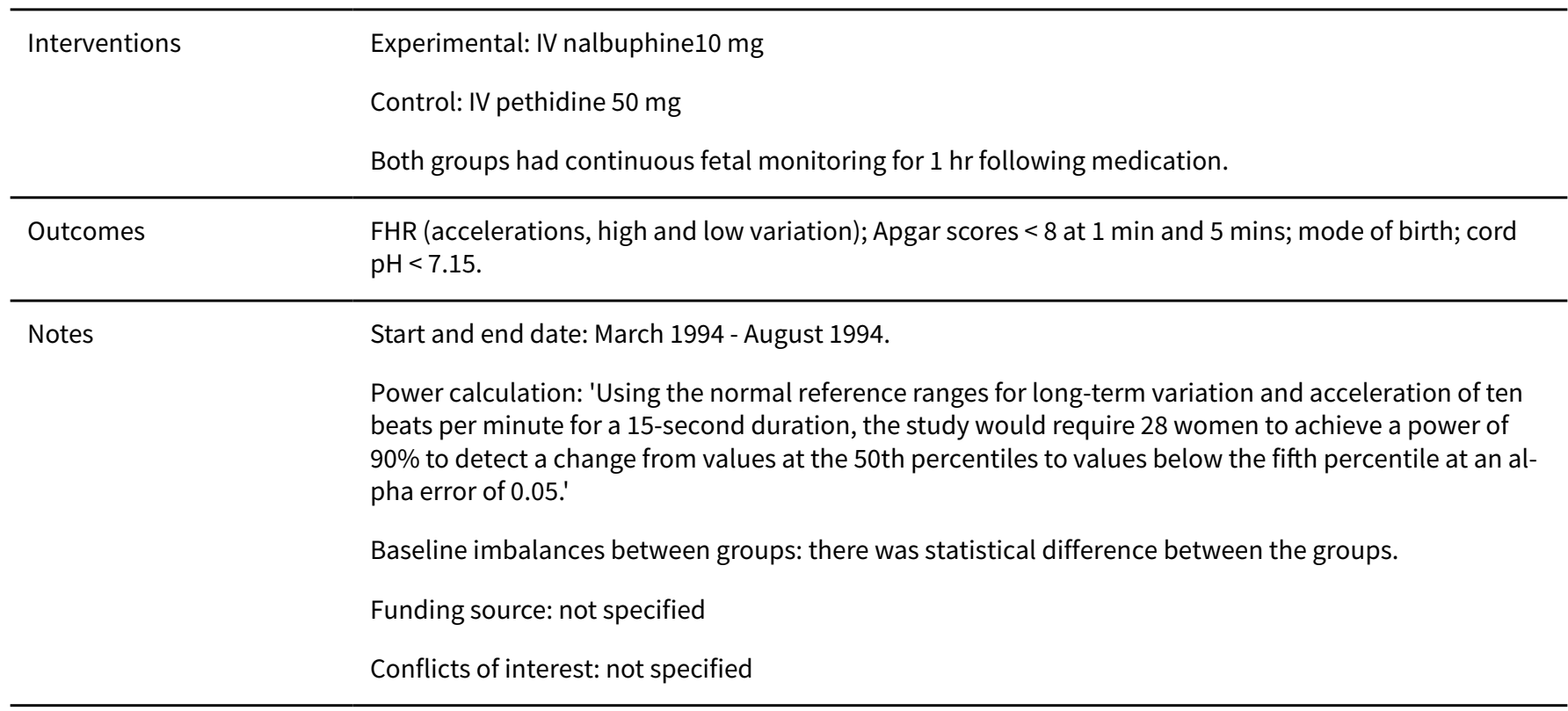

\section{Risk of bias}

\begin{tabular}{|c|c|c|}
\hline Bias & Authors' judgement & Support for judgement \\
\hline $\begin{array}{l}\text { Random sequence genera- } \\
\text { tion (selection bias) }\end{array}$ & Low risk & Computer-generated random number table \\
\hline $\begin{array}{l}\text { Allocation concealment } \\
\text { (selection bias) }\end{array}$ & Low risk & Sequentially-numbered, sealed envelopes \\
\hline $\begin{array}{l}\text { Blinding of participants } \\
\text { and personnel (perfor- } \\
\text { mance bias) } \\
\text { All outcomes }\end{array}$ & Unclear risk & Not specified \\
\hline $\begin{array}{l}\text { Blinding of outcome as- } \\
\text { sessment (detection bias) } \\
\text { All outcomes }\end{array}$ & Unclear risk & Not specified \\
\hline $\begin{array}{l}\text { Incomplete outcome data } \\
\text { (attrition bias) } \\
\text { All outcomes }\end{array}$ & Unclear risk & $\begin{array}{l}36 \text { women were enrolled. } 8 \text { women did not have sufficient FHR tracings and } \\
\text { were not included in the analysis ( } 22 \% \text { attrition). }\end{array}$ \\
\hline $\begin{array}{l}\text { Selective reporting (re- } \\
\text { porting bias) }\end{array}$ & Unclear risk & Unclear \\
\hline Other bias & Low risk & No apparent baseline imbalance \\
\hline
\end{tabular}

Gillam 1958

Methods RCT, 2-arm parallel-group design


Gillam 1958 (Continued)
Participants
Setting: hospital in USA
500 women admitted to hospital in labour. Little information provided.

Interventions Experimental: (185 women) alphaprodine (Nisentil), initial dose $40 \mathrm{mg}$ IV, subsequent doses IM

Control: (210 women) pethidine, initial dose $100 \mathrm{mg}$ IV, subsequent doses IM

Both groups received scopolamine. Analgesia was for the first stage of labour, birth was carried out

"with rare exception" under "saddle block or pudendal block terminal anesthesia".

\begin{tabular}{ll}
\hline Outcomes & Pain relief (rated just before leaving the room for childbirth); side effects and length of labour. \\
\hline Notes & Start and end date: not reported \\
Power calculation: not reported \\
Baseline imbalances between groups: unclear \\
Funding source: not reported \\
Conflicts of interest: not reported
\end{tabular}

\section{Risk of bias}

\begin{tabular}{lll}
\hline Bias & Authors' judgement & Support for judgement \\
\hline $\begin{array}{l}\text { Random sequence genera- } \\
\text { tion (selection bias) }\end{array}$ & Unclear risk & No information \\
\hline $\begin{array}{l}\text { Allocation concealment } \\
\text { (selection bias) }\end{array}$ & Low risk & Coded drug containers \\
\hline $\begin{array}{l}\text { Blinding of participants } \\
\text { and personnel (perfor- } \\
\text { mance bias) } \\
\text { All outcomes }\end{array}$ & Low risk & $\begin{array}{l}\text { Drugs were prepared by pharmacy in coded containers and the codes were not } \\
\text { revealed until after birth. }\end{array}$ \\
\hline
\end{tabular}

\begin{tabular}{|c|c|c|}
\hline $\begin{array}{l}\text { Blinding of outcome as- } \\
\text { sessment (detection bias) } \\
\text { All outcomes }\end{array}$ & Low risk & $\begin{array}{l}\text { Drugs were prepared by pharmacy in coded containers and the codes were not } \\
\text { revealed until after birth. }\end{array}$ \\
\hline
\end{tabular}

\begin{tabular}{ll}
\hline $\begin{array}{l}\text { Incomplete outcome data } \\
\text { (attrition bias) }\end{array}$ & High risk \\
All outcomes & $\begin{array}{l}500 \text { women were randomised, } 55 \text { women received no analgesia and were ex- } \\
\text { cluded, } 22 \text { women received more than } 1 \text { dose of opioid (not necessarily the }\end{array}$ \\
& $\begin{array}{l}\text { same drug) and were excluded, } 21 \text { women who were in preterm labour or had } \\
\text { a CS were excluded and } 1 \text { woman was excluded because she was sensitive to } \\
\text { study medication. Data available for } 395 \text { women ( } 21 \% \text { attrition). }\end{array}$ \\
\hline
\end{tabular}

\begin{tabular}{lll}
\hline $\begin{array}{l}\text { Selective reporting (re- } \\
\text { porting bias) }\end{array}$ & Unclear risk & Unclear \\
\hline Other bias & Unclear risk & $\begin{array}{l}\text { Study medication was for pain relief in the first stage of labour, most women } \\
\text { received a pudendal block for birth so outcomes relating to birth may not be } \\
\text { attributable to study medication alone. }\end{array}$ \\
\hline
\end{tabular}


Grant 1970

\begin{tabular}{|c|c|}
\hline Methods & RCT 2-arm parallel-group design \\
\hline \multirow[t]{2}{*}{ Participants } & Setting: hospital, UK \\
\hline & $\begin{array}{l}212 \text { women in spontaneous or induced labour with cephalic presentation at }>36 \text { weeks' gestation. Re- } \\
\text { cruited to the trial at } 36 \text { week antenatal clinic visit. }\end{array}$ \\
\hline \multirow[t]{2}{*}{ Interventions } & Experimental: IM phenazocine $3 \mathrm{mg}(\mathrm{N}=107)$ \\
\hline & Control: IM pethidine $150 \mathrm{mg}(\mathrm{N}=105)$ \\
\hline \multirow[t]{2}{*}{ Outcomes } & $\begin{array}{l}\text { Primary outcome: maternal analgesia assessed in labour as poor, fair, good, very good. Pain relief also } \\
\text { assessed in postnatal questionnaire within } 36 \mathrm{hrs} \text { of birth. }\end{array}$ \\
\hline & $\begin{array}{l}\text { Secondary outcomes: maternal: amnesia, restlessness, anxiety, vomiting. Neonatal: Apgar at } 1 \text { min and } \\
5 \text { mins. }\end{array}$ \\
\hline \multirow[t]{6}{*}{ Notes } & Epidural available if further analgesia required. \\
\hline & Start and end date: not reported \\
\hline & Power calculation: not reported \\
\hline & $\begin{array}{l}\text { Baseline imbalances between groups: 'There was no significant difference between the two groups } \\
\text { with respect to age, parity, height, weight, pelvic size, incidence of induced labour or cervical dilation } \\
\text { at the time of first dose of analgesia'. }\end{array}$ \\
\hline & Funding source: Smith and Nephew (Pharmaceutics) Ltd provided the marked drug ampoules \\
\hline & Conflicts of interest: not reported \\
\hline
\end{tabular}

\section{Risk of bias}

\begin{tabular}{|c|c|c|}
\hline Bias & Authors' judgement & Support for judgement \\
\hline $\begin{array}{l}\text { Random sequence genera- } \\
\text { tion (selection bias) }\end{array}$ & Unclear risk & Not reported \\
\hline $\begin{array}{l}\text { Allocation concealment } \\
\text { (selection bias) }\end{array}$ & Low risk & $\begin{array}{l}\text { Code kept by hospital pharmacist and remained unbroken until trial complet- } \\
\text { ed. }\end{array}$ \\
\hline $\begin{array}{l}\text { Blinding of participants } \\
\text { and personnel (perfor- } \\
\text { mance bias) } \\
\text { All outcomes }\end{array}$ & Low risk & States double-blind, coded ampoules but no further description given. \\
\hline
\end{tabular}

\begin{tabular}{|c|c|c|}
\hline $\begin{array}{l}\text { Blinding of outcome as- } \\
\text { sessment (detection bias) } \\
\text { All outcomes }\end{array}$ & Low risk & $\begin{array}{l}\text { Code kept by hospital pharmacist and remained unbroken until trial complet- } \\
\text { ed. }\end{array}$ \\
\hline
\end{tabular}

Incomplete outcome data $\quad$ Unclear risk
(attrition bias)

All outcomes

\begin{tabular}{lll}
\hline $\begin{array}{l}\text { Selective reporting (re- } \\
\text { porting bias) }\end{array}$ & Unclear risk & MW assessed maternal side effects in labour. \\
\hline Other bias & Unclear risk & $\begin{array}{l}\text { Although baseline characteristics described as similar - proportion of primips } \\
\text { to multips not provided. Balanced for age, parity, height, weight, cx dilatation. }\end{array}$
\end{tabular}




\begin{tabular}{ll}
\hline Methods & RCT. 2-arm parallel-group design \\
\hline Participants & 185 randomised. analysis for 160 women in labour. \\
& Inclusion criteria: primiparous, no pregnancy complications. \\
& Exclusions: women with hypertension or pre-eclampsia. It appeared that women who had any compli- \\
cations during birth (e.g. CS) were excluded after randomisation.
\end{tabular}

\section{Risk of bias}

\begin{tabular}{|c|c|c|}
\hline Bias & Authors' judgement & Support for judgement \\
\hline $\begin{array}{l}\text { Random sequence genera- } \\
\text { tion (selection bias) }\end{array}$ & Low risk & Table of random numbers \\
\hline $\begin{array}{l}\text { Allocation concealment } \\
\text { (selection bias) }\end{array}$ & Unclear risk & Described as a double-blind trial but methods were not described. \\
\hline $\begin{array}{l}\text { Blinding of participants } \\
\text { and personnel (perfor- } \\
\text { mance bias) } \\
\text { All outcomes }\end{array}$ & Unclear risk & Described as double-blind. \\
\hline $\begin{array}{l}\text { Blinding of outcome as- } \\
\text { sessment (detection bias) } \\
\text { All outcomes }\end{array}$ & Unclear risk & Unclear \\
\hline $\begin{array}{l}\text { Incomplete outcome data } \\
\text { (attrition bias) } \\
\text { All outcomes }\end{array}$ & High risk & $\begin{array}{l}185 \text { women approached, } 25 \text { were excluded and results suggest that any } \\
\text { women who had CS were excluded from the analysis along with women who } \\
\text { had long labours ( }>24 \mathrm{hrs} \text { ) or where no injections were given. }\end{array}$ \\
\hline $\begin{array}{l}\text { Selective reporting (re- } \\
\text { porting bias) }\end{array}$ & Unclear risk & Unclear \\
\hline
\end{tabular}


Hamann 1972 (Continued)
Other bias
Unclear risk
Assessment of risk of bias done using translation notes.

Hodgkinson 1979

\begin{tabular}{ll}
\hline Methods & RCT 4-arm parallel-group design \\
\hline Participants & Setting not clear, USA \\
& $\begin{array}{l}200 \text { women admitted to hospital in the 1st stage of normal labour, mean age 24 years, women received } \\
\text { medication if they complained of moderate or severe pain. }\end{array}$ \\
\hline Interventions & Experimental: (100 women) (i) IV butorphanol 1 mg (67 women) (ii) IV butorphanol 2 mg (33 women) \\
& Control: (100 women) (i) IV pethidine 40 mg (68 women) (ii) IV pethidine 80 mg (32 women) \\
\hline Outcomes & $\begin{array}{l}\text { Pain intensity (graphs with hourly readings); pain relief (4-point scale); neuro-behavioural assessment } 1 \\
\text { day after birth (Scanlon scale). }\end{array}$ \\
\hline Notes & Start and end date: not reported \\
& Power calculation: not reported \\
& Baseline imbalances between groups: unclear \\
& Funding source: not reported \\
Conflicts of interest: not reported
\end{tabular}

Risk of bias

\begin{tabular}{|c|c|c|}
\hline Bias & Authors' judgement & Support for judgement \\
\hline $\begin{array}{l}\text { Random sequence genera- } \\
\text { tion (selection bias) }\end{array}$ & Unclear risk & No information \\
\hline $\begin{array}{l}\text { Allocation concealment } \\
\text { (selection bias) }\end{array}$ & Unclear risk & No information. Described as "double-blind". \\
\hline $\begin{array}{l}\text { Blinding of participants } \\
\text { and personnel (perfor- } \\
\text { mance bias) } \\
\text { All outcomes }\end{array}$ & Unclear risk & $\begin{array}{l}\text { Described as double-blind but little detail of methods of allocation conceal- } \\
\text { ment or blinding. }\end{array}$ \\
\hline $\begin{array}{l}\text { Blinding of outcome as- } \\
\text { sessment (detection bias) } \\
\text { All outcomes }\end{array}$ & Unclear risk & $\begin{array}{l}\text { Described as double-blind but little detail of methods of allocation conceal- } \\
\text { ment or blinding. }\end{array}$ \\
\hline $\begin{array}{l}\text { Incomplete outcome data } \\
\text { (attrition bias) } \\
\text { All outcomes }\end{array}$ & Low risk & No loss to follow-up apparent \\
\hline $\begin{array}{l}\text { Selective reporting (re- } \\
\text { porting bias) }\end{array}$ & Unclear risk & Unclear \\
\hline Other bias & Unclear risk & Very little information on study methods. \\
\hline
\end{tabular}


Husslein 1987

\begin{tabular}{|c|c|}
\hline Methods & RCT 2-arm parallel-group design \\
\hline \multirow[t]{2}{*}{ Participants } & Setting: hospital, Austria \\
\hline & $\begin{array}{l}40 \text { women with no pregnancy complications, in spontaneous and induced labour, } \mathrm{cx} 3 \mathrm{~cm} \text { to } 5 \mathrm{~cm} \text { dilat- } \\
\text { ed. } 72.5 \% \text { primips, } 27.5 \% \text { multips. }\end{array}$ \\
\hline \multirow[t]{2}{*}{ Interventions } & Experimental: IM tramadol 100 mg $(\mathrm{N}=20)$ \\
\hline & Control: IM pethidine $100 \mathrm{mg}(\mathrm{N}=20)$ \\
\hline \multirow[t]{2}{*}{ Outcomes } & $\begin{array}{l}\text { Primary: pain relief, assessed 10,30,60, } 120 \text { mins after injection using VAS } 0-100,0=\text { pain free to } 100 \\
\text { strongest pain experienced. }\end{array}$ \\
\hline & Secondary: side effects, augmentation and type of birth. \\
\hline \multirow[t]{6}{*}{ Notes } & Not stated in 1 dose only \\
\hline & Start and end date: unclear \\
\hline & Power calculation: unclear \\
\hline & Baseline imbalances between groups: unclear \\
\hline & Funding source: unclear \\
\hline & Conflicts of interest: unclear \\
\hline
\end{tabular}

\section{Risk of bias}

Bias Authors' judgement Support for judgement

Random sequence genera- Unclear risk Not reported

tion (selection bias)

Allocation concealment $\quad$ Unclear risk not reported
(selection bias)

\begin{tabular}{lll}
\hline $\begin{array}{l}\text { Blinding of participants } \\
\text { and personnel (perfor- } \\
\text { mance bias) }\end{array}$ & Unclear risk & Blinding not described \\
$\begin{array}{l}\text { All outcomes } \\
\text { Blinding of outcome as- } \\
\text { sessment (detection bias) } \\
\text { All outcomes }\end{array}$ & Unclear risk & Blinding not described \\
\hline $\begin{array}{l}\text { Incomplete outcome data } \\
\text { (attrition bias) }\end{array}$ & Low risk & All women analysed \\
$\begin{array}{l}\text { All outcomes } \\
\text { Selective reporting (re- } \\
\text { porting bias) }\end{array}$ & Unclear risk & Unclear \\
\hline \begin{tabular}{l} 
Other bias \\
\hline
\end{tabular} & Unclear risk & Baseline characteristics stated as similar \\
\hline
\end{tabular}


Jackson 1983

\begin{tabular}{ll}
\hline Methods & RCT 2-arm parallel-group design \\
\hline Participants & Setting: hospital, UK \\
& 100 women in labour at term gestation with uncomplicated pregnancy. \\
\hline Interventions & Experimental: Meptazinol $1.8 \mathrm{mg} / \mathrm{kg}$ body weight ( $\mathrm{N}=50)$ \\
& Control: pethidine $1.8 \mathrm{mg} / \mathrm{kg}$ body weight ( $\mathrm{N}=50)$ \\
& All participants received promethazine $12.5 \mathrm{mg}$ with first injection. \\
\hline Outcomes & Primary: newborn effects: Apgar score at 1 min and 3 mins \\
\hline Notes & If additional analgesia required, a repeat injection could be administered 3-hourly. \\
6/50 women from each arm received a second dose at a 3-hourly interval. \\
Start and end date: not reported \\
Power calculation: not reported \\
Baseline imbalances between groups: unclear \\
Funding source: not reported \\
Conflicts of interest: not reported \\
\hline
\end{tabular}

\section{Risk of bias}

\begin{tabular}{lll}
\hline Bias & Authors' judgement & Support for judgement \\
\hline $\begin{array}{l}\text { Random sequence genera- } \\
\text { tion (selection bias) }\end{array}$ & Unclear risk & Not reported \\
\hline $\begin{array}{l}\text { Allocation concealment } \\
\text { (selection bias) }\end{array}$ & Unclear risk & Not reported \\
\hline $\begin{array}{l}\text { Blinding of participants } \\
\text { and personnel (perfor- } \\
\text { mance bias) } \\
\text { All outcomes }\end{array}$ & Unclear risk & States double-blind but method not described \\
\hline $\begin{array}{l}\text { Blinding of outcome as- } \\
\text { sessment (detection bias) } \\
\text { All outcomes }\end{array}$ & Unclear risk & States double-blind but method not described \\
\hline $\begin{array}{l}\text { Incomplete outcome data } \\
\text { (attrition bias) } \\
\text { All outcomes }\end{array}$ & High risk & \\
\hline $\begin{array}{l}\text { Selective reporting (re- } \\
\text { porting bias) }\end{array}$ & Unclear risk & B babies excluded from analysis due to heart defects and fetal distress. \\
\hline \begin{tabular}{l} 
Other bias \\
\hline
\end{tabular} & Unclear risk & Balanced for parity, weight and size of baby at baseline. \\
\hline
\end{tabular}


Jahani 2013

\begin{tabular}{|c|c|}
\hline Methods & RCT 2-arm parallel-group design \\
\hline \multirow[t]{4}{*}{ Participants } & Setting: Maternity Unit, Tamin Ejtemai Hospital, Iran \\
\hline & 70 women randomised \\
\hline & $\begin{array}{l}\text { Inclusion criteria: multiparous pregnant women (gravida 2-7); term singleton pregnancy; cephalic pre- } \\
\text { sentation; low-risk pregnancy with no history of drug tolerance (addiction), medical or mental dis- } \\
\text { eases. }\end{array}$ \\
\hline & $\begin{array}{l}\text { Exclusion criteria: respiratory rate }<8 \text { or maternal bradycardia (pulse rate less than } 60 \text { ) and severe con- } \\
\text { genital anomalies in neonate after birth. }\end{array}$ \\
\hline \multirow[t]{2}{*}{ Interventions } & $\begin{array}{l}\text { Experimental: Fentanyl - } 50 \mathrm{mcg} \text { fentanyl was prescribed in } 2 \text { doses with an interval of } 1 \mathrm{hr} \text { after being } \\
\text { diluted in } 4 \mathrm{cc} \text { normal saline (total volume } 5 \mathrm{cc}-25 \mu \mathrm{g} / 5 \mathrm{~mL} \text { during } 10 \text { mins infusion and repeated sec- } \\
\text { ond dose an hr later } 25 \mu \mathrm{g} / 5 \mathrm{~mL} \text { ) at zero and } 60 \text { mins. }\end{array}$ \\
\hline & Control: no analgesia \\
\hline Outcomes & $\begin{array}{l}\text { Outcomes: pain score, blood pressure, heart rate, FHR and maternal respiratory rate, duration of } \\
\text { labour, maternal side effects drowsiness, dizziness, nausea/vomiting, respiratory depression, hypoten- } \\
\text { sion (BP }<90 \mathrm{mmHg} \text { or less than }<20 \% \text { of baseline), bradycardia (HR }<60 \text { beats min-1), and pruri- } \\
\text { tus.Neonatal outcomes included Apgar scores at } 1 \text { min and } 5 \text { mins and resuscitation efforts (if any). }\end{array}$ \\
\hline \multirow[t]{4}{*}{ Notes } & $\begin{array}{l}\text { Power calculation: 'based on results from a pilot study on } 10 \text { parturients (and mean duration of the ac- } \\
\text { tive phase), effect size was obtained at } 0.4 \text { hours with power } 80 \% \text { and confidence level of } 95 \% \text {, the sam- } \\
\text { ple size was then calculated to be } 70 \text { parturients'. }\end{array}$ \\
\hline & $\begin{array}{l}\text { Baseline imbalances between groups: 'There was no statistically significant difference in mean age be- } \\
\text { tween the two groups. There were no significant differences in gravidity, parity, fetal heart rate, con- } \\
\text { traction duration or HR between the two groups'. }\end{array}$ \\
\hline & Funding source: not reported \\
\hline & Conflicts of interest: not reported \\
\hline
\end{tabular}

\section{Risk of bias}

\begin{tabular}{|c|c|c|}
\hline Bias & Authors' judgement & Support for judgement \\
\hline $\begin{array}{l}\text { Random sequence genera- } \\
\text { tion (selection bias) }\end{array}$ & Unclear risk & $\begin{array}{l}\text { A coin was tossed to determine the participants comprising the control and } \\
\text { case groups ( } 35 \text { women per group). It was not reported if this was at the point } \\
\text { of randomisation but no information on allocation concealment. }\end{array}$ \\
\hline $\begin{array}{l}\text { Allocation concealment } \\
\text { (selection bias) }\end{array}$ & High risk & $\begin{array}{l}\text { Coin toss to determine group. If this was at the point of randomisation this is a } \\
\text { high-risk method. There was no indication of allocation concealment. }\end{array}$ \\
\hline $\begin{array}{l}\text { Blinding of participants } \\
\text { and personnel (perfor- } \\
\text { mance bias) } \\
\text { All outcomes }\end{array}$ & High risk & Not feasible \\
\hline $\begin{array}{l}\text { Blinding of outcome as- } \\
\text { sessment (detection bias) } \\
\text { All outcomes }\end{array}$ & High risk & Outcome assessor likely to be aware of allocation. \\
\hline $\begin{array}{l}\text { Incomplete outcome data } \\
\text { (attrition bias) } \\
\text { All outcomes }\end{array}$ & Unclear risk & $\begin{array}{l}\text { No reported loss to follow-up, no denominators given in tables and no details } \\
\text { of women requesting further analgesia and changing groups. Not clear if there } \\
\text { was loss to follow-up or not. }\end{array}$ \\
\hline
\end{tabular}


Jahani 2013 (Continued)

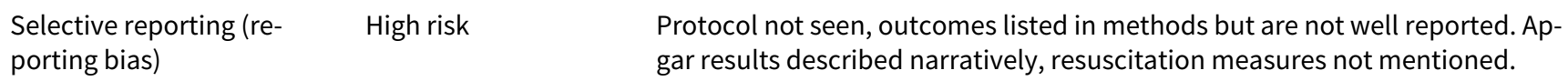

Other bias Low risk Baseline characteristics were balanced across groups.

Kainz 1992

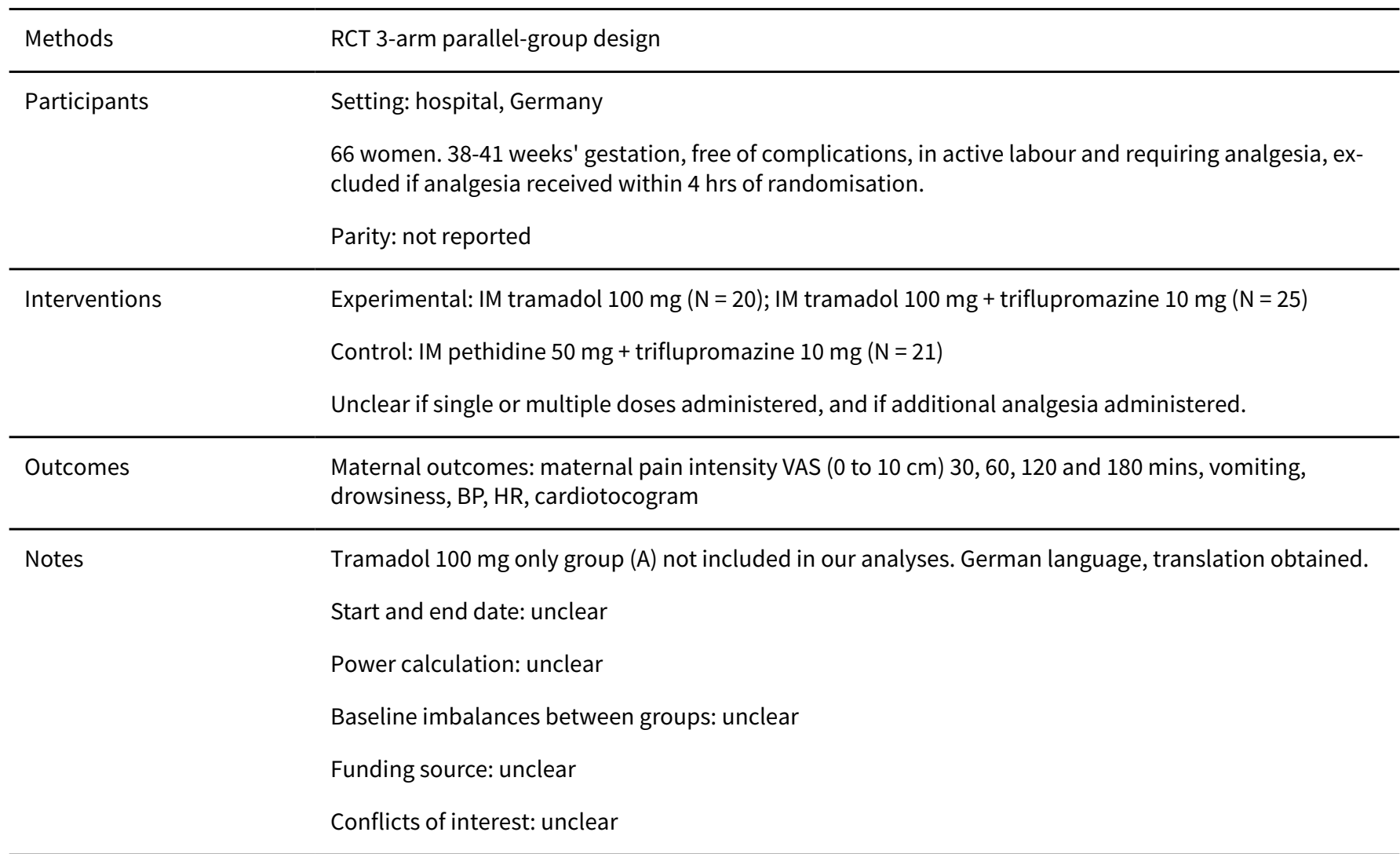

\section{Risk of bias}

\begin{tabular}{lll}
\hline Bias & Authors' judgement & Support for judgement \\
\hline $\begin{array}{l}\text { Random sequence genera- } \\
\text { tion (selection bias) }\end{array}$ & Low risk & "zulfallszahlentafel" coincidence number table. \\
\hline $\begin{array}{l}\text { Allocation concealment } \\
\text { (selection bias) }\end{array}$ & Unclear risk & Not reported \\
\hline $\begin{array}{l}\text { Blinding of participants } \\
\text { and personnel (perfor- } \\
\text { mance bias) } \\
\text { All outcomes }\end{array}$ & Unclear risk & Stated as double-blind but methods not described \\
\hline
\end{tabular}

\begin{tabular}{lll}
$\begin{array}{l}\text { Blinding of outcome as- } \\
\text { sessment (detection bias) } \\
\text { All outcomes }\end{array}$ & Unclear risk & Stated as double-blind but methods not described \\
\hline $\begin{array}{l}\text { Incomplete outcome data } \\
\text { (attrition bias) }\end{array}$ & Unclear risk & $\begin{array}{l}2 / 66 \text { women excluded due to giving birth within } 1 \text { hr of study drug administra- } \\
\text { tion. }\end{array}$ \\
\hline
\end{tabular}


Kainz 1992 (Continued)

All outcomes

\begin{tabular}{lll}
\hline $\begin{array}{l}\text { Selective reporting (re- } \\
\text { porting bias) }\end{array}$ & Unclear risk & Unclear \\
\hline Other bias & Unclear risk & Unclear \\
\hline
\end{tabular}

\section{Kamyabi 2003}

\begin{tabular}{ll}
\hline Methods & RCT 2-arm parallel-group design \\
\hline Participants & Setting: hospital in Iran \\
& 88 primiparous women in spontaneous labour, gestation $\geq 37$ weeks, and cervix $5 \mathrm{~cm}$ dilated.
\end{tabular}

Excluded if high-risk pregnancy, narcotic addiction.

\begin{tabular}{|c|c|}
\hline Interventions & $\begin{array}{l}\text { Experimental: IM (placebo) normal saline } 1.5 \mathrm{~mL}(\mathrm{~N}=44) \\
\text { Control: IM pethidine } 75 \mathrm{mg}(\mathrm{N}=44)\end{array}$ \\
\hline Outcomes & $\begin{array}{l}\text { Primary: analgesic effect. Pain assessed pre and post injection using Likert Scale VAS: } 10 \mathrm{~cm} \text { line, } 0 \%= \\
\text { minimum effect, } 100 \%=\text { maximum effect. }\end{array}$ \\
\hline & $\begin{array}{l}\text { Secondary: side effects on uterine contractions (contraction duration and interval recorded } 3 \text { times } 15 \\
\text { to } 60 \text { mins post injection) and neonatal Apgar score at } 1 \text { min and } 5 \text { mins. }\end{array}$ \\
\hline
\end{tabular}

Timing of maternal pain assessment not reported.
Start and end date: not reported
Power calculation: the required number of women was based on a pilot study and considering a power
of $90 \%, d \%$, and error $5 \%, 44$ women were needed in each group.
Baseline imbalances between groups: unclear
Funding source: not reported
Conflicts of interest: not reported

\section{Risk of bias}

\begin{tabular}{lll}
\hline Bias & Authors' judgement & Support for judgement \\
\hline $\begin{array}{l}\text { Random sequence genera- } \\
\text { tion (selection bias) }\end{array}$ & Unclear risk & States 'divided randomly'. \\
\hline $\begin{array}{l}\text { Allocation concealment } \\
\text { (selection bias) }\end{array}$ & Unclear risk & Not reported \\
\hline $\begin{array}{l}\text { Blinding of participants } \\
\text { and personnel (perfor- } \\
\text { mance bias) }\end{array}$ & Low risk & Study agents were of identical volume and appearance \\
$\begin{array}{l}\text { All outcomes } \\
\text { Blinding of outcome as- } \\
\text { sessment (detection bias) } \\
\text { All outcomes }\end{array}$ & Low risk & \\
\hline
\end{tabular}


Kamyabi 2003 (Continued)

Incomplete outcome data Unclear risk Number of participants analysed and planned analysis not reported (attrition bias)

Number of participants analysed and planned analysis not reported

All outcomes

\begin{tabular}{lll}
\hline $\begin{array}{l}\text { Selective reporting (re- } \\
\text { porting bias) }\end{array}$ & Unclear risk & Unclear \\
\hline Other bias & Unclear risk & $\begin{array}{l}\text { The number of women allocated to each group is not reported and unclear if } \\
\text { there are baseline imbalances in prognostic factors. }\end{array}$ \\
\hline
\end{tabular}

Kermani 2015

\begin{tabular}{ll}
\hline Methods & RCT, individual randomisation - difficult to assess abstract only \\
\hline Participants & Setting: not clear, Iran \\
& 48 women with term pregnancies in active labour. \\
& Exclusion criteria: not stated \\
\hline Interventions & Experimental group: pethidine ( $\mathrm{n}=$ not clear) route and dose not stated \\
& Control group: acupressure ( $\mathrm{n}=$ not clear) acupressure at spleen point 6 (SP6) \\
\hline Outcomes & No data - abstract only \\
\hline Notes & Dates of study: not stated \\
Funding: not stated \\
Conflicts of interest: not stated \\
15th June 2017 - email to $2^{\text {nd }}$ author. Awaiting response.
\end{tabular}

\section{Risk of bias}

\begin{tabular}{lll}
\hline Bias & Authors' judgement & Support for judgement \\
\hline $\begin{array}{l}\text { Random sequence genera- } \\
\text { tion (selection bias) }\end{array}$ & Unclear risk & Quote: "Subjects were randomly selected and divided". No further description. \\
\hline $\begin{array}{l}\text { Allocation concealment } \\
\text { (selection bias) }\end{array}$ & Unclear risk & Method not described \\
\hline $\begin{array}{l}\text { Blinding of participants } \\
\text { and personnel (perfor- } \\
\text { mance bias) }\end{array}$ & High risk & Not mentioned but not possible to blind intervention \\
All outcomes & \\
\hline $\begin{array}{l}\text { Blinding of outcome as- } \\
\text { sessment (detection bias) } \\
\text { All outcomes }\end{array}$ & Unclear risk & Outcomes probably assessed by caregiver \\
\hline $\begin{array}{l}\text { Incomplete outcome data } \\
\text { (attrition bias) } \\
\text { All outcomes }\end{array}$ & Unclear risk & Unclear due to lack of information in abstract \\
\hline
\end{tabular}


Kermani 2015 (Continued)

Selective reporting (re- Unclear risk $\quad$ Unable to assess
porting bias)

Other bias Unclear risk Unable to assess

Keskin 2003

\begin{tabular}{|c|c|}
\hline Methods & RCT 2-arm parallel-group design \\
\hline \multirow[t]{3}{*}{ Participants } & Setting: hospital, Turkey \\
\hline & $\begin{array}{l}59 \text { primiparous women with uncomplicated pregnancy at term gestation, in labour with cervix } 3 \mathrm{~cm} \text { to } \\
5 \mathrm{~cm} \text { dilated and reporting a pain score } 4-5 \text { according to Wong-Baker Faces Pain Rating Scales with } 0= \\
\text { no pain, } 5 \text { = most intense pain. }\end{array}$ \\
\hline & Exclusions: maternal medical disorders, history of drug or alcohol abuse \\
\hline \multirow[t]{2}{*}{ Interventions } & Experimental: IM tramadol $100 \mathrm{mg}$, single dose $(\mathrm{N}=30)$ \\
\hline & Control: IM pethidine $100 \mathrm{mg}$, single dose $(\mathrm{N}=29)$ \\
\hline \multirow[t]{2}{*}{ Outcomes } & $\begin{array}{l}\text { Primary: analgesic effect assessed } 30,60 \text { and } 120 \text { mins following injection using Wong-Baker Faces Pain } \\
\text { Rating Scales with } 0=\text { no pain, } 5=\text { most intense pain. }\end{array}$ \\
\hline & $\begin{array}{l}\text { Secondary: side effects: nausea, vomiting, drowsiness, fatigue and neonatal effects (Apgar score at } 1 \\
\text { min and } 5 \text { mins). }\end{array}$ \\
\hline \multirow[t]{5}{*}{ Notes } & Start and end date: not reported \\
\hline & Power calculation: not reported \\
\hline & Baseline imbalances between groups: unclear \\
\hline & Funding sources: not reported \\
\hline & Conflicts of interest: not reported \\
\hline
\end{tabular}

\section{Risk of bias}

\begin{tabular}{lll}
\hline Bias & Authors' judgement & Support for judgement \\
\hline $\begin{array}{l}\text { Random sequence genera- } \\
\text { tion (selection bias) }\end{array}$ & Unclear risk & Not reported. "randomly divided into two groups". \\
\hline $\begin{array}{l}\text { Allocation concealment } \\
\text { (selection bias) }\end{array}$ & Unclear risk & Not reported \\
\hline $\begin{array}{l}\text { Blinding of participants } \\
\text { and personnel (perfor- } \\
\text { mance bias) } \\
\text { All outcomes }\end{array}$ & Unclear risk & Not reported \\
\hline
\end{tabular}

\begin{tabular}{lll}
\hline $\begin{array}{l}\text { Blinding of outcome as- } \\
\text { sessment (detection bias) } \\
\text { All outcomes }\end{array}$ & Low risk & Outcome assessor unaware of treatment group \\
\hline $\begin{array}{l}\text { Incomplete outcome data } \\
\text { (attrition bias) }\end{array}$ & High risk & Losses to follow-up not explained and no ITT analysis. \\
\hline
\end{tabular}


Keskin 2003 (Continued)

All outcomes

Selective reporting (re- Unclear risk Unclear
porting bias)

Other bias Unclear risk Unclear

Khooshideh 2009

\begin{tabular}{ll}
\hline Methods & RCT 2-arm parallel-group design \\
\hline Participants & Setting: hospital, Iran \\
& 160 women. Free of complications, spontaneous and induced onset, cx $4 \mathrm{~cm}$ dilated, in active labour \\
& and requiring analgesia. Women excluded if cx dilated $>5 \mathrm{~cm}$. \\
& Parity: not reported
\end{tabular}

\begin{tabular}{ll}
\hline Interventions & Experimental: IM tramadol $100 \mathrm{mg}(\mathrm{N}=80)$ \\
& Control: IM pethidine $50 \mathrm{mg}(\mathrm{N}=80)$ \\
& 2nd dose on maternal request after 4 hrs but pethidine withheld if cx dilated $>8 \mathrm{~cm}$ and tramadol given \\
instead.
\end{tabular}

Maternal outcomes: maternal pain intensity VAS $(0$ to $10 \mathrm{~cm}) 10$ mins, 30 mins and 1-hourly intervals
until birth, maternal satisfaction 24 hrs postpartum 5 -point scale (excellent, very good, good, fair,
poor), drowsiness, nausea, vomiting. Neonatal outcomes: Apgar score at 1 min and 5 mins, naloxone
administration, respiratory depression

\begin{tabular}{|c|c|}
\hline \multirow[t]{5}{*}{ Notes } & Start and end date: 2004 \\
\hline & $\begin{array}{l}\text { Power calculation: based on the assumption that a difference of } 30 \text { mins in duration of labour would be } \\
\text { clinically significant, } 53 \text { women was needed in each group } 80 \% \text { power on a } 5 \% \text { significance }(\alpha=0.05, \beta \\
=0.2 \text { ). }\end{array}$ \\
\hline & $\begin{array}{l}\text { Baseline imbalances between groups: 'The two groups were comparable regarding age, parity, height, } \\
\text { weight, period of gestation, fetal weight, cervical dilatation at initiation of analgesia and need for oxy- } \\
\text { tocin use'. }\end{array}$ \\
\hline & Funding source: not specified \\
\hline & Conflicts of interest: not specified \\
\hline
\end{tabular}

\section{Risk of bias}

\begin{tabular}{lll}
\hline Bias & Authors' judgement & Support for judgement \\
\hline $\begin{array}{l}\text { Random sequence genera- } \\
\text { tion (selection bias) }\end{array}$ & Low risk & Computer-generated codes \\
\hline $\begin{array}{l}\text { Allocation concealment } \\
\text { (selection bias) }\end{array}$ & Low risk & Sequentially-numbered, sealed opaque envelopes \\
\hline $\begin{array}{l}\text { Blinding of participants } \\
\text { and personnel (perfor- } \\
\text { mance bias) }\end{array}$ & Unclear risk & $\begin{array}{l}\text { Drugs administered by clinician blind to group allocation, but does not state } \\
\text { All outcomes }\end{array}$ \\
\hline
\end{tabular}


Khooshideh 2009 (Continued)

Blinding of outcome as- Low risk Women fed back their maternal pain score to anaesthetist. sessment (detection bias)

All outcomes

\begin{tabular}{lll}
$\begin{array}{l}\text { Incomplete outcome data } \\
\text { (attrition bias) } \\
\text { All outcomes }\end{array}$ & Low risk & Flow chart addresses all data. \\
\hline $\begin{array}{l}\text { Selective reporting (re- } \\
\text { porting bias) }\end{array}$ & Unclear risk & Unclear \\
\hline Other bias & Unclear risk & Baseline characteristics similar \\
\hline
\end{tabular}

Kuti 2008

\begin{tabular}{|c|c|}
\hline Methods & Reported to be randomised clinical trial. Individual women randomised. \\
\hline \multirow[t]{3}{*}{ Participants } & Setting: labour ward of Wesley Guild Hospital, Ilesa Nigeria. \\
\hline & $\begin{array}{l}100 \text { women who were admitted in active spontaneous labour at term with uncomplicated singleton } \\
\text { pregnancies requesting analgesia. }\end{array}$ \\
\hline & Exclusion criteria: mothers with chronic medical diseases. \\
\hline \multirow[t]{2}{*}{ Interventions } & $\begin{array}{l}\text { Experimental group: IM injection of Pentazocine } 30 \mathrm{mg} \text { (Laborate Pharmaceuticals, India) }(\mathrm{N}=50,44 \\
\text { following exclusions) }\end{array}$ \\
\hline & Control group: IM tramadol 100 mg.(P.T Interbat, Indonesia) ( $n=50,42$ following exclusions) \\
\hline \multirow[t]{6}{*}{ Outcomes } & Satisfaction with analgesia \\
\hline & Pain in labour \\
\hline & Mode of birth \\
\hline & Maternal side effects \\
\hline & Neonatal admission to special care \\
\hline & Apgar scores \\
\hline \multirow[t]{2}{*}{ Notes } & Start and end dates: June 2005 - May 2006 \\
\hline & Funding and COI: not reported \\
\hline
\end{tabular}

\section{Risk of bias}

\begin{tabular}{lll}
\hline Bias & Authors' judgement & Support for judgement \\
\hline $\begin{array}{l}\text { Random sequence genera- } \\
\text { tion (selection bias) }\end{array}$ & Low risk & Computer-generated random numbers in blocks of 4 \\
\hline $\begin{array}{l}\text { Allocation concealment } \\
\text { (selection bias) }\end{array}$ & Low risk & $\begin{array}{l}\text { Randomisation codes were placed in sequentially-numbered, opaque, sealed } \\
\text { envelope. Envelope was opened when the woman requested pain relief and } \\
\text { the drug administered by the randomising midwife. }\end{array}$ \\
\hline
\end{tabular}




\section{Kuti 2008 (Continued)}

Blinding of participants and personnel (performance bias)

All outcomes
Low risk It is reported that the trial is double-blind.

When each woman requested pain relief, the next numbered envelope was opened and the appropriate drug administered by the randomising midwife. Not clear if this midwife cared for woman in labour. Both given IM so women should be unaware.

The labour ward resident doctor, unaware of the type of injection given, recorded the clinical data and assess the analgesic efficacy.

\begin{tabular}{|c|c|c|}
\hline $\begin{array}{l}\text { Blinding of outcome as- } \\
\text { sessment (detection bias) }\end{array}$ & Low risk & $\begin{array}{l}\text { The labour ward resident doctor, unaware of the type of injection given, } \\
\text { recorded the clinical data and assess the analgesic efficacy. }\end{array}$ \\
\hline
\end{tabular}

All outcomes

Incomplete outcome data Unclear risk

(attrition bias)

All outcomes
14 women ( 6 in the pentazocine group and 8 in the tramadol group) delivered within $1 \mathrm{hr}$ of drug administration and were therefore excluded from further analysis. Outcome data are available for the remaining women in the respective groups. Giving birth within the hr, the drug administered could have affected the neonate.

\begin{tabular}{lll}
\hline $\begin{array}{l}\text { Selective reporting (re- } \\
\text { porting bias) }\end{array}$ & Unclear risk & All essential outcomes are reported. Protocol not seen. \\
\hline Other bias & Unclear risk & $\begin{array}{l}\text { Women had similar characteristics at trial entry. Some lack of clarity in report- } \\
\text { ing outcomes. }\end{array}$ \\
\hline
\end{tabular}

Lalooha 2017

\begin{tabular}{ll} 
Methods & Reported to be randomised clinical trial. Individual women randomised. \\
\hline Participants & Setting: hospital in Iran \\
& $\begin{array}{l}120 \text { women randomised, nulliparous women with term singleton pregnancy who had induction of } \\
\text { labour (reasons for and methods of induction not stated in abstract). } \\
\text { Exclusion criteria: not stated }\end{array}$
\end{tabular}

\begin{tabular}{ll}
\hline Interventions & $\begin{array}{l}\text { Experimental group: single dose of } 50 \text { mg IV pethidine at } 4 \mathrm{~cm} \text { dilatation (it was not clear whether this } \\
\text { was at maternal request or whether all women received it) }(\mathrm{N}=60) \\
\text { Control group: IV normal saline (placebo) (N=60) }\end{array}$ \\
\hline Outcomes & Duration of labour \\
\hline Notes & Start and end dates: unclear \\
& Conflict of interest: not stated \\
& Funding not stated \\
& Translation requested 15th June 2017 - no data used in this review. \\
\hline Risk of bias & Authors' judgement Support for judgement \\
\hline Bias & Unclear risk No information "randomly assigned" \\
\hline $\begin{array}{l}\text { Random sequence genera- } \\
\text { tion (selection bias) }\end{array}$ &
\end{tabular}


Lalooha 2017 (Continued)

\begin{tabular}{lll}
$\begin{array}{l}\text { Allocation concealment } \\
\text { (selection bias) }\end{array}$ & Unclear risk & No information "randomly assigned" \\
\hline $\begin{array}{l}\text { Blinding of participants } \\
\begin{array}{l}\text { and personnel (perfor- } \\
\text { mance bias) }\end{array}\end{array}$ & Low risk & Participants: placebo-controlled trial. \\
All outcomes & & $\begin{array}{l}\text { Caregiver: placebo-controlled trial. Staff may have been aware of allocation if } \\
\text { there was sedation or other side effects. }\end{array}$
\end{tabular}

All outcomes

Unclear risk

Not clear when group assignment revealed and staff providing care recorded

Blinding of outcome asoutcomes.

All outcomes

Incomplete outcome data Unclear risk 120 women included. No information on dropouts or missing data. Not clear.
(attrition bias)
All outcomes

\begin{tabular}{lll}
\hline $\begin{array}{l}\text { Selective reporting (re- } \\
\text { porting bias) }\end{array}$ & Unclear risk & This was a very brief abstract. Key outcomes not reported. \\
\hline Other bias & Unclear risk & $\begin{array}{l}\text { Assessment from abstract. Full paper in Arabic. Very little information on } \\
\text { methods. Full translation requested. }\end{array}$ \\
\hline
\end{tabular}

Lardizabal 1999

\begin{tabular}{ll}
\hline Methods & RCT 2-arm parallel-group design \\
\hline Participants & Argentina: 2 hospitals \\
& $\begin{array}{l}310 \text { women of mixed parity, in labour } 37-42 \text { weeks' gestation with cervix } 4 \mathrm{~cm} \text { to } 6 \mathrm{~cm} \text { dilated, cephalic } \\
\text { presentation and requiring analgesia. } \\
\text { Exclusions: maternal medical condition, evidence of fetal distress, previous caesarean section }\end{array}$ \\
\hline
\end{tabular}

Interventions Experimental: IM nalbuphine $20 \mathrm{mg}$, single dose $(\mathrm{N}=152)$

Control: IM pethidine $100 \mathrm{mg}$, single dose $(\mathrm{N}=158)$

Outcomes Primary: neonatal Apgar score $<7$ at $1 \mathrm{~min}$

Secondary: maternal pain assessed using VAS pre-injection, and 30 mins and 120 mins afterwards (severe pain 75 or >), nausea, vomiting and type of birth. Neonatal side effects: condition over first $24 \mathrm{hrs,}$ admission to neonatal intensive care nursery.

Notes Stratified by hospital.

Start and end date: June 1991 - September 1993

Power calculation: based on previous literature, mean incidence of low Apgar score was $12 \%$ in women receiving meperidine and $3 \%$ in women receiving nalbuphine, $\alpha=0.05, \beta=0.20,152$ women in each group is needed for a $75 \%$ relative risk reduction in the primary endpoint.

Baseline imbalances between groups: the groups were balanced across various prognostic variables such as age, nulliparity, weeks of gestation, maternal weight, cervical dilatation at randomisation, uterine activity, number of women with induced labour, severe pain, nausea, vomiting, dizziness, and dry mouth.

Funding source: not reported 
Lardizabal 1999 (Continued)

Conflicts of interest: not reported

\section{Risk of bias}

\begin{tabular}{|c|c|c|}
\hline Bias & Authors' judgement & Support for judgement \\
\hline $\begin{array}{l}\text { Random sequence genera- } \\
\text { tion (selection bias) }\end{array}$ & Low risk & Computer-generated code \\
\hline $\begin{array}{l}\text { Allocation concealment } \\
\text { (selection bias) }\end{array}$ & Low risk & $\begin{array}{l}\text { Coded ampoules, sealed and prepared by independent pharmacist and identi- } \\
\text { cal in appearance }\end{array}$ \\
\hline $\begin{array}{l}\text { Blinding of participants } \\
\text { and personnel (perfor- } \\
\text { mance bias) } \\
\text { All outcomes }\end{array}$ & Low risk & Identical ampoules \\
\hline $\begin{array}{l}\text { Blinding of outcome as- } \\
\text { sessment (detection bias) } \\
\text { All outcomes }\end{array}$ & Unclear risk & Not reported \\
\hline $\begin{array}{l}\text { Incomplete outcome data } \\
\text { (attrition bias) } \\
\text { All outcomes }\end{array}$ & Low risk & Few losses to follow-up \\
\hline $\begin{array}{l}\text { Selective reporting (re- } \\
\text { porting bias) }\end{array}$ & Unclear risk & Not mentioned if women reported pain to their caregiver \\
\hline Other bias & Unclear risk & Data analyst unaware of coding. Balanced at baseline. \\
\hline
\end{tabular}

Levy 1971

\begin{tabular}{ll}
\hline Methods & RCT 2-arm parallel-group design \\
\hline Participants & USA: hospital setting \\
& $\begin{array}{l}93 \text { primiparous women in labour, uncomplicated pregnancy at } 37 \text { or more weeks' gestation and in pain } \\
\text { described as moderate or severe. }\end{array}$
\end{tabular}

Interventions

Experimental: IM pentazocine $60 \mathrm{mg}(\mathrm{N}=38)$

Control: IM pethidine $100 \mathrm{mg}(\mathrm{N}=45)$

Outcomes $\quad$ Primary: pain relief assessed at $1 \mathrm{hr}$, as good or poor.

Secondary: maternal side effects, nausea or vomiting, labour progress. Neonatal Apgar score at $1 \mathrm{~min}$ and 5 mins.

Notes If additional analgesia was required, a second injection could be administered at the discretion of medic. Not stated if IOL onset included.

Start and end date: not reported

Power calculation: not reported

Baseline imbalances between groups: unclear

Funding sources: Sterling drug company and NIH Grant RR 00404 
Levy 1971 (Continued)

Conflicts of interest: not reported

\section{Risk of bias}

\begin{tabular}{|c|c|c|}
\hline Bias & Authors' judgement & Support for judgement \\
\hline $\begin{array}{l}\text { Random sequence genera- } \\
\text { tion (selection bias) }\end{array}$ & Unclear risk & Not reported \\
\hline $\begin{array}{l}\text { Allocation concealment } \\
\text { (selection bias) }\end{array}$ & Unclear risk & Identical vials with code number but no further information given. \\
\hline $\begin{array}{l}\text { Blinding of participants } \\
\text { and personnel (perfor- } \\
\text { mance bias) } \\
\text { All outcomes }\end{array}$ & Low risk & Identical vials with code number \\
\hline $\begin{array}{l}\text { Blinding of outcome as- } \\
\text { sessment (detection bias) } \\
\text { All outcomes }\end{array}$ & Low risk & $\begin{array}{l}\text { No-one involved with the immediate care of the woman knew the drug identi- } \\
\text { ty. }\end{array}$ \\
\hline $\begin{array}{l}\text { Incomplete outcome data } \\
\text { (attrition bias) } \\
\text { All outcomes }\end{array}$ & High risk & $83 / 93$ women analysed and reasons for missing data not reported. \\
\hline $\begin{array}{l}\text { Selective reporting (re- } \\
\text { porting bias) }\end{array}$ & Unclear risk & Unclear \\
\hline Other bias & Unclear risk & $\begin{array}{l}\text { Unclear how many women randomised to each group and balance at baseline } \\
\text { unclear. }\end{array}$ \\
\hline
\end{tabular}

Li 1988

\begin{tabular}{ll}
\hline Methods & (Feasibility study) RCT, 2-arm parallel-group design \\
\hline Participants & $\begin{array}{l}10 \text { primiparous women in labour requesting pain relief, and who had no made any request for alterna- } \\
\text { tive analgesia. }\end{array}$ \\
\hline Interventions & Intervention group: meptazinol (PCA IM) up to $600 \mathrm{mg}(75 \mathrm{mg}$ per $\mathrm{mL})$ \\
& Comparison group: pethidine (PCA IM) up to $400 \mathrm{mg}$ (50 mg per mL) \\
& Doses described as equivalent. Nitrous oxide available to women in both groups. \\
\hline Outcomes & $\begin{array}{l}\text { Pain, drowsiness and nausea on a } 100 \text { mm VAS (0 = no pain) during labour and also rated on the day af- } \\
\text { ter birth; Apgar score and neonatal weight gain over } 3 \text { days. }\end{array}$ \\
\hline Fotes & Feasibility study focusing on PCA IM administration of opioids. \\
Start and end date: not reported \\
Power calculation: not reported \\
Baseline imbalances between groups: unclear \\
Funding sources: not reported
\end{tabular}


Li 1988 (Continued)

Conflicts of interest: not reported

\section{Risk of bias}

\begin{tabular}{|c|c|c|}
\hline Bias & Authors' judgement & Support for judgement \\
\hline $\begin{array}{l}\text { Random sequence genera- } \\
\text { tion (selection bias) }\end{array}$ & Unclear risk & Not described, "randomly allocated". \\
\hline $\begin{array}{l}\text { Allocation concealment } \\
\text { (selection bias) }\end{array}$ & Unclear risk & Described as a double-blind comparison but methods not described. \\
\hline $\begin{array}{l}\text { Blinding of participants } \\
\text { and personnel (perfor- } \\
\text { mance bias) } \\
\text { All outcomes }\end{array}$ & Unclear risk & Described as a double-blind comparison but methods not described. \\
\hline $\begin{array}{l}\text { Blinding of outcome as- } \\
\text { sessment (detection bias) } \\
\text { All outcomes }\end{array}$ & Unclear risk & Described as a double-blind comparison but methods not described. \\
\hline $\begin{array}{l}\text { Incomplete outcome data } \\
\text { (attrition bias) } \\
\text { All outcomes }\end{array}$ & Low risk & 10 women randomised and all accounted for in the analysis. \\
\hline $\begin{array}{l}\text { Selective reporting (re- } \\
\text { porting bias) }\end{array}$ & Unclear risk & Unclear \\
\hline Other bias & Unclear risk & No baseline imbalance apparent. \\
\hline
\end{tabular}

Li 1994

\begin{tabular}{ll}
\hline Methods & RCT. 2-arm parallel groups. \\
\hline Participants & Setting: Beijing hospital, China \\
& 60 women in early labour (cervical dilatation $2 \mathrm{~cm}$ to $3 \mathrm{~cm}$ ) at term, with singleton pregnancy, vertex \\
presentation, with no pregnancy complications.
\end{tabular}


Li 1994 (Continued)

\section{Risk of bias}

\begin{tabular}{|c|c|c|}
\hline Bias & Authors' judgement & Support for judgement \\
\hline $\begin{array}{l}\text { Random sequence genera- } \\
\text { tion (selection bias) }\end{array}$ & Unclear risk & Women were divided "at random" into groups. \\
\hline $\begin{array}{l}\text { Allocation concealment } \\
\text { (selection bias) }\end{array}$ & Unclear risk & Not described \\
\hline $\begin{array}{l}\text { Blinding of participants } \\
\text { and personnel (perfor- } \\
\text { mance bias) } \\
\text { All outcomes }\end{array}$ & High risk & Women in the control arm received no treatment. \\
\hline $\begin{array}{l}\text { Blinding of outcome as- } \\
\text { sessment (detection bias) } \\
\text { All outcomes }\end{array}$ & High risk & Women in the control arm received no treatment. \\
\hline $\begin{array}{l}\text { Incomplete outcome data } \\
\text { (attrition bias) } \\
\text { All outcomes }\end{array}$ & Unclear risk & Denominators not clear. No apparent loss to follow-up. \\
\hline $\begin{array}{l}\text { Selective reporting (re- } \\
\text { porting bias) }\end{array}$ & Unclear risk & Unclear \\
\hline Other bias & Unclear risk & $\begin{array}{l}\text { It was not clear whether or not women in the comparison group were given } \\
\text { any analgesia or whether they requested any. }\end{array}$ \\
\hline
\end{tabular}

Lisboa 1997

\begin{tabular}{ll}
\hline Methods & RCT 2-arm parallel-group design \\
\hline Participants & Setting: hospital, Brazil \\
& 56 women \\
& No information in abstract about participant inclusion criteria or characteristics. \\
\hline Interventions & Experimental: IM nalbuphine 10 mg \\
& Control: IM pethidine 100 mg \\
\hline Outcomes & Analgesia and side effects. \\
& Neonatal: Apgar score \\
\hline Notes & Abstract only: insufficient information about participants. \\
& Not reported if > 1 dose given or anti-emetic. \\
Start and end date: not reported \\
Power calculation: not reported \\
Baseline imbalances between groups: not reported \\
Funding sources: not reported
\end{tabular}


Lisboa 1997 (Continued)

Conflicts of interest: not reported

\section{Risk of bias}

\begin{tabular}{lll}
\hline Bias & Authors' judgement & Support for judgement \\
\hline $\begin{array}{l}\text { Random sequence genera- } \\
\text { tion (selection bias) }\end{array}$ & Unclear risk & Described as "randomly selected" but not explained how. \\
\hline $\begin{array}{l}\text { Allocation concealment } \\
\text { (selection bias) }\end{array}$ & Unclear risk & Not mentioned \\
\hline $\begin{array}{l}\text { Blinding of participants } \\
\text { and personnel (perfor- } \\
\text { mance bias) }\end{array}$ & Unclear risk & Not mentioned \\
All outcomes & \\
\hline $\begin{array}{l}\text { Blinding of outcome as- } \\
\text { sessment (detection bias) } \\
\text { All outcomes }\end{array}$ & Unclear risk & Not mentioned \\
\hline $\begin{array}{l}\text { Incomplete outcome data } \\
\text { (attrition bias) } \\
\text { All outcomes }\end{array}$ & Unclear risk & Not mentioned \\
\hline $\begin{array}{l}\text { Selective reporting (re- } \\
\text { porting bias) }\end{array}$ & Unclear risk & Impossible to decipher. \\
\hline \begin{tabular}{l} 
Other bias \\
\hline
\end{tabular} & Unclear risk & Impossible to decipher. \\
\hline
\end{tabular}

Liu 2015

\begin{tabular}{|c|c|}
\hline Methods & Randomised controlled trial with individual randomisation. \\
\hline \multirow[t]{3}{*}{ Participants } & Setting: Beijing Obstetrics and Gynecology Hospital, China. \\
\hline & $\begin{array}{l}120 \text { women randomised who had no previous poor obstetrical outcome; no experience in Han's Acu- } \\
\text { point Nerve Stimulator and TENS for other reasons; term pregnancy (> } 37 \text { weeks of gestation); at active } \\
\text { phase of the first stage of labour with cervical dilatation } 3 \mathrm{~cm} \text {. }\end{array}$ \\
\hline & $\begin{array}{l}\text { Exclusion criteria: had the history of experimental drug allergy; had been diagnosed with other dis- } \\
\text { eases such as preoperative presence of maternal mental, neurological diseases, affecting evaluation } \\
\text { of pains and disease conditions; had combined with gestational hypertension, gestational diabetes, } \\
\text { gestational thyroid diseases; had taken analgesic drugs or with a history of long-term use of analgesic } \\
\text { drugs; had used diazepam, piperazine hydrochloride or other sedative, analgesic drugs in the stages of } \\
\text { labour; were overweight or low pregnancy weight, } \mathrm{BMI}<18.5 \text { or } \mathrm{BMI}>25 \mathrm{~kg} / \mathrm{m} 2 \text {; were not agreeable to } \\
\text { receive painless labour and not sign the informed consent form. }\end{array}$ \\
\hline
\end{tabular}

Interventions

Experimental group 1: HANS (Han's acupoint nerve stimulator) group $(\mathrm{N}=30)$ received DC pulse stimulus at acupoints of Jiaji points (T 10-L 3) and Ciliao (BL 32)The stimulus was $100 \mathrm{~Hz}$ with a burst frequency of $2 \mathrm{~Hz}$ (dense dispersed waveform) The intensity was $15 \mathrm{~mA}$ to $30 \mathrm{~mA}$. The pulse duration was used for 30 mins.

Experimental group 2: PCIA (Patient-controlled intravenous analgesia) group $(\mathrm{N}=30)$ IV infused ondansetron $8 \mathrm{mg} ; 5$ mins later, $1.5 \mathrm{mg} / \mathrm{kg}$ tramadol injection was slowly dripped, connected to Baxter AP II electronic pump with $50 \mathrm{~mL}$ of $0.70 \%$ tramadol + ondansetron $8 \mathrm{mg}$, background infusion $2 \mathrm{~mL} / \mathrm{hr}$, PCA dose of $2 \mathrm{~mL}$, lockout interval of 10 mins. 
Liu 2015 (Continued)

Experimental group 3: PCEA (patient-controlled epidural analgesia) group ( $N=30)$ L2-3 combined spinal- epidural puncture, intrathecal injection of $3 \mathrm{mg}$ ropivacaine, epidural catheter connected to Baxter AP electronic pump, with $100 \mathrm{~mL} 0.1 \%$ ropivacaine and 50 ug sufentanil, background infusion 5 $\mathrm{mL}, \mathrm{PCA}$ dose of $5 \mathrm{~mL}$, lockout interval of 10 mins when the cervix was fully dilated $(10 \mathrm{~cm}) . \mathrm{N}=30$.

All treatments were stopped at the point of complete cervical dilatation.

Control group $(\mathrm{N}=30)$ did not receive analgesia.

Only experimental groups 1 and 2 are included in this review as per methods.

\begin{tabular}{|c|c|}
\hline \multirow[t]{7}{*}{ Outcomes } & $\begin{array}{l}\text { Outcomes } \\
\text { Mode of birth }\end{array}$ \\
\hline & Maternal side effects \\
\hline & Oxytocin use \\
\hline & Neonatal asphyxia \\
\hline & Pain scores \\
\hline & Duration of labour \\
\hline & Apgar (mean, SD) \\
\hline \multirow[t]{4}{*}{ Notes } & Trial dates: August 2010 - November 2013 \\
\hline & $\begin{array}{l}\text { Funding: The Scientific Achievement and Appropriate Technology Extension Project of Beijing Munici- } \\
\text { pal Commission of Health and Family Planning (TG-2014-12). }\end{array}$ \\
\hline & Conflict of interest: not reported \\
\hline & $\begin{array}{l}120 \text { women were randomised, so the number of women in each group should be } 30 \text {, this is what report- } \\
\text { ed in tables } 1-4 \text {, but different in trial profile. }\end{array}$ \\
\hline
\end{tabular}

\section{Risk of bias}

\section{Bias}

Random sequence genera- Low risk tion (selection bias)

\section{Authors' judgement Support for judgement}

Random number table method

\begin{tabular}{lll}
\hline $\begin{array}{l}\text { Allocation concealment } \\
\text { (selection bias) }\end{array}$ & Unclear risk & Not reported \\
\hline $\begin{array}{l}\text { Blinding of participants } \\
\text { and personnel (perfor- }\end{array}$ & High risk & It is not feasible to implement blinding. \\
mance bias) & & \\
All outcomes &
\end{tabular}

\begin{tabular}{|c|c|c|}
\hline $\begin{array}{l}\text { Blinding of outcome as- } \\
\text { sessment (detection bias) } \\
\text { All outcomes }\end{array}$ & High risk & It is not feasible to implement blinding. \\
\hline $\begin{array}{l}\text { Incomplete outcome data } \\
\text { (attrition bias) } \\
\text { All outcomes }\end{array}$ & Unclear risk & $\begin{array}{l}\text { No reports of loss to follow-up or women requesting other analgesia and } \\
\text { changing groups. Not clear if women in the control group requested analgesia } \\
\text { at all. Denominators given in the tables are lower than in flowchart. }\end{array}$ \\
\hline $\begin{array}{l}\text { Selective reporting (re- } \\
\text { porting bias) }\end{array}$ & Unclear risk & All outcomes from methods are reported. Protocol not seen. \\
\hline
\end{tabular}


Liu 2015 (Continued)
Other bias
Unclear risk
There was no statistical difference in the basic information between 4 groups $(P>0.05)$. Generally reporting is unclear.

Maduska 1978

\begin{tabular}{ll}
\hline Methods & RCT 2-arm parallel-group design \\
\hline Participants & Setting: hospital, USA \\
& 80 women at term gestation, in spontaneous and induced labour with moderate to severe pain. \\
& Exclusions: drug abuse history, systemic disease and women who planned to breastfeed their babies.
\end{tabular}

Interventions

Experimental: IM butorphanol 1 or $2 \mathrm{mg}(\mathrm{N}=40)$

Control: IM pethidine 40 or $80 \mathrm{mg}(\mathrm{N}=40)$

Primary: pain intensity assessed 30 and 60 mins post injection. Described as $1=$ slight relief, $2=$ moder-
ate relief, $3=$ good relief, $4=$ complete relief. Maternal satisfaction of overall drug effect assessed post-
natally as $1=$ poor, $2=$ fair, $3=$ very good, $4=$ excellent
Secondary: neonatal Apgar score at 1 and 5 mins, resuscitation. Maternal nausea and vomiting.

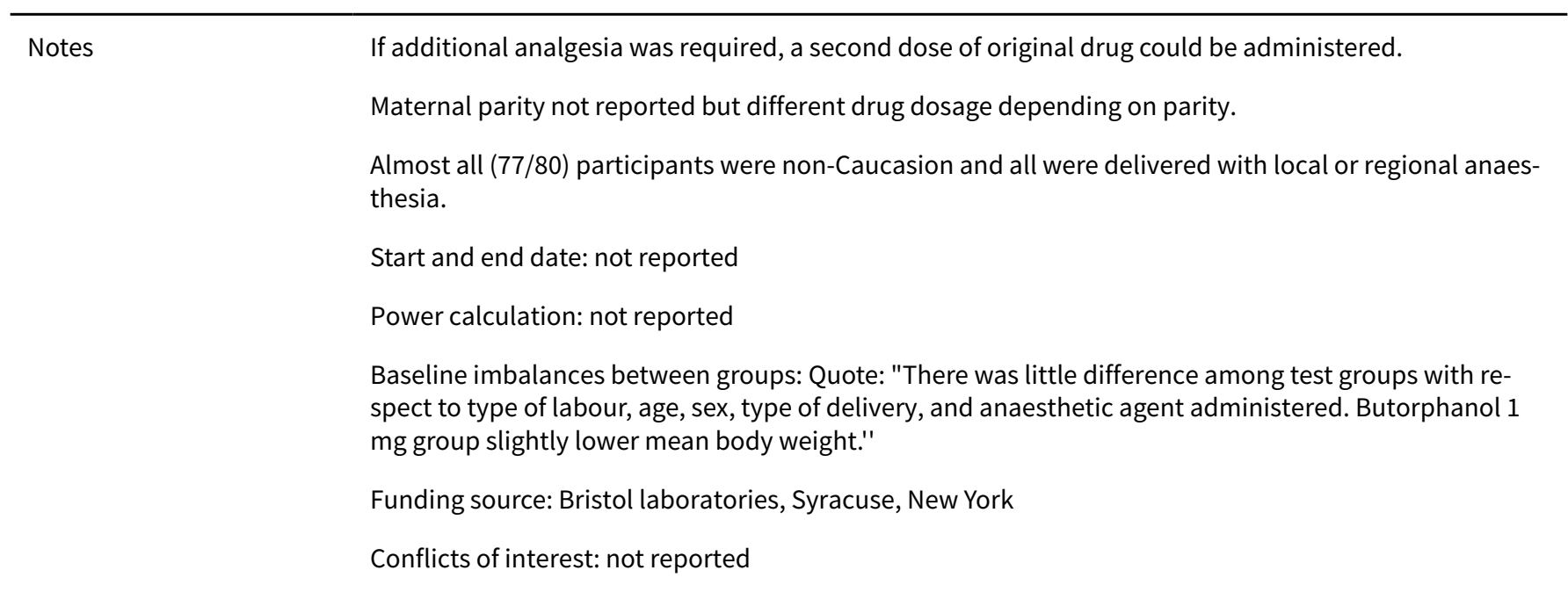

\section{Risk of bias}

\begin{tabular}{|c|c|c|}
\hline Bias & Authors' judgement & Support for judgement \\
\hline $\begin{array}{l}\text { Random sequence genera- } \\
\text { tion (selection bias) }\end{array}$ & Unclear risk & Not reported \\
\hline $\begin{array}{l}\text { Allocation concealment } \\
\text { (selection bias) }\end{array}$ & Low risk & $\begin{array}{l}\text { Drugs in consecutively-numbered, identical vials prepared by independent } \\
\text { laboratory. }\end{array}$ \\
\hline $\begin{array}{l}\text { Blinding of participants } \\
\text { and personnel (perfor- } \\
\text { mance bias) } \\
\text { All outcomes }\end{array}$ & Low risk & States double-blind, drugs in identical vials. \\
\hline $\begin{array}{l}\text { Blinding of outcome as- } \\
\text { sessment (detection bias) }\end{array}$ & Unclear risk & Not reported \\
\hline
\end{tabular}

Parenteral opioids for maternal pain management in labour (Review) 
Maduska 1978 (Continued)

All outcomes

\begin{tabular}{lll}
$\begin{array}{l}\text { Incomplete outcome data } \\
\text { (attrition bias) } \\
\text { All outcomes }\end{array}$ & Low risk & All women analysed. \\
\hline $\begin{array}{l}\text { Selective reporting (re- } \\
\text { porting bias) }\end{array}$ & Unclear risk & Unclear \\
\hline Other bias & Unclear risk & $\begin{array}{l}\text { Balanced at baseline for type of labour, weight, age, type of birth and anaes- } \\
\text { thetic agent. }\end{array}$ \\
\hline
\end{tabular}

\section{Mitterschiffthaler 1991}

\begin{tabular}{ll}
\hline Methods & RCT 2-arm parallel-group design \\
\hline Participants & Setting: Germany \\
& 40 women. Term pregnancy, cx dilated $2 \mathrm{~cm}$ to $3 \mathrm{~cm}$, spontaneous labour onset, in active labour and re- \\
& quiring analgesia. \\
& Parity: not reported \\
\hline
\end{tabular}

Interventions Experimental: IM nalbuphine $0.1 \mathrm{mg} / \mathrm{kg}(\mathrm{N}=20)$

Control: IM pethidine $0.8 \mathrm{mg} / \mathrm{kg}(\mathrm{N}=20)$

States dosing was 'on demand'. Unclear if single or multiple doses administered, and if additional analgesia administered.

\begin{tabular}{ll}
\hline Outcomes & Maternal outcomes: maternal pain relief VAS $(0 \mathrm{~cm}$ to $20 \mathrm{~cm}) 30,60,90$ and 120 mins, opinion of pain re- \\
& lief 12 hrs postpartum, sedation 4-point scale (awake, tired, sleeping but will wake if spoken to, sleep- \\
& ing but will wake if shaken, asleep not possible to wake up) 30, 60, 90 and 120 mins, 'side effects', blood \\
pressure, heart rate, CTG. Neonatal outcomes: Apgar score at 10 mins, respiratory depression.
\end{tabular}

Gotes
Start and end date: unclear
Power calculation: unclear
Baseline imbalances between groups: unclear
Funding source: unclear
Conflicts of interest: unclear

\section{Risk of bias}

\begin{tabular}{lll}
\hline Bias & Authors' judgement & Support for judgement \\
\hline $\begin{array}{l}\text { Random sequence genera- } \\
\text { tion (selection bias) }\end{array}$ & Unclear risk & Not reported \\
\hline $\begin{array}{l}\text { Allocation concealment } \\
\text { (selection bias) }\end{array}$ & Unclear risk & Not reported \\
\hline
\end{tabular}


Mitterschiffthaler 1991 (Continued)
Blinding of participants
Unclear risk
Not reported and personnel (perfor- mance bias)
All outcomes

\begin{tabular}{|c|c|c|}
\hline $\begin{array}{l}\text { Blinding of outcome as- } \\
\text { sessment (detection bias) } \\
\text { All outcomes }\end{array}$ & Unclear risk & Not reported \\
\hline
\end{tabular}

Incomplete outcome data High risk
(attrition bias)

4/40 women excluded due to insufficient pain relief.

All outcomes

\begin{tabular}{lll}
\hline $\begin{array}{l}\text { Selective reporting (re- } \\
\text { porting bias) }\end{array}$ & Unclear risk & Unclear \\
\hline Other bias & Unclear risk & Unclear \\
\hline
\end{tabular}

\section{Mobaraki 2016}

\begin{tabular}{ll}
\hline Methods & Randomised clinical trial, individually randomised \\
\hline Participants & Setting: hospital in Iran. \\
& 100 women randomised in spontaneous labour pain along with appropriate maternal and fetal indica- \\
tions for vaginal delivery. & \\
& $\begin{array}{l}\text { Exclusion criteria: presence of a personality disorder, an addiction, a complicated pregnancy, diabetes } \\
\text { mellitus, macrosomia, chronic obstructive pulmonary disease, an unconfident fetal heart rate, valvular } \\
\text { heart disease, an upper respiratory tract infection or sinus obstruction, a history of asthma, and con- } \\
\text { traindications for Entonox and pethidine usage. }\end{array}$
\end{tabular}

Interventions

Experimental group: pethidine (50 women)

The pethidine group received an intramuscular injection of $0.5 \mathrm{mg} / \mathrm{kg}$ of pethidine. If a patient's pain rated higher than 5 VAS, $0.25 \mathrm{mg} / \mathrm{kg}$ of pethidine was injected. Not clear if pethidine was limited to 2 doses.

Control group: Entonox (50 women)

Patients were taught to use an Entonox face mask at the beginning of uterine contractions and to continue deep inspirations at times when there was pain and cramps. Use of Entonox could be started or cut at any moment during labour according to the needs and preferences of the woman.

\section{Outcomes}

Pain scores after analgesia.

Duration of first and second stage of labour.

$\begin{array}{ll}\text { Notes } & \text { Dates: } 2015 \\ & \text { Funding: Ardabil Medical Sciences University } \\ & \text { Conflict of interest: not stated }\end{array}$

\section{Risk of bias}

Bias Authors' judgement Support for judgement


Mobaraki 2016 (Continued)

Random sequence genera- Unclear risk By using random numbers, the participants were randomly allocated into 2 tion (selection bias) groups. Equal groups and no further detail.

$\begin{aligned} & \text { Allocation concealment } \\ & \text { (selection bias) }\end{aligned}$
Unclear risk Not described

Blinding of participants High risk Infeasible to blind.
and personnel (perfor-
mance bias)
All outcomes

\begin{tabular}{lll}
\hline $\begin{array}{l}\text { Blinding of outcome as- } \\
\text { sessment (detection bias) } \\
\text { All outcomes }\end{array}$ & High risk & Not mentioned, but likely to be caregiver carrying out assessment. \\
\hline $\begin{array}{l}\text { Incomplete outcome data } \\
\text { (attrition bias) }\end{array}$ & Unclear risk & $\begin{array}{l}\text { No loss to follow-up reported, and no denominators given in results tables. De- } \\
\text { mographic data do not add up to total number of participants. Difficult to as- } \\
\text { All outcomes }\end{array}$ \\
\hline
\end{tabular}

\begin{tabular}{lll}
\hline $\begin{array}{l}\text { Selective reporting (re- } \\
\text { porting bias) }\end{array}$ & Unclear risk & No protocol seen and few outcomes pre-specified in the methods. \\
\hline Other bias & Unclear risk & $\begin{array}{l}\text { Parity is not reported in each group. There were } 16 / 50 \text { under } 20 \text { year olds in the } \\
\text { Entonox group and } 9 / 50 \text { in the pethidine group. These could be more likely to } \\
\text { be nulliparous. }\end{array}$
\end{tabular}

Moore 1970

\begin{tabular}{ll}
\hline Methods & RCT 2-arm parallel-group design \\
\hline Participants & Setting: hospital, UK \\
& $\begin{array}{l}206 \text { mixed parity healthy women, in spontaneous or induced labour, at > } 35 \text { weeks' gestation, cephalic } \\
\text { presentation and in pain described as severe, moderate or slight. }\end{array}$
\end{tabular}

\begin{tabular}{ll}
\hline Interventions & Experimental: IM pentazocine $40 \mathrm{mg}(\mathrm{N}=73)$ \\
& Control: IM pethidine $100 \mathrm{mg}$ or $50 \mathrm{mg}(\mathrm{N}=133)$ \\
\hline
\end{tabular}

Outcomes Primary: pain intensity assessed at 30, 60 and 90 mins post injection, described as severe, moderate or
slight. Asked at 12 to $24 \mathrm{hr}$ postnatal if drug had helped.

Secondary: neonatal Apgar score at 1 min and 5 mins, maternal side effects of nausea or vomiting.

Notes If additional analgesia required, a maximum of 3 further doses of study drug could be administered at

2- to 3-hourly intervals. Women could also use nitrous oxide and some had a paracervical block.

$>35$ weeks' gestation therefore preterm babies may be included.

Start and end date: not reported

Power calculation: not reported

Baseline imbalances between groups: the age, physical and obstetric characteristics were similar between groups except in fetal presentation.

Funding source: not reported 
Moore 1970 (Continued)

Conflicts of interest: not reported

\section{Risk of bias}

\begin{tabular}{|c|c|c|}
\hline Bias & Authors' judgement & Support for judgement \\
\hline $\begin{array}{l}\text { Random sequence genera- } \\
\text { tion (selection bias) }\end{array}$ & Unclear risk & Not reported \\
\hline $\begin{array}{l}\text { Allocation concealment } \\
\text { (selection bias) }\end{array}$ & Unclear risk & Coded ampoules but no further information given. \\
\hline $\begin{array}{l}\text { Blinding of participants } \\
\text { and personnel (perfor- } \\
\text { mance bias) } \\
\text { All outcomes }\end{array}$ & Unclear risk & $\begin{array}{l}\text { States double-blind. Coded ampoules but not stated if identical in appear- } \\
\text { ance. }\end{array}$ \\
\hline $\begin{array}{l}\text { Blinding of outcome as- } \\
\text { sessment (detection bias) } \\
\text { All outcomes }\end{array}$ & Unclear risk & $\begin{array}{l}\text { States double-blind. Coded ampoules but not stated if identical in appear- } \\
\text { ance. }\end{array}$ \\
\hline $\begin{array}{l}\text { Incomplete outcome data } \\
\text { (attrition bias) } \\
\text { All outcomes }\end{array}$ & High risk & 29/206 excluded because delivered or had paracervical block. \\
\hline $\begin{array}{l}\text { Selective reporting (re- } \\
\text { porting bias) }\end{array}$ & Unclear risk & Unclear \\
\hline Other bias & Unclear risk & Unclear \\
\hline
\end{tabular}

Morley-Forster 2000

\begin{tabular}{ll}
\hline Methods & RCT, 2-arm parallel-group design \\
\hline Participants & Setting: labour ward of a university health centre in Canada. \\
& $\begin{array}{l}23 \text { women randomised when they requested analgesia, } 83 \% \text { primips, gestational age }>32 \text { weeks, } \\
\text { weight < } 100 \mathrm{~kg} \text { or }>50 \mathrm{~kg}, \text { able to speak English, no history of opioid abuse and normal FHR tracing. } \\
\text { (Women recruited to the study had medical contraindications to epidural although it was no specified } \\
\text { what these were.) }\end{array}$ \\
\hline Interventions & $\begin{array}{l}\text { Experimental: fentanyl, PCA } 10 \text { mcg per mL, initial bolus dose } 1 \mathrm{~mL} \text {, basal infusion rate of } 2 \mathrm{~mL} \text { per hr } \\
\text { Control: alfentanil, PCA } 100 \text { micro g per mL, initial bolus dose } 1 \mathrm{~mL}, \text { basal infusion rate of } 2 \mathrm{~mL} \text { per hr } \\
\text { with PCA bolus } 2 \mathrm{~mL} . \\
\text { Doses described as equivalent. Drugs were discontinued in both groups when the attending midwife } \\
\text { estimated that birth was likely to take place within } 15 \text { mins. }\end{array}$ \\
\hline $\begin{array}{l}\text { Pain (rated on a } 100 \mathrm{~mm} \text { VAS, recorded at baseline and every } 30 \text { mins thereafter); sedation (nurse rated } \\
\text { hourly); side effects; satisfaction with pain relief (good, adequate, inadequate); Apgar scores at } 5 \text { and } \\
10 \text { mins; cord blood gases; naloxone dose; neonatal neuro-behavioural score at } 4 \text { and } 24 \text { hrs. }\end{array}$ \\
\hline $\begin{array}{l}\text { Start and end date: not reported } \\
\text { Power calculation: not reported }\end{array}$ \\
\hline Notes
\end{tabular}


Morley-Forster 2000 (Continued)

Baseline imbalances between groups: quote: "The two groups were similar in age, weight, gestational age, parity, inductions, type of delivery, baseline pain scores, rate of cervical dilatation, duration of PCA use. The only difference was that the opioid dose- to delivery time was shorter in the alfentanil group."

Funding sources: not reported

Conflicts of interest: not reported

\section{Risk of bias}

\begin{tabular}{|c|c|c|}
\hline Bias & Authors' judgement & Support for judgement \\
\hline $\begin{array}{l}\text { Random sequence genera- } \\
\text { tion (selection bias) }\end{array}$ & Low risk & Randomisation schedule prepared by pharmacy. \\
\hline $\begin{array}{l}\text { Allocation concealment } \\
\text { (selection bias) }\end{array}$ & Low risk & Plain, numbered vials prepared by pharmacy. \\
\hline $\begin{array}{l}\text { Blinding of participants } \\
\text { and personnel (perfor- } \\
\text { mance bias) } \\
\text { All outcomes }\end{array}$ & Low risk & Plain vials prepared by pharmacy. \\
\hline $\begin{array}{l}\text { Blinding of outcome as- } \\
\text { sessment (detection bias) } \\
\text { All outcomes }\end{array}$ & Low risk & Stated that assessment was carried out by staff blind to group assignment. \\
\hline $\begin{array}{l}\text { Incomplete outcome data } \\
\text { (attrition bias) } \\
\text { All outcomes }\end{array}$ & Unclear risk & $\begin{array}{l}25 \text { women were randomised. } 2 \text { did not follow the protocol and were not fol- } \\
\text { lowed up. There were missing data for some variables. }\end{array}$ \\
\hline $\begin{array}{l}\text { Selective reporting (re- } \\
\text { porting bias) }\end{array}$ & Unclear risk & Unclear \\
\hline Other bias & Unclear risk & Small sample size and the onset of analgesia varied. \\
\hline
\end{tabular}

\section{Morrison 1987}

\begin{tabular}{ll}
\hline Methods & RCT 2-arm parallel-group design \\
\hline Participants & Setting: hospital, UK \\
& 1100 women. $37-42$ weeks' gestation, in active labour and requiring analgesia. \\
& Parity: $44 \%$ primips, $56 \%$ multips. \\
\hline Interventions & Experimental: IM meptazinol $100 \mathrm{mg} \leq 70 \mathrm{~kg}, 150 \mathrm{mg}>70 \mathrm{~kg}(\mathrm{~N}=513)$ \\
& Control: IM pethidine $1100 \mathrm{mg} \leq 70 \mathrm{~kg}, 150 \mathrm{mg}>70 \mathrm{~kg}(\mathrm{~N}=522)$ \\
& Second dose, epidural or inhalation analgesia at maternal request. \\
\hline Outcomes & $\begin{array}{l}\text { Maternal outcomes: maternal pain at } 30,60,90 \text { and } 120 \mathrm{mins} \text { VAS (0 to } 100 \text { mm), nausea, vomiting, } \\
\text { sleepiness, use of supplementary analgesia, method of birth, opinion of analgesic effect assessed 3-5 } \\
\text { days postpartum (rated excellent, good, poor but just able to cope, no effect and required additional } \\
\text { analgesia). Neonatal outcomes: Apgar at } 1 \text { min and } 5 \text { mins, resuscitation, naloxone administration, fe- } \\
\text { tal distress, type of feeding. }\end{array}$
\end{tabular}


Morrison 1987 (Continued)

Notes
Start and end date: not reported

Power calculation: not reported

Baseline imbalances between groups: 'The groups were comparable with regard to age, maternal weight, parity and gestation'

Funding source: not reported

Conflicts of interest: not reported

\section{Risk of bias}

\begin{tabular}{lll}
\hline Bias & Authors' judgement & Support for judgement \\
\hline $\begin{array}{l}\text { Random sequence genera- } \\
\text { tion (selection bias) }\end{array}$ & Unclear risk & Not reported \\
\hline $\begin{array}{l}\text { Allocation concealment } \\
\text { (selection bias) }\end{array}$ & Low risk & Coded drug containers prepared at a site remote from the trial. \\
\hline $\begin{array}{l}\text { Blinding of participants } \\
\text { and personnel (perfor- } \\
\text { mance bias) }\end{array}$ & Low risk & States double-blind and used coded drug containers. \\
$\begin{array}{l}\text { All outcomes } \\
\text { Blinding of outcome as- } \\
\text { sessment (detection bias) } \\
\text { All outcomes }\end{array}$ & Low risk & States double-blind and used coded drug containers. \\
\hline $\begin{array}{l}\text { Incomplete outcome data } \\
\text { (attrition bias) } \\
\text { All outcomes }\end{array}$ & High risk & Un women excluded due to clerical errors or administration of wrong drug. \\
\hline $\begin{array}{l}\text { Selective reporting (re- } \\
\text { porting bias) }\end{array}$ & Unclear risk & Unclear \\
\hline \begin{tabular}{l} 
Other bias \\
\hline
\end{tabular} & Unclear risk & Women were balanced at baseline for age, weight, parity and gestation. \\
\hline
\end{tabular}

\section{Mowat 1970}

\begin{tabular}{ll}
\hline Methods & RCT 2-arm parallel-group design \\
\hline Participants & Setting: hospital, UK \\
& 94 women. $>35$ weeks' gestation, age $\geq 18$ years, excluded if diabetic, history of renal or hepatic impair- \\
ment or taking monoamine oxidase inhibitors, in active labour and requiring analgesia. & \\
& Parity: $\leq 3$ \\
\hline Interventions & Experimental: IM pentazocine $60 \leq \mathrm{mg}(\mathrm{N}=46)$ \\
& Control: IM pethidine $15 \leq 0 \mathrm{mg}(\mathrm{N}=48)$ \\
& Up to 3 injections $>3$ hrs apart at maternal request.
\end{tabular}


Mowat 1970 (Continued)

Outcomes

Maternal outcomes: satisfied with analgesia, nausea, vomiting, sleepiness, use of additional analgesia (study drug), method of birth. Neonatal outcomes: Apgar at 1 min and 5 mins.

Notes

Data for some outcomes available after first dose.

Start and end date: not reported

Power calculation: not reported

Baseline imbalances between groups: the groups were similar with respect to age, and number of previous pregnancies.

Funding source: Sterling Winthrop Research Division supplied the drugs.

Conflicts of interest: not reported

\section{Risk of bias}

\begin{tabular}{lll}
\hline Bias & Authors' judgement & Support for judgement \\
\hline $\begin{array}{l}\text { Random sequence genera- } \\
\text { tion (selection bias) }\end{array}$ & Unclear risk & Not reported \\
\hline $\begin{array}{l}\text { Allocation concealment } \\
\text { (selection bias) }\end{array}$ & Unclear risk & Not reported \\
\hline $\begin{array}{l}\text { Blinding of participants } \\
\text { and personnel (perfor- } \\
\text { mance bias) }\end{array}$ & Unclear risk & States double-blind but how achieved not reported. \\
All outcomes & \\
\hline
\end{tabular}

Blinding of outcome as- Unclear risk States double-blind but how achieved not reported.

sessment (detection bias)

All outcomes

Incomplete outcome data High risk Exclusions from most analyses.

(attrition bias)

All outcomes

Selective reporting (re- Unclear risk Unclear
porting bias)

Other bias Low risk Balanced at baseline for age, parity, induced labour onset.

Nel 1981

\begin{tabular}{ll}
\hline Methods & RCT 2-arm parallel-group design \\
\hline Participants & Setting: hospital, South Africa \\
& $\begin{array}{l}75 \text { women. Healthy with no clinically detectable abnormality, in active labour, spontaneous and in- } \\
\text { duced, and requiring analgesia. Excluded if history of hypersensitivity to any drug, previous caesarean, } \\
\text { preterm labour, cardiac, pulmonary or renal disease and significant hypertension. }\end{array}$ \\
& Parity: mixed
\end{tabular}

Interventions

Experimental: IM meptazinol $100 \mathrm{mg}(\mathrm{N}=37)$ 
Nel 1981 (Continued)

Control: IM pethidine $100 \mathrm{mg}(\mathrm{N}=38)$

No concomitant analgesia given, metoclopramide $10 \mathrm{mg}$ as required for nausea.

\begin{tabular}{ll} 
Outcomes & $\begin{array}{l}\text { Maternal outcomes: pain at } 1 \mathrm{hr} 5 \text {-point VAS scale, drug-related side effects. Neonatal outcomes: Apgar } \\
\text { at } 1 \mathrm{~min} \text { and } 5 \text { mins, paediatrician assessment at } 24 \text { hrs }\end{array}$ \\
\hline Notes & Start and end date: not reported \\
Power calculation: not reported \\
Baseline imbalances between groups: unclear \\
Funding source: not reported \\
Conflicts of interest: not reported
\end{tabular}

\section{Risk of bias}

\begin{tabular}{|c|c|c|}
\hline Bias & Authors' judgement & Support for judgement \\
\hline $\begin{array}{l}\text { Random sequence genera- } \\
\text { tion (selection bias) }\end{array}$ & Unclear risk & Not reported \\
\hline $\begin{array}{l}\text { Allocation concealment } \\
\text { (selection bias) }\end{array}$ & Unclear risk & Not reported \\
\hline $\begin{array}{l}\text { Blinding of participants } \\
\text { and personnel (perfor- } \\
\text { mance bias) } \\
\text { All outcomes }\end{array}$ & Unclear risk & States double-blind but does not describe how blinding achieved. \\
\hline $\begin{array}{l}\text { Blinding of outcome as- } \\
\text { sessment (detection bias) } \\
\text { All outcomes }\end{array}$ & Unclear risk & States double-blind but does not describe how blinding achieved. \\
\hline $\begin{array}{l}\text { Incomplete outcome data } \\
\text { (attrition bias) } \\
\text { All outcomes }\end{array}$ & High risk & $\begin{array}{l}\text { Number of women randomised not reported only number analysed, not same } \\
\text { numbers analysed for all outcomes. }\end{array}$ \\
\hline $\begin{array}{l}\text { Selective reporting (re- } \\
\text { porting bias) }\end{array}$ & Unclear risk & Unclear \\
\hline Other bias & Unclear risk & $\begin{array}{l}\text { Women requiring caesarean or epidural were excluded from further study, un- } \\
\text { clear if this is pre- or post-randomisation. }\end{array}$ \\
\hline
\end{tabular}

Nelson 2005

\begin{tabular}{ll}
\hline Methods & RCT, 3-arm parallel-group design \\
\hline Participants & Setting: hospital in North Carolina USA. \\
& 45 healthy women with singleton pregnancies requesting analgesia. \\
& $\begin{array}{l}\text { Women with allergies to the study medication, those that had already had medication and those taking } \\
\text { opioids for chronic conditions were excluded, along with those with any signs of fetal distress. }\end{array}$
\end{tabular}


Control: (15 women) IV pethidine, $50 \mathrm{mg}$ bolus

(A second control group received IV pethidine $25 \mathrm{mg}$ plus $0.5 \mathrm{mg}$ butorphanol; this group has not been included in the analyses in this review.)

Outcomes

Pain (measured on a 0 -10 numerical rating scale); sedation and nausea, Apgar scores at 1 min and 5 mins.

\section{Notes}

Results for pain outcomes were reported on bar charts and are difficult to interpret. We have not included these results in the analyses in this review.

Start and end date: not reported

Power calculation: 'the study was powered based on the increased variability in pain'.

Baseline imbalances between groups: 'Groups did not differ in demographic or labor characteristics'.

Funding source: National Institutes of Health, Bethesda, Maryland (grant No. NS41386)

Conflicts of interest: not reported

\section{Risk of bias}

\begin{tabular}{|c|c|c|}
\hline Bias & Authors' judgement & Support for judgement \\
\hline $\begin{array}{l}\text { Random sequence genera- } \\
\text { tion (selection bias) }\end{array}$ & Low risk & Quote: "computer generated balanced block design". Block size not stated. \\
\hline $\begin{array}{l}\text { Allocation concealment } \\
\text { (selection bias) }\end{array}$ & Unclear risk & $\begin{array}{l}\text { Study described as double-blind but not details on allocation concealment } \\
\text { provided. }\end{array}$ \\
\hline $\begin{array}{l}\text { Blinding of participants } \\
\text { and personnel (perfor- } \\
\text { mance bias) } \\
\text { All outcomes }\end{array}$ & Low risk & $\begin{array}{l}\text { Quote: "drug was prepared by an anaesthesiologist not involved with the } \\
\text { treatment of the patient or obtaining study measures". Described as dou- } \\
\text { ble-blind. }\end{array}$ \\
\hline $\begin{array}{l}\text { Blinding of outcome as- } \\
\text { sessment (detection bias) } \\
\text { All outcomes }\end{array}$ & Unclear risk & Not described \\
\hline $\begin{array}{l}\text { Incomplete outcome data } \\
\text { (attrition bias) } \\
\text { All outcomes }\end{array}$ & High risk & $\begin{array}{l}\text { It was not clear how many women were randomised. Any women undergoing } \\
\text { ARM, commencing oxytocin or requesting epidural were excluded after ran- } \\
\text { domisation and were replaced Quote: "their randomization was re-entered for } \\
\text { another patient". Women who reached } 10 \mathrm{~cm} \text { dilation within } 1 \mathrm{hr} \text { of drug ad- } \\
\text { ministration were also excluded from the analysis. }\end{array}$ \\
\hline $\begin{array}{l}\text { Selective reporting (re- } \\
\text { porting bias) }\end{array}$ & Unclear risk & Unclear \\
\hline Other bias & Unclear risk & Unclear \\
\hline
\end{tabular}

Neumark 1978

\begin{tabular}{ll}
\hline Methods $\quad$ Randomised trial (methods unclear) \\
\hline
\end{tabular}

Participants

30 women 
Neumark 1978 (Continued)

Inclusion criteria: Quote: "co-operative patients" with no drug dependency. Various ages and social groups.

Exclusion criteria: unclear

Interventions
1. TENS group - TENS to lower back (10 women);
2. 50 mg IV pethidine (5 women);
3. placebo TENS (no current) (5 women);
4. "Wrong" TENS (electrodes applied to wrong positions) (5 women);
5. no analgesia or intervention (5 women).

Outcomes

Pain intensity (grades 1 - 6 - no pain, light, bearable, heavy, very heavy, unbearable) over 70-min period. Satisfaction with analgesia 1 day after the birth "Reaction of the subjects the day after the birth to analgesia - rated as "good", "inadequate analgesia" or "none" - table 2. Progress in labour.

Notes

Paper in German. Translation notes used for data extraction.

We were unable to use the data from this paper in the review. We had intended comparing outcomes for women receiving IV pethidine versus no treatment. The only outcome reported in the paper was the amount of relief obtained from the analgesia and no outcomes were reported for the control group (no treatment). 5 women received pethidine and 5 women no treatment. It was reported that $2 / 5$ women receiving pethidine had "good relief", 3 had insufficient or no relief. All women in the control group were reported as having an increase in pain.

Results - categories for pain relief (good, insufficient, none) do not correspond with pain scale - 6 perceptions reported in the translation.

Start and end date: not reported

Power calculation: unclear

Baseline imbalances between groups: unclear

Funding source: unclear

Conflicts of interest: unclear

\section{Risk of bias}

\begin{tabular}{|c|c|c|}
\hline Bias & Authors' judgement & Support for judgement \\
\hline $\begin{array}{l}\text { Random sequence genera- } \\
\text { tion (selection bias) }\end{array}$ & Unclear risk & Not described - "randomly divided". \\
\hline $\begin{array}{l}\text { Allocation concealment } \\
\text { (selection bias) }\end{array}$ & Unclear risk & Not described \\
\hline $\begin{array}{l}\text { Blinding of participants } \\
\text { and personnel (perfor- } \\
\text { mance bias) } \\
\text { All outcomes }\end{array}$ & Unclear risk & $\begin{array}{l}1 \text { group received no treatment. TENS groups - } 1 \text { without current and } 1 \text { where it } \\
\text { was applied to wrong positions were blinded to the TENS intervention. Pethi- } \\
\text { dine group presumably were not blinded. blinding of personnel is unclear. }\end{array}$ \\
\hline $\begin{array}{l}\text { Blinding of outcome as- } \\
\text { sessment (detection bias) } \\
\text { All outcomes }\end{array}$ & Unclear risk & Not clear \\
\hline $\begin{array}{l}\text { Incomplete outcome data } \\
\text { (attrition bias) }\end{array}$ & Unclear risk & 1 woman was lost to follow-up. \\
\hline
\end{tabular}


Neumark 1978 (Continued)

All outcomes

Selective reporting (re- Unclear risk $\quad$ Small study and results were difficult to interpret.
porting bias)

Other bias Unclear risk Translation, so difficult to evaluate other bias.

Nicholas 1982

\begin{tabular}{ll}
\hline Methods & RCT 2-arm parallel-group design \\
\hline Participants & Setting: hospital, UK \\
& 450 women. Healthy women with no obstetric complications, full-term pregnancy, in active labour and \\
requiring analgesia. Excluded if history of hypersensitivity to any drug, previous caesarean, preterm \\
labour, cardiac, pulmonary or renal disease and significant hypertension. \\
Parity: not reported
\end{tabular}

Interventions $\quad$ Experimental: IM meptazinol ( $\mathrm{N}=186$ analysed).

Control: IM pethidine ( $\mathrm{N}=172$ analysed).

Both given according to body weight. $75 \mathrm{mg}$ if $38 \mathrm{~kg}$ to $50 \mathrm{~kg}, 100 \mathrm{mg}$ if $51 \mathrm{~kg}$ to $69 \mathrm{~kg}$ or $150 \mathrm{mg}$ if $70-85$ $\mathrm{kg}$. Each patient received up to 2 injections of study drug, and if analgesia still inadequate epidural given.

\section{Outcomes}

Maternal outcomes: maternal assessment of pain relief at 15, 30, 45, 60, 90 and 120 mins (rated none, poor, satisfactory, good, very good or complete), type of birth, epidural, sleepiness, nausea and vomiting. Neonatal outcomes: Apgar at $1 \mathrm{~min}$ and 5 mins, apnoea, resuscitation, and lethargy, muscle tone, irritability success of feeding within first 24-hr period.

\begin{tabular}{|c|c|}
\hline \multirow[t]{6}{*}{ Notes } & Does not report number randomised to each group. \\
\hline & Start and end date:not reported \\
\hline & Power calculation: not reported \\
\hline & Baseline imbalances between groups: not reported \\
\hline & Funding source: not reported \\
\hline & Conflicts of interest: not reported \\
\hline
\end{tabular}

\section{Risk of bias}

\begin{tabular}{lll}
\hline Bias & Authors' judgement & Support for judgement \\
\hline $\begin{array}{l}\text { Random sequence genera- } \\
\text { tion (selection bias) }\end{array}$ & Unclear risk & Not reported \\
\hline $\begin{array}{l}\text { Allocation concealment } \\
\text { (selection bias) }\end{array}$ & Unclear risk & Not reported \\
\hline $\begin{array}{l}\text { Blinding of participants } \\
\text { and personnel (perfor- } \\
\text { mance bias) } \\
\text { All outcomes }\end{array}$ & Unclear risk & States double-blind but does not describe methods used. \\
\hline
\end{tabular}


Nicholas 1982 (Continued)

Blinding of outcome as- Unclear risk States double-blind but does not describe methods used. sessment (detection bias)

All outcomes

\begin{tabular}{lll}
$\begin{array}{l}\text { Incomplete outcome data } \\
\text { (attrition bias) } \\
\text { All outcomes }\end{array}$ & High risk & 79.5\% follow-up but no ITT analysis. \\
\hline $\begin{array}{l}\text { Selective reporting (re- } \\
\text { porting bias) }\end{array}$ & Unclear risk & Unclear \\
\hline Other bias & Unclear risk & Unclear
\end{tabular}

\section{O'Dwyer 1971}

\begin{tabular}{ll}
\hline Methods & RCT 2-arm parallel-group design \\
\hline Participants & Setting: hospital, UK \\
& $\begin{array}{l}100 \text { women. Age }>18 \text { years, }>35 \text { weeks' gestation, uncomplicated singleton, vaginal birth expected, in } \\
\text { active labour and requiring analgesia. } \\
\text { Parity: } 9 \% \text { primips, } 76 \% \text { multips, } 15 \% \text { grand multips. }\end{array}$ \\
\hline
\end{tabular}

Experimental: IM pentazocine $30 \mathrm{mg}(\mathrm{N}=48$ analysed $)$
Control: IM Pethilorfan ${ }^{\circledR} 100 \mathrm{mg}(\mathrm{N}=50$ analysed $)$
Second injection possible after $2 \mathrm{hr}$, each patient could receive up to 4 injections of study drug, and ni-
trous oxide or trilene to supplement analgesia if required.

$\begin{array}{ll}\text { Outcomes } & \text { Maternal outcomes: maternal assessment of pain relief (numbers obtaining or not obtaining pain re- } \\ \text { lief), type of birth, additional analgesia required (study drug). Neonatal outcomes: Apgar at } 1 \text { min and } 5 \\ \text { mins, naloxone administration. }\end{array}$

Does not state actual number randomised to each group.
Start and end date: not reported
Power calculation: not reported
Baseline imbalances between groups: the group was balanced in most of the variables such as age,
number of previous pregnancies, and cervical dilatation
Funding source: not reported
Conflicts of interest: not reported

\section{Risk of bias}

\begin{tabular}{lll}
\hline Bias & Authors' judgement & Support for judgement \\
\hline $\begin{array}{l}\text { Random sequence genera- } \\
\text { tion (selection bias) }\end{array}$ & Unclear risk & Not reported \\
\hline $\begin{array}{l}\text { Allocation concealment } \\
\text { (selection bias) }\end{array}$ & Unclear risk & Not reported \\
\hline
\end{tabular}


O'Dwyer 1971 (Continued)

Blinding of participants Unclear risk States double-blind but does not describe methods used. and personnel (performance bias)

All outcomes

\begin{tabular}{lll}
\hline $\begin{array}{l}\text { Blinding of outcome as- } \\
\text { sessment (detection bias) } \\
\text { All outcomes }\end{array}$ & Unclear risk & States double-blind but does not describe methods used. \\
\hline $\begin{array}{l}\text { Incomplete outcome data } \\
\begin{array}{l}\text { (attrition bias) } \\
\text { All outcomes }\end{array}\end{array}$ & High risk & $\begin{array}{l}31 / 98 \text { excluded from primary outcome as delivered within } 1 \text { hr of administra- } \\
\text { tion of study drug, and } 16 \text { babies excluded from Apgar assessment as study } \\
\text { drug administered more than } 4 \text { hrs before birth. }\end{array}$ \\
\hline $\begin{array}{l}\text { Selective reporting (re- } \\
\text { porting bias) }\end{array}$ & Unclear risk & Unclear \\
\hline \begin{tabular}{l} 
Other bias \\
\hline
\end{tabular} & Unclear risk & Balanced at baseline for age, parity, contractions and vital signs. \\
\hline
\end{tabular}

\section{Olofsson 1996}

\begin{tabular}{ll}
\hline Methods & RCT 2-arm parallel-group design \\
\hline Participants & Setting: hospital, Stockholm, Sweden \\
& $\begin{array}{l}20 \text { healthy nulliparous women in active labour after spontaneous rupture of the membranes, cephalic } \\
\text { presentation. No exclusion criteria specified. }\end{array}$ \\
\hline Interventions & Experimental: $0.05 \mathrm{mg} / \mathrm{kg}$ IV morphine up to 3 doses (max $0.15 \mathrm{mg} / \mathrm{kg}$ body weight) \\
& Control: $0.5 \mathrm{mg} / \mathrm{kg}$ IV pethidine up to 3 doses (max $1.5 \mathrm{mg} / \mathrm{kg}$ body weight) \\
& Both groups had continuous FHR monitoring. \\
\hline Outcomes & Sedation rates; CS, nausea and vomiting. \\
\hline Notes & Start and end date: not reported \\
& Power calculation: not reported \\
Baseline imbalances between groups: the demographic variables were balanced between the groups \\
Funding source: Karolinska Institute foundations and the Swedish Medical Research Council \\
Conflicts of interest: not reported
\end{tabular}

\section{Risk of bias}

\begin{tabular}{lll}
\hline Bias & Authors' judgement & Support for judgement \\
\hline $\begin{array}{l}\text { Random sequence genera- } \\
\text { tion (selection bias) }\end{array}$ & Unclear risk & Quote: "assigned at random." \\
\hline $\begin{array}{l}\text { Allocation concealment } \\
\text { (selection bias) }\end{array}$ & Low risk & Coded ampoules provided by pharmacy.
\end{tabular}


Olofsson 1996 (Continued)

Blinding of participants Low risk Described as double-blind; pharmacy provided identical coded ampoules. and personnel (performance bias)

All outcomes

\begin{tabular}{lll}
\hline $\begin{array}{l}\text { Blinding of outcome as- } \\
\text { sessment (detection bias) } \\
\text { All outcomes }\end{array}$ & Unclear risk & Unclear \\
\hline $\begin{array}{l}\text { Incomplete outcome data } \\
\text { (attrition bias) } \\
\text { All outcomes }\end{array}$ & Low risk & No apparent loss to follow-up. \\
\hline $\begin{array}{l}\text { Selective reporting (re- } \\
\text { porting bias) }\end{array}$ & Unclear risk & Unclear \\
\hline $\begin{array}{l}\text { Other bias } \\
\text { Unclear risk }\end{array}$ & $\begin{array}{l}\text { Small sample and no clear information that groups were comparable at base- } \\
\text { line. Range of cervical dilations at recruitment between } 4 \mathrm{~cm} \text { and } 9 \mathrm{~cm} .\end{array}$
\end{tabular}

Olson 1964

\begin{tabular}{ll}
\hline Methods & RCT, 2-arm parallel-group design \\
\hline Participants & Setting: Washington, USA \\
& $\begin{array}{l}194 \text { women in established labour. Analgesia was given at approximately } 4 \mathrm{~cm} \text { to } 5 \mathrm{~cm} \text { cervical dilata- } \\
\text { tion. }\end{array}$ \\
\hline Interventions & $\begin{array}{l}\text { Experimental: IV phenazocine } 1 \mathrm{mg} \\
\text { Control: IV pethidine } 50 \text { mg }\end{array}$ \\
& $\begin{array}{l}\text { Both groups received promethazine } 50 \text { mg, and for both groups "birth was accomplished under puden- } \\
\text { dal nerve block anaesthesia with terminal self-administered trichloroethylene". }\end{array}$ \\
\hline Outcomes & $\begin{array}{l}\text { Pain relief (recorded by women on the first postpartum day); nausea and vomiting; adverse effects; } \\
\text { progress in labour; Apgar scores at } 1 \text { min and } 5 \text { mins. }\end{array}$ \\
\hline Notes & $\begin{array}{l}\text { Start and end date: not reported } \\
\text { Power calculation: not reported } \\
\text { Baseline imbalances between groups: unclear } \\
\text { Funding source: not reported } \\
\text { Conflicts of interest: not reported }\end{array}$ \\
\hline
\end{tabular}

\section{Risk of bias}

\begin{tabular}{lll}
\hline Bias & Authors' judgement & Support for judgement \\
\hline $\begin{array}{l}\text { Random sequence genera- } \\
\text { tion (selection bias) }\end{array}$ & Unclear risk & Not described \\
\hline $\begin{array}{l}\text { Allocation concealment } \\
\text { (selection bias) }\end{array}$ & Low risk & $\begin{array}{l}\text { Drugs were prepared by pharmacy in identical coded vials and the code was } \\
\text { not broken by the pharmacist until the study had been completed. }\end{array}$ \\
\hline
\end{tabular}


Olson 1964 (Continued)
Blinding of participants
Unclear risk
Drugs in identical vials. Pharmacy prepared identical coded drugs. and personnel (performance bias)

All outcomes

\begin{tabular}{|c|c|c|}
\hline $\begin{array}{l}\text { Blinding of outcome as- } \\
\text { sessment (detection bias) } \\
\text { All outcomes }\end{array}$ & Unclear risk & Unclear \\
\hline $\begin{array}{l}\text { Incomplete outcome data } \\
\text { (attrition bias) } \\
\text { All outcomes }\end{array}$ & Low risk & $\begin{array}{l}\text { Missing data for some outcomes (approximately } 5 \% \text { for maternal postpartum } \\
\text { outcomes, and } 10 \% \text { for nurse recorded evaluations in labour). }\end{array}$ \\
\hline $\begin{array}{l}\text { Selective reporting (re- } \\
\text { porting bias) }\end{array}$ & Unclear risk & None apparent, protocol not seen. \\
\hline Other bias & Low risk & None apparent \\
\hline
\end{tabular}

Osler 1987

\begin{tabular}{ll}
\hline Methods & RCT 2-arm parallel-group design \\
\hline Participants & Setting: hospital, Denmark \\
& 199 women. Spontaneous or induced labour onset, in active labour and requiring analgesia. \\
& Parity: $78 \%$ nullips, $22 \%$ multips \\
\hline Interventions & $\begin{array}{l}\text { Experimental: IM meptazinol } 100 \mathrm{mg}(\mathrm{N}=100) \text {. Control: IM pethidine } 750 \text { mg ( } \mathrm{N}=99) . \text { Each patient } \\
\text { Could receive up to } 3 \text { injections of study drug with an interval of not less than } 2 \text { hrs between doses. }\end{array}$ \\
\hline Outcomes & $\begin{array}{l}\text { Maternal outcomes: maternal assessment of pain relief 5, 15, 30, 60, 90, } 120 \text { mins (rated complete, } \\
\text { good, satisfactory, unsatisfactory), type of birth, additional analgesia required, epidural, adverse ef- } \\
\text { fects. Neonatal outcomes: Apgar at } 1 \text { min and } 5 \text { mins, neonatal distress, admission to SCBU. }\end{array}$ \\
\hline Start and end date: not reported \\
Power calculation: not reported \\
Baseline imbalances between groups: 'There were no differences between the two groups in age, body \\
weight or height, or number of previous deliveries. \\
Funding source: not reported \\
Conflicts of interest: not reported
\end{tabular}

\section{Risk of bias}

\begin{tabular}{lll}
\hline Bias & Authors' judgement & Support for judgement \\
\hline $\begin{array}{l}\text { Random sequence genera- } \\
\text { tion (selection bias) }\end{array}$ & Unclear risk & Not reported \\
\hline $\begin{array}{l}\text { Allocation concealment } \\
\text { (selection bias) }\end{array}$ & Unclear risk & Not reported \\
\hline
\end{tabular}


Osler 1987 (Continued)

Blinding of participants Unclear risk Described as double-blind but no methods described. and personnel (perfor-

mance bias)

All outcomes

Blinding of outcome as-
sessment (detection bias) $\quad$ Unclear risk Described as double blind but no methods described.

All outcomes

Incomplete outcome data Low risk All women analysed.

(attrition bias)

All outcomes

\begin{tabular}{lll}
\hline $\begin{array}{l}\text { Selective reporting (re- } \\
\text { porting bias) }\end{array}$ & Unclear risk & Unclear \\
\hline Other bias & Unclear risk & No baseline imbalance in age, weight, height or number of previous deliveries.
\end{tabular}

\section{Prasertsawat 1986}

\begin{tabular}{ll}
\hline Methods & RCT 3-arm parallel-group design \\
\hline Participants & Setting: hospital, Thailand \\
& 135 women. 37 to 42 weeks' gestation, $c x \geq 3 \mathrm{~cm}$, in active labour and requiring analgesia. \\
& Parity: not reported \\
\hline Interventions & $\begin{array}{l}\text { Experimental: IM tramadol } 100 \mathrm{mg}(\mathrm{N}=45) ; \text { IM morphine } 100 \mathrm{mg} \text { ( } \mathrm{N}=45) \text {. Control: IM pethidine } 100 \mathrm{mg} \\
\text { maximum of } 2 \text { doses. }\end{array}$ \\
\hline Outcomes & $\begin{array}{l}\text { Maternal outcomes: pain severity/relief } 30 \mathrm{mins}, 1,2,3 \text {, and } 4 \text { hrs (rated good, satisfactory, no re- } \\
\text { sponse), drowsiness, nausea, vomiting. Neonatal outcomes: Apgar at } 1 \text { min and } 5 \text { mins, neonatal resus- } \\
\text { citation. }\end{array}$ \\
\hline Start and end date: 1 February 1986 - 28 February 1986 \\
Power calculation: not reported \\
Baseline imbalances between groups: unclear \\
Funding sources: not reported \\
Conflicts of interest: not reported
\end{tabular}

\section{Risk of bias}

\begin{tabular}{lll}
\hline Bias & Authors' judgement & Support for judgement \\
\hline $\begin{array}{l}\text { Random sequence genera- } \\
\text { tion (selection bias) }\end{array}$ & Unclear risk & Not reported \\
\hline $\begin{array}{l}\text { Allocation concealment } \\
\text { (selection bias) }\end{array}$ & Unclear risk & Not reported \\
\hline
\end{tabular}


Prasertsawat 1986 (Continued)

Blinding of participants Unclear risk States blind but does not describe the method. and personnel (perfor-

mance bias)

All outcomes

Blinding of outcome as- Low risk Medical students unaware of group allocation assessed outcome.

sessment (detection bias)

All outcomes

Incomplete outcome data Low risk All participants analysed.
(attrition bias)

Alloutcomes

Selective reporting (re- Unclear risk Unclear
porting bias)

Other bias Low risk Age and maternal weight balanced at baseline.

Quilligan 1980

\begin{tabular}{ll}
\hline Methods & RCT, 2-arm parallel-group design \\
\hline Participants & Setting not clear (hospital in USA) \\
& $\begin{array}{l}100 \text { women in good health in active labour, with no addiction to or tolerance to drugs and complaining } \\
\text { of moderate to severe pain. Women who "planned to nurse" were excluded. }\end{array}$
\end{tabular}

Experimental: (50 women) IV butorphanol $1 \mathrm{mg}$ to $2 \mathrm{mg}$ ( 44 women had an initial dose of $1 \mathrm{mg}$ and 6 an
initial dose of $2 \mathrm{mg}$, after $1 \mathrm{hr}$ or more a $2 \mathrm{nd} \mathrm{dose}$ was given if requested).
Control: ( 50 women) IV pethidine $40 \mathrm{mg}$ to $80 \mathrm{mg}$ ( 45 women had an initial dose of $40 \mathrm{mg}$ and 5 an ini-
tial dose of $80 \mathrm{mg}$, a 2 nd dose was given after $1 \mathrm{hr}$ or more if requested).

Outcomes Pain (5-point scale 0 - no pain, 4 - very severe pain); pain relief (5-point scale 0 - none, 4 - complete relief); FHR; Apgar scores at 1 min and 5 mins.

Start and end date: not reported
Power calculation: not reported
Baseline imbalances between groups: unclear
Funding sources: not reported
Conflicts of interest: not reported

\section{Risk of bias}

\begin{tabular}{lll}
\hline Bias & Authors' judgement & Support for judgement \\
\hline $\begin{array}{l}\text { Random sequence genera- } \\
\text { tion (selection bias) }\end{array}$ & Unclear risk & Not described \\
\hline $\begin{array}{l}\text { Allocation concealment } \\
\text { (selection bias) }\end{array}$ & Unclear risk & Not described \\
\hline
\end{tabular}


Quilligan 1980 (Continued)

Blinding of participants Unclear risk Described as double-blind study but no details provided. and personnel (performance bias)

All outcomes

\begin{tabular}{lll}
\hline $\begin{array}{l}\text { Blinding of outcome as- } \\
\text { sessment (detection bias) } \\
\text { All outcomes }\end{array}$ & Unclear risk & Unclear \\
\hline $\begin{array}{l}\text { Incomplete outcome data } \\
\text { (attrition bias) } \\
\text { All outcomes }\end{array}$ & Unclear risk & Outcome data were available for all women randomised. \\
\hline $\begin{array}{l}\text { Selective reporting (re- } \\
\text { porting bias) }\end{array}$ & Unclear risk & Unclear \\
\hline $\begin{array}{l}\text { Other bias } \\
\text { Unclear risk }\end{array}$ & $\begin{array}{l}\text { No baseline imbalance was apparent although } 8 \text { women in the butorphanol } \\
\text { group were induced compared with } 1 \text { woman in the pethidine group. }\end{array}$
\end{tabular}

Rayburn 1989a

\begin{tabular}{ll}
\hline Methods & RCT. 2-arm parallel groups \\
\hline Participants & Setting: Nebraska university hospital, USA \\
& 105 women in early active labour $(3 \mathrm{~cm}$ to $4 \mathrm{~cm}$ cervical dilation); at or beyond 37 weeks' gestation with \\
& no medical or obstetric complications, with no signs of fetal distress and requesting narcotic analgesia \\
& rather than an epidural. (Intervention group: $55 \%$ nulliparous, $71 \%$ non-white race, mean age 23 years; \\
& control group: $48 \%$ nulliparous, $70 \%$ non-white race, mean age 23 years.)
\end{tabular}

Interventions $\quad$ Experimental: (49 women) IV fentanyl $50 \mu \mathrm{g}$ to $100 \mu \mathrm{g}$ per hr

Control: (56 women) IV pethidine $25 \mathrm{mg}$ to $50 \mathrm{mg}$ per hr

Outcomes Pain (measured on 10-point VAS recorded by labour ward nurses); nausea and vomiting; sedation; itching; FHR changes.

Notes
Women were recruited only between 8 am and 3 pm on weekdays.
Start and end date: January 1988 - August 1988
Power calculation: not reported
Baseline imbalances between groups: 'There were no statistically significant differences in maternal demographic characteristics and need for oxytocin augmentation.'
Funding source: not reported
Conflicts of interest: not reported

\section{Risk of bias}

\section{Bias}

Random sequence genera- Low risk tion (selection bias)

\section{Authors' judgement Support for judgement}

Pharmacy randomisation table. 
Rayburn 1989a (Continued)

\begin{tabular}{lll}
$\begin{array}{l}\text { Allocation concealment } \\
\text { (selection bias) }\end{array}$ & Unclear risk & Not described \\
\hline $\begin{array}{l}\text { Blinding of participants } \\
\text { and personnel (perfor- } \\
\text { mance bias) }\end{array}$ & High risk & Staff not blinded to group allocation. \\
All outcomes & &
\end{tabular}

\begin{tabular}{lll}
\hline $\begin{array}{l}\text { Blinding of outcome as- } \\
\text { sessment (detection bias) } \\
\text { All outcomes }\end{array}$ & High risk & Staff not blinded to group allocation. \\
\hline $\begin{array}{l}\text { Incomplete outcome data } \\
\text { (attrition bias) } \\
\text { All outcomes }\end{array}$ & Low risk & All women randomised seem to be included in the results. \\
\hline $\begin{array}{l}\text { Selective reporting (re- } \\
\text { porting bias) }\end{array}$ & Unclear risk & Unclear \\
\hline $\begin{array}{l}\text { Other bias } \\
\text { Unclear risk }\end{array}$ & $\begin{array}{l}\text { Women were recruited only on weekdays between 8am and 3pm so may not } \\
\text { represent the population attending the study hospital. }\end{array}$ \\
\hline
\end{tabular}

Refstad 1980

\begin{tabular}{|c|c|}
\hline Methods & $\mathrm{RCT}$, 2-arm parallel-group design \\
\hline \multirow[t]{3}{*}{ Participants } & Setting: hospital, Norway \\
\hline & $\begin{array}{l}85 \text { women. Healthy women at term, expected to have a normal birth in active labour and requiring } \\
\text { analgesia. }\end{array}$ \\
\hline & Parity: not reported \\
\hline \multirow[t]{3}{*}{ Interventions } & Experimental: IM pentazocine $45 \mathrm{mg}(\mathrm{N}=43)$ \\
\hline & Control: IM pethidine $100 \mathrm{mg}(\mathrm{N}=42)$ \\
\hline & $\begin{array}{l}\text { Half dose repeated after } 1 \mathrm{hr} \text { if required and further full dose after } 3 \mathrm{hrs} \text { if labour prolonged. All women } \\
\text { received promazine } 25 \mathrm{mg} \text { IM before } 1 \text { st injection, nitrous oxide or pudendal block or both allowed at } \\
\text { end of } 2 \text { nd stage. }\end{array}$ \\
\hline Outcomes & $\begin{array}{l}\text { Maternal outcomes: pain relief at } 1 \mathrm{hr}(0=\text { no pain, } 1=\text { slight pain, } 2=\text { moderate pain, } 3=\text { severe pain }) \text {, } \\
\text { type of birth, additional analgesia required. Neonatal outcomes: Apgar at } 1 \mathrm{~min} \text { and } 5 \text { mins, naloxone } \\
\text { administration, FHR changes. }\end{array}$ \\
\hline \multirow[t]{5}{*}{ Notes } & Start and end date: not reported \\
\hline & Power calculation: not reported \\
\hline & Baseline imbalances between groups: unclear \\
\hline & Funding source: Sterling-Winthrop company supplied trial drugs \\
\hline & Conflicts of interest: not reported \\
\hline
\end{tabular}

\section{Risk of bias}


Refstad 1980 (Continued)

\begin{tabular}{lll} 
Bias & Authors' judgement & Support for judgement \\
\hline $\begin{array}{l}\text { Random sequence genera- } \\
\text { tion (selection bias) }\end{array}$ & Unclear risk & Not reported \\
\hline $\begin{array}{l}\text { Allocation concealment } \\
\text { (selection bias) }\end{array}$ & Unclear risk & Not reported \\
\hline
\end{tabular}

Blinding of participants High risk $\quad$ No blinding
and personnel (perfor-
mance bias)
All outcomes

Blinding of outcome as- High risk No blinding

sessment (detection bias)

All outcomes

\begin{tabular}{|c|c|c|}
\hline $\begin{array}{l}\text { Incomplete outcome data } \\
\text { (attrition bias) } \\
\text { All outcomes }\end{array}$ & High risk & $\begin{array}{l}25 / 85 \text { women excluded from analysis as delivered within } 1 \mathrm{hr} \text { of } 1 \text { st dose of } \\
\text { study drug. }\end{array}$ \\
\hline
\end{tabular}

\begin{tabular}{lll}
\hline $\begin{array}{l}\text { Selective reporting (re- } \\
\text { porting bias) }\end{array}$ & Unclear risk & Unclear \\
\hline Other bias & Unclear risk & Nitrous oxide or pudendal block permitted during second stage. \\
\hline
\end{tabular}

Sekhavat 2009

\begin{tabular}{ll}
\hline Methods & Reported to be a randomised clinical trial with individual randomisation. \\
\hline Participants & Setting: hospital in Iran \\
150 women \\
Healthy women, with singleton cephalic presentation pregnancy in spontaneous labour, $3 \mathrm{~cm}$ or more \\
cervical dilatation requesting analgesia. \\
Exclusion criteria: pethidine allergy, contraindication to vaginal delivery, fetal death or distress, fetal \\
congenital heart malformation or obstetric complications such as antepartum haemorrhage.
\end{tabular}

Interventions
Control group: placebo, IM saline. $(\mathrm{N}=75)$
Women in both groups received routine care which included FHR surveillance and 2-hourly vaginal ex-
aminations, with a protocol for oxytocin augmentation for delay.

\begin{tabular}{ll}
\hline Outcomes & Apgar scores \\
& Fetal heart rate changes \\
& Oxytocin administration \\
\hline Notes & Start and end date: October 2004 to September 2005 \\
It was reported that the study was not supported by any pharmaceutical company. \\
Conflicts of interest: not reported
\end{tabular}


Sekhavat 2009 (Continued)

Risk of bias

\begin{tabular}{lll}
\hline Bias & Authors' judgement & Support for judgement \\
\hline $\begin{array}{l}\text { Random sequence genera- } \\
\text { tion (selection bias) }\end{array}$ & Unclear risk & $\begin{array}{l}\text { It was reported that women were allocated "randomly (using a randomized } \\
\text { consecutive numbered chart)". It was not clear whether the chart had random } \\
\text { numbers or that numbers were ordered consecutively. }\end{array}$ \\
\hline
\end{tabular}

\begin{tabular}{lll}
\hline $\begin{array}{l}\text { Allocation concealment } \\
\text { (selection bias) }\end{array}$ & Unclear risk & Method not described \\
\hline $\begin{array}{l}\text { Blinding of participants } \\
\begin{array}{l}\text { and personnel (perfor- } \\
\text { mance bias) }\end{array}\end{array}$ & Low risk & Participants: study was placebo controlled. \\
All outcomes & $\begin{array}{l}\text { Caregiver: study was placebo controlled - staff may have been aware of alloca- } \\
\text { tion as some women received no analgesia. }\end{array}$
\end{tabular}

\begin{tabular}{ll}
\hline Blinding of outcome as- & Low risk
\end{tabular}

Incomplete outcome data Unclear risk

(attrition bias)

All outcomes

Selective reporting (re- High risk
porting bias)

150 women were randomised, 75 in each group. There was no mention of dropouts or any missing data.

$\begin{array}{ll}\text { Other bias } \quad \text { Unclear risk } & \begin{array}{l}\text { There was little information on methods so it was not possible to assess } \\ \text { whether other risk of bias was present. }\end{array}\end{array}$

\section{Sheikh 1986}

\begin{tabular}{ll}
\hline Methods & RCT, 2-arm parallel-group design \\
\hline Participants & Setting: hospital, UK \\
& 205 women. Healthy women 38 to 41 weeks' gestation, uncomplicated pregnancy, spontaneous or in- \\
duced labour onset, in active labour and requiring analgesia. Excluded if epidural or forceps birth like- \\
ly. \\
Parity: mixed
\end{tabular}

Interventions

Experimental: IM meptazinol $100 \mathrm{mg}(\mathrm{N}=98)$

Control: IM pethidine $100 \mathrm{mg}(\mathrm{N}=99)$

Additional doses of test drug allowed at intervals no less than $2 \mathrm{hrs}$ if required to a maximum of 3 doses. All women could receive nitrous oxide if required and prochlorperazine $12.5 \mathrm{mg} \mathrm{IM}$ for nausea and vomiting. Epidural at midwife discretion.
Outcomes
Maternal outcomes: pain intensity 30 mins and then hourly intervals until birth (rated none, mild, mod- erate, severe), pain relief (rated none, slight, moderate, strong or complete), type of birth, additional analgesia required, nausea and vomiting. Neonatal outcomes: Apgar at $1 \mathrm{~min}$ and 5 mins, resuscitation. Within 72 hrs postpartum feeding problems, irritability and muscle tone.

Notes Start and end date: not reported


Sheikh 1986 (Continued)

Power calculation: not reported

Baseline imbalances between groups: both the groups were balanced for age, body weight, and parity.

Funding sources: Wyeth laboratories supplied the coded ampoules of the trial drugs

Conflicts of interest: not reported

\section{Risk of bias}

\begin{tabular}{|c|c|c|}
\hline Bias & Authors' judgement & Support for judgement \\
\hline $\begin{array}{l}\text { Random sequence genera- } \\
\text { tion (selection bias) }\end{array}$ & Unclear risk & Not reported \\
\hline $\begin{array}{l}\text { Allocation concealment } \\
\text { (selection bias) }\end{array}$ & Low risk & Coded ampoules kept at a site remote from trial. \\
\hline $\begin{array}{l}\text { Blinding of participants } \\
\text { and personnel (perfor- } \\
\text { mance bias) } \\
\text { All outcomes }\end{array}$ & Low risk & $\begin{array}{l}\text { Described as double-blind, used coded ampoules and states that identity of } \\
\text { drug unknown. }\end{array}$ \\
\hline $\begin{array}{l}\text { Blinding of outcome as- } \\
\text { sessment (detection bias) } \\
\text { All outcomes }\end{array}$ & Low risk & Blind outcome assessor for all bar $15 \%$ of women. \\
\hline $\begin{array}{l}\text { Incomplete outcome data } \\
\text { (attrition bias) } \\
\text { All outcomes }\end{array}$ & Low risk & $\begin{array}{l}8 \text { women excluded from analysis as delivered within } 30 \text { mins of administra- } \\
\text { tion. }\end{array}$ \\
\hline $\begin{array}{l}\text { Selective reporting (re- } \\
\text { porting bias) }\end{array}$ & Unclear risk & Unclear \\
\hline Other bias & Unclear risk & $\begin{array}{l}\text { Balanced at baseline for age and weight, but imbalance in parity. } 43 / 98 \text { multip } \\
\text { meptazinol group versus } 34 / 99 \text { in pethidine group. }\end{array}$ \\
\hline
\end{tabular}

\section{Sliom 1970}

\begin{tabular}{ll}
\hline Methods & RCT, 3-arm parallel-group design \\
\hline Participants & Setting: hospital, South Africa \\
& 196 women. Healthy women at term, uncomplicated labour, in active labour expected to deliver in next \\
& 4 hrs and requiring analgesia. Excluded if likely to deliver within 30 mins and had received analgesia \\
& within previous 6 hrs. \\
& Parity: mixed
\end{tabular}

\begin{tabular}{ll}
\hline Interventions & Experimental: IM dihydrocodeine $50 \mathrm{mg}(\mathrm{N}=80)$ \\
& Control: IM pethidine $100 \mathrm{mg}(\mathrm{N}=58)$, placebo (saline) $(\mathrm{N}=58)$ \\
& Single dose of study drug. \\
\hline Outcomes & $\begin{array}{l}\text { Maternal outcomes: pain relief at } 1 \mathrm{hr} \text { (rated good, fair, poor), sedation (rated drowsy, alert but calm, } \\
\text { restless), nausea, vomiting. Neonatal outcomes: Modified Apgar at } 1 \text { min and } 5 \text { mins (minus colour). }\end{array}$
\end{tabular}


Sliom 1970 (Continued)

Notes
Women excluded after randomisation if delivered more than $4 \mathrm{hrs}$ after injection of study drug.

Start and end date: not reported

Power calculation: not reported

Baseline imbalances between groups: all the groups were balanced for age, race, and parity.

Funding sources: BDH (South Africa) Pty Ltd supplied dihydrocodeine bitartrate

Conflicts of interest: not reported

\section{Risk of bias}

\begin{tabular}{|c|c|c|}
\hline Bias & Authors' judgement & Support for judgement \\
\hline $\begin{array}{l}\text { Random sequence genera- } \\
\text { tion (selection bias) }\end{array}$ & Unclear risk & Not reported \\
\hline $\begin{array}{l}\text { Allocation concealment } \\
\text { (selection bias) }\end{array}$ & Unclear risk & Not reported \\
\hline $\begin{array}{l}\text { Blinding of participants } \\
\text { and personnel (perfor- } \\
\text { mance bias) } \\
\text { All outcomes }\end{array}$ & Unclear risk & States double-blind. Not reported how blinding was achieved. \\
\hline $\begin{array}{l}\text { Blinding of outcome as- } \\
\text { sessment (detection bias) } \\
\text { All outcomes }\end{array}$ & Unclear risk & States double-blind. Not reported how blinding was achieved. \\
\hline $\begin{array}{l}\text { Incomplete outcome data } \\
\text { (attrition bias) } \\
\text { All outcomes }\end{array}$ & Unclear risk & $\begin{array}{l}\text { Number of women randomised not reported, authors only report the number } \\
\text { of women analysed. }\end{array}$ \\
\hline $\begin{array}{l}\text { Selective reporting (re- } \\
\text { porting bias) }\end{array}$ & Unclear risk & Unclear \\
\hline Other bias & Unclear risk & $\begin{array}{l}\text { Unequal number of women in each treatment group due to post-randomisa- } \\
\text { tion exclusions. Exclusions included women who delivered }<30 \text { mins or }>4 \mathrm{hrs} \\
\text { after administration of study agents. }\end{array}$ \\
\hline
\end{tabular}

Tawfik 1982

\begin{tabular}{ll}
\hline Methods & RCT: methods not clear \\
\hline Participants & Setting: Egypt \\
& 90 primiparous women with normal presentation and position and expected to deliver normally. \\
\hline Interventions & Intervention: pethidine $50 \mathrm{mg}$ IM 4- to 5-hourly \\
& $\begin{array}{l}\text { Comparison: TENS applied to back. The position arranged to suit the mother and moved to lower ab- } \\
\text { domen if preferred. } \\
\text { Both groups were given } 10 \mathrm{mg} \text { diazepam IM. Both groups had artificial rupture of membranes at } 5 \mathrm{~cm} \\
\text { and oxytocin augmentation. }\end{array}$ \\
\end{tabular}


Tawfik 1982 (Continued)

Outcomes

Pain intensity (scored as being: severe $=3$; moderate $=2$; mild $=1$ ) - only measured before intervention; pain relief scored (complete $=4$, excellent $=3$, good $=2$, slight (satisfactory) $=1$ ) at 30 mins, $5 \mathrm{~cm}$ and at full cervical dilatation; patient's opinion on the technique - satisfaction (during whole period of delivery), scored as (excellent $=3$, good $=2$, satisfactory $=1$ ); Apgar score; side effects (drowsiness, nausea, vomiting).

\begin{tabular}{ll}
\hline Notes & Start and end date: \\
& Funding sources: \\
Conflicts of interest:
\end{tabular}

\section{Risk of bias}

\begin{tabular}{|c|c|c|}
\hline Bias & Authors' judgement & Support for judgement \\
\hline $\begin{array}{l}\text { Random sequence genera- } \\
\text { tion (selection bias) }\end{array}$ & Unclear risk & "Randomly divided between 2 groups." \\
\hline $\begin{array}{l}\text { Allocation concealment } \\
\text { (selection bias) }\end{array}$ & Unclear risk & No information provided. \\
\hline $\begin{array}{l}\text { Blinding of participants } \\
\text { and personnel (perfor- } \\
\text { mance bias) } \\
\text { All outcomes }\end{array}$ & High risk & Not reported - but not feasible with nature of interventions. \\
\hline $\begin{array}{l}\text { Blinding of outcome as- } \\
\text { sessment (detection bias) } \\
\text { All outcomes }\end{array}$ & High risk & Not reported - but not feasible with nature of interventions. \\
\hline $\begin{array}{l}\text { Incomplete outcome data } \\
\text { (attrition bias) } \\
\text { All outcomes }\end{array}$ & Low risk & No apparent loss to follow-up. \\
\hline $\begin{array}{l}\text { Selective reporting (re- } \\
\text { porting bias) }\end{array}$ & Unclear risk & $\begin{array}{l}\text { All outcomes described within the methods are reported upon within the re- } \\
\text { sults. However, the study protocol was not evaluated. }\end{array}$ \\
\hline Other bias & Unclear risk & $\begin{array}{l}\text { Unbalanced groups; } 35 \text { in the intervention group and } 55 \text { in the comparison } \\
\text { group. }\end{array}$ \\
\hline
\end{tabular}

\section{Thakur 2004}

\begin{tabular}{ll}
\hline Methods & RCT \\
\hline Participants & Setting: Indore, India \\
& 300 women in established labour attending for care in a hospital in India. The participants were de- \\
scribed as being predominantly from low socio-economic groups and from urban areas. & \\
Inclusion criteria: term pregnancy (37 to 42 weeks), vertex presentation, cervical dilatation $3 \mathrm{~cm}$ or \\
more with contractions. \\
Exclusion criteria: previous uterine scar, malpresentation, multiple pregnancy, cephalo-pelvic dispro- \\
portion, antepartum haemorrhage, pre-eclampsia or other medical disorders.
\end{tabular}

Interventions Interventions group: TENS to back


Thakur 2004 (Continued)

Comparison group 1: $100 \mathrm{mg}$ IM tramadol

Comparison group 2: no intervention

$\begin{array}{ll}\text { Outcomes } & \text { Maternal pain score measured on a verbal response scale during labour "degree of analgesia" (degree } \\ & \text { of pain relief: no relief, mild relief, moderate relief, complete relief - dichotomised as a percentage); } \\ \text { mean time for onset and duration of analgesia; duration of stages of labour; mode of delivery (normal, } \\ \text { forceps, CS); mean Apgar score of neonates; side effects for mothers. }\end{array}$

Notes

Start and end date: not reported in translation.

Funding sources: not reported in translation.

Conflicts of interest: not reported in translation.

\section{Risk of bias}

\begin{tabular}{|c|c|c|}
\hline Bias & Authors' judgement & Support for judgement \\
\hline $\begin{array}{l}\text { Random sequence genera- } \\
\text { tion (selection bias) }\end{array}$ & Unclear risk & $\begin{array}{l}\text { Described as "randomly allocated" but groups were of identical size with iden- } \\
\text { tical numbers of primiparous and multiparous women in each group. }\end{array}$ \\
\hline $\begin{array}{l}\text { Allocation concealment } \\
\text { (selection bias) }\end{array}$ & Unclear risk & Method of randomisation not described. \\
\hline $\begin{array}{l}\text { Blinding of participants } \\
\text { and personnel (perfor- } \\
\text { mance bias) } \\
\text { All outcomes }\end{array}$ & High risk & No blinding reported - but not possible due to nature of intervention. \\
\hline $\begin{array}{l}\text { Blinding of outcome as- } \\
\text { sessment (detection bias) } \\
\text { All outcomes }\end{array}$ & High risk & No blinding reported - but not possible due to nature of intervention. \\
\hline $\begin{array}{l}\text { Incomplete outcome data } \\
\text { (attrition bias) } \\
\text { All outcomes }\end{array}$ & Low risk & Apparently there was no loss to follow-up. \\
\hline $\begin{array}{l}\text { Selective reporting (re- } \\
\text { porting bias) }\end{array}$ & Unclear risk & $\begin{array}{l}\text { All outcomes described within the methods are reported upon within the re- } \\
\text { sults. However, the study protocol was not evaluated. }\end{array}$ \\
\hline Other bias & Unclear risk & $\begin{array}{l}\text { Groups were unusually similar and it was not clear that there had been stratifi- } \\
\text { cation to achieve such balanced groups. }\end{array}$ \\
\hline
\end{tabular}

Tharamas 1999

\begin{tabular}{ll}
\hline Methods & RCT. 2-arm parallel groups \\
\hline Participants & 200 nulliparous women in labour. \\
& Inclusion criteria: at term ( 37 to 42 weeks) spontaneous labour, in active labour, vertex presentation. \\
& $\begin{array}{l}\text { Exclusions: age }<16 \text { or }>35, \text { weight }<50 \mathrm{~kg} \text { or }>75 \mathrm{~kg}, \text { infant birthweight estimated }<2500 \mathrm{~g} \text { or }>4000 \mathrm{~g}, \\
\text { medical or surgical complication or unable to understand VAS. }\end{array}$
\end{tabular}

Interventions Intervention group: IM buprenorphine $300 \mu \mathrm{g}$


Tharamas 1999 (Continued)

Comparison group: IM pethidine $75 \mathrm{mg}$

Outcomes Analgesic effect at 1, 2, 3, $4 \mathrm{hrs,} \mathrm{side} \mathrm{effects} \mathrm{(nausea,} \mathrm{drowsiness,} \mathrm{use} \mathrm{of} \mathrm{antidote)}$

Notes

Data extraction from translation notes.

Start and end date: January 1996 - December 1996

Power calculation: unclear

Baseline imbalances between groups: unclear

Funding source: unclear

Conflicts of interest: unclear

\section{Risk of bias}

\begin{tabular}{lll}
\hline Bias & Authors' judgement & Support for judgement \\
\hline $\begin{array}{l}\text { Random sequence genera- } \\
\text { tion (selection bias) }\end{array}$ & Low risk & Random number table \\
\hline $\begin{array}{l}\text { Allocation concealment } \\
\text { (selection bias) }\end{array}$ & Unclear risk & Not described \\
\hline $\begin{array}{l}\text { Blinding of participants } \\
\text { and personnel (perfor- } \\
\text { mance bias) } \\
\text { All outcomes }\end{array}$ & Unclear risk & Treatment described as blinded. \\
\hline $\begin{array}{l}\text { Blinding of outcome as- } \\
\text { sessment (detection bias) }\end{array}$ & Unclear risk & \\
All outcomes & & \\
\hline $\begin{array}{l}\text { Incomplete outcome data } \\
\text { (attrition bias) } \\
\text { All outcomes }\end{array}$ & Unclear risk & Unclear \\
\hline $\begin{array}{l}\text { Selective reporting (re- } \\
\text { porting bias) }\end{array}$ & Unclear risk & Unclear \\
\hline \begin{tabular}{l} 
Other bias \\
\hline
\end{tabular} & Unclear risk & Unclear \\
\hline
\end{tabular}

Tsui 2004

\begin{tabular}{ll}
\hline Methods & RCT, 2-arm parallel-group design \\
\hline Participants & Setting: hospital, Hong Kong \\
& 50 women. Healthy women in early active labour and requiring analgesia. Uncomplicated singleton \\
& term pregnancy, cephalic presentation. Spontaneous and induced labour onset. Excluded if epidural \\
& already requested. \\
& Parity: 3:2 nullip:multip ratio \\
\hline
\end{tabular}


Tsui 2004 (Continued)

Control: placebo (saline) $(\mathrm{N}=25)$

Single dose of study drug.

Rescue analgesia allowed after 30 mins nitrous oxide or epidural for women in pethidine group and pethidine for women in placebo group.

Outcomes

Maternal outcomes: pain intensity at 15 mins and 30 mins VAS ( 0 to 100 ), maternal assessment of sedation at 15 mins and 30 mins VAS ( 0 to 100), type of birth, additional analgesia required, vomiting, maternal satisfaction at 30 mins 5 -point scale ( $1=$ totally dissatisfied to $5=$ very satisfied). Neonatal outcomes: Apgar at 1 min and 5 mins, resuscitation and admission to SCBU.

Notes Study terminated after 50 women recruited as interim analysis demonstrated benefit for pethidine. Stratified by parity.

Start and end date: September 2000 to May 2001.

Power calculation: Using published and unpublished data, a sample size of 56 women per group was needed to have $90 \%$ power at $5 \%$ significant level to detect a mean difference of $13 \mathrm{~mm}$ in VAS pain score between groups.

Baseline imbalances between groups: Table 1 provides this information, but it is unclear if the groups were balanced or not.

Funding source: not reported

Conflicts of interest: not reported

\section{Risk of bias}

\begin{tabular}{lll}
\hline Bias & Authors' judgement & Support for judgement \\
\hline $\begin{array}{l}\text { Random sequence genera- } \\
\text { tion (selection bias) }\end{array}$ & Low risk & Computer generated in blocks of 10. \\
\hline $\begin{array}{l}\text { Allocation concealment } \\
\text { (selection bias) }\end{array}$ & Low risk & Sequentially-numbered, opaque sealed envelopes. \\
\hline $\begin{array}{l}\text { Blinding of participants } \\
\text { and personnel (perfor- } \\
\text { mance bias) }\end{array}$ & Low risk & States double-blind and women blind to contents of syringe. \\
$\begin{array}{l}\text { All outcomes } \\
\begin{array}{l}\text { Blinding of outcome as- } \\
\text { sessment (detection bias) } \\
\text { All outcomes }\end{array}\end{array}$ & Unclear risk & $\begin{array}{l}\text { States double-blind and women blind to contents of syringe. No further detail } \\
\text { given. }\end{array}$ \\
\hline
\end{tabular}

Incomplete outcome data Low risk All women accounted for in the analysis.

(attrition bias)

All outcomes

Selective reporting (re- Unclear risk Unclear
porting bias)

$\begin{array}{ll}\text { Other bias } \quad \text { High risk } & \begin{array}{l}20 / 25 \text { women in pethidine group versus 12/25 women in placebo group had } \\ \text { labour induced which may affect maternal and neonatal outcomes. }\end{array}\end{array}$


Viegas 1993

\begin{tabular}{|c|c|}
\hline Methods & RCT, 3-arm parallel-group design \\
\hline \multirow[t]{3}{*}{ Participants } & Setting: hospital, Singapore \\
\hline & $\begin{array}{l}90 \text { women. Women aged } 18 \text { to } 35 \text { years in active labour and requiring analgesia, } c \times 3 \mathrm{~cm} \text { to } 5 \mathrm{~cm} \text {, un- } \\
\text { complicated term pregnancy with uncomplicated birth expected, spontaneous or induced labour on- } \\
\text { set. Excluded if preterm labour. }\end{array}$ \\
\hline & Parity: $100 \%$ nullips \\
\hline \multirow[t]{3}{*}{ Interventions } & Experimental: IM tramadol $50 \mathrm{mg}(\mathrm{N}=30)$, tramadol $100 \mathrm{mg}(\mathrm{N}=30)$ \\
\hline & Control: IM pethidine $75 \mathrm{mg}(\mathrm{N}=30)$ \\
\hline & Single dose of study drug. \\
\hline Outcomes & $\begin{array}{l}\text { Maternal outcomes: pain relief at } 10,20,30,45 \mathrm{mins} \text { and } 1 \mathrm{hr} 4 \text {-point scale }(0=\text { none, } 1=\text { insufficient, } 2 \\
=\text { sufficient, } 3=\text { complete pain relief), type of birth, drowsiness, nausea, vomiting. Neonatal outcomes: } \\
\text { Apgar at } 1 \mathrm{~min} \text { and } 5 \text { mins, resuscitation and admission to SCBU. }\end{array}$ \\
\hline \multirow[t]{5}{*}{ Notes } & Start and end date: not reported \\
\hline & Power calculation: not reported \\
\hline & Baseline imbalances between groups: Table 1 suggests that the groups were balanced \\
\hline & Funding source: not reported \\
\hline & Conflicts of interest: not reported \\
\hline
\end{tabular}

\section{Risk of bias}

\begin{tabular}{|c|c|c|}
\hline Bias & Authors' judgement & Support for judgement \\
\hline $\begin{array}{l}\text { Random sequence genera- } \\
\text { tion (selection bias) }\end{array}$ & Unclear risk & Not reported \\
\hline $\begin{array}{l}\text { Allocation concealment } \\
\text { (selection bias) }\end{array}$ & Unclear risk & Not reported \\
\hline $\begin{array}{l}\text { Blinding of participants } \\
\text { and personnel (perfor- } \\
\text { mance bias) } \\
\text { All outcomes }\end{array}$ & Low risk & $\begin{array}{l}\text { States double-blind, identical syringes prepared separately from clinical ob- } \\
\text { server. }\end{array}$ \\
\hline $\begin{array}{l}\text { Blinding of outcome as- } \\
\text { sessment (detection bias) } \\
\text { All outcomes }\end{array}$ & Low risk & $\begin{array}{l}\text { States double-blind, identical syringes prepared separately from clinical ob- } \\
\text { server. }\end{array}$ \\
\hline $\begin{array}{l}\text { Incomplete outcome data } \\
\text { (attrition bias) } \\
\text { All outcomes }\end{array}$ & Low risk & All participants analysed. \\
\hline $\begin{array}{l}\text { Selective reporting (re- } \\
\text { porting bias) }\end{array}$ & Unclear risk & Unclear \\
\hline Other bias & Unclear risk & Unclear \\
\hline
\end{tabular}


Volikas 2001

\begin{tabular}{|c|c|}
\hline Methods & RCT, 2-arm parallel-group design \\
\hline \multirow[t]{2}{*}{ Participants } & Setting: hospital in Surrey, UK \\
\hline & $\begin{array}{l}17 \text { healthy women } 36 \text { to } 40 \text { weeks' gestation requesting pethidine for pain relief in labour, ASA I or II. } \\
\text { Women with a contraindication to pethidine or remifentanil or requesting epidural were excluded. }\end{array}$ \\
\hline \multirow[t]{3}{*}{ Interventions } & $\begin{array}{l}\text { Experimental: IV PCA remifentanil, } 0.5 \mu \mathrm{g} \text { bolus per kg (based on antenatal booking weight) with } 2 \text { mins } \\
\text { lock-out, no hourly max. }\end{array}$ \\
\hline & Control: IV PCA pethidine, 10 mg bolus, 5 mins lock-out, 100 mg hourly max. \\
\hline & All women were given $10 \mathrm{mg}$ metoclopramide IV over $8 \mathrm{hrs}$. \\
\hline \multirow[t]{2}{*}{ Outcomes } & $\begin{array}{l}\text { Maternal: pain on } 10 \mathrm{~cm} \text { VAS recorded hourly; nausea recorded on a } 10 \mathrm{~cm} \text { VAS; itching; BP pulse and } \\
\text { resps. }\end{array}$ \\
\hline & Neonate: 1 min and 5 mins Apgar scores. \\
\hline \multirow[t]{5}{*}{ Notes } & Start and end date: not reported \\
\hline & $\begin{array}{l}\text { Power calculation: 'Power analysis }(\beta=0.2) \text { revealed that } 17 \text { women would be required in each group, } \\
\text { assuming } 10 \mathrm{~mm} \text { change in visual analogue pain score to be clinically significant.' }\end{array}$ \\
\hline & Baseline imbalances between groups: the groups were balanced for baseline characteristics \\
\hline & Funding source: not reported \\
\hline & Conflicts of interest: not reported \\
\hline
\end{tabular}

\section{Risk of bias}

\begin{tabular}{|c|c|c|}
\hline Bias & Authors' judgement & Support for judgement \\
\hline $\begin{array}{l}\text { Random sequence genera- } \\
\text { tion (selection bias) }\end{array}$ & Unclear risk & Not described "randomly allocated". \\
\hline $\begin{array}{l}\text { Allocation concealment } \\
\text { (selection bias) }\end{array}$ & Low risk & $\begin{array}{l}\text { Quote: "by selecting the next in a series of sealed envelopes prepared by phar- } \\
\text { macy." }\end{array}$ \\
\hline $\begin{array}{l}\text { Blinding of participants } \\
\text { and personnel (perfor- } \\
\text { mance bias) } \\
\text { All outcomes }\end{array}$ & Low risk & $\begin{array}{l}\text { Women were described as blinded. Quote: "One investigator selected the en- } \\
\text { velope and prepared the PCA pump. the pump was covered so that the other } \\
\text { investigator, the observer, was unable to see which drug the woman was re- } \\
\text { ceiving." }\end{array}$ \\
\hline $\begin{array}{l}\text { Blinding of outcome as- } \\
\text { sessment (detection bias) } \\
\text { All outcomes }\end{array}$ & Low risk & $\begin{array}{l}\text { Quote: "One investigator selected the envelope and prepared the PCA pump. } \\
\text { the pump was covered so that the other investigator, the observer, was unable } \\
\text { to see which drug the woman was receiving." }\end{array}$ \\
\hline $\begin{array}{l}\text { Incomplete outcome data } \\
\text { (attrition bias) } \\
\text { All outcomes }\end{array}$ & Low risk & $\begin{array}{l}\text { No loss to follow-up apparent although for some outcomes it was not clear } \\
\text { what the denominators were. }\end{array}$ \\
\hline $\begin{array}{l}\text { Selective reporting (re- } \\
\text { porting bias) }\end{array}$ & Unclear risk & Unclear \\
\hline Other bias & Low risk & None apparent \\
\hline
\end{tabular}


Wahab 1988

\begin{tabular}{|c|c|}
\hline Methods & $\begin{array}{l}\text { RCT. 4-arm parallel groups } \\
\text { Start and end date: May } 1984 \text { to November } 1985\end{array}$ \\
\hline Participants & $\begin{array}{l}\text { Setting: hospital in Cairo, Egypt } \\
80 \text { multiparous women at term ( } 39 \text { to } 41 \text { weeks), } 19 \text { to } 27 \text { years (parity } 2 \text { to } 6 \text { ), in the first stage of labour } \\
\text { following uncomplicated pregnancies, spontaneous labour. } \\
\text { Women with respiratory or cardiac disease were excluded. }\end{array}$ \\
\hline Interventions & $\begin{array}{l}\text { Group 1: IM nalbuphine } 0.13 \text { mg/kg } \\
\text { Group 2: IM butorphanol } 0.16 \text { mg/kg } \\
\text { Group 3: IM pentazocine } 0.4 \text { mg/kg } \\
\text { Group 4: IM placebo }\end{array}$ \\
\hline Outcomes & $\begin{array}{l}\text { Pain relief } 0=\text { complete relief, } 3=\text { no relief. Apgar score at } 1 \mathrm{~min} \text { and } 5 \text { mins. Maternal and fetal blood } \\
\text { gases. }\end{array}$ \\
\hline Notes & $\begin{array}{l}\text { Data were reported as means and have not been included in data tables. We describe findings briefly in } \\
\text { the text. } \\
\text { Start and end date: May } 1984 \text { - September } 1985 \\
\text { Power calculation: not reported } \\
\text { Baseline imbalances between groups: the groups were balanced for baseline characteristics } \\
\text { Funding source: not reported } \\
\text { Conflicts of interest: not reported }\end{array}$ \\
\hline
\end{tabular}

\section{Risk of bias}

\begin{tabular}{lll}
\hline Bias & Authors' judgement & Support for judgement \\
\hline $\begin{array}{l}\text { Random sequence genera- } \\
\text { tion (selection bias) }\end{array}$ & Unclear risk & Not described "randomly divided". \\
\hline $\begin{array}{l}\text { Allocation concealment } \\
\text { (selection bias) }\end{array}$ & Unclear risk & Not described "four equal groups". \\
\hline $\begin{array}{l}\text { Blinding of participants } \\
\text { and personnel (perfor- } \\
\text { mance bias) }\end{array}$ & Unclear risk & Unclear \\
All outcomes & \\
\hline $\begin{array}{l}\text { Blinding of outcome as- } \\
\text { sessment (detection bias) } \\
\text { All outcomes }\end{array}$ & Unclear risk & Unclear \\
\hline $\begin{array}{l}\text { Incomplete outcome data } \\
\text { (attrition bias) } \\
\text { All outcomes }\end{array}$ & Unclear risk & \\
\hline
\end{tabular}


Wahab 1988 (Continued)

$\begin{array}{ll}\begin{array}{l}\text { Selective reporting (re- } \\ \text { porting bias) }\end{array} & \begin{array}{l}\text { Not clear when randomisation took place and denominators in tables not } \\ \text { clear. }\end{array}\end{array}$

porting bias)

Unclear risk

The equal division into groups suggests that there may not have been true random allocation.

Wali 2012

\begin{tabular}{ll}
\hline Methods & Double-blind randomised trial \\
\hline Participants & 231 women with term, singleton pregnancy in cephalic position in the active stage of labour. \\
\hline Interventions & IM $100 \mathrm{mg}$ tramadol (114 women) versus IM 30 mg pentazocine (117 women). \\
\hline Outcomes & Pain at 30 and 60 mins, maternal satisfaction, side effects, neonatal outcomes. \\
\hline Notes & $\begin{array}{l}\text { No raw data were reported in this brief abstract. We have contacted the author for more information } \\
\text { (27th June 2017). No data are included in the analyses. }\end{array}$ \\
\hline
\end{tabular}

\section{Risk of bias}

\begin{tabular}{|c|c|c|}
\hline Bias & Authors' judgement & Support for judgement \\
\hline $\begin{array}{l}\text { Random sequence genera- } \\
\text { tion (selection bias) }\end{array}$ & Unclear risk & Not described \\
\hline $\begin{array}{l}\text { Allocation concealment } \\
\text { (selection bias) }\end{array}$ & Unclear risk & Not described \\
\hline $\begin{array}{l}\text { Blinding of participants } \\
\text { and personnel (perfor- } \\
\text { mance bias) } \\
\text { All outcomes }\end{array}$ & Low risk & Reported to be double-blind. \\
\hline $\begin{array}{l}\text { Blinding of outcome as- } \\
\text { sessment (detection bias) } \\
\text { All outcomes }\end{array}$ & Low risk & Reported to be double-blind. \\
\hline $\begin{array}{l}\text { Incomplete outcome data } \\
\text { (attrition bias) } \\
\text { All outcomes }\end{array}$ & Unclear risk & $\begin{array}{l}\text { Insufficient information to assess (not clear how many women were ran- } \\
\text { domised or if there were missing data). }\end{array}$ \\
\hline $\begin{array}{l}\text { Selective reporting (re- } \\
\text { porting bias) }\end{array}$ & Unclear risk & Brief abstract so unable to assess. \\
\hline Other bias & Unclear risk & $\begin{array}{l}\text { Unable to assess. The trial author has been contacted to provide more infor- } \\
\text { mation on methods. }\end{array}$ \\
\hline
\end{tabular}

Wee 2014

Methods $\quad$ Prospective, parallel-arm 2-centre RCT.

Block randomisation. Blocks of 2 to 10 . Women randomised individually. 
Wee 2014 (Continued)

Participants
Setting: 2 large hospitals in the UK.

484 women

Nulliparous and multiparous women aged 16 years or older who had given written informed consent, who were in active labour defined as regular uterine contractions of at least 2 in 10 mins, with a singleton pregnancy, cervical dilatation of at least $3 \mathrm{~cm}$, with gestation of 37 to 42 weeks, and weight between $60 \mathrm{~kg}$ and $120 \mathrm{~kg}$. The weight eligibility criterion was reduced from $70 \mathrm{~kg}$ to $60 \mathrm{~kg}$ with a substantial amendment in June 2009 approximately 3 months after the start of recruitment.

Exclusion criteria: allergy or previous adverse reaction to opioids or opioid dependency, use of parenteral opioids within the previous $24 \mathrm{hrs}$ or presence of severe systemic disease.
Experimental group 1: diamorphine $7.5 \mathrm{mg}$ group

Given into the muscles of the gluteus or lateral thigh by the midwife looking after the women from the trial syringes provided by the research midwife. IM. (244 women).

Experimental group 2: pethidine $150 \mathrm{mg}$ group

Given into the muscles of the gluteus or lateral thigh by the midwife looking after the women from the trial syringes provided by the research midwife. IM. ( 240 women).

A maximum of 2 doses of opioid were given with a minimum interval of $2 \mathrm{hrs}$ if the women requested additional analgesia. Women also received metoclopramide $10 \mathrm{mg}$ with the first dose. Regional analgesia or Entonox were available as rescue analgesia.

$\begin{array}{ll}\text { Outcomes } & \text { Satisfaction with analgesia } \\ \text { Severe pain } & \text { Mode of birth } \\ \text { Additional analgesia required } & \text { Naloxone admin } \\ \text { Neonatal resuscitation } & \text { Admission to special care } \\ \text { Breastfeeding problems } \\ \text { Apgar scores } \\ \text { Abnormal CTG } \\ \text { Umbilical cord gases }\end{array}$

Funding: independent research funded by the National Institute for Health Research (NIHR) under its Research for Patient Benefit (RfPB) Programme (Grant Reference Number PB-PG-0407-13170) with additional support costs funded by the Western Comprehensive Local Research Network. The views expressed are those of the authors and not necessarily those of the NHS, the NIHR or the Department of Health.

Conflict of interest: all authors have completed the Unified Competing Interest form and there are no competing interests. 3 authors received travel expenses for meetings in relation to the trial.

\section{Risk of bias}


Wee 2014 (Continued)

Random sequence genera- Low risk tion (selection bias)
The trial statistician provided the computer-generated block randomisation using block sizes between 2 and 10 to ensure approximately equal group sizes, and stratified by centre.

\begin{tabular}{|c|c|c|}
\hline $\begin{array}{l}\text { Allocation concealment } \\
\text { (selection bias) }\end{array}$ & Low risk & $\begin{array}{l}\text { The pharmacies of both trial centres prepared batches of } 2 \text { identical syringes } \\
\text { labelled only with the trial number to conceal group allocation and to ensure } \\
\text { that if } 2 \text { doses were given, the same opioid was given both times. }\end{array}$ \\
\hline
\end{tabular}

\begin{tabular}{|c|c|c|}
\hline $\begin{array}{l}\text { Blinding of participants } \\
\text { and personnel (perfor- }\end{array}$ & Low risk & $\begin{array}{l}\text { Women, researchers, maternity unit staff and trial statistician were blinded to } \\
\text { allocation. The actual identities of the } 2 \text { groups were not revealed until after }\end{array}$ \\
\hline
\end{tabular}
mance bias) full analysis and discussion of the results.

All outcomes

\begin{tabular}{|c|c|c|}
\hline $\begin{array}{l}\text { Blinding of outcome as- } \\
\text { sessment (detection bias) } \\
\text { All outcomes }\end{array}$ & Low risk & $\begin{array}{l}\text { Women, researchers, maternity unit staff and trial statistician were blinded to } \\
\text { allocation. The actual identities of the } 2 \text { groups were not revealed until after } \\
\text { full analysis and discussion of the results. }\end{array}$ \\
\hline
\end{tabular}

\begin{tabular}{ll}
\hline $\begin{array}{l}\text { Incomplete outcome data } \\
\text { (attrition bias) }\end{array}$ & No loss to follow-up reported except Quote: "from the 60 -minute measure- \\
All outcomes & ment onwards there was significantly more missing data in the pethidine \\
& group than the diamorphine group (for example $19 \%$ versus $10 \%$ at 60 min- \\
& utes, $53 \%$ versus $34 \%$ at 120 minutes). The difference in quantity of missing \\
data was largely because the women in the pethidine group tended to deliver & earlier.". The study recruited over their target recruitment to account for the \\
missing data.
\end{tabular}

ITT analysis adhered to. Not all denominators reported in tables.

\begin{tabular}{lll}
\hline $\begin{array}{l}\text { Selective reporting (re- } \\
\text { porting bias) }\end{array}$ & Low risk & All outcomes reported as per protocol \\
\hline Other bias & Low risk & Similar baseline characteristics \\
\hline
\end{tabular}

\section{Wheble 1988}

\begin{tabular}{ll}
\hline Methods & RCT, 2-arm parallel-group design \\
\hline Participants & Setting: hospital, UK \\
& 47 women. Women in active labour and requiring analgesia, 37 to 42 weeks' gestation, singleton preg- \\
& nancies with no known disorders, spontaneous or induced labour onset. \\
& Parity: mixed
\end{tabular}

\begin{tabular}{|c|c|}
\hline \multirow[t]{2}{*}{ Interventions } & $\begin{array}{l}\text { Experimental: IM meptazinol }(\mathrm{N}=17) \\
\text { Control: IM pethidine }(\mathrm{N}=17)\end{array}$ \\
\hline & $\begin{array}{l}\text { Study dose dependent on woman's weight: } 100 \mathrm{mg} \text { if weight }<70 \mathrm{~kg}, 150 \mathrm{mg} \text { if weight } \geq 70 \mathrm{~kg} \text {. Addition- } \\
\text { al analgesia at discretion of caregiver, either } 2 \mathrm{nd} \text { dose of study drug, epidural or nitrous oxide, meto- } \\
\text { clopramide as required for nausea and vomiting. }\end{array}$ \\
\hline
\end{tabular}

$\begin{array}{ll}\text { Outcomes } & \text { Maternal outcomes: type of birth, additional analgesia, epidural. Neonatal outcomes: Apgar at } 1 \text { min } \\ & \text { and } 5 \text { mins, FHR changes. }\end{array}$

Notes $\quad$ Open non-randomised control arm
Start and end date: not reported


Wheble 1988 (Continued)

Power calculation: not reported

Baseline imbalances between groups: unclear

Funding source: Medical Research Council and Wyeth Research (UK)

Conflicts of interest: not reported

\section{Risk of bias}

\begin{tabular}{|c|c|c|}
\hline Bias & Authors' judgement & Support for judgement \\
\hline $\begin{array}{l}\text { Random sequence genera- } \\
\text { tion (selection bias) }\end{array}$ & Unclear risk & Not reported \\
\hline $\begin{array}{l}\text { Allocation concealment } \\
\text { (selection bias) }\end{array}$ & Unclear risk & Not reported \\
\hline $\begin{array}{l}\text { Blinding of participants } \\
\text { and personnel (perfor- } \\
\text { mance bias) } \\
\text { All outcomes }\end{array}$ & Unclear risk & Described as double-blind but methods not described. \\
\hline $\begin{array}{l}\text { Blinding of outcome as- } \\
\text { sessment (detection bias) } \\
\text { All outcomes }\end{array}$ & Unclear risk & Described as double-blind but methods not described. \\
\hline $\begin{array}{l}\text { Incomplete outcome data } \\
\text { (attrition bias) } \\
\text { All outcomes }\end{array}$ & Low risk & All patients analysed in an ITT analysis. \\
\hline $\begin{array}{l}\text { Selective reporting (re- } \\
\text { porting bias) }\end{array}$ & Unclear risk & Unclear \\
\hline Other bias & Unclear risk & $\begin{array}{l}\text { Balanced at baseline for height, weight, age, socioeconomic group, gestation, } \\
\text { cervical dilation, parity and smoking. }\end{array}$ \\
\hline
\end{tabular}

\section{Wilson 1986}

\begin{tabular}{ll}
\hline Methods & RCT, 2-arm parallel-group design \\
\hline Participants & Setting: hospital, UK \\
& 80 women. Healthy women in active labour and requiring analgesia, $\geq 38$ weeks' gestation, uncompli- \\
cated pregnancy. & Parity: 4 or less \\
\hline Interventions & $\begin{array}{l}\text { Experimental: IM nalbuphine } 20 \mathrm{mg}(\mathrm{N}=37) \text {. Control: IM pethidine } 100 \text { mg ( } \mathrm{N}=35) \text {. Additional doses of } \\
\text { test drug allowed at intervals no less than } 2 \text { hrs if required to a maximum of } 3 \text { doses. Epidural if analge- } \\
\text { sia inadequate at discretion of caregiver and subsequently removed from trial. }\end{array}$ \\
\hline Outcomes & $\begin{array}{l}\text { Maternal outcomes: pain intensity at peak of contraction at } 30,60 \text { and } 90 \text { mins (rated very severe, se- } \\
\text { vere, moderate, slight) and with VAS (0 to 100), type of birth, sleepiness, nausea and vomiting. Neona- } \\
\text { tal outcomes: Apgar at } 1 \text { min and } 5 \text { mins, naloxone administration, Scanlon score (neuro-behavioural } \\
\text { score) at } 2 \text { to } 4 \text { hrs and } 24 \text { hrs. }\end{array}$ \\
\hline Notes & Start and end date: not reported \\
\hline
\end{tabular}


Wilson 1986 (Continued)

Power calculation: not reported

Baseline imbalances between groups: unclear

Funding source: not reported

Conflicts of interest: not reported

\section{Risk of bias}

\begin{tabular}{|c|c|c|}
\hline Bias & Authors' judgement & Support for judgement \\
\hline $\begin{array}{l}\text { Random sequence genera- } \\
\text { tion (selection bias) }\end{array}$ & Unclear risk & Not reported \\
\hline $\begin{array}{l}\text { Allocation concealment } \\
\text { (selection bias) }\end{array}$ & Unclear risk & Not reported \\
\hline $\begin{array}{l}\text { Blinding of participants } \\
\text { and personnel (perfor- } \\
\text { mance bias) } \\
\text { All outcomes }\end{array}$ & Low risk & States double-blind and study drugs were dispensed in coded ampoules. \\
\hline $\begin{array}{l}\text { Blinding of outcome as- } \\
\text { sessment (detection bias) } \\
\text { All outcomes }\end{array}$ & Unclear risk & Not reported \\
\hline $\begin{array}{l}\text { Incomplete outcome data } \\
\text { (attrition bias) } \\
\text { All outcomes }\end{array}$ & High risk & $8 / 80$ excluded from analyses due to inadequate pain relief. \\
\hline $\begin{array}{l}\text { Selective reporting (re- } \\
\text { porting bias) }\end{array}$ & Unclear risk & Unclear \\
\hline Other bias & Unclear risk & $\begin{array}{l}\text { Does not report actual number randomised per group. Broadly comparable at } \\
\text { baseline with respect to physical and obstetric characteristics. }\end{array}$ \\
\hline
\end{tabular}

\section{Zafar 2016}

Methods RCT with individual randomisation.

Participants Setting: Islamic International Medical college trust - Rawalpindi (Punjab province) and Islamabad, Pakistan.

150 women in early labour $(3 \mathrm{~cm}$ to $6 \mathrm{~cm}$ ) (spontaneous or induced) with uncomplicated singleton term pregnancy and cephalic presentation.

Exclusion criteria: women, who requested for other forms of analgesia, had a complicated pregnancy (e.g. pre-eclampsia, antepartum haemorrhage)/pre-existing medical disease, had any contraindication to vaginal delivery, or contraindication to opioids.

Interventions

Experimental group $1(n=50)$ (conventional group) received a single intramuscular injection of $1 \mathrm{~mL}$ of pentazocine $(30 \mathrm{mg})$ and oral placebo.

Experimental group $2(n=50)$ (homeopathy group) received $1 \mathrm{~mL}$ of saline injection and oral homeopathic medicine prescribed by a qualified homeopath. The homeopathic medicine used wasChamomilla recutita with strength of $1 \mathrm{M}$, manufactured by William Schwabe Karlsruhe (Schwabe) and origin was from Germany. It was used in a dose of 3 drops. This medicine comes in a dilution of _30,_200 and $1 \mathrm{M}$. 
Zafar 2016 (Continued)

Control group $(n=50)$ (placebo group) received oral placebo and $1 \mathrm{~mL}$ of saline injection.

\begin{tabular}{ll}
\hline Outcomes & Mode of birth \\
& Side effects \\
& Pain intensity \\
Duration of labour
\end{tabular}

Notes Start and end dates: August 2008 to September 2009

Funding: the funding for this project was provided by the Higher Education Commission Pakistan.

Conflict of interest: not reported

\section{Risk of bias}

\begin{tabular}{lll}
\hline Bias & Authors' judgement & Support for judgement \\
\hline $\begin{array}{l}\text { Random sequence genera- } \\
\text { tion (selection bias) }\end{array}$ & Low risk & Randomisation codes were generated through computer. \\
\hline $\begin{array}{l}\text { Allocation concealment } \\
\text { (selection bias) }\end{array}$ & Low risk & $\begin{array}{l}\text { Randomisation codes were placed in sequential numbers in sealed envelopes. } \\
\text { Women were asked to pick from a shuffled deck of cards with a number that } \\
\text { was assigned to an envelope. The selected envelope containing the treatment } \\
\text { was opened up by a health worker who prepared the study drugs and had no } \\
\text { further involvement with women's assessment. }\end{array}$
\end{tabular}

\begin{tabular}{|c|c|c|}
\hline $\begin{array}{l}\text { Blinding of participants } \\
\text { and personnel (perfor- } \\
\text { mance bias) }\end{array}$ & Low risk & $\begin{array}{l}\text { The study drugs and the placebo were dispensed in similar packing to ensure } \\
\text { blinding of patients as well as dispensers. }\end{array}$ \\
\hline All outcomes & & $\begin{array}{l}\text { Caregiver: a health worker, who was blinded to the contents of the drug inject- } \\
\text { ed the medicine and dispensed oral preparation of small, white sugar pellets. }\end{array}$ \\
\hline
\end{tabular}

Blinding of outcome as- Low risk sessment (detection bias) All outcomes
Not mentioned though if caregiver recorded outcomes, assessors were blinded.

$\begin{array}{ll}\begin{array}{l}\text { Incomplete outcome data } \\ \text { (attrition bias) }\end{array} & \text { Unclear risk } \\ \text { All outcomes } & \begin{array}{l}1 \text { women in placebo group opted for epidural and was withdrawn from the } \\ \text { study. }\end{array} \\ & 3 \text { women form conventional group, } 8 \text { women from homeopathy group, and } \\ & 8 \text { women from placebo group were lost to follow-up. It is reported that 'the } \\ \text { missing values were observed as some women delivered before any pain as- } & \text { sessment or the observations were not recorded.' There were no further rea- } \\ \text { sons provided. }\end{array}$

\begin{tabular}{|c|c|c|}
\hline $\begin{array}{l}\text { Selective reporting (re- } \\
\text { porting bias) }\end{array}$ & Unclear risk & $\begin{array}{l}\text { All essential outcomes are reported, protocol not seen and outcomes not } \\
\text { clearly specified in text. }\end{array}$ \\
\hline
\end{tabular}

Other bias Unclear risk The baseline demographic characteristics, age, weight and height, were similar in the 3 groups. However Camomilla group had fewer primips, and fewer $>$ para 3. Denominators not clearly specified. Abstract reports 99 women randomised, full-text reports 150 before exclusions. 
Zhu 2013

\begin{tabular}{ll}
\hline Methods & Randomised trial with individual randomisation. \\
\hline Participants & 150 full-term primiparous women intending to have normal vaginal birth. \\
& No exclusion criteria (abstract only) \\
\hline Interventions & Group 1 ( 50 women): fentanyl-droperidol mixed liquor via acupoint injection at different time stages: \\
& BL 23 in active phase and BL 32 in second stage. \\
& Group 2 (50 women): fentanyl-droperidol mixed liquor via subcutaneous injection \\
& Group 3 (50 women): NaCl 0.9\% via subcutaneous injection \\
\hline Outcomes & VAS score \\
level or norepinephrine \\
Blood pressure \\
Dates: not in abstract \\
Funding: not reported \\
Conflict of interest: not reported \\
ABSTRACT ONLY - no data. Full text in Chinese
\end{tabular}

\section{Risk of bias}

\begin{tabular}{|c|c|c|}
\hline Bias & Authors' judgement & Support for judgement \\
\hline $\begin{array}{l}\text { Random sequence genera- } \\
\text { tion (selection bias) }\end{array}$ & Unclear risk & "Randomly divided". Method not described \\
\hline $\begin{array}{l}\text { Allocation concealment } \\
\text { (selection bias) }\end{array}$ & Unclear risk & Method not described \\
\hline $\begin{array}{l}\text { Blinding of participants } \\
\text { and personnel (perfor- } \\
\text { mance bias) } \\
\text { All outcomes }\end{array}$ & High risk & $\begin{array}{l}\text { Women receiving the subcutaneous injections may have been blinded, unlike- } \\
\text { ly that blinding would have been maintained for staff. }\end{array}$ \\
\hline $\begin{array}{l}\text { Blinding of outcome as- } \\
\text { sessment (detection bias) } \\
\text { All outcomes }\end{array}$ & High risk & Not mentioned, likely to have outcomes collected by staff. \\
\hline $\begin{array}{l}\text { Incomplete outcome data } \\
\text { (attrition bias) } \\
\text { All outcomes }\end{array}$ & Unclear risk & Unable to assess - abstract only \\
\hline $\begin{array}{l}\text { Selective reporting (re- } \\
\text { porting bias) }\end{array}$ & Unclear risk & Unable to assess - abstract only \\
\hline Other bias & Unclear risk & Unable to assess - abstract only \\
\hline
\end{tabular}

ARM: artificial rupture of the membranes

ASA: American Society of Anesthesiologists Classification

BMI: body mass index

BP: blood pressure 
CS: caesarean section

CTG: cardiotocograph

Cx: cervix

FGR: fetal growth restriction

FHR: fetal heart rate

GA: gestational age

HR: heart rate

IM: intramuscular

IOL: induction of labour

ITT: intention-to-treat

$\mathrm{hr}(\mathrm{s})$ : hour(s)

IV: intravenous

$\min (\mathrm{s})$ : minute(s)

multips: multiparous women

MW: midwife

NACS: Neurologic and Adaptive Capacity Score

nullips: nulliparous women

PCA: patient controlled analgesia

PN: postnatal

primips: primiparous women

$\mathrm{RCT}$ : randomised controlled trial

resps: respirations

SC: subcutaneous

SCBU: special care baby unit

SD: standard deviation

TENS: transcutaneous electrical nerve stimulation

VAS: visual analogue scale

Characteristics of excluded studies [ordered by study ID]

\section{Study Reason for exclusion}

Abd-El-Maeboud 2014

Abdollahi 2014

Aiken 1971

This study compares the use of diazepam versus a placebo. Both groups had pethidine.

Alhashemi 2011

Ankumah 2016

IM pethidine was compared with IV paracetamol. The comparison of opiates with non-opioid drugs is not a relevant comparison for this review.

IM pethidine was compared with IV paracetamol. The comparison of opiates with non-opioid drugs is not a relevant comparison for this review.

\section{IV morphine was compared with IV paracetamol. The comparison of opiates with non-opioid drugs} is not a relevant comparison for this review.

Balcioglu 2007

In this study group allocation was by order of hospital admission (alternate allocation). Not an RCT.

\section{Balki 2007}

In this study both groups received the same drug (remifentanil) by PCA. The focus of the study was on variation in the bolus size versus variation in the background infusion rate. Studies that examine variation in mode of administration will be considered in a separate related Cochrane review.

Balki 2012

In this study both groups had opioids (remifentanil administration in the form of either an infusion or PCA demand bolus (intravenous injection of a single dose over a short period of time).

Ballas 1976

There was no evidence that this study was an RCT. There were 3 study groups and all 3 received pethidine (1 after 1-hour delay). The aim of the study was to monitor uterine activity over $60 \mathrm{~min}$ utes. 


\begin{tabular}{ll}
\hline Study & Reason for exclusion \\
\hline Bare 1962 & $\begin{array}{l}\text { This study examined the effects of hydroxine hydrochloride, an antihistamine. None of the study } \\
\text { groups received an opioid analgesic drug. }\end{array}$ \\
\hline Bhatia 2013 & $\begin{array}{l}\text { IM tramadol was compared with IV paracetamol. The comparison of opiates with non-opioid drugs } \\
\text { is not a relevant comparison for this review. }\end{array}$
\end{tabular}

\begin{tabular}{ll}
\hline Bredow 1992 & This study was not an RCT. Alternate allocation to groups. \\
\hline Brelje 1966 & $\begin{array}{l}\text { This was a quasi-randomised study with group allocation by month of birth. The aim of the study } \\
\text { was to look at hydroxine as an adjunct to pethidine. both study groups had pethidine. }\end{array}$ \\
\hline Brookes 2013 & This trial compares different routes of administration as well as different drugs. \\
\hline Busacca 1982 & $\begin{array}{l}\text { In this study, } 1 \text { group received pethidine with promethazine and } 1 \text { received no treatment. As the } \\
\text { opioid group received a combination of drugs any differences between groups may have been due } \\
\text { to the effect of the add-on drug. }\end{array}$ \\
\hline
\end{tabular}

Cahal 1960

This study had 3 groups: SC pethidine, SC benzethidine and SC flurethidine. We are not aware that, apart from pethidine, these drugs are used any longer for pain relief in labour.

\section{Calderon 2006}

In this study, 1 group received IV remifentanil and 1 group received IM pethidine with haloperidol. With 1 group receiving an add-on drug it would not be possible to compare the effects of the 2 opioids.

\begin{tabular}{ll}
\hline Callaghan 1966 & In this study pethidine was compared with the use of a sedative. It was not clear that this was an \\
RCT.
\end{tabular}

Camann 1992

This study compared IV sufentanil with epidural analgesia. Epidural analgesia in labour is covered in a related Cochrane review.

\begin{tabular}{ll}
\hline Castro 2004 & $\begin{array}{l}\text { This study was for pain relief during second trimester labour for termination of pregnancy and so } \\
\text { not for pain relief for labour of childbirth. }\end{array}$
\end{tabular}

\begin{tabular}{ll}
\hline Cavanagh 1966 & $\begin{array}{l}\text { This study had } 4 \text { groups: pethidine IM, anileridine IM, pethidine + perphenazine IM and anileridine + } \\
\text { perphenazine IM. We are not aware that anileridine is used any longer in obstetric practice. }\end{array}$ \\
\hline Chandnani 2013 & $\begin{array}{l}\text { It was not clear whether or not this was a randomised trial. Women were divided into } 2 \text { equal-sized } \\
\text { groups but there was no indication that allocation was random. }\end{array}$
\end{tabular}
Chang 1976 It was not clear that participants in this trial were all in labour. The aim of the study was to examine fetal acid balance, with maternal and fetal blood sampling 30 and 60 minutes after administering the drugs. No other outcomes were recorded.

\begin{tabular}{ll}
\hline Cincadze 1978 & Brief conference abstract. It was not clear that this was an RCT. We attempted to trace the authors \\
for more information without success.
\end{tabular}

Cullhed 1961 This was not an RCT. Groups were divided into groups according to date of hospital attendance.

Dahiya 2015 IM tramadol was compared with IV paracetamol. The comparison of opiates with non-opioid drugs
is not a relevant comparison for this review.

Dan 1991 In this study 1 group received IV nalbuphine and the other pethidine with promethazine, as the
pethidine group had an add-on drug it is not possible to compare the 2 opioids.
pethidine group had an add-on drug it is not possible to compare the 2 opioids.

De Kornfeld 1964

This study was excluded for methodological reasons; there was extremely high attrition for some outcomes (>50\%). SC pethidine and placebo were compared in this study; however, it appeared that the drugs were administered very late in labour. Of 224 women included in the analysis, it ap- 


\begin{tabular}{ll}
\hline Study & Reason for exclusion \\
\hline $\begin{array}{l}\text { peared that more than half had given birth within an hour of drug administration. There were data } \\
\text { on pain relief for only approximately } 103 \text { women at } 1 \text { hour. Results were very difficult to interpret. }\end{array}$
\end{tabular}

\section{De Lamerens 1964}

All study groups received pethidine. The aim of the study was to examine the effects of tranquillisers as adjuncts to analgesics.

\section{Eames 1964 \\ This study had 2 groups: pethidine $100 \mathrm{mg} \mathrm{IM}$ and oxymorphone $1.5 \mathrm{mg} \mathrm{IM}$. Oxymorphone is no longer used for pain relief in labour.

$\begin{array}{ll}\text { Easton } 2016 & \begin{array}{l}\text { The trial registration refers to "crossover assignment" in the methods. Cross-over trials are not eli- } \\ \text { gible for inclusion in this review. }\end{array}\end{array}$

\begin{tabular}{ll} 
El Kinawy 2015b & This study compares pethidine with an NSAID; this is not a eligible comparison for this review. \\
\hline El-Kerdawy 2010 & $\begin{array}{l}\text { This study compared opioids with epidural analgesia. Epidural analgesia in labour is covered in a } \\
\text { related Cochrane review. }\end{array}$
\end{tabular}

\begin{tabular}{ll}
\hline Elbohoty 2012 & IV pethidine was compared with IV paracetamol. The comparison of opiates with non-opioid drugs \\
is not a relevant comparison for this review.
\end{tabular}
is not a relevant comparison for this review.

\begin{tabular}{ll}
\hline Elhalwagy 2017 & This study examines ketamine which is not an opioid. \\
\hline Eliot 1975 & $\begin{array}{l}\text { There was no evidence that there was random allocation in this study. There were } 2 \text { study groups } \\
\text { and both received pethidine, the aim of the study was to compare drugs administered as an ad- } \\
\text { junct to the opioid analgesia (diazepam vs promazine). }\end{array}$
\end{tabular}

Evron 2005 In this study 2 different drugs using different modes of administration were compared. IV pethidine
(with dummy PCA) was compared with PCA remifentanil (with dummy background IV infusion).
With both the drug and method being different in each arm of the trial results from this study are
very difficult to interpret.

\begin{tabular}{ll}
\hline Evron 2007 & PCA IV pethidine was compared with epidural analgesia. \\
\hline Evron 2008 & $\begin{array}{l}\text { In this study with } 4 \text { different treatment arms, } 1 \text { group received IV remifentanil, the remaining } 3 \text { re- } \\
\text { ceived epidural analgesia. Epidurals are covered in a separate Cochrane review. }\end{array}$ \\
\hline
\end{tabular}

\begin{tabular}{ll}
\hline Fernandez 2015 & $\begin{array}{l}\text { In this study pethidine was given with haloperidol compared with a birth ball. The addition of } \\
\text { haloperidol means this comparison is not relevant for this review. }\end{array}$ \\
\hline Fleet 2015 & $\begin{array}{l}\text { In this study all the } 3 \text { groups received fentanyl but in different doses and by different routes of ad- } \\
\text { ministration. }\end{array}$ \\
\hline Freeman 2012 & $\begin{array}{l}\text { PCA remifentanil was compared with epidural (this comparison is eligible for inclusion in a related } \\
\text { review). }\end{array}$ \\
\hline Gambling 1998 & This study compared IV pethidine versus a combined spinal epidural. \\
\hline Ginosar 2003 & Study examining IV versus epidural fentanyl. \\
\hline Goodlin 1988 & $\begin{array}{l}\text { Entry in trials register. It is not clear that this study was completed. We attempted to contact the } \\
\text { author and searched for any published results relating to this trial without success. }\end{array}$ \\
\hline Grandjean 1979 & Study examining IV versus epidural analgesia. \\
\hline Greer 1988 & The study evaluated the effects of the interventions on platelet function in the newborn. \\
\hline
\end{tabular}




\begin{tabular}{|c|c|}
\hline Study & Reason for exclusion \\
\hline Gupta 2016 & This study is looking at IV paracetamol ad an adjunct to PCA epidural analgesia. \\
\hline Hashemiyan 2014 & $\begin{array}{l}\text { This study examine an opioid compared with paracetamol. This is not a relevant comparison for } \\
\text { this review. }\end{array}$ \\
\hline Hodgkinson 1978 & $\begin{array}{l}\text { In this study both randomised groups received pethidine. One group also received naloxone. A } \\
\text { third, non-randomised "matched" group received no narcotic drugs. }\end{array}$ \\
\hline Isenor 1993 & $\begin{array}{l}\text { In this study both groups received the same drug (pethidine). The focus of the study was on vari- } \\
\text { ation in route of administration; IM was compared with PCA (IV) pethidine. Studies that examine } \\
\text { variation in mode of administration will be considered in a separate related Cochrane review. }\end{array}$ \\
\hline John 2013 & $\begin{array}{l}\text { Study examining cortisol levels in women receiving IV opioid vs epidural. This comparison is eligi- } \\
\text { ble for a related review. }\end{array}$ \\
\hline Jost 2015 & $\begin{array}{l}\text { This was a cross-over study which is not eligible for inclusion in this review. The study was examin- } \\
\text { ing different bolus doses of PCA remifentanil. }\end{array}$ \\
\hline Kalaskar 2007 & $\begin{array}{l}\text { No results were reported in this brief abstract. We attempted to contact the author without suc- } \\
\text { cess. }\end{array}$ \\
\hline Kaltreider 1967 & $\begin{array}{l}\text { Only women in preterm labour were recruited to this study. This study was excluded for method- } \\
\text { ological reasons: there was no information about the number of women randomised and women } \\
\text { who received any additional non-study medications were excluded post randomisation. Under } \\
\text { these circumstances interpreting the findings of this study are very difficult. }\end{array}$ \\
\hline
\end{tabular}

\begin{tabular}{|c|c|}
\hline Karadjova 2016 & IV PCA opioid vs epidural. This comparison is eligible for inclusion in a related review. \\
\hline Kaur 2015 & $\begin{array}{l}\text { IM opioid (tramadol) was compared with non opioid (IV paracetamol). This comparison is not eligi- } \\
\text { ble for inclusion in this review. }\end{array}$ \\
\hline Khooshideh 2015 & Intervention and control were both IV remifentanil, comparing different regimens. \\
\hline Krins 1969 & Study participants were not women in labour. \\
\hline Lallar 2015 & $\begin{array}{l}\text { IM opioid (tramadol) was compared with non opioid (IV paracetamol). This comparison is not eligi- } \\
\text { ble for inclusion in this review. }\end{array}$ \\
\hline Li 1995 & $\begin{array}{l}\text { In this study, } 2 \text { opioid drugs were compared (tramadol and dihydroetorphine hydrochloride). How- } \\
\text { ever, the drugs were administered by different routes (sublingual versus oral) and results are there- } \\
\text { fore very difficult to interpret. }\end{array}$ \\
\hline Logtenberg 2017 & This study compared PCA remifentanil with epidural; this comparison is not eligible for this review. \\
\hline MacVicar 1960 & $\begin{array}{l}\text { Not an RCT; consecutive allocation to groups. Study examining the sedative effects of drugs and } \\
\text { their effects on memory. }\end{array}$ \\
\hline Malkasian 1967 & $\begin{array}{l}\text { In this study both groups received pethidine. The focus of the trial was on the use of promethazine } \\
\text { versus hydroxyzine as add-on drugs. }\end{array}$ \\
\hline Marshalov 2012 & $\begin{array}{l}\text { This study compared and opiate (not clear what drug, route or dose) with epidural. This compari- } \\
\text { son is not eligible for this review. }\end{array}$ \\
\hline McDonald 1964 & $\begin{array}{l}\text { This study included } 5 \text { study arms and focused specifically on neonatal serum bilirubin, an outcome } \\
\text { not relevant to this review. }\end{array}$ \\
\hline
\end{tabular}




\begin{tabular}{ll}
\hline Study & Reason for exclusion \\
\hline McGrath 1992 & A study examining epidural versus IV analgesia. \\
\hline McInnes 2004 & $\begin{array}{l}\text { In this study both groups received the same drug (diamorphine) either by PCA or IM. Studies that } \\
\text { examine variation in mode of administration will be considered in a separate related Cochrane re- } \\
\text { view. }\end{array}$
\end{tabular}

\begin{tabular}{ll}
\hline McQuitty 1967 & $\begin{array}{l}\text { This study focused on promethazine, promazine and propiomazine ad adjuncts to pethidine. All } \\
\text { study groups received pethidine. }\end{array}$ \\
\hline Moore 1974 & $\begin{array}{l}\text { It was not clear that this was a randomised trial. Women were paired and then allocated in se- } \\
\text { quence to } 4 \text { study arms. }\end{array}$ \\
\hline Morgan 2004 & $\begin{array}{l}\text { This was a pilot study reported as an abstract only and there was too little information on methods } \\
\text { and results to assess risk of bias and results did not include outcomes relevant to this review. }\end{array}$
\end{tabular}

\begin{tabular}{ll}
\hline Morris 1994 & Study focusing on IV versus epidural fentanyl. \\
\hline Nafisi 2006 & Study comparing IV pethidine versus epidural. \\
\hline Ng 2011 & Although both the groups received different opioids, the mode of administration was not the same.
\end{tabular}

\begin{tabular}{ll}
$\mathrm{Ng} 2011$ & Although both the groups received different opioids, the mode of administration was not the same. \\
\hline Nikkola 2000 & $\begin{array}{l}\text { In this study, women in the } 2 \text { arms of the trials were given different drugs with different routes of } \\
\text { administration. PCA IV fentanyl was compared with paracervical blockade; } 10 \mathrm{~mL} 0.25 \% \text { bupiva- } \\
\text { caine injected into } 4 \text { locations in the cervix. }\end{array}$ \\
\hline
\end{tabular}

\begin{tabular}{ll}
\hline Overton 1992 & This study comparing sublingual diamorphine with IM pethidine was reported in a brief abstract; \\
no denominators for study groups were provided. We attempted to contact the study author for \\
more information without success.
\end{tabular}

\begin{tabular}{ll}
\hline Pandole 2003 & In this study, women received either IM tramadol or IM pethidine. It was not clear that this was an \\
RCT.
\end{tabular}
Polley $2000 \quad$ This study compared IV vs epidural fentanyl (epidural analgesia is the subject of separate Cochrane reviews).

\begin{tabular}{ll}
\hline Posner 1960 & In this study both groups received pethidine; the focus of the study was on a narcotic antagonist \\
(levallorphan) as an adjunct to pethidine.
\end{tabular}

Powe 19623 groups in this study received pethidine. The aim of the study was to examine the effects of
promethazine and propiomazine as adjuncts to pethidine.

\begin{tabular}{ll}
\hline Rabie 2006 & This study compared the use of IV PCA remifentanil versus epidural. \\
\hline Rahimi 2012 & This was a cross-over study. This design is not eligible for inclusion in the review. \\
\hline Ransom 1966 & This study had 2 groups: pethidine $125 \mathrm{mg}$ IM and oxymorphone $1.25 \mathrm{mg}$ IM. \\
\hline Rayburn 1989 & $\begin{array}{l}\text { In this study both groups received the same drug (pethidine) by PCA versus nurse administered (IV). } \\
\text { Studies that examine variation in mode of administration will be considered in a separate related } \\
\text { Cochrane review. }\end{array}$
\end{tabular}

Rayburn 1991 In this study both groups received the same drug (fentanyl) 1 group by PCA and 1 nurse adminis-
tered (IV). Studies that examine variation in mode of administration will be considered in a sepa-
rate related Cochrane review.
dine). The outcome was not pain relief but fetal expiratory volume. There was no comparison of 


\begin{tabular}{ll}
\hline Study & Reason for exclusion \\
\hline Roberts 1960 & $\begin{array}{l}\text { analgesic drugs in labour. We are not aware that methylpentonol is any longer used during child- } \\
\text { birth. }\end{array}$ \\
\hline Robinson 1980 & $\begin{array}{l}\text { In this study both groups received the same IM opioid analgesia (alphaprodine). The study exam- } \\
\text { ined the effects of a narcotic antagonist (levallorphan) as an adjunct to the opioid. }\end{array}$ \\
\hline $\begin{array}{l}\text { This study compared different ways of administering pethidine (IM vs IV); the IM group received } \\
\text { an anti-emetic the IV group did not. 386 women were randomised but there appears to have been } \\
\text { serious attrition with complete data for only approximately a third of women randomised. Attri- } \\
\text { tion was mainly due to protocol deviations. With these methodological problems findings from this } \\
\text { study are very difficult to interpret. }\end{array}$
\end{tabular}

Ron $1984 \begin{aligned} & \text { Study examining the value of promethazine as an adjunct to pethidine. The study did include a } \\ & \text { placebo group but the only result reported was maternal blood pressure } 10 \text { minutes after injection } \\ & \text { of the drug/ placebo. }\end{aligned}$

\begin{tabular}{ll}
\hline Rowley 1963 & $\begin{array}{l}\text { This was a quasi-randomised study. The outcomes collected in this study were neonate bilirubin } \\
\text { levels. }\end{array}$ \\
\hline Sabry 2011 & $\begin{array}{l}\text { In this study the comparison group received epidural. This comparison is examined in a related re- } \\
\text { view. }\end{array}$ \\
\hline Samanta 2013 & $\begin{array}{l}\text { In this study the comparison group received epidural. This comparison is examined in a related re- } \\
\text { view. }\end{array}$
\end{tabular}

\begin{tabular}{ll}
\hline Savage 1955 & Quasi-randomised study with alternate allocation. \\
\hline Sentnor 1966 & This study had 4 groups: pethidine $50 \mathrm{mg}, 75 \mathrm{mg}$ or $100 \mathrm{mg} \mathrm{IM}$, oxymorphone $0.75 \mathrm{mg}, 1.125 \mathrm{mg}$ or \\
& $\begin{array}{l}1.5 \mathrm{mg}, \text { pethidine + noroxymorphone IM and oxymorphone + noroxymorphone IM. Oxymorphone is } \\
\text { no longer used in clinical practice. }\end{array}$
\end{tabular}

\begin{tabular}{ll}
\hline Shahriari 2007 & $\begin{array}{l}\text { In this study IV remifentanil was compared with IM pethidine. As both the drug and the route were } \\
\text { different, we excluded this study as results are difficult to interpret. }\end{array}$ \\
\hline Singh 2001 & Not an RCT. \\
\hline Solek-Pastuszka 2009 & $\begin{array}{l}\text { This study compared opioids with epidural analgesia. Epidural analgesia in labour is covered in a } \\
\text { related Cochrane review. }\end{array}$ \\
\hline Soontrapa 2002 & $\begin{array}{l}\text { This was a quasi-randomised study and allocation could be anticipated. } \\
\text { Sosa } 2004\end{array}$ \\
\hline $\begin{array}{l}\text { This study focused on women with dystocia and the use of pethidine to promote progress in } \\
\text { labour. Women requiring pain relief were excluded. }\end{array}$ \\
\hline $\begin{array}{l}\text { Spellacy } 1966 \\
\text { Stocki } 2014\end{array}$ \\
$\begin{array}{l}\text { In this study the comparison group received epidural. This comparison is examined in a related re- } \\
\text { view. }\end{array}$ \\
\hline $\begin{array}{l}\text { In this study the comparison group received epidural. This comparison is examined in a related re- } \\
\text { view. }\end{array}$ \\
\hline $\begin{array}{l}\text { In this study comparing IM pethidine and IM tramadol the report states that the sample was ran- } \\
\text { domly selected, but there was no indication that there was random allocation to groups. }\end{array}$
\end{tabular}




\begin{tabular}{ll}
\hline Study & Reason for exclusion \\
\hline Taskin 1993 & $\begin{array}{l}\text { In this study the focus was on the rate of cervical dilatation rather than pain relief. The study was } \\
\text { reported in a brief abstract; we attempted to contact the authors for more information without } \\
\text { success. }\end{array}$
\end{tabular}

Thurlow 2002 In this study 2 different drugs with different modes of administration were compared. IM pethidine
(with an antiemetic) was compared with PCA remifentanil. In view of the different modes of admin-
istration we decided to exclude this study as results are very difficult to interpret.

Tomlin 1965

It was not clear that the women included in this study were in labour; women were recruited in the third trimester admitted to hospital following complications or "awaiting caesarean section or the birth of multiple pregnancies".

\section{Tournaire 1980}

This study, otherwise eligible for the review, focused on the effect of pethidine on the frequency and intensity of uterine contractions and the rate of cervical dilatation; no other outcomes were reported.

\section{Treisser 1981}

This study did not focus on pain relief in labour; rather, it examined the effects of different drugs on progress in labour for women with dystocia (oxytocin, chlorpromazine, ritodine and pethidine were compared).

\begin{tabular}{|c|c|}
\hline Tripti 2006 & Quasi-randomised study with alternate allocation. \\
\hline Vavrinkova 2005 & There was no evidence that this was an RCT. \\
\hline Volmanen 2005 & $\begin{array}{l}\text { This study compares IV remifentanil with inhaled } 50 \% \text { nitrous oxide in a cross-over trial. Results } \\
\text { were not reported separately for the first stage of this trial. }\end{array}$ \\
\hline Volmanen 2008 & This study compared IV remifentanil versus epidural analgesia. \\
\hline Volmanen 2009 & This study reported on different regimens of IVPCA remifentanil. \\
\hline Von Vorherr 1963 & $\begin{array}{l}\text { This study focused on speeding up progress in labour. In this group study groups received oxytocin } \\
\text { as well as analgesics and women in the control arm received an higher dose of oxytocin. }\end{array}$ \\
\hline Walker 1992 & $\begin{array}{l}\text { In this study pethidine was compared with a NSAID ketorolac. Ketorolac is not used nowadays in } \\
\text { obstetric analgesia. }\end{array}$ \\
\hline Wan 1965 & $\begin{array}{l}\text { Both study groups received pethidine; the aim of the study was to look at the effects of a sedative } \\
\text { as an adjuvant therapy. }\end{array}$ \\
\hline Weissman 2006 & $\begin{array}{l}\text { The comparison group in this study received epidural; this is not a relevant comparison in this re- } \\
\text { view. }\end{array}$ \\
\hline Wiener 1979 & $\begin{array}{l}\text { In this study epidural analgesia was compared with IM pethidine. It was not clear that this was an } \\
\text { RCT. }\end{array}$ \\
\hline Williams 1962 & $\begin{array}{l}\text { Both groups in this study received pethidine. The aim of the study was to examine the effects of a } \\
\text { narcotic antagonist (levallorphan) as an adjunct to pethidine. }\end{array}$ \\
\hline Wilson 2016 & In this study different opioids were compared but the route of administration was also different. \\
\hline Wong 2005 & $\begin{array}{l}\text { This study is reported in a series of papers and conference abstracts. The study examined the use } \\
\text { of an intrathecal opioid as part of a combined spinal epidural compared to a systemic opioid. } \\
\text { Epidural analgesia is covered in a separate related Cochrane review. }\end{array}$ \\
\hline
\end{tabular}

IM: intramuscular 
IV: intravenous

NSAID: non-steroidal anti-inflammatory drug

PCA: patient controlled analgesia

$\mathrm{RCT}$ : randomised controlled trial

SC: subcutaneous

Characteristics of studies awaiting assessment [ordered by study ID]

Mohan 2015

\begin{tabular}{ll}
\hline Methods & Unclear \\
\hline Participants & Unclear \\
\hline Interventions & Unclear \\
\hline Outcomes & Unclear \\
\hline Notes & This report is awaiting classification pending further investigation. \\
\hline
\end{tabular}

\section{Sereshti 2013}

\begin{tabular}{ll}
\hline Methods & RCT with individual randomisation \\
\hline Participants & 120 women randomised. \\
\hline Interventions & Group 1: massage \\
& Group 2: intramuscular pethidine \\
& Group 3: standard care \\
\hline Outcomes & Pain intensity \\
\hline Notes & Duration of labour only \\
\hline & Setting: Valiasr hospital in Broojen, Iran \\
\hline
\end{tabular}

$\mathrm{RCT}$ : randomised controlled trial

Characteristics of ongoing studies [ordered by study ID]

Kokki 2015

\begin{tabular}{ll}
\hline Trial name or title & $\begin{array}{l}\text { The effect of oxycodone to placental and fetal circulation during the phase I of labour and the effi- } \\
\text { cacy, safety and neonatal effects of oxycodone }\end{array}$ \\
\hline Methods & Clinical trial (methods not clear) \\
\hline Participants & Women at the onset of labour \\
\hline Interventions & IV oxycodone versus placebo \\
\hline Outcomes & Fetal circulation and condition of the newborn. \\
\hline
\end{tabular}


Kokki 2015 (Continued)

Starting date Not clear

Author contacted 26th June 2017.

Notes

\section{Raheja 2016}

\begin{tabular}{ll}
\hline Trial name or title & Tramadol for labour analgesia in low-risk women: a placebo controlled randomised trial \\
\hline Methods & Placebo controlled RCT with parallel assignment \\
\hline Participants & 86 women in labour \\
\hline Interventions & 50 mg IM tramadol vs placebo (IV water) \\
\hline Outcomes & Pain (VAS), satisfaction (1-5 Likert), fetal distress, mode of birth, duration of labour \\
\hline Starting date & December 2018 (completion planned for May 2018 \\
\hline Contact information & aastha_raheja2000@yahoo.com Dr Aastha Raheja, Maulana Azad Medical College \\
\hline Notes &
\end{tabular}

Reyes 2013

\begin{tabular}{ll}
\hline Trial name or title & Tramadol for labour analgesia in low-risk primiparous women \\
\hline Methods & Double-blind randomised trial \\
\hline Participants & Primiparous women with singleton pregnancy in labour with intact membranes. \\
\hline Interventions & Subcutaneous 100 mg tramadol vs placebo \\
\hline Outcomes & Pain in labour, duration of labour, neonatal outcomes, side effects, oxytocin \\
\hline Starting date & October 2012. (Reported to be completed by June 2013) \\
\hline Contact information & Osvaldo A. Reyes T., Saint Thomas Hospital, Panama \\
\hline Notes & No email address and unable to contact author. \\
\hline
\end{tabular}

\section{Sahin 2012}

\begin{tabular}{ll}
\hline Trial name or title & $\begin{array}{l}\text { Study of the effectiveness of administration of meperidine on the length of active phase of labour } \\
\text { in women }\end{array}$ \\
\hline Methods & Clinical trial \\
\hline
\end{tabular}


Sahin 2012 (Continued)

\begin{tabular}{ll} 
Participants & Not clear \\
\hline Interventions & Not clear \\
\hline Outcomes & Not clear \\
\hline Starting date & $\begin{array}{l}\text { The recruitment status of this study is unknown. The completion date has passed and the status } \\
\text { has not been verified in more than } 2 \text { years. }\end{array}$ \\
\hline Contact information & $\begin{array}{l}\text { This study was due for completion in 2012. There is no email address. Orhan SAHIN, M.D., Kanuni } \\
\text { Sultan Suleyman Training and Research }\end{array}$ \\
\hline
\end{tabular}

Notes

Shen 2008

\begin{tabular}{ll}
\hline Trial name or title & Intravenous Remifentanil for Labour Analgesia (IRELAN) \\
\hline Methods & Reported to be parallel RCT. \\
\hline Participants & Planned enrolment 1000 nulliparous women in spontaneous labour requesting analgesia. \\
\hline Interventions & IV PCA remifentanil versus IV intermittent hydromorphone 1 mg (on request) \\
\hline Outcomes & $\begin{array}{l}\text { Pain (VAS) during labour, mode of birth, maternal satisfaction with analgesia, use of other analge- } \\
\text { sia, use of oxytocin, breastfeeding at 6 weeks, neonatal outcomes. }\end{array}$ \\
\hline Starting date & $\begin{array}{l}\text { July 2008, planned completion September 2009. There is no evidence that this study was complet- } \\
\text { ed. No email address. The record has not been updated since 2009. }\end{array}$ \\
\hline Contact information & XiaoFeng Shen, Nanjing Medical University \\
\hline Notes & ClinicalTrials.gov: NCT00710086 \\
\hline
\end{tabular}

IV: intravenous

RCT: randomised controlled trial:

PCA: patient-controlled analgesia

VAS: visual analogue scale

\section{DATA AND ANALYSES}

\section{Comparison 1. IM pethidine $50 \mathrm{mg} / \mathbf{1 0 0} \mathrm{mg}$ versus placebo}

\begin{tabular}{lllll}
\hline Outcome or subgroup title & No. of studies & $\begin{array}{l}\text { No. of partici- } \\
\text { pants }\end{array}$ & Statistical method & Effect size \\
\hline $\begin{array}{l}1 \text { Maternal satisfaction with analgesia } \\
\text { measured during labour (number of } \\
\text { women satisfied or very satisfied af- }\end{array}$ & 1 & 50 & Risk Ratio (M-H, Fixed, 95\% & $7.0[0.38,128.87]$ \\
ter 30 minutes) & & & \\
\hline
\end{tabular}




\begin{tabular}{|c|c|c|c|c|}
\hline Outcome or subgroup title & No. of studies & $\begin{array}{l}\text { No. of partici- } \\
\text { pants }\end{array}$ & Statistical method & Effect size \\
\hline $\begin{array}{l}2 \text { Maternal pain score or pain mea- } \\
\text { sured in labour (described as good or } \\
\text { fair after } 1 \text { hour) }\end{array}$ & 1 & 116 & $\begin{array}{l}\text { Risk Ratio (M-H, Fixed, 95\% } \\
\mathrm{Cl})\end{array}$ & $1.75[1.24,2.47]$ \\
\hline $\begin{array}{l}3 \text { Maternal pain score or pain mea- } \\
\text { sured in labour (reduction in VAS of at } \\
\text { least } 40 \mathrm{~mm} \text { after } 30 \text { minutes) }\end{array}$ & 1 & 50 & $\begin{array}{l}\text { Risk Ratio (M-H, Fixed, 95\% } \\
\mathrm{Cl})\end{array}$ & $25.0[1.56,400.54]$ \\
\hline 4 Additional analgesia required & 1 & 50 & $\begin{array}{l}\text { Risk Ratio (M-H, Fixed, 95\% } \\
\mathrm{Cl})\end{array}$ & $0.71[0.54,0.94]$ \\
\hline 5 Epidural & 1 & 50 & $\begin{array}{l}\text { Risk Ratio (M-H, Fixed, 95\% } \\
\mathrm{Cl})\end{array}$ & $0.5[0.14,1.78]$ \\
\hline 6 Nausea and vomiting & 2 & 166 & $\begin{array}{l}\text { Risk Ratio (M-H, Fixed, 95\% } \\
\mathrm{Cl})\end{array}$ & $1.47[0.65,3.31]$ \\
\hline 7 Maternal sleepiness & 2 & 166 & $\begin{array}{l}\text { Risk Ratio (M-H, Fixed, 95\% } \\
\mathrm{Cl})\end{array}$ & $4.67[2.43,8.95]$ \\
\hline 8 Assisted vaginal delivery & 1 & 50 & $\begin{array}{l}\text { Risk Ratio (M-H, Fixed, 95\% } \\
\mathrm{Cl})\end{array}$ & $0.86[0.34,2.19]$ \\
\hline 9 Caesarean section & 2 & 140 & $\begin{array}{l}\text { Risk Ratio (M-H, Fixed, 95\% } \\
\mathrm{Cl})\end{array}$ & $0.71[0.36,1.37]$ \\
\hline 10 Neonatal resuscitation & 1 & 50 & $\begin{array}{l}\text { Risk Ratio (M-H, Fixed, 95\% } \\
\mathrm{Cl})\end{array}$ & $1.67[0.45,6.24]$ \\
\hline $\begin{array}{l}11 \text { Low Apgar score }(\leq 7) \text { at } 1 \text { and } 5 \\
\text { minutes }\end{array}$ & 3 & & $\begin{array}{l}\text { Risk Ratio (M-H, Random, } \\
95 \% \mathrm{Cl})\end{array}$ & Subtotals only \\
\hline 11.1 Low scores at 1 minute & 2 & 166 & $\begin{array}{l}\text { Risk Ratio (M-H, Random, } \\
95 \% \mathrm{Cl} \text { ) }\end{array}$ & $1.64[0.52,5.18]$ \\
\hline 11.2 Low scores at 5 minutes & 2 & 200 & $\begin{array}{l}\text { Risk Ratio (M-H, Random, } \\
95 \% \mathrm{Cl} \text { ) }\end{array}$ & $0.0[0.0,0.0]$ \\
\hline 12 Admission to NICU & 1 & 50 & $\begin{array}{l}\text { Risk Ratio (M-H, Fixed, 95\% } \\
\text { Cl) }\end{array}$ & $1.0[0.07,15.12]$ \\
\hline
\end{tabular}

Analysis 1.1. Comparison $1 \mathrm{IM}$ pethidine $50 \mathrm{mg} / 100 \mathrm{mg}$ versus placebo, Outcome 1 Maternal satisfaction with analgesia measured during labour (number of women satisfied or very satisfied after $\mathbf{3 0}$ minutes).

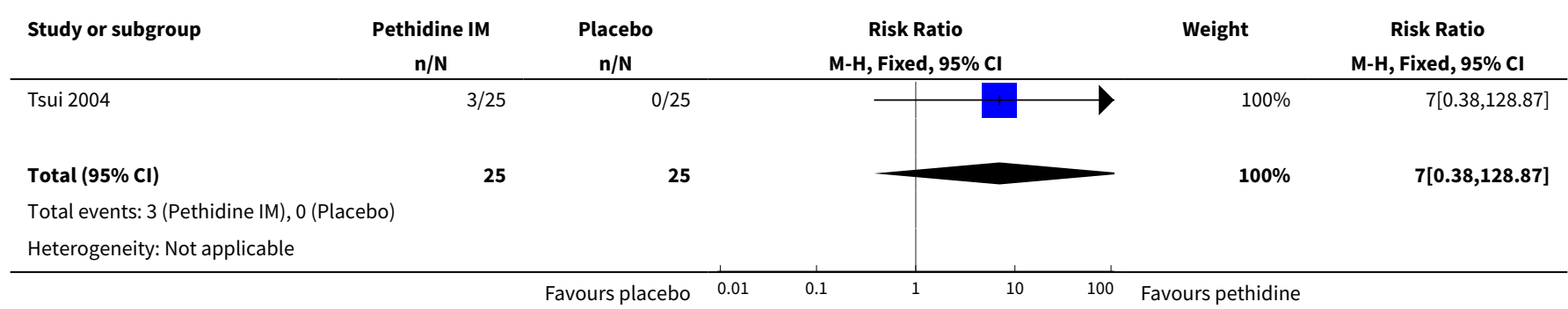




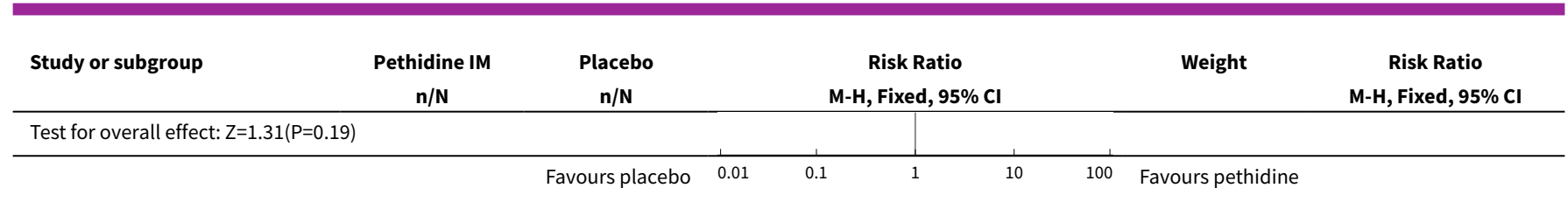

Analysis 1.2. Comparison $1 \mathrm{IM}$ pethidine $50 \mathrm{mg} / 100 \mathrm{mg}$ versus placebo, Outcome 2 Maternal pain score or pain measured in labour (described as good or fair after 1 hour).

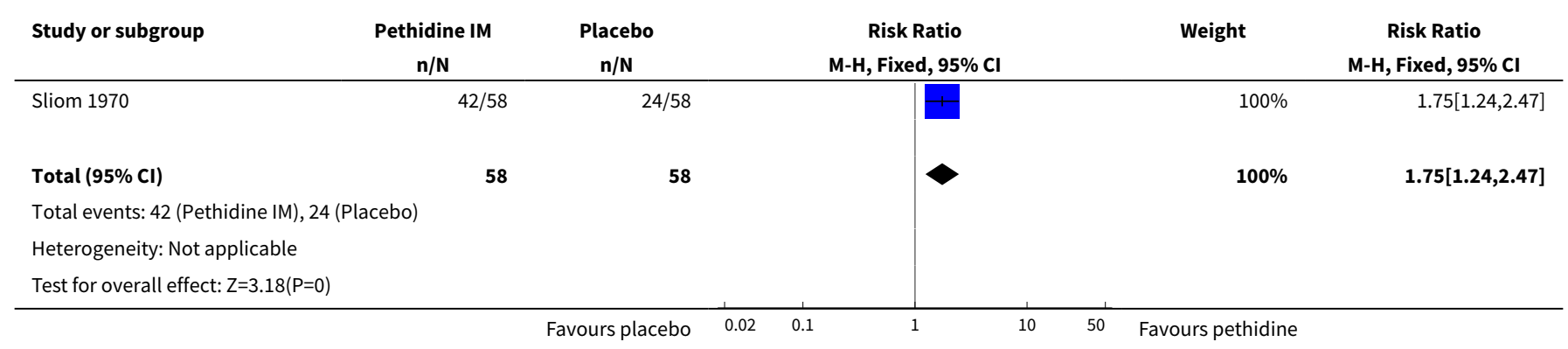

Analysis 1.3. Comparison $1 \mathrm{IM}$ pethidine $50 \mathrm{mg} / 100 \mathrm{mg}$ versus placebo, Outcome 3 Maternal pain score or pain measured in labour (reduction in VAS of at least $\mathbf{4 0 ~} \mathbf{m m}$ after 30 minutes).

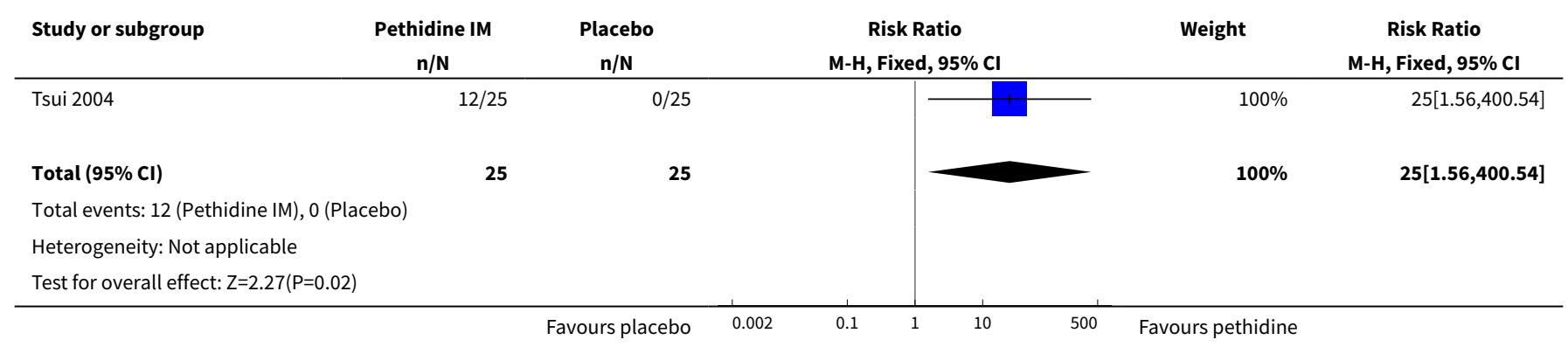

Analysis 1.4. Comparison $1 \mathrm{IM}$ pethidine $50 \mathrm{mg} / 100 \mathrm{mg}$ versus placebo, Outcome 4 Additional analgesia required.

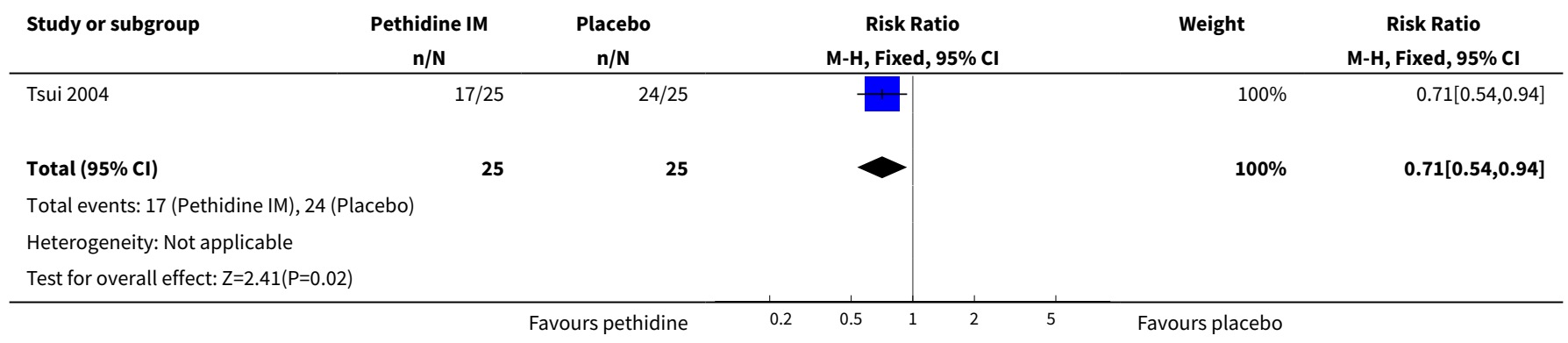


Analysis 1.5. Comparison $1 \mathrm{IM}$ pethidine $50 \mathrm{mg} / 100 \mathrm{mg}$ versus placebo, Outcome 5 Epidural.

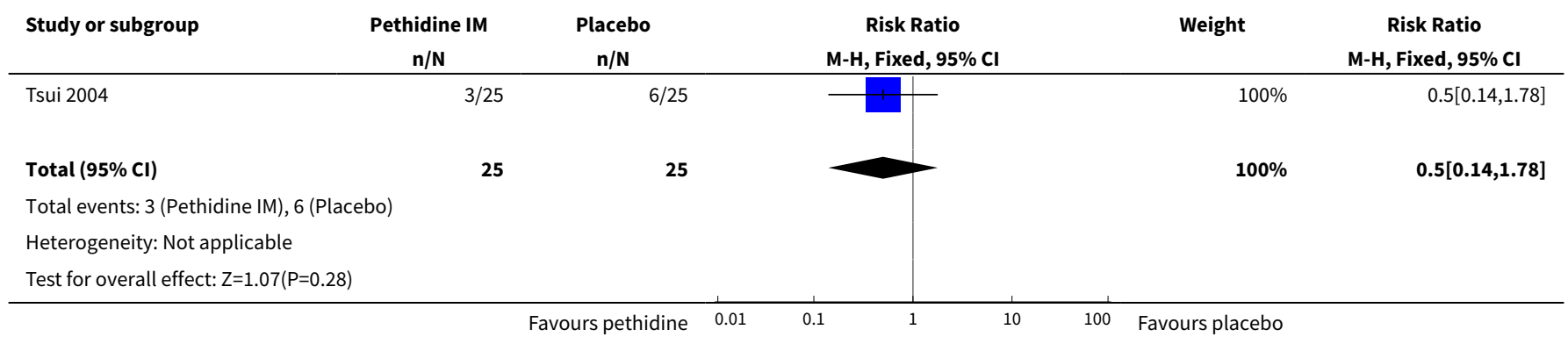

Analysis 1.6. Comparison $1 \mathrm{IM}$ pethidine $50 \mathrm{mg} / 100 \mathrm{mg}$ versus placebo, Outcome 6 Nausea and vomiting.

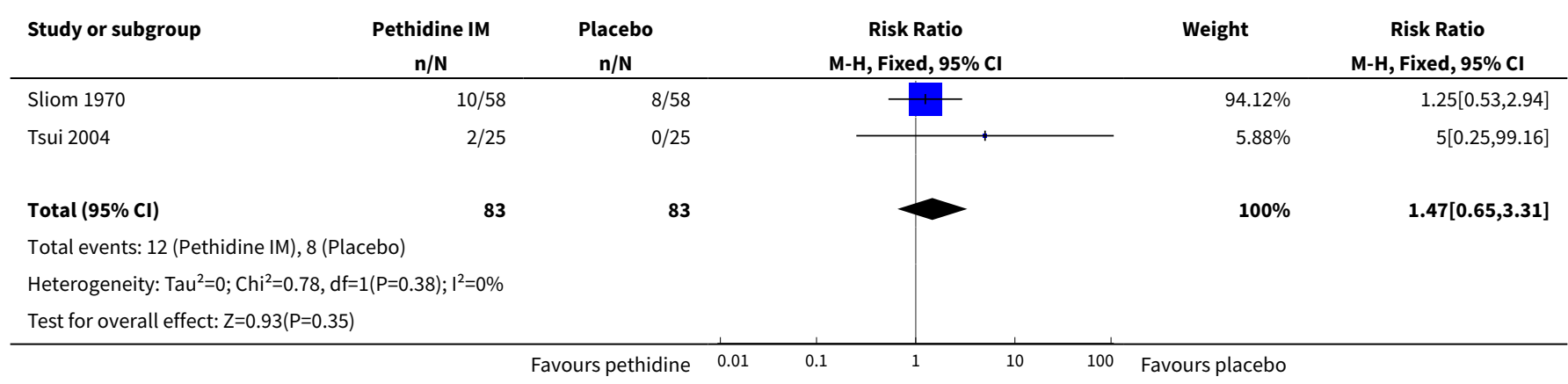

Analysis 1.7. Comparison $1 \mathrm{IM}$ pethidine $50 \mathrm{mg} / 100 \mathrm{mg}$ versus placebo, Outcome 7 Maternal sleepiness.

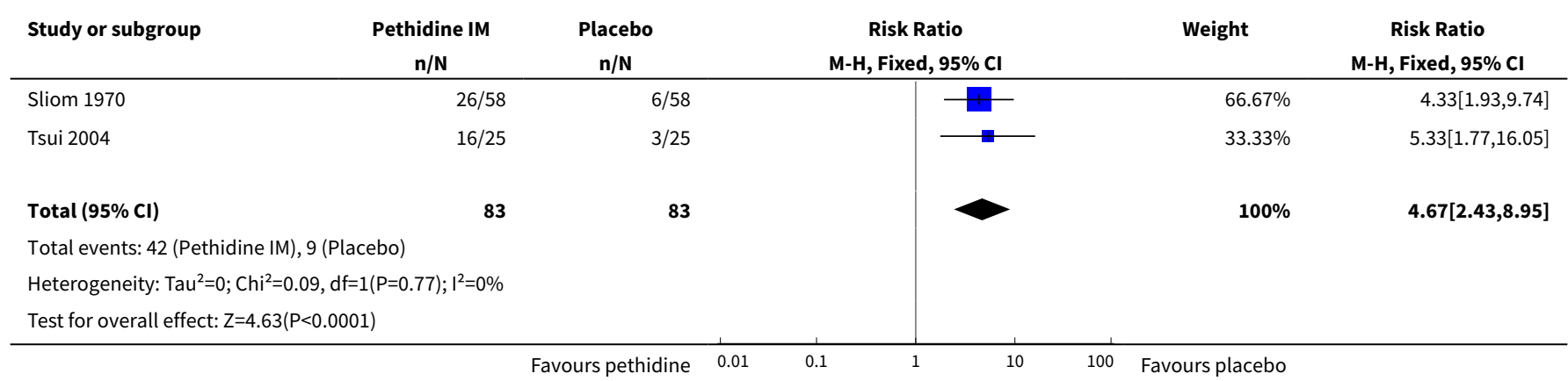

Analysis 1.8. Comparison $1 \mathrm{IM}$ pethidine $50 \mathrm{mg} / 100 \mathrm{mg}$ versus placebo, Outcome 8 Assisted vaginal delivery.

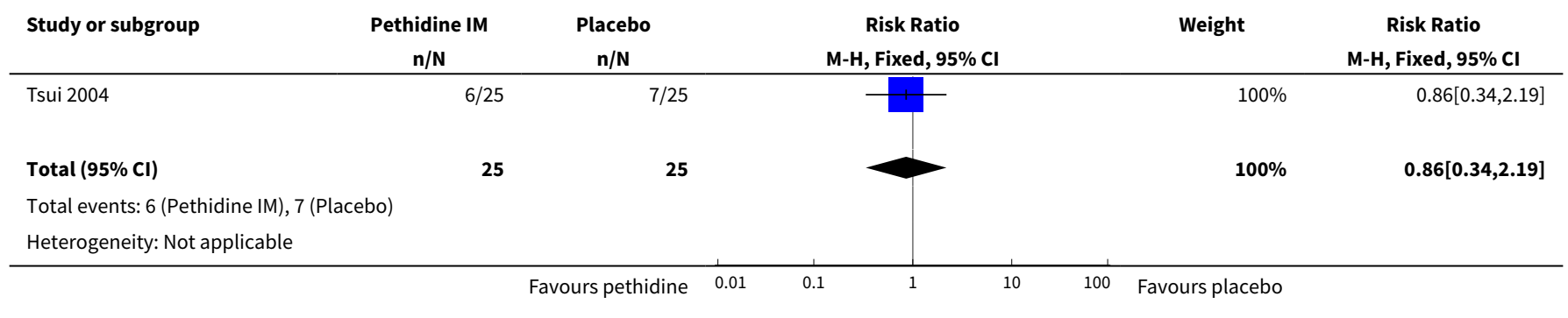




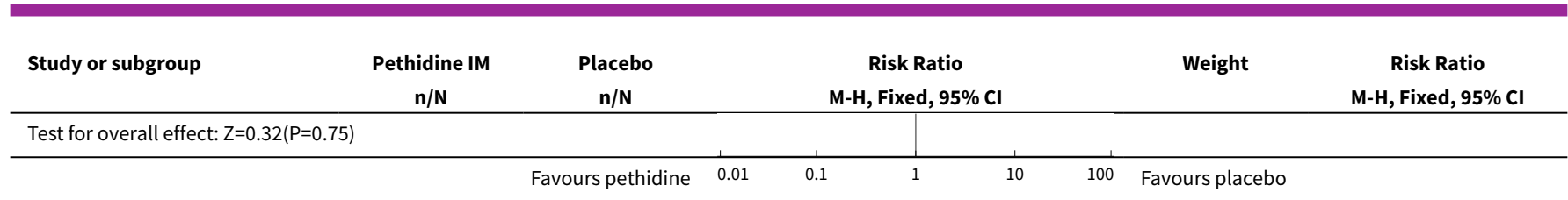

Analysis 1.9. Comparison $1 \mathrm{IM}$ pethidine $50 \mathrm{mg} / 100 \mathrm{mg}$ versus placebo, Outcome 9 Caesarean section.

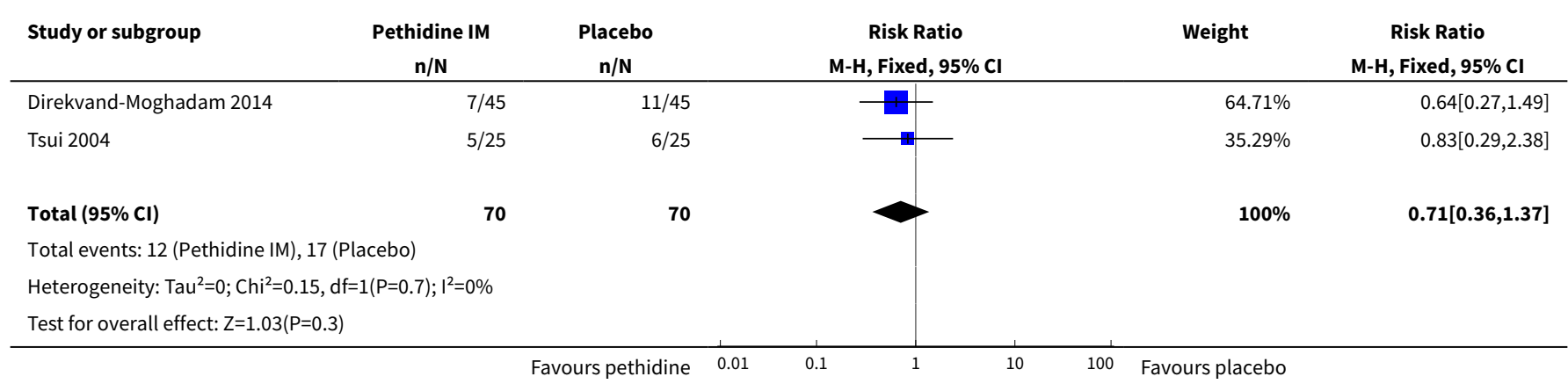

Analysis 1.10. Comparison $1 \mathrm{IM}$ pethidine $50 \mathrm{mg} / 100 \mathrm{mg}$ versus placebo, Outcome 10 Neonatal resuscitation.

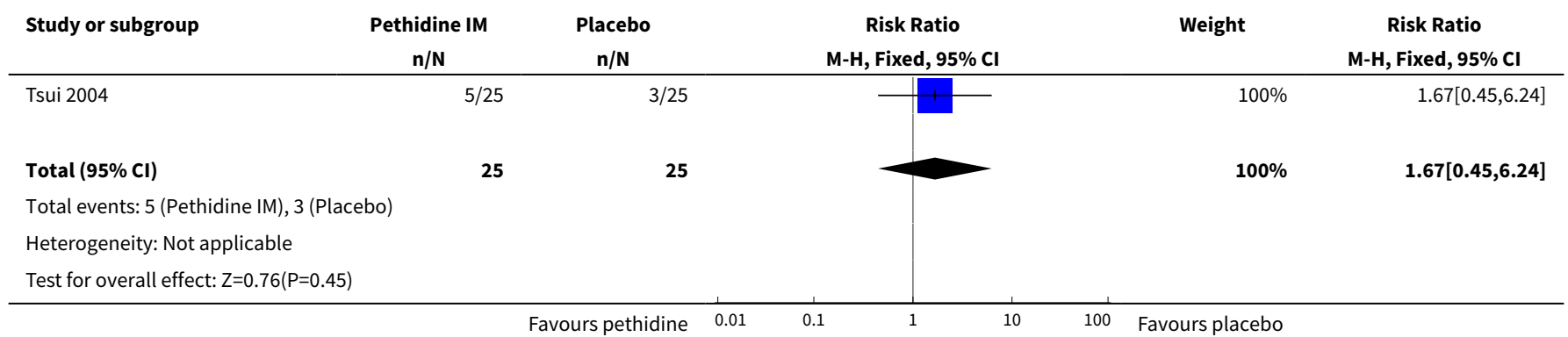

Analysis 1.11. Comparison $1 \mathrm{IM}$ pethidine $50 \mathrm{mg} / 100 \mathrm{mg}$ versus placebo, Outcome 11 Low Apgar score ( $\leq 7)$ at 1 and 5 minutes.

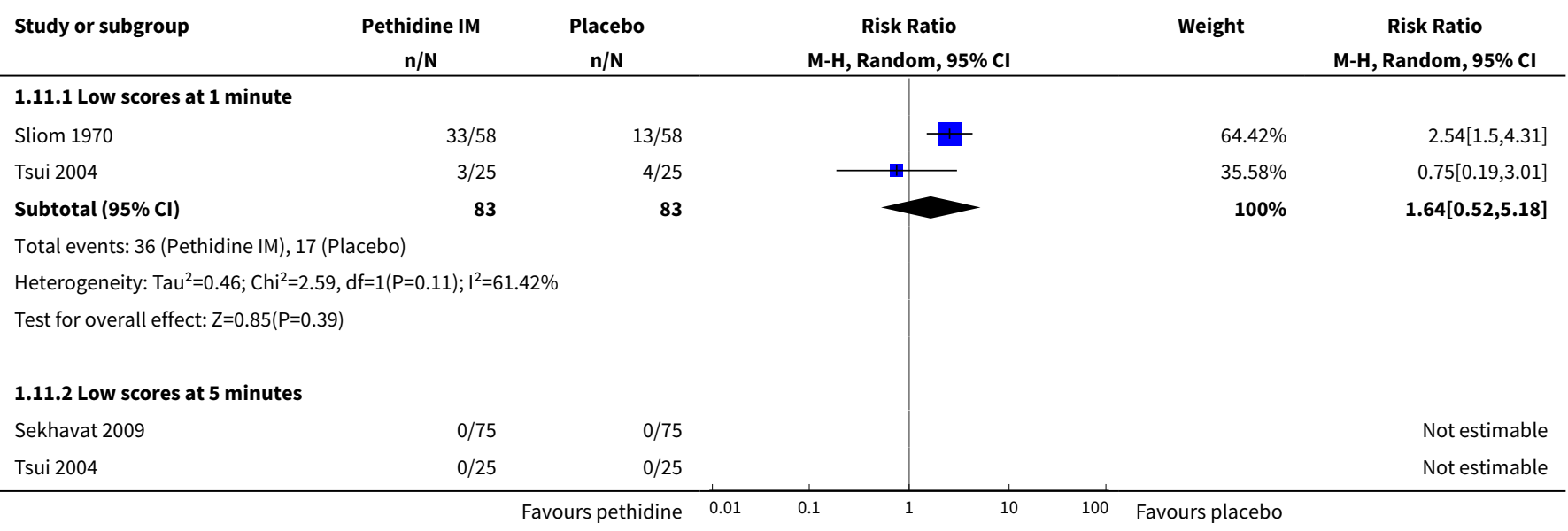




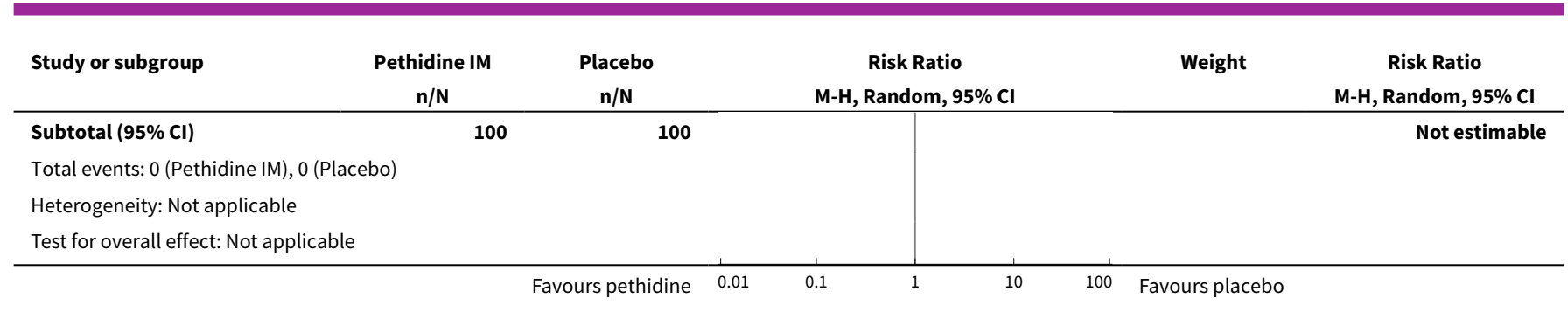

\section{Analysis 1.12. Comparison $1 \mathrm{IM}$ pethidine $50 \mathrm{mg} / 100 \mathrm{mg}$ versus placebo, Outcome 12 Admission to NICU.}

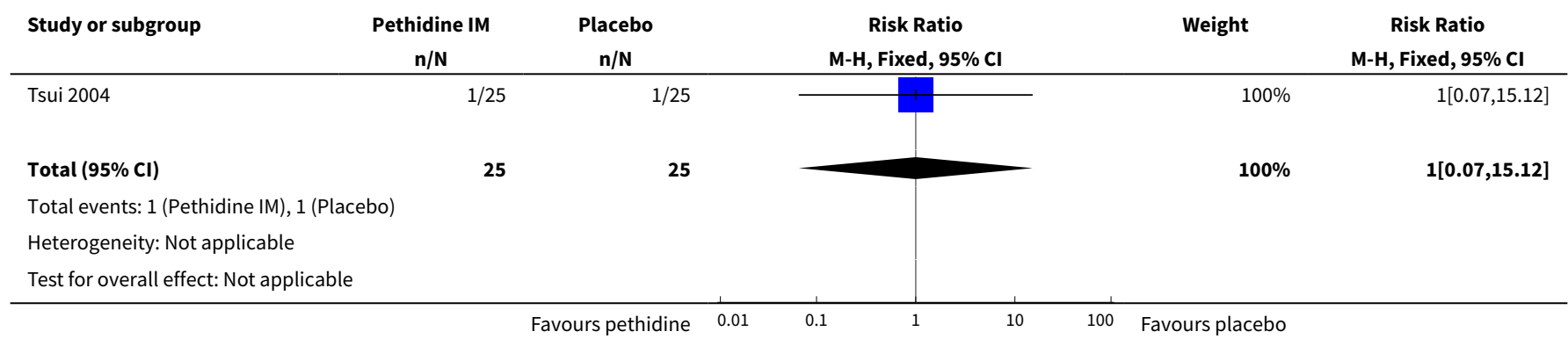

\section{Comparison 2. IM pentazocine versus placebo}

\begin{tabular}{llllll}
\hline Outcome or subgroup title & No. of studies & $\begin{array}{l}\text { No. of partici- } \\
\text { pants }\end{array}$ & Statistical method & Effect size \\
\hline $\begin{array}{l}\text { 1 Maternal pain score mea- } \\
\text { sured during labour }\end{array}$ & 1 & 89 & Mean Difference (IV, Fixed, 95\% Cl) & $-3.60[-9.91,2.71]$ \\
\hline 2 Nausea and vomiting & 1 & 89 & Risk Ratio (M-H, Fixed, 95\% Cl) & $0.0[0.0,0.0]$ \\
\hline 3 Caesarean section & 1 & 89 & Risk Ratio (M-H, Fixed, 95\% Cl) & $0.89[0.24,3.35]$ \\
\hline 4 Assisted vaginal birth & 1 & 89 & Risk Ratio (M-H, Fixed, 95\% Cl) & $0.60[0.10,3.39]$ \\
\hline
\end{tabular}

Analysis 2.1. Comparison 2 IM pentazocine versus placebo, Outcome 1 Maternal pain score measured during labour.

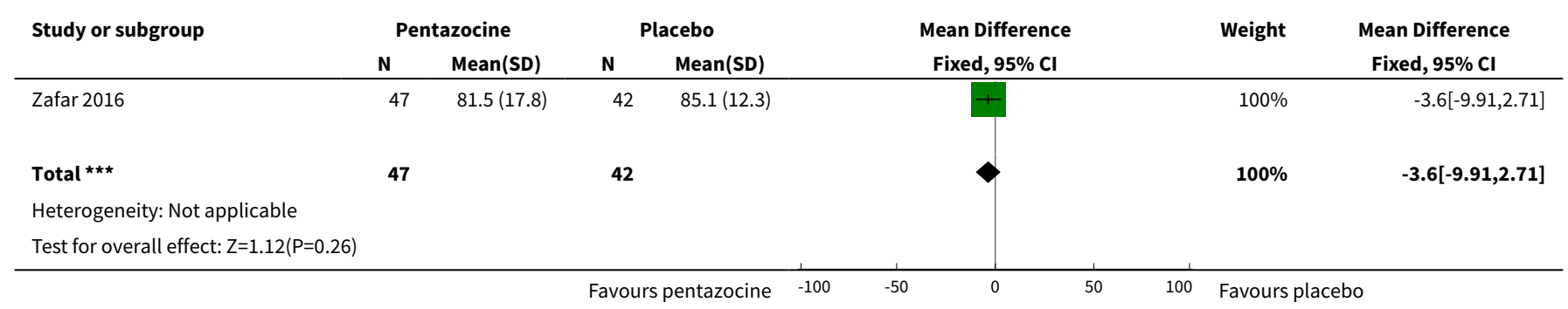


Analysis 2.2. Comparison 2 IM pentazocine versus placebo, Outcome 2 Nausea and vomiting.

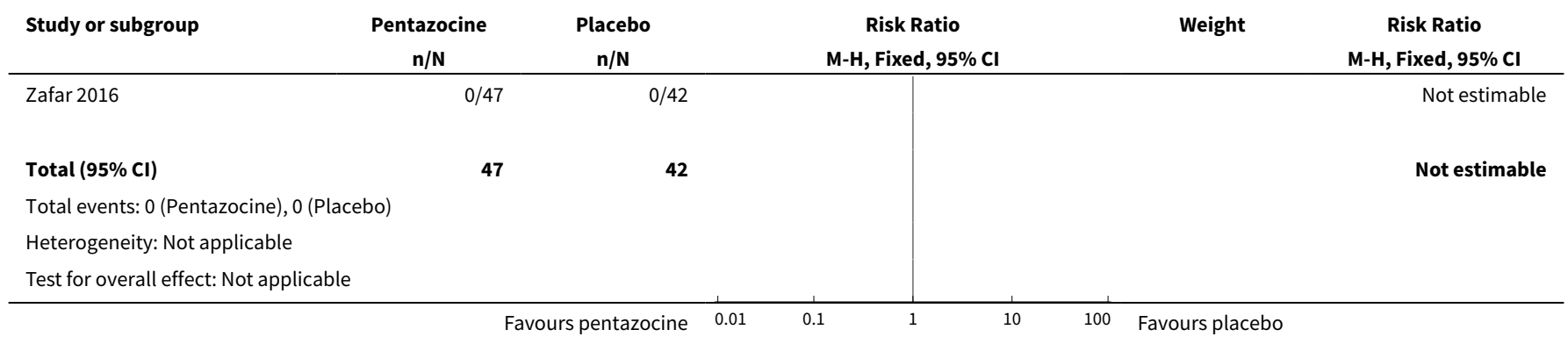

Analysis 2.3. Comparison $2 \mathrm{IM}$ pentazocine versus placebo, Outcome 3 Caesarean section.

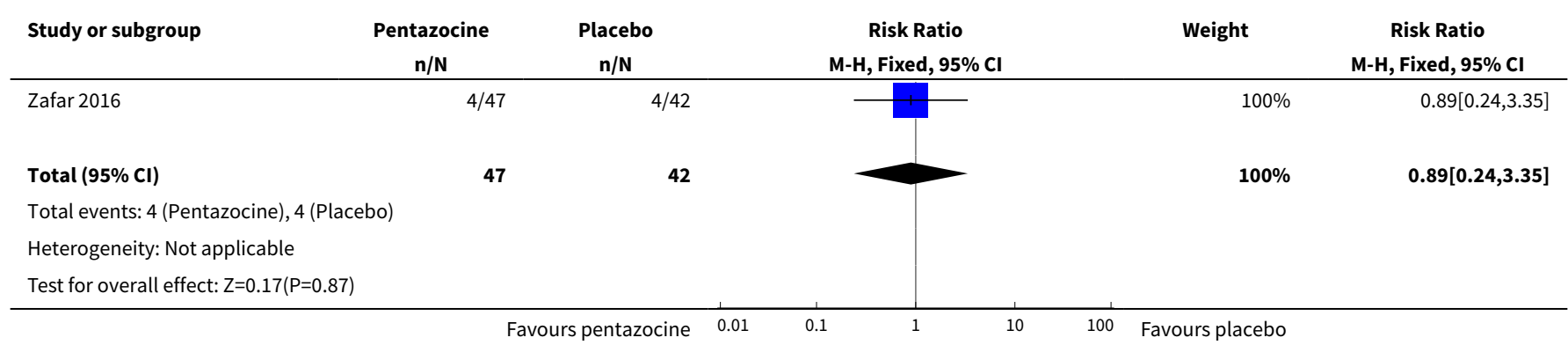

Analysis 2.4. Comparison $2 \mathrm{IM}$ pentazocine versus placebo, Outcome 4 Assisted vaginal birth.

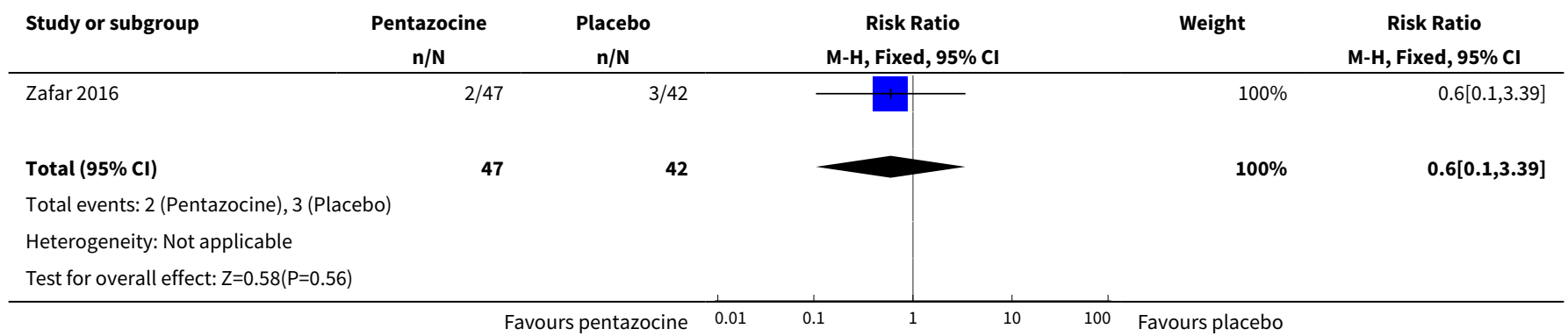

\section{Comparison 3. IM tramadol versus no treatment}

\begin{tabular}{lllll}
\hline Outcome or subgroup title & No. of studies & $\begin{array}{l}\text { No. of partici- } \\
\text { pants }\end{array}$ & Statistical method & Effect size \\
\hline $\begin{array}{l}1 \text { Maternal satisfaction with analgesia (Analgesic } \\
\text { effect described as satisfactory (not clear when } \\
\text { measured)) }\end{array}$ & 60 & $\begin{array}{l}\text { Risk Ratio (M-H, } \\
\text { Fixed, 95\% Cl) }\end{array}$ & $\begin{array}{l}11.0[0.64, \\
190.53]\end{array}$ \\
\hline
\end{tabular}


Analysis 3.1. Comparison $3 \mathrm{IM}$ tramadol versus no treatment, Outcome 1 Maternal satisfaction with analgesia (Analgesic effect described as satisfactory (not clear when measured)).

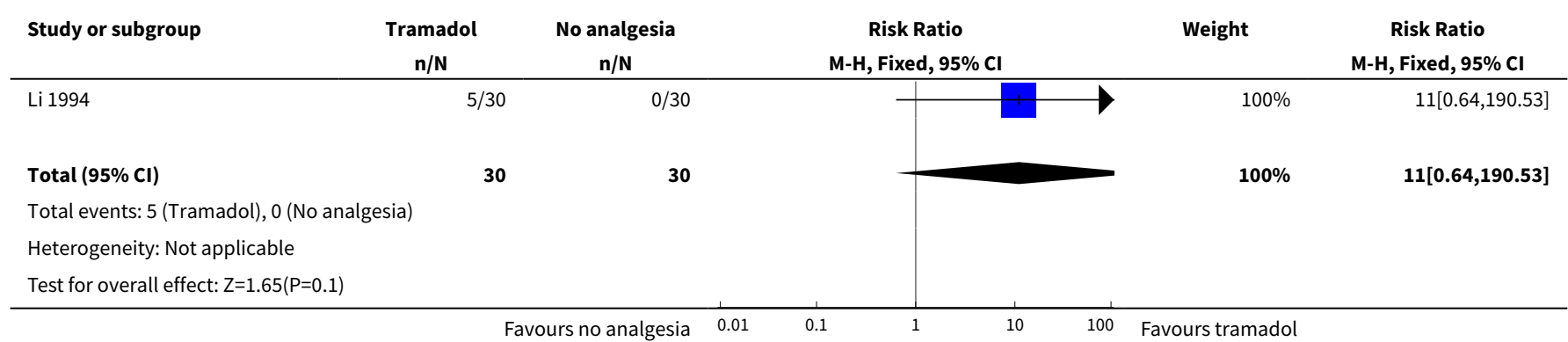

\section{Comparison 4. IM meptazinol versus pethidine}

\begin{tabular}{|c|c|c|c|c|}
\hline Outcome or subgroup title & No. of studies & $\begin{array}{l}\text { No. of partici- } \\
\text { pants }\end{array}$ & Statistical method & Effect size \\
\hline $\begin{array}{l}1 \text { Maternal pain score or pain } \\
\text { measured in labour (Maternal } \\
\text { pain relief poor or none ( } 3-5 \mathrm{PN}) \text { ) }\end{array}$ & 1 & 801 & Risk Ratio (M-H, Fixed, 95\% Cl) & $1.01[0.91,1.12]$ \\
\hline $\begin{array}{l}2 \text { Maternal pain score or pain } \\
\text { measured in labour (Pain inten- } \\
\text { sity } 4 \text { or } 5 \text { on } 5 \text {-point scale ( } 1 \\
\text { hour)) }\end{array}$ & 2 & 239 & $\begin{array}{l}\text { Risk Ratio (M-H, Random, 95\% } \\
\mathrm{Cl})\end{array}$ & $1.11[0.69,1.80]$ \\
\hline 3 Additional analgesia required & 2 & 233 & Risk Ratio (M-H, Fixed, 95\% Cl) & $1.03[0.88,1.20]$ \\
\hline 4 Epidural & 4 & 788 & Risk Ratio (M-H, Fixed, 95\% Cl) & $0.96[0.71,1.29]$ \\
\hline 5 Maternal sleepiness & 3 & 1590 & $\begin{array}{l}\text { Risk Ratio (M-H, Random, 95\% } \\
\mathrm{Cl})\end{array}$ & $0.55[0.28,1.07]$ \\
\hline 6 Nausea and vomiting & 3 & & Risk Ratio (M-H, Fixed, 95\% Cl) & Subtotals only \\
\hline 6.1 Nausea & 3 & 1590 & Risk Ratio (M-H, Fixed, 95\% Cl) & $1.11[0.95,1.28]$ \\
\hline 6.2 Vomiting & 3 & 1589 & Risk Ratio (M-H, Fixed, 95\% Cl) & $1.25[1.06,1.47]$ \\
\hline 7 Caesarean section & 3 & 1266 & $\begin{array}{l}\text { Risk Ratio (M-H, Random, 95\% } \\
\mathrm{Cl})\end{array}$ & $0.56[0.16,2.00]$ \\
\hline 8 Assisted vaginal birth & 3 & 1266 & Risk Ratio (M-H, Fixed, 95\% Cl) & $1.00[0.81,1.22]$ \\
\hline $\begin{array}{l}9 \text { Breastfeeding at discharge } \\
\text { (problems) }\end{array}$ & 1 & 197 & Risk Ratio (M-H, Fixed, 95\% Cl) & $0.76[0.17,3.30]$ \\
\hline $\begin{array}{l}10 \text { Fetal heart rate changes (de- } \\
\text { celerations) }\end{array}$ & 1 & 34 & Risk Ratio (M-H, Fixed, 95\% Cl) & $1.23[0.92,1.64]$ \\
\hline 11 Naloxone administration & 1 & 998 & Risk Ratio (M-H, Fixed, 95\% Cl) & $0.89[0.77,1.02]$ \\
\hline $11.1<36$ weeks' gestation & 1 & 23 & Risk Ratio (M-H, Fixed, 95\% Cl) & $0.96[0.49,1.89]$ \\
\hline
\end{tabular}




\begin{tabular}{|c|c|c|c|c|}
\hline Outcome or subgroup title & No. of studies & $\begin{array}{l}\text { No. of partici- } \\
\text { pants }\end{array}$ & Statistical method & Effect size \\
\hline $11.2 \geq 36$ weeks' gestation & 1 & 975 & Risk Ratio (M-H, Fixed, 95\% Cl) & $0.89[0.77,1.02]$ \\
\hline $\begin{array}{l}12 \text { Neonatal resuscitation (by } \\
\text { gestation) }\end{array}$ & 2 & 1356 & Risk Ratio (M-H, Fixed, 95\% Cl) & $1.00[0.95,1.05]$ \\
\hline $12.1<36$ weeks' gestation & 1 & 23 & Risk Ratio (M-H, Fixed, 95\% Cl) & $0.89[0.69,1.16]$ \\
\hline $12.2 \geq 36$ weeks' gestation & 2 & 1333 & Risk Ratio (M-H, Fixed, 95\% Cl) & $1.00[0.95,1.05]$ \\
\hline 13 Neonatal resuscitation & 1 & 100 & Risk Ratio (M-H, Fixed, 95\% Cl) & $1.5[0.26,8.60]$ \\
\hline 14 Apgar score $\leq 7$ at 1 minute & 6 & 791 & Risk Ratio (M-H, Fixed, 95\% Cl) & $0.79[0.56,1.11]$ \\
\hline 15 Apgar score $\leq 7$ at 5 minutes & 3 & 616 & Risk Ratio (M-H, Fixed, 95\% Cl) & $0.50[0.05,5.37]$ \\
\hline 16 Admission to NICU & 1 & 199 & Risk Ratio (M-H, Fixed, 95\% Cl) & $0.88[0.48,1.63]$ \\
\hline
\end{tabular}

Analysis 4.1. Comparison $4 \mathrm{IM}$ meptazinol versus pethidine, Outcome 1 Maternal pain score or pain measured in labour (Maternal pain relief poor or none (3-5 PN)).

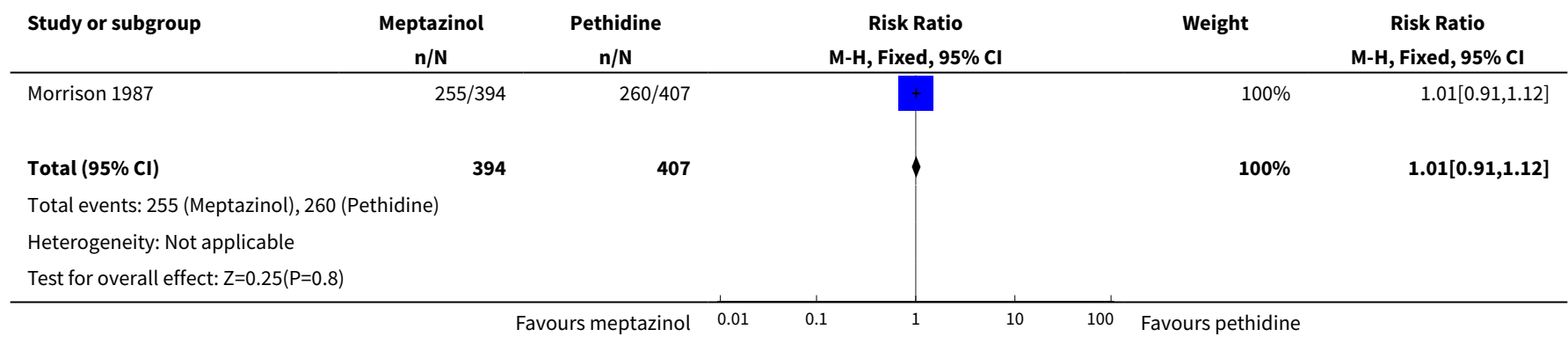

Analysis 4.2. Comparison $4 \mathrm{IM}$ meptazinol versus pethidine, Outcome 2 Maternal pain score or pain measured in labour (Pain intensity 4 or 5 on 5-point scale (1 hour)).

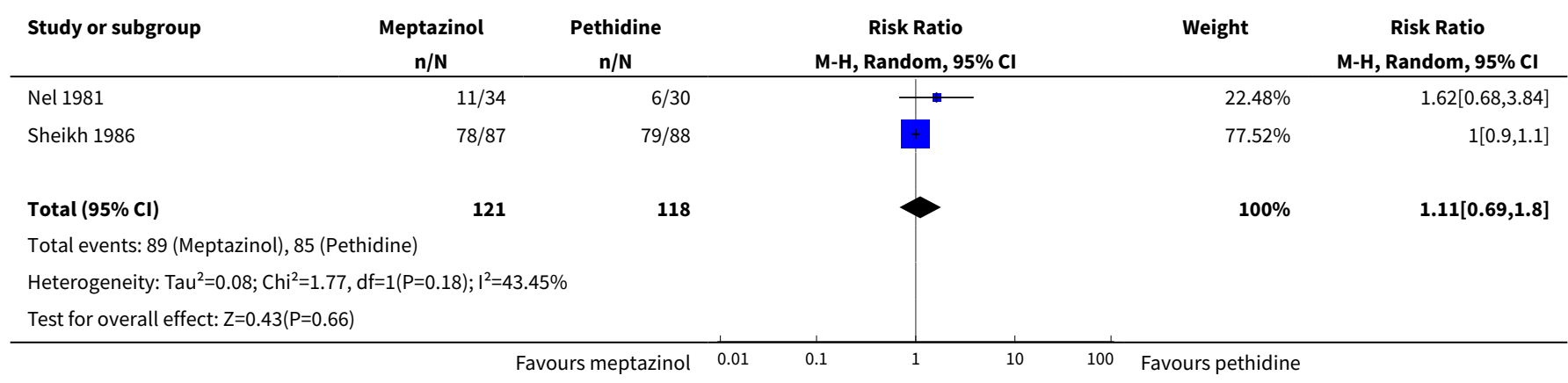


Analysis 4.3. Comparison 4 IM meptazinol versus pethidine, Outcome 3 Additional analgesia required.

\begin{tabular}{|c|c|c|c|c|c|}
\hline Study or subgroup & $\begin{array}{c}\text { Meptazinol } \\
n / N\end{array}$ & $\begin{array}{c}\text { Pethidine } \\
n / N\end{array}$ & $\begin{array}{c}\text { Risk Ratio } \\
\text { M-H, Fixed, 95\% CI }\end{array}$ & Weight & $\begin{array}{c}\text { Risk Ratio } \\
\text { M-H, Fixed, } 95 \% \mathrm{Cl}\end{array}$ \\
\hline Osler 1987 & $79 / 100$ & $76 / 99$ & & $97.45 \%$ & $1.03[0.89,1.19]$ \\
\hline Wheble 1988 & $2 / 17$ & $2 / 17$ & & $2.55 \%$ & $1[0.16,6.3]$ \\
\hline Total $(95 \% \mathrm{Cl})$ & 117 & 116 & \rangle & $100 \%$ & $1.03[0.88,1.2]$ \\
\hline \multicolumn{6}{|c|}{ Total events: 81 (Meptazinol), 78 (Pethidine) } \\
\hline Test for overall effect & & & & & \\
\hline
\end{tabular}

Analysis 4.4. Comparison 4 IM meptazinol versus pethidine, Outcome 4 Epidural.

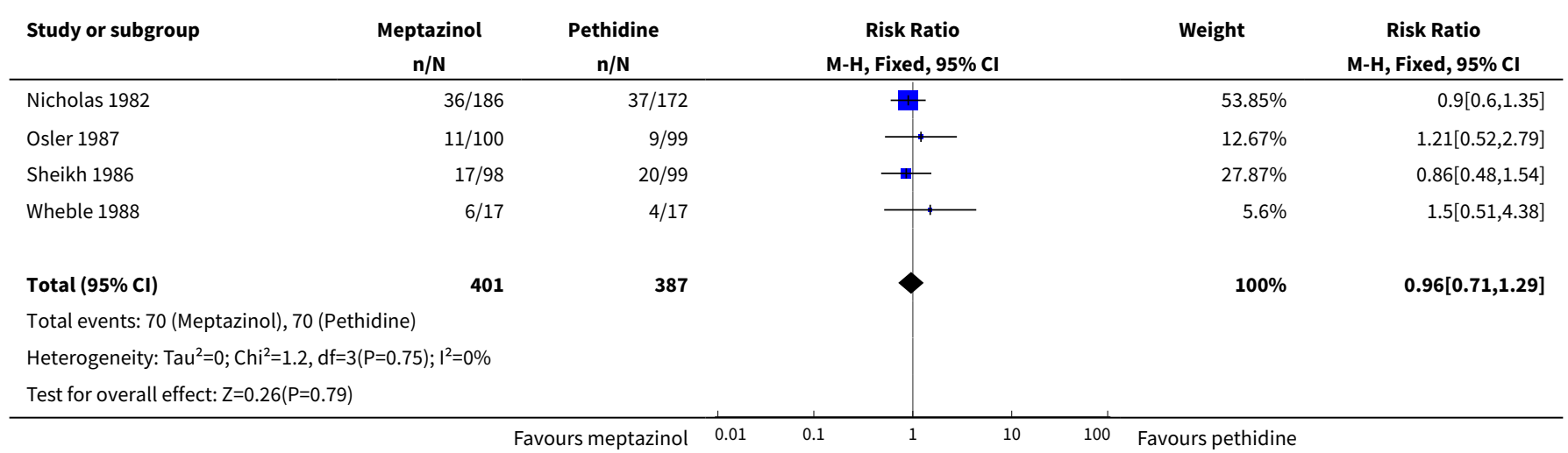

Analysis 4.5. Comparison $4 \mathrm{IM}$ meptazinol versus pethidine, Outcome 5 Maternal sleepiness.

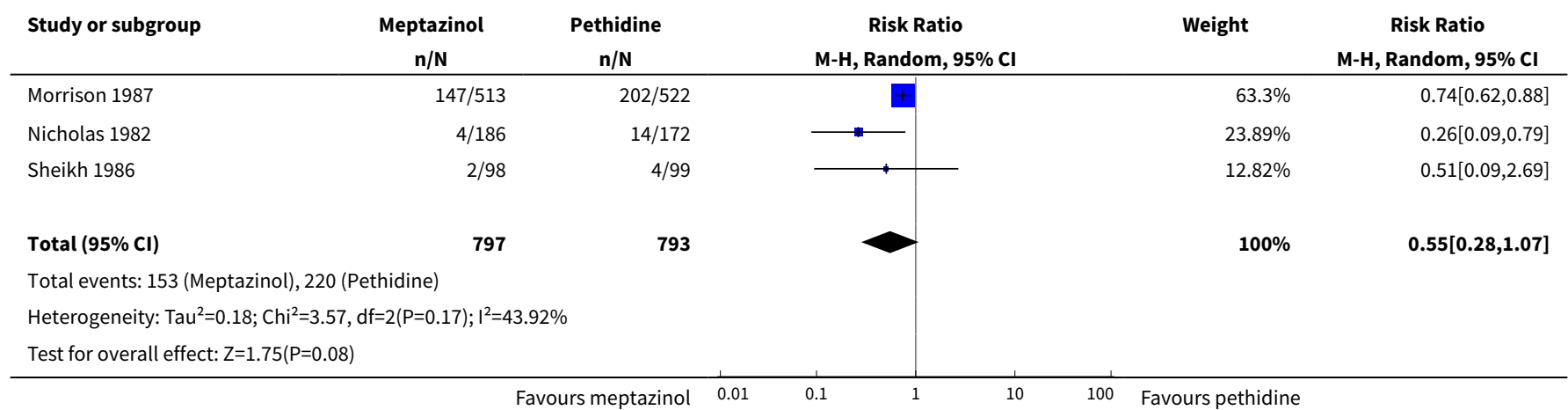

Analysis 4.6. Comparison 4 IM meptazinol versus pethidine, Outcome 6 Nausea and vomiting.

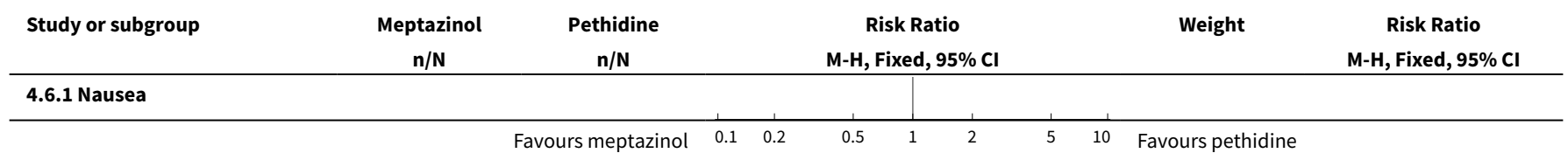




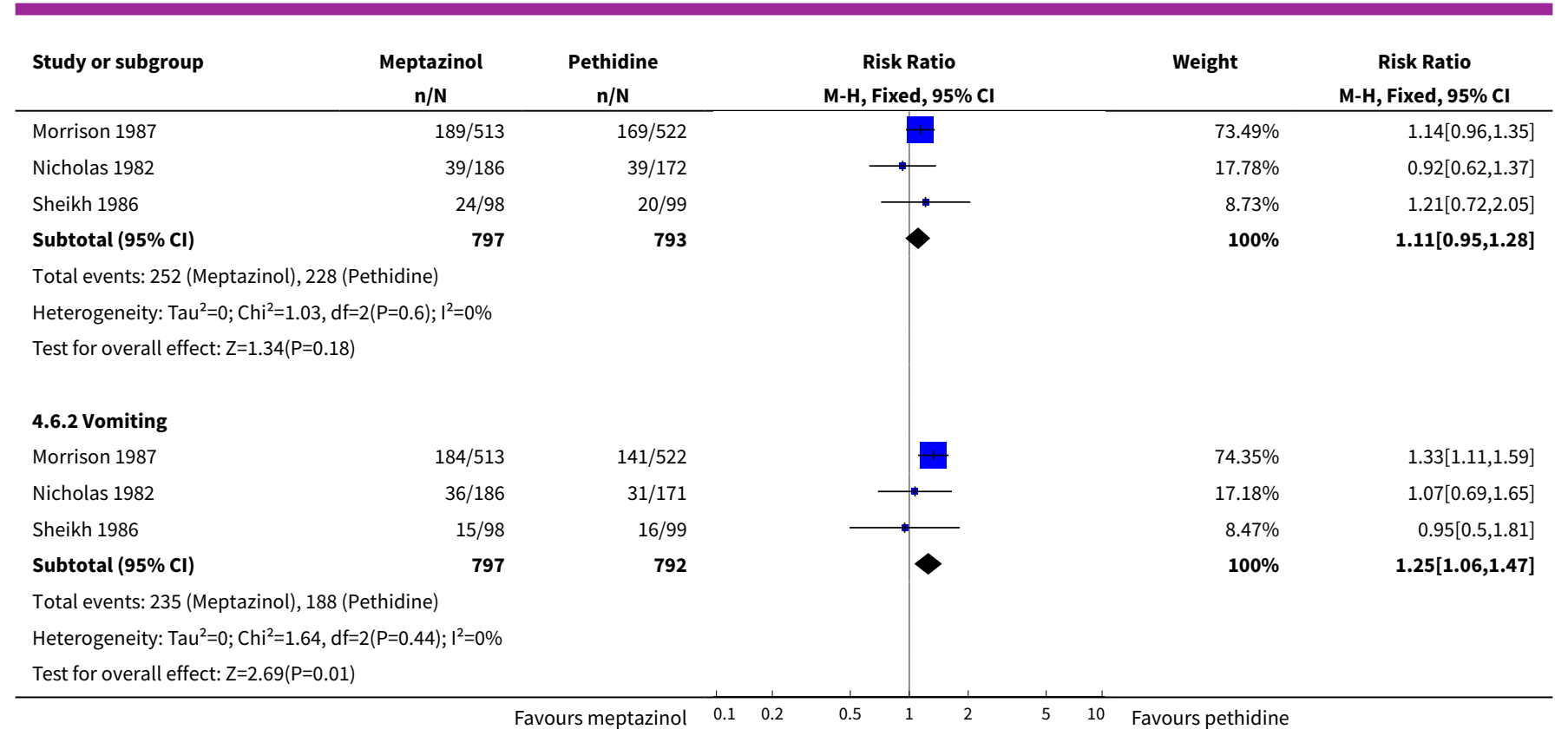

Analysis 4.7. Comparison $4 \mathrm{IM}$ meptazinol versus pethidine, Outcome 7 Caesarean section.

\begin{tabular}{|c|c|c|c|c|c|}
\hline Study or subgroup & $\begin{array}{l}\text { Meptazinol } \\
\mathrm{n} / \mathrm{N}\end{array}$ & $\begin{array}{l}\text { Pethidine } \\
n / \mathrm{N}\end{array}$ & $\begin{array}{c}\text { Risk Ratio } \\
\text { M-H, Random, 95\% Cl }\end{array}$ & Weight & $\begin{array}{c}\text { Risk Ratio } \\
\text { M-H, Random, } 95 \% \mathrm{Cl}\end{array}$ \\
\hline Morrison 1987 & $33 / 512$ & $25 / 521$ & 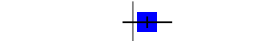 & $46.78 \%$ & $1.34[0.81,2.23]$ \\
\hline Osler 1987 & $5 / 100$ & $13 / 99$ & 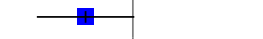 & $38.66 \%$ & $0.38[0.14,1.03]$ \\
\hline Wheble 1988 & $0 / 17$ & $5 / 17$ & - & $14.56 \%$ & $0.09[0.01,1.53]$ \\
\hline Total $(95 \% \mathrm{CI})$ & 629 & 637 & & $100 \%$ & $0.56[0.16,2]$ \\
\hline \multicolumn{6}{|c|}{ Heterogeneity: $\mathrm{Tau}^{2}=0.84 ; \mathrm{Chi}^{2}=7.85, \mathrm{df}=2(\mathrm{P}=0.02) ; \mathrm{I}^{2}=74.53 \%$} \\
\hline \multicolumn{6}{|c|}{ Test for overall effect: $Z=0.9(P=0.37)$} \\
\hline
\end{tabular}

Analysis 4.8. Comparison $4 \mathrm{IM}$ meptazinol versus pethidine, Outcome 8 Assisted vaginal birth.

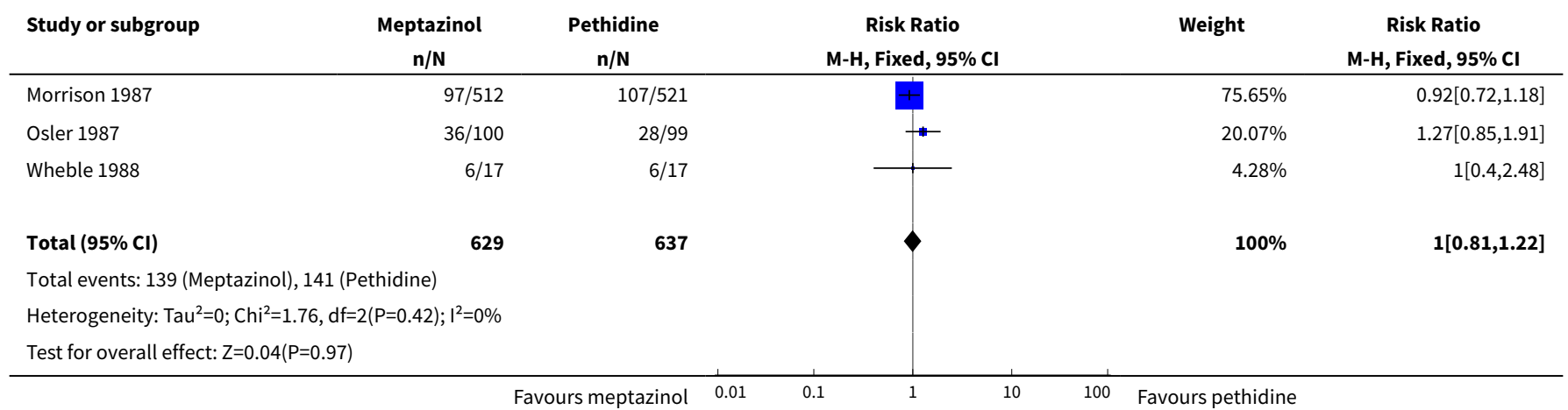


Analysis 4.9. Comparison $4 \mathrm{IM}$ meptazinol versus pethidine, Outcome 9 Breastfeeding at discharge (problems).

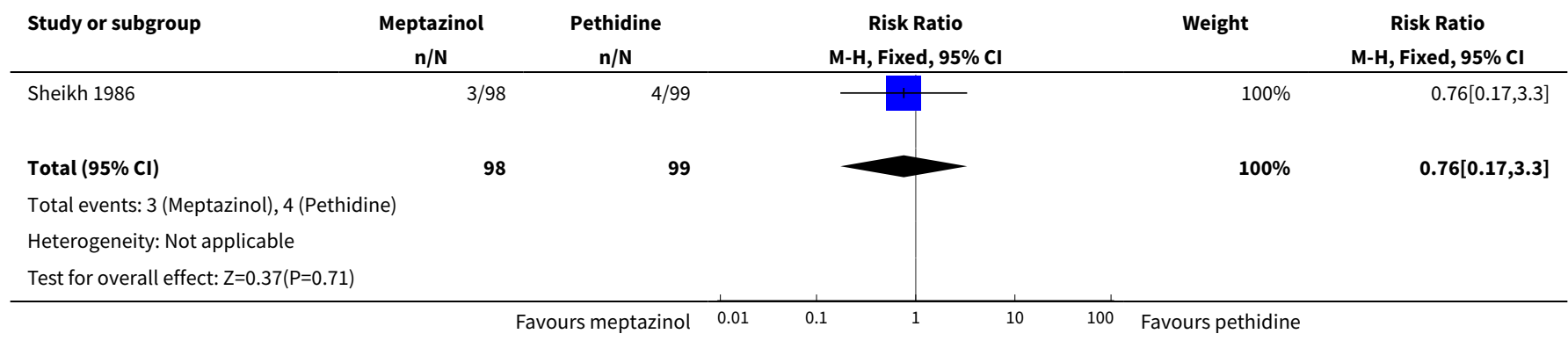

Analysis 4.10. Comparison $4 \mathrm{IM}$ meptazinol versus pethidine, Outcome 10 Fetal heart rate changes (decelerations).

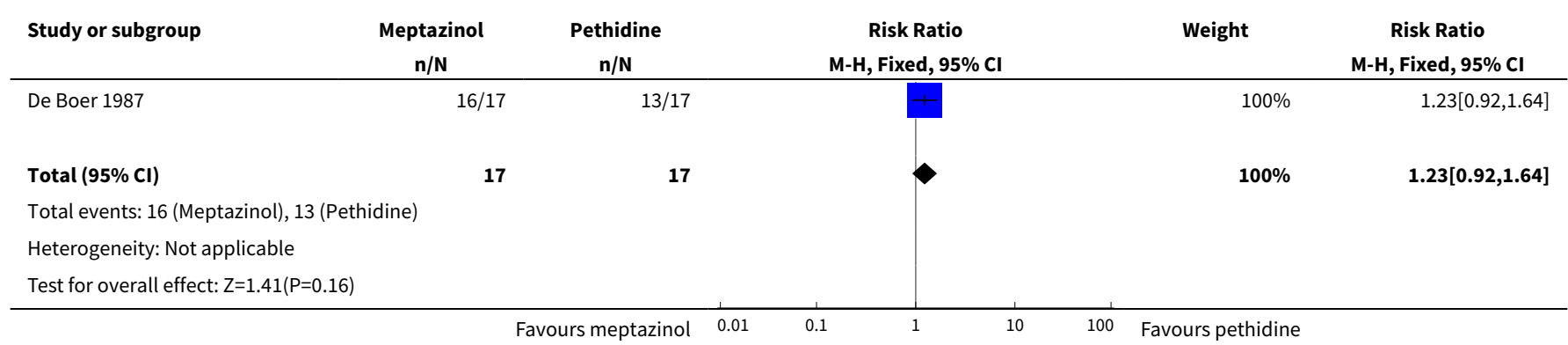

Analysis 4.11. Comparison 4 IM meptazinol versus pethidine, Outcome 11 Naloxone administration.

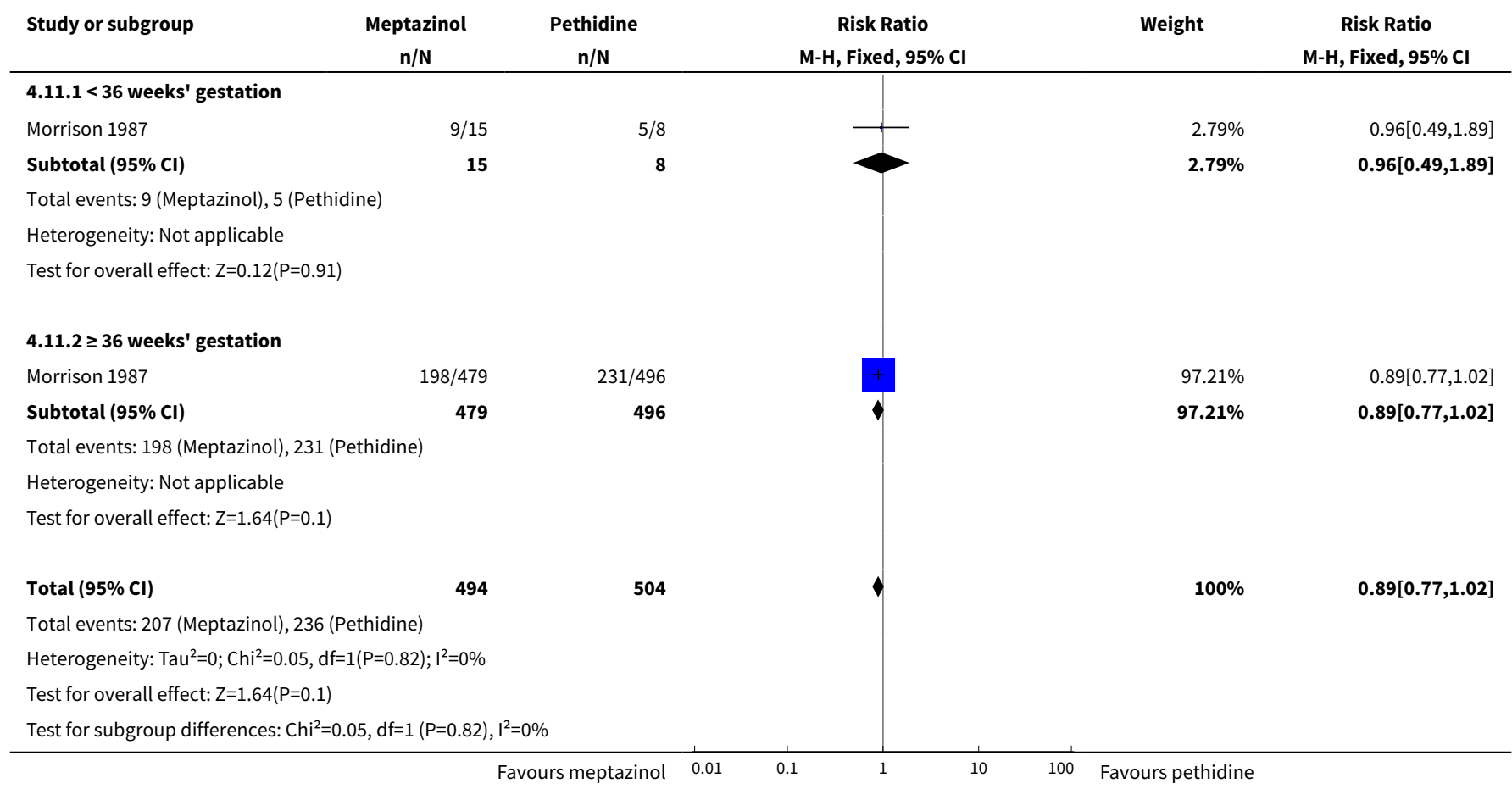


Analysis 4.12. Comparison 4 IM meptazinol versus pethidine, Outcome 12 Neonatal resuscitation (by gestation).

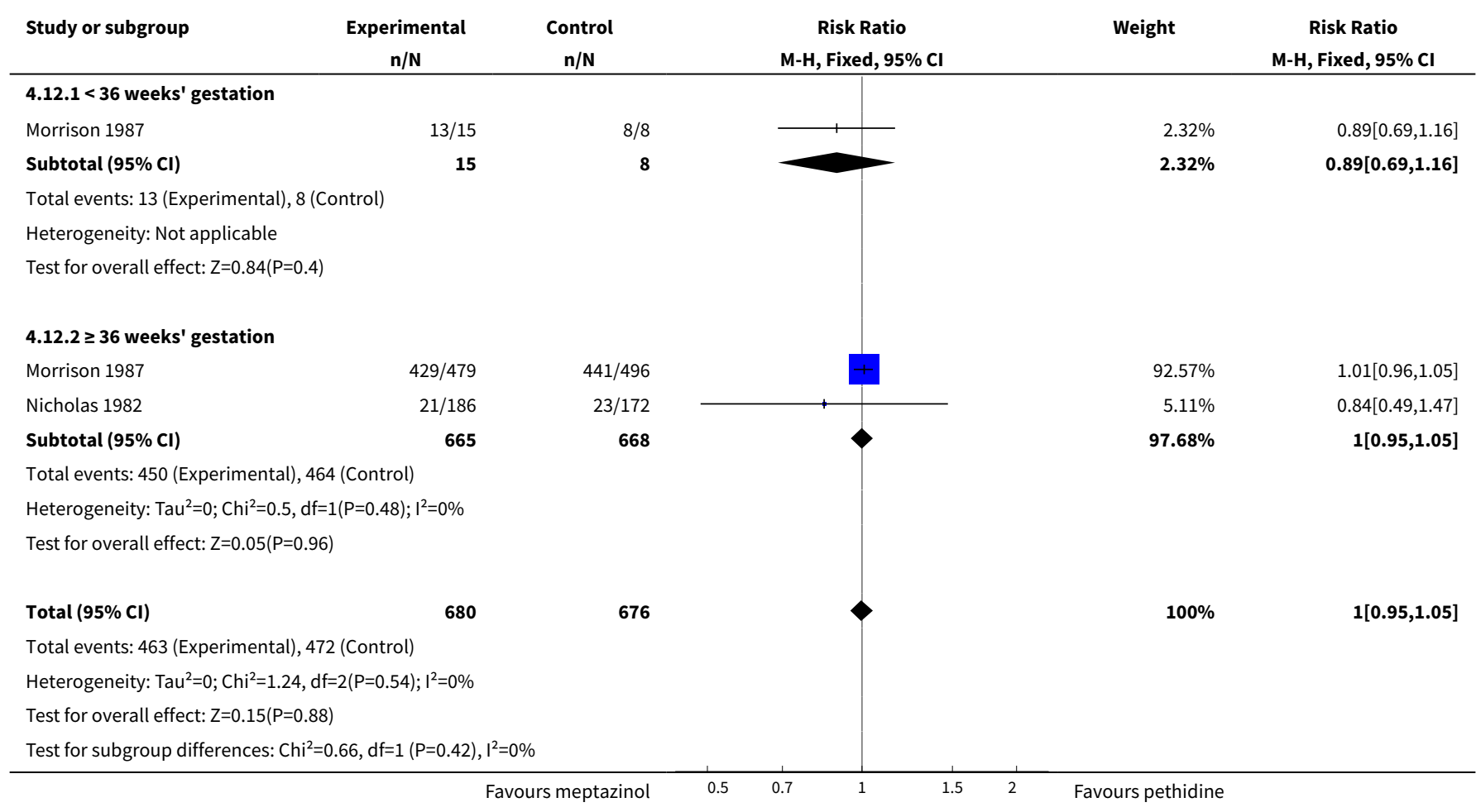

Analysis 4.13. Comparison 4 IM meptazinol versus pethidine, Outcome 13 Neonatal resuscitation.

\begin{tabular}{|c|c|c|c|c|c|}
\hline Study or subgroup & $\begin{array}{c}\text { Meptazinol } \\
n / \mathbf{N}\end{array}$ & $\begin{array}{c}\text { Pethidine } \\
\mathrm{n} / \mathrm{N}\end{array}$ & $\begin{array}{c}\text { Risk Ratio } \\
\text { M-H, Fixed, 95\% Cl }\end{array}$ & Weight & $\begin{array}{c}\text { Risk Ratio } \\
\text { M-H, Fixed, } 95 \% \mathrm{Cl}\end{array}$ \\
\hline Jackson 1983 & $3 / 50$ & $2 / 50$ & + & $100 \%$ & $1.5[0.26,8.6]$ \\
\hline Total $(95 \% \mathrm{Cl})$ & 50 & 50 & & $100 \%$ & $1.5[0.26,8.6]$ \\
\hline \multicolumn{6}{|c|}{ Total events: 3 (Meptazinol), 2 (Pethidine) } \\
\hline \multicolumn{6}{|c|}{ Heterogeneity: Not applicable } \\
\hline \multicolumn{6}{|c|}{ Test for overall effect: $Z=0.46(P=0.65)$} \\
\hline
\end{tabular}

Analysis 4.14. Comparison $4 \mathrm{IM}$ meptazinol versus pethidine, Outcome 14 Apgar score $\leq 7$ at 1 minute.

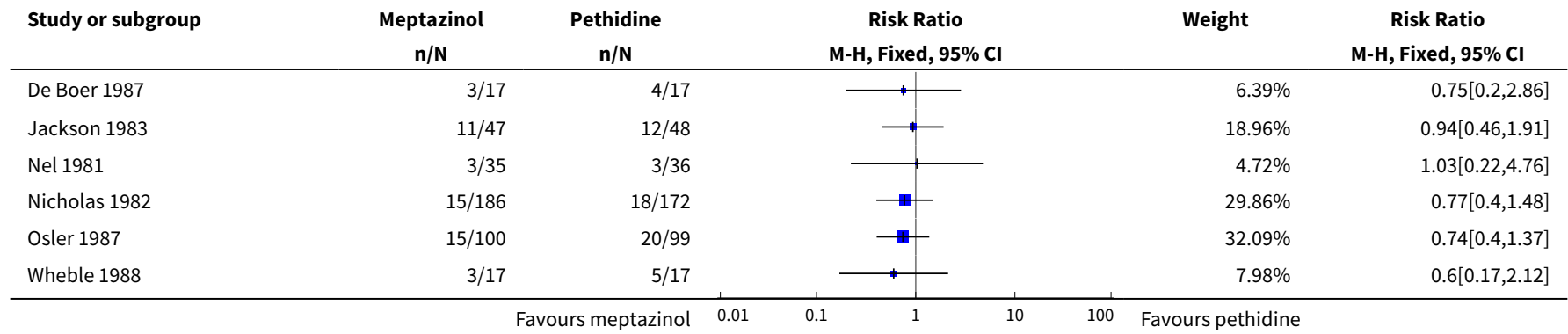




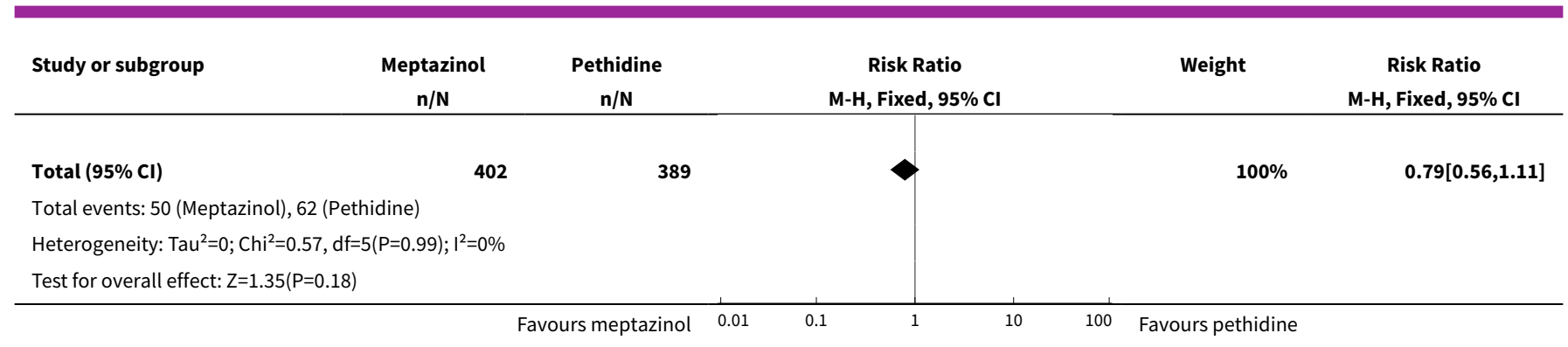

Analysis 4.15. Comparison $4 \mathrm{IM}$ meptazinol versus pethidine, Outcome 15 Apgar score $\leq 7$ at 5 minutes.

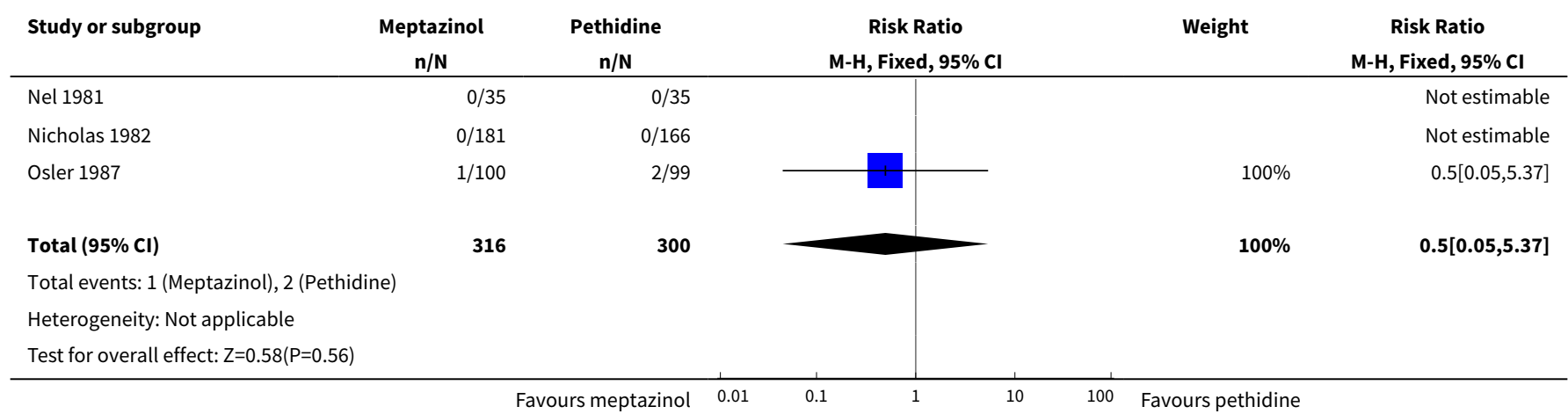

Analysis 4.16. Comparison 4 IM meptazinol versus pethidine, Outcome 16 Admission to NICU.

\begin{tabular}{|c|c|c|c|c|c|}
\hline Study or subgroup & $\begin{array}{c}\text { Meptazinol } \\
\mathrm{n} / \mathrm{N} \\
\end{array}$ & $\begin{array}{c}\text { Pethidine } \\
\mathrm{n} / \mathrm{N}\end{array}$ & $\begin{array}{c}\text { Risk Ratio } \\
\text { M-H, Fixed, 95\% Cl }\end{array}$ & Weight & $\begin{array}{c}\text { Risk Ratio } \\
\text { M-H, Fixed, 95\% Cl }\end{array}$ \\
\hline Osler 1987 & $16 / 100$ & $18 / 99$ & - & $100 \%$ & $0.88[0.48,1.63]$ \\
\hline Total $(95 \% \mathrm{CI})$ & 100 & 99 & & $100 \%$ & $0.88[0.48,1.63]$ \\
\hline \multicolumn{6}{|c|}{ Total events: 16 (Meptazinol), 18 (Pethidine) } \\
\hline \multicolumn{6}{|c|}{ Heterogeneity: Not applicable } \\
\hline
\end{tabular}

Comparison 5. IM diamorphine + prochlorperazine versus pethidine + prochlorperazine

\begin{tabular}{lllll}
\hline Outcome or subgroup title & No. of studies & $\begin{array}{l}\text { No. of partici- } \\
\text { pants }\end{array}$ & Statistical method & Effect size \\
\hline $\begin{array}{l}1 \text { Maternal satisfaction with analgesia } \\
\text { in labour measured during the post- } \\
\text { natal period (Global assessment of } \\
\text { pain relief at 24 hours) }\end{array}$ & 1 & 133 & $\begin{array}{l}\text { Risk Ratio (M-H, Fixed, 95\% } \\
\mathrm{Cl})\end{array}$ & $0.88[0.67,1.16]$ \\
\hline $\begin{array}{l}2 \text { Maternal pain score or pain mea- } \\
\text { sured in labour (Pain intensity at 1 } \\
\text { hour (moderate or severe)) }\end{array}$ & 1 & 133 & $\begin{array}{l}\text { Risk Ratio (M-H, Fixed, 95\% } \\
\text { Cl) }\end{array}$ & $0.85[0.72,1.01]$ \\
\hline
\end{tabular}




\begin{tabular}{|c|c|c|c|c|}
\hline Outcome or subgroup title & No. of studies & $\begin{array}{l}\text { No. of partici- } \\
\text { pants }\end{array}$ & Statistical method & Effect size \\
\hline 3 Additonal analgesia required & 1 & 133 & $\begin{array}{l}\text { Risk Ratio (M-H, Fixed, 95\% } \\
\mathrm{Cl})\end{array}$ & $1.35[0.53,3.40]$ \\
\hline 4 Epidural & 1 & 133 & $\begin{array}{l}\text { Risk Ratio (M-H, Fixed, 95\% } \\
\mathrm{Cl} \text { ) }\end{array}$ & $1.22[0.72,2.07]$ \\
\hline 5 Maternal sleepiness during labour & 1 & 133 & $\begin{array}{l}\text { Risk Ratio (M-H, Fixed, 95\% } \\
\mathrm{Cl})\end{array}$ & $0.93[0.52,1.66]$ \\
\hline 6 Vomiting in labour & 1 & 133 & $\begin{array}{l}\text { Risk Ratio (M-H, Fixed, 95\% } \\
\mathrm{Cl})\end{array}$ & $0.39[0.17,0.86]$ \\
\hline 7 Caesarean section & 1 & 133 & $\begin{array}{l}\text { Risk Ratio (M-H, Fixed, 95\% } \\
\mathrm{Cl})\end{array}$ & $0.52[0.10,2.76]$ \\
\hline 8 Assisted vaginal birth & 1 & 133 & $\begin{array}{l}\text { Risk Ratio (M-H, Fixed, 95\% } \\
\mathrm{Cl})\end{array}$ & $0.96[0.46,2.02]$ \\
\hline 9 Neonatal resuscitation & 1 & 133 & $\begin{array}{l}\text { Risk Ratio (M-H, Fixed, 95\% } \\
\mathrm{Cl})\end{array}$ & $1.21[0.73,2.02]$ \\
\hline 10 Apgar $<7$ at 1 minute & 1 & 133 & $\begin{array}{l}\text { Risk Ratio (M-H, Fixed, 95\% } \\
\mathrm{Cl})\end{array}$ & $0.41[0.18,0.91]$ \\
\hline 11 Apgar $<7$ at 5 minutes & 1 & 133 & $\begin{array}{l}\text { Risk Ratio (M-H, Fixed, 95\% } \\
\mathrm{Cl} \text { ) }\end{array}$ & $0.35[0.04,3.27]$ \\
\hline 12 Admission to NICU & 1 & 133 & $\begin{array}{l}\text { Risk Ratio (M-H, Fixed, 95\% } \\
\mathrm{Cl})\end{array}$ & $0.58[0.21,1.64]$ \\
\hline
\end{tabular}

Analysis 5.1. Comparison $5 \mathrm{IM}$ diamorphine + prochlorperazine versus pethidine

+ prochlorperazine, Outcome 1 Maternal satisfaction with analgesia in labour measured during the postnatal period (Global assessment of pain relief at 24 hours).

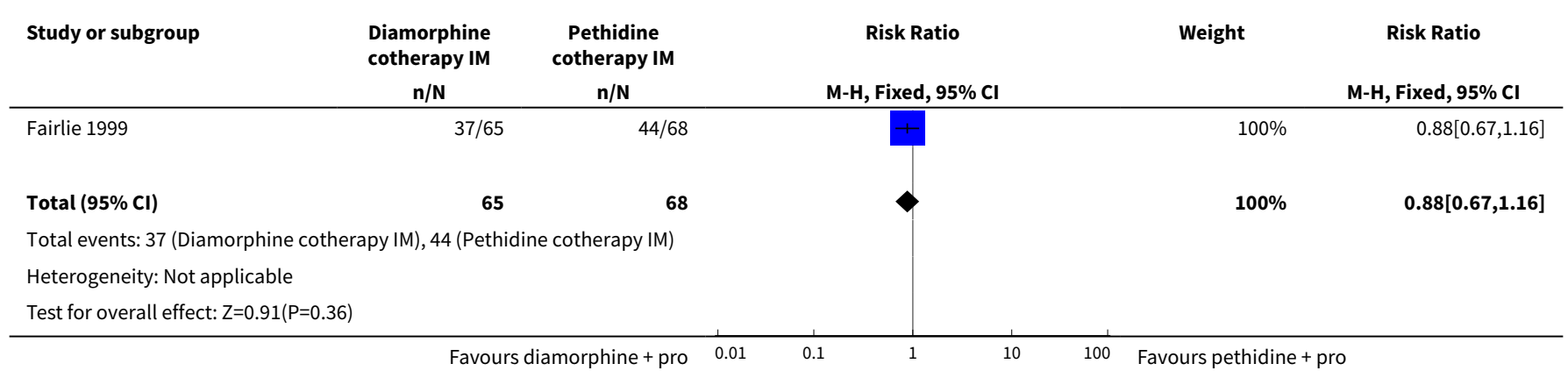


Analysis 5.2. Comparison 5 IM diamorphine + prochlorperazine versus pethidine + prochlorperazine, Outcome $\mathbf{2}$ Maternal pain score or pain measured in labour (Pain intensity at $\mathbf{1}$ hour (moderate or severe)).

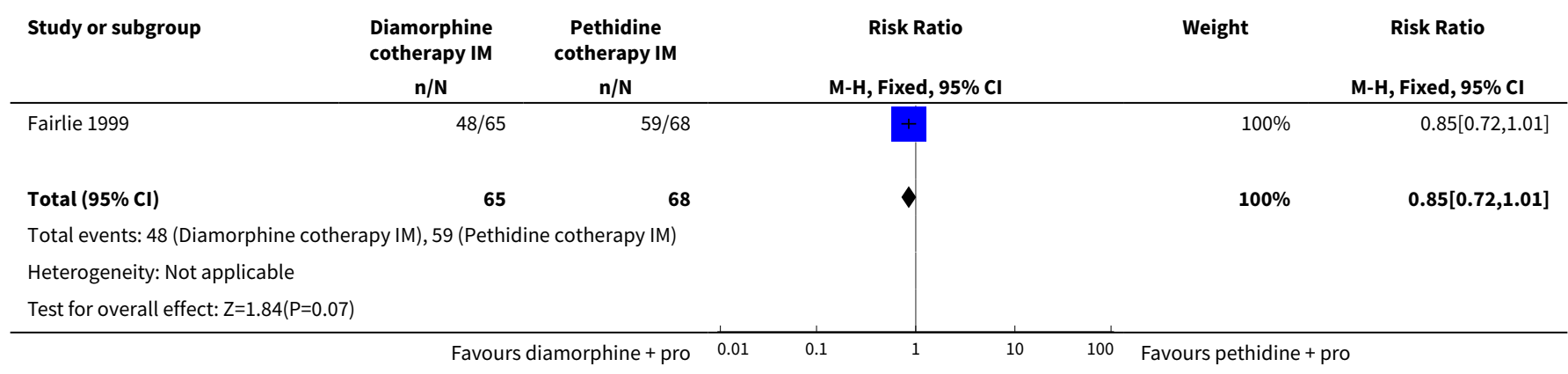

Analysis 5.3. Comparison 5 IM diamorphine + prochlorperazine versus pethidine + prochlorperazine, Outcome 3 Additonal analgesia required.

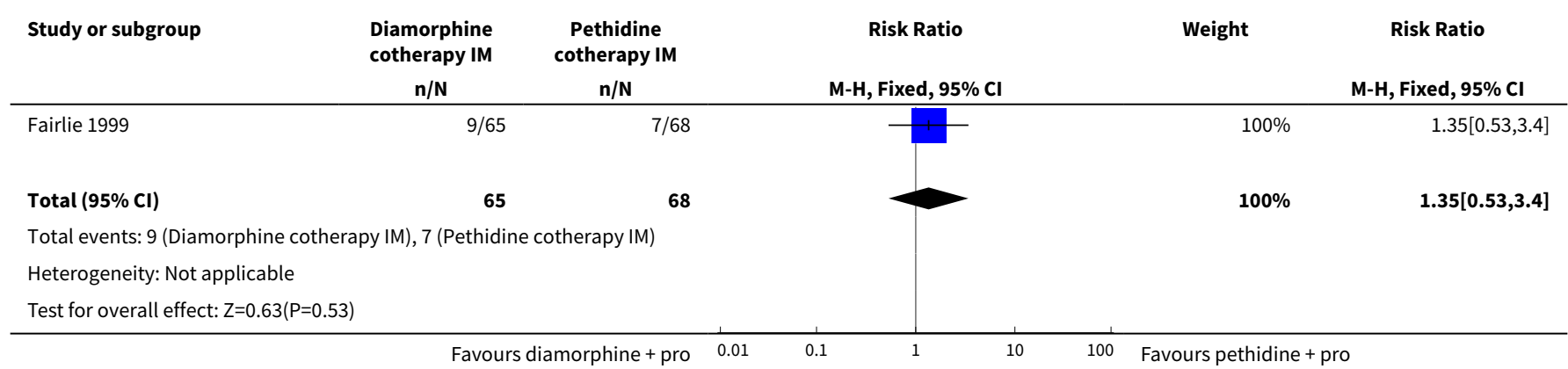

Analysis 5.4. Comparison 5 IM diamorphine + prochlorperazine versus pethidine + prochlorperazine, Outcome 4 Epidural.

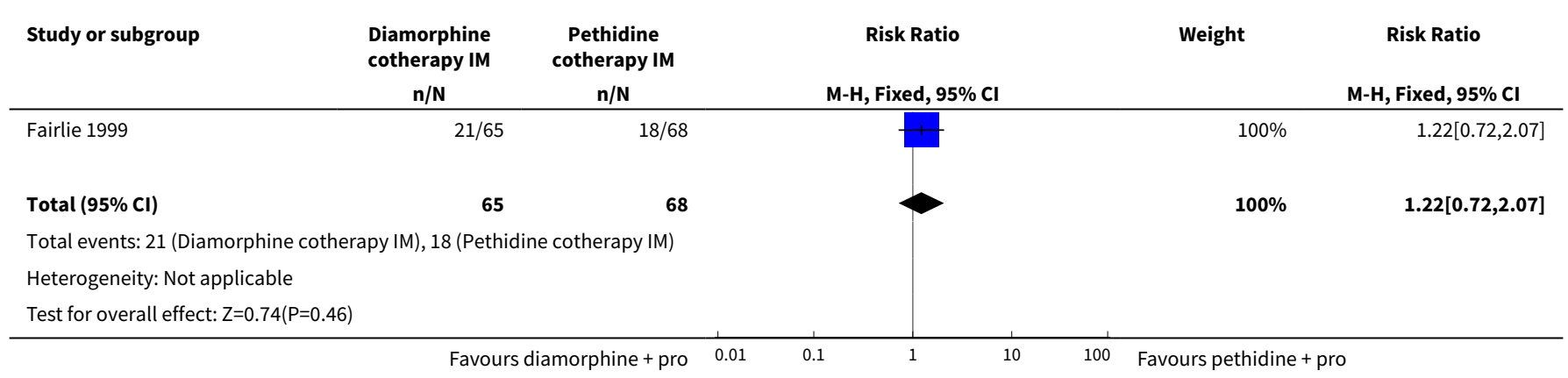


Analysis 5.5. Comparison $5 \mathrm{IM}$ diamorphine + prochlorperazine versus pethidine + prochlorperazine, Outcome 5 Maternal sleepiness during labour.

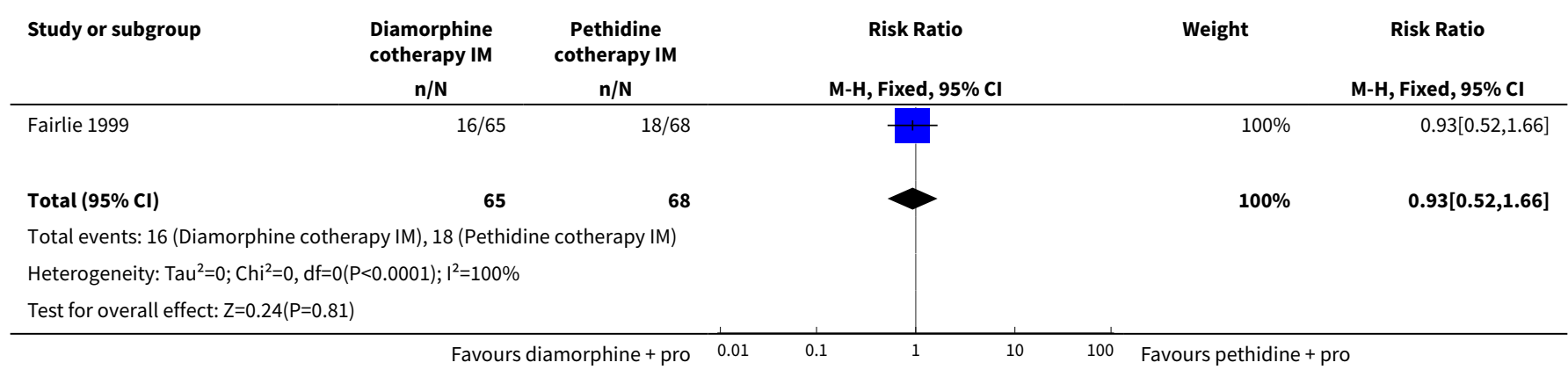

Analysis 5.6. Comparison 5 IM diamorphine + prochlorperazine versus pethidine + prochlorperazine, Outcome 6 Vomiting in labour.

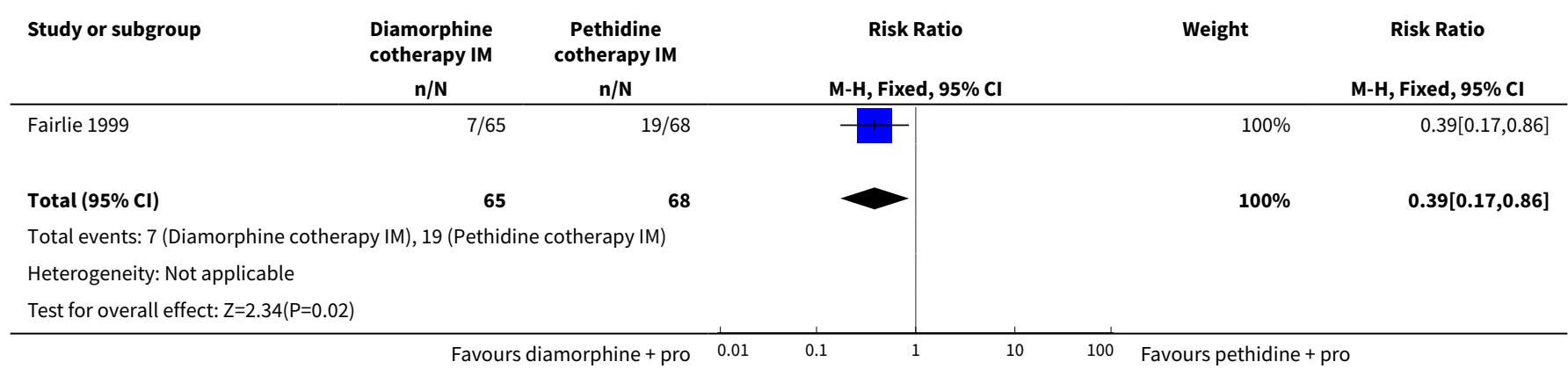

Analysis 5.7. Comparison $5 \mathrm{IM}$ diamorphine + prochlorperazine versus pethidine + prochlorperazine, Outcome 7 Caesarean section.

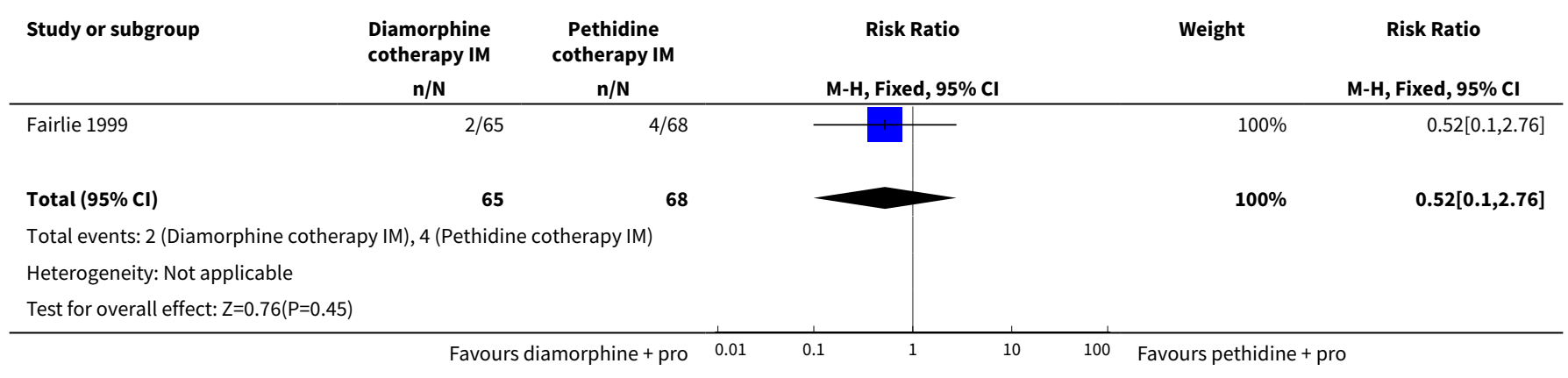


Analysis 5.8. Comparison 5 IM diamorphine + prochlorperazine versus pethidine + prochlorperazine, Outcome 8 Assisted vaginal birth.

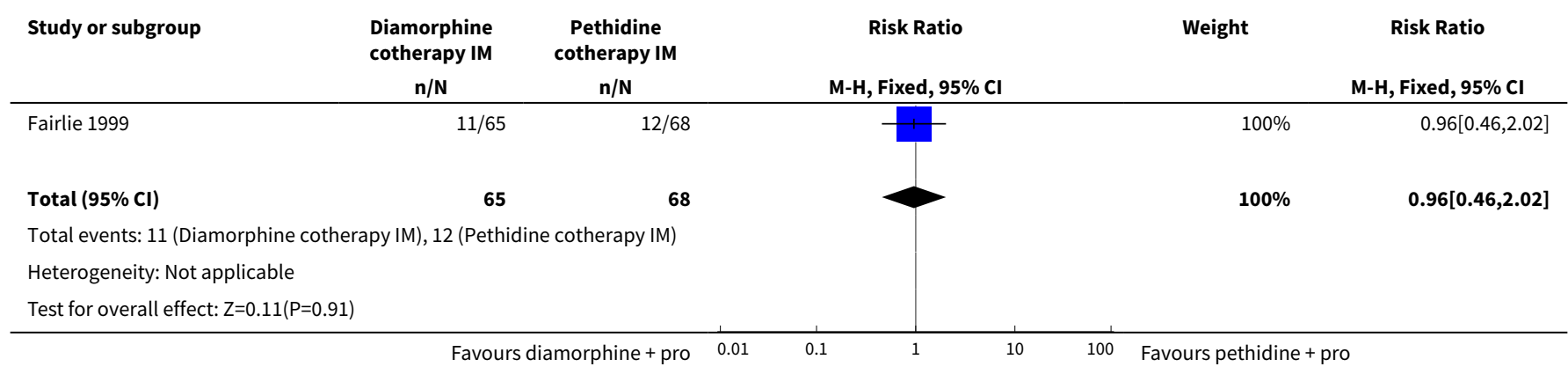

Analysis 5.9. Comparison $5 \mathrm{IM}$ diamorphine + prochlorperazine versus pethidine + prochlorperazine, Outcome 9 Neonatal resuscitation.

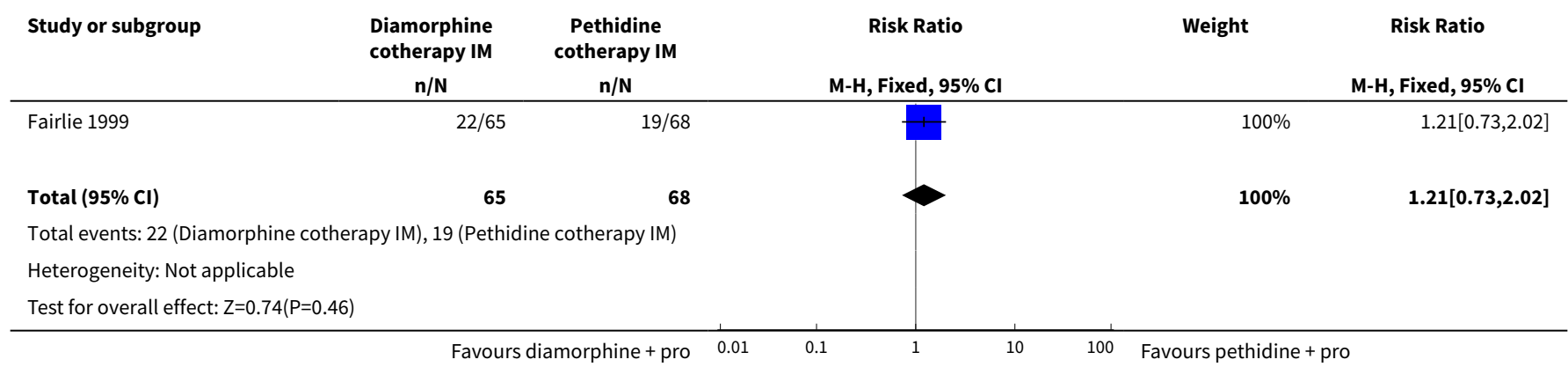

Analysis 5.10. Comparison 5 IM diamorphine + prochlorperazine versus pethidine + prochlorperazine, Outcome $10 \mathrm{Apgar}<7$ at 1 minute.

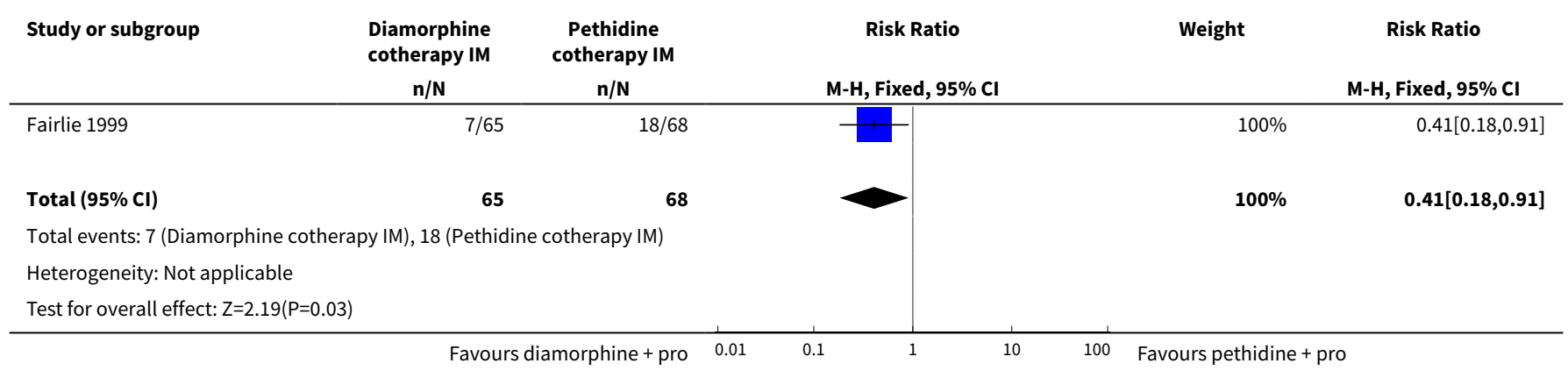


Analysis 5.11. Comparison 5 IM diamorphine + prochlorperazine versus pethidine + prochlorperazine, Outcome 11 Apgar $<7$ at 5 minutes.

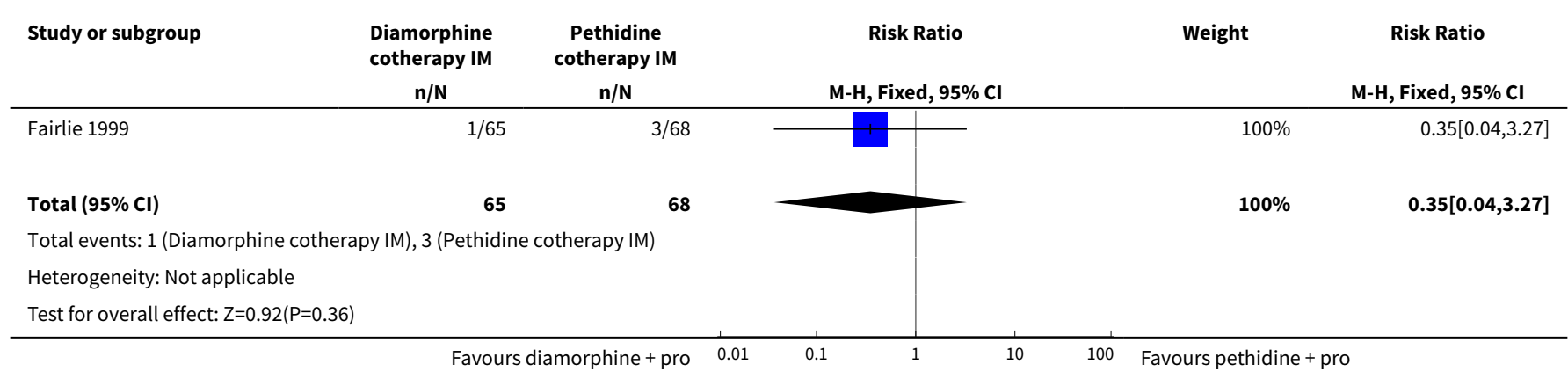

Analysis 5.12. Comparison 5 IM diamorphine + prochlorperazine versus pethidine + prochlorperazine, Outcome 12 Admission to NICU.

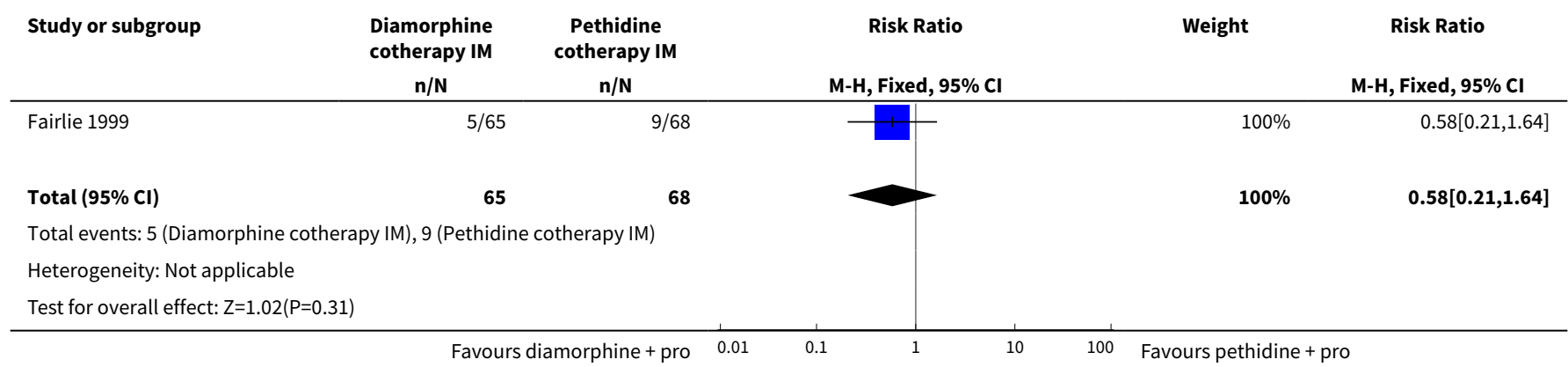

\section{Comparison 6. IM tramadol versus pethidine}

\begin{tabular}{lllll}
\hline Outcome or subgroup title & No. of studies & $\begin{array}{l}\text { No. of partici- } \\
\text { pants }\end{array}$ & Statistical method & Effect size \\
\hline $\begin{array}{l}1 \text { Maternal pain score or pain } \\
\text { measured in labour (Pain intensi- } \\
\text { ty: women with poor pain relief) }\end{array}$ & 4 & 243 & Risk Ratio (M-H, Fixed, 95\% Cl) & $1.56[1.10,2.21]$ \\
\hline $\begin{array}{llll}\text { 2 Additional analgesia required } \\
\text { 3 Maternal sleepiness in labour }\end{array}$ & 5 & 295 & $\begin{array}{l}\text { Risk Ratio (M-H, Random, 95\% } \\
\text { Cl) }\end{array}$ & $1.07[0.60,1.91]$ \\
\hline 4 Nausea and vomiting in labour & 6 & 409 & $\begin{array}{l}\text { Risk Ratio (M-H, Random, 95\% } \\
\text { Cl) }\end{array}$ & $0.57[0.33,0.97]$ \\
\hline 5 Caesarean section & 3 & 454 & $\begin{array}{l}\text { Risk Ratio (M-H, Random, 95\% } \\
\text { Cl) }\end{array}$ & $0.97[0.34,2.76]$ \\
\hline 6 Assisted vaginal birth & 3 & Risk Ratio (M-H, Fixed, 95\% Cl) & $0.71[0.23,2.18]$ \\
\hline 7 Neonatal resuscitation & 1 & 260 & Risk Ratio (M-H, Fixed, 95\% Cl) & $0.56[0.12,2.56]$ \\
\hline
\end{tabular}




\begin{tabular}{lllll}
\hline Outcome or subgroup title & No. of studies & $\begin{array}{l}\text { No. of partici- } \\
\text { pants }\end{array}$ & Statistical method & Effect size \\
\hline $\begin{array}{l}\text { 8 Apgar scores } 17 \text { at } 1 \text { and } 5 \text { min- } \\
\text { utes }\end{array}$ & 2 & & Risk Ratio (M-H, Fixed, 95\% Cl) & Subtotals only \\
\hline 8.1 Less than 7 at 1 minute & 2 & 250 & Risk Ratio (M-H, Fixed, 95\% Cl) & $0.0[0.0,0.0]$ \\
\hline 8.2 Less than 7 at 5 minutes & 1 & 160 & Risk Ratio (M-H, Fixed, 95\% Cl) & $0.0[0.0,0.0]$ \\
\hline 9 Neonatal respiratory distress & 1 & 59 & Risk Ratio (M-H, Fixed, 95\% Cl) & $2.26[0.64,7.89]$ \\
\hline 10 Admission to NICU & 1 & 59 & Risk Ratio (M-H, Fixed, 95\% Cl) & $2.26[0.64,7.89]$ \\
\hline
\end{tabular}

Analysis 6.1. Comparison $6 \mathrm{IM}$ tramadol versus pethidine, Outcome 1 Maternal pain score or pain measured in labour (Pain intensity: women with poor pain relief).

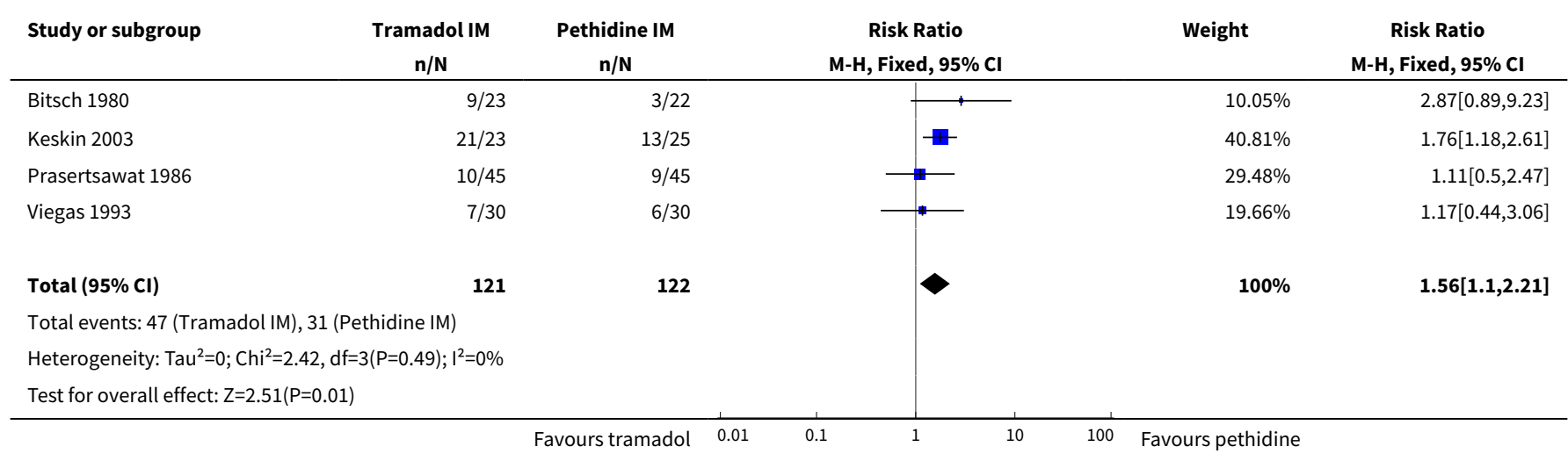

Analysis 6.2. Comparison $6 \mathrm{IM}$ tramadol versus pethidine, Outcome 2 Additional analgesia required.

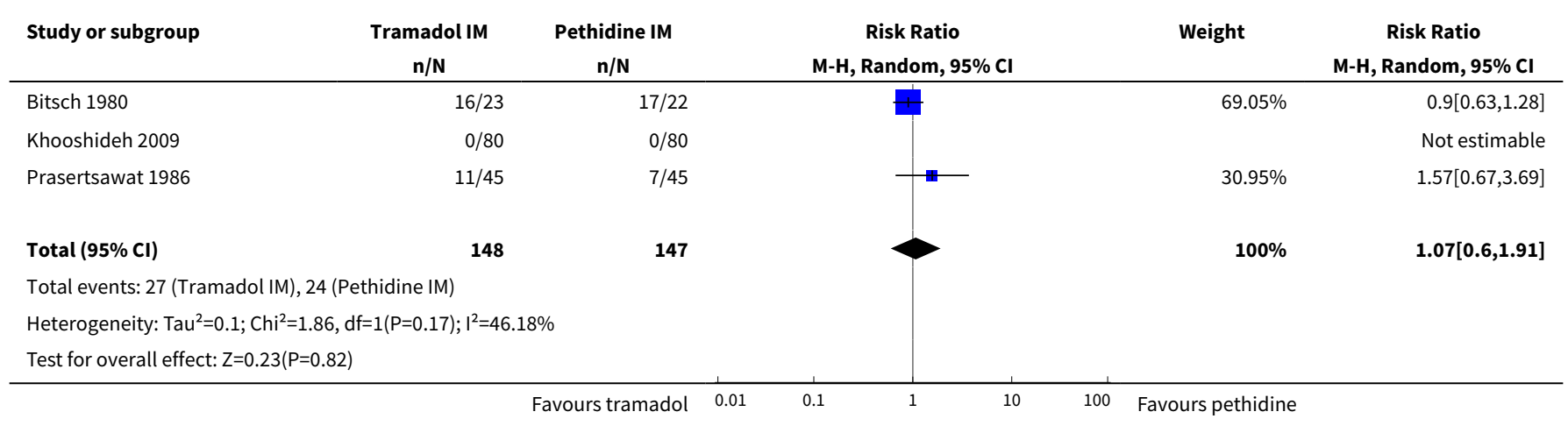


Analysis 6.3. Comparison $6 \mathrm{IM}$ tramadol versus pethidine, Outcome 3 Maternal sleepiness in labour.

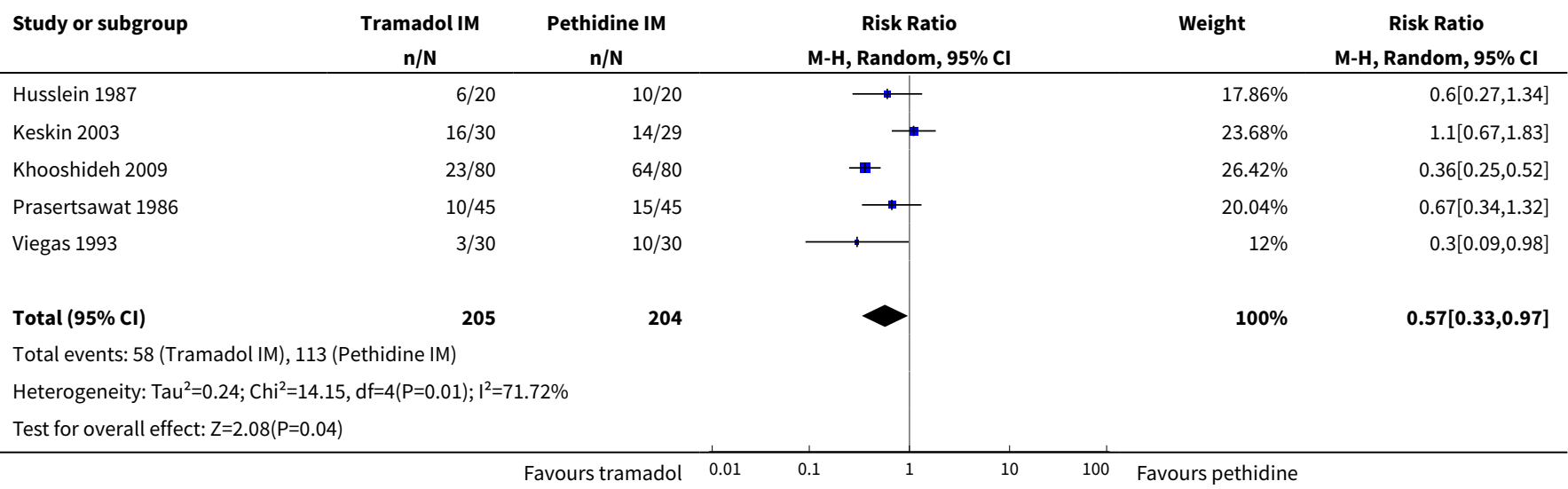

Analysis 6.4. Comparison $6 \mathrm{IM}$ tramadol versus pethidine, Outcome 4 Nausea and vomiting in labour.

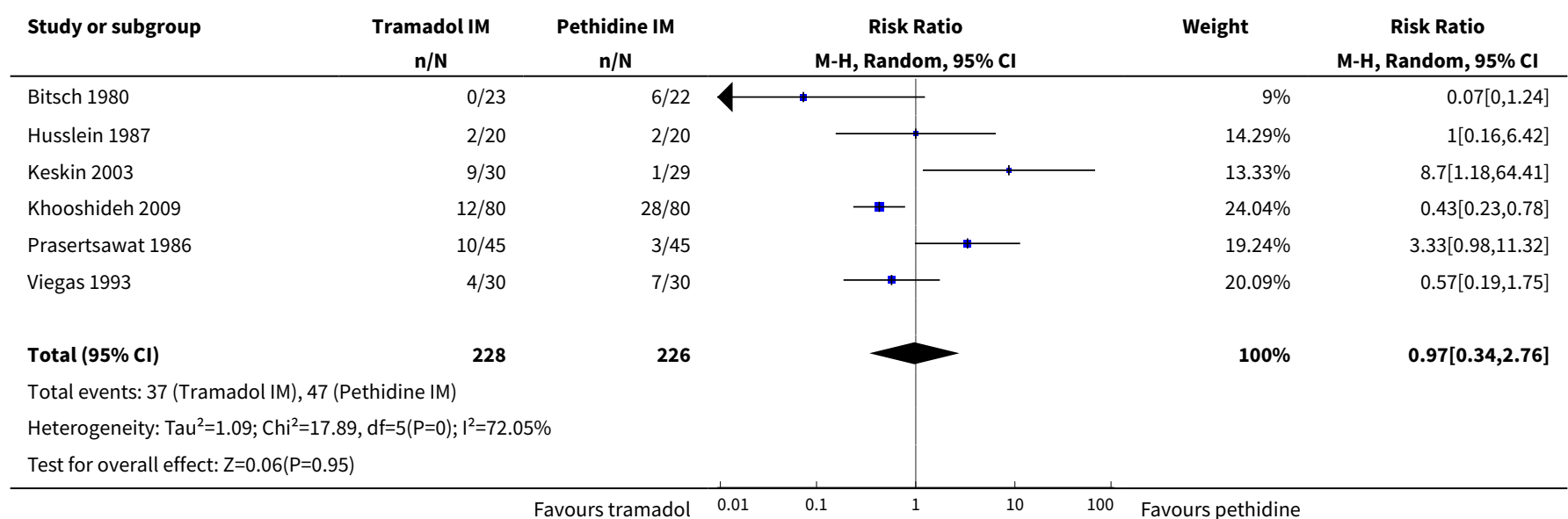

Analysis 6.5. Comparison 6 IM tramadol versus pethidine, Outcome 5 Caesarean section.

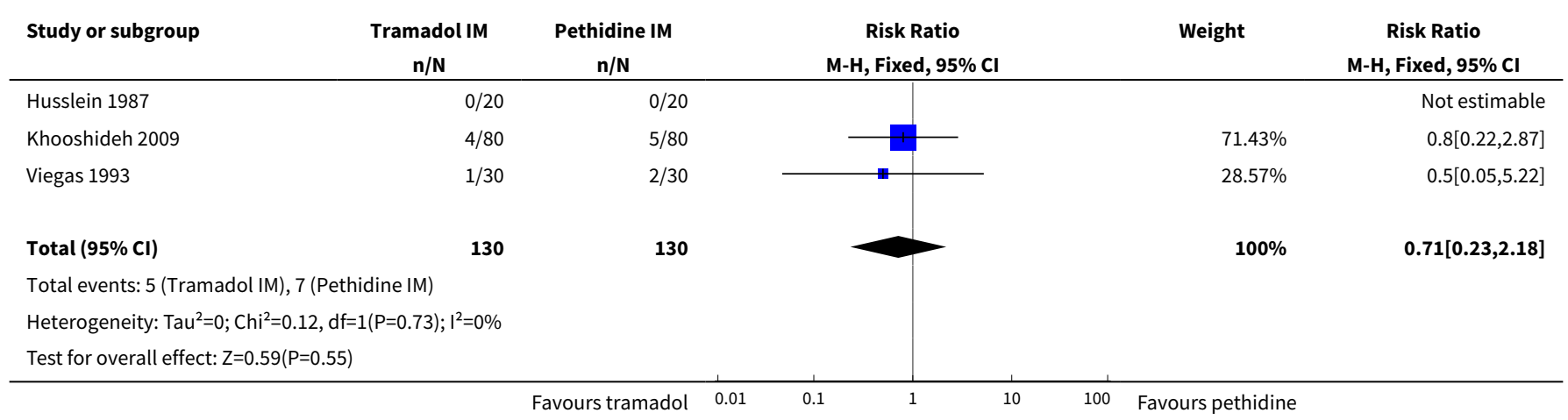


Analysis 6.6. Comparison 6 IM tramadol versus pethidine, Outcome 6 Assisted vaginal birth.

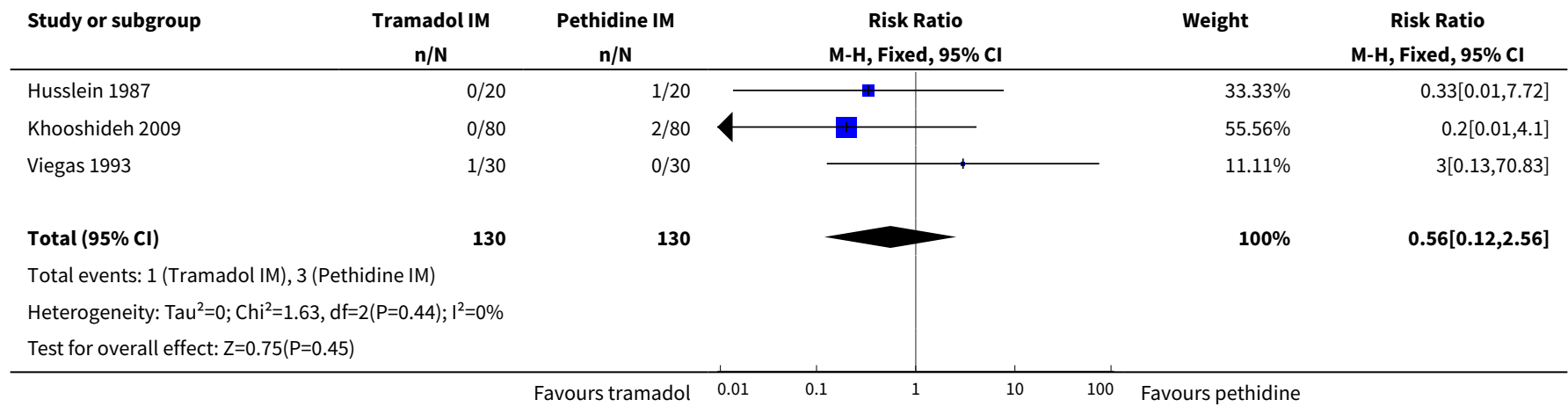

Analysis 6.7. Comparison $6 \mathrm{IM}$ tramadol versus pethidine, Outcome 7 Neonatal resuscitation.

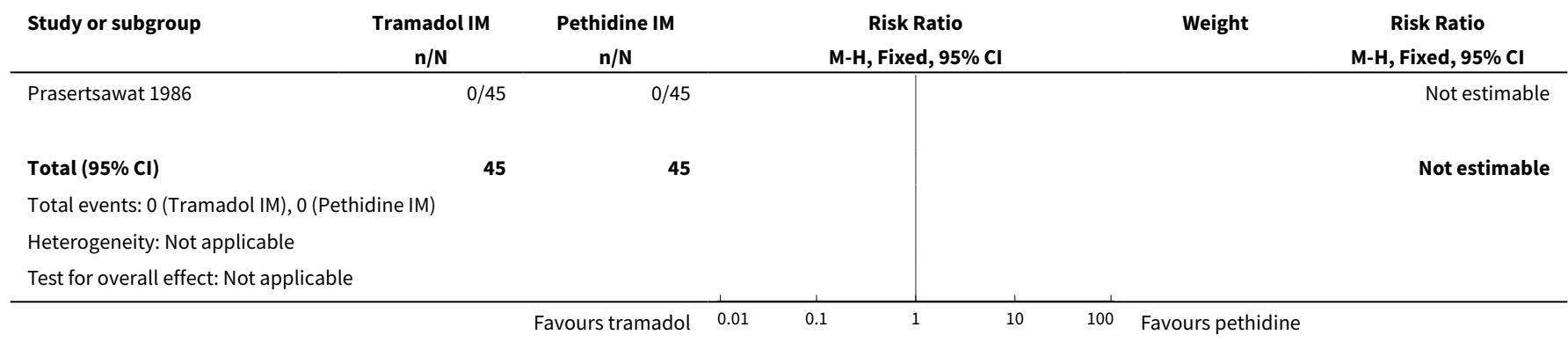

Analysis 6.8. Comparison $6 \mathrm{IM}$ tramadol versus pethidine, Outcome $8 \mathrm{Apgar}$ scores $\leq 7$ at 1 and 5 minutes.

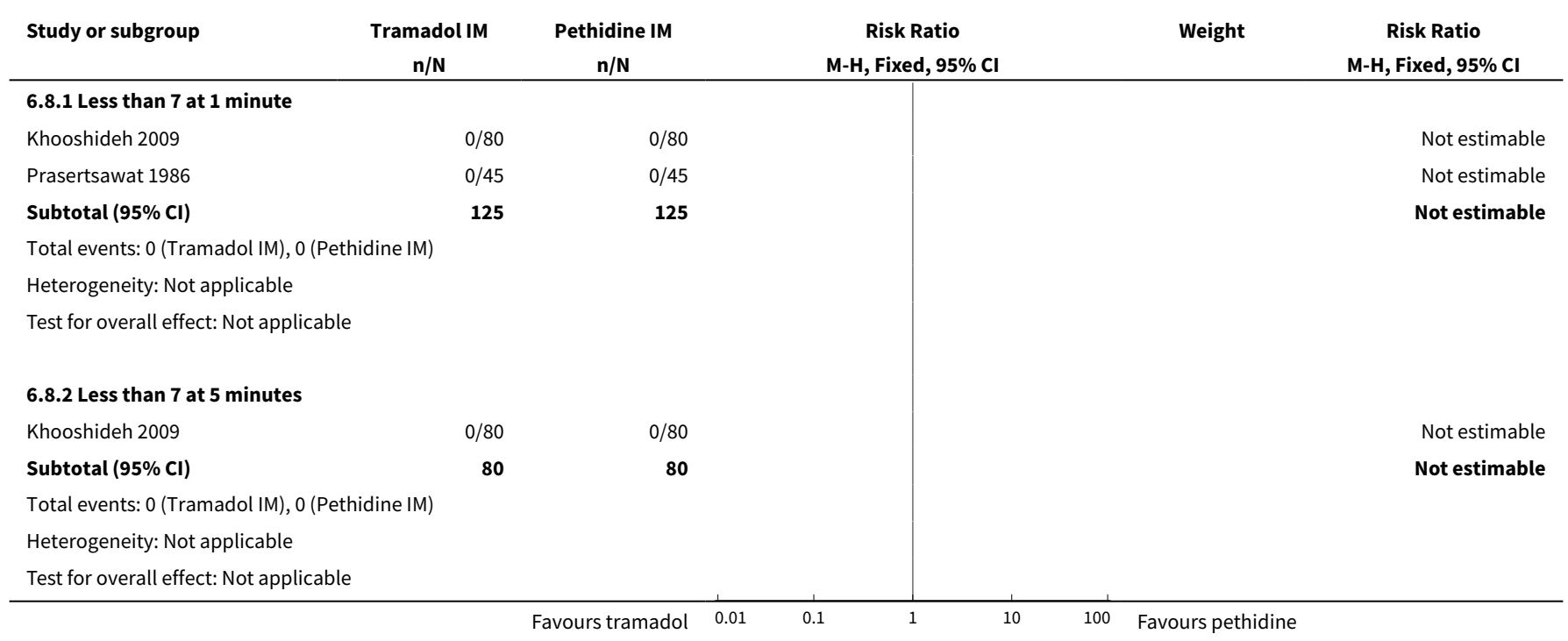


Analysis 6.9. Comparison 6 IM tramadol versus pethidine, Outcome 9 Neonatal respiratory distress.

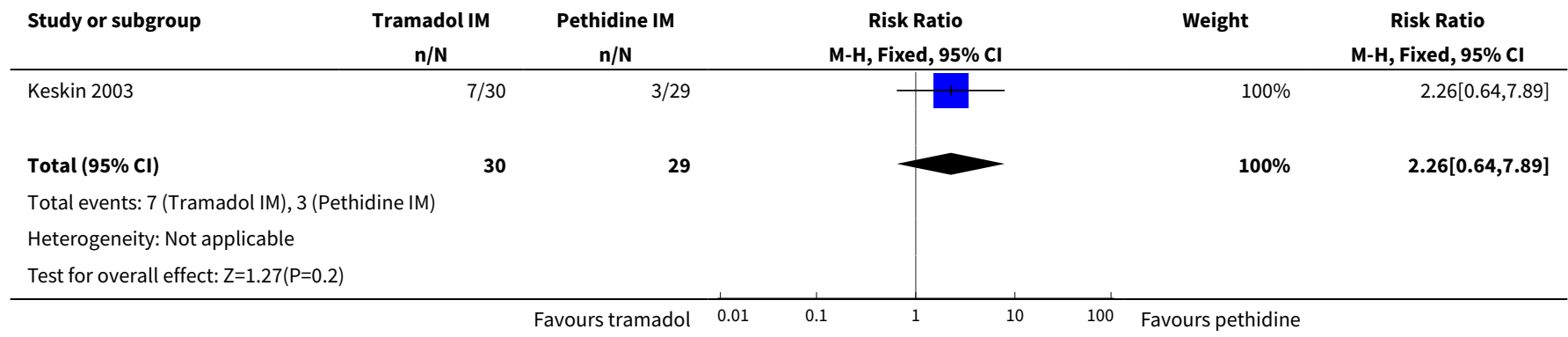

Analysis 6.10. Comparison 6 IM tramadol versus pethidine, Outcome 10 Admission to NICU.

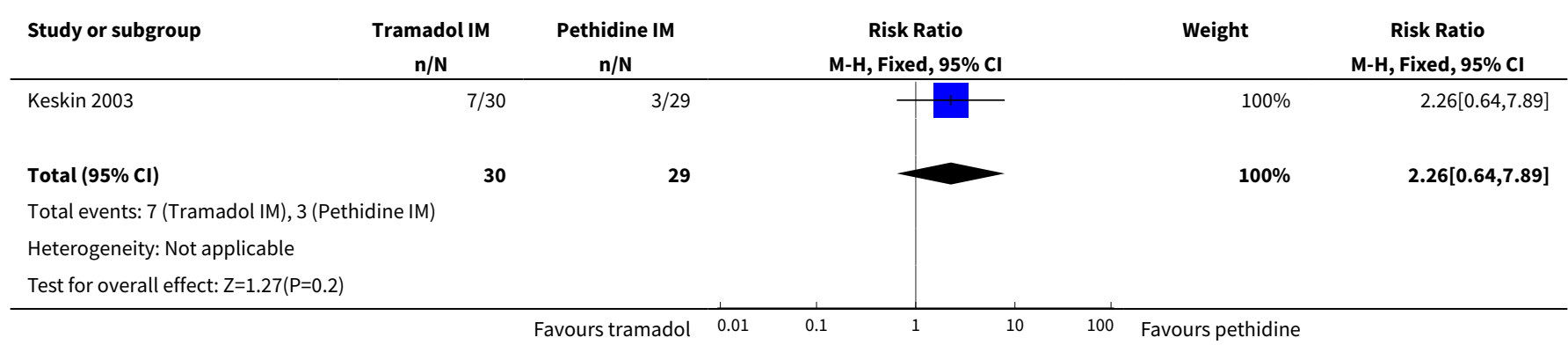

Comparison 7. IM tramadol + triflupromazine versus pethidine + triflupromazine

\begin{tabular}{lllll}
\hline Outcome or subgroup title & No. of studies & $\begin{array}{l}\text { No. of partici- } \\
\text { pants }\end{array}$ & Statistical method & Effect size \\
\hline $\begin{array}{l}1 \text { Maternal sleepiness in } \\
\text { labour }\end{array}$ & 1 & 40 & Risk Ratio (M-H, Fixed, 95\% Cl) & $2.86[0.68,12.12]$ \\
\hline $\begin{array}{l}2 \text { Nausea and vomiting in } \\
\text { labour }\end{array}$ & 1 & Risk Ratio (M-H, Fixed, 95\% Cl) & Subtotals only \\
\hline $\begin{array}{l}2.1 \text { Nausea } \\
2.2 \text { Vomiting }\end{array}$ & 1 & Risk Ratio (M-H, Fixed, 95\% Cl) & $0.82[0.13,5.25]$ \\
\hline & 1 & 40 & Risk Ratio (M-H, Fixed, 95\% Cl) & $0.40[0.02,9.35]$ \\
\hline
\end{tabular}

Analysis 7.1. Comparison 7 IM tramadol + triflupromazine versus pethidine + triflupromazine, Outcome 1 Maternal sleepiness in labour.

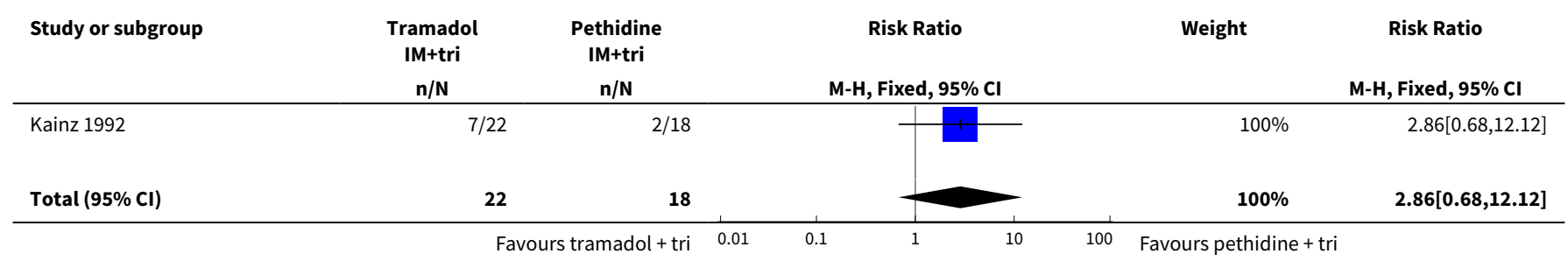




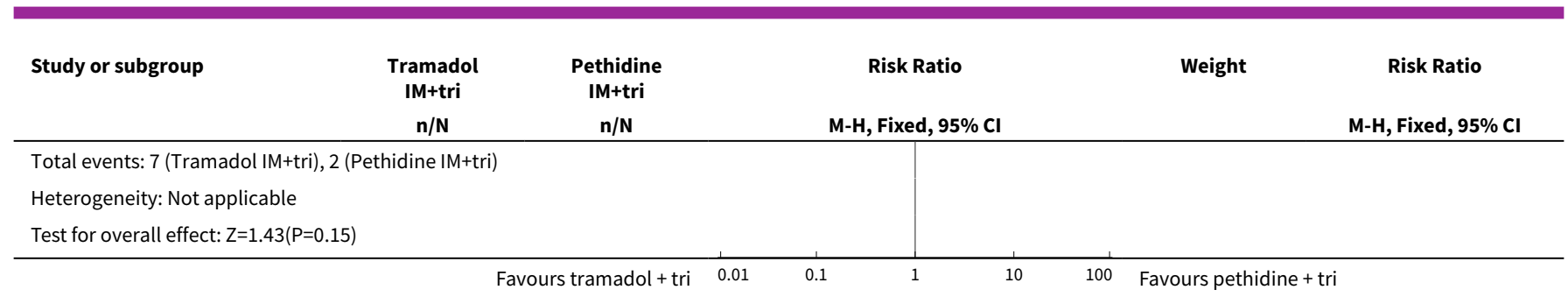

Analysis 7.2. Comparison $7 \mathrm{IM}$ tramadol + triflupromazine versus pethidine + triflupromazine, Outcome 2 Nausea and vomiting in labour.

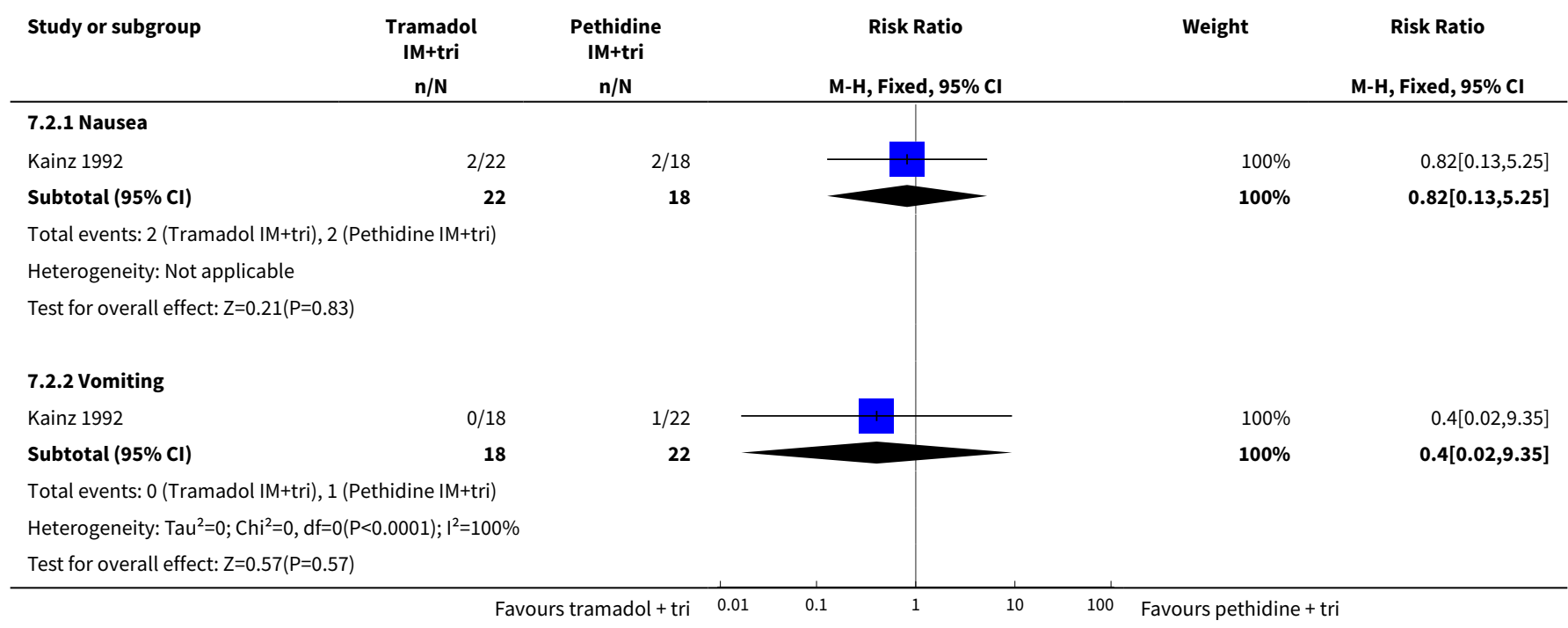

\section{Comparison 8. IM dihydrocodeine $50 \mathrm{mg}$ versus pethidine $100 \mathrm{mg}$}

\begin{tabular}{|c|c|c|c|c|}
\hline Outcome or subgroup title & No. of studies & $\begin{array}{l}\text { No. of partici- } \\
\text { pants }\end{array}$ & Statistical method & Effect size \\
\hline $\begin{array}{l}1 \text { Maternal pain score or pain mea- } \\
\text { sured in labour (Maternal pain relief } \\
\text { poor at } 1 \text { hour) }\end{array}$ & 1 & 138 & $\begin{array}{l}\text { Risk Ratio (M-H, Fixed, 95\% } \\
\mathrm{Cl} \text { ) }\end{array}$ & $1.09[0.64,1.86]$ \\
\hline 2 Maternal sleepiness in labour & 1 & 138 & $\begin{array}{l}\text { Risk Ratio (M-H, Fixed, 95\% } \\
\mathrm{Cl} \text { ) }\end{array}$ & $0.67[0.43,1.04]$ \\
\hline 3 Nausea and vomiting in labour & 1 & 138 & $\begin{array}{l}\text { Risk Ratio (M-H, Fixed, 95\% } \\
\mathrm{Cl} \text { ) }\end{array}$ & $0.87[0.40,1.88]$ \\
\hline 4 Apgar $\leq 7$ at 1 minute & 1 & 138 & $\begin{array}{l}\text { Risk Ratio (M-H, Fixed, 95\% } \\
\text { Cl) }\end{array}$ & $0.57[0.39,0.84]$ \\
\hline
\end{tabular}


Analysis 8.1. Comparison $8 \mathrm{IM}$ dihydrocodeine $50 \mathrm{mg}$ versus pethidine $\mathbf{1 0 0} \mathrm{mg}$, Outcome 1 Maternal pain score or pain measured in labour (Maternal pain relief poor at 1 hour).

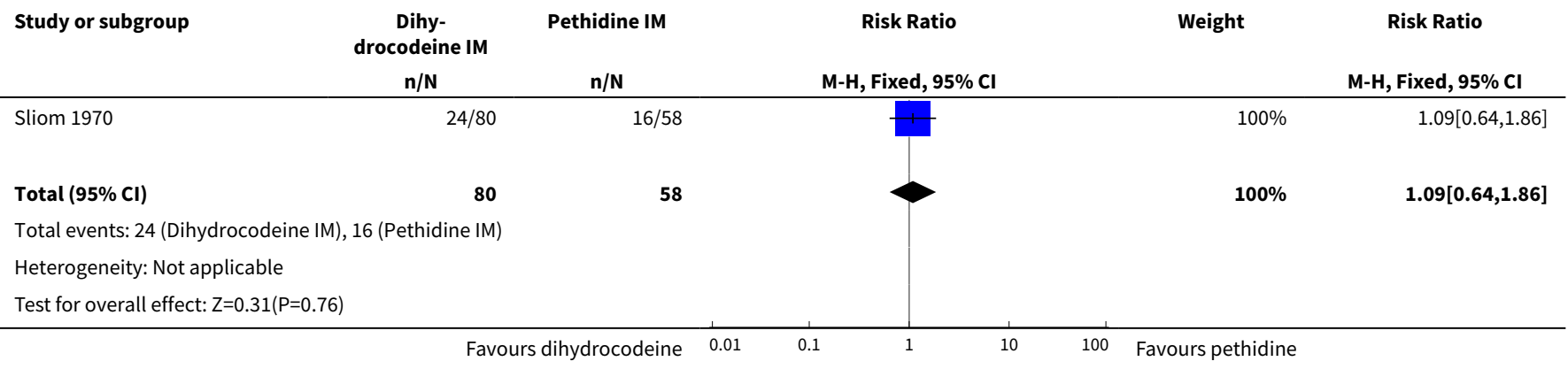

Analysis 8.2. Comparison $8 \mathrm{IM}$ dihydrocodeine $\mathbf{5 0} \mathrm{mg}$ versus pethidine $100 \mathrm{mg}$, Outcome 2 Maternal sleepiness in labour.

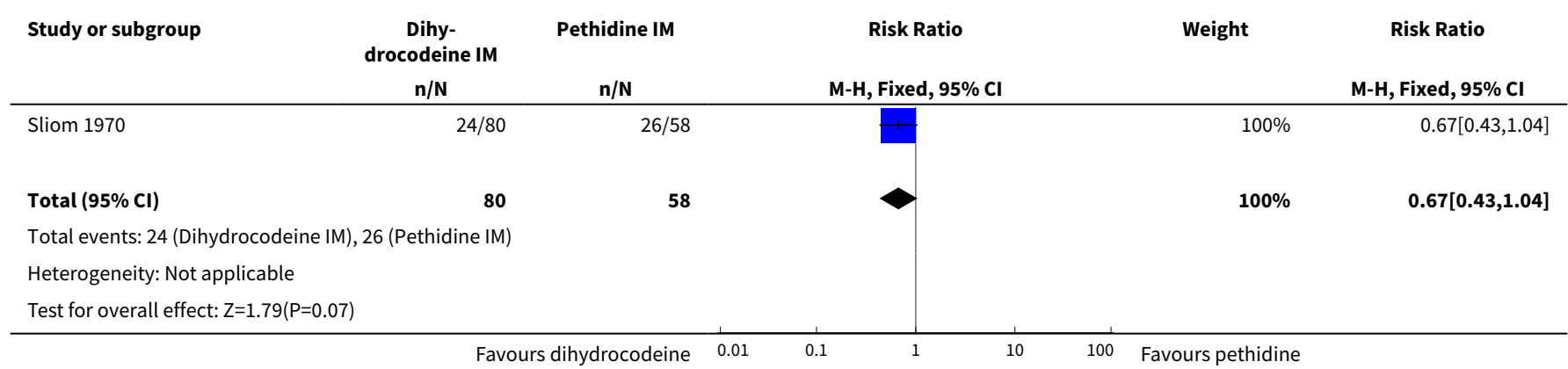

Analysis 8.3. Comparison $8 \mathrm{IM}$ dihydrocodeine $50 \mathrm{mg}$ versus pethidine $100 \mathrm{mg}$, Outcome 3 Nausea and vomiting in labour.

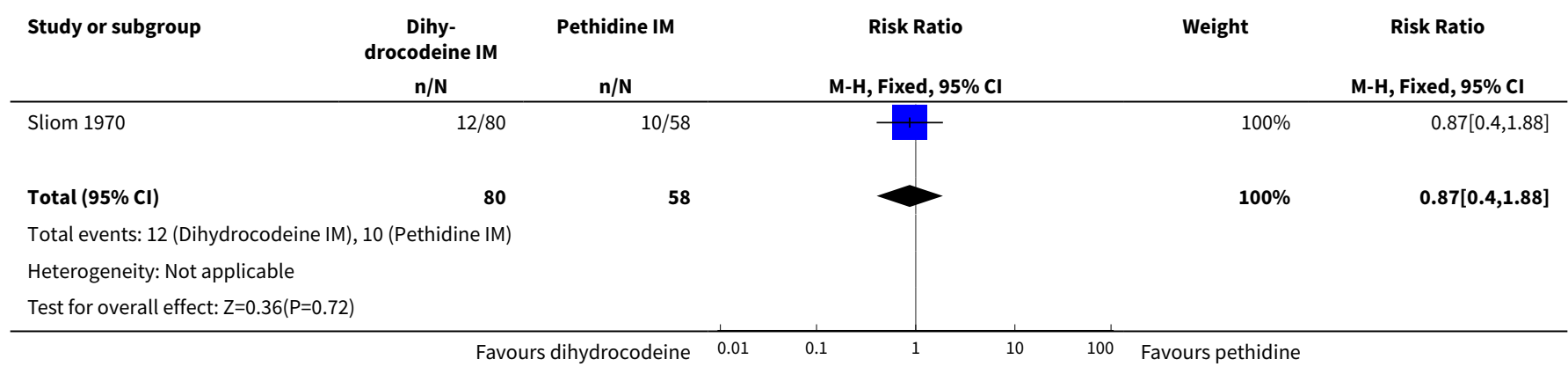

Analysis 8.4. Comparison $8 \mathrm{IM}$ dihydrocodeine $50 \mathrm{mg}$ versus pethidine $100 \mathrm{mg}$, Outcome 4 Apgar $\leq 7$ at $1 \mathrm{minute}$.

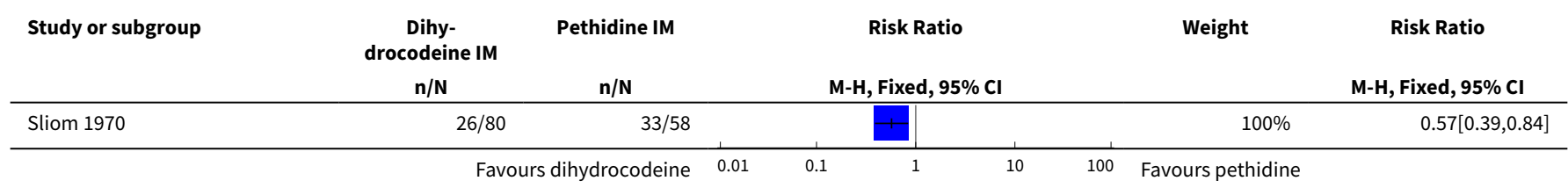




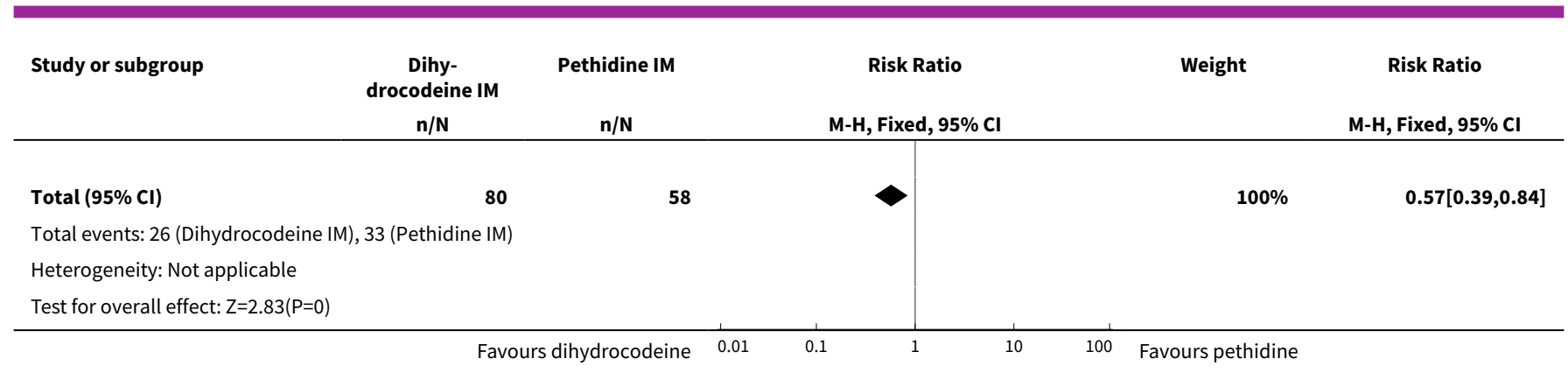

\section{Comparison 9. IM pentazocine versus pethidine}

\begin{tabular}{|c|c|c|c|c|}
\hline Outcome or subgroup title & No. of studies & $\begin{array}{l}\text { No. of partici- } \\
\text { pants }\end{array}$ & Statistical method & Effect size \\
\hline $\begin{array}{l}1 \text { Maternal satisfaction with } \\
\text { analgesia measured during } \\
\text { labour (Pain relief (good or } \\
\text { very good) at delivery) }\end{array}$ & 2 & 253 & Risk Ratio (M-H, Fixed, 95\% Cl) & $1.08[0.92,1.27]$ \\
\hline $\begin{array}{l}2 \text { Maternal pain score or pain } \\
\text { measured in labour (Pain relief } \\
\text { poor (partial, none or worse)) }\end{array}$ & 4 & & Risk Ratio (M-H, Random, 95\% Cl) & Subtotals only \\
\hline 2.1 No add-on drugs & 3 & 365 & Risk Ratio (M-H, Random, 95\% Cl) & $1.23[0.74,2.05]$ \\
\hline 2.2 With promazine & 1 & 85 & Risk Ratio (M-H, Random, 95\% Cl) & $1.53[0.66,3.58]$ \\
\hline $\begin{array}{l}3 \text { Additional analgesia re- } \\
\text { quired }\end{array}$ & 2 & & Risk Ratio (M-H, Fixed, 95\% Cl) & Subtotals only \\
\hline 3.1 Pentazocine & 1 & 94 & Risk Ratio (M-H, Fixed, 95\% Cl) & $0.91[0.50,1.65]$ \\
\hline 3.2 Pentazocine + promazine & 1 & 85 & Risk Ratio (M-H, Fixed, 95\% Cl) & $1.67[0.73,3.84]$ \\
\hline 4 Maternal sleepiness in labour & 3 & 391 & Risk Ratio (M-H, Fixed, 95\% Cl) & $1.00[0.89,1.12]$ \\
\hline $\begin{array}{l}5 \text { Nausea and vomiting in } \\
\text { labour }\end{array}$ & 3 & & Risk Ratio (M-H, Fixed, 95\% Cl) & Subtotals only \\
\hline 5.1 Nausea & 3 & 391 & Risk Ratio (M-H, Fixed, 95\% Cl) & $0.46[0.24,0.90]$ \\
\hline 5.2 Vomiting & 1 & 73 & Risk Ratio (M-H, Fixed, 95\% Cl) & $0.92[0.27,3.14]$ \\
\hline 6 Assisted vaginal birth & 2 & & Risk Ratio (M-H, Fixed, 95\% Cl) & Subtotals only \\
\hline 6.1 No add-on drugs & 1 & 94 & Risk Ratio (M-H, Fixed, 95\% CI) & $5.22[0.63,42.97]$ \\
\hline 6.2 With promazine & 1 & 85 & Risk Ratio $(\mathrm{M}-\mathrm{H}$, Fixed, 95\% Cl) & $0.78[0.23,2.71]$ \\
\hline 7 Naloxone administration & 1 & 85 & Risk Ratio (M-H, Fixed, 95\% Cl) & $0.49[0.09,2.53]$ \\
\hline 7.1 With promazine & 1 & 85 & Risk Ratio (M-H, Fixed, 95\% Cl) & $0.49[0.09,2.53]$ \\
\hline 8 Apgar score $\leq 7$ at 1 minute & 3 & & Risk Ratio (M-H, Random, 95\% Cl) & Subtotals only \\
\hline
\end{tabular}

Parenteral opioids for maternal pain management in labour (Review) 


\begin{tabular}{llllll}
\hline Outcome or subgroup title & No. of studies & $\begin{array}{l}\text { No. of partici- } \\
\text { pants }\end{array}$ & Statistical method & Effect size \\
\hline 8.1 No add-on drugs & 2 & 242 & Risk Ratio (M-H, Random, 95\% Cl) & $1.39[0.06,32.97]$ \\
\hline 8.2 With promazine & 1 & 66 & Risk Ratio (M-H, Random, 95\% Cl) & $1.13[0.07,17.30]$ \\
\hline 9 Apgar score 7 at 5 minutes & 2 & & Risk Ratio (M-H, Fixed, 95\% Cl) & Subtotals only \\
\hline 9.1 No add-on drugs & 1 & 62 & Risk Ratio (M-H, Fixed, 95\% Cl) & $0.23[0.01,4.54]$ \\
\hline 9.2 With promazine & 1 & 66 & Risk Ratio (M-H, Fixed, 95\% Cl) & $0.38[0.02,8.88]$ \\
\hline
\end{tabular}

\section{Analysis 9.1. Comparison $9 \mathrm{IM}$ pentazocine versus pethidine, Outcome 1 Maternal satisfaction with analgesia measured during labour (Pain relief (good or very good) at delivery).}

\begin{tabular}{|c|c|c|c|c|c|}
\hline Study or subgroup & $\begin{array}{c}\text { Pentazocine IM } \\
\mathbf{n} / \mathbf{N}\end{array}$ & $\begin{array}{l}\text { Pethidine IM } \\
\mathrm{n} / \mathrm{N} \\
\end{array}$ & $\begin{array}{c}\text { Risk Ratio } \\
\text { M-H, Fixed, 95\% Cl }\end{array}$ & Weight & $\begin{array}{c}\text { Risk Ratio } \\
\text { M-H, Fixed, 95\% Cl }\end{array}$ \\
\hline Borglin 1971 & $74 / 91$ & $65 / 89$ & & $81.51 \%$ & $1.11[0.95,1.31]$ \\
\hline Mowat 1970 & $13 / 34$ & $16 / 39$ & $\rightarrow$ & $18.49 \%$ & $0.93[0.53,1.65]$ \\
\hline Total $(95 \% \mathrm{Cl})$ & 125 & 128 & & $100 \%$ & $1.08[0.92,1.27]$ \\
\hline \multicolumn{6}{|c|}{ Total events: 87 (Pentazocine IM), 81 (Pethidine IM) } \\
\hline \multicolumn{6}{|c|}{ Test for overall effect: $Z=0.91(P=0.36)$} \\
\hline
\end{tabular}

Analysis 9.2. Comparison $9 \mathrm{IM}$ pentazocine versus pethidine, Outcome 2 Maternal pain score or pain measured in labour (Pain relief poor (partial, none or worse)).

\begin{tabular}{|c|c|c|c|c|c|}
\hline Study or subgroup & $\begin{array}{c}\text { Pentazocine IM } \\
n / N\end{array}$ & $\begin{array}{l}\text { Pethidine IM } \\
n / \mathbf{N}\end{array}$ & $\begin{array}{c}\text { Risk Ratio } \\
\text { M-H, Random, 95\% Cl }\end{array}$ & Weight & $\begin{array}{c}\text { Risk Ratio } \\
\text { M-H, Random, } 95 \% \mathrm{Cl}\end{array}$ \\
\hline \multicolumn{6}{|c|}{ 9.2.1 No add-on drugs } \\
\hline Duncan 1969 & $77 / 83$ & $73 / 77$ & $\boldsymbol{\Phi}$ & $42.62 \%$ & $0.98[0.9,1.06]$ \\
\hline Levy 1971 & $14 / 38$ & $9 / 45$ & $\div$ & $23.21 \%$ & $1.84[0.9,3.77]$ \\
\hline Moore 1970 & $33 / 65$ & $23 / 57$ & & $34.16 \%$ & $1.26[0.85,1.87]$ \\
\hline Subtotal $(95 \% \mathrm{Cl})$ & 186 & 179 & & $100 \%$ & $1.23[0.74,2.05]$ \\
\hline \multicolumn{6}{|c|}{ Heterogeneity: $\operatorname{Tau}^{2}=0.16 ; \mathrm{Chi}^{2}=11.59, \mathrm{df}=2(\mathrm{P}=0) ; \mathrm{I}^{2}=82.75 \%$} \\
\hline \multicolumn{6}{|c|}{ Test for overall effect: $Z=0.81(P=0.42)$} \\
\hline \multicolumn{6}{|c|}{ 9.2.2 With promazine } \\
\hline Refstad 1980 & $11 / 43$ & $7 / 42$ & & $100 \%$ & $1.53[0.66,3.58]$ \\
\hline Subtotal $(95 \% \mathrm{CI})$ & 43 & 42 & & $100 \%$ & $1.53[0.66,3.58]$ \\
\hline \multicolumn{6}{|c|}{ Heterogeneity: Not applicable } \\
\hline Test for overall effect & & & & & \\
\hline
\end{tabular}


Analysis 9.3. Comparison $9 \mathrm{IM}$ pentazocine versus pethidine, Outcome 3 Additional analgesia required.

\begin{tabular}{|c|c|c|c|c|c|}
\hline Study or subgroup & $\begin{array}{c}\text { Pentazocine IM } \\
\text { n/N }\end{array}$ & $\begin{array}{c}\text { Pethidine IM } \\
\mathrm{n} / \mathrm{N} \\
\end{array}$ & $\begin{array}{c}\text { Risk Ratio } \\
\text { M-H, Fixed, 95\% CI }\end{array}$ & Weight & $\begin{array}{c}\text { Risk Ratio } \\
\text { M-H, Fixed, 95\% Cl }\end{array}$ \\
\hline \multicolumn{6}{|l|}{ 9.3.1 Pentazocine } \\
\hline Subtotal $(95 \% \mathrm{Cl})$ & 46 & 48 & & $100 \%$ & $0.91[0.5,1.65]$ \\
\hline \multicolumn{6}{|c|}{ Total events: 14 (Pentazocine IM), 16 (Pethidine IM) } \\
\hline \multicolumn{6}{|c|}{ Heterogeneity: Not applicable } \\
\hline \multicolumn{6}{|c|}{ Test for overall effect: $Z=0.3(P=0.76)$} \\
\hline \multicolumn{6}{|c|}{ 9.3.2 Pentazocine + promazine } \\
\hline Refstad 1980 & $12 / 43$ & $7 / 42$ & & $100 \%$ & $1.67[0.73,3.84]$ \\
\hline Subtotal $(95 \% \mathrm{Cl})$ & 43 & 42 & & $100 \%$ & $1.67[0.73,3.84]$ \\
\hline \multicolumn{6}{|c|}{ Total events: 12 (Pentazocine IM), 7 (Pethidine IM) } \\
\hline \multicolumn{6}{|c|}{ Heterogeneity: Not applicable } \\
\hline
\end{tabular}

Analysis 9.4. Comparison $9 \mathrm{IM}$ pentazocine versus pethidine, Outcome 4 Maternal sleepiness in labour.

\begin{tabular}{|c|c|c|c|c|c|}
\hline Study or subgroup & $\begin{array}{c}\text { Pentazocine IM } \\
\mathrm{n} / \mathrm{N}\end{array}$ & $\begin{array}{c}\text { Pethidine IM } \\
\mathrm{n} / \mathrm{N} \\
\end{array}$ & $\begin{array}{c}\text { Risk Ratio } \\
\text { M-H, Fixed, 95\% Cl }\end{array}$ & Weight & $\begin{array}{c}\text { Risk Ratio } \\
\text { M-H, Fixed, 95\% Cl }\end{array}$ \\
\hline Borglin 1971 & $82 / 91$ & $80 / 89$ & - & $62.74 \%$ & $1[0.91,1.11]$ \\
\hline Moore 1970 & $21 / 73$ & $19 / 65$ & $\rightarrow$ & $15.59 \%$ & $0.98[0.58,1.66]$ \\
\hline Mowat 1970 & $26 / 34$ & $30 / 39$ & $\rightarrow$ & $21.67 \%$ & $0.99[0.77,1.28]$ \\
\hline Total $(95 \% \mathrm{Cl})$ & 198 & 193 & 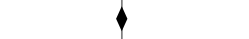 & $100 \%$ & $1[0.89,1.12]$ \\
\hline \multicolumn{6}{|c|}{ Heterogeneity: $\mathrm{Tau}^{2}=0 ; \mathrm{Chi}^{2}=0.01, \mathrm{df}=2(\mathrm{P}=0.99) ; \mathrm{I}^{2}=0 \%$} \\
\hline Test for overall effect & & & & & \\
\hline
\end{tabular}

Analysis 9.5. Comparison $9 \mathrm{IM}$ pentazocine versus pethidine, Outcome 5 Nausea and vomiting in labour.

\begin{tabular}{|c|c|c|c|c|c|}
\hline Study or subgroup & $\begin{array}{c}\text { Pentazocine IM } \\
n / N\end{array}$ & $\begin{array}{c}\text { Pethidine IM } \\
n / N\end{array}$ & $\begin{array}{c}\text { Risk Ratio } \\
\text { M-H, Fixed, 95\% Cl }\end{array}$ & Weight & $\begin{array}{c}\text { Risk Ratio } \\
\text { M-H, Fixed, } 95 \% \mathrm{Cl}\end{array}$ \\
\hline \multicolumn{6}{|l|}{ 9.5.1 Nausea } \\
\hline Borglin 1971 & $1 / 91$ & $1 / 89$ & & $4.32 \%$ & $0.98[0.06,15.4]$ \\
\hline Moore 1970 & $7 / 73$ & $15 / 65$ & & $67.82 \%$ & $0.42[0.18,0.96]$ \\
\hline Mowat 1970 & $3 / 34$ & $7 / 39$ & - & $27.86 \%$ & $0.49[0.14,1.75]$ \\
\hline Subtotal $(95 \% \mathrm{Cl})$ & 198 & 193 & & $100 \%$ & $0.46[0.24,0.9]$ \\
\hline \multicolumn{6}{|c|}{ Heterogeneity: $\operatorname{Tau}^{2}=0 ; \mathrm{Chi}^{2}=0.36, \mathrm{df}=2(\mathrm{P}=0.84) ;\left.\right|^{2}=0 \%$} \\
\hline \multicolumn{6}{|c|}{ Test for overall effect: $Z=2.26(P=0.02)$} \\
\hline \multicolumn{6}{|l|}{ 9.5.2 Vomiting } \\
\hline Mowat 1970 & $4 / 34$ & $5 / 39$ & 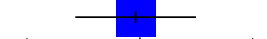 & $100 \%$ & $0.92[0.27,3.14]$ \\
\hline
\end{tabular}




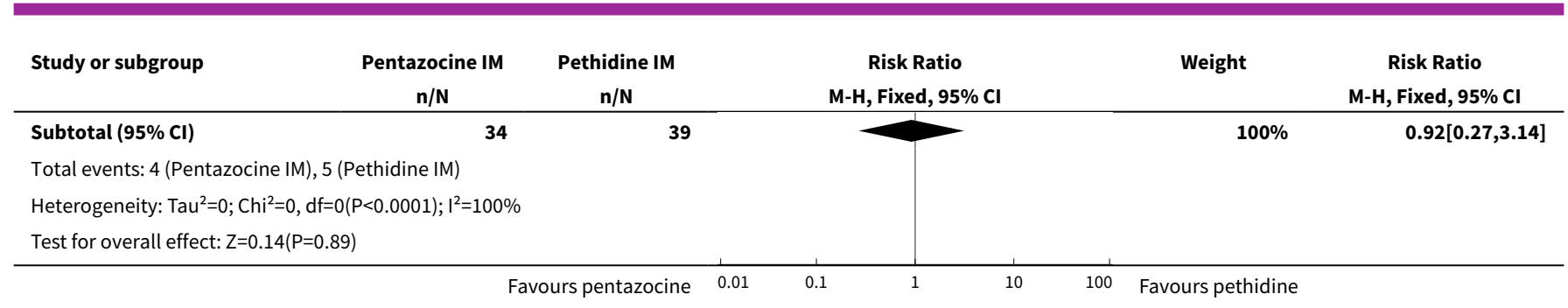

Analysis 9.6. Comparison 9 IM pentazocine versus pethidine, Outcome 6 Assisted vaginal birth.

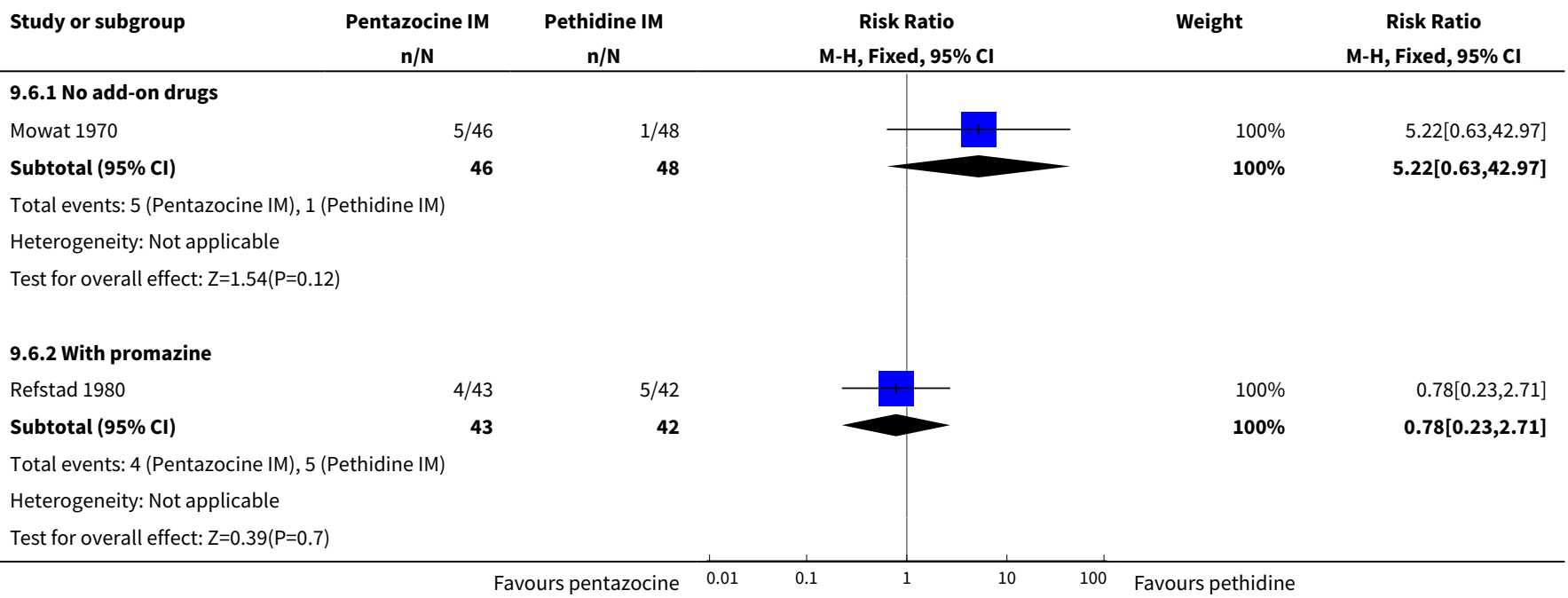

\section{Analysis 9.7. Comparison 9 IM pentazocine versus pethidine, Outcome 7 Naloxone administration.}

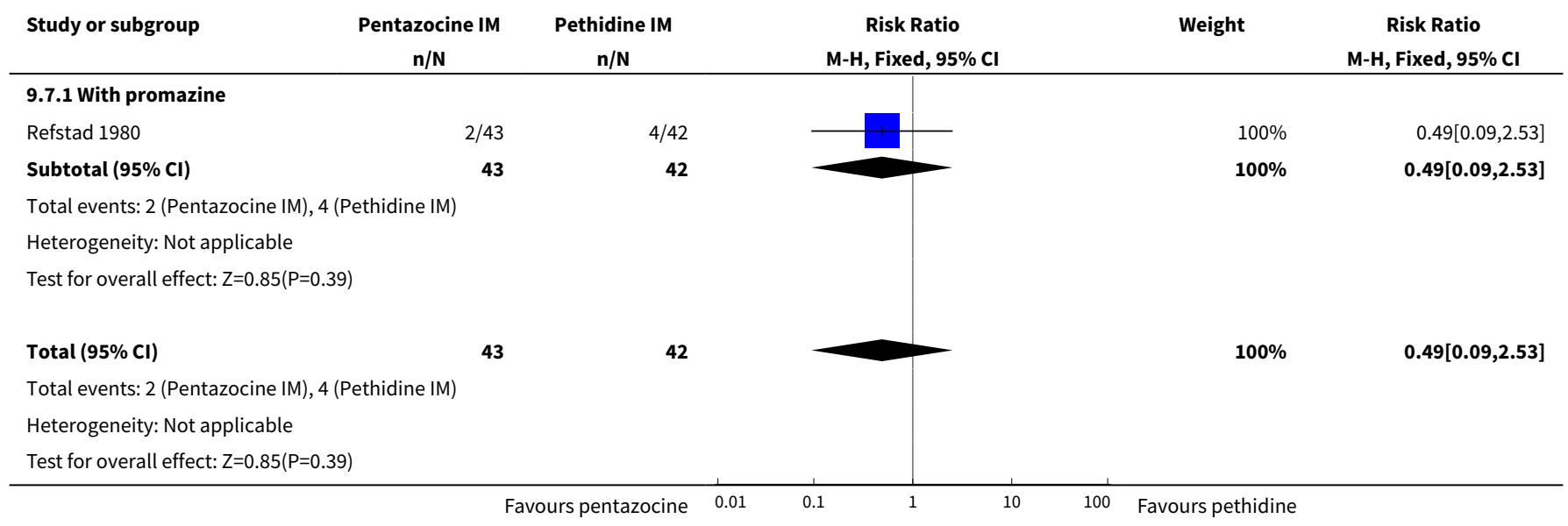


Analysis 9.8. Comparison 9 IM pentazocine versus pethidine, Outcome 8 Apgar score $\leq 7$ at 1 minute.

\begin{tabular}{|c|c|c|c|c|c|}
\hline Study or subgroup & $\begin{array}{c}\text { Pentazocine IM } \\
\mathrm{n} / \mathrm{N}\end{array}$ & $\begin{array}{c}\text { Pethidine IM } \\
n / N\end{array}$ & $\begin{array}{c}\text { Risk Ratio } \\
\text { M-H, Random, } 95 \% \text { CI }\end{array}$ & Weight & $\begin{array}{c}\text { Risk Ratio } \\
\text { M-H, Random, } 95 \% \text { Cl }\end{array}$ \\
\hline \multicolumn{6}{|c|}{ 9.8.1 No add-on drugs } \\
\hline Borglin 1971 & $6 / 91$ & $1 / 89$ & 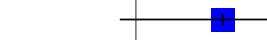 & $55.63 \%$ & $5.87[0.72,47.76]$ \\
\hline Levy 1971 & $0 / 29$ & $2 / 33$ & & $44.37 \%$ & $0.23[0.01,4.54]$ \\
\hline Subtotal $(95 \% \mathrm{CI})$ & 120 & 122 & & $100 \%$ & $1.39[0.06,32.97]$ \\
\hline \multicolumn{6}{|c|}{ Total events: 6 (Pentazocine IM), 3 (Pethidine IM) } \\
\hline \multicolumn{6}{|c|}{ Test for overall effect: $Z=0.2(P=0.84)$} \\
\hline \multicolumn{6}{|c|}{ 9.8.2 With promazine } \\
\hline Refstad 1980 & $1 / 31$ & $1 / 35$ & & $100 \%$ & $1.13[0.07,17.3]$ \\
\hline Subtotal $(95 \% \mathrm{Cl})$ & 31 & 35 & & $100 \%$ & $1.13[0.07,17.3]$ \\
\hline \multicolumn{6}{|c|}{ Total events: 1 (Pentazocine IM), 1 (Pethidine IM) } \\
\hline Test for overall effect & & & & & \\
\hline
\end{tabular}

Analysis 9.9. Comparison $9 \mathrm{IM}$ pentazocine versus pethidine, Outcome 9 Apgar score $\leq 7$ at 5 minutes.

\begin{tabular}{|c|c|c|c|c|c|}
\hline Study or subgroup & $\begin{array}{c}\text { Pentazocine IM } \\
\mathrm{n} / \mathrm{N}\end{array}$ & $\begin{array}{c}\text { Pethidine IM } \\
n / N\end{array}$ & $\begin{array}{c}\text { Risk Ratio } \\
\text { M-H, Fixed, } 95 \% \mathrm{CI}\end{array}$ & Weight & $\begin{array}{c}\text { Risk Ratio } \\
\text { M-H, Fixed, } 95 \% \mathrm{Cl}\end{array}$ \\
\hline \multicolumn{6}{|c|}{ 9.9.1 No add-on drugs } \\
\hline Levy 1971 & $0 / 29$ & $2 / 33$ & & $100 \%$ & $0.23[0.01,4.54]$ \\
\hline Subtotal (95\% CI) & 29 & 33 & & $100 \%$ & $0.23[0.01,4.54]$ \\
\hline \multicolumn{6}{|c|}{ Total events: 0 (Pentazocine IM), 2 (Pethidine IM) } \\
\hline \multicolumn{6}{|c|}{ Heterogeneity: Not applicable } \\
\hline \multicolumn{6}{|c|}{ 9.9.2 With promazine } \\
\hline Refstad 1980 & $0 / 31$ & $1 / 35$ & & $100 \%$ & $0.38[0.02,8.88]$ \\
\hline Subtotal $(95 \% \mathrm{Cl})$ & 31 & 35 & & $100 \%$ & $0.38[0.02,8.88]$ \\
\hline \multicolumn{6}{|c|}{ Total events: 0 (Pentazocine IM), 1 (Pethidine IM) } \\
\hline \multicolumn{6}{|c|}{ Heterogeneity: Not applicable } \\
\hline
\end{tabular}

\section{Comparison 10. IM nalbuphine versus pethidine}

\begin{tabular}{lllll}
\hline Outcome or subgroup title & No. of studies & $\begin{array}{l}\text { No. of partici- } \\
\text { pants }\end{array}$ & Statistical method & Effect size \\
\hline $\begin{array}{l}1 \text { Maternal satisfaction with analge- } \\
\text { sia measured during the postnatal } \\
\text { period (numbers dissatisfied) }\end{array}$ & 1 & 72 & $\begin{array}{l}\text { Risk Ratio (M-H, Fixed, 95\% } \\
\mathrm{Cl})\end{array}$ & $0.73[0.55,0.96]$ \\
\hline $\begin{array}{l}2 \text { Maternal satisfaction with analge- } \\
\text { sia measured during labour (Pain } \\
\text { free) }\end{array}$ & 1 & 40 & Risk Ratio (M-H, Fixed, 95\% & $6.0[0.79,45.42]$ \\
\hline \hline
\end{tabular}




\begin{tabular}{|c|c|c|c|c|}
\hline Outcome or subgroup title & No. of studies & $\begin{array}{l}\text { No. of partici- } \\
\text { pants }\end{array}$ & Statistical method & Effect size \\
\hline $\begin{array}{l}3 \text { Maternal pain score or pain mea- } \\
\text { sured in labour (Pain intensity at } 30 \\
\text { minutes: women with severe pain) }\end{array}$ & 1 & 295 & $\begin{array}{l}\text { Risk Ratio (M-H, Fixed, 95\% } \\
\mathrm{Cl})\end{array}$ & $0.86[0.59,1.26]$ \\
\hline $\begin{array}{l}4 \text { Maternal pain score or pain mea- } \\
\text { sured in labour (VAS at } 60 \text { minutes } \\
\text { (at peak of contraction)) }\end{array}$ & 1 & 72 & $\begin{array}{l}\text { Mean Difference (IV, Fixed, } \\
95 \% \mathrm{CI})\end{array}$ & $-8.0[-18.55,2.55]$ \\
\hline 5 Additional analgesia required & 1 & 72 & $\begin{array}{l}\text { Risk Ratio (M-H, Fixed, 95\% } \\
\mathrm{Cl})\end{array}$ & $1.26[0.49,3.27]$ \\
\hline 6 Epidural & 1 & 307 & $\begin{array}{l}\text { Risk Ratio (M-H, Fixed, 95\% } \\
\mathrm{Cl})\end{array}$ & $1.65[0.55,4.94]$ \\
\hline 7 Maternal sleepiness in labour & 1 & 72 & $\begin{array}{l}\text { Risk Ratio (M-H, Fixed, 95\% } \\
\mathrm{CI})\end{array}$ & $3.78[0.86,16.60]$ \\
\hline 8 Nausea and vomiting in labour & 2 & & $\begin{array}{l}\text { Risk Ratio (M-H, Fixed, 95\% } \\
\mathrm{CI})\end{array}$ & Subtotals only \\
\hline 8.1 Nausea & 1 & 301 & $\begin{array}{l}\text { Risk Ratio (M-H, Fixed, 95\% } \\
\mathrm{Cl})\end{array}$ & $0.62[0.42,0.91]$ \\
\hline 8.2 Vomiting & 1 & 301 & $\begin{array}{l}\text { Risk Ratio (M-H, Fixed, 95\% } \\
\mathrm{Cl})\end{array}$ & $0.41[0.22,0.76]$ \\
\hline 8.3 Nausea and vomiting & 1 & 72 & $\begin{array}{l}\text { Risk Ratio (M-H, Fixed, 95\% } \\
\mathrm{Cl})\end{array}$ & $0.41[0.18,0.94]$ \\
\hline 9 Caesarean section & 1 & 310 & $\begin{array}{l}\text { Risk Ratio (M-H, Fixed, 95\% } \\
\mathrm{Cl})\end{array}$ & $0.45[0.12,1.69]$ \\
\hline 10 Assisted vaginal birth & 2 & 382 & $\begin{array}{l}\text { Risk Ratio (M-H, Random, } \\
95 \% \mathrm{Cl} \text { ) }\end{array}$ & $0.98[0.25,3.85]$ \\
\hline 11 Naloxone administration & 1 & 72 & $\begin{array}{l}\text { Risk Ratio (M-H, Fixed, 95\% } \\
\text { Cl) }\end{array}$ & $6.63[0.35,123.93]$ \\
\hline $\begin{array}{l}12 \text { Apgar score } \leq 7 \text { at } 1 \text { and } 5 \text { min- } \\
\text { utes }\end{array}$ & 2 & & $\begin{array}{l}\text { Risk Ratio (M-H, Random, } \\
95 \% \mathrm{Cl} \text { ) }\end{array}$ & Subtotals only \\
\hline 12.1 Low score at 1 minute & 2 & 382 & $\begin{array}{l}\text { Risk Ratio (M-H, Random, } \\
95 \% \mathrm{Cl} \text { ) }\end{array}$ & $1.18[0.72,1.95]$ \\
\hline 12.2 Low score at 5 minutes & 1 & 72 & $\begin{array}{l}\text { Risk Ratio (M-H, Random, } \\
95 \% \mathrm{Cl} \text { ) }\end{array}$ & $0.47[0.04,4.99]$ \\
\hline 13 Admission to NICU & 1 & 299 & $\begin{array}{l}\text { Risk Ratio (M-H, Fixed, 95\% } \\
\mathrm{Cl} \text { ) }\end{array}$ & $1.07[0.61,1.89]$ \\
\hline $\begin{array}{l}14 \text { Neonatal neurobehavioural } \\
\text { (Scanlon) } 2-4 \text { hours PN }\end{array}$ & 1 & 72 & $\begin{array}{l}\text { Mean Difference (IV, Fixed, } \\
95 \% \mathrm{Cl} \text { ) }\end{array}$ & $-3.70[-6.14,-1.26]$ \\
\hline
\end{tabular}


Analysis 10.1. Comparison $10 \mathrm{IM}$ nalbuphine versus pethidine, Outcome 1 Maternal satisfaction with analgesia measured during the postnatal period (numbers dissatisfied).

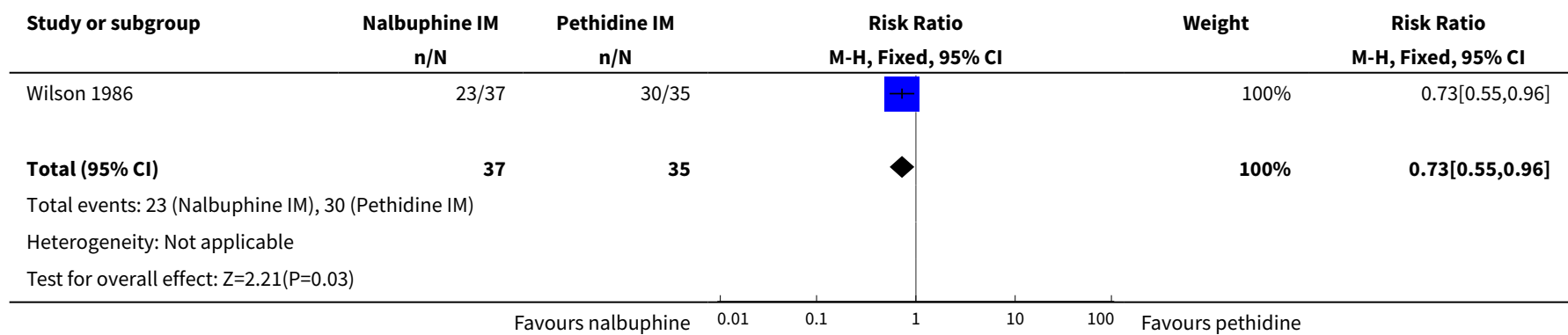

Analysis 10.2. Comparison 10 IM nalbuphine versus pethidine, Outcome 2 Maternal satisfaction with analgesia measured during labour (Pain free).

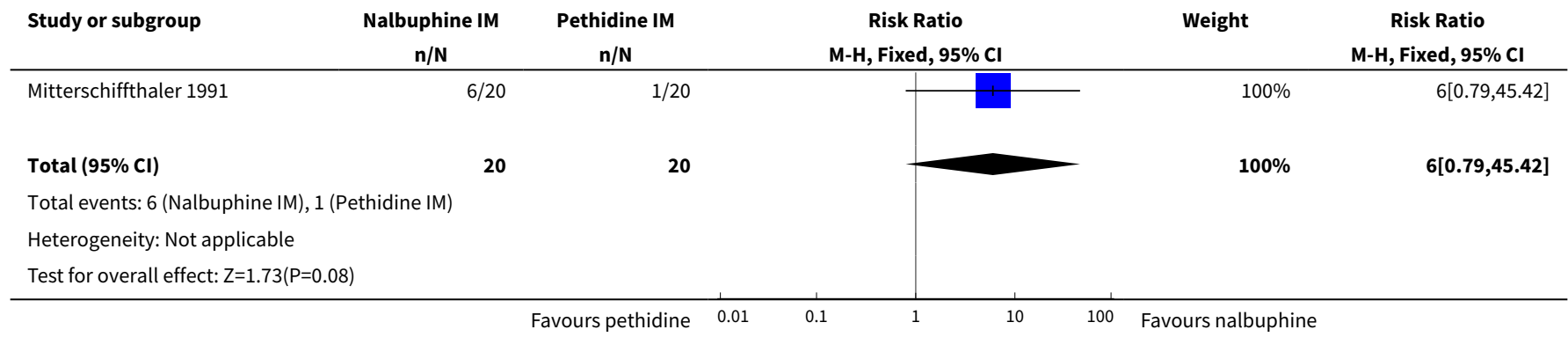

Analysis 10.3. Comparison $10 \mathrm{IM}$ nalbuphine versus pethidine, Outcome 3 Maternal pain score or pain measured in labour (Pain intensity at $\mathbf{3 0}$ minutes: women with severe pain).

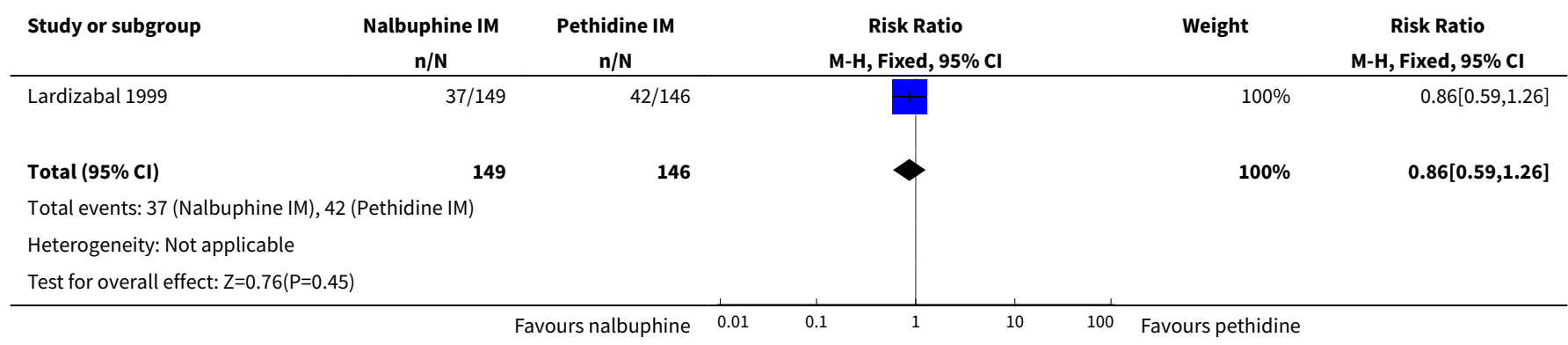

Analysis 10.4. Comparison $10 \mathrm{IM}$ nalbuphine versus pethidine, Outcome 4 Maternal pain score or pain measured in labour (VAS at 60 minutes (at peak of contraction)).

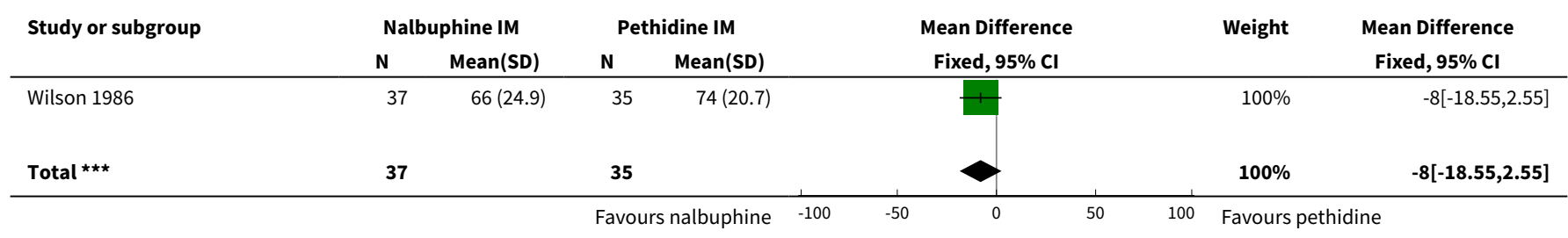




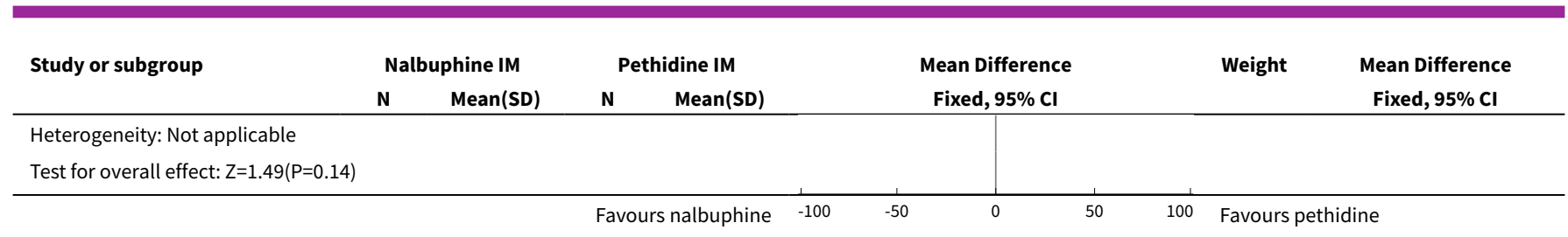

\section{Analysis 10.5. Comparison $10 \mathrm{IM}$ nalbuphine versus pethidine, Outcome 5 Additional analgesia required.}

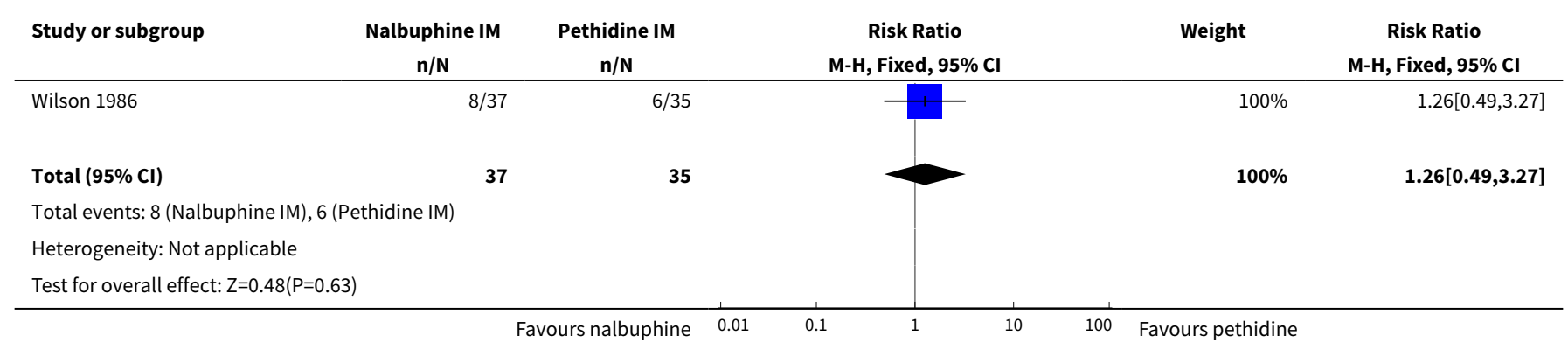

Analysis 10.6. Comparison $10 \mathrm{IM}$ nalbuphine versus pethidine, Outcome 6 Epidural.

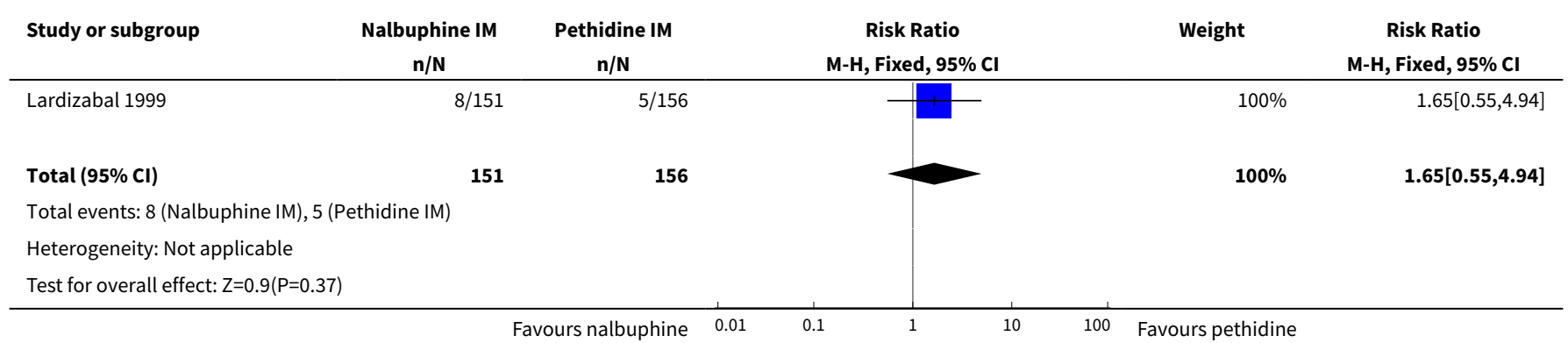

\section{Analysis 10.7. Comparison $10 \mathrm{IM}$ nalbuphine versus pethidine, Outcome 7 Maternal sleepiness in labour.}

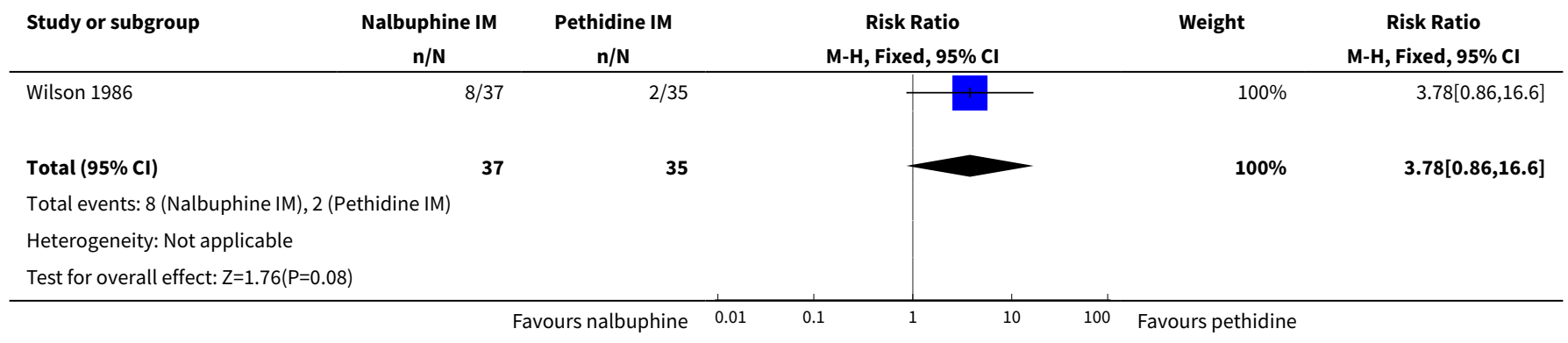


Analysis 10.8. Comparison $10 \mathrm{IM}$ nalbuphine versus pethidine, Outcome 8 Nausea and vomiting in labour.

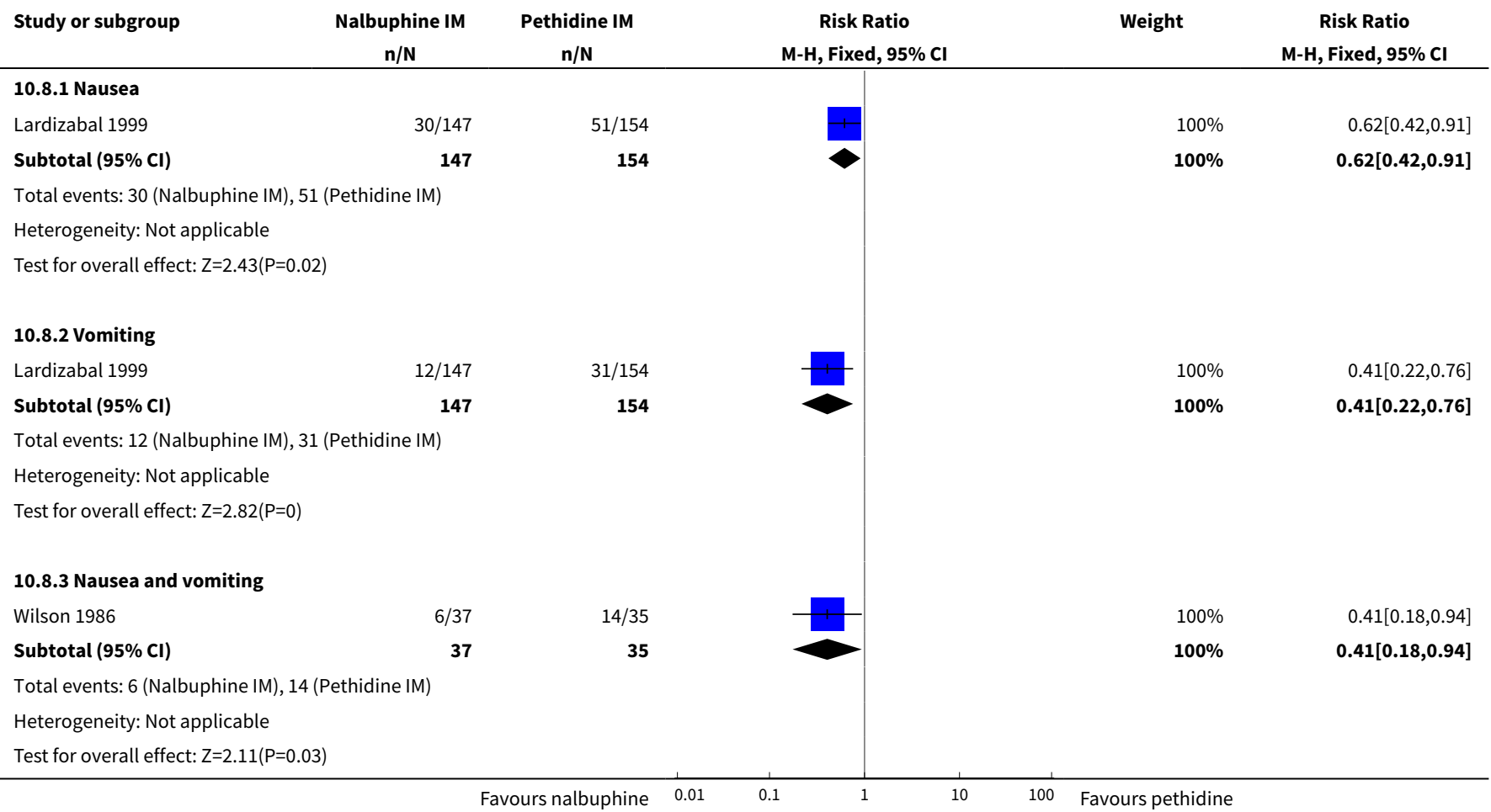

Analysis 10.9. Comparison $10 \mathrm{IM}$ nalbuphine versus pethidine, Outcome 9 Caesarean section.

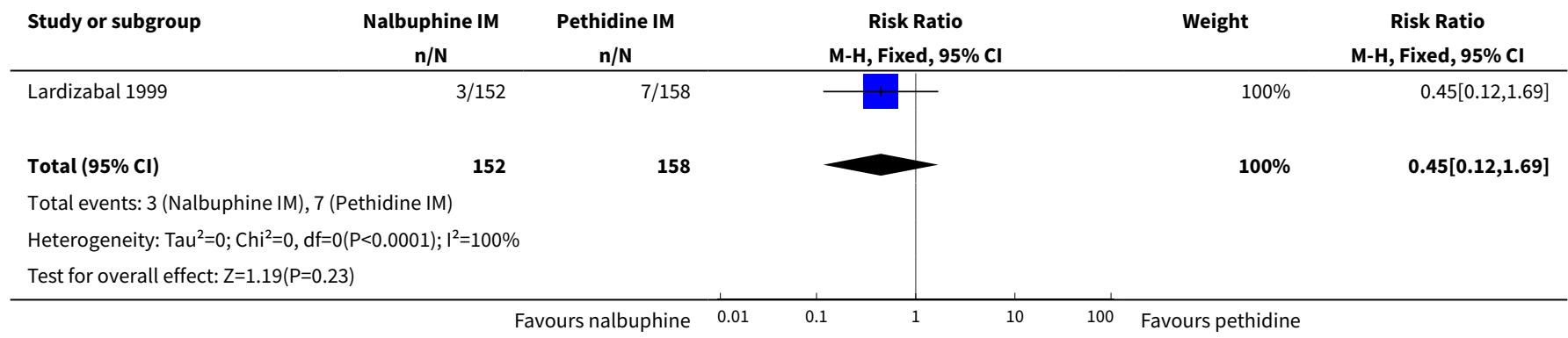

\section{Analysis 10.10. Comparison $10 \mathrm{IM}$ nalbuphine versus pethidine, Outcome 10 Assisted vaginal birth.}

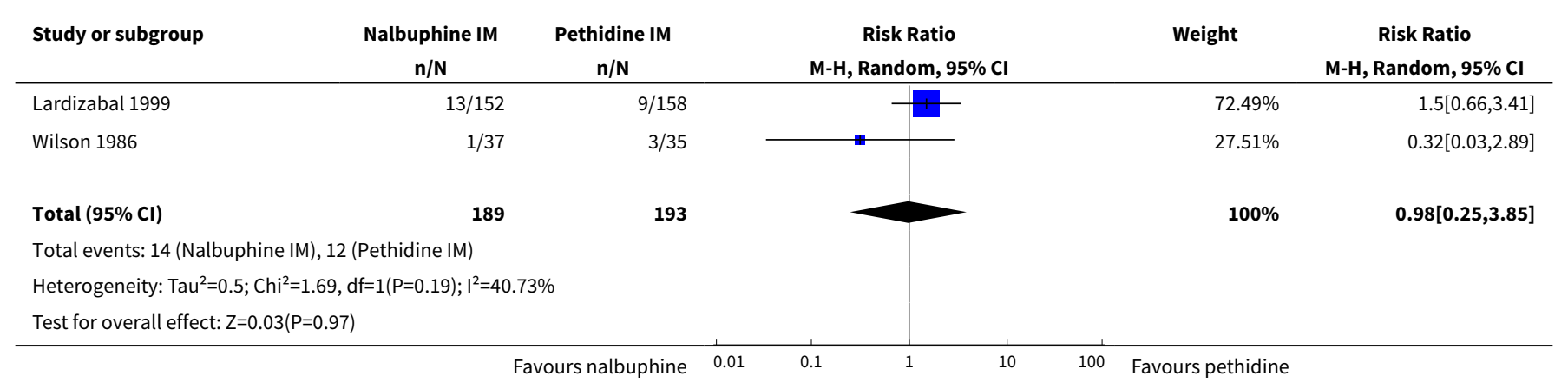


Analysis 10.11. Comparison $10 \mathrm{IM}$ nalbuphine versus pethidine, Outcome 11 Naloxone administration.

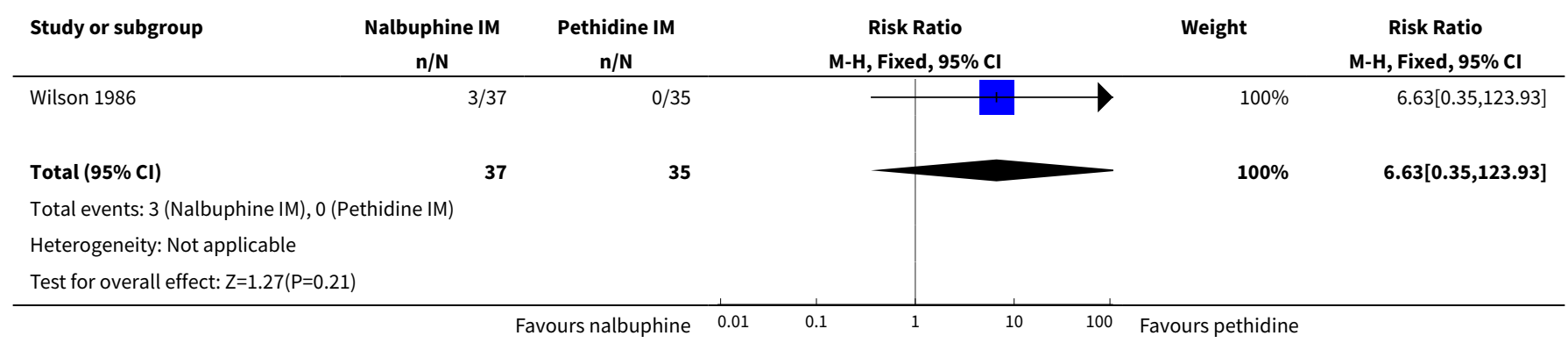

Analysis 10.12. Comparison $10 \mathrm{IM}$ nalbuphine versus pethidine, Outcome $12 \mathrm{Apgar}$ score $\leq 7$ at 1 and 5 minutes.

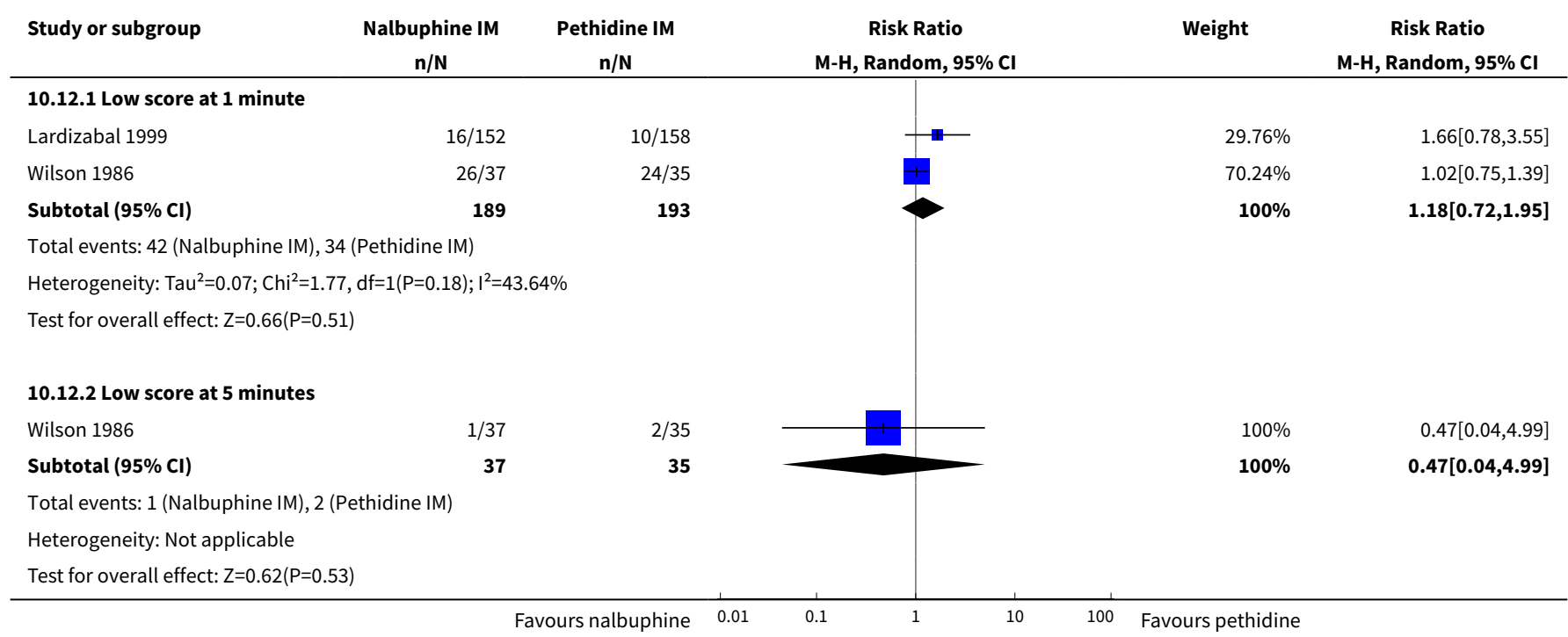

Analysis 10.13. Comparison 10 IM nalbuphine versus pethidine, Outcome 13 Admission to NICU.

\begin{tabular}{|c|c|c|c|c|c|}
\hline Study or subgroup & $\begin{array}{c}\text { Nalbuphine IM } \\
n / N\end{array}$ & $\begin{array}{c}\text { Pethidine IM } \\
n / \mathrm{N}\end{array}$ & $\begin{array}{c}\text { Risk Ratio } \\
\text { M-H, Fixed, 95\% Cl }\end{array}$ & Weight & $\begin{array}{c}\text { Risk Ratio } \\
\text { M-H, Fixed, } 95 \% \mathrm{CI}\end{array}$ \\
\hline Lardizabal 1999 & $21 / 148$ & $20 / 151$ & & $100 \%$ & $1.07[0.61,1.89]$ \\
\hline Total $(95 \% \mathrm{CI})$ & 148 & 151 & & $100 \%$ & $1.07[0.61,1.89]$ \\
\hline \multicolumn{6}{|c|}{ Total events: 21 (Nalbuphine IM), 20 (Pethidine IM) } \\
\hline \multicolumn{6}{|c|}{ Heterogeneity: Not applicable } \\
\hline Test for overall effect & & & & & \\
\hline
\end{tabular}


Analysis 10.14. Comparison $10 \mathrm{IM}$ nalbuphine versus pethidine, Outcome 14 Neonatal neurobehavioural (Scanlon) 2-4 hours PN.

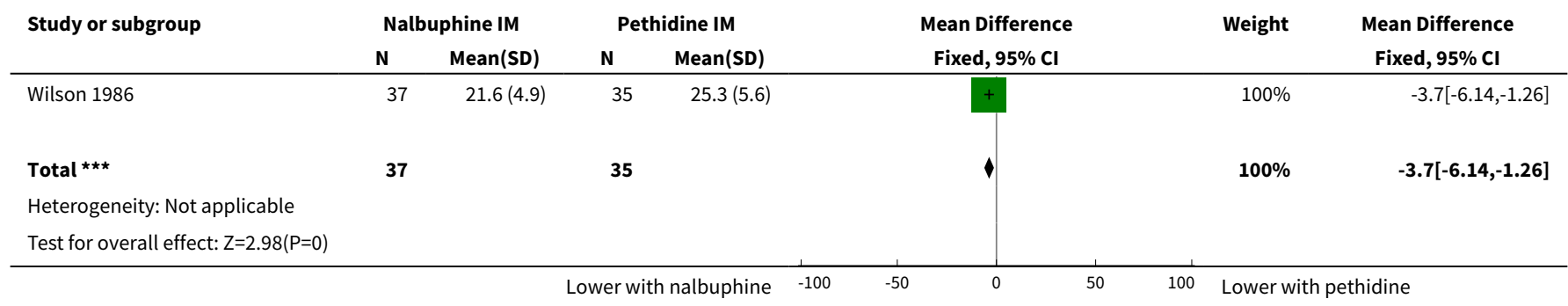

Comparison 11. IM phenazocine versus pethidine

\begin{tabular}{lllll}
\hline $\begin{array}{l}\text { Outcome or sub- } \\
\text { group title }\end{array}$ & No. of studies & $\begin{array}{l}\text { No. of partici- } \\
\text { pants }\end{array}$ & Statistical method & Effect size \\
\hline 1 Epidural & 1 & 212 & Risk Ratio (M-H, Fixed, 95\% Cl) & $1.31[0.58,2.97]$ \\
\hline 2 Vomiting & 1 & 212 & Risk Ratio (M-H, Fixed, 95\% Cl) & $0.39[0.20,0.78]$ \\
\hline
\end{tabular}

Analysis 11.1. Comparison 11 IM phenazocine versus pethidine, Outcome 1 Epidural.

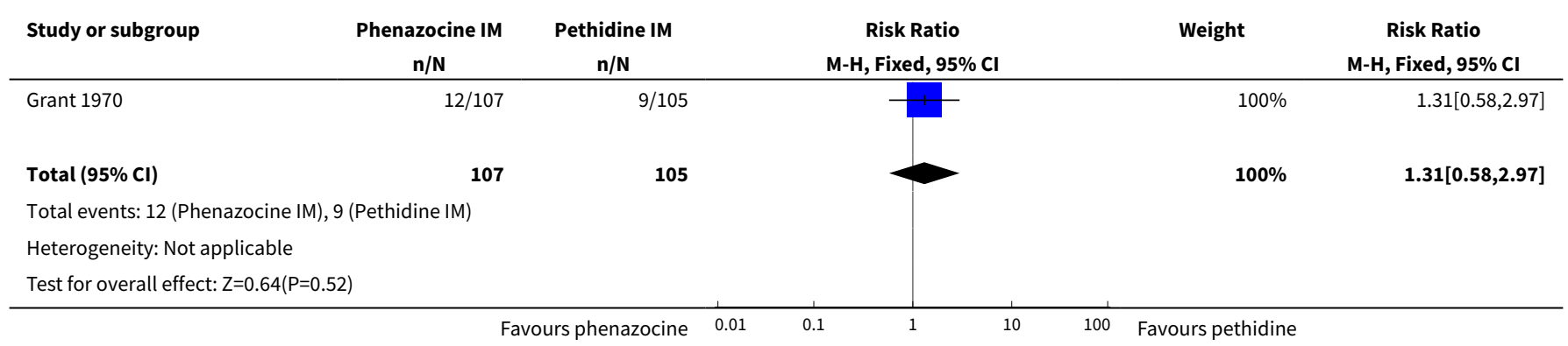

Analysis 11.2. Comparison 11 IM phenazocine versus pethidine, Outcome 2 Vomiting.

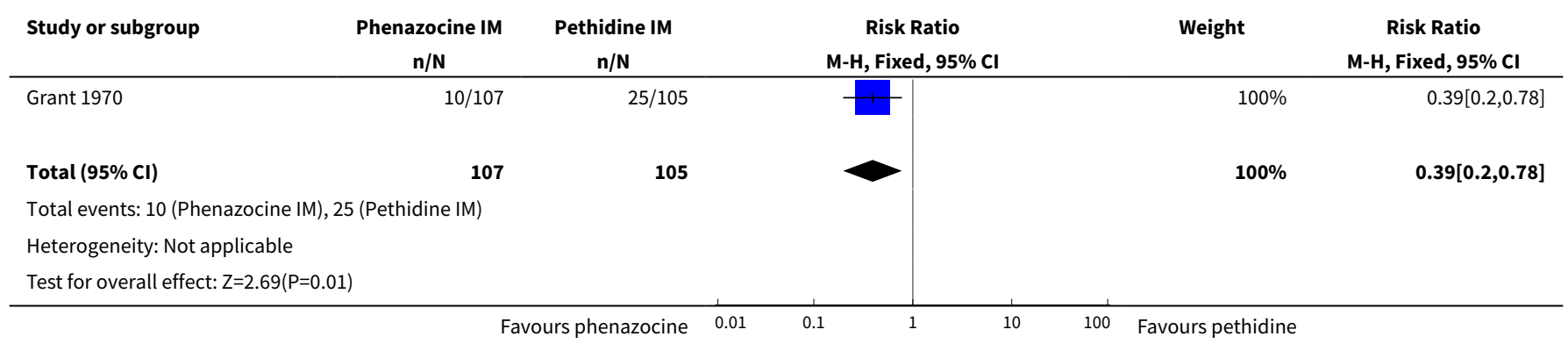


Comparison 12. IM diamorphine/morphine versus pethidine

\begin{tabular}{|c|c|c|c|c|}
\hline Outcome or subgroup title & No. of studies & $\begin{array}{l}\text { No. of partici- } \\
\text { pants }\end{array}$ & Statistical method & Effect size \\
\hline $\begin{array}{l}1 \text { Maternal satisfaction with analgesia } \\
\text { (number of women satisfied or very } \\
\text { satisfied) }\end{array}$ & 1 & 484 & $\begin{array}{l}\text { Risk Ratio (M-H, Fixed, 95\% } \\
\mathrm{Cl} \text { ) }\end{array}$ & $1.13[1.02,1.26]$ \\
\hline $\begin{array}{l}2 \text { Maternal satisfaction with analgesia } \\
\text { measured during labour or during the } \\
\text { postnatal period (Pain relief described } \\
\text { as poor) }\end{array}$ & 1 & 90 & $\begin{array}{l}\text { Risk Ratio (M-H, Fixed, 95\% } \\
\mathrm{Cl} \text { ) }\end{array}$ & $1.22[0.56,2.66]$ \\
\hline $\begin{array}{l}3 \text { Maternal pain score or pain mea- } \\
\text { sured in labour (pain relief at } 30 \text { mins) }\end{array}$ & 1 & 484 & $\begin{array}{l}\text { Mean Difference (IV, Fixed, } \\
95 \% \mathrm{Cl})\end{array}$ & $-0.80[-1.24,-0.36]$ \\
\hline $\begin{array}{l}4 \text { Maternal pain score or pain mea- } \\
\text { sured in labour (pain relief at } 60 \text { mins) }\end{array}$ & 1 & 484 & $\begin{array}{l}\text { Mean Difference (IV, Fixed, } \\
95 \% \mathrm{Cl})\end{array}$ & $-0.80[-1.26,-0.34]$ \\
\hline 5 Additional analgesia required & 2 & 574 & $\begin{array}{l}\text { Risk Ratio (M-H, Fixed, 95\% } \\
\mathrm{Cl})\end{array}$ & $1.00[0.92,1.10]$ \\
\hline 6 Maternal sleepiness & 1 & 90 & $\begin{array}{l}\text { Risk Ratio (M-H, Fixed, 95\% } \\
\mathrm{Cl} \text { ) }\end{array}$ & $0.6[0.29,1.23]$ \\
\hline 7 Nausea and vomiting & 1 & 90 & $\begin{array}{l}\text { Risk Ratio (M-H, Fixed, 95\% } \\
\mathrm{Cl})\end{array}$ & $1.0[0.21,4.69]$ \\
\hline 8 Caesarean section & 1 & 484 & $\begin{array}{l}\text { Risk Ratio (M-H, Fixed, 95\% } \\
\mathrm{Cl})\end{array}$ & $0.94[0.66,1.35]$ \\
\hline 9 Assisted vaginal birth & 1 & 484 & $\begin{array}{l}\text { Risk Ratio (M-H, Fixed, 95\% } \\
\mathrm{Cl})\end{array}$ & $1.28[0.91,1.80]$ \\
\hline 10 Naloxone administration & 1 & 484 & $\begin{array}{l}\text { Risk Ratio (M-H, Fixed, 95\% } \\
\mathrm{Cl})\end{array}$ & $0.98[0.20,4.83]$ \\
\hline 11 Neonatal resuscitation & 2 & 574 & $\begin{array}{l}\text { Risk Ratio (M-H, Fixed, 95\% } \\
\mathrm{Cl} \text { ) }\end{array}$ & $0.96[0.66,1.41]$ \\
\hline 12 Apgar $<7$ at 1 minute & 2 & 574 & $\begin{array}{l}\text { Risk Ratio (M-H, Fixed, 95\% } \\
\mathrm{Cl})\end{array}$ & $1.15[0.76,1.73]$ \\
\hline 13 Admission to NICU & 1 & 484 & $\begin{array}{l}\text { Risk Ratio (M-H, Fixed, 95\% } \\
\mathrm{Cl})\end{array}$ & $0.87[0.34,2.23]$ \\
\hline
\end{tabular}

Analysis 12.1. Comparison $12 \mathrm{IM}$ diamorphine/morphine versus pethidine, Outcome 1 Maternal satisfaction with analgesia (number of women satisfied or very satisfied).

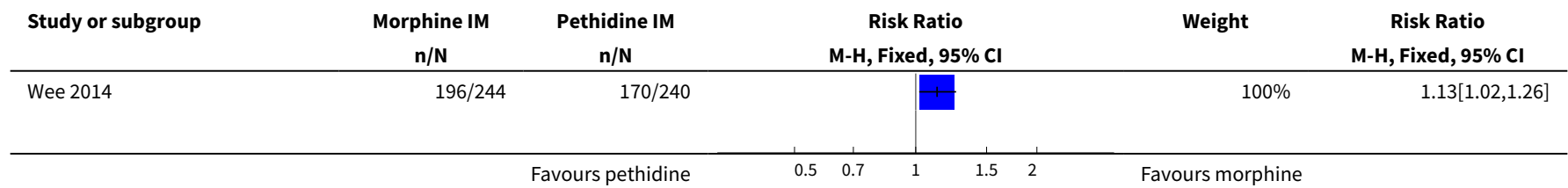




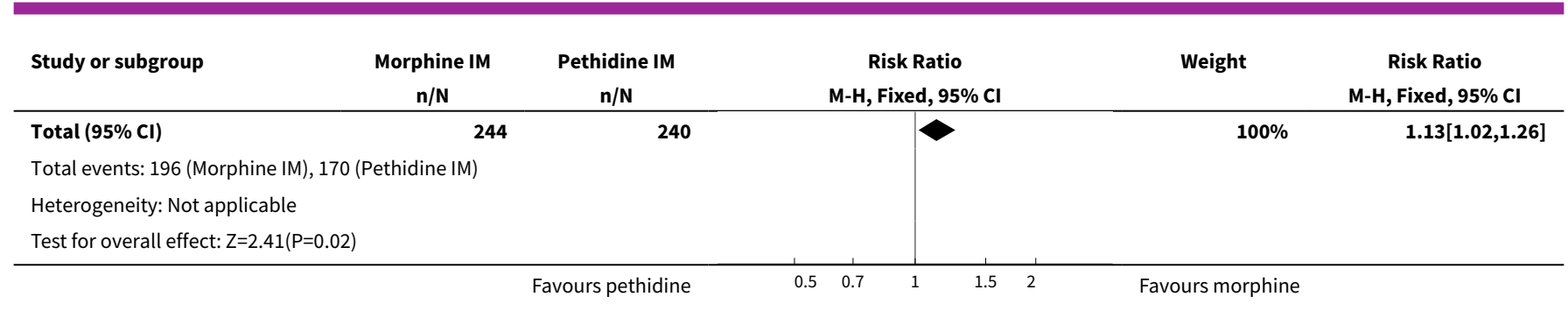

\section{Analysis 12.2. Comparison 12 IM diamorphine/morphine versus pethidine, Outcome 2 Maternal satisfaction} with analgesia measured during labour or during the postnatal period (Pain relief described as poor).

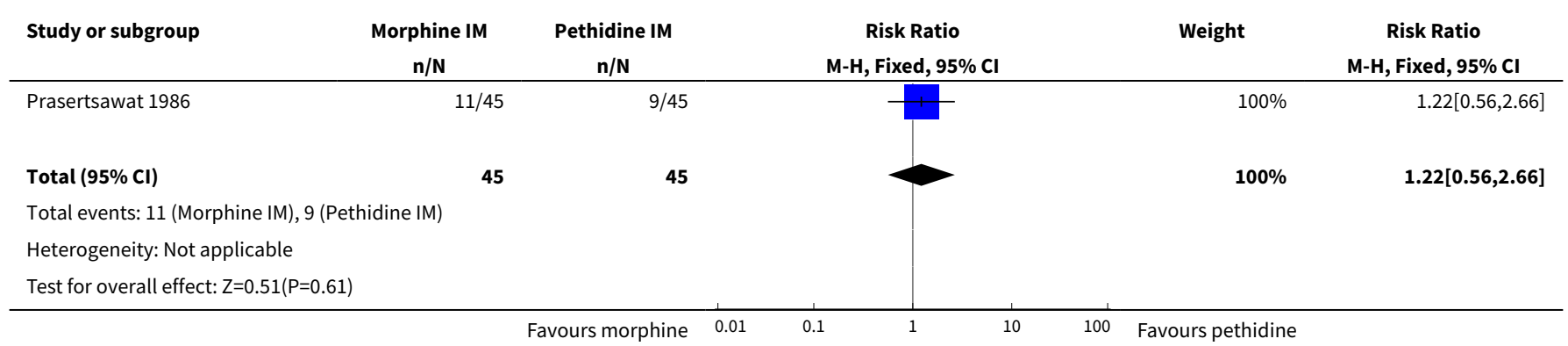

Analysis 12.3. Comparison $12 \mathrm{IM}$ diamorphine/morphine versus pethidine, Outcome 3 Maternal pain score or pain measured in labour (pain relief at $\mathbf{3 0} \mathrm{mins}$ ).

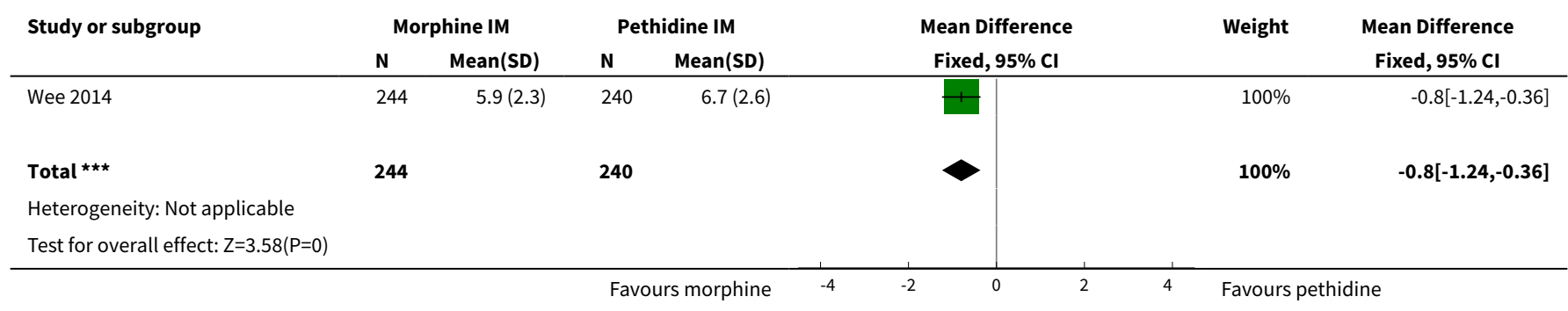

Analysis 12.4. Comparison $12 \mathrm{IM}$ diamorphine/morphine versus pethidine, Outcome 4 Maternal pain score or pain measured in labour (pain relief at 60 mins).

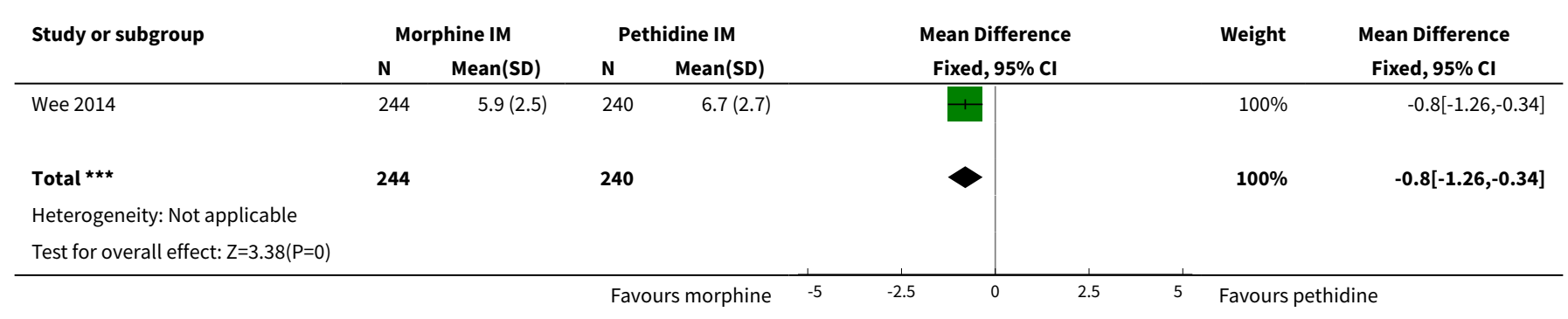


Analysis 12.5. Comparison 12 IM diamorphine/morphine versus pethidine, Outcome 5 Additional analgesia required.

\begin{tabular}{|c|c|c|c|c|c|}
\hline Study or subgroup & $\begin{array}{c}\text { Morphine IM } \\
\mathrm{n} / \mathrm{N} \\
\end{array}$ & $\begin{array}{c}\text { Pethidine IM } \\
\mathrm{n} / \mathrm{N} \\
\end{array}$ & $\begin{array}{c}\text { Risk Ratio } \\
\text { M-H, Fixed, } 95 \% \mathrm{Cl}\end{array}$ & Weight & $\begin{array}{c}\text { Risk Ratio } \\
\text { M-H, Fixed, } 95 \% \mathrm{CI}\end{array}$ \\
\hline Prasertsawat 1986 & $8 / 45$ & $7 / 45$ & & $3.44 \%$ & $1.14[0.45,2.89]$ \\
\hline Wee 2014 & $198 / 244$ & $195 / 240$ & & $96.56 \%$ & $1[0.92,1.09]$ \\
\hline Total $(95 \% \mathrm{CI})$ & 289 & 285 & & $100 \%$ & $1[0.92,1.1]$ \\
\hline \multicolumn{6}{|c|}{ Total events: 206 (Morphine IM), 202 (Pethidine IM) } \\
\hline Test for overall effec & & & & & \\
\hline
\end{tabular}

Analysis 12.6. Comparison 12 IM diamorphine/morphine versus pethidine, Outcome 6 Maternal sleepiness.

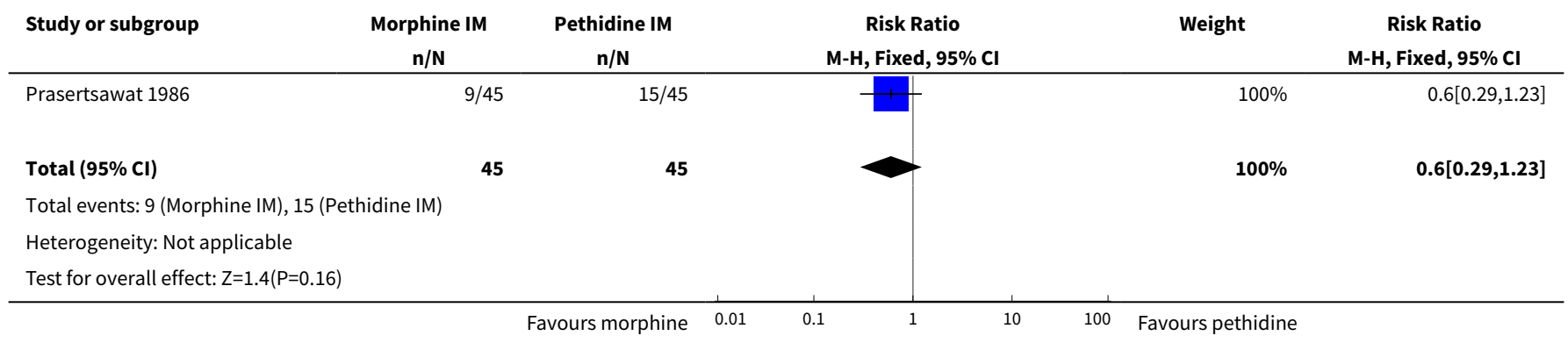

Analysis 12.7. Comparison $12 \mathrm{IM}$ diamorphine/morphine versus pethidine, Outcome 7 Nausea and vomiting.

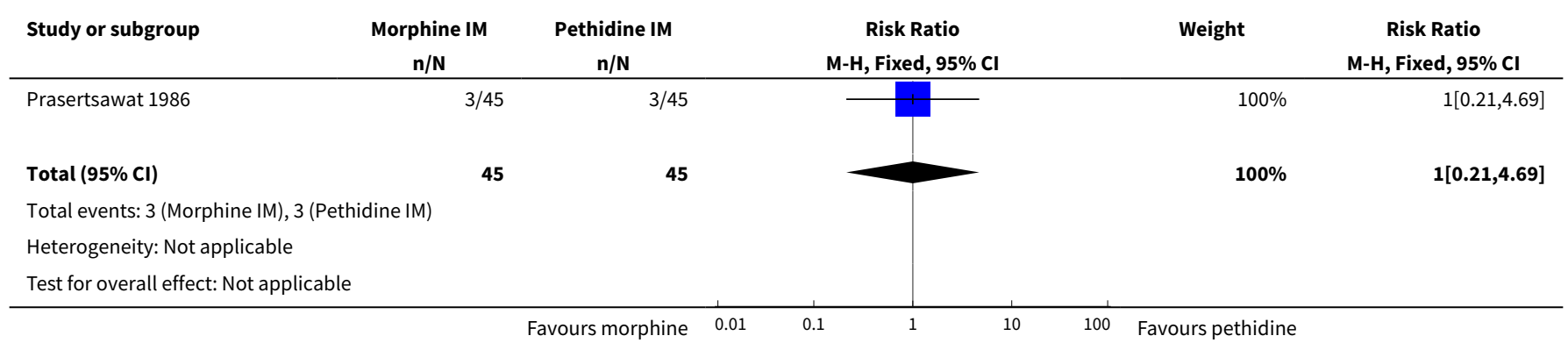

Analysis 12.8. Comparison 12 IM diamorphine/morphine versus pethidine, Outcome 8 Caesarean section.

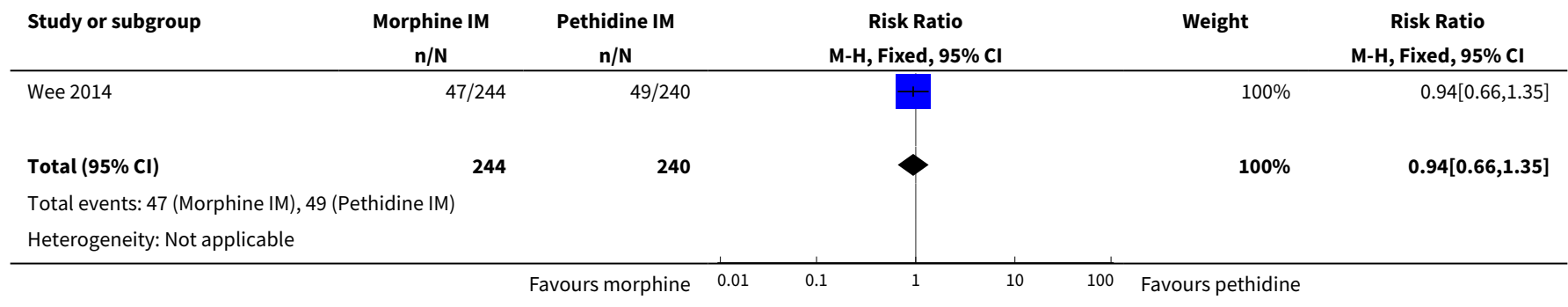




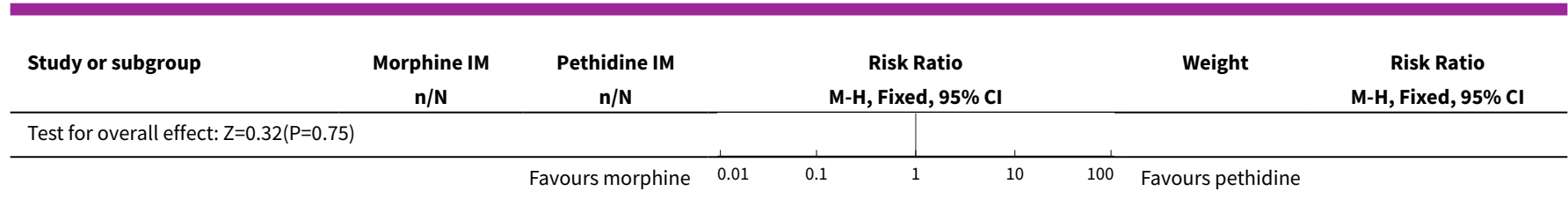

Analysis 12.9. Comparison $12 \mathrm{IM}$ diamorphine/morphine versus pethidine, Outcome 9 Assisted vaginal birth.

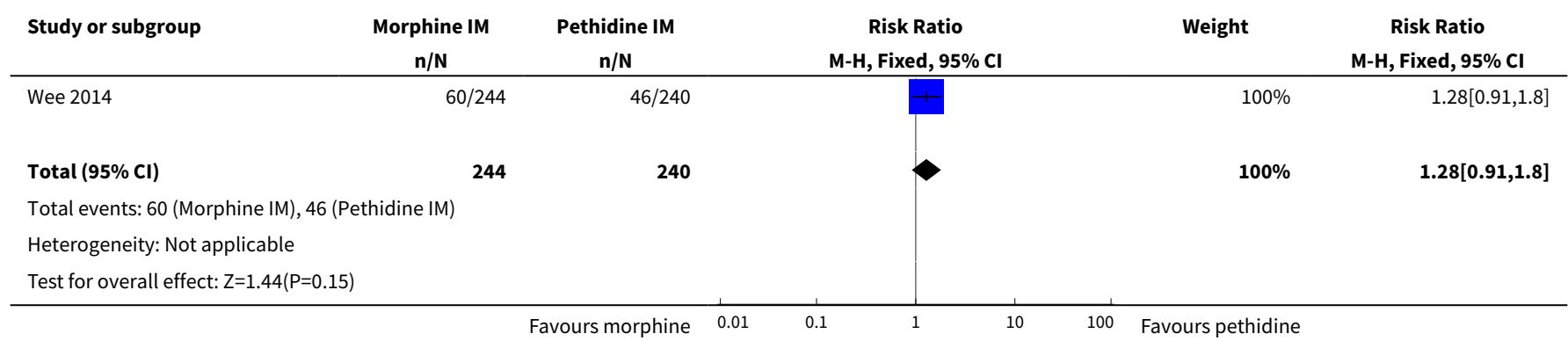

Analysis 12.10. Comparison $12 \mathrm{IM}$ diamorphine/morphine versus pethidine, Outcome 10 Naloxone administration.

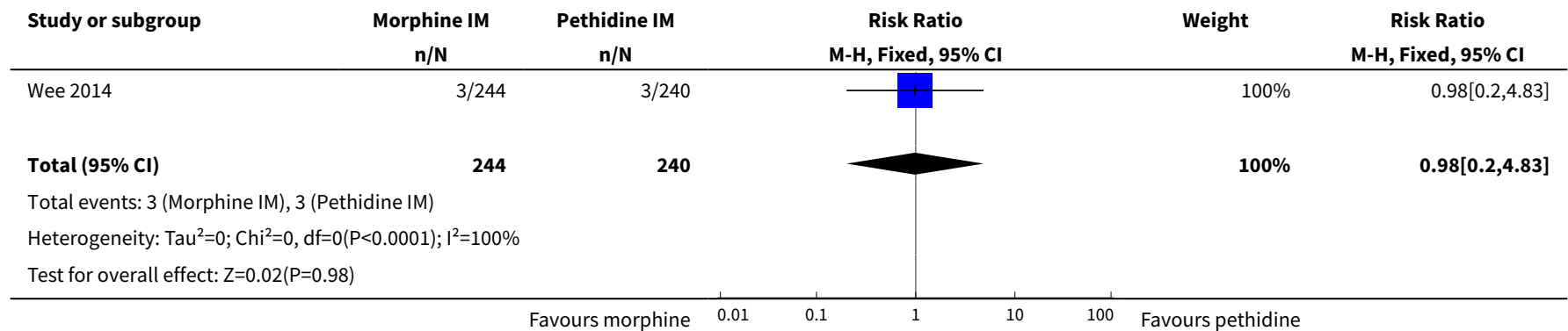

Analysis 12.11. Comparison 12 IM diamorphine/morphine versus pethidine, Outcome 11 Neonatal resuscitation.

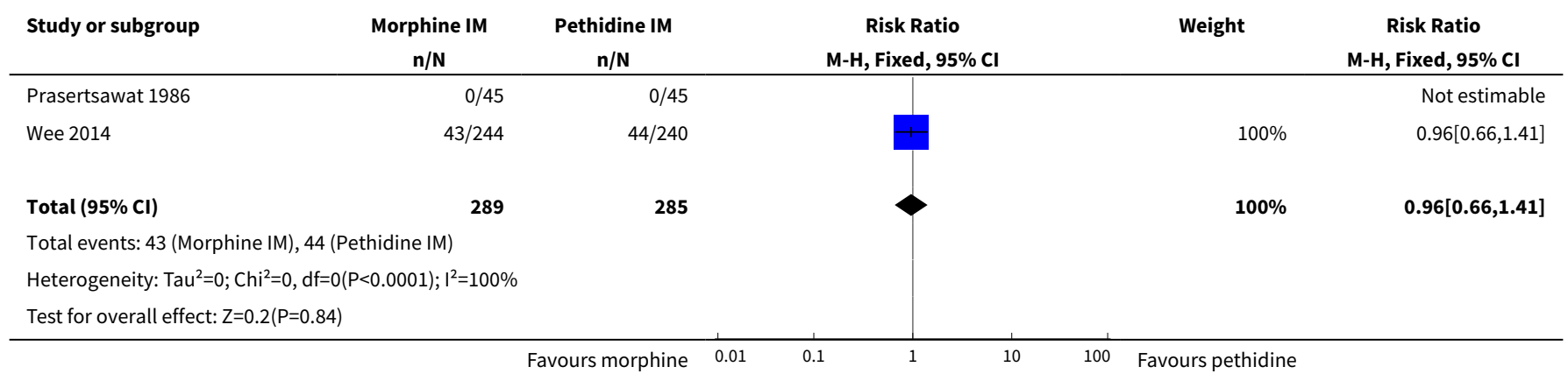


Analysis 12.12. Comparison 12 IM diamorphine/morphine versus pethidine, Outcome 12 Apgar $<7$ at 1 minute.

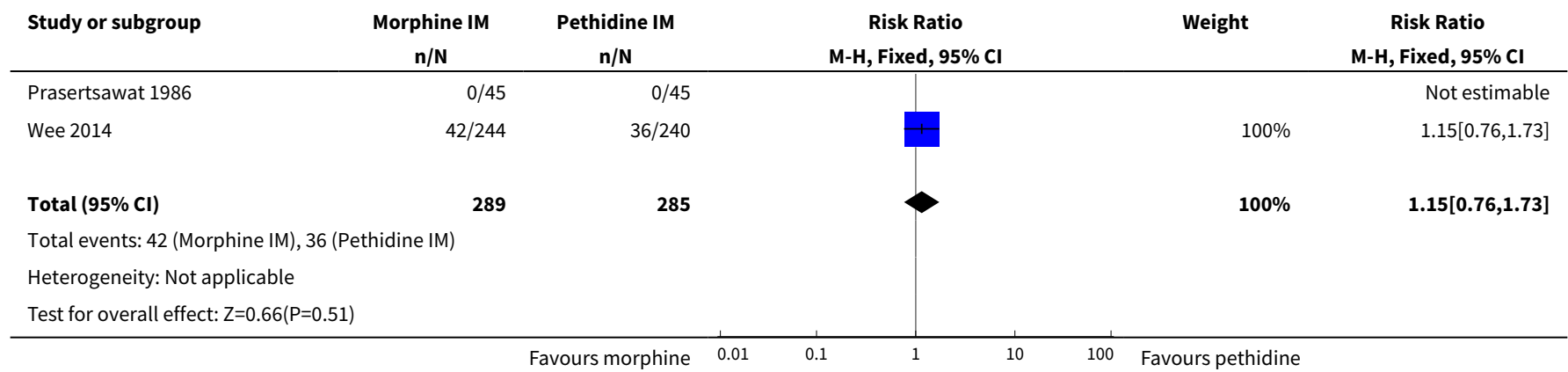

Analysis 12.13. Comparison 12 IM diamorphine/morphine versus pethidine, Outcome 13 Admission to NICU.

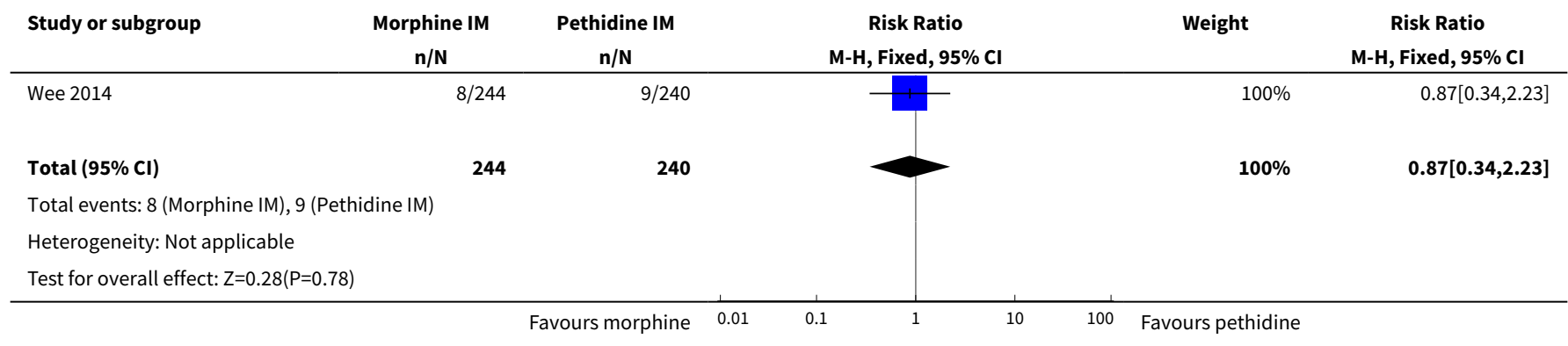

\section{Comparison 13. IM butorphanol versus pethidine}

\begin{tabular}{lllll}
\hline Outcome or subgroup title & No. of studies & $\begin{array}{l}\text { No. of partici- } \\
\text { pants }\end{array}$ & Statistical method & Effect size \\
\hline $\begin{array}{l}\text { 1 Additional analgesia re- } \\
\text { quired }\end{array}$ & 1 & 80 & Risk Ratio (M-H, Fixed, 95\% Cl) & $0.89[0.55,1.45]$ \\
\hline 2 Nausea & 1 & 80 & Risk Ratio (M-H, Fixed, 95\% Cl) & $0.2[0.01,4.04]$ \\
\hline 3 Vomiting & 1 & Risk Ratio (M-H, Fixed, 95\% Cl) & $0.5[0.05,5.30]$ \\
\hline 4 Neonatal resuscitation & 1 & Risk Ratio (M-H, Fixed, 95\% Cl) & $0.33[0.01,7.95]$ \\
\hline $\begin{array}{l}5 \text { Naloxone administration } \\
\text { (neonatal) }\end{array}$ & 1 & 80 & Risk Ratio (M-H, Fixed, 95\% Cl) & $0.33[0.01,7.95]$ \\
\hline
\end{tabular}

Analysis 13.1. Comparison $13 \mathrm{IM}$ butorphanol versus pethidine, Outcome 1 Additional analgesia required.

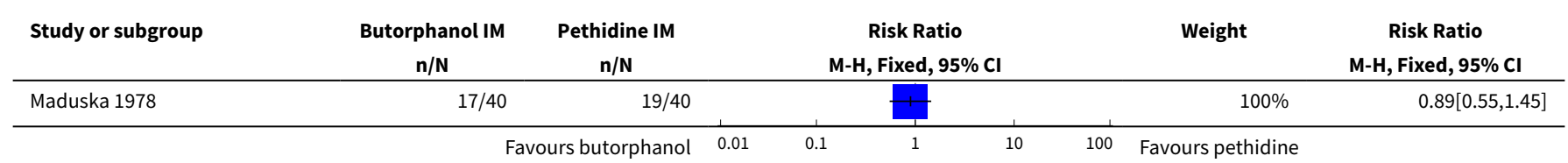




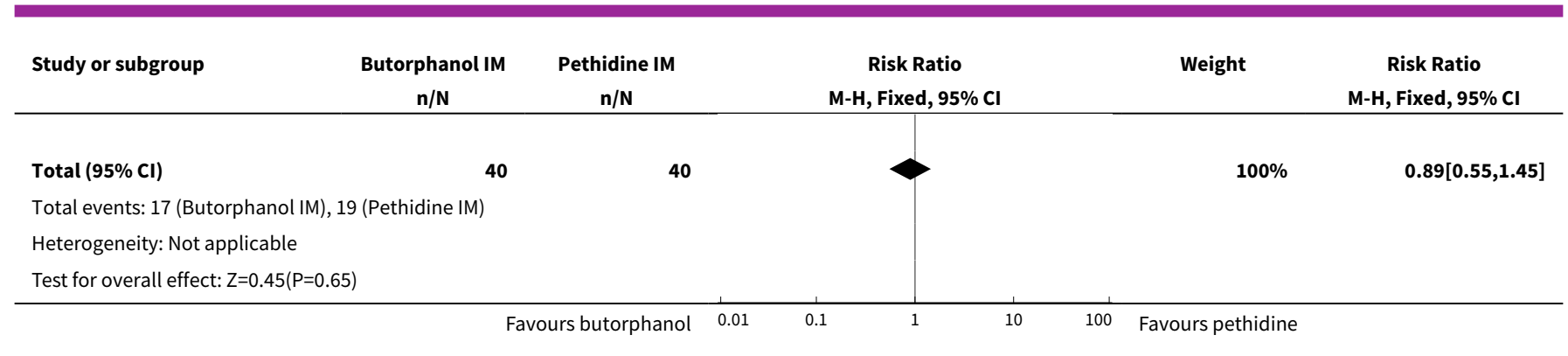

Analysis 13.2. Comparison 13 IM butorphanol versus pethidine, Outcome 2 Nausea.

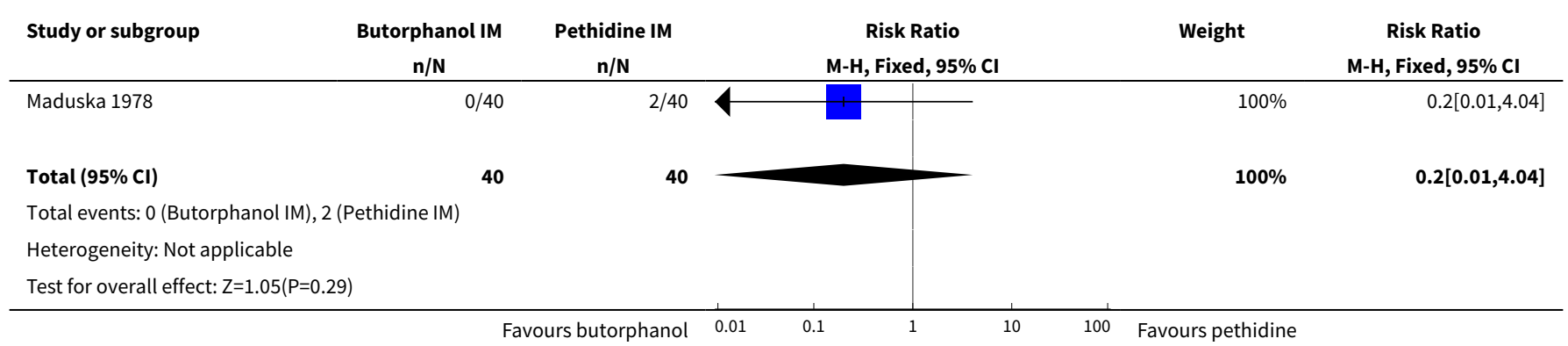

Analysis 13.3. Comparison $13 \mathrm{IM}$ butorphanol versus pethidine, Outcome 3 Vomiting.

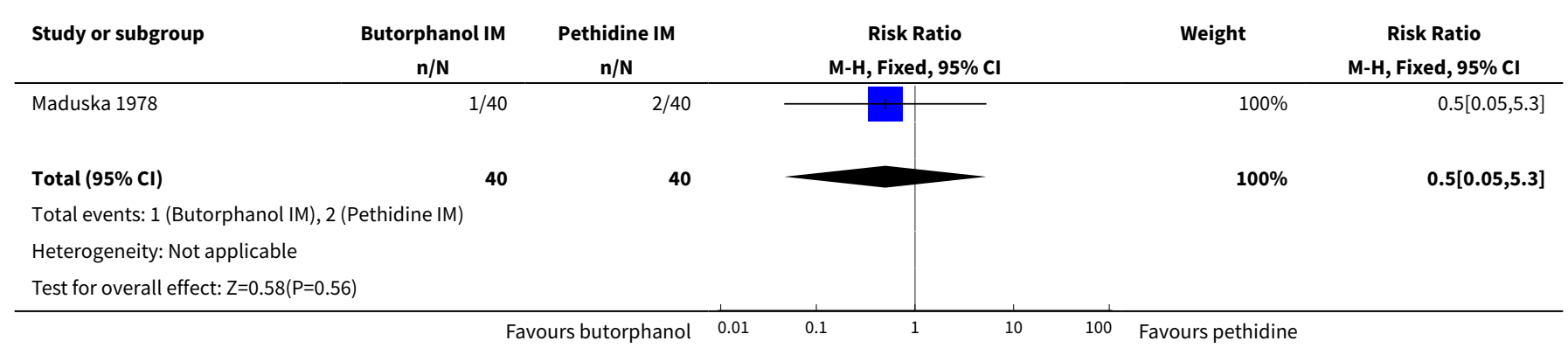

Analysis 13.4. Comparison $13 \mathrm{IM}$ butorphanol versus pethidine, Outcome 4 Neonatal resuscitation.

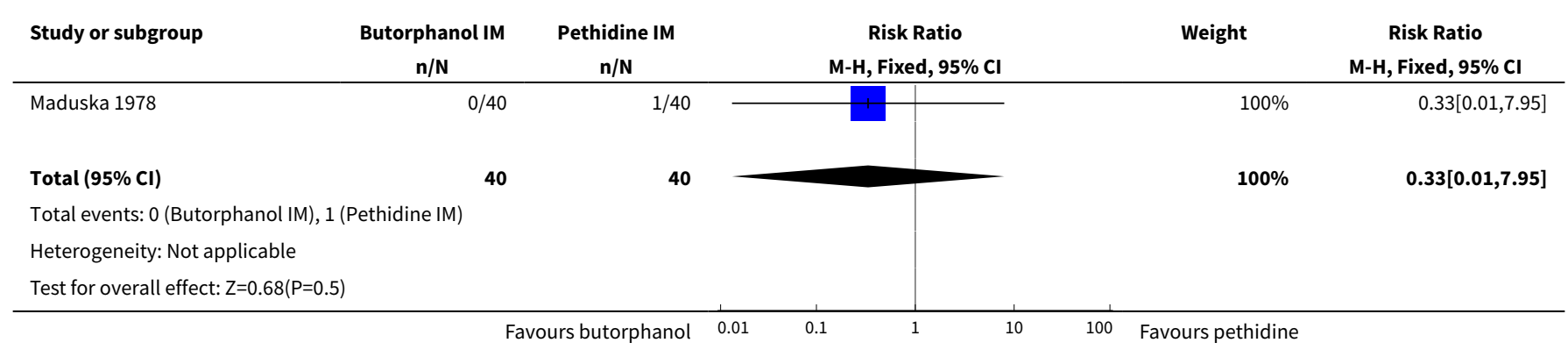


Analysis 13.5. Comparison $13 \mathrm{IM}$ butorphanol versus pethidine, Outcome 5 Naloxone administration (neonatal).

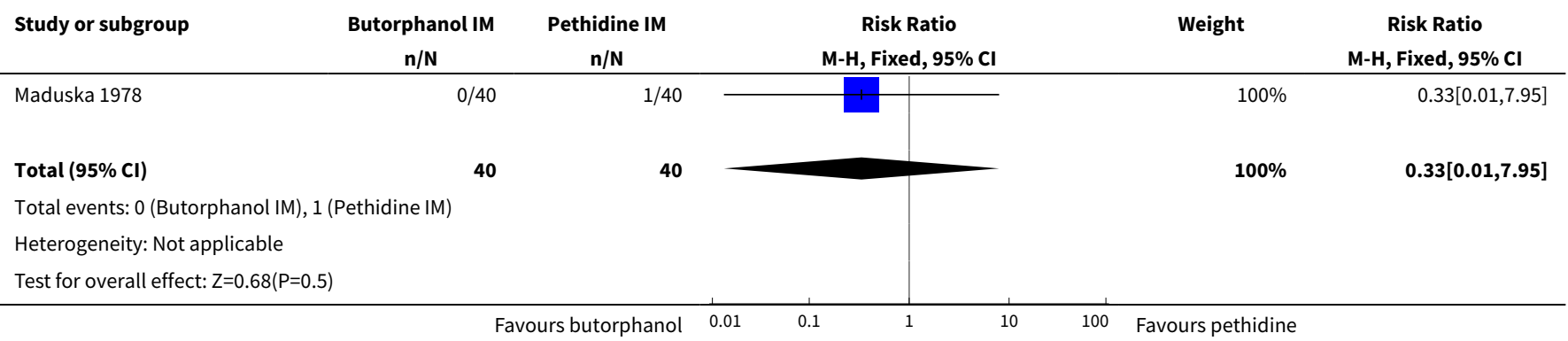

\section{Comparison 14. IM Avacan ${ }^{\circledR}$ versus IM pentazocine}

\begin{tabular}{|c|c|c|c|c|}
\hline Outcome or subgroup title & No. of studies & $\begin{array}{l}\text { No. of partici- } \\
\text { pants }\end{array}$ & Statistical method & Effect size \\
\hline $\begin{array}{l}1 \text { Additional analgesia required - } \\
\text { Entonox }\end{array}$ & 1 & 160 & $\begin{array}{l}\text { Risk Ratio (M-H, Fixed, 95\% } \\
\mathrm{Cl} \text { ) }\end{array}$ & $0.92[0.53,1.63]$ \\
\hline $\begin{array}{l}2 \text { Additional analgesia required - pu- } \\
\text { dendal-paracervical block }\end{array}$ & 1 & 160 & $\begin{array}{l}\text { Risk Ratio (M-H, Fixed, 95\% } \\
\mathrm{Cl})\end{array}$ & $2.02[1.16,3.53]$ \\
\hline 3 Caesarean section & 1 & 184 & $\begin{array}{l}\text { Risk Ratio (M-H, Fixed, 95\% } \\
\mathrm{Cl} \text { ) }\end{array}$ & $0.63[0.21,1.84]$ \\
\hline 4 Low Apgar score $(<7)$ "at birth" & 1 & 160 & $\begin{array}{l}\text { Risk Ratio (M-H, Fixed, 95\% } \\
\mathrm{Cl})\end{array}$ & $0.59[0.27,1.26]$ \\
\hline
\end{tabular}

Analysis 14.1. Comparison 14 IM Avacan ${ }^{\circledR}$ versus IM pentazocine, Outcome 1 Additional analgesia required - Entonox.

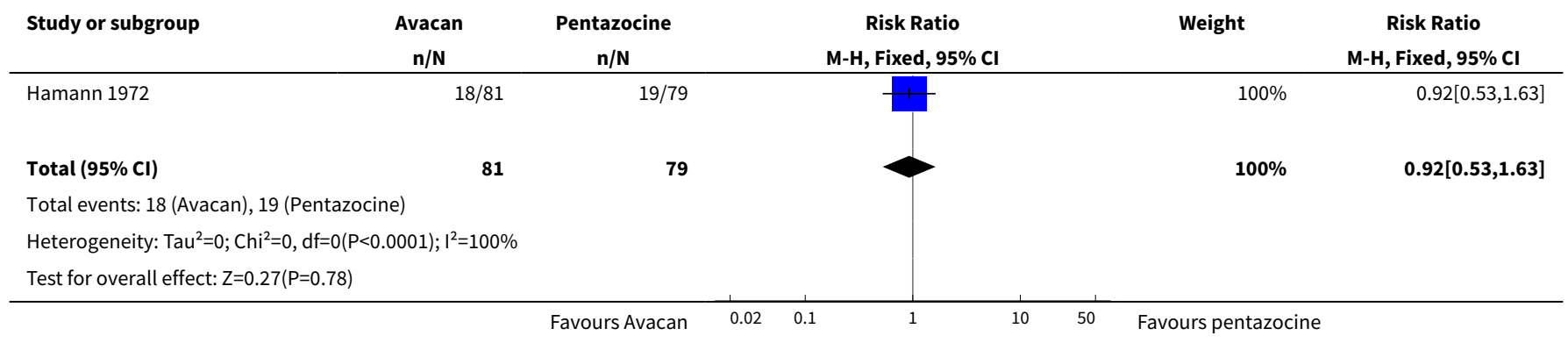


Analysis 14.2. Comparison 14 IM Avacan ${ }^{\circledR}$ versus IM pentazocine,

Outcome 2 Additional analgesia required - pudendal-paracervical block.

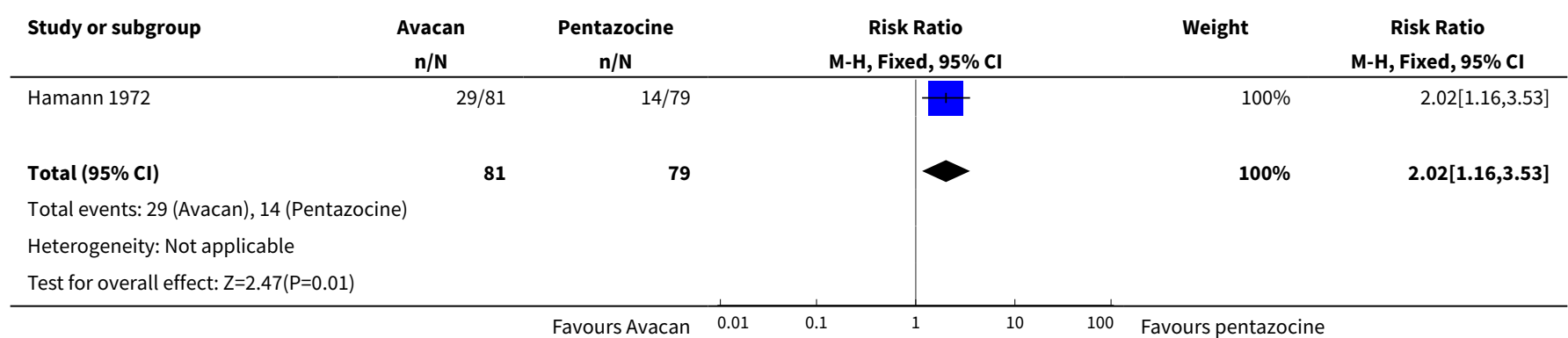

Analysis 14.3. Comparison 14 IM Avacan ${ }^{\circledR}$ versus IM pentazocine, Outcome 3 Caesarean section.

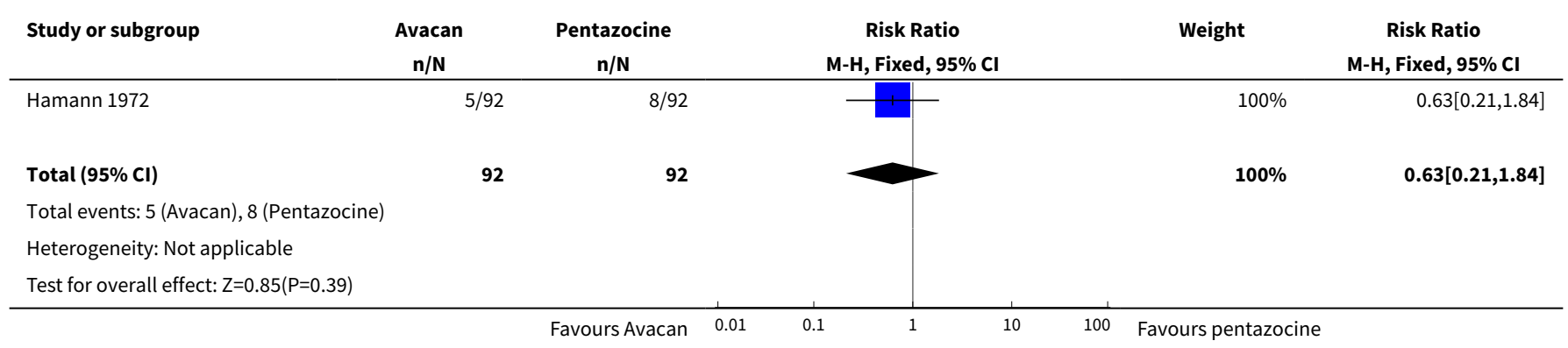

Analysis 14.4. Comparison 14 IM Avacan ${ }^{\circledR}$ versus IM pentazocine, Outcome 4 Low Apgar score (<7) "at birth".

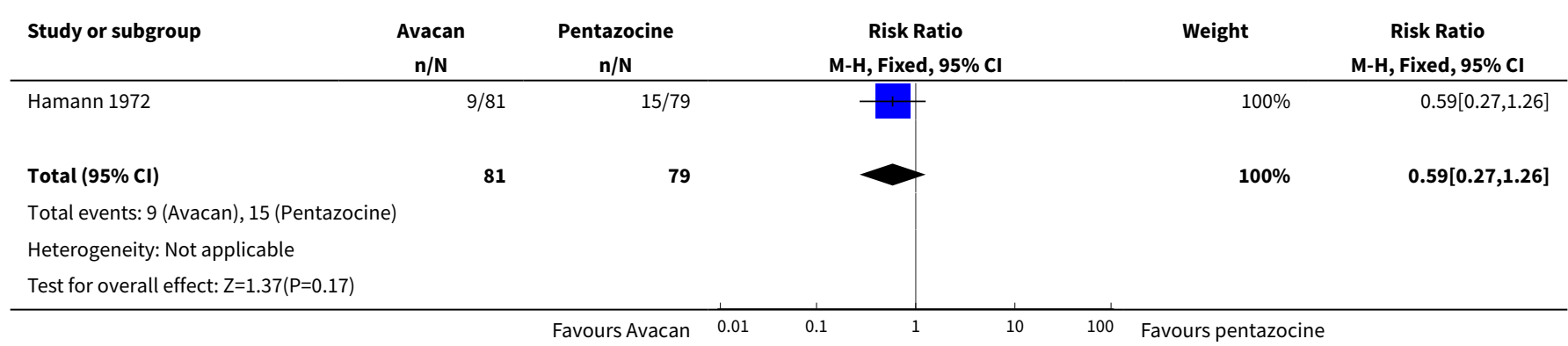

\section{Comparison 15. IM pentazocine versus IM Pethilorfan ${ }^{\circledast}$}

\begin{tabular}{lllll}
\hline Outcome or subgroup title & No. of studies & $\begin{array}{l}\text { No. of partici- } \\
\text { pants }\end{array}$ & Statistical method & Effect size \\
\hline $\begin{array}{l}\text { 1 Maternal pain score measured during } \\
\text { labour (Pain relief (women NOT obtaining } \\
\text { pain relief) at 1 hour) }\end{array}$ & 1 & 69 & $\begin{array}{l}\text { Risk Ratio (M-H, Fixed, } \\
95 \% \mathrm{Cl})\end{array}$ & $1.22[0.77,1.95]$ \\
\hline $\begin{array}{l}\text { 2 Additional analgesia required } \\
\text { A }\end{array}$ & 1 & 98 & $\begin{array}{l}\text { Risk Ratio (M-H, Fixed, } \\
95 \% \mathrm{Cl})\end{array}$ & $0.52[0.10,2.71]$ \\
\hline
\end{tabular}




\begin{tabular}{lllll}
\hline Outcome or subgroup title & No. of studies & $\begin{array}{l}\text { No. of partici- } \\
\text { pants }\end{array}$ & Statistical method & Effect size \\
\hline 3 Assisted vaginal birth & 1 & 98 & $\begin{array}{l}\text { Risk Ratio (M-H, Fixed, } \\
95 \% \mathrm{Cl})\end{array}$ & $1.04[0.07,16.19]$ \\
\hline $\begin{array}{l}4 \text { Apgar < } 8 \text { at } 1 \text { minute (non pre-speci- } \\
\text { fied) }\end{array}$ & 1 & 82 & $\begin{array}{l}\text { Risk Ratio (M-H, Fixed, } \\
95 \% \mathrm{Cl})\end{array}$ & $5.71[0.72,45.39]$ \\
\hline $\begin{array}{l}5 \text { Apgar < } 8 \text { at } 5 \text { minutes (non pre-speci- } \\
\text { fied) }\end{array}$ & 1 & 82 & $\begin{array}{l}\text { Risk Ratio (M-H, Fixed, } \\
95 \% \mathrm{Cl})\end{array}$ & $0.0[0.0,0.0]$ \\
\hline
\end{tabular}

Analysis 15.1. Comparison 15 IM pentazocine versus IM Pethilorfan ${ }^{\circledast}$, Outcome 1 Maternal pain score measured during labour (Pain relief (women NOT obtaining pain relief) at 1 hour).

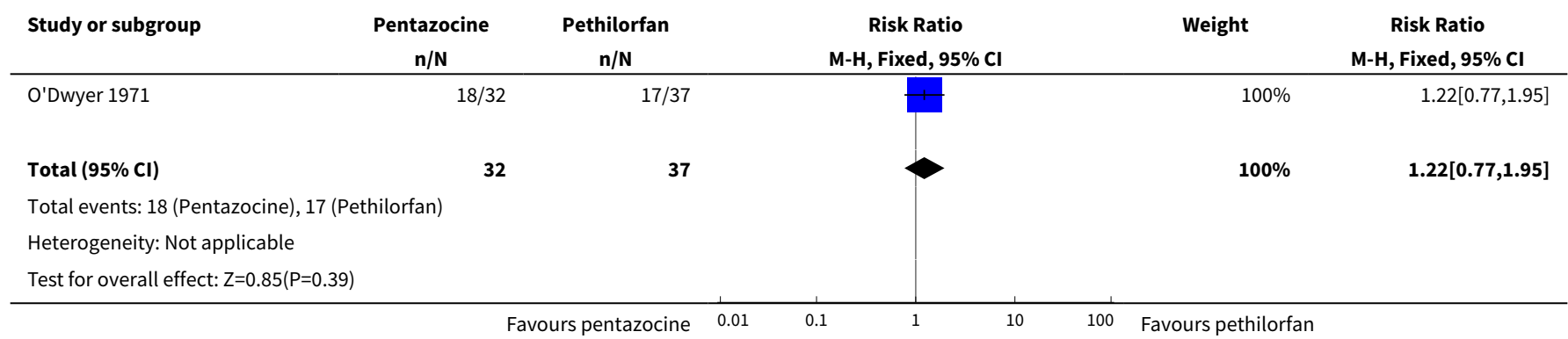

Analysis 15.2. Comparison 15 IM pentazocine versus IM Pethilorfan ${ }^{\circledR}$, Outcome 2 Additional analgesia required.

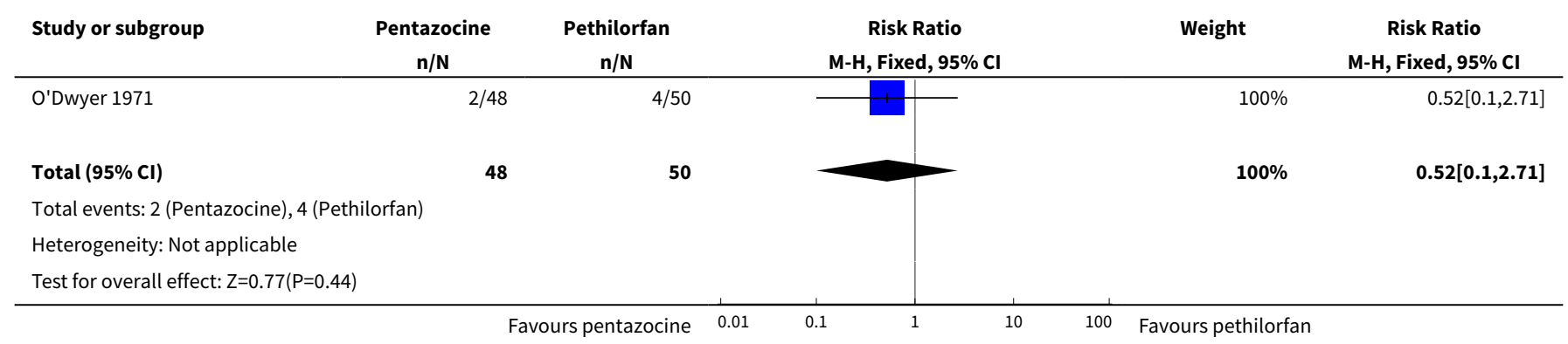

Analysis 15.3. Comparison 15 IM pentazocine versus IM Pethilorfan ${ }^{\circledR}$, Outcome 3 Assisted vaginal birth.

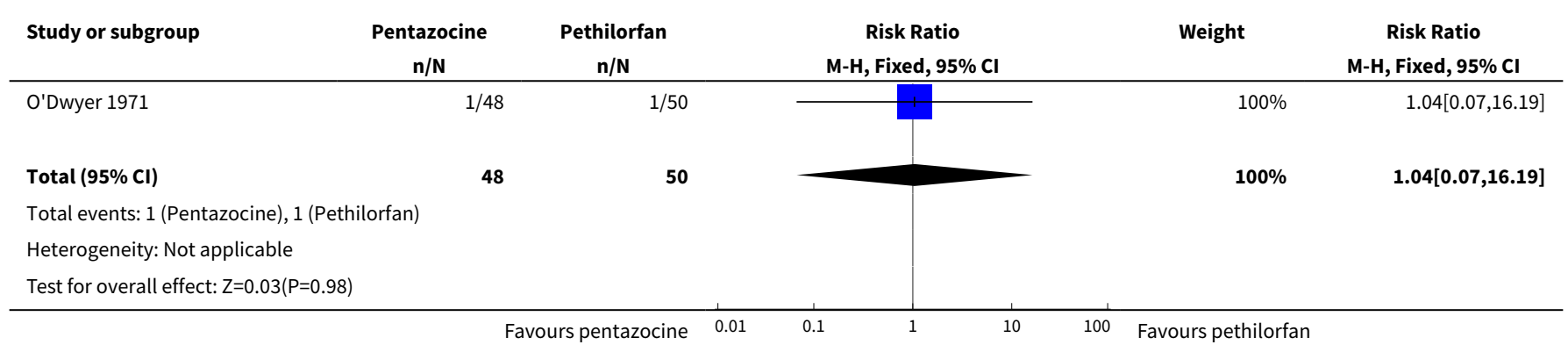


Analysis 15.4. Comparison 15 IM pentazocine versus IM Pethilorfan ${ }^{\circledR}$, Outcome 4 Apgar $<8$ at 1 minute (non pre-specified).

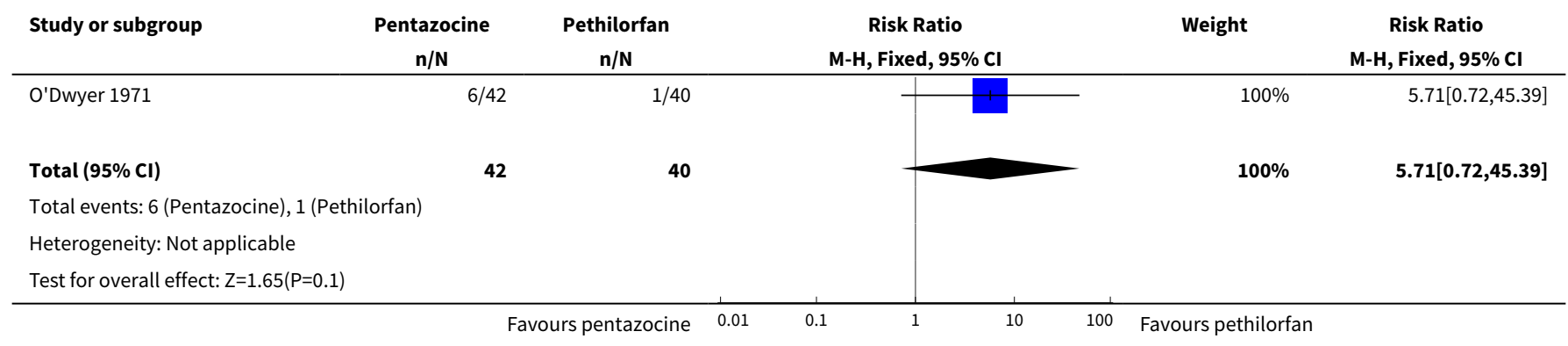

Analysis 15.5. Comparison 15 IM pentazocine versus IM Pethilorfan ${ }^{\circledR}$, Outcome 5 Apgar $<8$ at 5 minutes (non pre-specified).

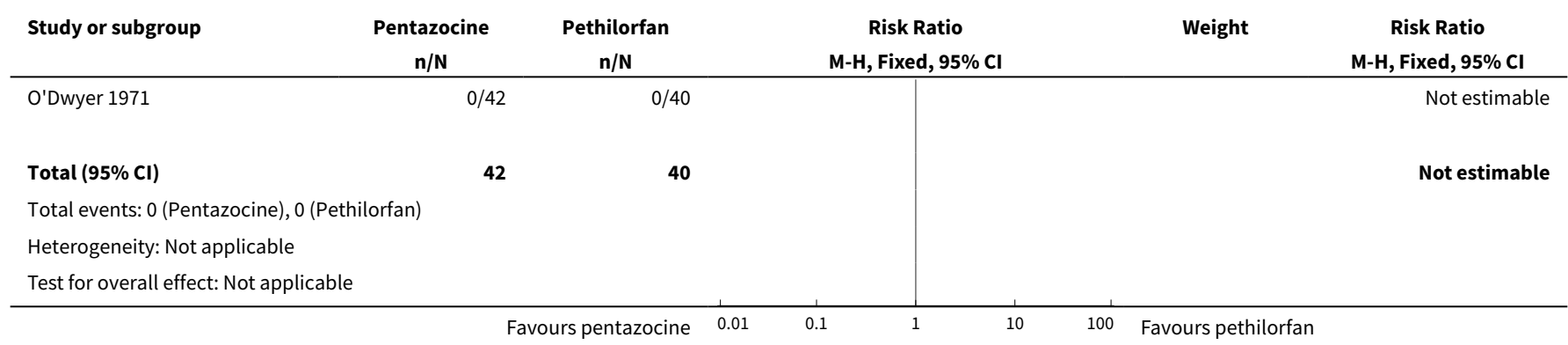

\section{Comparison 16. IM pentazocine versus complementary and alternate medicine (CAM)}

\begin{tabular}{|c|c|c|c|c|}
\hline Outcome or subgroup title & No. of studies & $\begin{array}{l}\text { No. of partici- } \\
\text { pants }\end{array}$ & Statistical method & Effect size \\
\hline $\begin{array}{l}1 \text { Maternal pain score mea- } \\
\text { sured during labour }\end{array}$ & 1 & 89 & Mean Difference (IV, Fixed, 95\% CI) & $-0.40[-7.61,6.81]$ \\
\hline 2 Nausea and vomiting & 1 & 89 & Risk Ratio (M-H, Fixed, 95\% Cl) & $0.30[0.01,7.14]$ \\
\hline 3 Caesarean section & 1 & 89 & Risk Ratio (M-H, Fixed, 95\% Cl) & $0.89[0.24,3.35]$ \\
\hline 4 Assisted vaginal delivery & 1 & 89 & Risk Ratio (M-H, Fixed, 95\% Cl) & $0.89[0.13,6.07]$ \\
\hline
\end{tabular}


Analysis 16.1. Comparison 16 IM pentazocine versus complementary and alternate medicine (CAM), Outcome 1 Maternal pain score measured during labour.

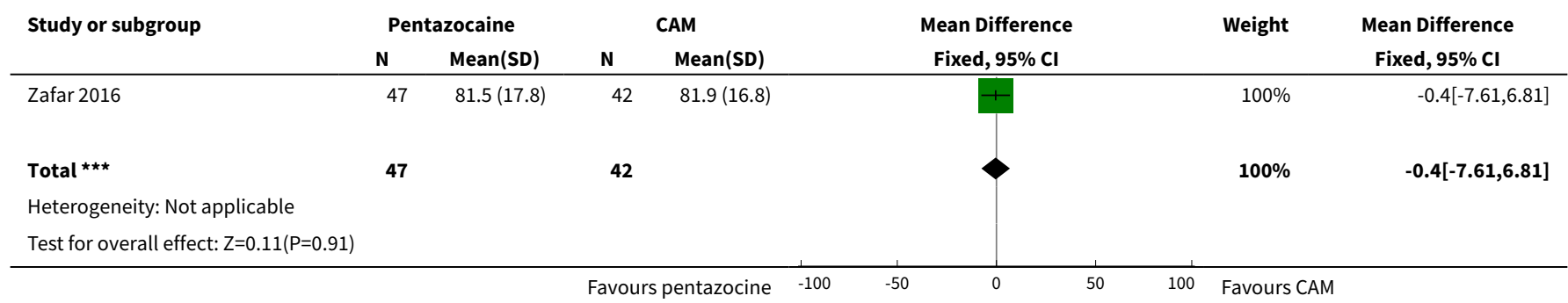

Analysis 16.2. Comparison $16 \mathrm{IM}$ pentazocine versus complementary and alternate medicine (CAM), Outcome 2 Nausea and vomiting.

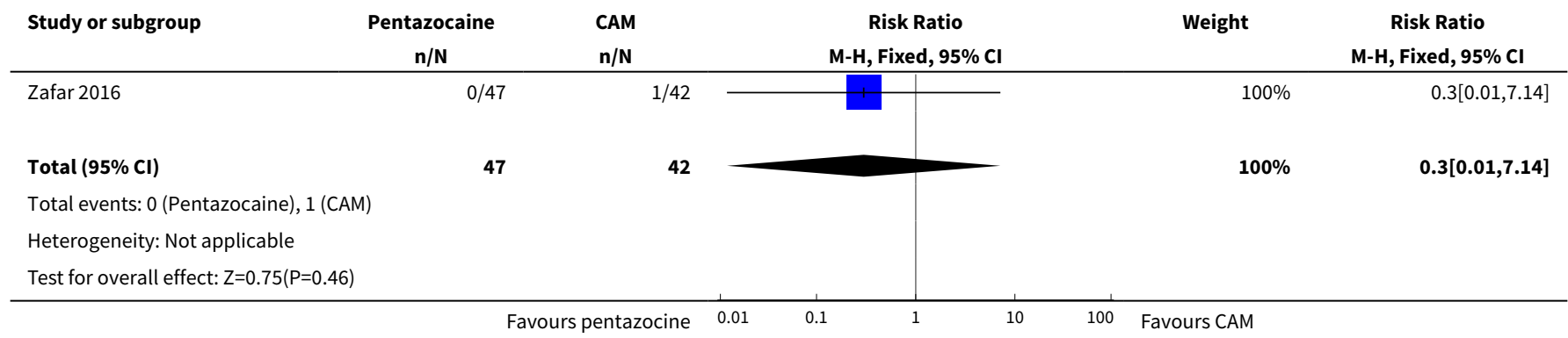

Analysis 16.3. Comparison $16 \mathrm{IM}$ pentazocine versus complementary and alternate medicine (CAM), Outcome 3 Caesarean section.

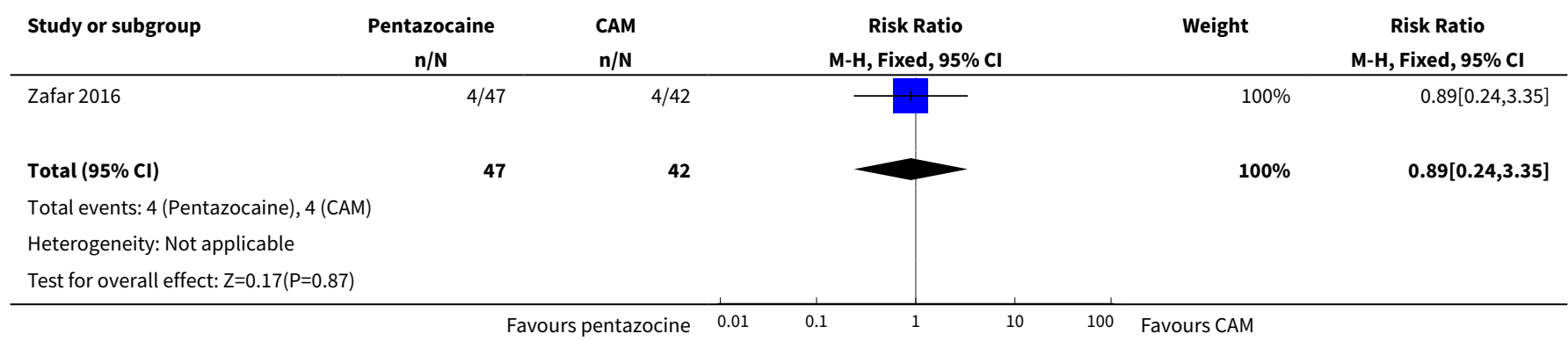

Analysis 16.4. Comparison $16 \mathrm{IM}$ pentazocine versus complementary and alternate medicine (CAM), Outcome 4 Assisted vaginal delivery.

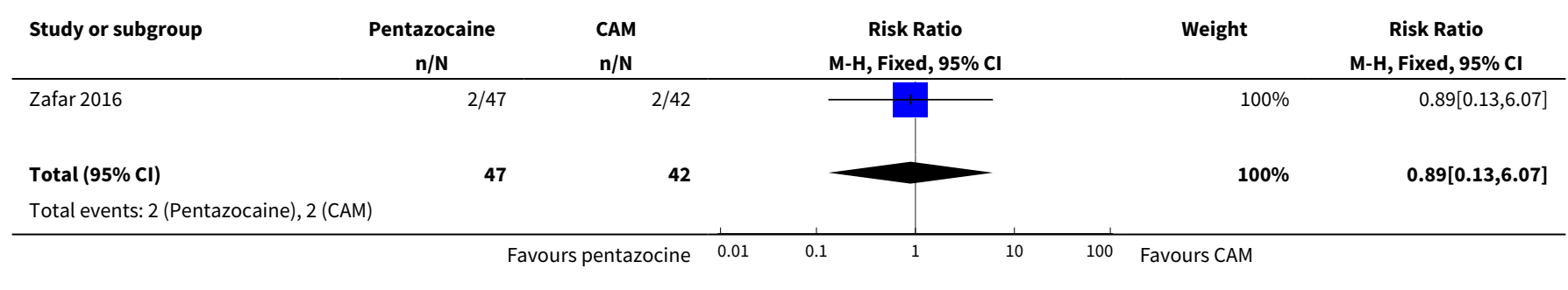




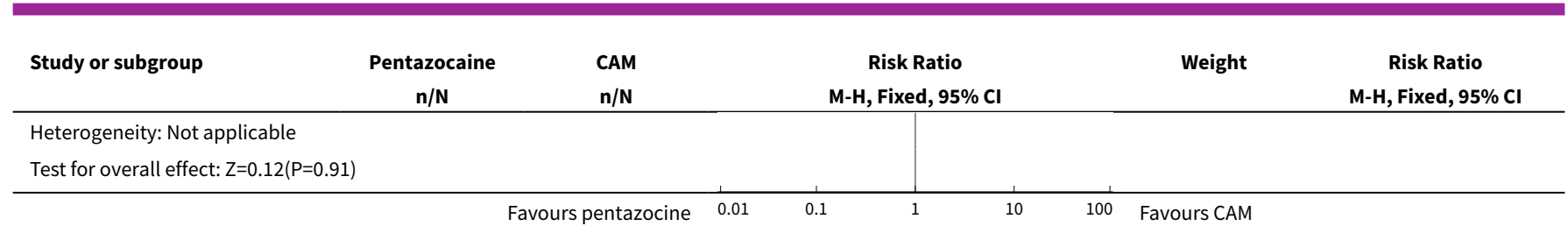

\section{Comparison 17. IM pentazocine versus IM tramadol}

\begin{tabular}{|c|c|c|c|c|}
\hline Outcome or subgroup title & No. of studies & $\begin{array}{l}\text { No. of partici- } \\
\text { pants }\end{array}$ & Statistical method & Effect size \\
\hline $\begin{array}{l}1 \text { Maternal satisfaction with analgesia } \\
\text { measured during labour (pain relief af- } \\
\text { ter } 30 \text { mins) }\end{array}$ & 1 & 100 & $\begin{array}{l}\text { Risk Ratio (M-H, Fixed, 95\% } \\
\mathrm{Cl} \text { ) }\end{array}$ & $2.4[1.28,4.48]$ \\
\hline $\begin{array}{l}2 \text { Maternal satisfaction with analgesia } \\
\text { measured during labour (pain after } 60 \\
\text { mins) }\end{array}$ & 1 & 100 & $\begin{array}{l}\text { Risk Ratio (M-H, Fixed, 95\% } \\
\mathrm{Cl} \text { ) }\end{array}$ & $1.62[0.91,2.86]$ \\
\hline $\begin{array}{l}3 \text { Maternal pain score or pain mea- } \\
\text { sured in labour (moderate or severe at } \\
30 \text { mins) }\end{array}$ & 1 & 100 & $\begin{array}{l}\text { Risk Ratio (M-H, Fixed, 95\% } \\
\mathrm{Cl} \text { ) }\end{array}$ & $0.75[0.55,1.02]$ \\
\hline $\begin{array}{l}4 \text { Maternal pain score or pain mea- } \\
\text { sured in labour (moderate or severe at } \\
60 \text { mins) }\end{array}$ & 1 & 100 & $\begin{array}{l}\text { Risk Ratio (M-H, Fixed, 95\% } \\
\mathrm{Cl} \text { ) }\end{array}$ & $0.81[0.60,1.08]$ \\
\hline 5 Maternal sleepiness during labour & 1 & 100 & $\begin{array}{l}\text { Risk Ratio (M-H, Fixed, 95\% } \\
\mathrm{Cl} \text { ) }\end{array}$ & $1.67[0.66,4.24]$ \\
\hline 6 Nausea and vomiting & 1 & 100 & $\begin{array}{l}\text { Risk Ratio (M-H, Fixed, 95\% } \\
\mathrm{Cl} \text { ) }\end{array}$ & $1.0[0.06,15.55]$ \\
\hline 7 Caesarean section & 1 & 100 & $\begin{array}{l}\text { Risk Ratio (M-H, Fixed, 95\% } \\
\mathrm{Cl})\end{array}$ & $1.5[0.45,4.99]$ \\
\hline 8 Assisted vaginal delivery & 1 & 100 & $\begin{array}{l}\text { Risk Ratio (M-H, Fixed, 95\% } \\
\mathrm{Cl})\end{array}$ & $2.0[0.19,21.36]$ \\
\hline 9 Apgar score $<7$ at 1 minute & 1 & 100 & $\begin{array}{l}\text { Risk Ratio (M-H, Fixed, 95\% } \\
\text { Cl) }\end{array}$ & $1.67[0.42,6.60]$ \\
\hline 10 Apgar score $<7$ at 5 minutes & 1 & 100 & $\begin{array}{l}\text { Risk Ratio (M-H, Fixed, 95\% } \\
\mathrm{Cl} \text { ) }\end{array}$ & $3.0[0.13,71.92]$ \\
\hline 11 Admission to NICU & 1 & 86 & $\begin{array}{l}\text { Risk Ratio (M-H, Fixed, 95\% } \\
\mathrm{Cl} \text { ) }\end{array}$ & $2.87[0.12,68.47]$ \\
\hline
\end{tabular}


Analysis 17.1. Comparison 17 IM pentazocine versus IM tramadol, Outcome 1 Maternal satisfaction with analgesia measured during labour (pain relief after $\mathbf{3 0}$ mins).

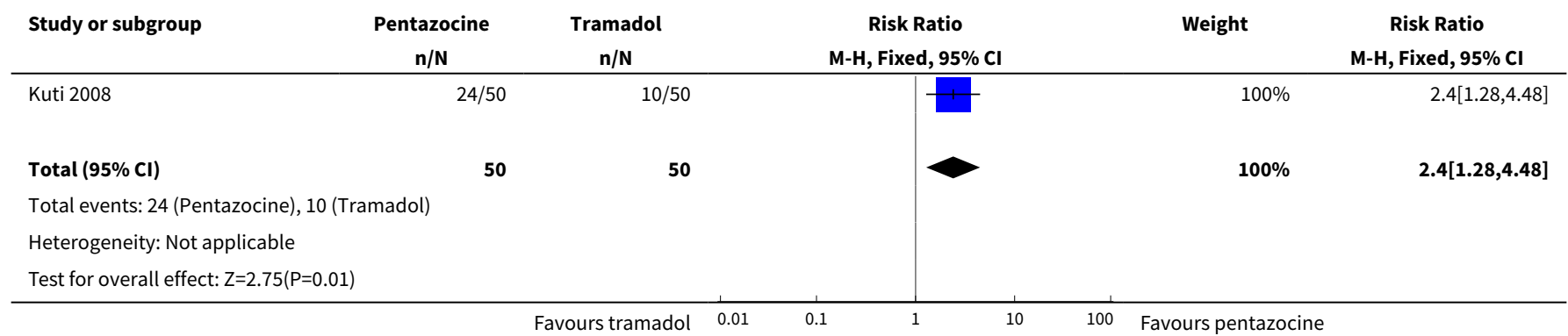

Analysis 17.2. Comparison 17 IM pentazocine versus IM tramadol, Outcome 2 Maternal satisfaction with analgesia measured during labour (pain after $60 \mathrm{mins}$ ).

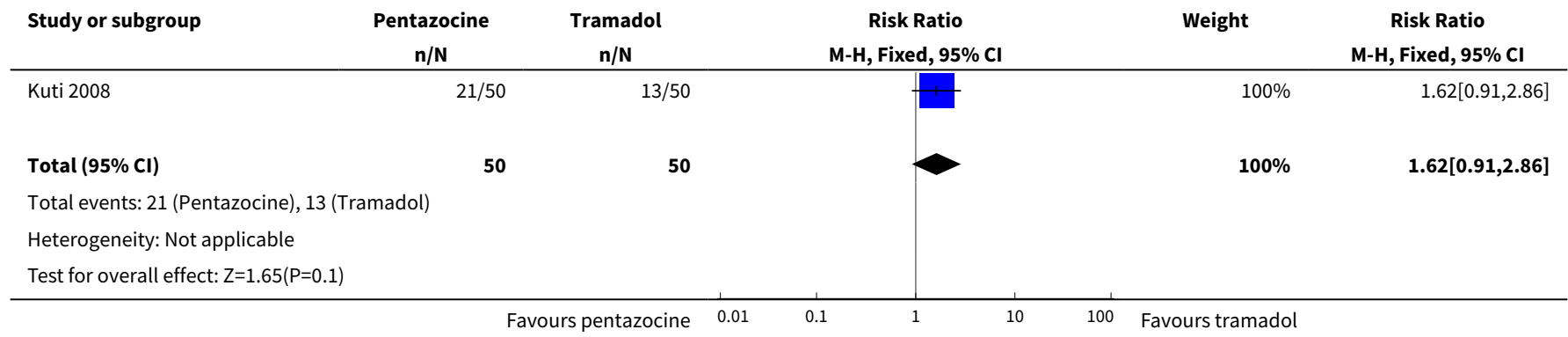

Analysis 17.3. Comparison 17 IM pentazocine versus IM tramadol, Outcome 3 Maternal pain score or pain measured in labour (moderate or severe at $\mathbf{3 0}$ mins).

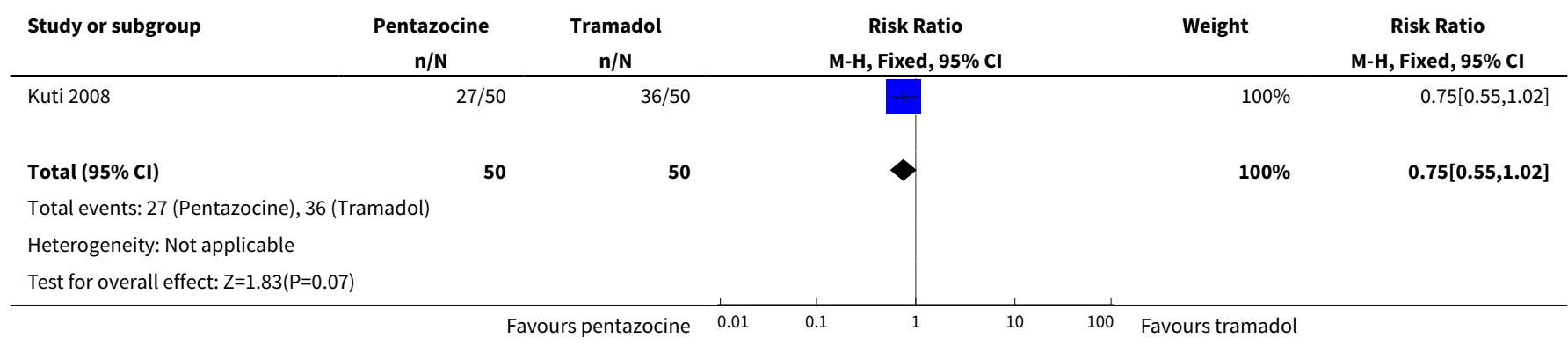

Analysis 17.4. Comparison 17 IM pentazocine versus IM tramadol, Outcome 4 Maternal pain score or pain measured in labour (moderate or severe at 60 mins).

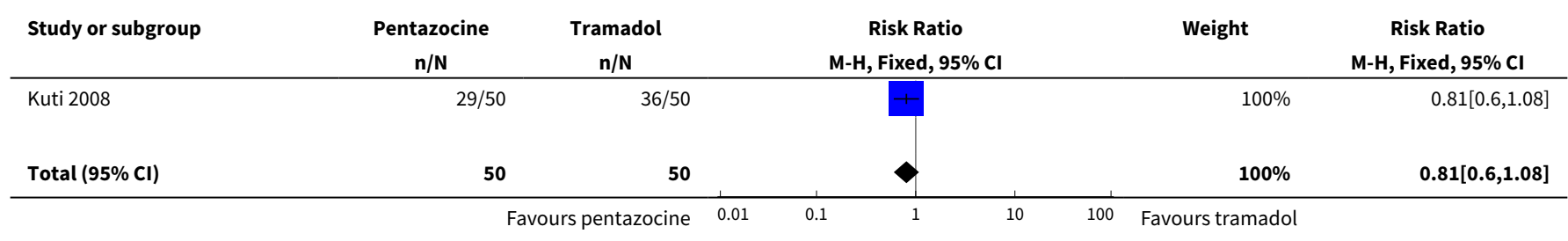




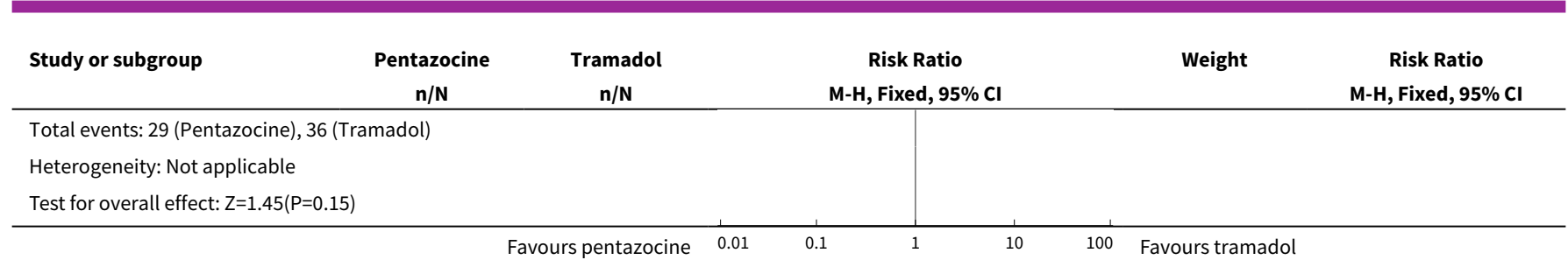

Analysis 17.5. Comparison 17 IM pentazocine versus IM tramadol, Outcome 5 Maternal sleepiness during labour.

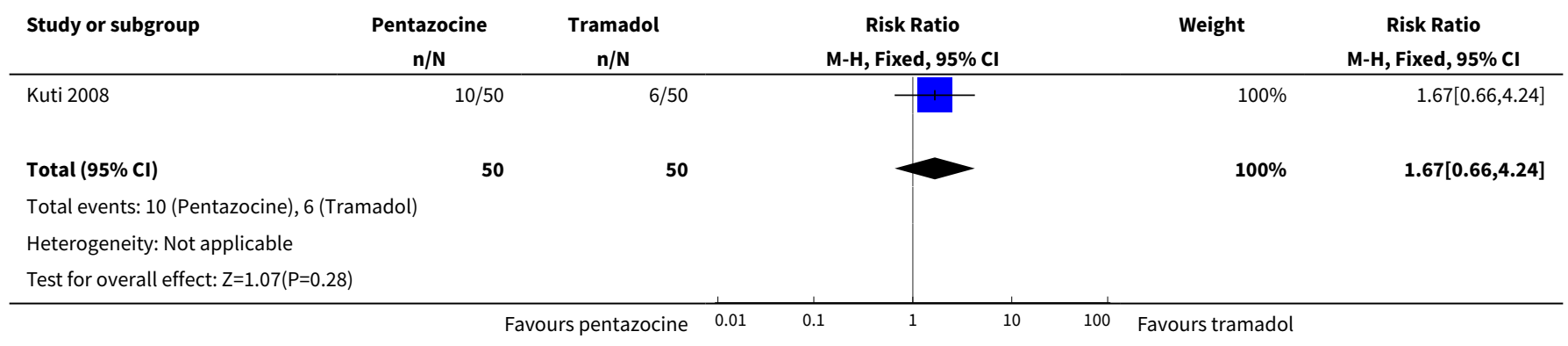

Analysis 17.6. Comparison 17 IM pentazocine versus IM tramadol, Outcome 6 Nausea and vomiting.

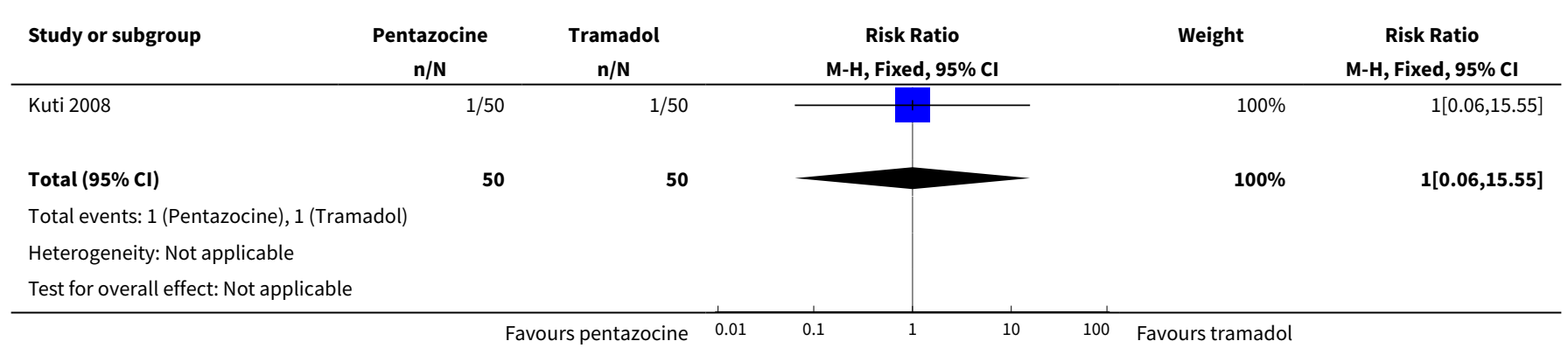

Analysis 17.7. Comparison 17 IM pentazocine versus IM tramadol, Outcome 7 Caesarean section.

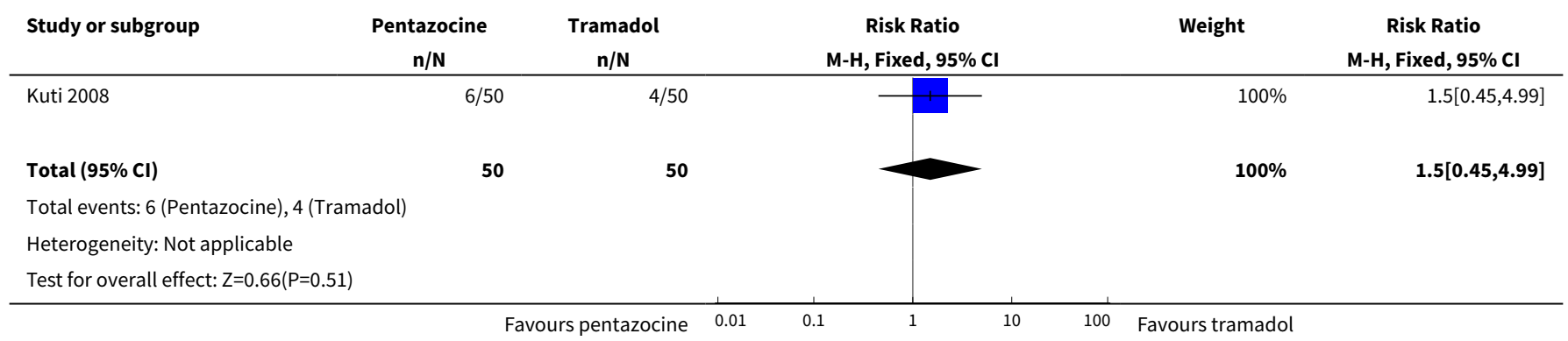


Analysis 17.8. Comparison 17 IM pentazocine versus IM tramadol, Outcome 8 Assisted vaginal delivery.

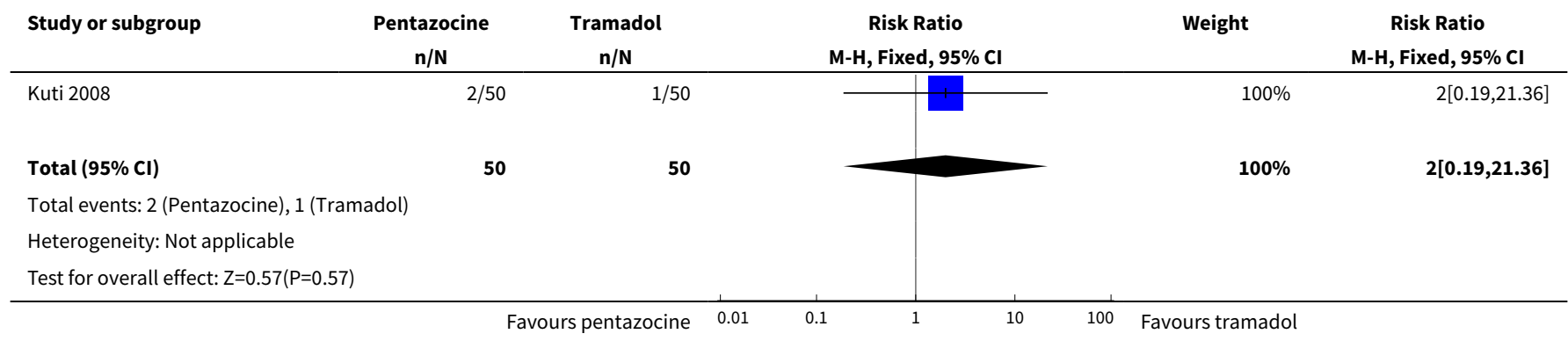

Analysis 17.9. Comparison 17 IM pentazocine versus IM tramadol, Outcome 9 Apgar score $<7$ at 1 minute.

\begin{tabular}{|c|c|c|c|c|c|}
\hline Study or subgroup & $\begin{array}{c}\text { Pentazocine } \\
\mathrm{n} / \mathrm{N}\end{array}$ & $\begin{array}{c}\text { Tramadol } \\
n / N\end{array}$ & $\begin{array}{c}\text { Risk Ratio } \\
\text { M-H, Fixed, } 95 \% \mathrm{CI}\end{array}$ & Weight & $\begin{array}{c}\text { Risk Ratio } \\
\text { M-H, Fixed, } 95 \% \mathrm{Cl} \\
\end{array}$ \\
\hline Kuti 2008 & $5 / 50$ & $3 / 50$ & - & $100 \%$ & $1.67[0.42,6.6]$ \\
\hline Total $(95 \% \mathrm{Cl})$ & 50 & 50 & & $100 \%$ & $1.67[0.42,6.6]$ \\
\hline \multicolumn{6}{|c|}{ Total events: 5 (Pentazocine), 3 (Tramadol) } \\
\hline \multicolumn{6}{|c|}{ Heterogeneity: Not applicable } \\
\hline Test for overall effec & & & & & \\
\hline
\end{tabular}

Analysis 17.10. Comparison $17 \mathrm{IM}$ pentazocine versus IM tramadol, Outcome 10 Apgar score $<7$ at 5 minutes.

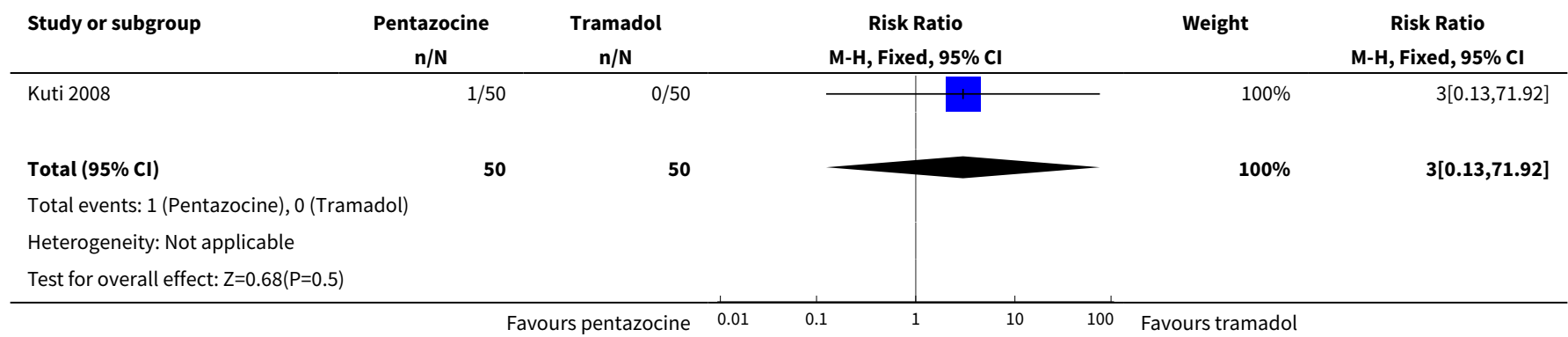

Analysis 17.11. Comparison 17 IM pentazocine versus IM tramadol, Outcome 11 Admission to NICU.

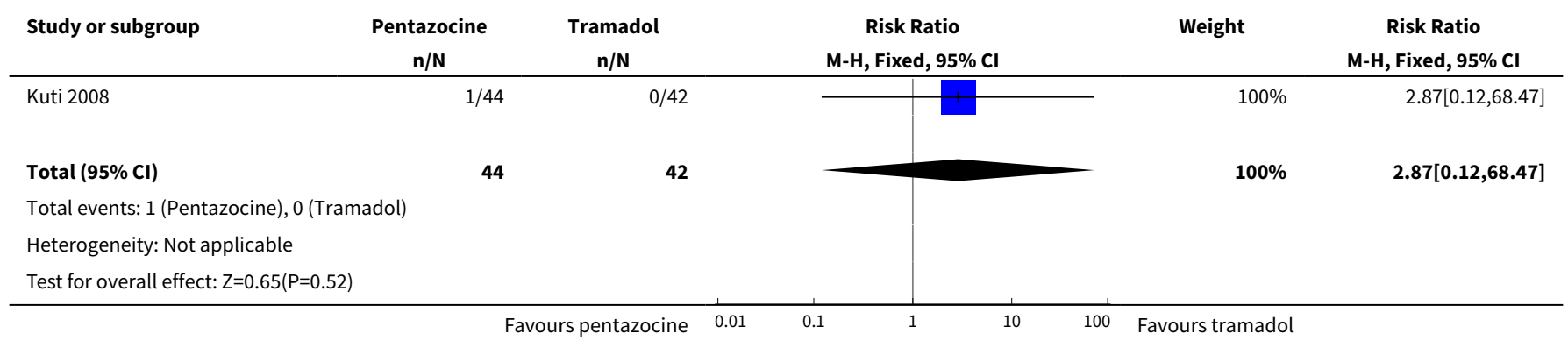


Comparison 18. IM pethidine versus Entonox

\begin{tabular}{lllll}
\hline Outcome or subgroup title & No. of studies & $\begin{array}{l}\text { No. of partici- } \\
\text { pants }\end{array}$ & Statistical method & Effect size \\
\hline $\begin{array}{l}\text { 1 Maternal pain score or pain measured in } \\
\text { labour (after } 30 \text { mins) }\end{array}$ & 1 & 100 & $\begin{array}{l}\text { Mean Difference (IV, Fixed, } \\
95 \% \text { CI) }\end{array}$ & $1.66[1.17,2.15]$ \\
\hline $\begin{array}{l}\text { 2 Maternal pain score or pain measured in } \\
\text { labour (after } 60 \text { mins) }\end{array}$ & 1 & 100 & $\begin{array}{l}\text { Mean Difference (IV, Fixed, } \\
95 \% \text { Cl) }\end{array}$ & $-0.36[-0.85,0.13]$ \\
\hline
\end{tabular}

Analysis 18.1. Comparison 18 IM pethidine versus Entonox, Outcome 1 Maternal pain score or pain measured in labour (after $\mathbf{3 0}$ mins).

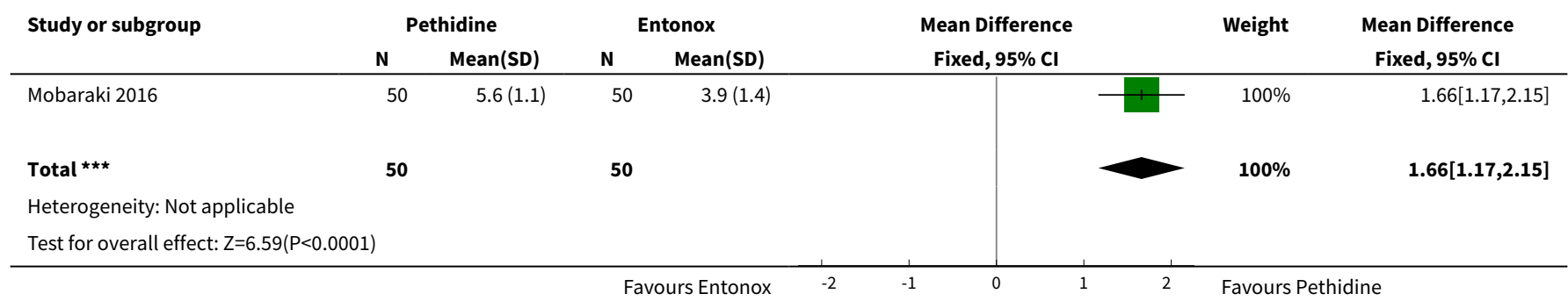

Analysis 18.2. Comparison 18 IM pethidine versus Entonox, Outcome 2 Maternal pain score or pain measured in labour (after $60 \mathrm{mins}$ ).

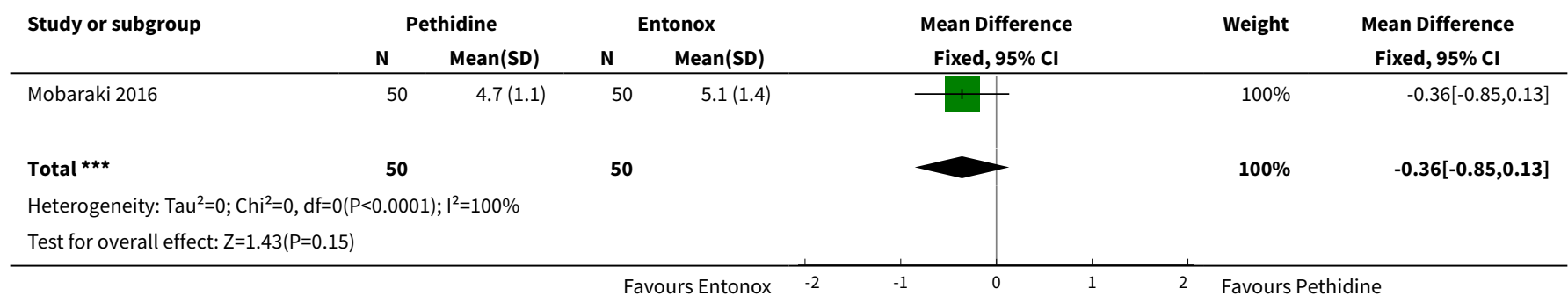

\section{Comparison 19. IV pethidine versus placebo}

\begin{tabular}{|c|c|c|c|c|}
\hline Outcome or subgroup title & No. of studies & $\begin{array}{l}\text { No. of partici- } \\
\text { pants }\end{array}$ & Statistical method & Effect size \\
\hline $\begin{array}{l}1 \text { Maternal pain score or pain mea- } \\
\text { sured in labour (Pain score } 30 \text { mins } \\
\text { post analgesia) }\end{array}$ & 1 & 240 & $\begin{array}{l}\text { Mean Difference (IV, Fixed, 95\% } \\
\mathrm{CI})\end{array}$ & $-4.1[-4.56,-3.64]$ \\
\hline 2 Nausea and vomiting & 1 & 240 & Risk Ratio (M-H, Fixed, 95\% Cl) & $2.43[1.05,5.64]$ \\
\hline 3 Caesarean section & 1 & 240 & Risk Ratio (M-H, Fixed, 95\% Cl) & $0.88[0.46,1.68]$ \\
\hline
\end{tabular}




\begin{tabular}{lllll}
\hline Outcome or subgroup title & No. of studies & $\begin{array}{l}\text { No. of partici- } \\
\text { pants }\end{array}$ & Statistical method & Effect size \\
\hline 4 Assisted vaginal birth & 1 & 240 & Risk Ratio (M-H, Fixed, 95\% Cl) & $0.75[0.33,1.71]$ \\
\hline 5 Admission to NICU & 1 & 240 & Risk Ratio (M-H, Fixed, 95\% Cl) & $0.67[0.11,3.92]$ \\
\hline
\end{tabular}

Analysis 19.1. Comparison 19 IV pethidine versus placebo, Outcome 1 Maternal pain score or pain measured in labour (Pain score $\mathbf{3 0}$ mins post analgesia).

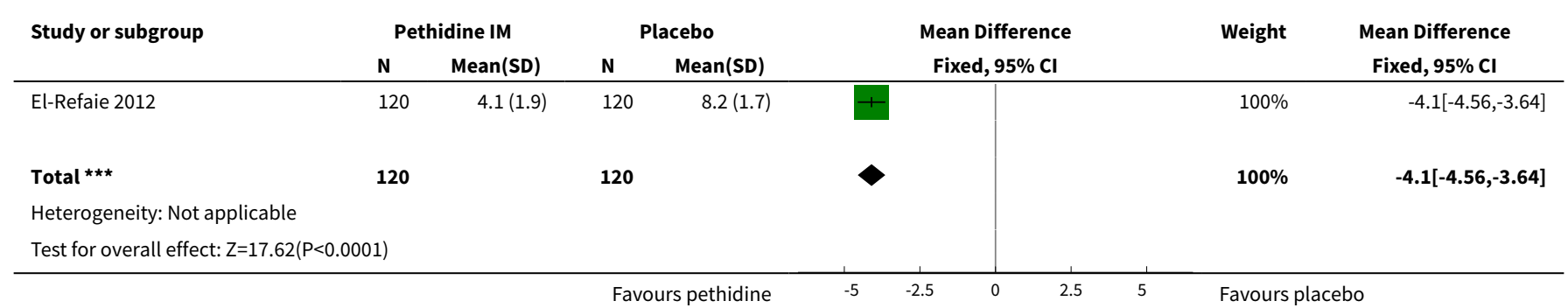

Analysis 19.2. Comparison 19 IV pethidine versus placebo, Outcome 2 Nausea and vomiting.

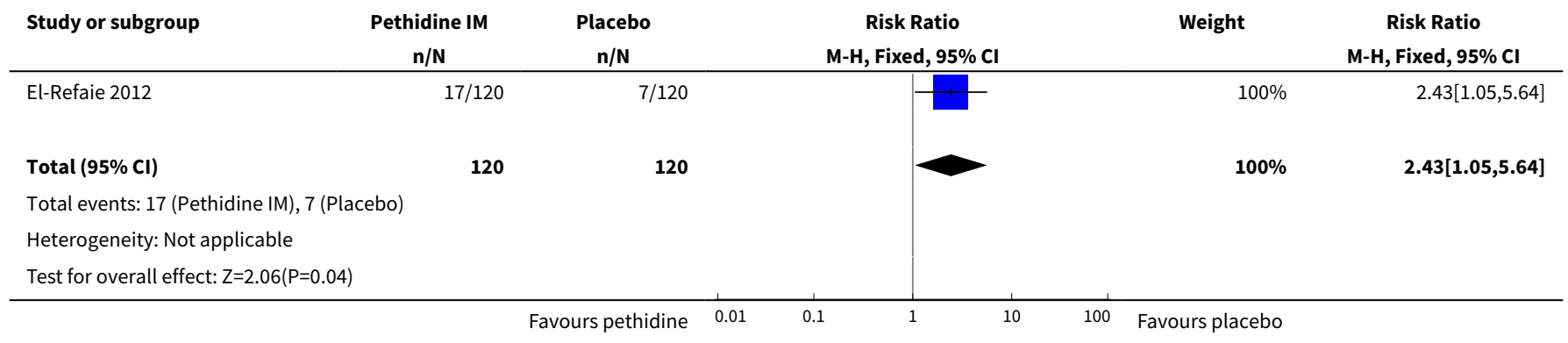

Analysis 19.3. Comparison 19 IV pethidine versus placebo, Outcome 3 Caesarean section.

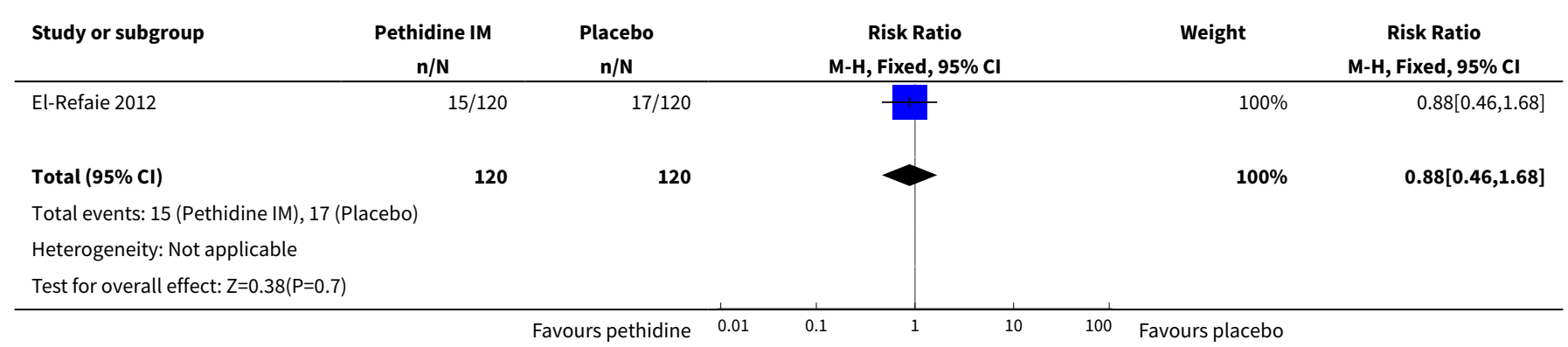


Analysis 19.4. Comparison 19 IV pethidine versus placebo, Outcome 4 Assisted vaginal birth.

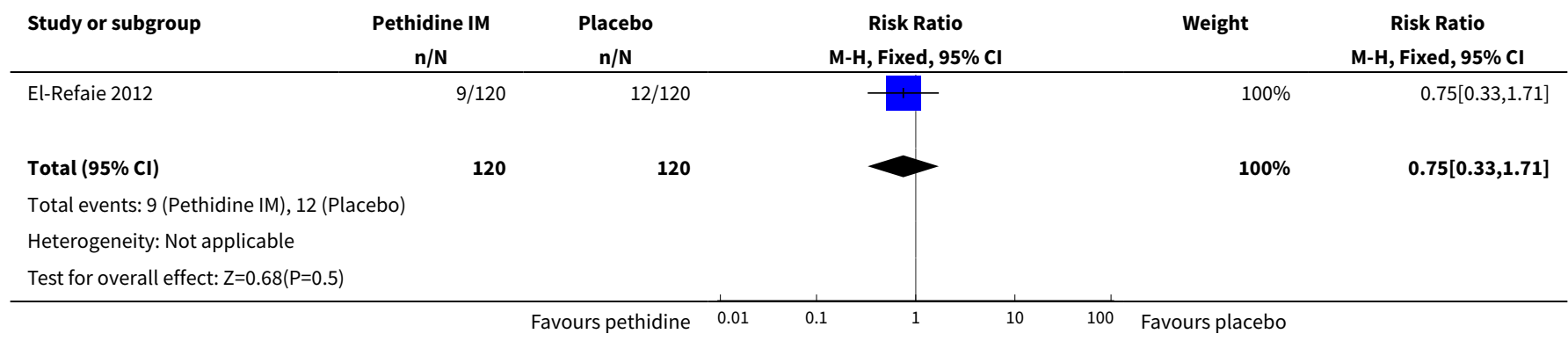

Analysis 19.5. Comparison 19 IV pethidine versus placebo, Outcome 5 Admission to NICU.

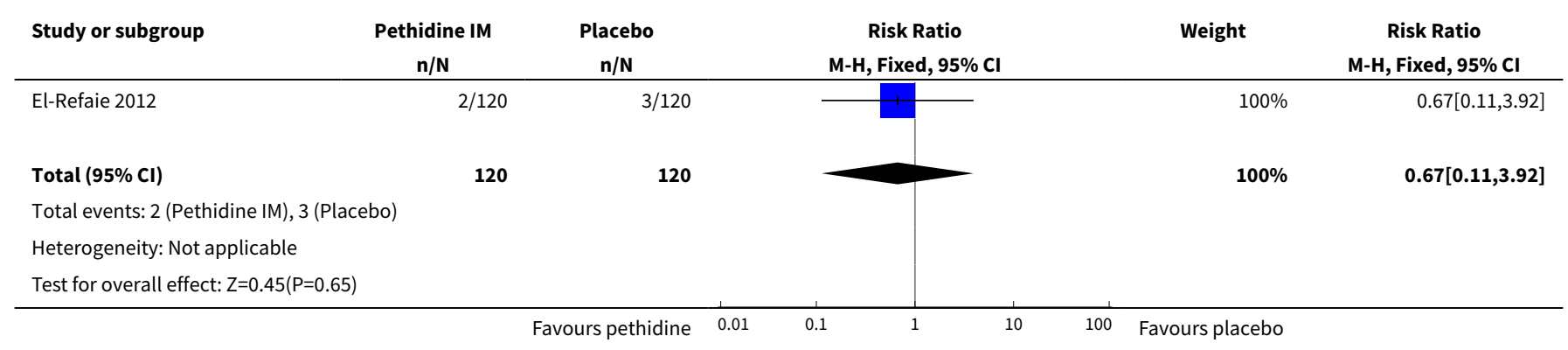

\section{Comparison 20. IV fentanyl versus no treatment}

\begin{tabular}{lllll}
\hline Outcome or subgroup title & No. of studies & $\begin{array}{l}\text { No. of partici- } \\
\text { pants }\end{array}$ & Statistical method & Effect size \\
\hline $\begin{array}{l}\text { 1 Maternal pain score or pain measured in } \\
\text { labour (Pain score 1 hour post-analgesia) }\end{array}$ & 1 & 70 & $\begin{array}{l}\text { Mean Difference (IV, } \\
\text { Fixed, 95\% Cl) }\end{array}$ & $-5.0[-5.47,-4.53]$ \\
\hline $\begin{array}{l}\text { 2 Maternal pain score or pain measured in } \\
\text { labour (Pain intensity (Severe) after 1 hour) }\end{array}$ & 1 & 70 & $\begin{array}{l}\text { Risk Ratio (M-H, Fixed, } \\
95 \% \mathrm{Cl})\end{array}$ & $0.02[0.00,0.25]$ \\
\hline 3 Caesarean section & 1 & Risk Ratio (M-H, Fixed, & $95 \% \mathrm{Cl})$ \\
\hline
\end{tabular}

Analysis 20.1. Comparison 20 IV fentanyl versus no treatment, Outcome 1 Maternal pain score or pain measured in labour (Pain score 1 hour post-analgesia).

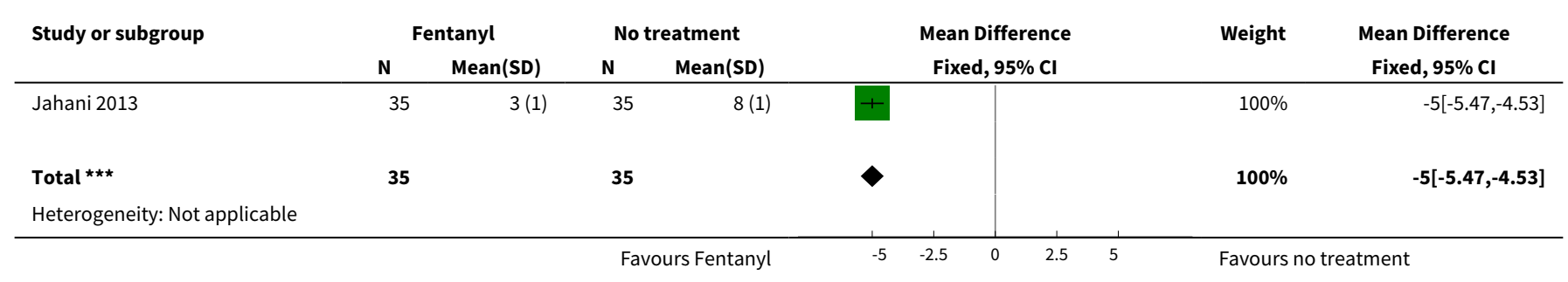




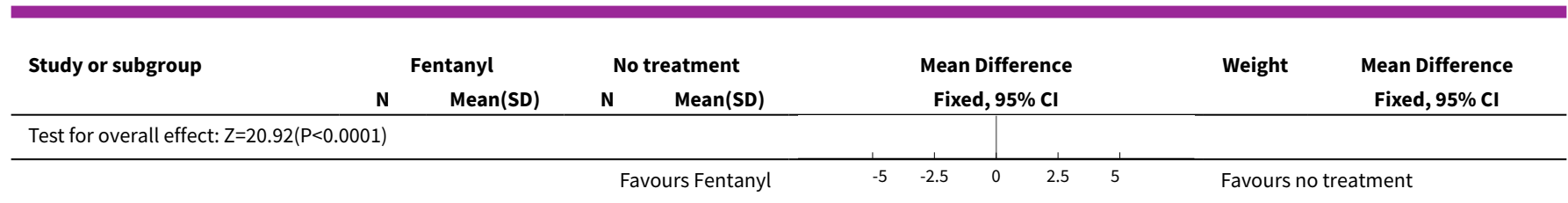

Analysis 20.2. Comparison 20 IV fentanyl versus no treatment, Outcome 2 Maternal pain score or pain measured in labour (Pain intensity (Severe) after 1 hour).

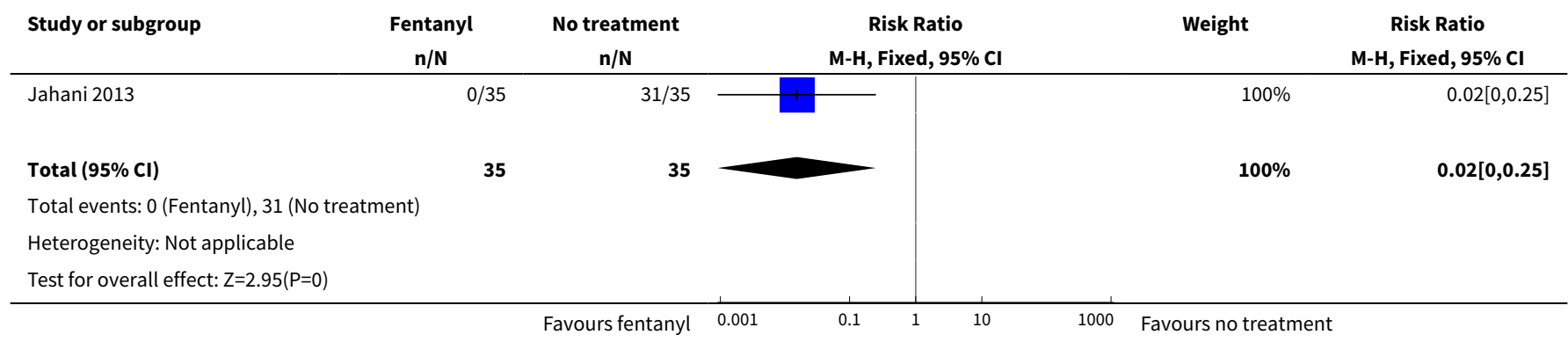

Analysis 20.3. Comparison 20 IV fentanyl versus no treatment, Outcome 3 Caesarean section.

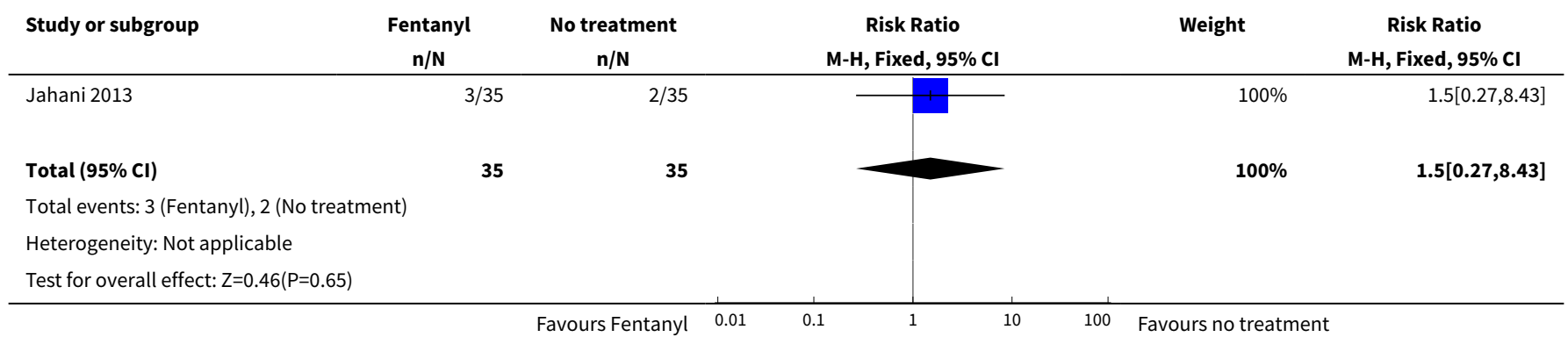

\section{Comparison 21. IV fentanyl versus IV pethidine}

\begin{tabular}{|c|c|c|c|c|}
\hline Outcome or subgroup title & No. of studies & $\begin{array}{l}\text { No. of partici- } \\
\text { pants }\end{array}$ & Statistical method & Effect size \\
\hline $\begin{array}{l}1 \text { Maternal pain score or pain mea- } \\
\text { sured in labour (Pain score } 1 \text { hour af- } \\
\text { ter drug administration) }\end{array}$ & 1 & 105 & $\begin{array}{l}\text { Mean Difference (IV, Fixed, } \\
95 \% \mathrm{Cl} \text { ) }\end{array}$ & $-0.20[-1.18,0.78]$ \\
\hline $\begin{array}{l}2 \text { Mean doses of analgesia (non pre- } \\
\text { specified) }\end{array}$ & 1 & 105 & $\begin{array}{l}\text { Mean Difference (IV, Fixed, } \\
95 \% \mathrm{CI} \text { ) }\end{array}$ & $0.40[0.14,0.66]$ \\
\hline $\begin{array}{l}3 \text { Maternal sleepiness in labour (seda- } \\
\text { tion) }\end{array}$ & 1 & 105 & $\begin{array}{l}\text { Risk Ratio (M-H, Fixed, 95\% } \\
\mathrm{Cl})\end{array}$ & $0.05[0.00,0.82]$ \\
\hline 4 Nausea and/or vomiting & 1 & 105 & $\begin{array}{l}\text { Risk Ratio (M-H, Fixed, 95\% } \\
\text { Cl) }\end{array}$ & $0.51[0.17,1.55]$ \\
\hline
\end{tabular}




\begin{tabular}{|c|c|c|c|c|}
\hline Outcome or subgroup title & No. of studies & $\begin{array}{l}\text { No. of partici- } \\
\text { pants }\end{array}$ & Statistical method & Effect size \\
\hline $\begin{array}{l}5 \text { Anti-emetic required (non pre-spec- } \\
\text { ified) }\end{array}$ & 1 & 105 & $\begin{array}{l}\text { Risk Ratio (M-H, Fixed, 95\% } \\
\mathrm{Cl} \text { ) }\end{array}$ & $0.09[0.01,1.52]$ \\
\hline 6 Caesarean section & 1 & 105 & $\begin{array}{l}\text { Risk Ratio (M-H, Fixed, 95\% } \\
\mathrm{Cl} \text { ) }\end{array}$ & $1.14[0.24,5.40]$ \\
\hline 7 Naloxone administered & 1 & 105 & $\begin{array}{l}\text { Risk Ratio (M-H, Fixed, 95\% } \\
\mathrm{Cl})\end{array}$ & $0.16[0.02,1.28]$ \\
\hline $\begin{array}{l}8 \text { Babies requiring resuscitation/ven- } \\
\text { tilatory support }\end{array}$ & 1 & 105 & $\begin{array}{l}\text { Risk Ratio (M-H, Fixed, 95\% } \\
\mathrm{Cl})\end{array}$ & $1.03[0.46,2.32]$ \\
\hline 9 Apgar score $<7$ at 1 minute & 1 & & $\begin{array}{l}\text { Risk Ratio (M-H, Fixed, 95\% } \\
\mathrm{Cl})\end{array}$ & Subtotals only \\
\hline 10 Apgar score $<7$ at 5 minutes & 1 & & $\begin{array}{l}\text { Risk Ratio (M-H, Fixed, 95\% } \\
\mathrm{Cl})\end{array}$ & Subtotals only \\
\hline $\begin{array}{l}11 \text { Neurobehavioural score (1 - } 2 \\
\text { hours after delivery) }\end{array}$ & 1 & 105 & $\begin{array}{l}\text { Mean Difference (IV, Fixed, } \\
95 \% \mathrm{CI} \text { ) }\end{array}$ & $1.30[0.15,2.45]$ \\
\hline $\begin{array}{l}12 \text { Neurobehavioural score ( } 2 \text { hours - } \\
24 \text { hours) }\end{array}$ & 1 & 105 & $\begin{array}{l}\text { Mean Difference (IV, Fixed, } \\
95 \% \mathrm{CI})\end{array}$ & $0.90[-0.42,2.22]$ \\
\hline
\end{tabular}

Analysis 21.1. Comparison 21 IV fentanyl versus IV pethidine, Outcome 1 Maternal pain score or pain measured in labour (Pain score 1 hour after drug administration).

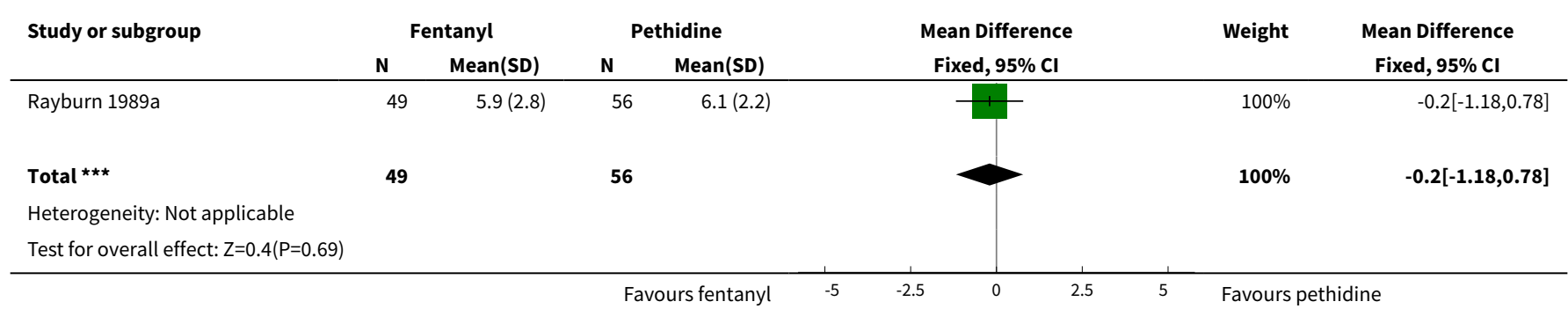

Analysis 21.2. Comparison 21 IV fentanyl versus IV pethidine, Outcome 2 Mean doses of analgesia (non pre-specified).

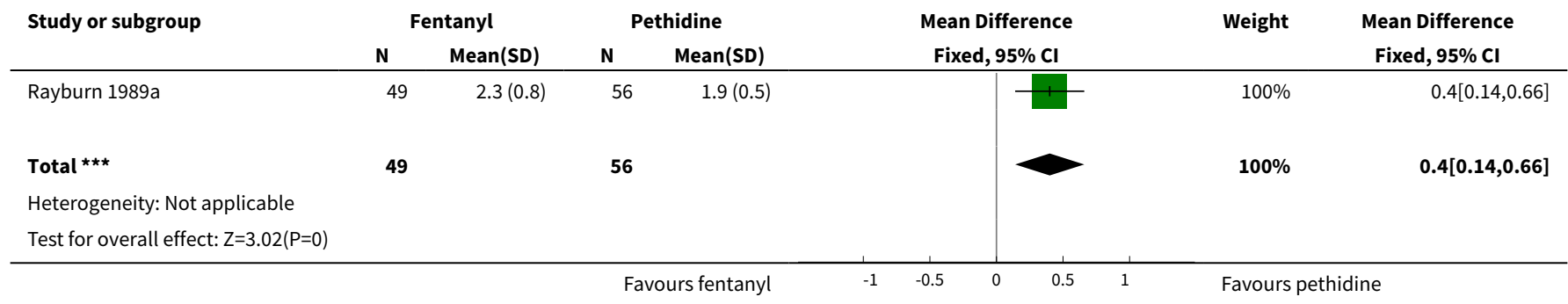


Analysis 21.3. Comparison 21 IV fentanyl versus IV pethidine, Outcome 3 Maternal sleepiness in labour (sedation).

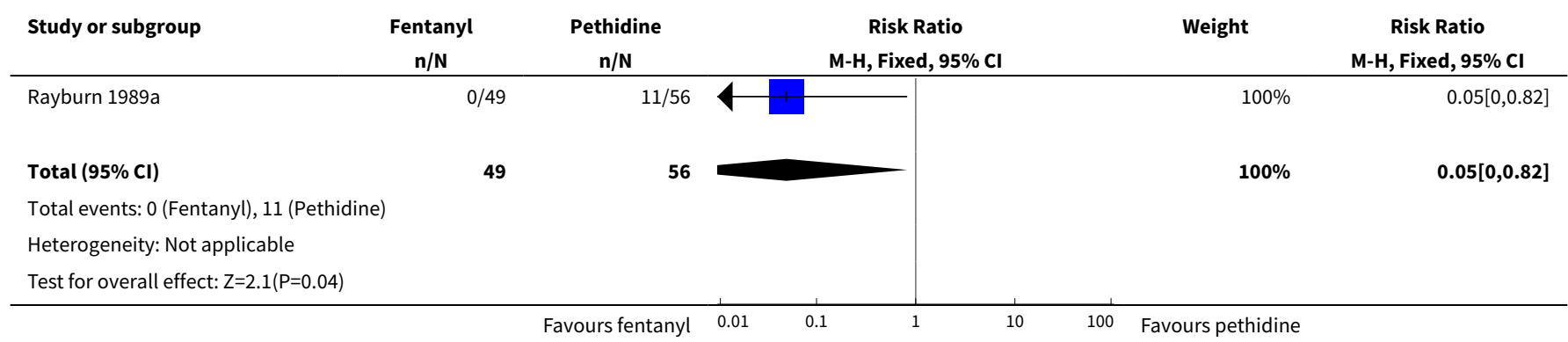

Analysis 21.4. Comparison 21 IV fentanyl versus IV pethidine, Outcome 4 Nausea and/or vomiting.

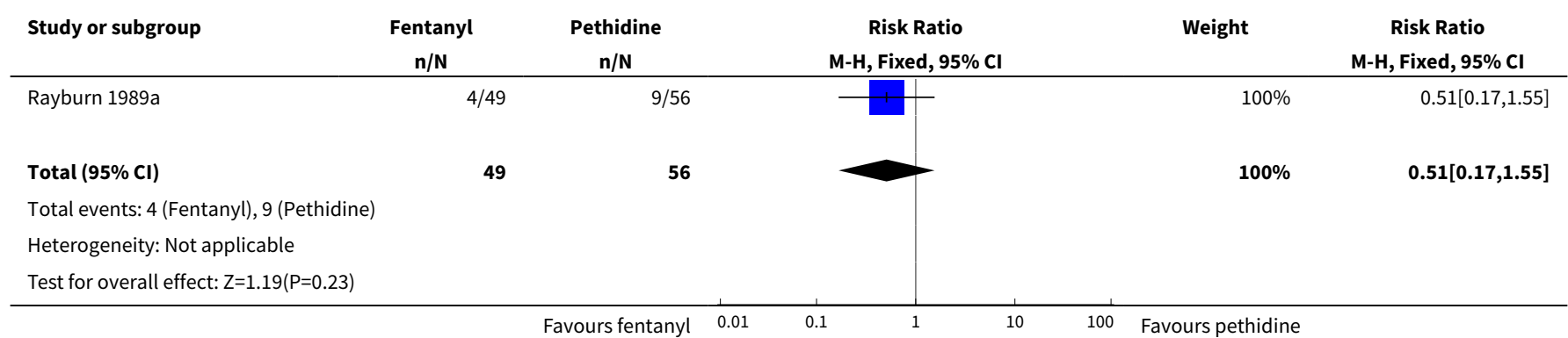

Analysis 21.5. Comparison 21 IV fentanyl versus IV pethidine, Outcome 5 Anti-emetic required (non pre-specified).

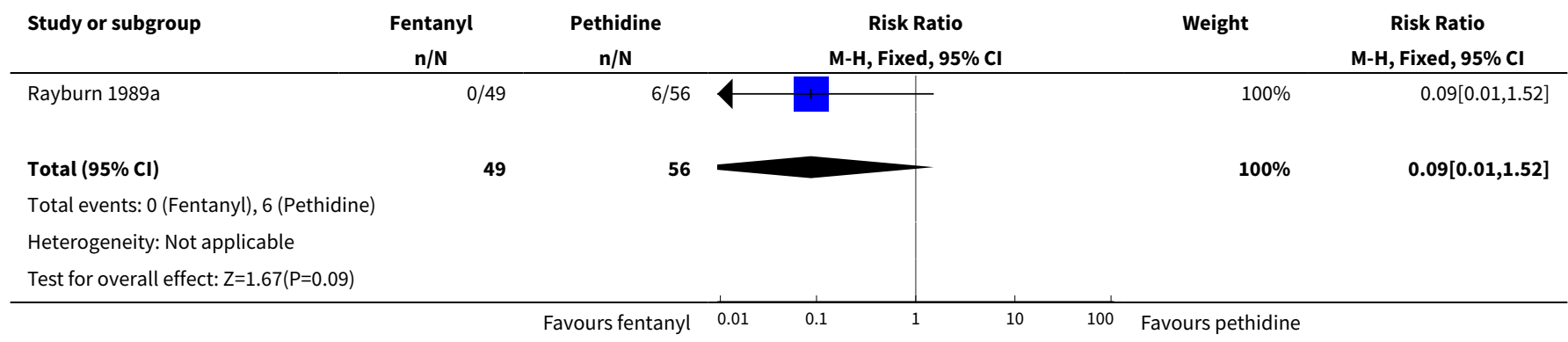

Analysis 21.6. Comparison 21 IV fentanyl versus IV pethidine, Outcome 6 Caesarean section.

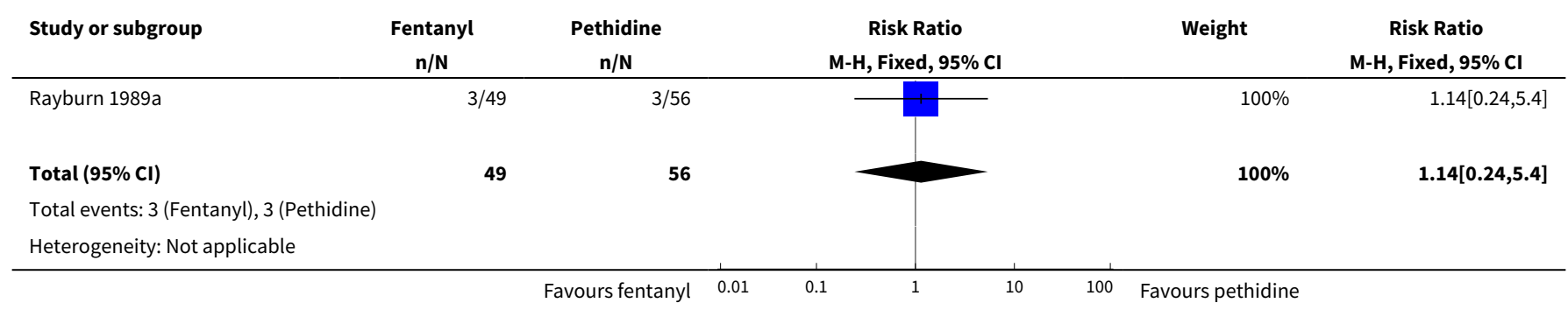




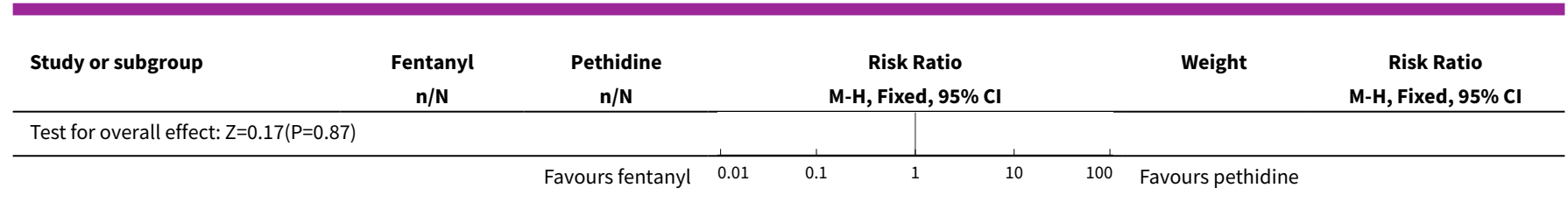

Analysis 21.7. Comparison 21 IV fentanyl versus IV pethidine, Outcome 7 Naloxone administered.

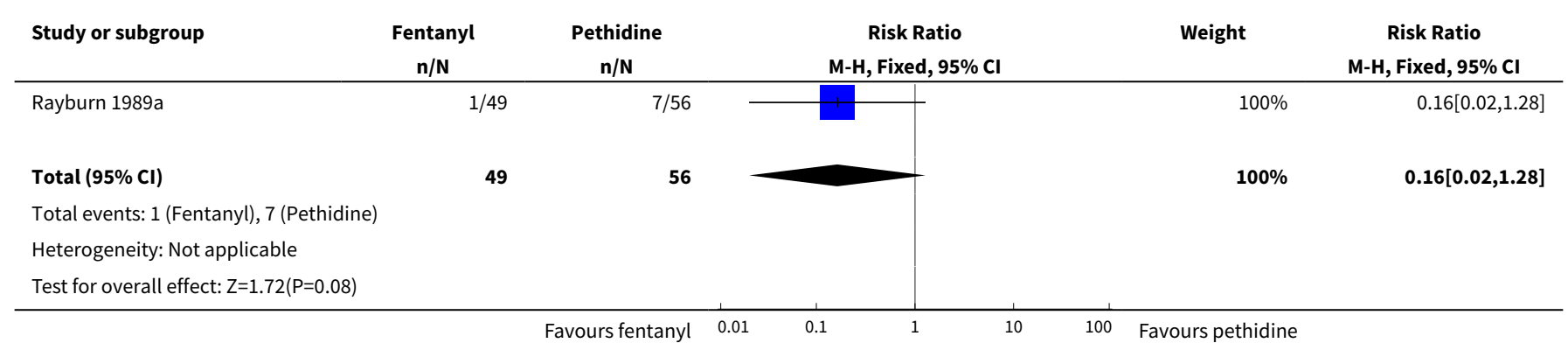

Analysis 21.8. Comparison 21 IV fentanyl versus IV pethidine, Outcome 8 Babies requiring resuscitation/ventilatory support.

\begin{tabular}{|c|c|c|c|c|c|}
\hline Study or subgroup & $\begin{array}{c}\text { Experimental } \\
n / N\end{array}$ & $\begin{array}{c}\text { Pethidine } \\
\mathrm{n} / \mathrm{N}\end{array}$ & $\begin{array}{c}\text { Risk Ratio } \\
\text { M-H, Fixed, 95\% Cl }\end{array}$ & Weight & $\begin{array}{c}\text { Risk Ratio } \\
\text { M-H, Fixed, 95\% Cl }\end{array}$ \\
\hline Rayburn 1989a & $9 / 49$ & $10 / 56$ & . & $100 \%$ & $1.03[0.46,2.32]$ \\
\hline Total $(95 \% \mathrm{Cl})$ & 49 & 56 & & $100 \%$ & $1.03[0.46,2.32]$ \\
\hline \multicolumn{6}{|c|}{ Total events: 9 (Experimental), 10 (Pethidine) } \\
\hline \multicolumn{6}{|c|}{ Heterogeneity: Not applicable } \\
\hline
\end{tabular}

Analysis 21.9. Comparison 21 IV fentanyl versus IV pethidine, Outcome 9 Apgar score $<7$ at 1 minute.

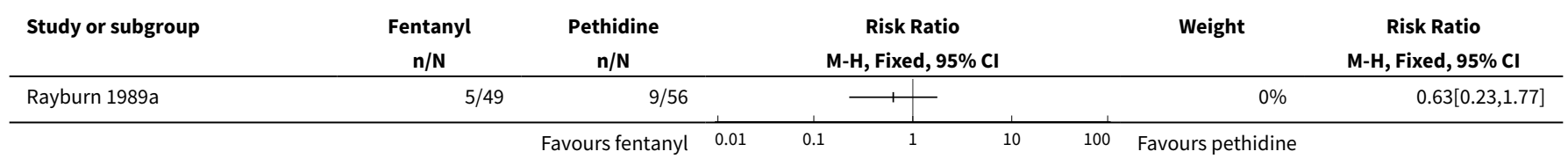

Analysis 21.10. Comparison 21 IV fentanyl versus IV pethidine, Outcome 10 Apgar score $<7$ at 5 minutes.

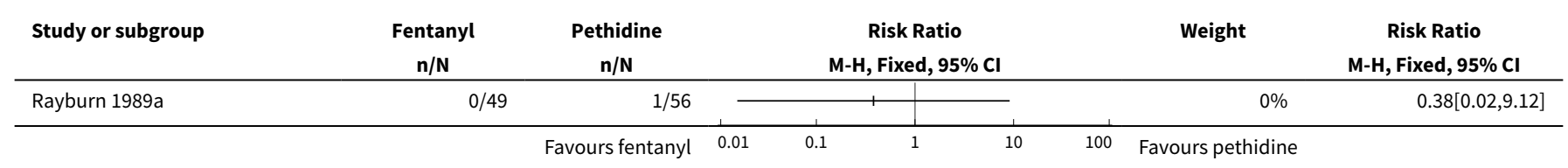


Analysis 21.11. Comparison 21 IV fentanyl versus IV pethidine, Outcome 11 Neurobehavioural score (1 - 2 hours after delivery).

\begin{tabular}{|c|c|c|c|c|c|c|c|}
\hline \multirow{3}{*}{$\begin{array}{l}\text { Study or subgroup } \\
\text { Rayburn 1989a }\end{array}$} & \multicolumn{2}{|c|}{ Fentanyl } & \multicolumn{2}{|c|}{ Pethidine } & \multirow{2}{*}{$\begin{array}{c}\text { Mean Difference } \\
\text { Fixed, } 95 \% \mathrm{Cl}\end{array}$} & \multirow[t]{2}{*}{ Weight } & \multirow{2}{*}{$\begin{array}{c}\text { Mean Difference } \\
\text { Fixed, } 95 \% \mathrm{Cl}\end{array}$} \\
\hline & $\mathbf{N}$ & Mean(SD) & $\mathbf{N}$ & Mean(SD) & & & \\
\hline & 49 & $33.2(2.9)$ & 56 & $31.9(3.1)$ & & $100 \%$ & $1.3[0.15,2.45]$ \\
\hline Total $\star \star \star ~$ & 49 & & 56 & & & $100 \%$ & $1.3[0.15,2.45]$ \\
\hline \multicolumn{8}{|l|}{ Heterogeneity: Not applicable } \\
\hline \multicolumn{8}{|l|}{ Test for overall effect: $Z=2.22(P=0.03)$} \\
\hline
\end{tabular}

Analysis 21.12. Comparison 21 IV fentanyl versus IV pethidine, Outcome 12 Neurobehavioural score (2 hours - 24 hours).

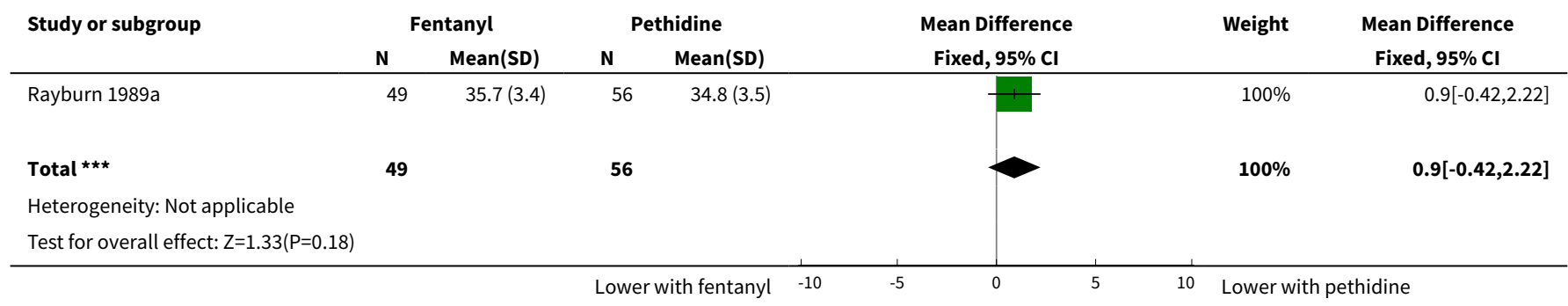

\section{Comparison 22. IV nalbuphine versus IV pethidine}

\begin{tabular}{lllll}
\hline Outcome or subgroup title & No. of studies & $\begin{array}{l}\text { No. of partici- } \\
\text { pants }\end{array}$ & Statistical method & Effect size \\
\hline 1 Caesarean section & 1 & 28 & Risk Ratio (M-H, Fixed, 95\% Cl) & $5.0[0.26,95.61]$ \\
\hline 2 Apgar score < 7 at 1 minute & 1 & Risk Ratio (M-H, Fixed, 95\% Cl) & Subtotals only \\
\hline 3 Apgar score $<7$ at 5 minutes & 1 & Risk Ratio (M-H, Fixed, 95\% Cl) & Subtotals only \\
\hline
\end{tabular}

Analysis 22.1. Comparison 22 IV nalbuphine versus IV pethidine, Outcome 1 Caesarean section.

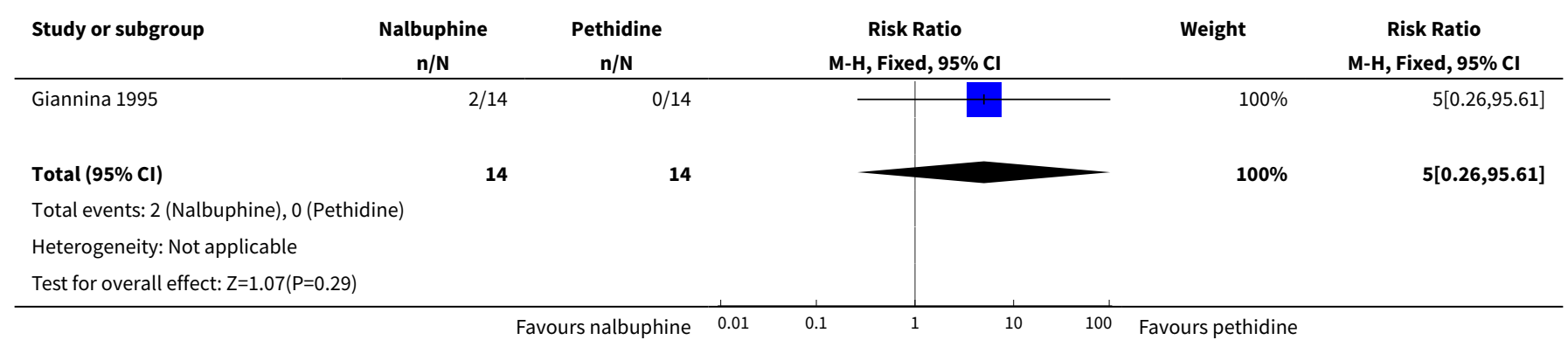


Analysis 22.2. Comparison 22 IV nalbuphine versus IV pethidine, Outcome 2 Apgar score $<7$ at 1 minute.

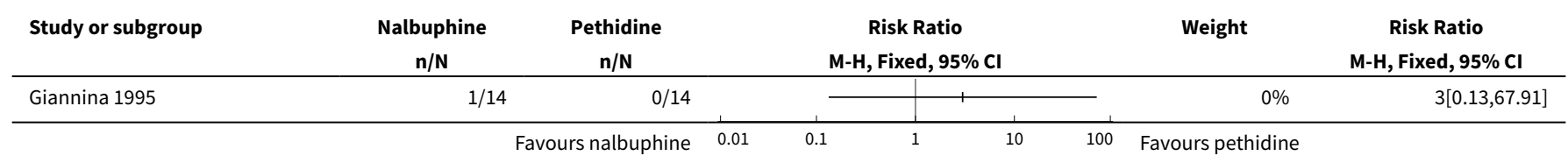

Analysis 22.3. Comparison 22 IV nalbuphine versus IV pethidine, Outcome 3 Apgar score $<7$ at 5 minutes.

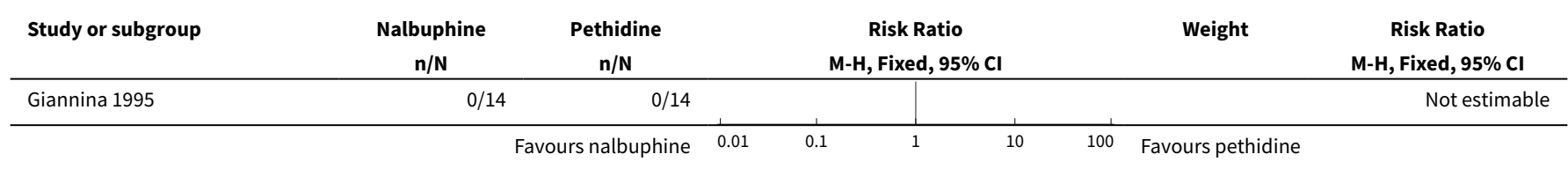

\section{Comparison 23. IV phenazocine versus IV pethidine}

\begin{tabular}{lllll}
\hline Outcome or subgroup title & No. of studies & $\begin{array}{l}\text { No. of partici- } \\
\text { pants }\end{array}$ & Statistical method & Effect size \\
\hline $\begin{array}{l}\text { 1 Maternal satisfaction with analgesia } \\
\text { measured during labour (women with } \\
\text { fair or poor relief) }\end{array}$ & 1 & 194 & $\begin{array}{l}\text { Risk Ratio (M-H, Fixed, 95\% } \\
\text { Cl) }\end{array}$ & $0.72[0.48,1.10]$ \\
\hline $\begin{array}{l}\text { 2 Nausea with vomiting } \\
\text { 3 Perinatal death }\end{array}$ & 1 & 194 & $\begin{array}{l}\text { Risk Ratio (M-H, Fixed, 95\% } \\
\text { Cl) }\end{array}$ & $0.4[0.08,2.01]$ \\
\hline 4 Apgar score $<7$ at 1 minute & 1 & 194 & $\begin{array}{l}\text { Risk Ratio (M-H, Fixed, 95\% } \\
\text { Cl) }\end{array}$ & $0.0[0.0,0.0]$ \\
\hline
\end{tabular}

Analysis 23.1. Comparison 23 IV phenazocine versus IV pethidine, Outcome 1 Maternal satisfaction with analgesia measured during labour (women with fair or poor relief).

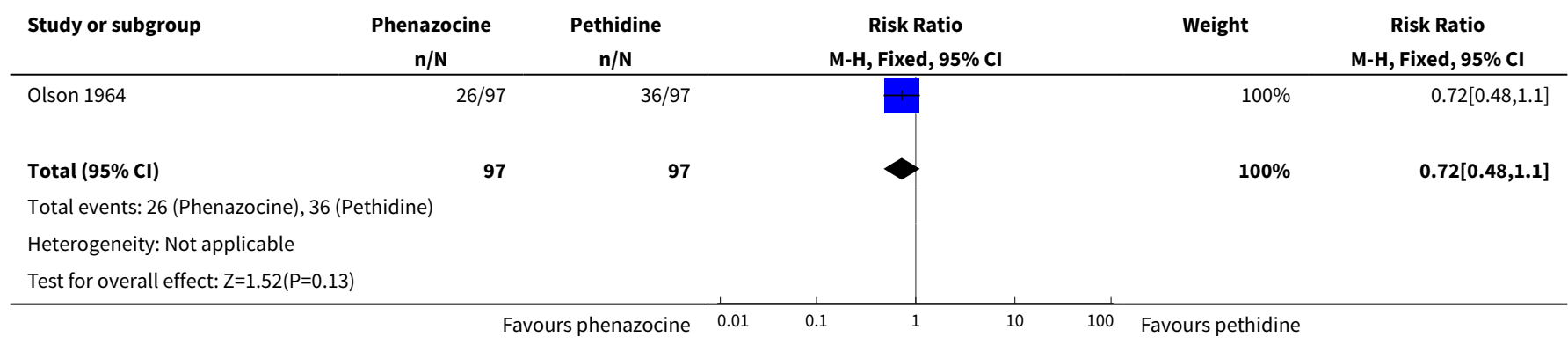


Analysis 23.2. Comparison 23 IV phenazocine versus IV pethidine, Outcome 2 Nausea with vomiting.

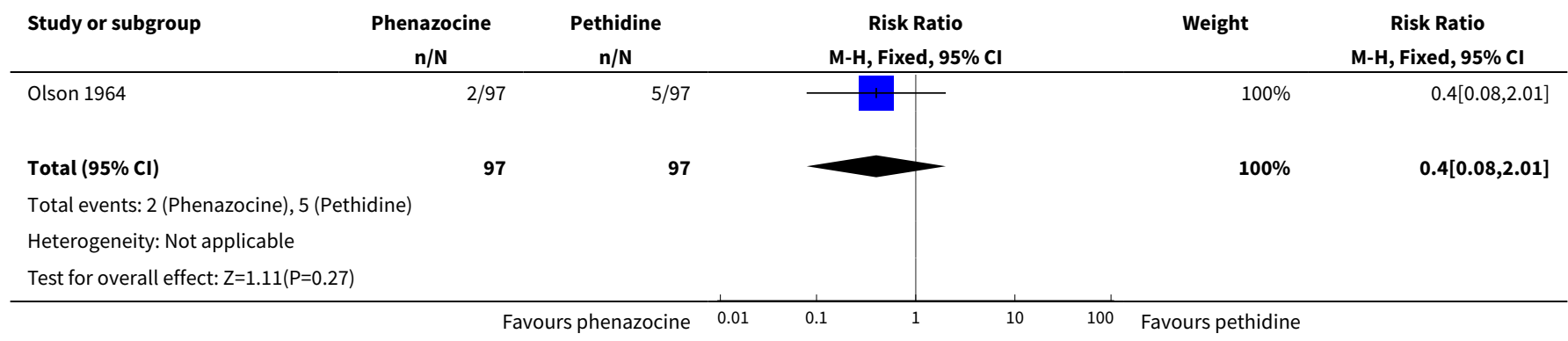

Analysis 23.3. Comparison 23 IV phenazocine versus IV pethidine, Outcome 3 Perinatal death.

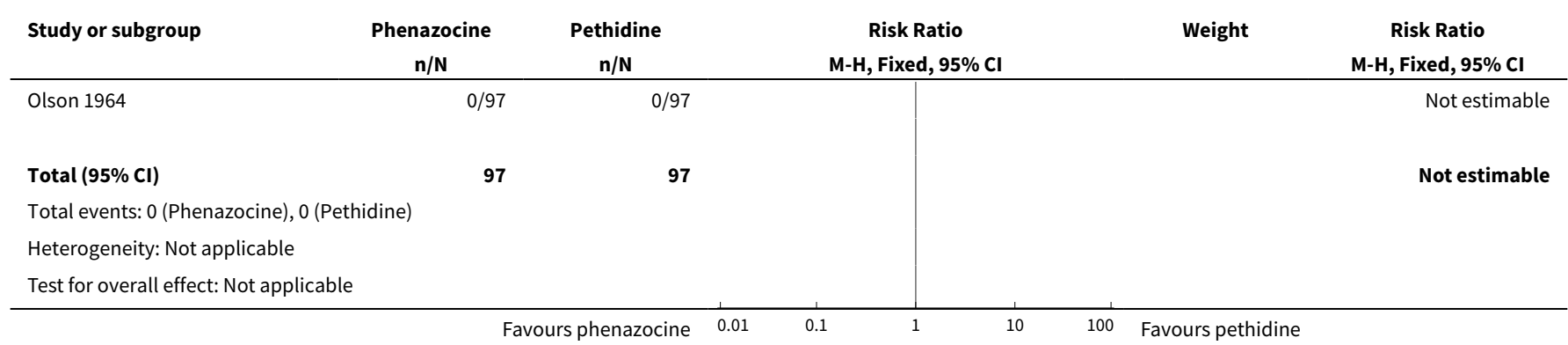

Analysis 23.4. Comparison 23 IV phenazocine versus IV pethidine, Outcome 4 Apgar score $<7$ at 1 minute.

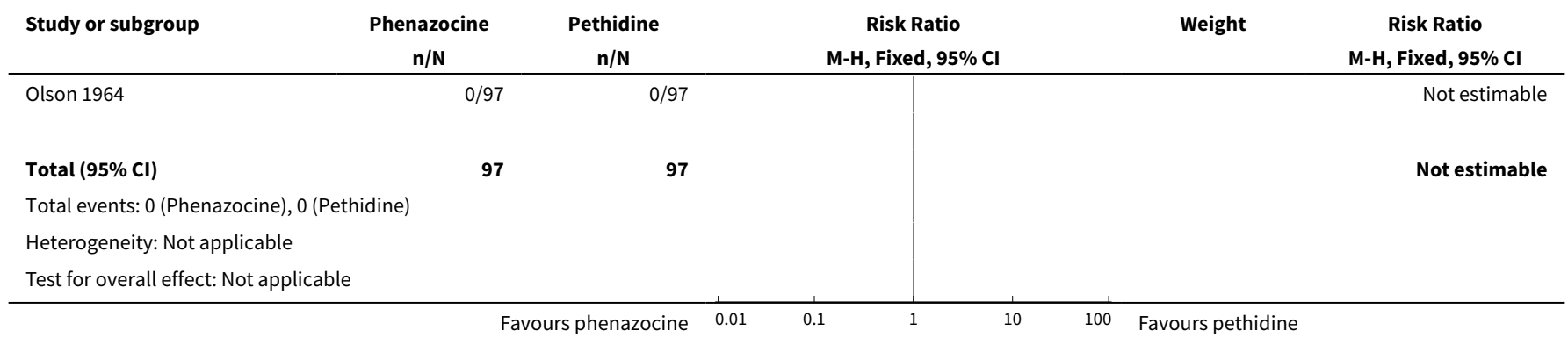

\section{Comparison 24. IV butorphanol versus IV pethidine}

\begin{tabular}{lllll}
\hline Outcome or subgroup title & No. of studies & $\begin{array}{l}\text { No. of partici- } \\
\text { pants }\end{array}$ & Statistical method & Effect size \\
\hline $\begin{array}{l}1 \text { Maternal pain score or pain mea- } \\
\text { sured in labour (Pain relief score) }\end{array}$ & 1 & 80 & $\begin{array}{l}\text { Mean Difference (IV, Fixed, 95\% } \\
\text { Cl) }\end{array}$ & $0.67[0.25,1.09]$ \\
\hline $\begin{array}{l}2 \text { Maternal pain score or pain mea- } \\
\text { sured in labour (Pain score (1 hour } \\
\text { after drug administration)) }\end{array}$ & 1 & 80 & $\begin{array}{l}\text { Mean Difference (IV, Fixed, 95\% } \\
\text { Cl) }\end{array}$ & $-0.60[-1.02,-0.18]$ \\
\hline
\end{tabular}




\begin{tabular}{lllll}
\hline Outcome or subgroup title & No. of studies & $\begin{array}{l}\text { No. of partici- } \\
\text { pants }\end{array}$ & Statistical method & Effect size \\
\hline 3 Additional analgesia required & 1 & 100 & Risk Ratio (M-H, Fixed, 95\% Cl) & $0.96[0.63,1.45]$ \\
\hline 4 Epidural & 1 & 200 & Risk Ratio (M-H, Fixed, 95\% Cl) & $1.0[0.30,3.35]$ \\
\hline 5 Nausea and/or vomiting & 1 & 200 & Risk Ratio (M-H, Fixed, 95\% Cl) & $0.04[0.00,0.67]$ \\
\hline 6 Caesarean section & 1 & 200 & Risk Ratio (M-H, Fixed, 95\% Cl) & $0.8[0.22,2.89]$ \\
\hline 7 Assisted vaginal birth & 1 & 200 & Risk Ratio (M-H, Fixed, 95\% Cl) & $1.3[0.60,2.83]$ \\
\hline 8 Apgar score $<7$ at 1 minute & 2 & Risk Ratio (M-H, Fixed, 95\% Cl) & Subtotals only \\
\hline 9 Apgar score $<7$ at 5 minutes & 2 & Risk Ratio $(\mathrm{M}-\mathrm{H}$, Fixed, 95\% Cl) & Subtotals only \\
\hline
\end{tabular}

Analysis 24.1. Comparison 24 IV butorphanol versus IV pethidine, Outcome 1 Maternal pain score or pain measured in labour (Pain relief score).

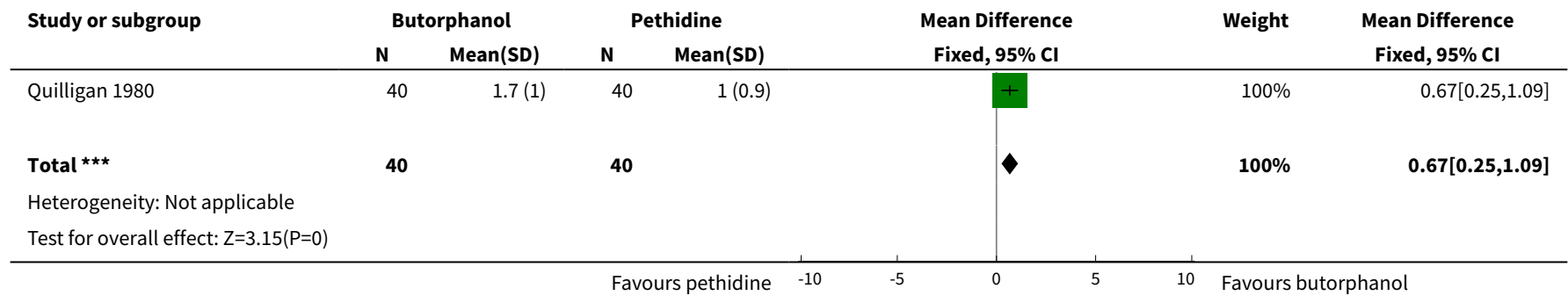

Analysis 24.2. Comparison 24 IV butorphanol versus IV pethidine, Outcome 2 Maternal pain score or pain measured in labour (Pain score (1 hour after drug administration)).

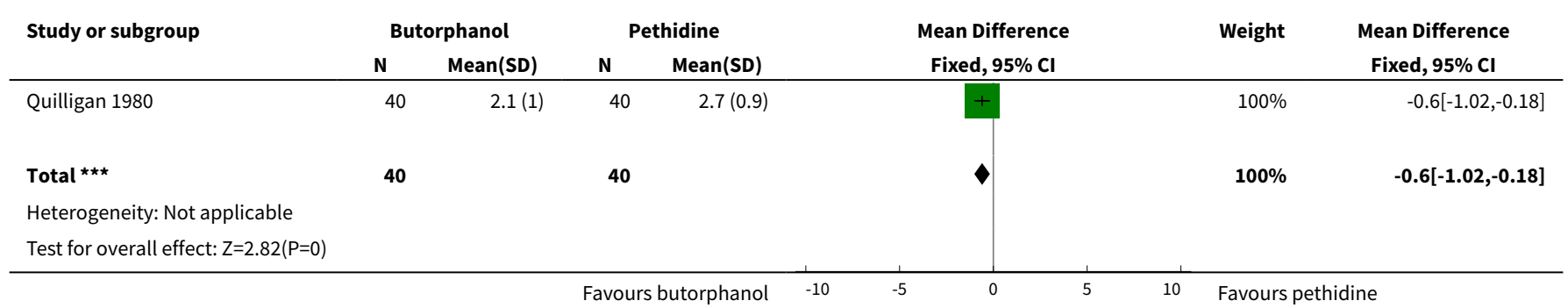

Analysis 24.3. Comparison 24 IV butorphanol versus IV pethidine, Outcome 3 Additional analgesia required.

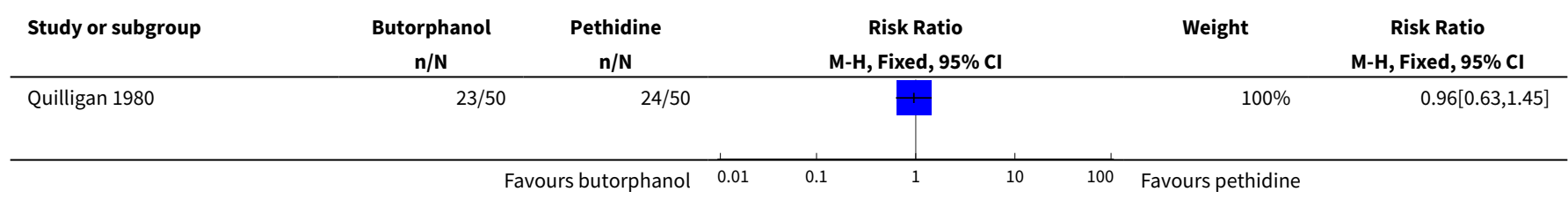




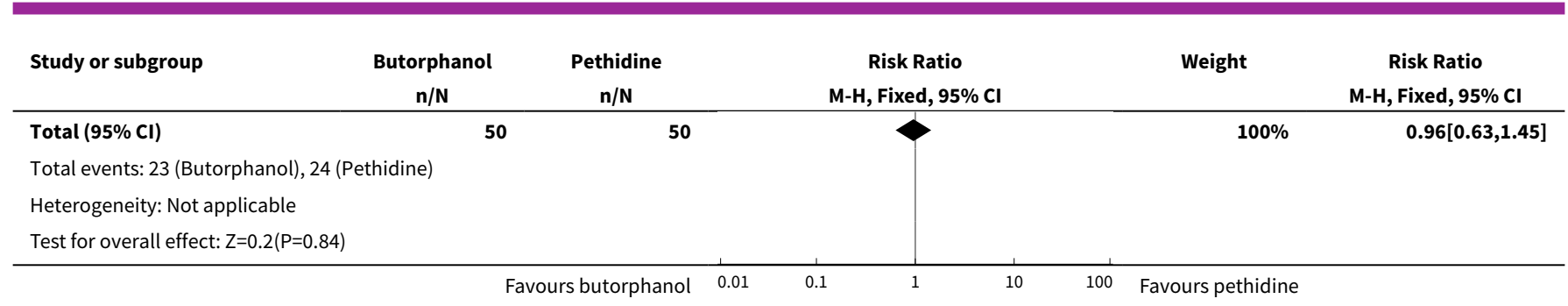

Analysis 24.4. Comparison 24 IV butorphanol versus IV pethidine, Outcome 4 Epidural.

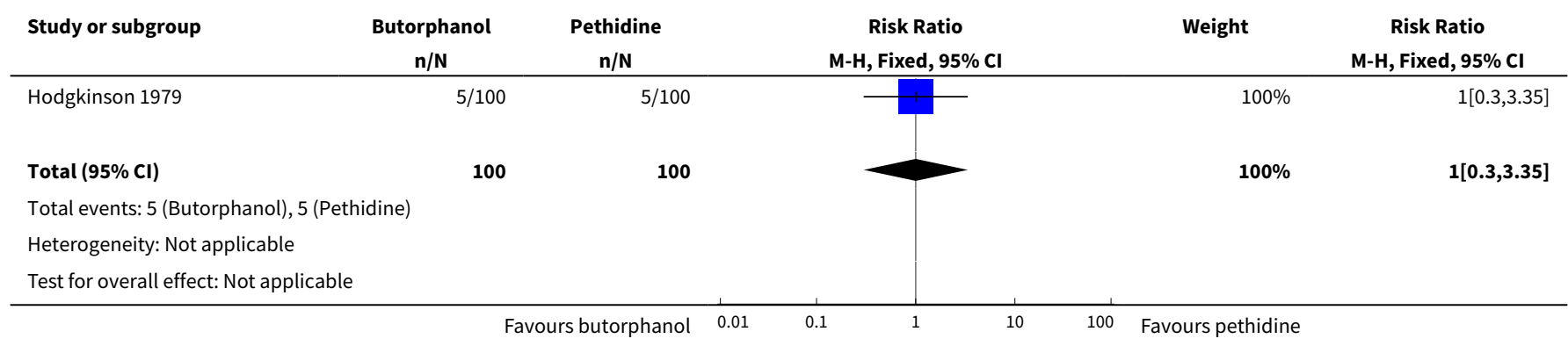

Analysis 24.5. Comparison 24 IV butorphanol versus IV pethidine, Outcome 5 Nausea and/or vomiting.

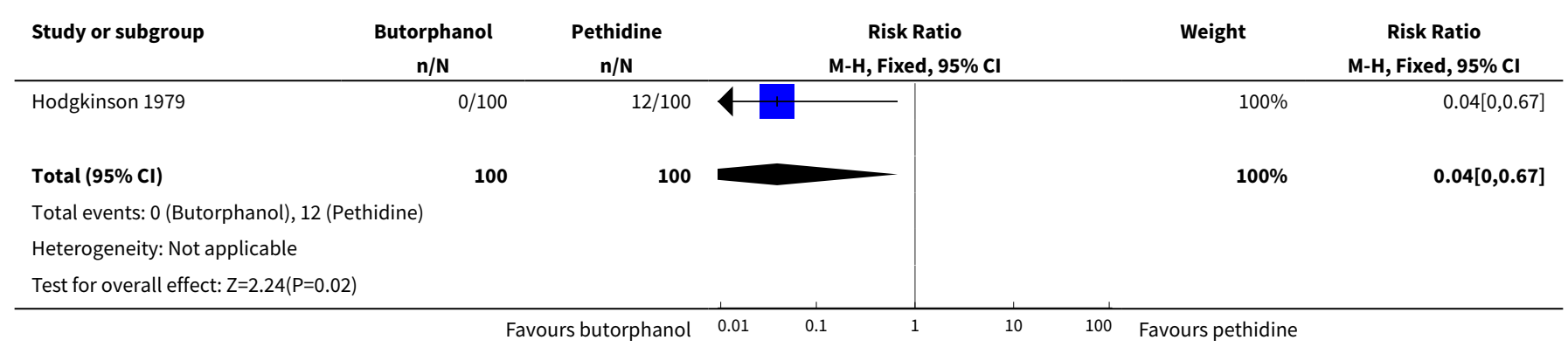

Analysis 24.6. Comparison 24 IV butorphanol versus IV pethidine, Outcome 6 Caesarean section.

\begin{tabular}{|c|c|c|c|c|c|}
\hline Study or subgroup & $\begin{array}{c}\text { Butorphanol } \\
n / N\end{array}$ & $\begin{array}{c}\text { Pethidine } \\
\mathrm{n} / \mathrm{N}\end{array}$ & $\begin{array}{c}\text { Risk Ratio } \\
\text { M-H, Fixed, 95\% Cl }\end{array}$ & Weight & $\begin{array}{c}\text { Risk Ratio } \\
\text { M-H, Fixed, } 95 \% \mathrm{Cl}\end{array}$ \\
\hline Hodgkinson 1979 & $4 / 100$ & $5 / 100$ & - & $100 \%$ & $0.8[0.22,2.89]$ \\
\hline Total $(95 \% \mathrm{Cl})$ & 100 & 100 & & $100 \%$ & $0.8[0.22,2.89]$ \\
\hline \multicolumn{6}{|c|}{ Total events: 4 (Butorphanol), 5 (Pethidine) } \\
\hline \multicolumn{6}{|c|}{ Heterogeneity: Not applicable } \\
\hline \multicolumn{6}{|c|}{ Test for overall effect: $Z=0.34(P=0.73)$} \\
\hline
\end{tabular}


Analysis 24.7. Comparison 24 IV butorphanol versus IV pethidine, Outcome 7 Assisted vaginal birth.

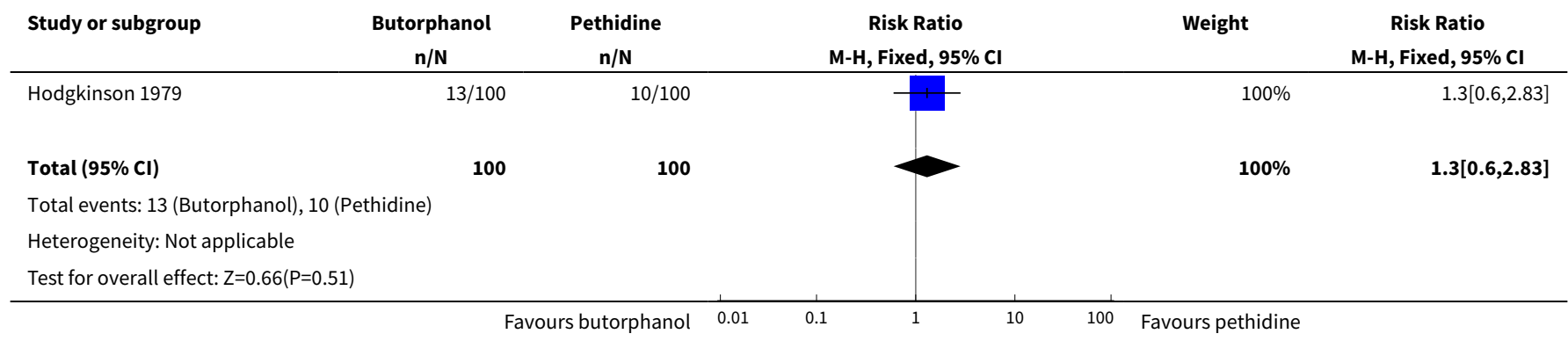

Analysis 24.8. Comparison 24 IV butorphanol versus IV pethidine, Outcome 8 Apgar score $<7$ at 1 minute.

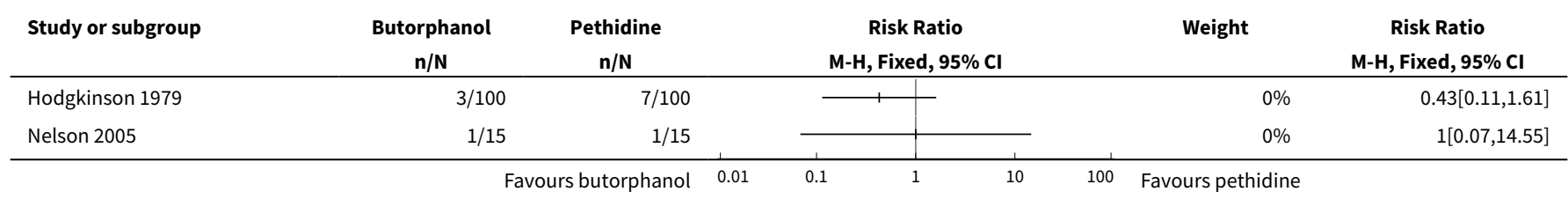

Analysis 24.9. Comparison 24 IV butorphanol versus IV pethidine, Outcome 9 Apgar score $<7$ at 5 minutes.

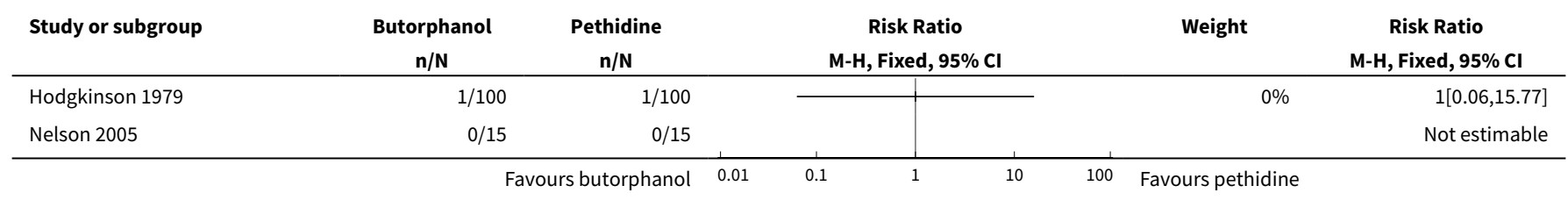

\section{Comparison 25. IV morphine versus IV pethidine}

\begin{tabular}{|c|c|c|c|c|}
\hline Outcome or subgroup title & No. of studies & $\begin{array}{l}\text { No. of partici- } \\
\text { pants }\end{array}$ & Statistical method & Effect size \\
\hline $\begin{array}{l}1 \text { Maternal satisfaction with } \\
\text { analgesia (assessed } 3 \text { days } \\
\text { postpartum) }\end{array}$ & 1 & 141 & Risk Ratio (M-H, Fixed, 95\% Cl) & $0.87[0.78,0.98]$ \\
\hline $\begin{array}{l}2 \text { Additional analgesia re- } \\
\text { quired }\end{array}$ & 1 & 143 & Risk Ratio (M-H, Fixed, 95\% Cl) & $3.41[1.90,6.12]$ \\
\hline 3 Nausea and vomiting & 1 & & Risk Ratio (M-H, Fixed, 95\% Cl) & Subtotals only \\
\hline 3.1 Nausea & 1 & 20 & Risk Ratio (M-H, Fixed, 95\% Cl) & $0.17[0.02,1.14]$ \\
\hline 3.2 Vomiting & 1 & 20 & Risk Ratio (M-H, Fixed, 95\% Cl) & $0.25[0.03,1.86]$ \\
\hline 4 Caesarean section & 1 & 20 & Risk Ratio (M-H, Fixed, 95\% Cl) & $0.0[0.0,0.0]$ \\
\hline
\end{tabular}


Analysis 25.1. Comparison 25 IV morphine versus IV pethidine, Outcome

1 Maternal satisfaction with analgesia (assessed 3 days postpartum).

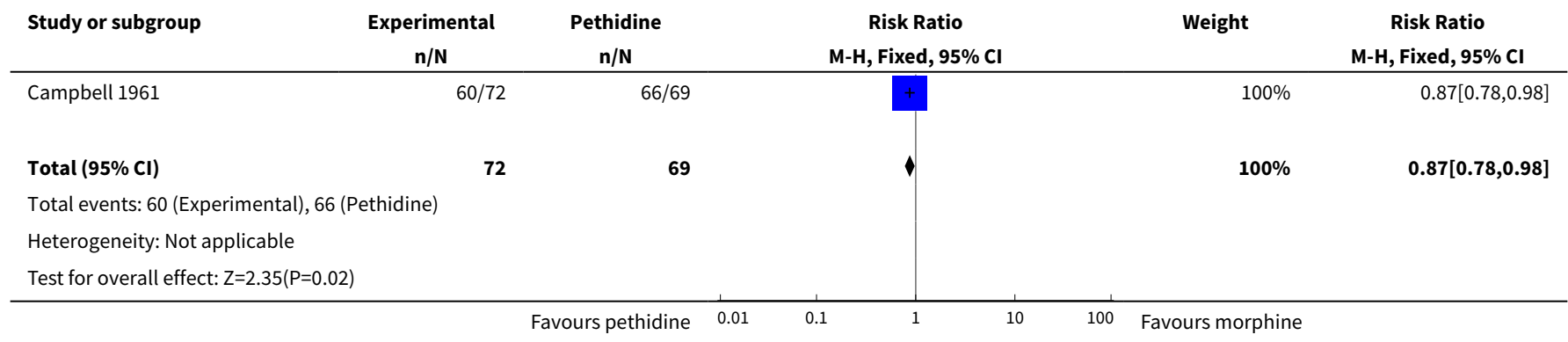

Analysis 25.2. Comparison 25 IV morphine versus IV pethidine, Outcome 2 Additional analgesia required.

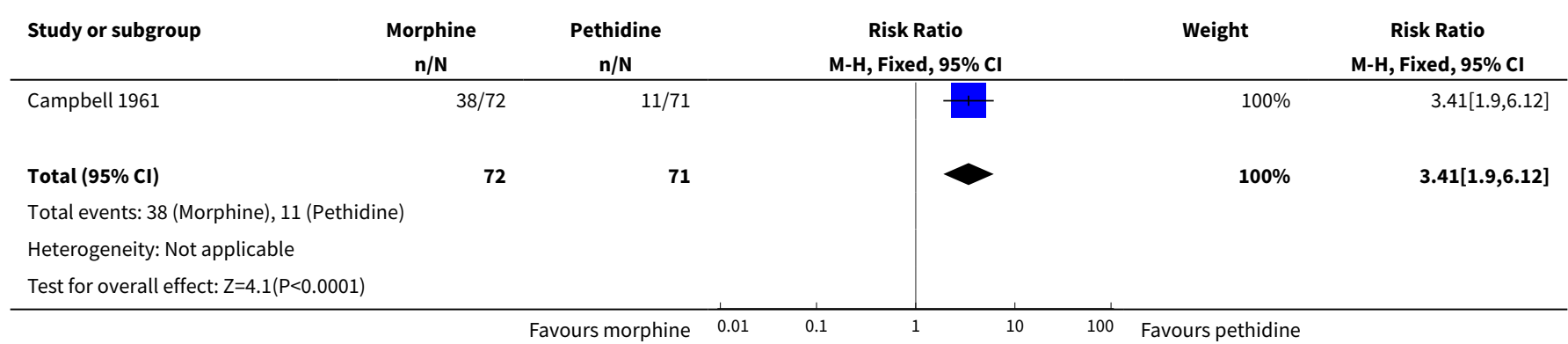

Analysis 25.3. Comparison 25 IV morphine versus IV pethidine, Outcome 3 Nausea and vomiting.

\begin{tabular}{|c|c|c|c|c|c|}
\hline Study or subgroup & $\begin{array}{c}\text { Morphine } \\
\mathrm{n} / \mathrm{N}\end{array}$ & $\begin{array}{c}\text { Pethidine } \\
\mathrm{n} / \mathrm{N}\end{array}$ & $\begin{array}{c}\text { Risk Ratio } \\
\text { M-H, Fixed, 95\% Cl }\end{array}$ & Weight & $\begin{array}{c}\text { Risk Ratio } \\
\text { M-H, Fixed, } 95 \% \mathrm{Cl}\end{array}$ \\
\hline \multicolumn{6}{|l|}{ 25.3.1 Nausea } \\
\hline Olofsson 1996 & $1 / 10$ & $6 / 10$ & & $100 \%$ & $0.17[0.02,1.14]$ \\
\hline Subtotal $(95 \% \mathrm{CI})$ & 10 & 10 & & $100 \%$ & $0.17[0.02,1.14]$ \\
\hline \multicolumn{6}{|c|}{ Total events: 1 (Morphine), 6 (Pethidine) } \\
\hline \multicolumn{6}{|c|}{ Heterogeneity: Not applicable } \\
\hline \multicolumn{6}{|l|}{ 25.3.2 Vomiting } \\
\hline Olofsson 1996 & $1 / 10$ & $4 / 10$ & - & $100 \%$ & $0.25[0.03,1.86]$ \\
\hline Subtotal $(95 \% \mathrm{Cl})$ & 10 & 10 & & $100 \%$ & $0.25[0.03,1.86]$ \\
\hline \multicolumn{6}{|c|}{ Total events: 1 (Morphine), 4 (Pethidine) } \\
\hline \multicolumn{6}{|c|}{ Heterogeneity: Not applicable } \\
\hline
\end{tabular}


Analysis 25.4. Comparison 25 IV morphine versus IV pethidine, Outcome 4 Caesarean section.

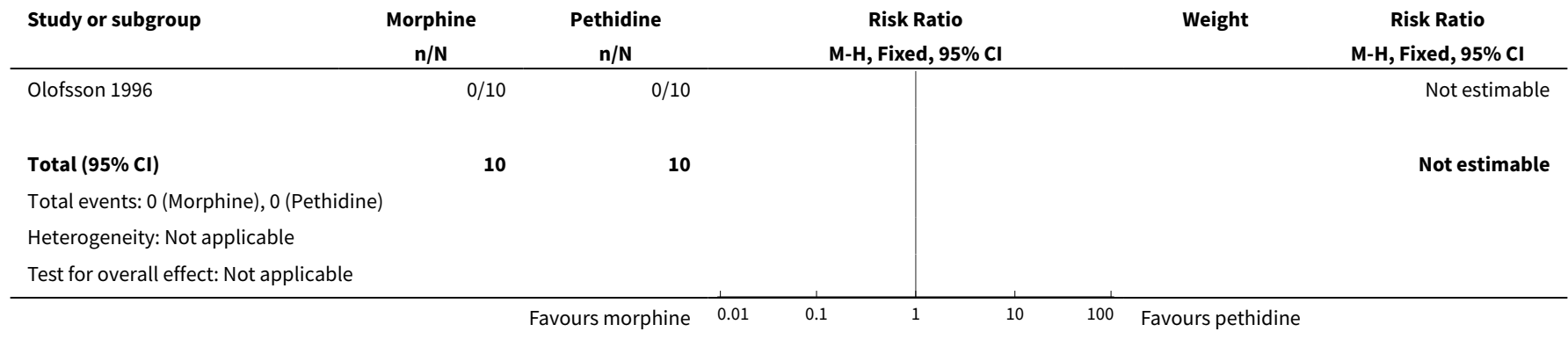

\section{Comparison 26. IV Nisentil versus IV pethidine}

\begin{tabular}{lllll}
\hline Outcome or subgroup title & No. of studies & $\begin{array}{l}\text { No. of partici- } \\
\text { pants }\end{array}$ & Statistical method & Effect size \\
\hline 1 Nausea and vomiting & 1 & & Risk Ratio (M-H, Fixed, 95\% Cl) & Subtotals only \\
\hline 1.1 Nausea & 1 & 395 & Risk Ratio (M-H, Fixed, 95\% Cl) & $0.71[0.33,1.52]$ \\
\hline 1.2 Vomiting & 1 & 395 & Risk Ratio (M-H, Fixed, 95\% Cl) & $0.38[0.22,0.66]$ \\
\hline $\begin{array}{l}2 \text { Neonatal resuscita- } \\
\text { tion/ventilatory support }\end{array}$ & 1 & 395 & Risk Ratio (M-H, Fixed, 95\% Cl) & $1.99[0.85,4.63]$ \\
\hline
\end{tabular}

Analysis 26.1. Comparison 26 IV Nisentil versus IV pethidine, Outcome 1 Nausea and vomiting.

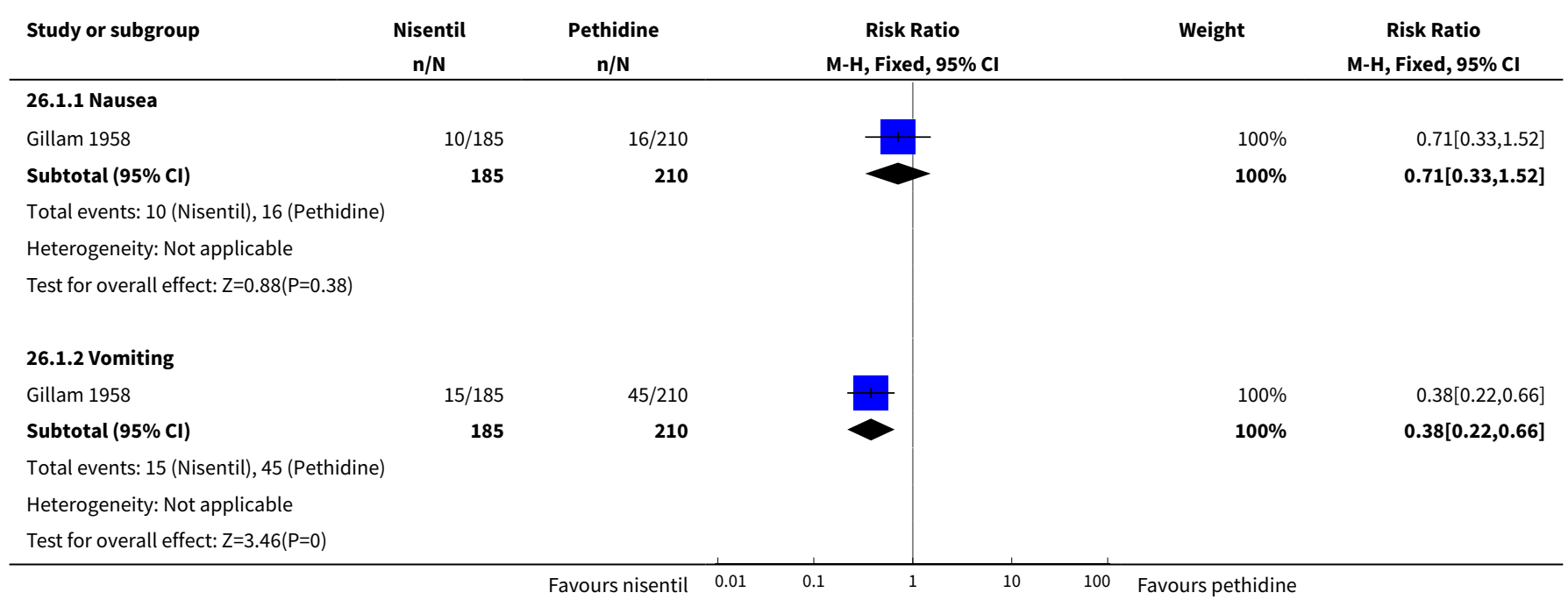


Analysis 26.2. Comparison 26 IV Nisentil versus IV pethidine, Outcome 2 Neonatal resuscitation/ventilatory support.

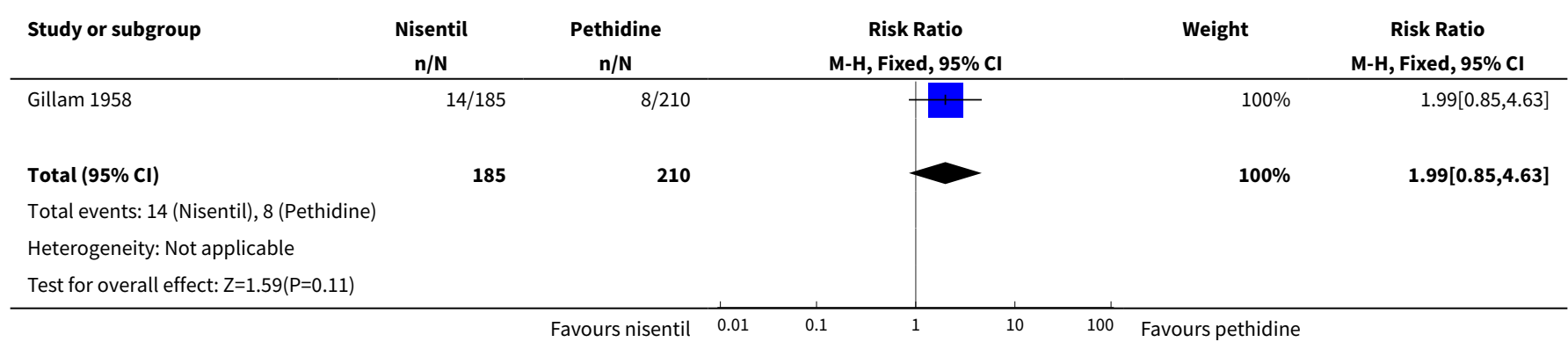

\section{Comparison 27. IV fentanyl versus IV butorphanol}

\begin{tabular}{|c|c|c|c|c|}
\hline Outcome or subgroup title & No. of studies & $\begin{array}{l}\text { No. of partici- } \\
\text { pants }\end{array}$ & Statistical method & Effect size \\
\hline 1 Additional analgesia required & 1 & 100 & Risk Ratio (M-H, Fixed, 95\% Cl) & $1.39[1.05,1.85]$ \\
\hline 2 Epidural & 1 & 100 & Risk Ratio (M-H, Fixed, 95\% Cl) & $2.0[1.00,4.02]$ \\
\hline $\begin{array}{l}3 \text { Matenal sleepiness (required tac- } \\
\text { tile rousing) }\end{array}$ & 1 & 100 & Risk Ratio (M-H, Fixed, 95\% Cl) & $3.0[0.64,14.16]$ \\
\hline 4 Caesarean section & 1 & 100 & Risk Ratio (M-H, Fixed, 95\% Cl) & $0.8[0.23,2.81]$ \\
\hline 5 Naloxone required & 1 & 100 & Risk Ratio (M-H, Fixed, 95\% Cl) & $1.75[0.81,3.80]$ \\
\hline $\begin{array}{l}6 \text { Neonatal resuscitation (Babies } \\
\text { requiring ventilatory support) }\end{array}$ & 1 & 100 & Risk Ratio (M-H, Fixed, 95\% Cl) & $11.0[0.62,193.80]$ \\
\hline 7 Apgar score $<7$ at 5 minutes & 1 & 100 & Risk Ratio (M-H, Fixed, 95\% Cl) & $1.2[0.39,3.68]$ \\
\hline $\begin{array}{l}8 \text { Newborn neurobehavioural } \\
\text { score at 2-4 hours }\end{array}$ & 1 & 100 & $\begin{array}{l}\text { Mean Difference (IV, Fixed, 95\% } \\
\mathrm{CI} \text { ) }\end{array}$ & $0.0[-1.61,1.61]$ \\
\hline $\begin{array}{l}9 \text { Newborn neurobehavioural } \\
\text { score at } 24-36 \text { hours }\end{array}$ & 1 & 100 & $\begin{array}{l}\text { Mean Difference (IV, Fixed, 95\% } \\
\mathrm{CI} \text { ) }\end{array}$ & $-0.50[-1.62,0.62]$ \\
\hline
\end{tabular}

Analysis 27.1. Comparison 27 IV fentanyl versus IV butorphanol, Outcome 1 Additional analgesia required.

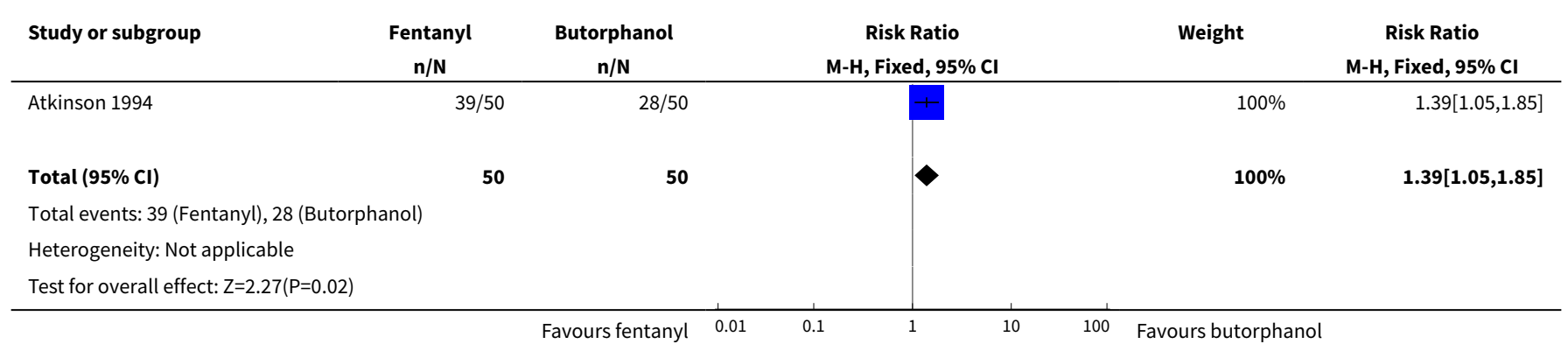


Analysis 27.2. Comparison 27 IV fentanyl versus IV butorphanol, Outcome 2 Epidural.

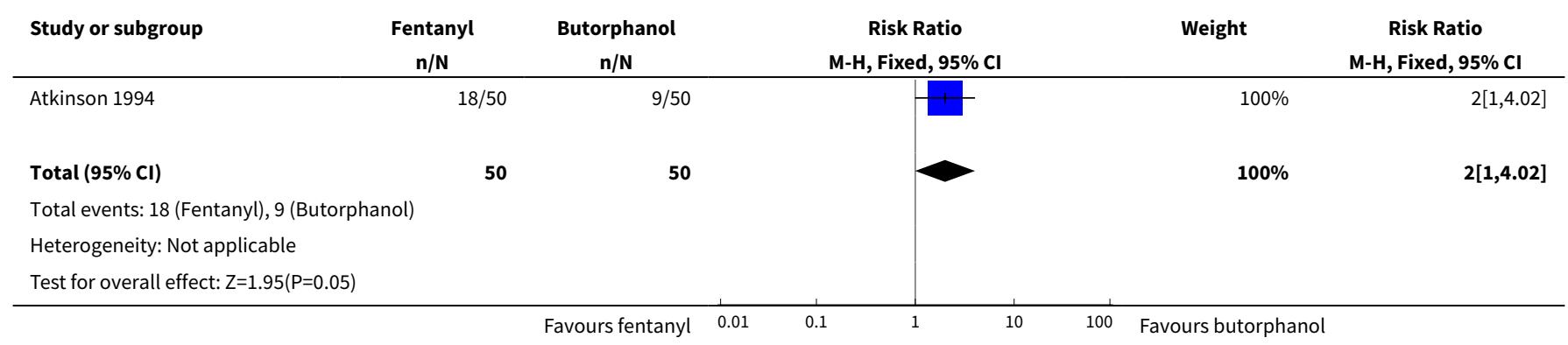

Analysis 27.3. Comparison 27 IV fentanyl versus IV butorphanol, Outcome 3 Matenal sleepiness (required tactile rousing).

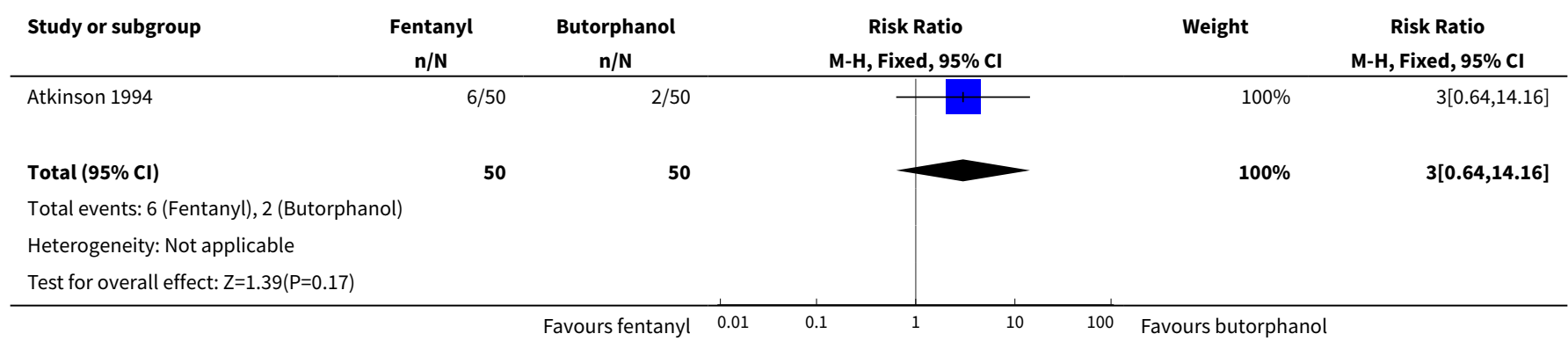

Analysis 27.4. Comparison 27 IV fentanyl versus IV butorphanol, Outcome 4 Caesarean section.

\begin{tabular}{|c|c|c|c|c|c|}
\hline Study or subgroup & $\begin{array}{c}\text { Fentanyl } \\
\mathrm{n} / \mathrm{N}\end{array}$ & $\begin{array}{c}\text { Butorphanol } \\
\mathrm{n} / \mathrm{N}\end{array}$ & $\begin{array}{c}\text { Risk Ratio } \\
\text { M-H, Fixed, } 95 \% \text { Cl } \\
\end{array}$ & Weight & $\begin{array}{c}\text { Risk Ratio } \\
\text { M-H, Fixed, } 95 \% \mathrm{CI} \\
\end{array}$ \\
\hline Atkinson 1994 & $4 / 50$ & $5 / 50$ & L & $100 \%$ & $0.8[0.23,2.81]$ \\
\hline Total $(95 \% \mathrm{Cl})$ & 50 & 50 & & $100 \%$ & $0.8[0.23,2.81]$ \\
\hline \multicolumn{6}{|c|}{ Total events: 4 (Fentanyl), 5 (Butorphanol) } \\
\hline \multicolumn{6}{|c|}{ Heterogeneity: Not applicable } \\
\hline
\end{tabular}

Analysis 27.5. Comparison 27 IV fentanyl versus IV butorphanol, Outcome 5 Naloxone required.

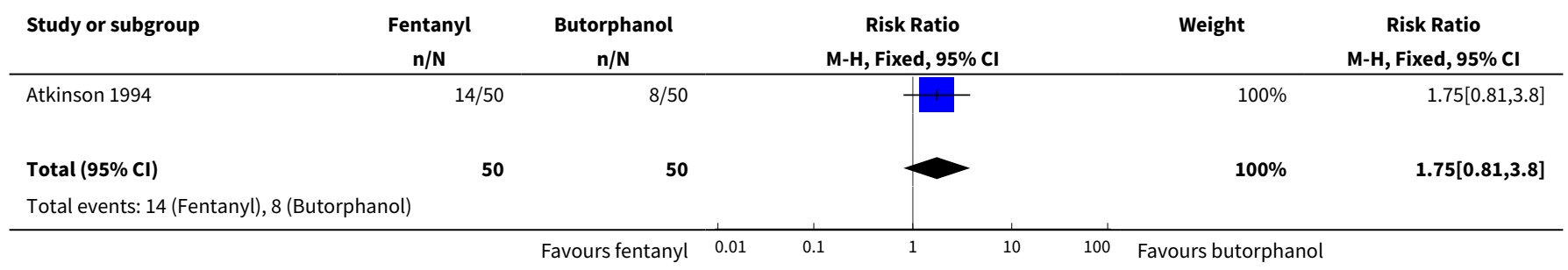




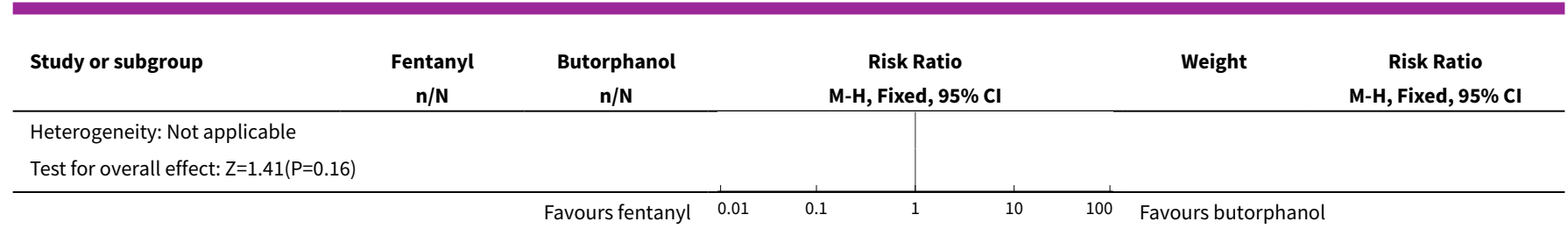

Analysis 27.6. Comparison 27 IV fentanyl versus IV butorphanol, Outcome 6 Neonatal resuscitation (Babies requiring ventilatory support).

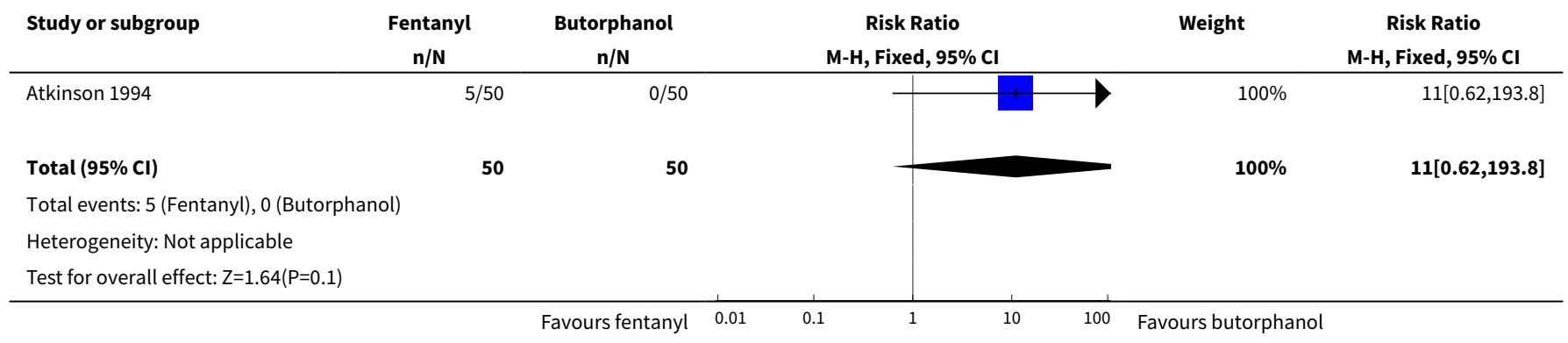

Analysis 27.7. Comparison 27 IV fentanyl versus IV butorphanol, Outcome 7 Apgar score $<7$ at 5 minutes.

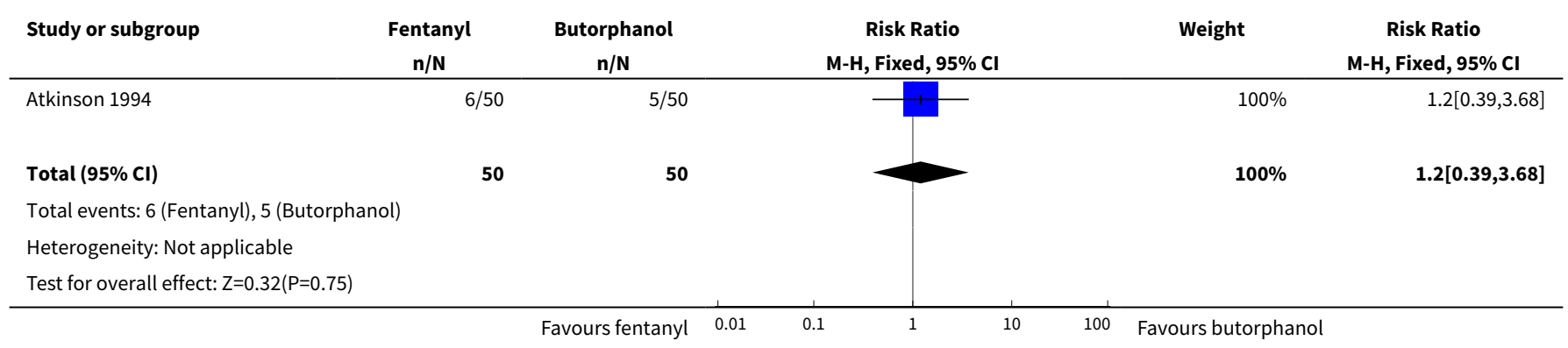

Analysis 27.8. Comparison 27 IV fentanyl versus IV butorphanol, Outcome 8 Newborn neurobehavioural score at 2-4 hours.

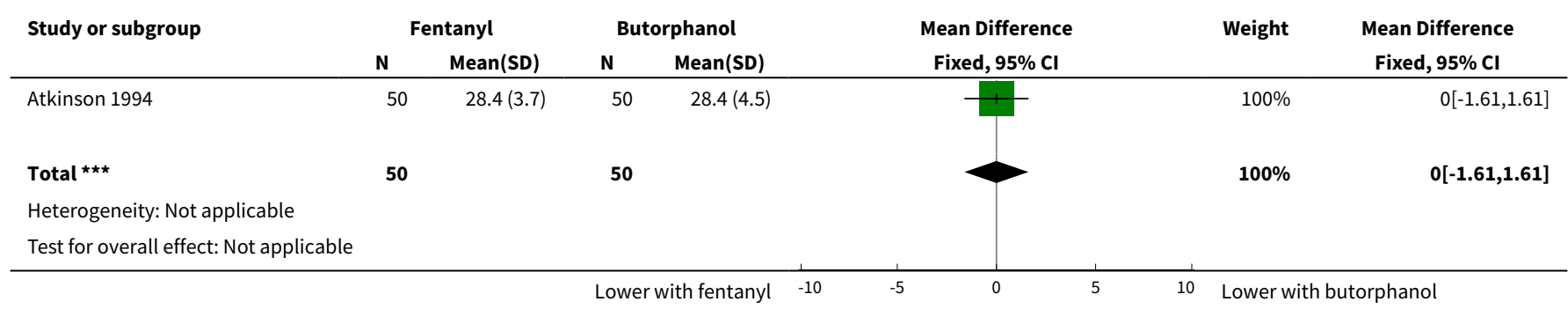


Analysis 27.9. Comparison 27 IV fentanyl versus IV butorphanol, Outcome 9 Newborn neurobehavioural score at 24-36 hours.

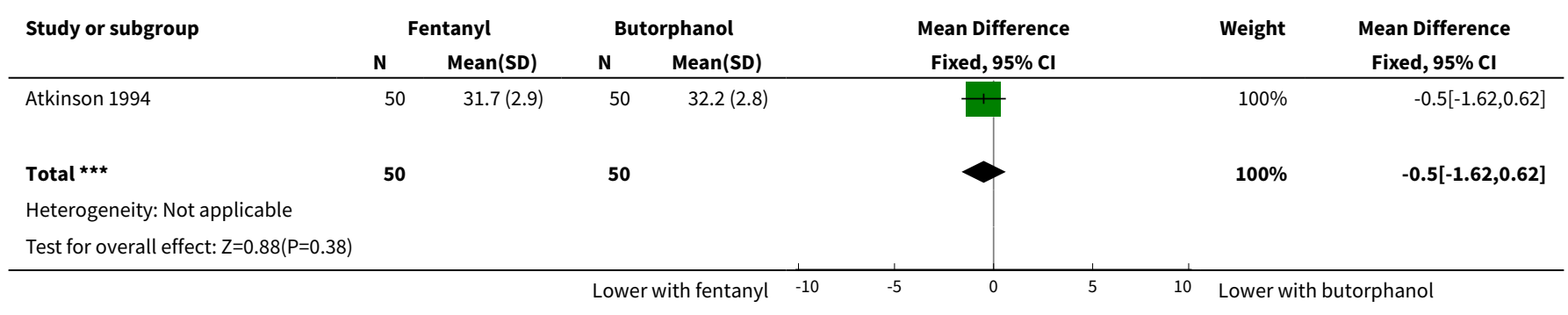

\section{Comparison 28. PCA pentazocine versus PCA pethidine}

\begin{tabular}{|c|c|c|c|c|}
\hline Outcome or subgroup title & No. of studies & $\begin{array}{l}\text { No. of partici- } \\
\text { pants }\end{array}$ & Statistical method & Effect size \\
\hline $\begin{array}{l}1 \text { Maternal pan score or pain } \\
\text { measured in labour }\end{array}$ & 1 & 23 & $\begin{array}{l}\text { Mean Difference (IV, Fixed, 95\% } \\
\mathrm{CI} \text { ) }\end{array}$ & $-1.45[-2.96,0.06]$ \\
\hline $\begin{array}{l}2 \text { Maternal pan score or pain } \\
\text { measured in labour (rated as } \\
\text { good one day after birth) }\end{array}$ & 1 & 28 & Risk Ratio (M-H, Fixed, 95\% Cl) & $0.82[0.51,1.32]$ \\
\hline 3 Epidural & 1 & 28 & Risk Ratio (M-H, Fixed, 95\% Cl) & $1.5[0.29,7.65]$ \\
\hline 4 Nausea and vomiting & 1 & 29 & Risk Ratio (M-H, Fixed, 95\% Cl) & $0.10[0.01,1.61]$ \\
\hline $\begin{array}{l}5 \text { Maternal sleepiness during } \\
\text { labour (Sedation) }\end{array}$ & 1 & 29 & Risk Ratio (M-H, Fixed, 95\% Cl) & $0.21[0.01,4.09]$ \\
\hline 6 Caesarean section & 1 & 29 & Risk Ratio (M-H, Fixed, 95\% Cl) & $0.36[0.02,8.07]$ \\
\hline 7 Breastfeeding at discharge & 1 & 23 & Risk Ratio (M-H, Fixed, 95\% Cl) & $1.0[0.85,1.17]$ \\
\hline 8 Apgar score $<7$ at 5 minutes & 1 & 29 & Risk Ratio (M-H, Fixed, 95\% Cl) & $0.0[0.0,0.0]$ \\
\hline
\end{tabular}

Analysis 28.1. Comparison 28 PCA pentazocine versus PCA pethidine, Outcome 1 Maternal pan score or pain measured in labour.

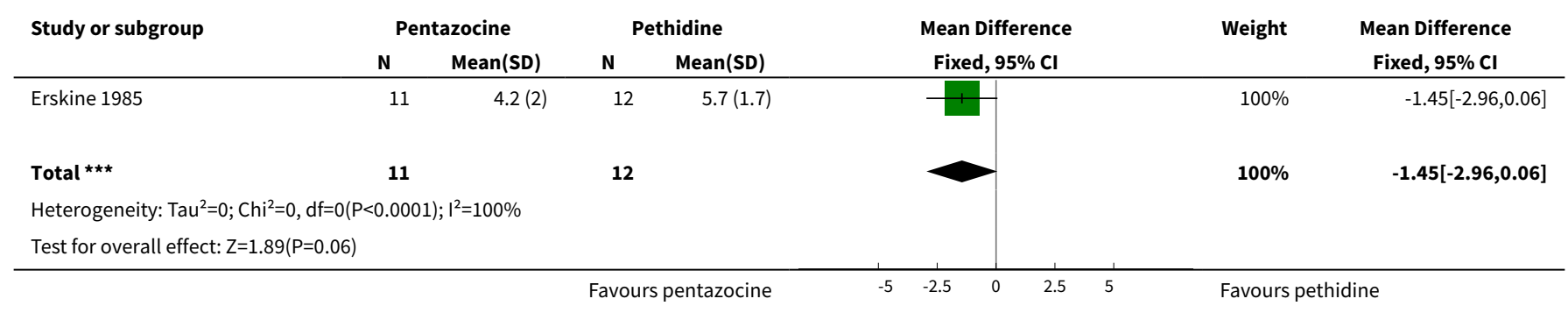


Analysis 28.2. Comparison 28 PCA pentazocine versus PCA pethidine, Outcome 2 Maternal pan score or pain measured in labour (rated as good one day after birth).

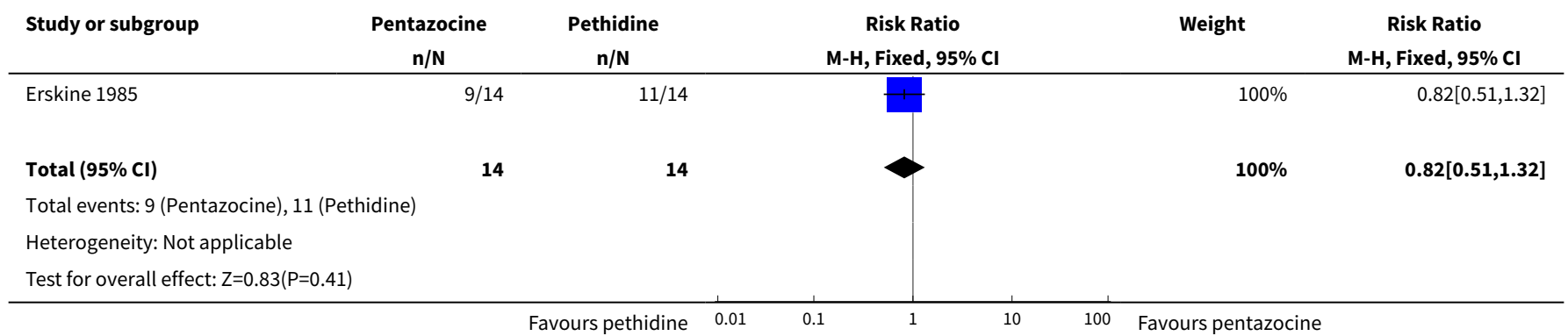

Analysis 28.3. Comparison 28 PCA pentazocine versus PCA pethidine, Outcome 3 Epidural.

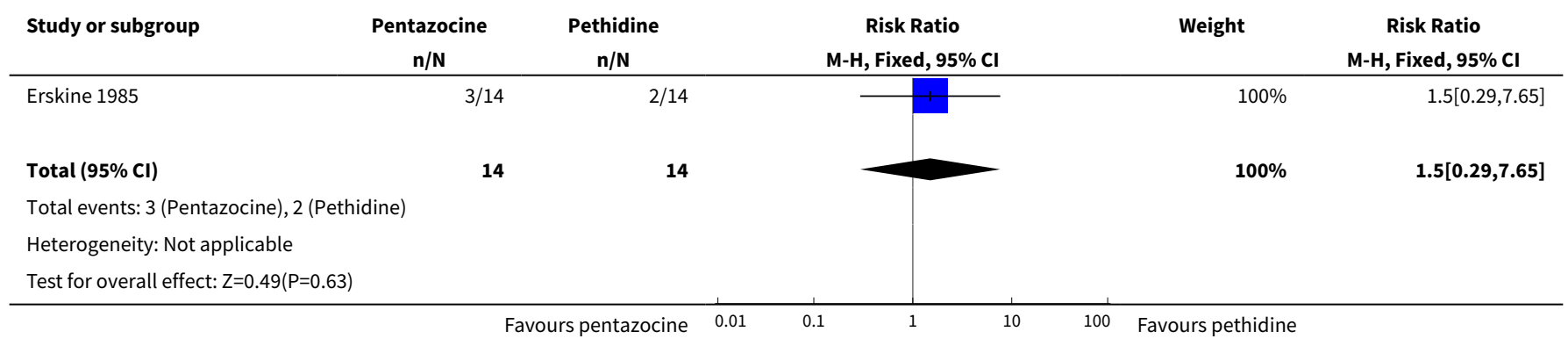

Analysis 28.4. Comparison 28 PCA pentazocine versus PCA pethidine, Outcome 4 Nausea and vomiting.

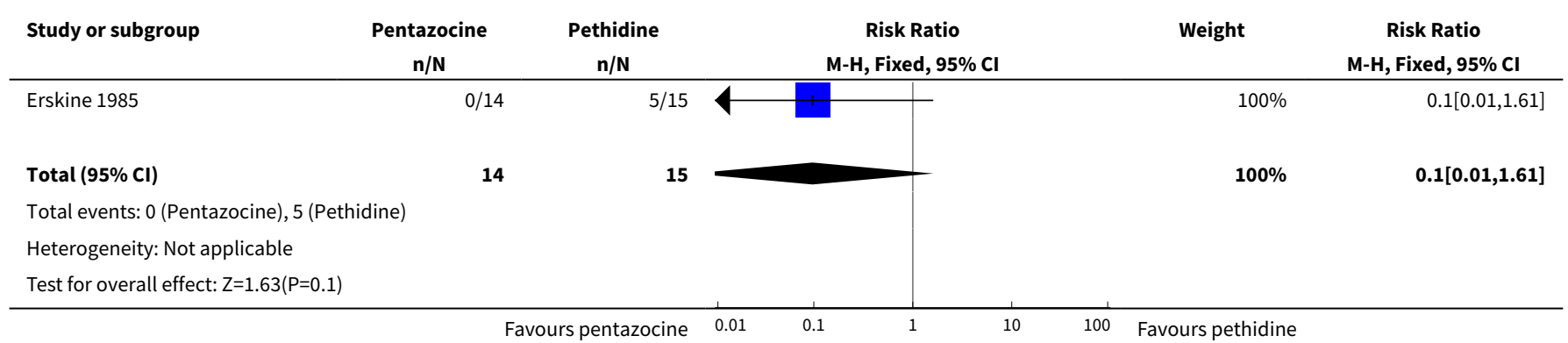

Analysis 28.5. Comparison 28 PCA pentazocine versus PCA pethidine, Outcome 5 Maternal sleepiness during labour (Sedation).

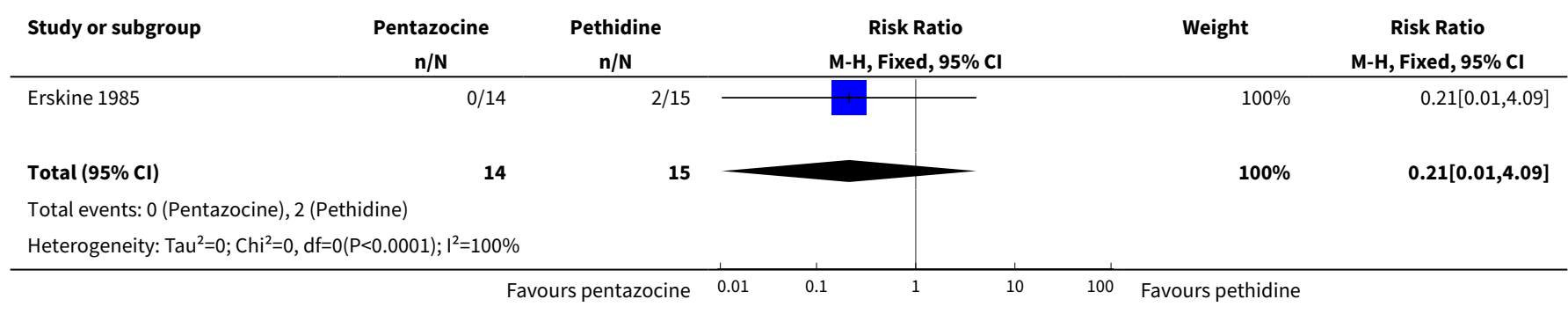




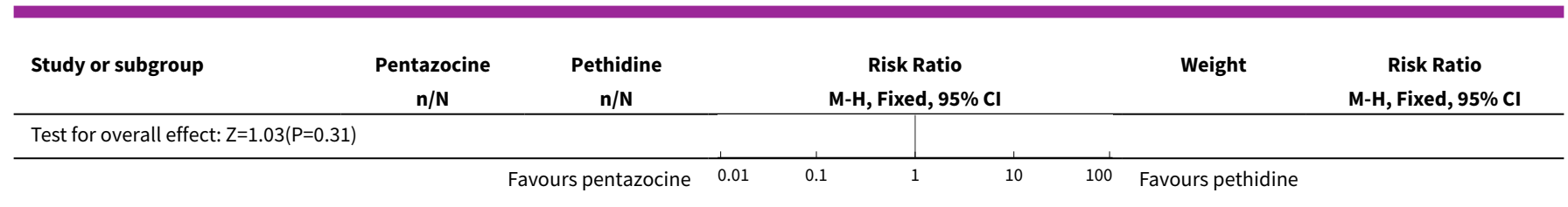

Analysis 28.6. Comparison 28 PCA pentazocine versus PCA pethidine, Outcome 6 Caesarean section.

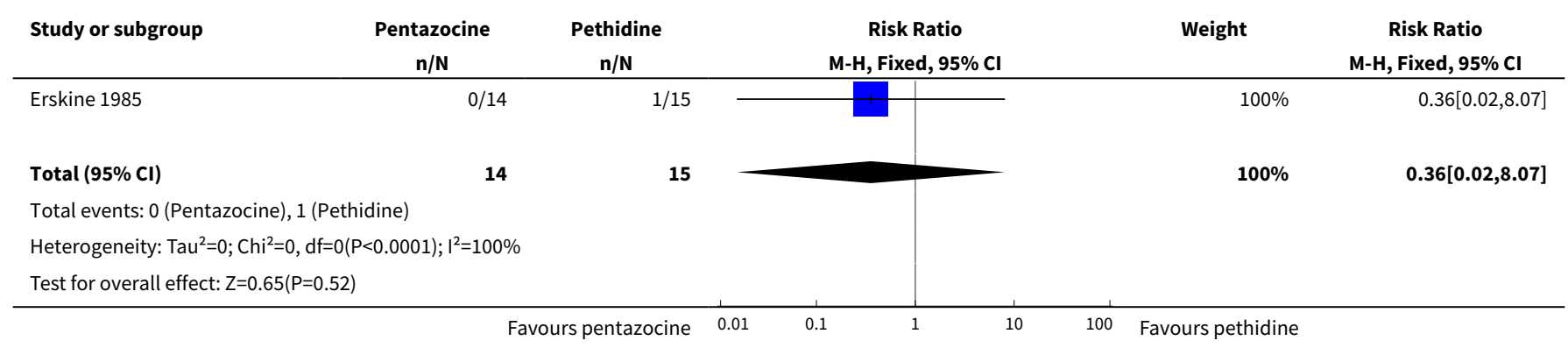

\section{Analysis 28.7. Comparison 28 PCA pentazocine versus PCA pethidine, Outcome 7 Breastfeeding at discharge.}

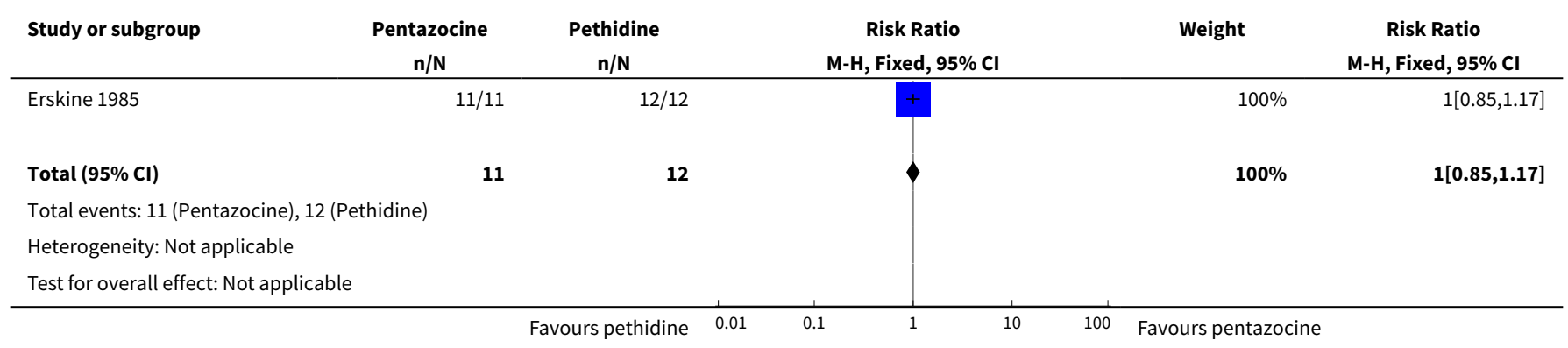

Analysis 28.8. Comparison 28 PCA pentazocine versus PCA pethidine, Outcome 8 Apgar score $<7$ at 5 minutes.

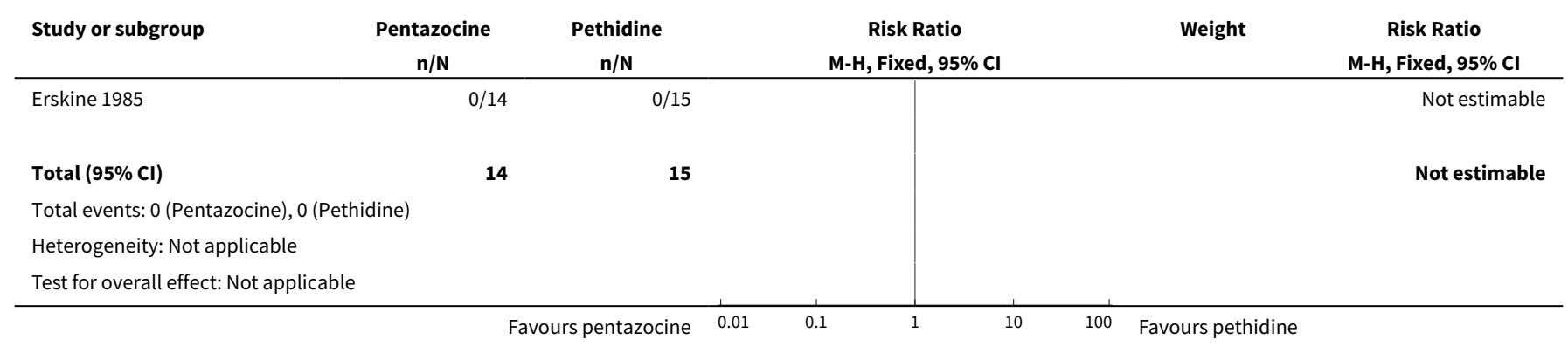


Comparison 29. PCA remifentanil versus PCA pethidine

\begin{tabular}{|c|c|c|c|c|}
\hline Outcome or subgroup title & No. of studies & $\begin{array}{l}\text { No. of partici- } \\
\text { pants }\end{array}$ & Statistical method & Effect size \\
\hline 1 Maternal pain score in labour & 2 & 122 & $\begin{array}{l}\text { Mean Difference (IV, Random, 95\% } \\
\mathrm{CI} \text { ) }\end{array}$ & $-8.59[-27.61,10.44]$ \\
\hline $\begin{array}{l}2 \text { Additional analgesia re- } \\
\text { quired }\end{array}$ & 2 & 56 & Risk Ratio (M-H, Fixed, 95\% Cl) & $0.86[0.69,1.08]$ \\
\hline 3 Epidural & 2 & 122 & Risk Ratio (M-H, Fixed, 95\% Cl) & $0.42[0.20,0.89]$ \\
\hline $\begin{array}{l}4 \text { Maternal sleepiness during } \\
\text { labour }\end{array}$ & 1 & 105 & Mean Difference (IV, Fixed, 95\% CI) & $0.40[0.14,0.66]$ \\
\hline 5 Nausea and vomiting & 2 & 119 & Risk Ratio (M-H, Fixed, 95\% Cl) & $0.95[0.61,1.49]$ \\
\hline 6 Caesarean section & 2 & 97 & Risk Ratio (M-H, Fixed, 95\% Cl) & $1.81[0.60,5.46]$ \\
\hline 7 Assisted vaginal birth & 2 & 97 & Risk Ratio (M-H, Fixed, 95\% Cl) & $0.96[0.46,2.00]$ \\
\hline $\begin{array}{l}8 \text { Satisfaction with childbirth } \\
\text { experience }\end{array}$ & 1 & 68 & Mean Difference (IV, Fixed, 95\% CI) & $1.10[0.46,1.74]$ \\
\hline 9 Naloxone administered & 2 & 56 & Risk Ratio (M-H, Fixed, 95\% Cl) & $0.3[0.01,6.47]$ \\
\hline 10 Apgar score $<7$ at 5 minutes & 1 & 17 & Risk Ratio (M-H, Fixed, 95\% Cl) & $0.13[0.01,2.16]$ \\
\hline 11 Admission to NICU & 1 & 17 & Risk Ratio (M-H, Fixed, 95\% Cl) & $0.3[0.01,6.47]$ \\
\hline $\begin{array}{l}12 \text { Newborn neurobehaviour- } \\
\text { al score ( } 15 \text { minutes post deliv- } \\
\text { ery) }\end{array}$ & 1 & 56 & Mean Difference (IV, Fixed, 95\% CI) & $0.20[-0.93,1.33]$ \\
\hline $\begin{array}{l}13 \text { Newborn neurobehavioural } \\
\text { score ( } 2 \text { hours post delivery) }\end{array}$ & 1 & 56 & Mean Difference (IV, Fixed, 95\% CI) & $0.60[-0.66,1.86]$ \\
\hline
\end{tabular}

Analysis 29.1. Comparison 29 PCA remifentanil versus PCA pethidine, Outcome 1 Maternal pain score in labour.

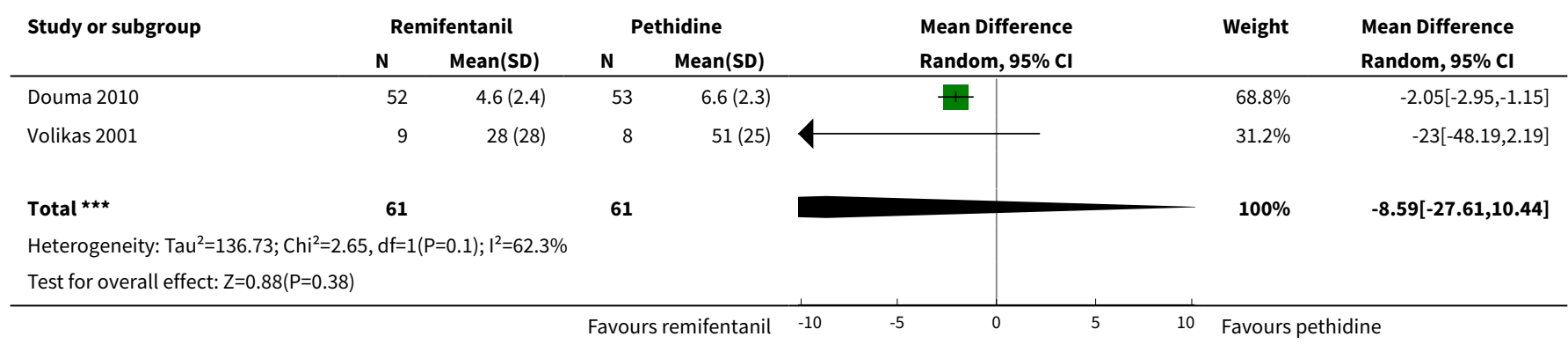


Analysis 29.2. Comparison 29 PCA remifentanil versus PCA pethidine, Outcome 2 Additional analgesia required.

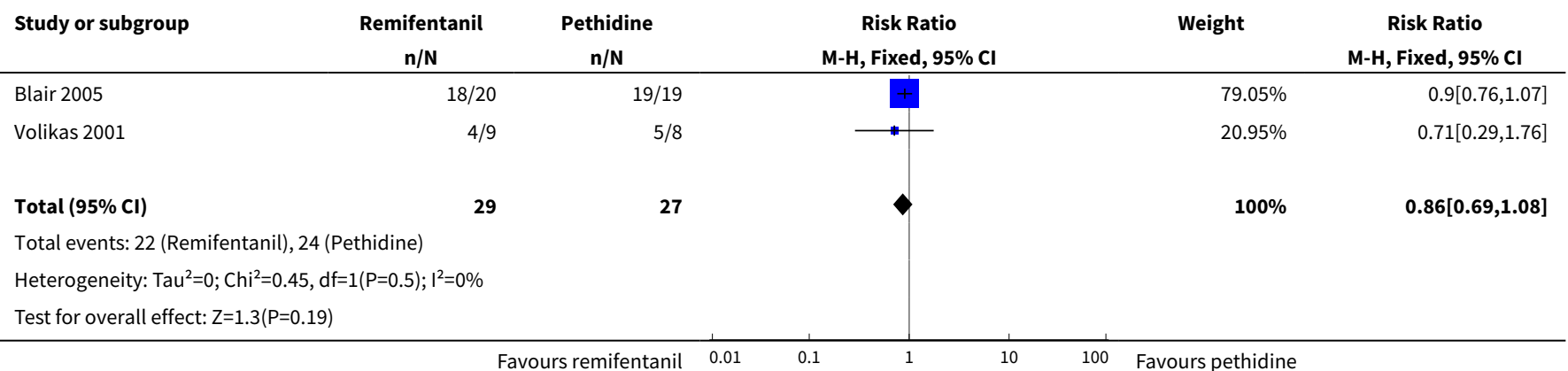

Analysis 29.3. Comparison 29 PCA remifentanil versus PCA pethidine, Outcome 3 Epidural.

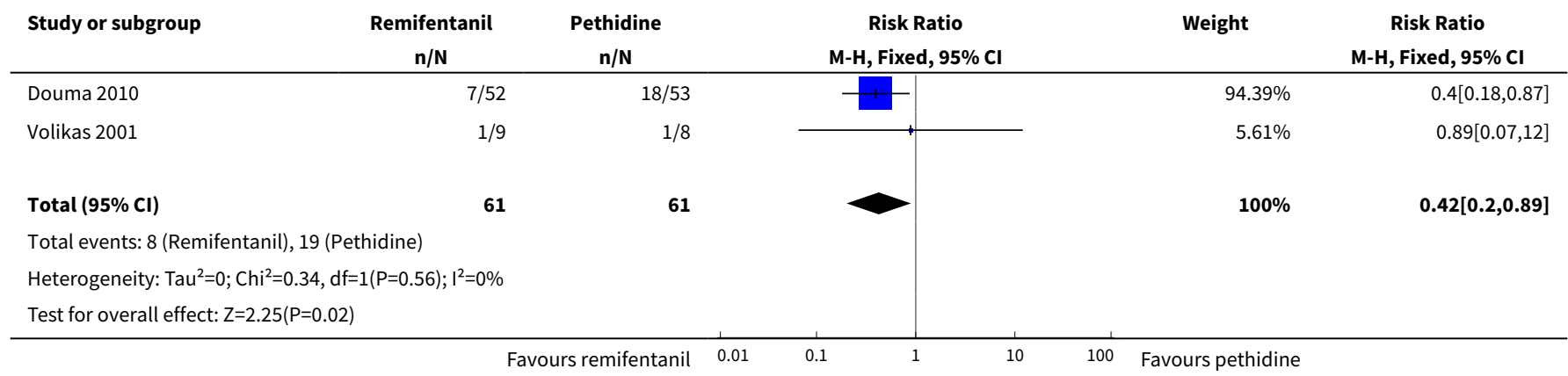

Analysis 29.4. Comparison 29 PCA remifentanil versus PCA pethidine, Outcome 4 Maternal sleepiness during labour.

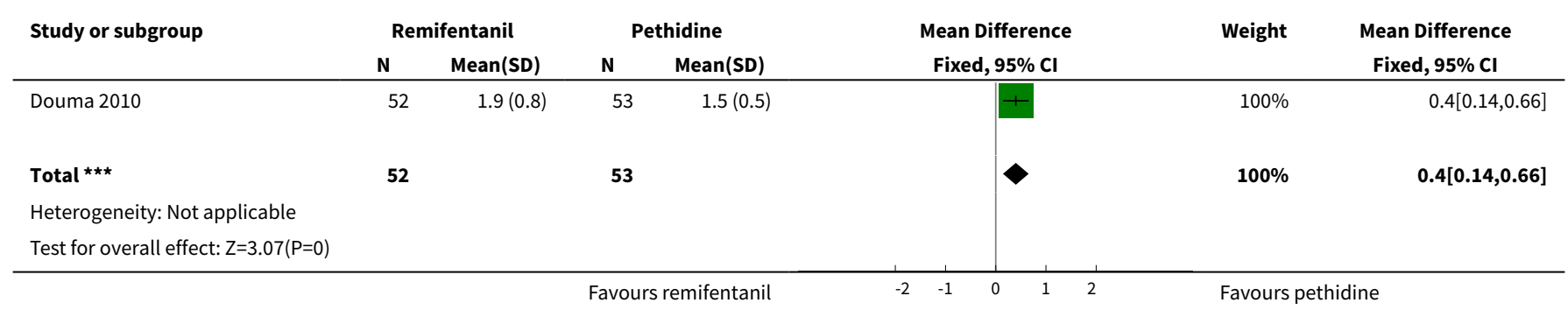

Analysis 29.5. Comparison 29 PCA remifentanil versus PCA pethidine, Outcome 5 Nausea and vomiting.

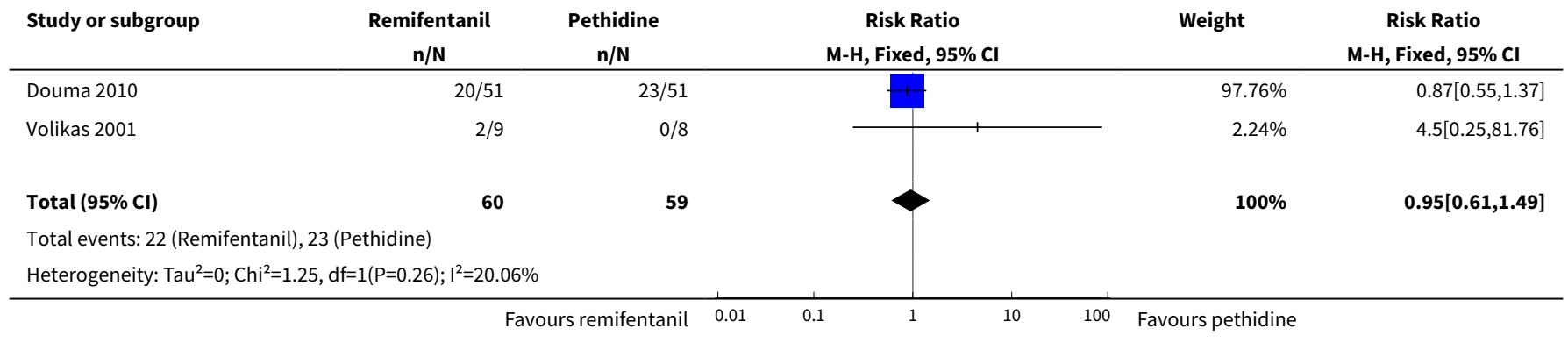




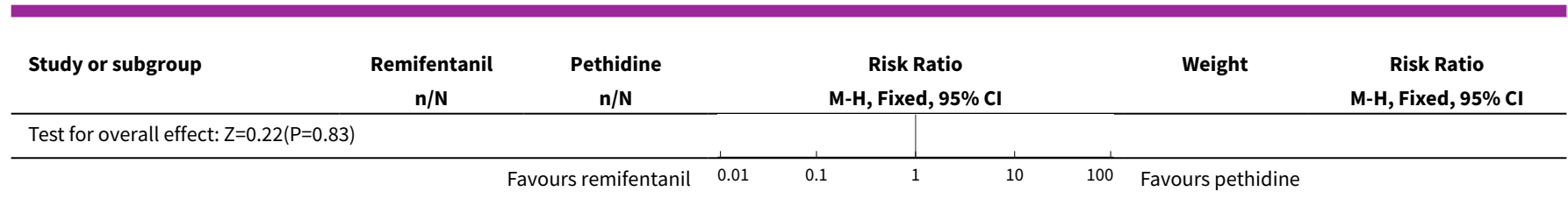

Analysis 29.6. Comparison 29 PCA remifentanil versus PCA pethidine, Outcome 6 Caesarean section.

\begin{tabular}{|c|c|c|c|c|c|}
\hline Study or subgroup & $\begin{array}{c}\text { Remifentanil } \\
\mathbf{n} / \mathbf{N}\end{array}$ & $\begin{array}{c}\text { Pethidine } \\
\mathrm{n} / \mathrm{N}\end{array}$ & $\begin{array}{c}\text { Risk Ratio } \\
\text { M-H, Fixed, 95\% Cl }\end{array}$ & Weight & $\begin{array}{c}\text { Risk Ratio } \\
\text { M-H, Fixed, } 95 \% \mathrm{Cl}\end{array}$ \\
\hline Douma 2010 & $7 / 45$ & $3 / 35$ & 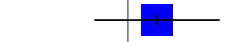 & $76.12 \%$ & $1.81[0.51,6.52]$ \\
\hline Volikas 2001 & $2 / 9$ & $1 / 8$ & - & $23.88 \%$ & $1.78[0.2,16.1]$ \\
\hline Total $(95 \% \mathrm{Cl})$ & 54 & 43 & & $100 \%$ & $1.81[0.6,5.46]$ \\
\hline \multicolumn{6}{|c|}{ Total events: 9 (Remifentanil), 4 (Pethidine) } \\
\hline \multicolumn{6}{|c|}{ Heterogeneity: $\mathrm{Tau}^{2}=0 ; \mathrm{Chi}^{2}=0, \mathrm{df}=1(\mathrm{P}=0.99) ; \mathrm{I}^{2}=0 \%$} \\
\hline \multicolumn{6}{|c|}{ Test for overall effect: $\mathrm{Z}=1.05(\mathrm{P}=0.3)$} \\
\hline
\end{tabular}

Analysis 29.7. Comparison 29 PCA remifentanil versus PCA pethidine, Outcome 7 Assisted vaginal birth.

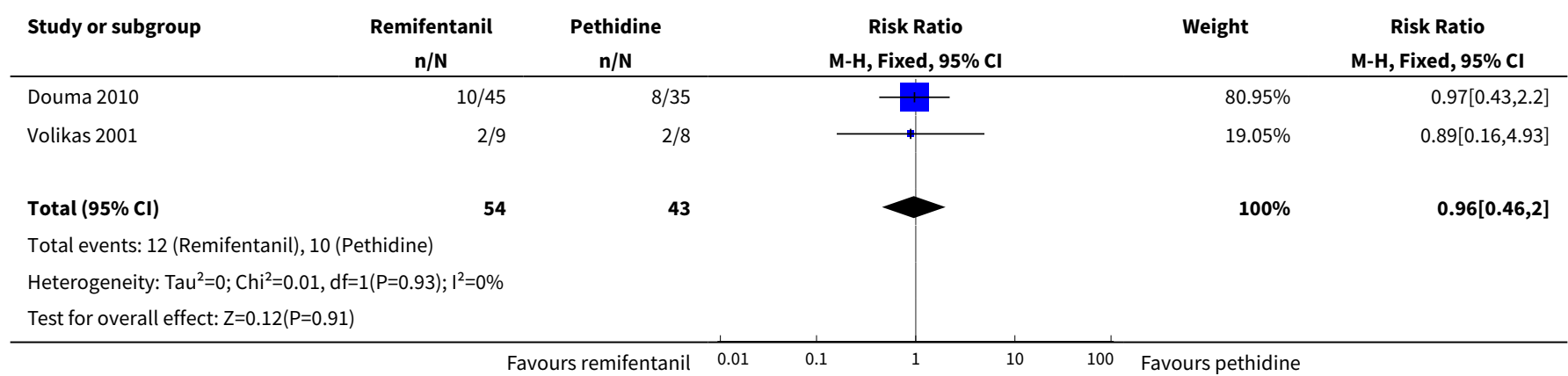

Analysis 29.8. Comparison 29 PCA remifentanil versus PCA pethidine, Outcome 8 Satisfaction with childbirth experience.

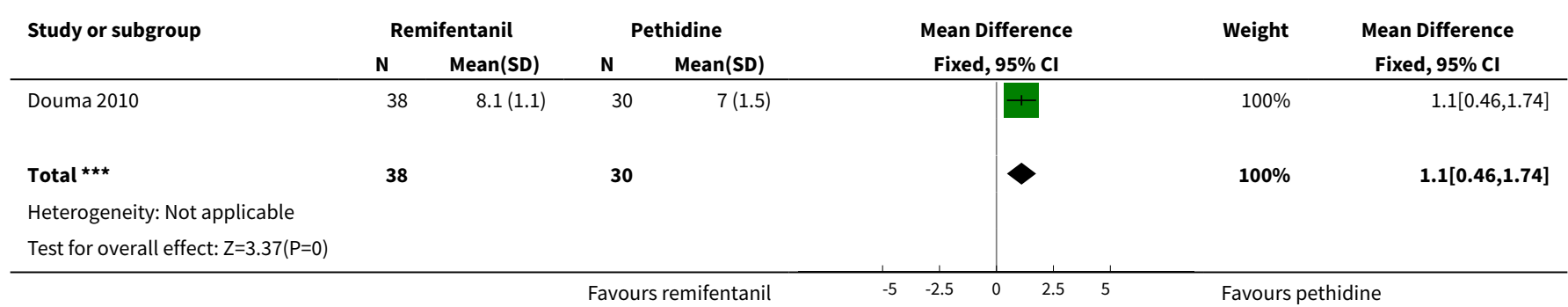


Analysis 29.9. Comparison 29 PCA remifentanil versus PCA pethidine, Outcome 9 Naloxone administered.

\begin{tabular}{|c|c|c|c|c|c|}
\hline Study or subgroup & $\begin{array}{c}\text { Remifentanil } \\
\mathrm{n} / \mathrm{N}\end{array}$ & $\begin{array}{c}\text { Pethidine } \\
n / N\end{array}$ & $\begin{array}{c}\text { Risk Ratio } \\
\text { M-H, Fixed, } 95 \% \mathrm{CI}\end{array}$ & Weight & $\begin{array}{c}\text { Risk Ratio } \\
\text { M-H, Fixed, 95\% Cl }\end{array}$ \\
\hline Blair 2005 & $0 / 20$ & $0 / 19$ & & & Not estimable \\
\hline Volikas 2001 & $0 / 9$ & $1 / 8$ & 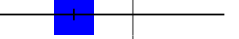 & $100 \%$ & $0.3[0.01,6.47]$ \\
\hline Total $(95 \% \mathrm{CI})$ & 29 & 27 & & $100 \%$ & $0.3[0.01,6.47]$ \\
\hline \multicolumn{6}{|c|}{ Total events: 0 (Remifentanil), 1 (Pethidine) } \\
\hline Test for overall effec & & & & & \\
\hline
\end{tabular}

Analysis 29.10. Comparison 29 PCA remifentanil versus PCA pethidine, Outcome 10 Apgar score $<7$ at 5 minutes.

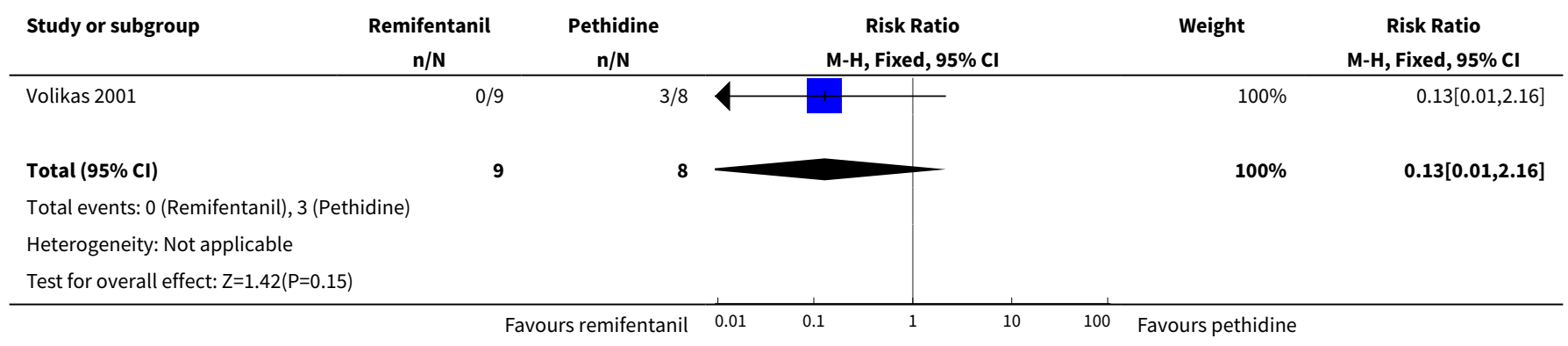

Analysis 29.11. Comparison 29 PCA remifentanil versus PCA pethidine, Outcome 11 Admission to NICU.

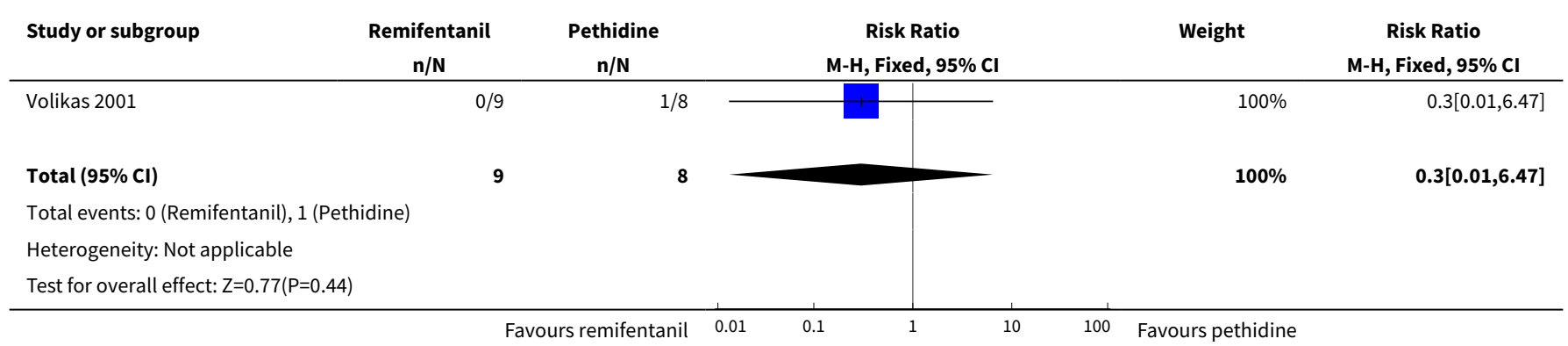

Analysis 29.12. Comparison 29 PCA remifentanil versus PCA pethidine, Outcome 12 Newborn neurobehavioural score (15 minutes post delivery).

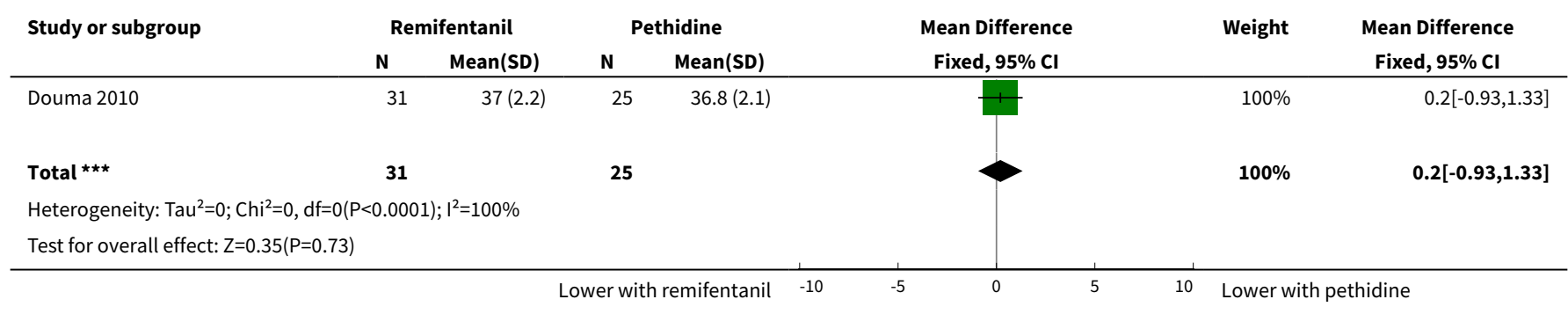


Analysis 29.13. Comparison 29 PCA remifentanil versus PCA pethidine, Outcome 13 Newborn neurobehavioural score ( 2 hours post delivery).

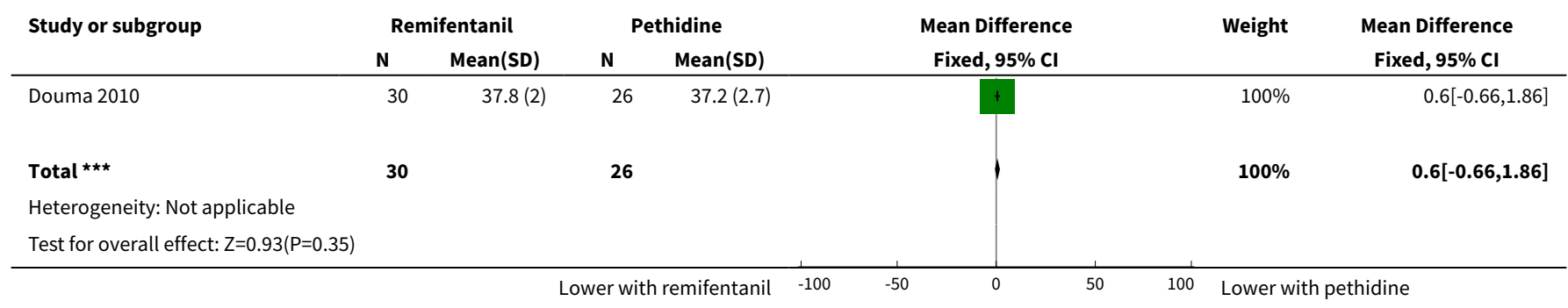

\section{Comparison 30. PCA nalbuphine versus PCA pethidine}

\begin{tabular}{|c|c|c|c|c|}
\hline Outcome or subgroup title & No. of studies & $\begin{array}{l}\text { No. of partici- } \\
\text { pants }\end{array}$ & Statistical method & Effect size \\
\hline $\begin{array}{l}1 \text { Maternal satisfaction with analgesia in } \\
\text { labour measured during the postnatal peri- } \\
\text { od (rated good or excellent) }\end{array}$ & 1 & 60 & $\begin{array}{l}\text { Risk Ratio (M-H, Fixed, } \\
95 \% \mathrm{Cl})\end{array}$ & $1.29[0.88,1.89]$ \\
\hline $\begin{array}{l}2 \text { Maternal satisfaction with analgesia in } \\
\text { labour measured during the postnatal peri- } \\
\text { od (Would use the same pain relief again) }\end{array}$ & 1 & 59 & $\begin{array}{l}\text { Risk Ratio (M-H, Fixed, } \\
95 \% \mathrm{Cl})\end{array}$ & $1.06[0.79,1.43]$ \\
\hline $\begin{array}{l}3 \text { Maternal pain score or pain measured in } \\
\text { labour }\end{array}$ & 1 & 60 & $\begin{array}{l}\text { Mean Difference (IV, } \\
\text { Fixed, } 95 \% \mathrm{CI} \text { ) }\end{array}$ & $\begin{array}{l}-0.40[-0.79 \\
-0.01]\end{array}$ \\
\hline 4 Additional analgesia required & 1 & 59 & $\begin{array}{l}\text { Risk Ratio (M-H, Fixed, } \\
95 \% \mathrm{Cl})\end{array}$ & $0.83[0.46,1.48]$ \\
\hline 5 Nausea and vomiting & 1 & 59 & $\begin{array}{l}\text { Risk Ratio (M-H, Fixed, } \\
95 \% \mathrm{Cl})\end{array}$ & $0.68[0.30,1.54]$ \\
\hline 6 Apgar score $<7$ at 5 minutes & 1 & 41 & $\begin{array}{l}\text { Risk Ratio (M-H, Fixed, } \\
95 \% \mathrm{Cl})\end{array}$ & $0.42[0.02,9.76]$ \\
\hline
\end{tabular}

Analysis 30.1. Comparison 30 PCA nalbuphine versus PCA pethidine, Outcome 1 Maternal satisfaction with analgesia in labour measured during the postnatal period (rated good or excellent).

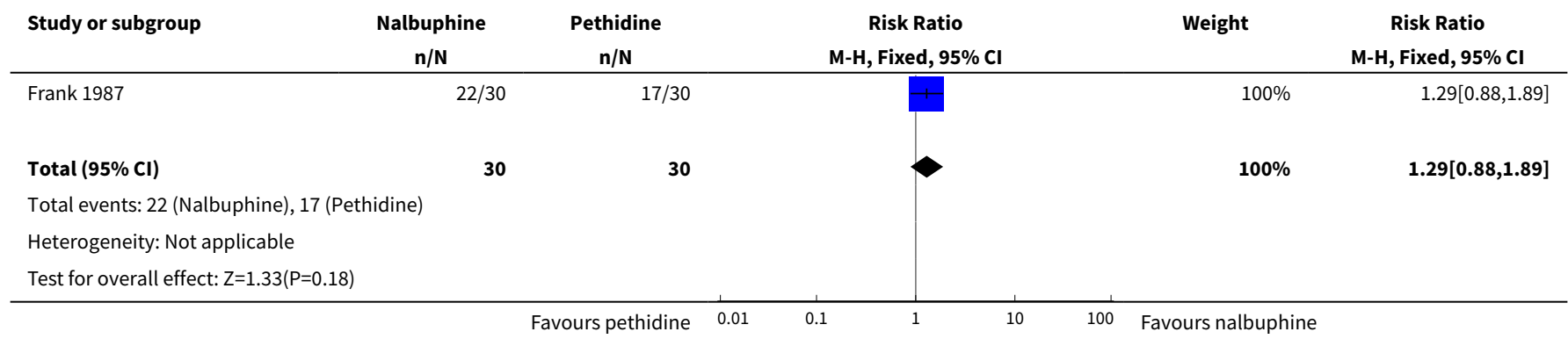


Analysis 30.2. Comparison 30 PCA nalbuphine versus PCA pethidine, Outcome 2 Maternal satisfaction with analgesia in labour measured during the postnatal period (Would use the same pain relief again).

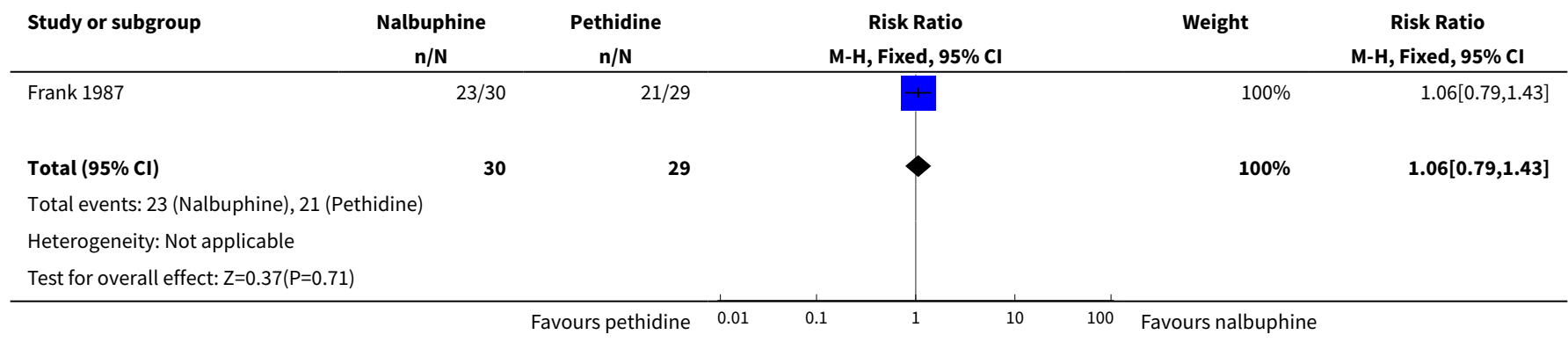

Analysis 30.3. Comparison 30 PCA nalbuphine versus PCA pethidine, Outcome 3 Maternal pain score or pain measured in labour.

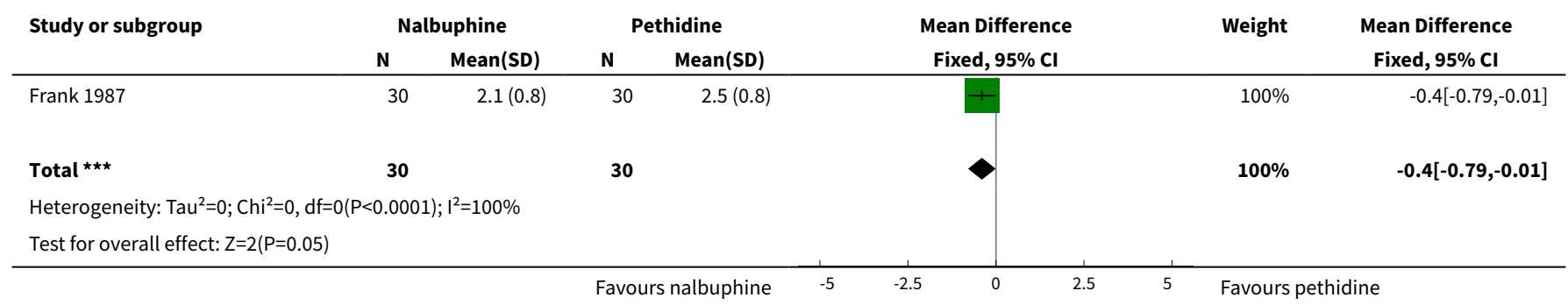

Analysis 30.4. Comparison 30 PCA nalbuphine versus PCA pethidine, Outcome 4 Additional analgesia required.

\begin{tabular}{|c|c|c|c|c|c|}
\hline Study or subgroup & $\begin{array}{c}\text { Nalbuphine } \\
\mathbf{n} / \mathbf{N} \\
\end{array}$ & $\begin{array}{c}\text { Pethidine } \\
\mathrm{n} / \mathrm{N}\end{array}$ & $\begin{array}{c}\text { Risk Ratio } \\
\text { M-H, Fixed, 95\% Cl }\end{array}$ & Weight & $\begin{array}{c}\text { Risk Ratio } \\
\text { M-H, Fixed, } 95 \% \mathrm{Cl}\end{array}$ \\
\hline Frank 1987 & $12 / 30$ & $14 / 29$ & & $100 \%$ & $0.83[0.46,1.48]$ \\
\hline Total $(95 \% \mathrm{Cl})$ & 30 & 29 & & $100 \%$ & $0.83[0.46,1.48]$ \\
\hline \multicolumn{6}{|c|}{ Total events: 12 (Nalbuphine), 14 (Pethidine) } \\
\hline \multicolumn{6}{|c|}{ Heterogeneity: Not applicable } \\
\hline
\end{tabular}

Analysis 30.5. Comparison 30 PCA nalbuphine versus PCA pethidine, Outcome 5 Nausea and vomiting.

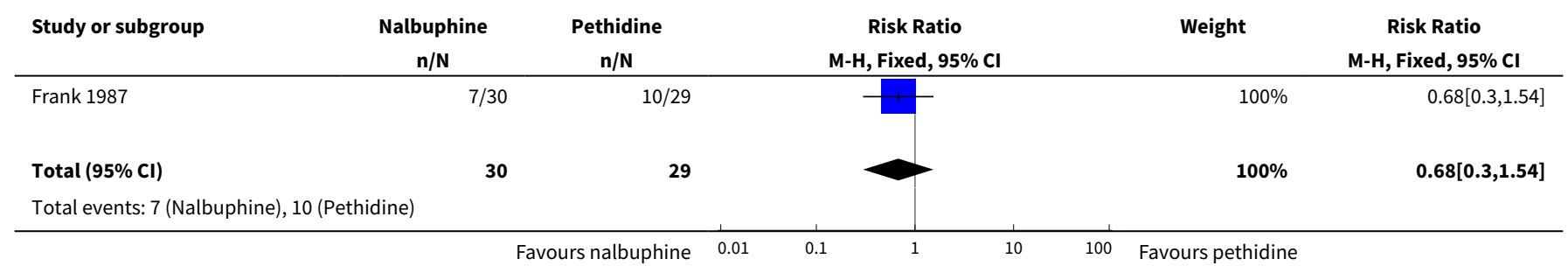




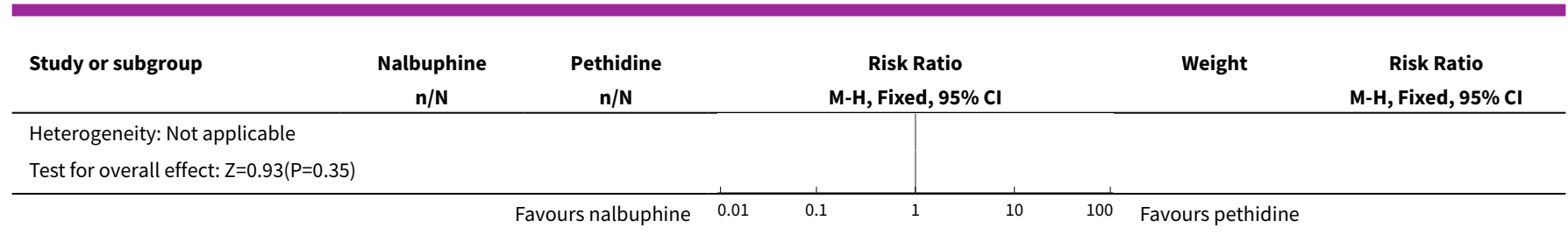

Analysis 30.6. Comparison 30 PCA nalbuphine versus PCA pethidine, Outcome 6 Apgar score $<7$ at 5 minutes.

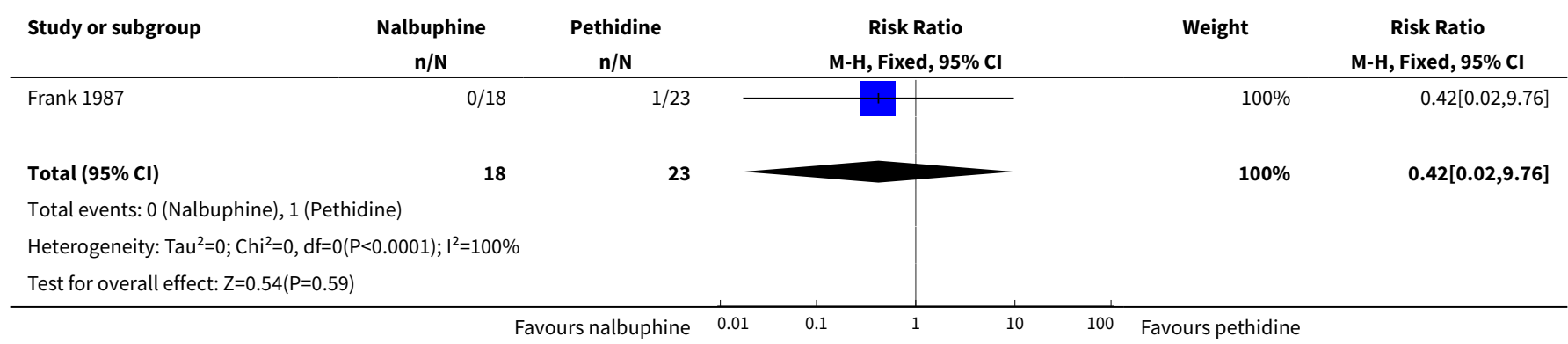

\section{Comparison 31. PCA fentanyl versus PCA alfentanil}

\begin{tabular}{|c|c|c|c|c|}
\hline Outcome or subgroup title & No. of studies & $\begin{array}{l}\text { No. of partici- } \\
\text { pants }\end{array}$ & Statistical method & Effect size \\
\hline $\begin{array}{l}1 \text { Maternal satisfaction with analgesia in } \\
\text { labour measured during the postnatal } \\
\text { period (described as adequate) }\end{array}$ & 1 & 23 & $\begin{array}{l}\text { Risk Ratio (M-H, Fixed, } \\
95 \% \mathrm{Cl})\end{array}$ & $1.56[0.93,2.60]$ \\
\hline $\begin{array}{l}2 \text { Maternal pain score or pain measured } \\
\text { in labour (Pain score at } 4-6 \mathrm{~cm} \text { cervical } \\
\text { dilatation) }\end{array}$ & 1 & 21 & $\begin{array}{l}\text { Mean Difference (IV, Fixed, } \\
95 \% \mathrm{CI})\end{array}$ & $\begin{array}{l}-12.80[-32.12 \\
6.52]\end{array}$ \\
\hline 3 Nausea & 1 & 23 & $\begin{array}{l}\text { Risk Ratio (M-H, Fixed, } \\
95 \% \mathrm{Cl})\end{array}$ & $2.73[0.66,11.30]$ \\
\hline 4 Caesarean section & 1 & 23 & $\begin{array}{l}\text { Risk Ratio (M-H, Fixed, } \\
95 \% \mathrm{Cl})\end{array}$ & $1.64[0.33,8.03]$ \\
\hline 5 Naloxone required & 1 & 24 & $\begin{array}{l}\text { Risk Ratio (M-H, Fixed, } \\
95 \% \mathrm{Cl})\end{array}$ & $2.36[0.53,10.55]$ \\
\hline
\end{tabular}

Analysis 31.1. Comparison 31 PCA fentanyl versus PCA alfentanil, Outcome 1 Maternal satisfaction with analgesia in labour measured during the postnatal period (described as adequate).

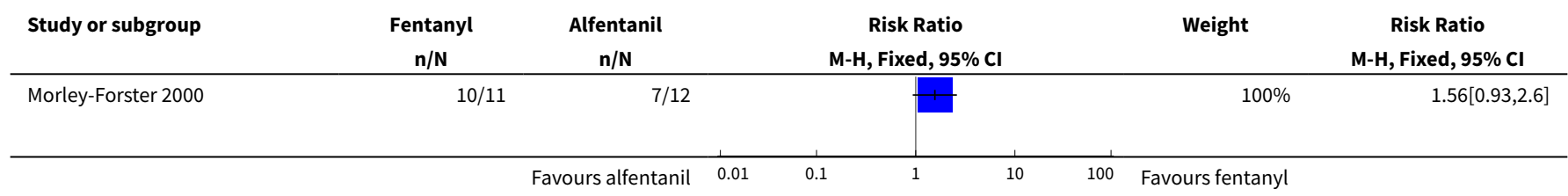




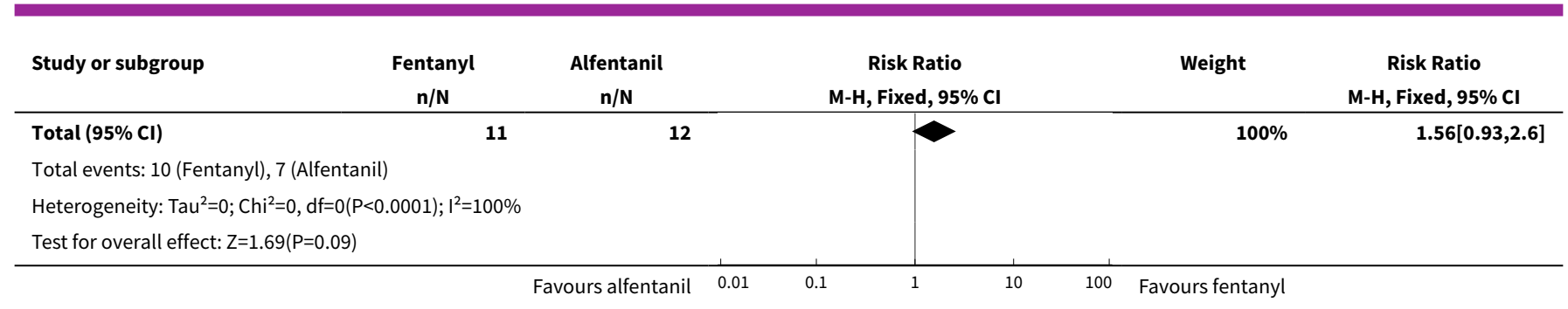

\section{Analysis 31.2. Comparison 31 PCA fentanyl versus PCA alfentanil, Outcome 2 Maternal pain score or pain measured in labour (Pain score at $4-6 \mathrm{~cm}$ cervical dilatation).}

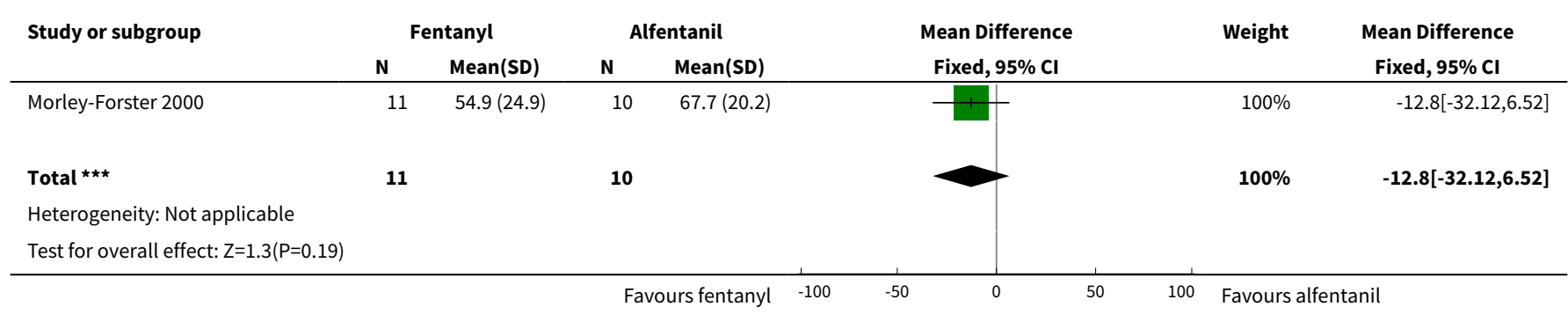

Analysis 31.3. Comparison 31 PCA fentanyl versus PCA alfentanil, Outcome 3 Nausea.

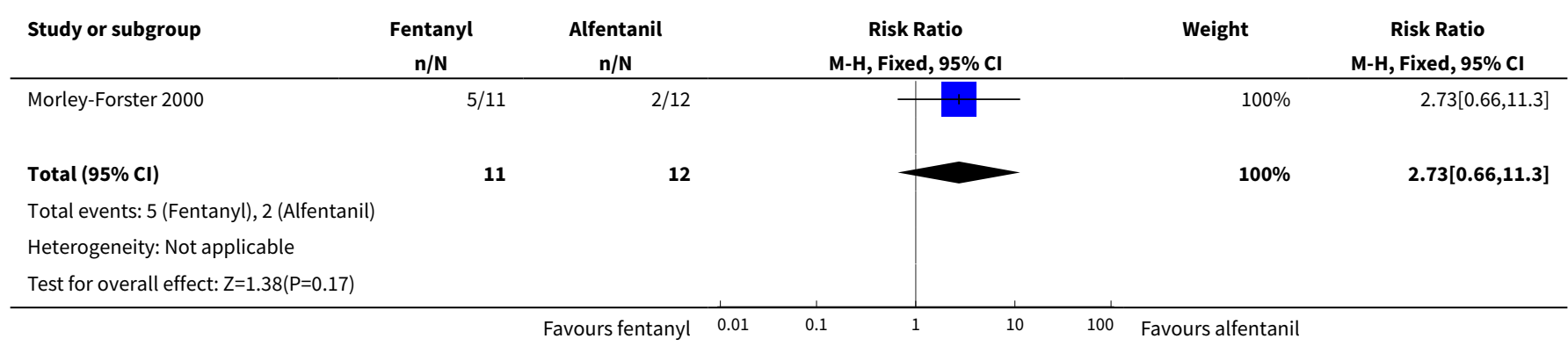

Analysis 31.4. Comparison 31 PCA fentanyl versus PCA alfentanil, Outcome 4 Caesarean section.

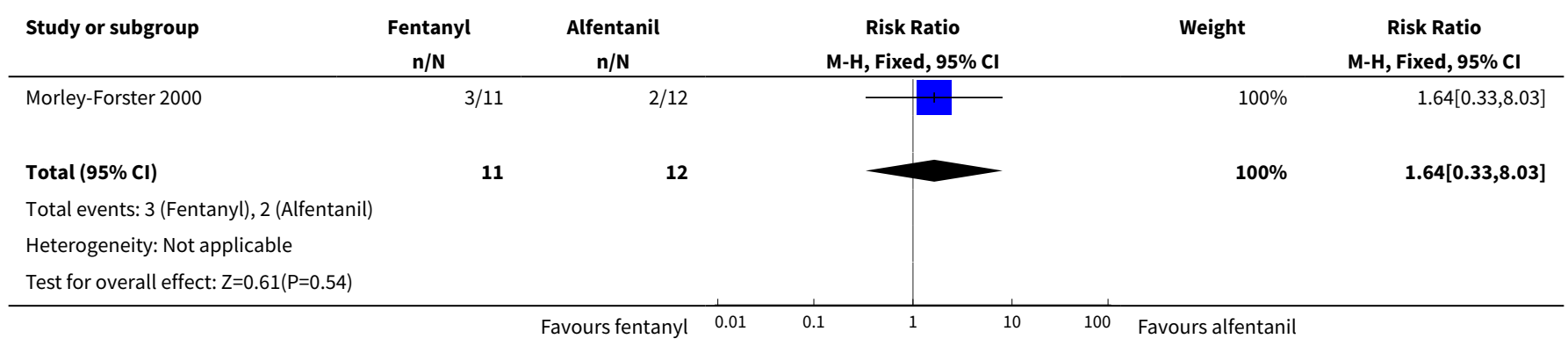


Analysis 31.5. Comparison 31 PCA fentanyl versus PCA alfentanil, Outcome 5 Naloxone required.

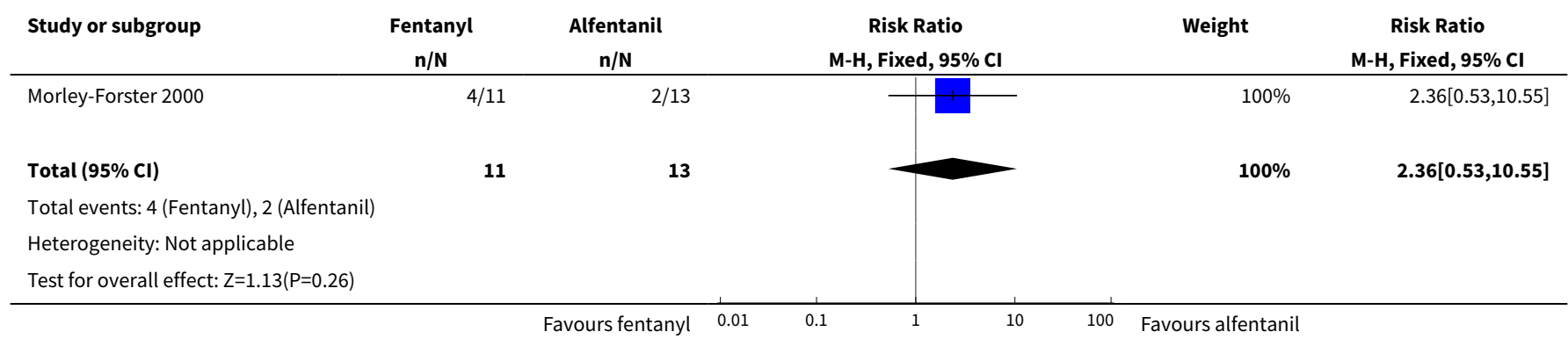

\section{Comparison 32. PCA fentanyl versus PCA pethidine}

\begin{tabular}{|c|c|c|c|c|}
\hline Outcome or subgroup title & No. of studies & $\begin{array}{l}\text { No. of partici- } \\
\text { pants }\end{array}$ & Statistical method & Effect size \\
\hline $\begin{array}{l}1 \text { Maternla pain score measured } \\
\text { in labour }\end{array}$ & 1 & 107 & $\begin{array}{l}\text { Mean Difference (IV, Fixed, 95\% } \\
\mathrm{CI})\end{array}$ & $-0.65[-1.56,0.26]$ \\
\hline 2 Epidural & 1 & 107 & Risk Ratio (M-H, Fixed, 95\% Cl) & $0.44[0.21,0.92]$ \\
\hline $\begin{array}{l}3 \text { Maternal sleepiness during } \\
\text { labour }\end{array}$ & 1 & 107 & $\begin{array}{l}\text { Mean Difference (IV, Fixed, 95\% } \\
\mathrm{CI})\end{array}$ & $-0.06[-0.25,0.13]$ \\
\hline 4 Nausea and vomiting & 1 & 102 & Risk Ratio (M-H, Fixed, 95\% Cl) & $0.87[0.55,1.37]$ \\
\hline 5 Caesarean section & 1 & 81 & Risk Ratio (M-H, Fixed, 95\% Cl) & $0.25[0.03,2.34]$ \\
\hline 6 Assisted vaginal birth & 1 & 81 & Risk Ratio (M-H, Fixed, 95\% Cl) & $0.57[0.22,1.49]$ \\
\hline $\begin{array}{l}7 \text { Newborn neurobehavioural } \\
\text { score ( } 15 \text { minutes post delivery) }\end{array}$ & 1 & 63 & $\begin{array}{l}\text { Mean Difference (IV, Fixed, 95\% } \\
\mathrm{CI} \text { ) }\end{array}$ & $-0.90[-2.31,0.51]$ \\
\hline $\begin{array}{l}8 \text { Newborn neurobehavioural } \\
\text { score ( } 2 \text { hours post delivery) }\end{array}$ & 1 & 64 & $\begin{array}{l}\text { Mean Difference (IV, Fixed, 95\% } \\
\mathrm{CI} \text { ) }\end{array}$ & $-0.5[-1.95,0.95]$ \\
\hline
\end{tabular}

Analysis 32.1. Comparison 32 PCA fentanyl versus PCA pethidine, Outcome 1 Maternla pain score measured in labour.

\begin{tabular}{|c|c|c|c|c|c|c|c|}
\hline \multirow[t]{2}{*}{ Study or subgroup } & \multicolumn{2}{|c|}{ Fentanyl } & \multicolumn{2}{|c|}{ Pethidine } & \multirow{2}{*}{$\begin{array}{c}\text { Mean Difference } \\
\text { Fixed, } 95 \% \mathrm{Cl}\end{array}$} & \multirow[t]{2}{*}{ Weight } & \multirow{2}{*}{$\begin{array}{c}\text { Mean Difference } \\
\text { Fixed, } 95 \% \mathrm{Cl}\end{array}$} \\
\hline & $\mathbf{N}$ & Mean(SD) & $\mathbf{N}$ & Mean(SD) & & & \\
\hline Douma 2010 & 54 & $6(2.5)$ & 53 & $6.6(2.3)$ & & $100 \%$ & $-0.65[-1.56,0.26]$ \\
\hline 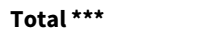 & 54 & & 53 & & & $100 \%$ & $-0.65[-1.56,0.26]$ \\
\hline \multicolumn{8}{|c|}{ Heterogeneity: Not applicable } \\
\hline \multicolumn{8}{|c|}{ Test for overall effect: $\mathrm{Z}=1.4(\mathrm{P}=0.16)$} \\
\hline
\end{tabular}


Analysis 32.2. Comparison 32 PCA fentanyl versus PCA pethidine, Outcome 2 Epidural.

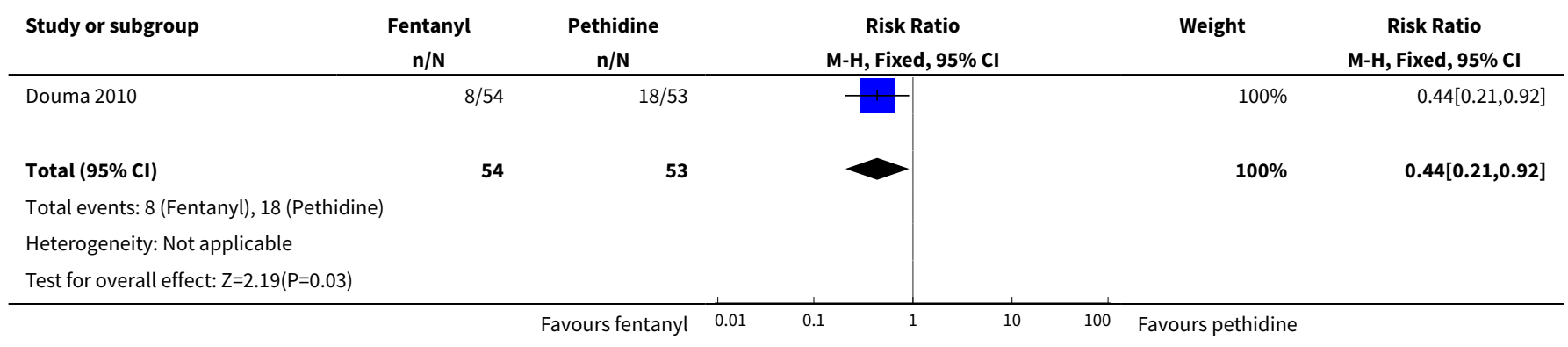

Analysis 32.3. Comparison 32 PCA fentanyl versus PCA pethidine, Outcome 3 Maternal sleepiness during labour.

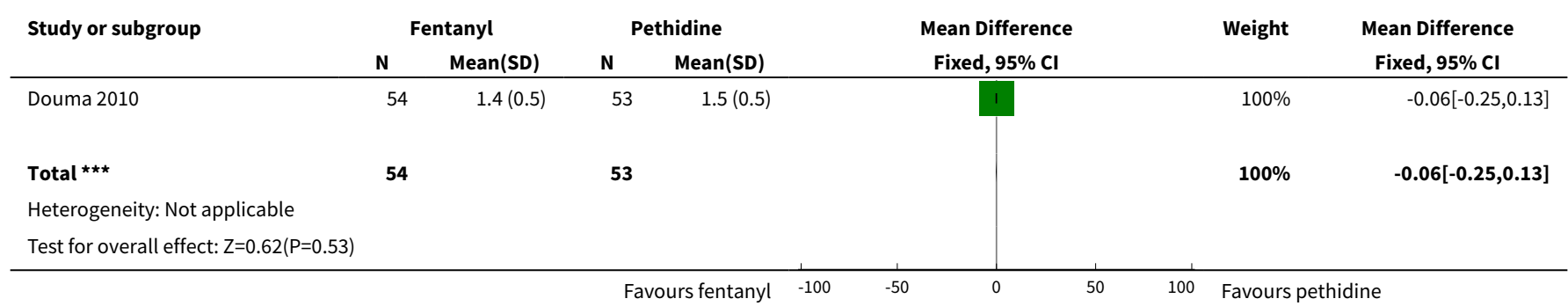

Analysis 32.4. Comparison 32 PCA fentanyl versus PCA pethidine, Outcome 4 Nausea and vomiting.

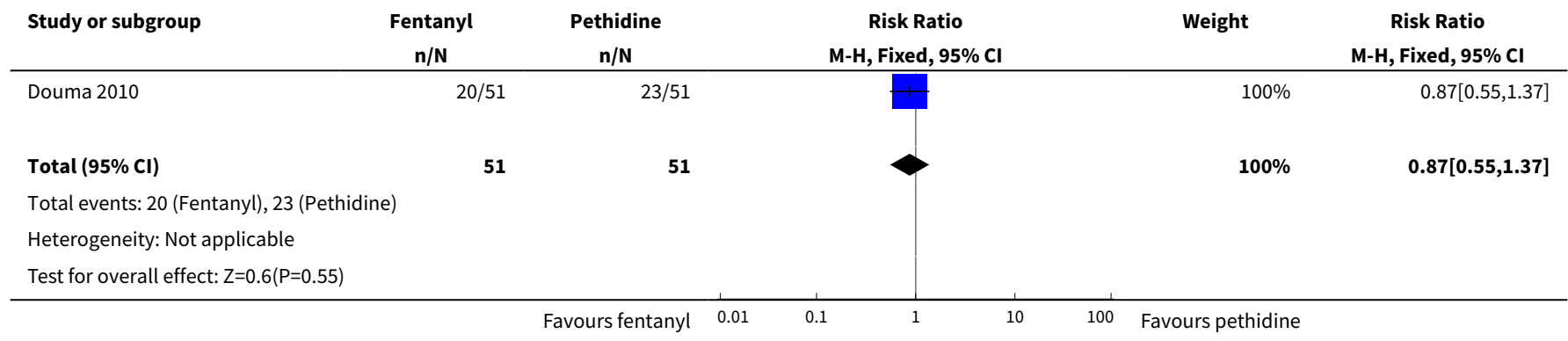

Analysis 32.5. Comparison 32 PCA fentanyl versus PCA pethidine, Outcome 5 Caesarean section.

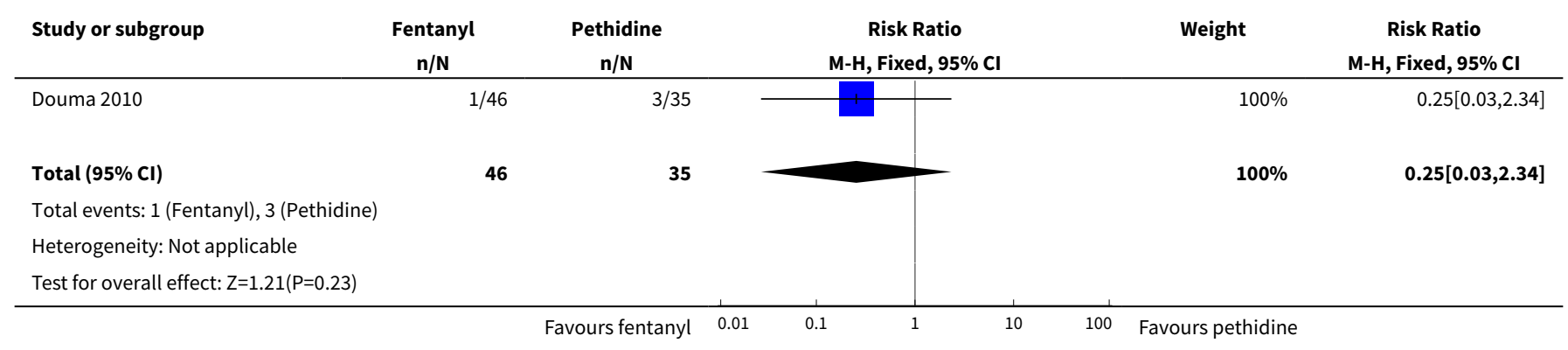


Analysis 32.6. Comparison 32 PCA fentanyl versus PCA pethidine, Outcome 6 Assisted vaginal birth.

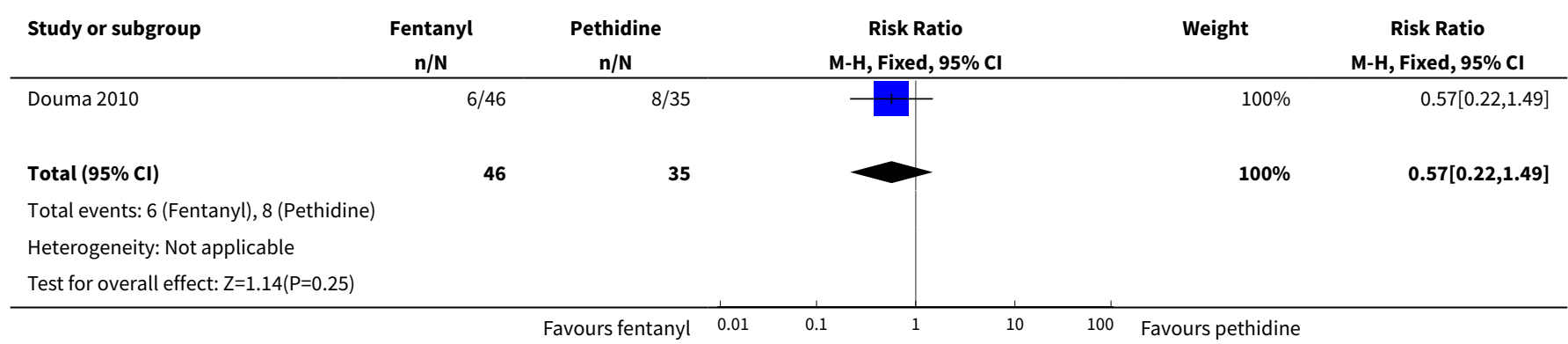

Analysis 32.7. Comparison 32 PCA fentanyl versus PCA pethidine, Outcome 7 Newborn neurobehavioural score (15 minutes post delivery).

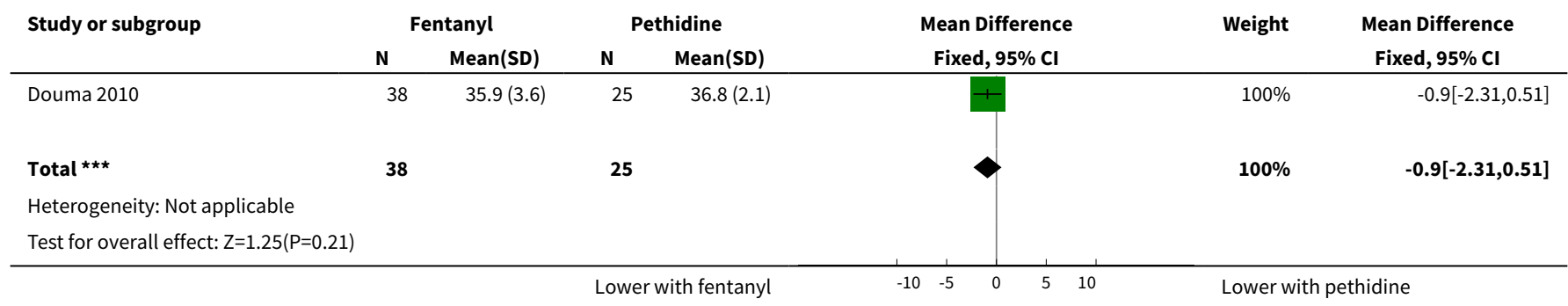

Analysis 32.8. Comparison 32 PCA fentanyl versus PCA pethidine, Outcome 8 Newborn neurobehavioural score (2 hours post delivery).

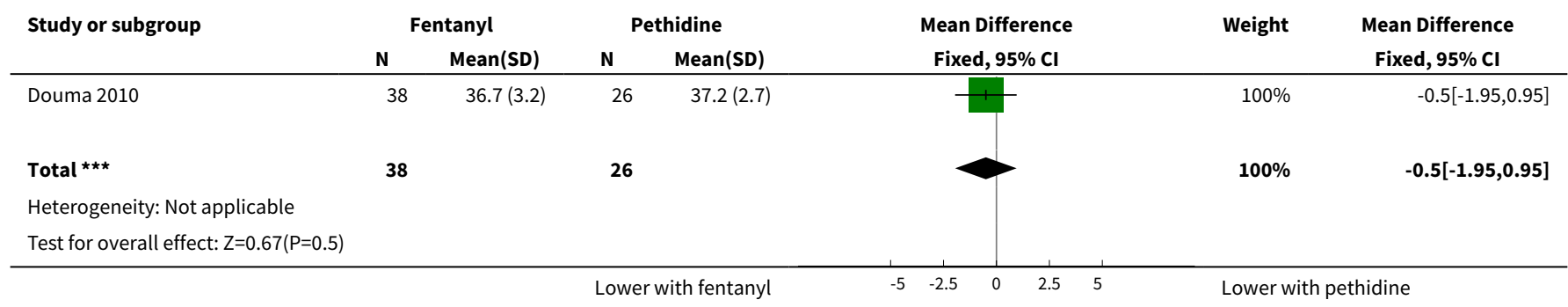

\section{Comparison 33. PCA (IM) meptazinol versus PCA (IM) pethidine}

\begin{tabular}{lllll}
\hline Outcome or subgroup title & No. of studies & $\begin{array}{l}\text { No. of partici- } \\
\text { pants }\end{array}$ & Statistical method & Effect size \\
\hline $\begin{array}{l}\text { 1 Maternal pain score or pain measured } \\
\text { in labour (measured 1 day after delivery) }\end{array}$ & 1 & 10 & $\begin{array}{l}\text { Mean Difference (IV, Fixed, } \\
95 \% \text { Cl) }\end{array}$ & $\begin{array}{l}-17.60[-49.93, \\
14.73]\end{array}$ \\
\hline $\begin{array}{l}\text { 2 Satisfied with mode of administration } \\
\text { (PCA IM) (non pre-specified) }\end{array}$ & 1 & 10 & $\begin{array}{l}\text { Risk Ratio (M-H, Fixed, } \\
95 \% \text { Cl) }\end{array}$ & $1.0[0.71,1.41]$ \\
\hline
\end{tabular}




\begin{tabular}{lllll}
\hline Outcome or subgroup title & No. of studies & $\begin{array}{l}\text { No. of partici- } \\
\text { pants }\end{array}$ & Statistical method & Effect size \\
\hline 3 Epidural & 1 & 10 & $\begin{array}{l}\text { Risk Ratio (M-H, Fixed, } \\
95 \% \text { Cl) }\end{array}$ & $3.0[0.15,59.89]$ \\
\hline $\begin{array}{l}\text { 4 Maternal sleepiness in labour (Drowsi- } \\
\text { ness score in labour rated 1 day after de- } \\
\text { livery) }\end{array}$ & 1 & 10 & $\begin{array}{l}\text { Mean Difference (IV, Fixed, } \\
95 \% \text { Cl) }\end{array}$ & 5.60 [-28.19, 39.39] \\
\hline $\begin{array}{l}5 \text { Nausea (score in labour rated 1 day af- } \\
\text { ter delivery) }\end{array}$ & 1 & 10 & $\begin{array}{l}\text { Mean Difference (IV, Fixed, } \\
95 \% \text { Cl) }\end{array}$ & -8.0 [-48.70, 32.70] \\
\hline 6 Naloxone administered & 1 & 10 & $\begin{array}{l}\text { Risk Ratio (M-H, Fixed, } \\
95 \% \text { Cl) }\end{array}$ & 1.0 [0.08, 11.93] \\
\hline
\end{tabular}

Analysis 33.1. Comparison 33 PCA (IM) meptazinol versus PCA (IM) pethidine, Outcome 1 Maternal pain score or pain measured in labour (measured 1 day after delivery).

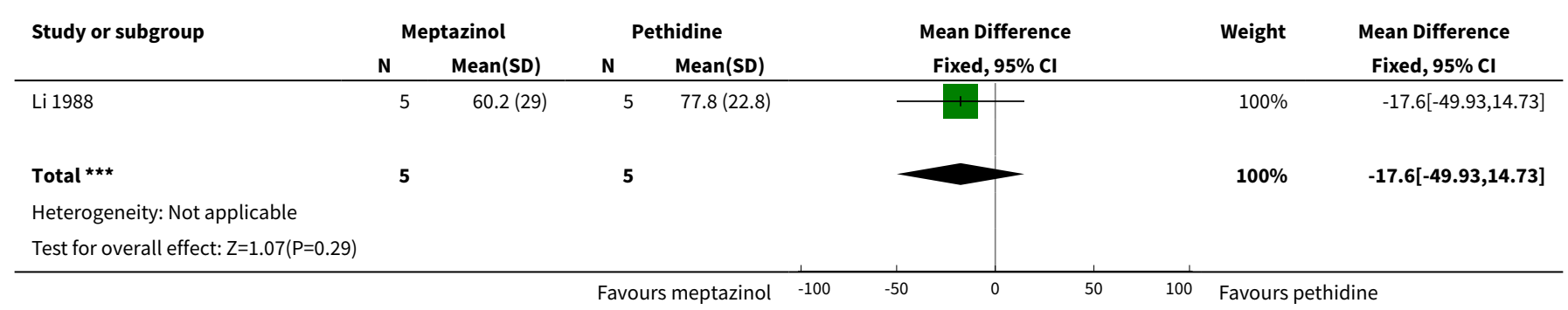

Analysis 33.2. Comparison 33 PCA (IM) meptazinol versus PCA (IM) pethidine, Outcome 2 Satisfied with mode of administration (PCA IM) (non pre-specified).

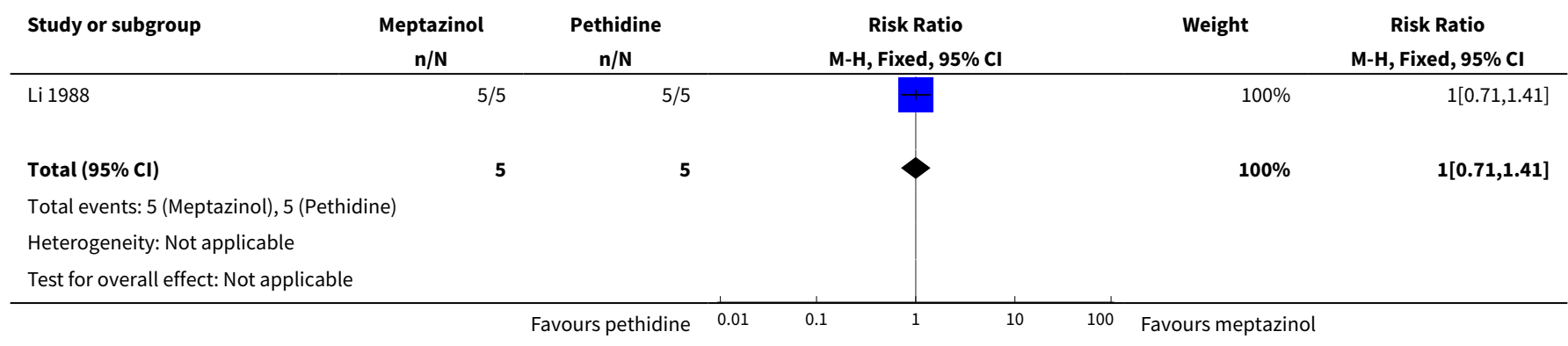

Analysis 33.3. Comparison 33 PCA (IM) meptazinol versus PCA (IM) pethidine, Outcome 3 Epidural.

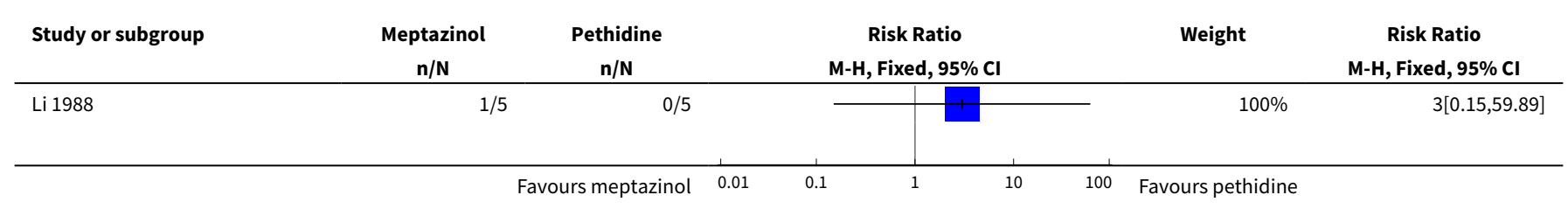




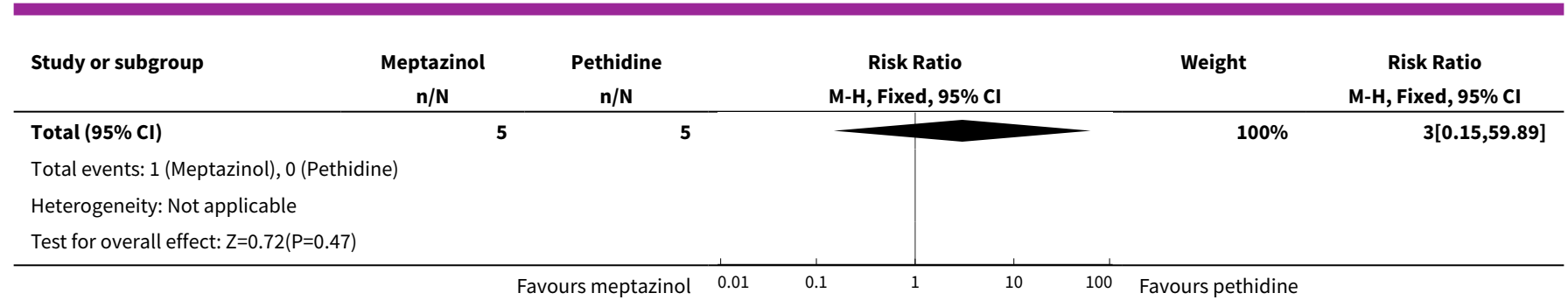

Analysis 33.4. Comparison 33 PCA (IM) meptazinol versus PCA (IM) pethidine, Outcome 4 Maternal sleepiness in labour (Drowsiness score in labour rated 1 day after delivery).

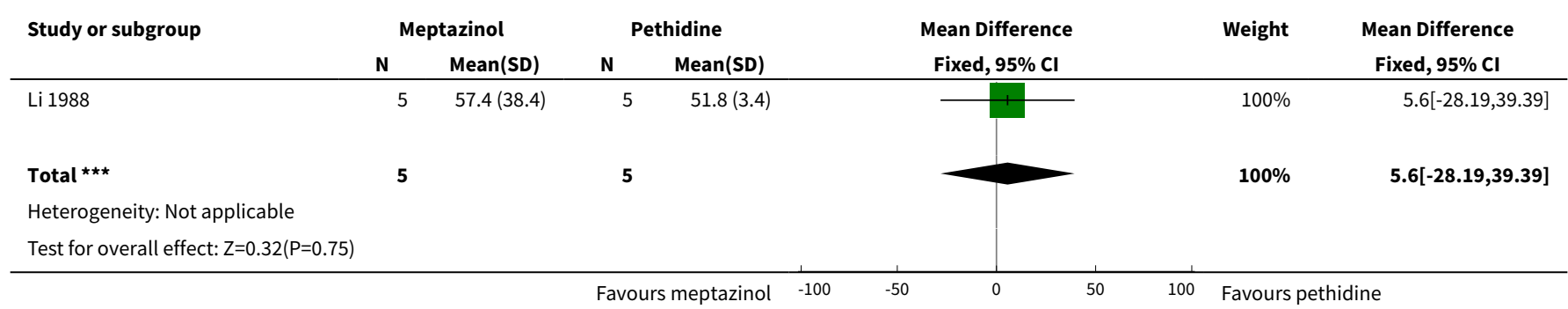

Analysis 33.5. Comparison 33 PCA (IM) meptazinol versus PCA (IM) pethidine, Outcome 5 Nausea (score in labour rated 1 day after delivery).

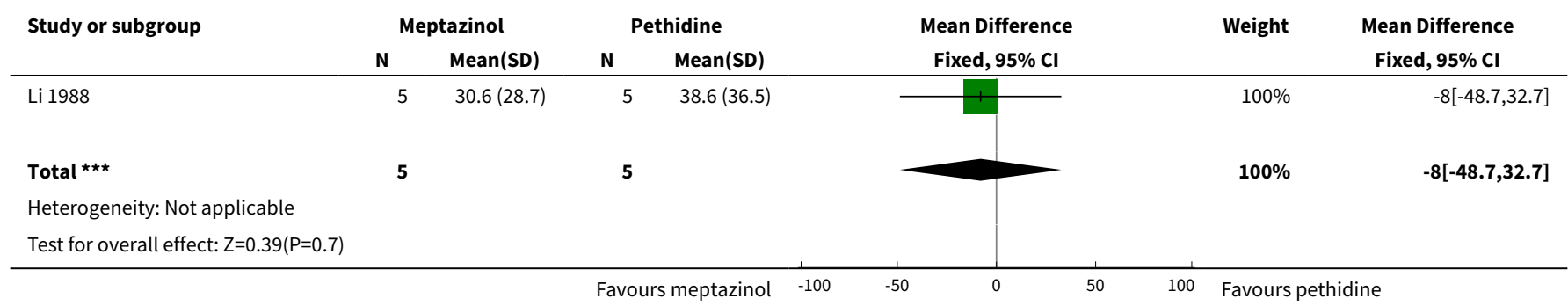

\section{Analysis 33.6. Comparison 33 PCA (IM) meptazinol versus PCA (IM) pethidine, Outcome 6 Naloxone administered.}

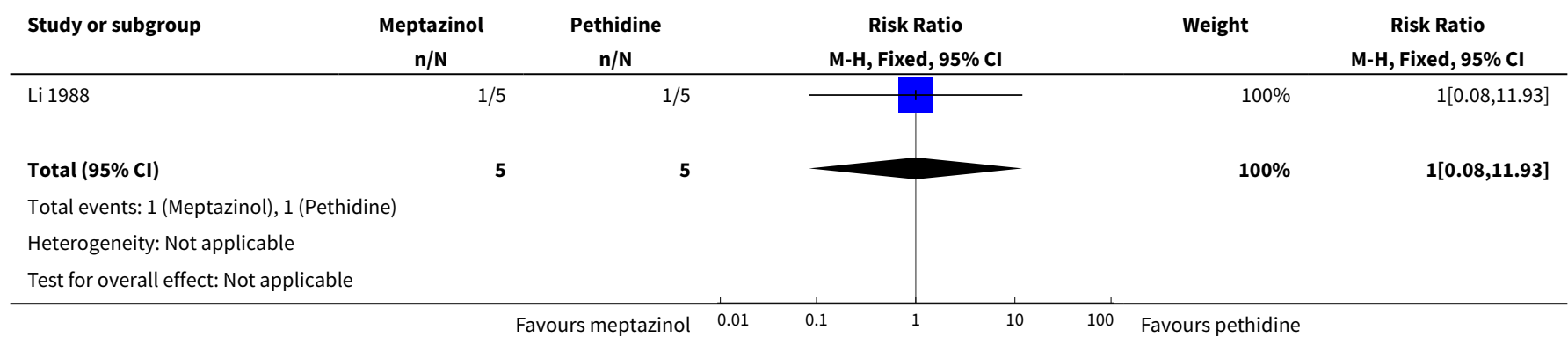


Comparison 34. Opioids versus TENS

\begin{tabular}{|c|c|c|c|c|}
\hline Outcome or subgroup title & No. of studies & $\begin{array}{l}\text { No. of partici- } \\
\text { pants }\end{array}$ & Statistical method & Effect size \\
\hline $\begin{array}{l}1 \text { Maternal satisfaction with analge- } \\
\text { sia measured post delivery (rated as } \\
\text { good) }\end{array}$ & 2 & 104 & $\begin{array}{l}\text { Risk Ratio (M-H, Fixed, 95\% } \\
\text { Cl) }\end{array}$ & $1.23[0.79,1.92]$ \\
\hline $\begin{array}{l}2 \text { Maternal pain score measured } \\
\text { during labour }\end{array}$ & 2 & 290 & $\begin{array}{l}\text { Risk Ratio (M-H, Random, } \\
95 \% \mathrm{Cl})\end{array}$ & $1.15[0.81,1.61]$ \\
\hline 3 Maternal pain score in labour & 1 & & $\begin{array}{l}\text { Mean Difference (IV, Fixed, } \\
95 \% \mathrm{CI})\end{array}$ & Subtotals only \\
\hline 3.1 Pain score (after 30 minutes) & 1 & 60 & $\begin{array}{l}\text { Mean Difference (IV, Fixed, } \\
95 \% \mathrm{CI})\end{array}$ & $\begin{array}{l}-20.0[-26.09 \\
-13.91]\end{array}$ \\
\hline 3.2 Pain score (after 60 minutes) & 1 & 60 & $\begin{array}{l}\text { Mean Difference (IV, Fixed, } \\
95 \% \mathrm{CI})\end{array}$ & $\begin{array}{l}-20.0[-25.16 \\
-14.84]\end{array}$ \\
\hline $\begin{array}{l}4 \text { Maternal sleepiness during labour } \\
\text { (Drowsiness) }\end{array}$ & 2 & 290 & $\begin{array}{l}\text { Risk Ratio (M-H, Fixed, 95\% } \\
\text { Cl) }\end{array}$ & $8.96[1.13,71.07]$ \\
\hline 5 Nausea and vomiting & 3 & 350 & $\begin{array}{l}\text { Risk Ratio (M-H, Fixed, 95\% } \\
\text { Cl) }\end{array}$ & $13.73[2.72,69.24]$ \\
\hline 6 Caesarean section & 2 & 260 & $\begin{array}{l}\text { Risk Ratio (M-H, Fixed, 95\% } \\
\text { Cl) }\end{array}$ & $2.0[0.19,20.90]$ \\
\hline 7 Assisted vaginal birth & 2 & 260 & $\begin{array}{l}\text { Risk Ratio (M-H, Fixed, 95\% } \\
\text { Cl) }\end{array}$ & $1.8[0.40,8.18]$ \\
\hline $\begin{array}{l}8 \text { Fetal heart rate changes in labour } \\
\text { (Fetal distress) }\end{array}$ & 1 & 200 & $\begin{array}{l}\text { Risk Ratio (M-H, Fixed, 95\% } \\
\mathrm{Cl})\end{array}$ & $5.0[0.24,102.85]$ \\
\hline
\end{tabular}

Analysis 34.1. Comparison 34 Opioids versus TENS, Outcome 1 Maternal
satisfaction with analgesia measured post delivery (rated as good).

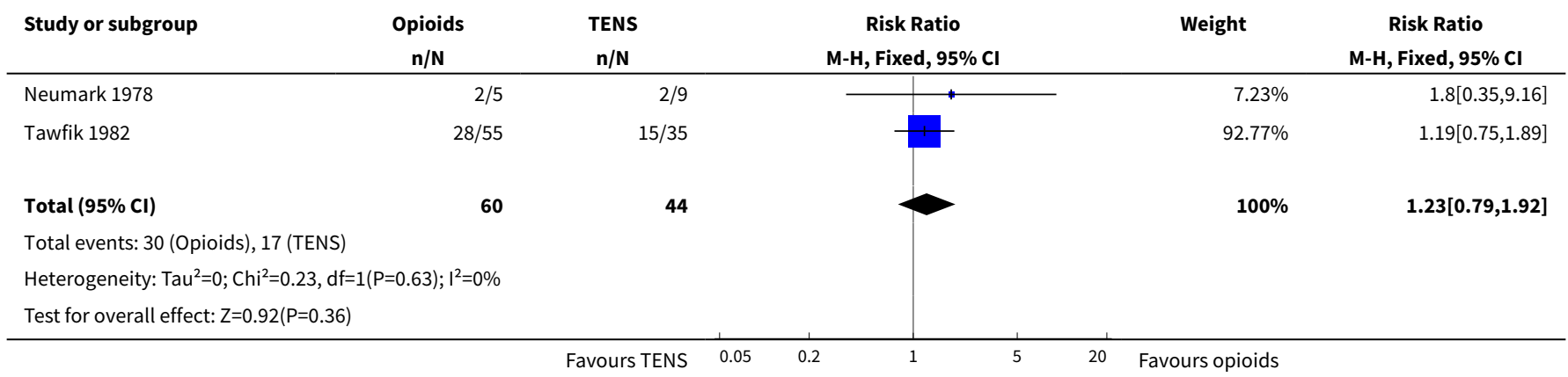


Analysis 34.2. Comparison 34 Opioids versus TENS, Outcome 2 Maternal pain score measured during labour.

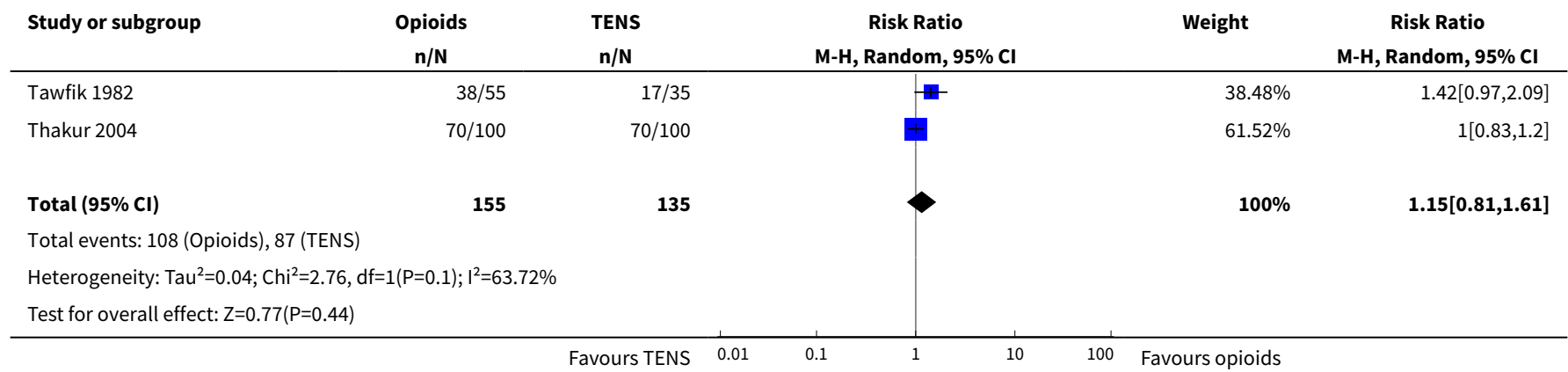

Analysis 34.3. Comparison 34 Opioids versus TENS, Outcome 3 Maternal pain score in labour.

\begin{tabular}{|c|c|c|c|c|c|c|c|}
\hline \multirow[t]{2}{*}{ Study or subgroup } & \multicolumn{2}{|c|}{ Opioids } & \multicolumn{2}{|c|}{ TENS } & \multirow{2}{*}{$\begin{array}{c}\text { Mean Difference } \\
\text { Fixed, } 95 \% \mathrm{Cl}\end{array}$} & \multirow[t]{2}{*}{ Weight } & \multirow{2}{*}{$\begin{array}{c}\text { Mean Difference } \\
\text { Fixed, } 95 \% \mathrm{Cl}\end{array}$} \\
\hline & $\mathbf{N}$ & Mean(SD) & $\mathbf{N}$ & Mean(SD) & & & \\
\hline \multicolumn{8}{|c|}{ 34.3.1 Pain score (after 30 minutes) } \\
\hline Liu 2015 & 30 & $51(11)$ & 30 & $71(13)$ & 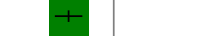 & $100 \%$ & $-20[-26.09,-13.91]$ \\
\hline Subtotal $\star \star \star$ & 30 & & 30 & & 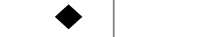 & $100 \%$ & $-20[-26.09,-13.91]$ \\
\hline \multicolumn{8}{|c|}{ Heterogeneity: Not applicable } \\
\hline \multicolumn{8}{|c|}{ Test for overall effect: $Z=6.43(P<0.0001)$} \\
\hline \multicolumn{8}{|c|}{ 34.3.2 Pain score (after 60 minutes) } \\
\hline Liu 2015 & 30 & $45(8)$ & 30 & $65(12)$ & + & $100 \%$ & $-20[-25.16,-14.84]$ \\
\hline Subtotal $\star \star \star$ & 30 & & 30 & & $\diamond$ & $100 \%$ & $-20[-25.16,-14.84]$ \\
\hline \multicolumn{8}{|c|}{ Heterogeneity: Not applicable } \\
\hline \multicolumn{8}{|c|}{ Test for overall effect: $Z=7.6(P<0.0001)$} \\
\hline \multicolumn{8}{|c|}{ Test for subgroup differences: Not applicable } \\
\hline
\end{tabular}

Analysis 34.4. Comparison 34 Opioids versus TENS, Outcome 4 Maternal sleepiness during labour (Drowsiness).

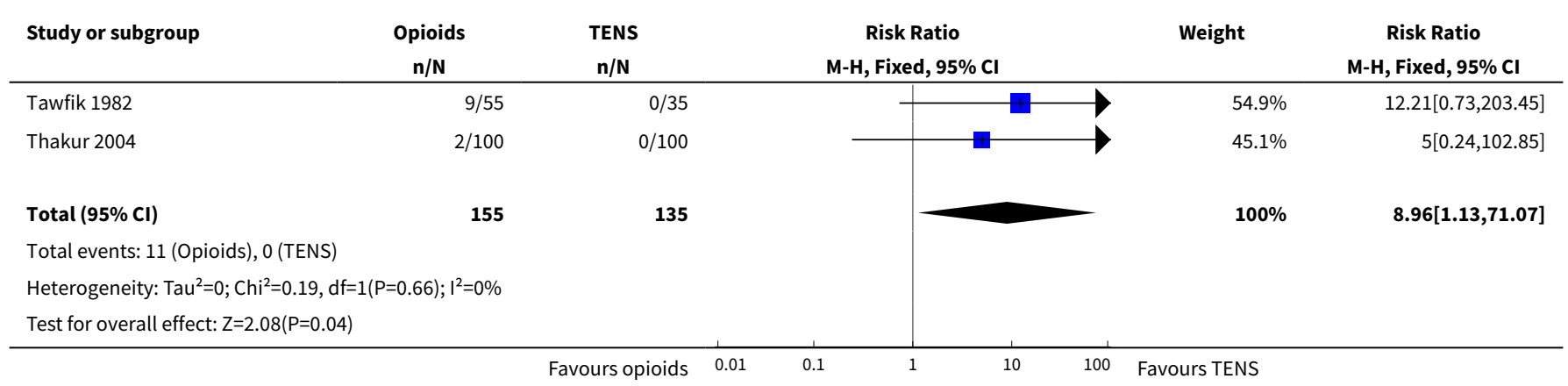


Analysis 34.5. Comparison 34 Opioids versus TENS, Outcome 5 Nausea and vomiting.

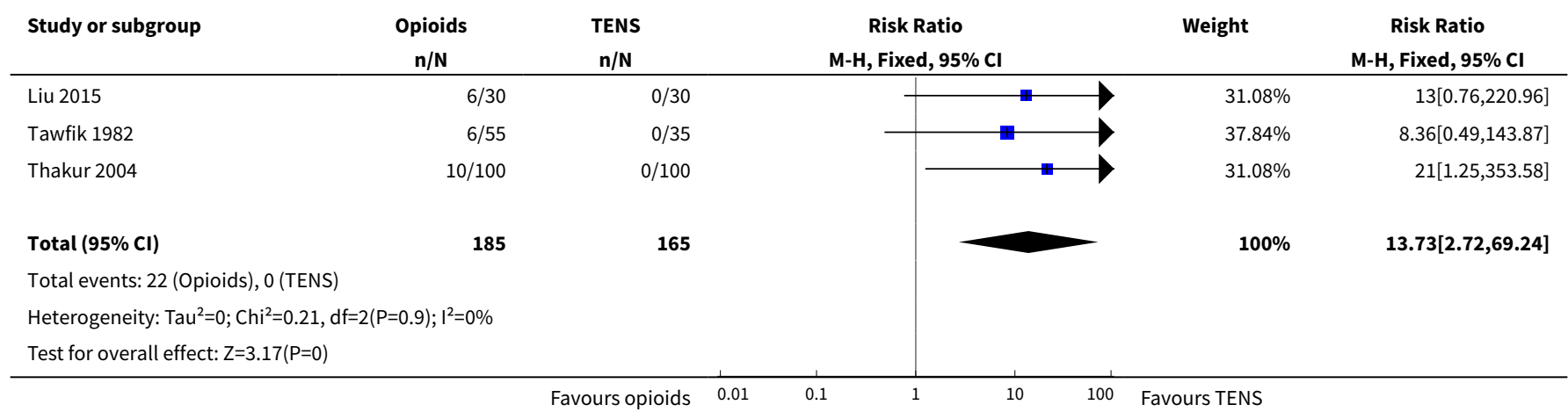

Analysis 34.6. Comparison 34 Opioids versus TENS, Outcome 6 Caesarean section.

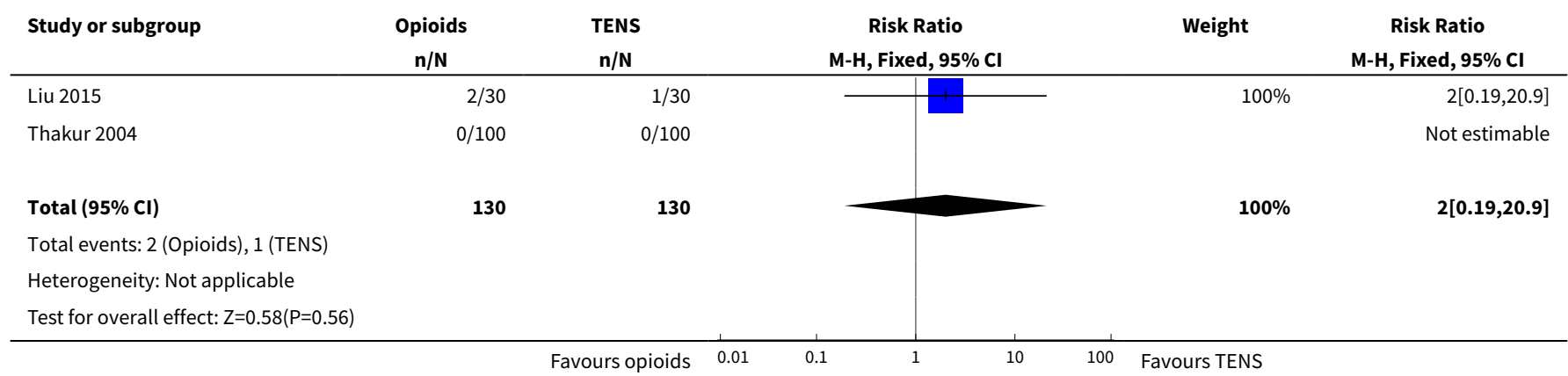

Analysis 34.7. Comparison 34 Opioids versus TENS, Outcome 7 Assisted vaginal birth.

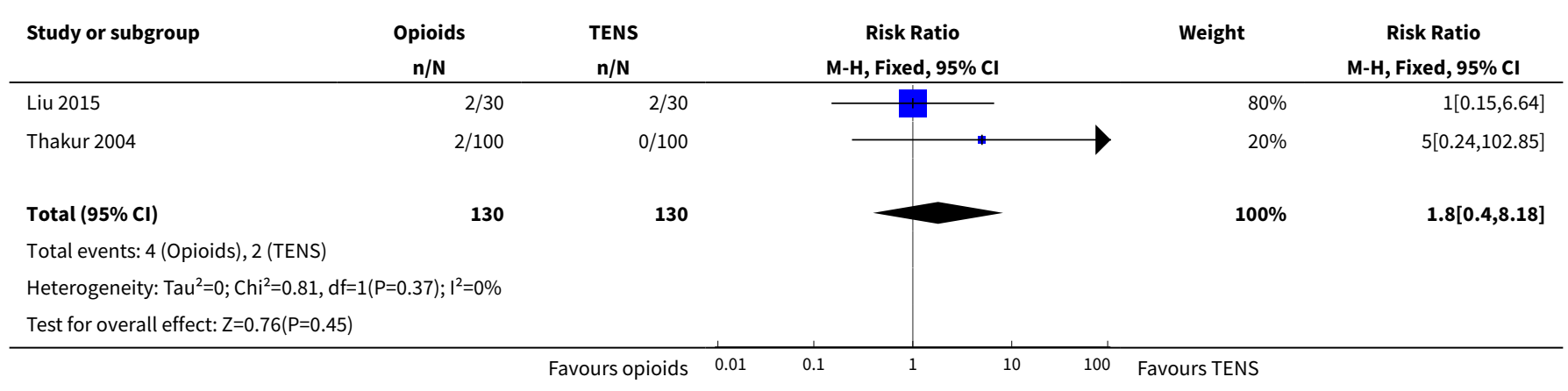

\section{Analysis 34.8. Comparison 34 Opioids versus TENS, Outcome 8 Fetal heart rate changes in labour (Fetal distress).}

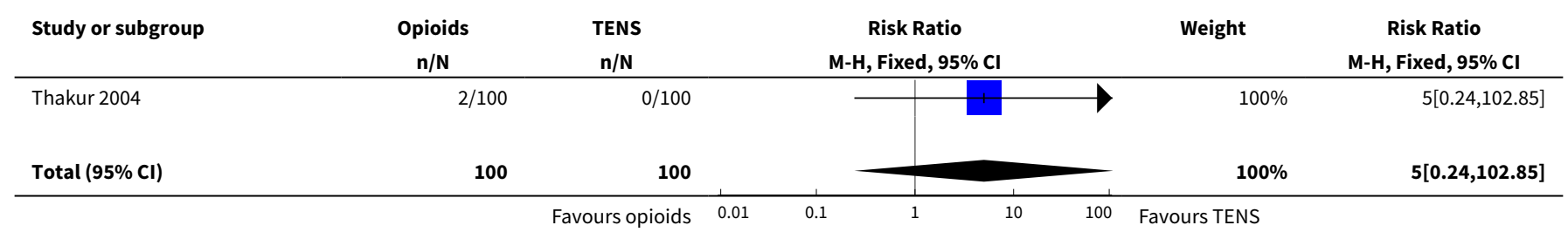




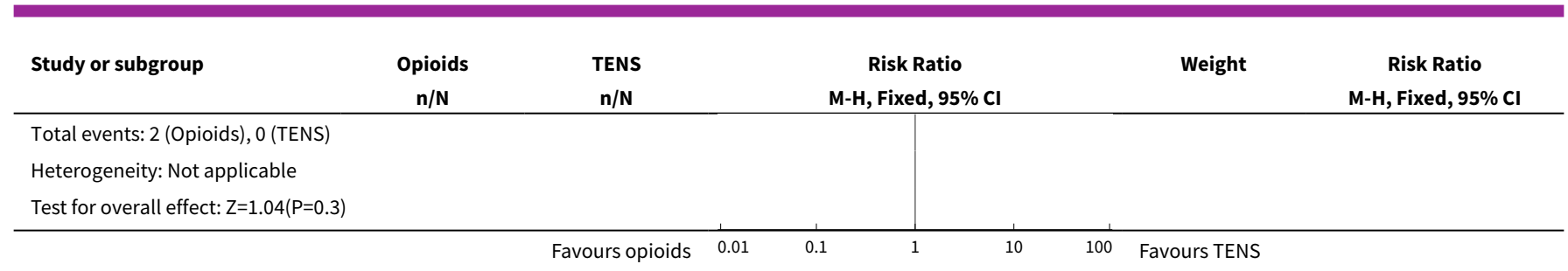

\section{APPENDICES}

\section{Appendix 1. Search terms for ICTRP and ClinicalTrials.gov}

(intravenous OR intramuscular OR opioids or opioid) AND (birth OR labour OR labor)

\section{WHAT'S NEW}

\begin{tabular}{lll}
\hline Date & Event & Description \\
\hline 11 May 2017 & New search has been performed & $\begin{array}{l}\text { Search updated, } 70 \text { new reports assessed. 'Summary of findings' } \\
\text { tables have been incorporated in this update. }\end{array}$ \\
\hline 11 May 2017 & $\begin{array}{l}\text { New citation required but conclusions } \\
\text { have not changed }\end{array}$ & $\begin{array}{l}\text { We included } 13 \text { new trials in this update. We also excluded a fur- } \\
\text { ther 34 trials, identified five ongoing studies and added two to } \\
\text { the awaiting classification section. Altogether, the review now in- } \\
\text { cludes 70 trials. }\end{array}$ \\
\hline
\end{tabular}

\section{H IST O R Y}

Protocol first published: Issue 4, 2008

Review first published: Issue 9, 2010

\begin{tabular}{lll}
\hline Date & Event & Description \\
\hline 21 June 2011 & New search has been performed & $\begin{array}{l}\text { Search updated. We have included data from three new studies } \\
\text { (Douma 2010; Tawfik 1982; Thakur 2004). These changes have } \\
\text { not altered the conclusions of the review. }\end{array}$ \\
& $\begin{array}{l}\text { New outcome added - see Differences between protocol and re- } \\
\text { view. }\end{array}$ \\
&
\end{tabular}

\section{CONTRIBUTIONS OF AUTHORS}

In this 2017 version of the review, Anna Cuthbert and Lesley Smith assessed eligibility and carried out data extraction. Lesley Smith and Ethel Burns updated the background and discussion.

\section{DECLARATIONS OF INTEREST}

Lesley A Smith: none known.

Ethel Burns: none known.

Anna Cuthbert: is supported by a grant to her Institution from WHO to work on this review, and has received support via an NIHR grant to her Institution to work on other Cochrane reviews. 


\section{SOURCES OF SUPPORT}

\section{Internal sources}

- (AC) The University of Liverpool, UK.

\section{External sources}

- National Institute for Health Research, UK.

2010 Update - NIHR NHS Cochrane Collaboration Programme Grant Scheme award for NHS-prioritised centrally-managed, pregnancy and childbirth systematic reviews:CPGS02

- 2017 Update - WHO UNDP-UNFPA-UNICEF-WHO-World Bank Special Programme of Research, Development and Research Training in Human Reproduction (HRP), Department of Reproductive Health and Research (RHR), World Health Organization, Switzerland.

\section{DIFFERENCES BETWEEN PROTOCOLANDREVIEW}

The Background section of the review has been updated and amended since publication of the protocol and has been revised for this update.

The focus of some of the reports we identified using the search strategy was on the route of administration, rather than on the effectiveness of opioids compared with placebo or other opioids. That is, in several trials, women in both arms received the same opioid and the same dose but the drug was given by a different route (e.g. intravenous (staff administered) versus patient-controlled analgesia, or intramuscular versus intravenous). Although in the original protocol we had specified that we would examine different routes, in retrospect we thought that including such comparisons would add several more potentially large sections to the review (each report requiring a different comparison) and would throw little light on the main review questions: whether opioids are effective for pain relief in labour without causing unpleasant side effects or harm to mothers and babies. Studies focusing on route of administration will be examined in the future in a separate, related Cochrane review.

For the 2017 update, we split the outcome "Additional analgesia: Epidural" into two separate outcomes: "Additional analgesia required" and "Epidural". This meant we were able to capture second doses of study drugs that were already reported in the previous update. The review now includes GRADE methods and one new 'Summary of findings' table. Given the nature of this review, with many different comparisons and small sample sizes, we also added an additional table with GRADE including all outcomes relating to pain.

The previous update of this review was one of a series of reviews included in an overview of reviews examining methods of pain management in labour Jones 2012. It has been updated to follow the generic protocol developed in 2011 for reviews contributing to the overview (Jones 2011), as a result of which we have added a new comparison (opioids versus TENS).

For the 2017 update, we added in a search of ClinicalTrials.gov and the WHO International Clinical Trials Registry Platform (ICTRP).

\section{N DEX TERMS}

\section{Medical Subject Headings (MeSH)}

Analgesia, Obstetrical [ ${ }^{\star}$ methods]; Analgesics, Opioid [*administration \& dosage] [adverse effects]; Injections, Intramuscular; Injections, Intravenous; Labor Pain [ ${ }^{\star}$ drug therapy]; Meperidine [administration \& dosage]; Randomized Controlled Trials as Topic; Transcutaneous Electric Nerve Stimulation

\section{MeSH check words}

Female; Humans; Pregnancy 